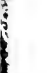

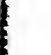

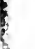





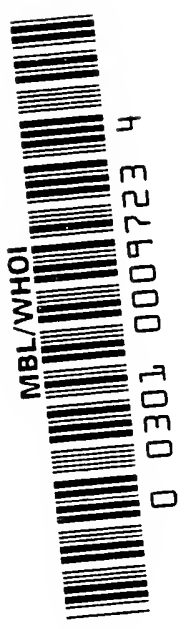







The Classification of Lower Organisms 




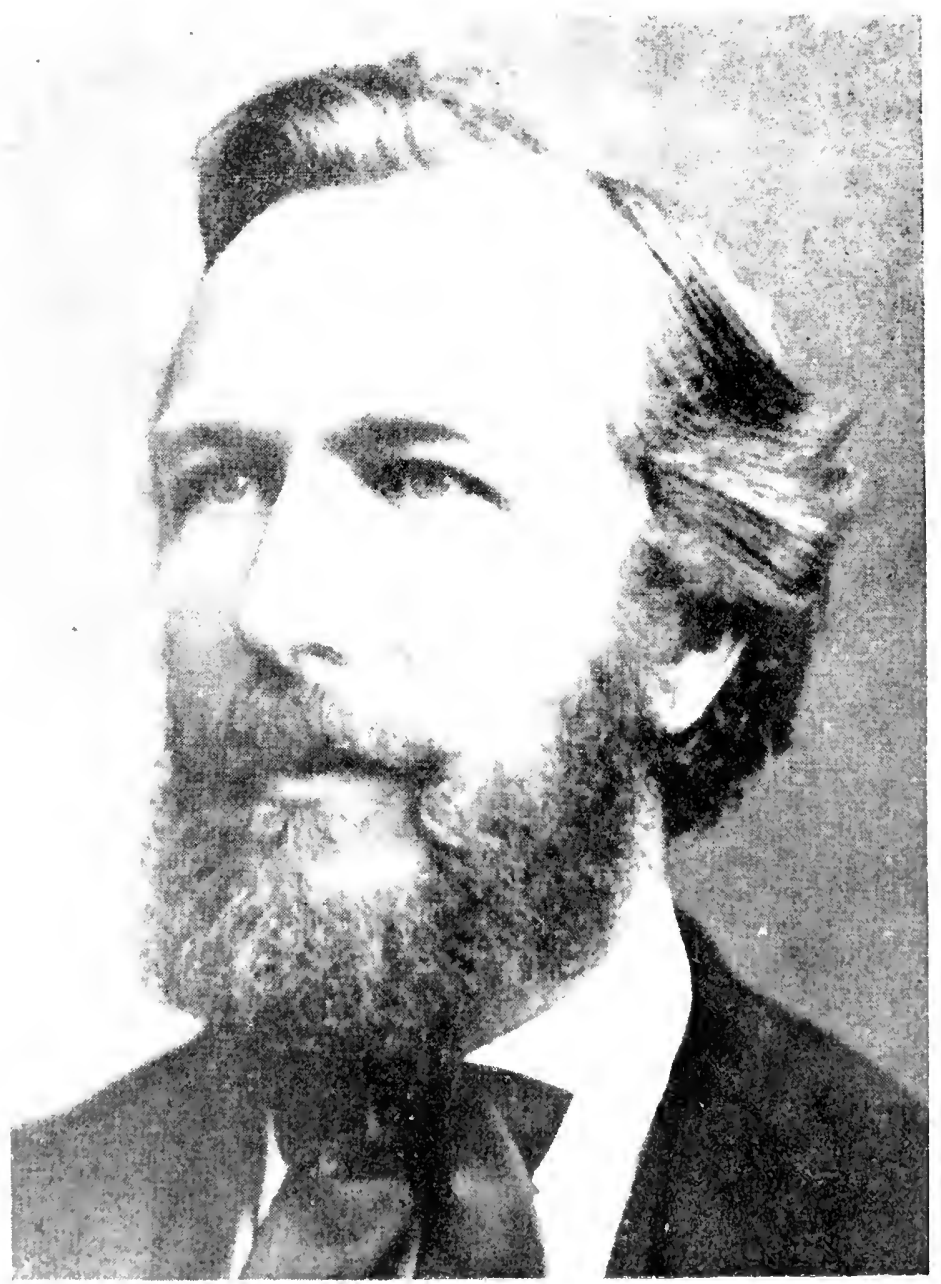

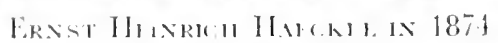

From Biiluhe lgatio.

lig perminion of Marrar Smith Compant. 


\section{The Classification of}

\section{LOWER ORGANISMS}

By

HERBERT FAULKNER COPELAND

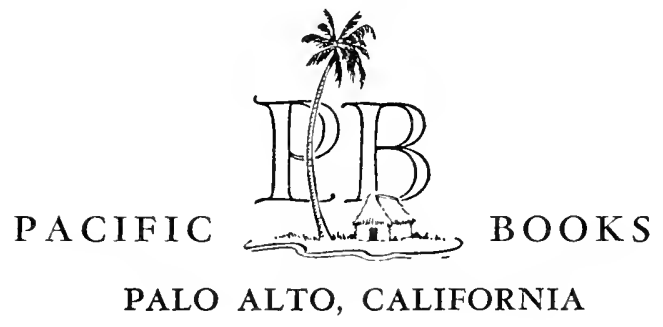


Copyright 1956 by Herbert F. Copeland

Library of Congress Catalog Card Number 56-7944

\author{
Published by \\ PACIFIG BOOKS \\ Palo Alto, California
}

Printed and bound in the United States of America 


\section{CONTENTS}

Chapter

Page

I. INTRODUCTION

II. An Essay on Nonenclature . . . . . . . . . . . . . . . . . 6

III. Kingdom Mrchota . . . . . . . . . . . . . . 12

Phylum Archezoa . . . . . . . . . . . . . . . 17

Glass 1. Schizophyta . . . . . . . . . . . . . 18

Order 1. Schizosporea . . . . . . . . . . 18

Orcler 2. Actinomycetalea . . . . . . . . . 24

Order 3. Caulobacterialea . . . . . . . . . 25

Class 2. Mýxoschizonycetes . . . . . . . . . . 27

Order 1. Myxobactralea . . . . . . . . . 27

Order 2. Spirochaetalea . . . . . . . . . . . . 28

Class 3. Archiplastidea . . . . . . . . . . . . 29

Order 1. Rhodobacteria . . . . . . . . . 31

Order 2. Sphaerotilalea . . . . . . . . . 33

Order 3. Coccogonea . . . . . . . . . . . 33

Order 4. Gloiophycea . . . . . . . . . . . 33

IV. Kingdon Protoctista. . . . . . . . . . . . . . . . . . 37

V. Phylum Rhodophyta . . . . . . . . . . . . . . . 40

Glass 1. Bangialea . . . . . . . . . . . . 41

Order Bangiacea . . . . . . . . . . . 41

Class 2. Heterocarpea . . . . . . . . . . . 44

Order 1. Cryptospermea . . . . . . . . . 47

Order 2. Sphacrococcoidea . . . . . . . . 47

Order 3. Gelidialea . . . . . . . . . . . 49

Order 4. Furcellariea . . . . . . . . . . 50

Order 5. Coeloblastea . . . . . . . . . . . 51

Order 6. Floridea . . . . . . . . . . . . 51

VI. Phylum Pilaeophyta . . . . . . . . . . . . . . . . 53

Class 1. Heterokonta . . . . . . . . . . . 55

Order 1. Ochromonadalea . . . . . . . . . 57

Order 2. Silicoflagellata . . . . . . . . . 61

Order 3. Vaucheriacea . . . . . . . . . . 63

Order 4. Choanoflagellata . . . . . . . . . 67

Order 5. Hyphochytrialea . . . . . . . . . 69

Class 2. Bacillariacea . . . . . . . . . . . . 69

Order 1. Disciformia . . . . . . . . . . . . 73

Order 2. Diatomea . . . . . . . . . . 74

Class 3. Oomycetes . . . . . . . . . . . 76

Order 1. Saprolegnina . . . . . . . . . . 77

Order 2. Peronosporina . . . . . . . . . 80

Order 3. Lagenidialca . . . . . . . . . . 81

Class 4. Melanophycea . . . . . . . . . . . . . 82

Order 1. Phacozoosporea . . . . . . . . . 86

Order 2. Sphacelarialea . . . . . . . . . . 86

Order 3. Dictyotea . . . . . . . . . . . . 86

Order 4. Sporochnoidea . . . . . . . . . 58 
Order 5. Cutlerialea

Order 6. Laminariea .

Order 7. Fucoidea . . . . . . . . . . . . . . . 91

VII. Phylum Pyrrhophyta . . . . . . . . . . . . . . . 94

Class Mastigophora . . . . . . . . . . . . . 95

Order 1. Cryptomonadalea . . . . . . . . . . 96

Order 2. Adiniferidea . . . . . . . . . . . . . 989

Order 3. Cystoflagellata . . . . . . . . . . . . 909

Order 4. Cilioflagellata . . . . . . . . 102

Order 5. Astoma . . . . . . . . . . . . 105

VIII. Phylum Opisthokonta . . . . . . . . . . . . 110

Class Archimycetes . . . . . . . . . . . 111

Order 1. Monoblepharidalea . . . . . . . . 111

Order 2. Chytridinea . . . . . . . . . . 113

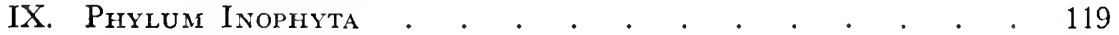

Class 1. Zygomycetes . . . . . . . . . . . . . 121

Order 1. Mucorina . . . . . . . . . . . . . .

Order 2. Entomophthorinea . . . . . . . . 124

Class 2. Ascomycetes . . . . . . . . . . . . . 125

Order 1. Endomycetalea . . . . . . . . . . . 129

Order 2. Mucedines . . . . . . . . . . . 130

Order 3. Perisporiacea . . . . . . . . . . 131

Order 4. Phacidialea . . . . . . . . . . . 133

Order 5. Cupulata . . . . . . . . . . . . 134

Order 6. Exoascalea . . . . . . . . . . . 137

Order 7. Sclerocarpa . . . . . . . . . . . 137

Order 8. Laboulbenialea . . . . . . . . . 140

Class 3. Hyphomycetes . . . . . . . . . . . 140

Order 1. Phomatalea . . . . . . . . . . . . 141

Order 2. Melanconialea . . . . . . . . . . 141

Order 3. Nematothecia . . . . . . . . . 141

Class 4. Basidiomyectes . . . . . . . . . . . 142

Order 1. Protobasidiomycetes . . . . . . . . 146

Order 2. Hypodermia . . . . . . . . . . . 147

Order 3. Ustilaginca . . . . . . . . . . 149

Order 4. Tremellina . . . . . . . . . . . 149

Order 5. Dacryomycetalea . . . . . . . . . 150

Order 6. Fungi . . . . . . . . . . . 150

Orler 7. Dermatocarpa . . . . . . . . . . 152

X. Purlum Protoriasta

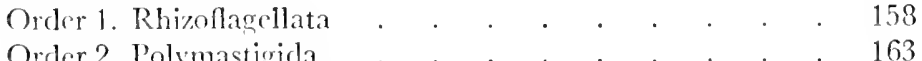

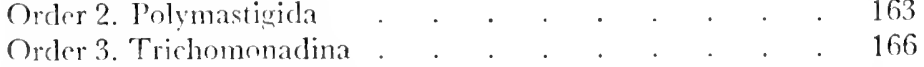

Order 4. Iypermastigina . . . . . . . . . . 168

Class 2. Mycrtozoa . . . . . . . . . . . 171

Orcler 1. Fnteridica . . . . . . . . . . 171

Order 2. Exosporea . . . . . . . . . . . 177 
Order 3. Phytomyxida . . . . . . . . . . 177

Class 3. Rhizopoda . . . . . . . . . . . . . . $\quad . \quad 179$

Order 1. Monosomatia . . . . . . . . . . . . 183

Order 2. Miliolidea . . . . . . . . . . 185

Order 3. Foraminifera . . . . . . . . . . . 185

Order 4. Globigerinidea . . . . . . . . . 187

Order 5. Nummulitinidea . . . . . . . . . . 188

Class 4. Heliozoa

Order 1. Radioflagellata . . . . . . . . . 190

Order 2. Radiolaria . . . . . . . . . . 194

Order 3. Acantharia . . . . . . . . . . 195

Order 4. Monopylaria . . . . . . . . . . . . 198

Order 5. Phaeosphaeria . . . . . . . . . 198

Class 5. Sarkodina . . . . . . . . . . . . . . $\quad . \quad 200$

Order 1. Nuda . . . . . . . . . . . 201

Order 2. Lampramoebae . . . . . . . . . . 205

XI. Phylum Fungilli . . . . . . . . . . . . 206

Class 1. Sporozoa . . . . . . . . . . . . . . 207

Order 1. Oligosporea . . . . . . . . . . . . . 209

Order 2. Polysporea . . . . . . . . . . . . 211

Order 3. Gymnosporidiida . . . . . . . . . 211

Order 4. Dolichocystida . . . . . . . . . 214

Order 5. Schizogregarinida . . . . . . . . 215

Order 6. Monocystidea . . . . . . . . . 215

Order 7. Polycystidea . . . . . . . . . . . . 216

Order 8. Haplosporidiidea . . . . . . . . . . 218

Class 2. Neosporidia . . . . . . . . . . . . . . 219

Order 1. Phaenocystes . . . . . . . . . . 219

Order 2. Actinomyxida . . . . . . . . . . . 221

Order 3. Cryptocystes . . . . . . . . . . . . 222

XII. Phylum Giliophora . . . . . . . . . . . . . . . 223

Class 1. Infusoria . . . . . . . . . . . . . 228

Order 1. Opalinalea . . . . . . . . . . . . 228

Order 2. Holotricha . . . . . . . . . . 229

Order 3. Heterotricha . . . . . . . . . . 230

Order 4. Hypotricha . . . . . . . . . . . . 233

Order 5. Stomatoda . . . . . . . . . . . . . . . $\quad$. 233

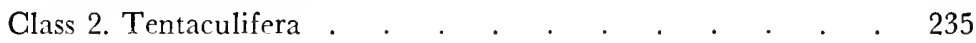

Order Suctoria . . . . . . . . . . . 235

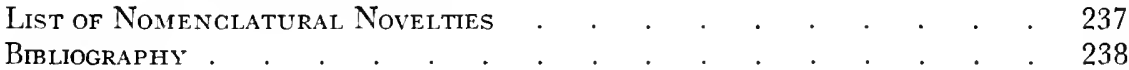

INDEX 



\section{LIST OF ILLUSTRATIONS}

Portrait of Ernst Heinrich Haeckel . . . . . . . . Frontispiece

FIGURE

PAGE

1. Structure of cells of blue-green algae . . . . . . . . . 13

2. Photographs of Escherichia coli . . . . . . . . . . 15

3. Caulobacterialea; Myxobactralea; Cristispira Veneris . . . . . . 26

4. Coccogonea; Gloiophycea . . . . . . . . . . . 32

5. Bangialea . . . . . . . . . . . . . . . 42

6. Nuclear phenomena in Polysiphonia violacea . . . . . . . 45

7. Heterocarpea . . . . . . . . . . . . . . 48

8. Ochromonadalea . . . . . . . . . . . . . 54

9. Ochromonadalea; Silicoflagellata . . . . . . . . . . 56

10. Vaucheriacea . . . . . . . . . . . . . 64

11. Choanoflagellata . . . . . . . . . . . . . . 68

12. Hyphochytrialea . . . . . . . . . . . . . . 70

13. Bacillariacea . . . . . . . . . . . . . . . 72

14. Oomycetes . . . . . . . . . . . . . . . . . 78

15. Stages of nuclear division in Stypocaulon . . . . . . . . . . 84

16. Familiar kelps of Pacific North America . . . . . . . . . 90

17. Microscopic reproductive structures of Laminaria yezoensis . . . 92

18. Cryptomonadalea . . . . . . . . . . . . . 97

19. Cystoflagellata; Cilioflagellata . . . . . . . . . . 104

20. Astoma . . . . . . . . . . . . . . . . 106

21. Astoma . . . . . . . . . . . . . . . . 108

22. Monoblepharidalea . . . . . . . . . . . . . 114

23. Chytridinea . . . . . . . . . . . . . . . 116

24. Zygomycetes . . . . . . . . . . . . . . . 122

25. Ascomycetes . . . . . . . . . . . . . . . 132

26. Ascomycetes . . . . . . . . . . . . . . . . . 136

27. Mycosphaerella personata . . . . . . . . . . . 138

28. Basidionycetes . . . . . . . . . . . . . . 144

29. Fruits of Agaricacca . . . . . . . . . . . . . 153

30. Rhizoflagellata . . . . . . . . . . . . . . 160

31. Polymastigida; Trichomonadina . . . . . . . . . . . 164

32. Hypermastigina . . . . . . . . . . . . . . 170

33. Mycetozoa . . . . . . . . . . . . . . .176

34. Ceratiomyxa fruticulosa . . . . . . . . . . . . . . 178

35. Life cycle of "Tretomphalus," i. e., Discorbis or Cymbalopora . . . 180

36. Shells of Rhizopoda . . . . . . . . . . . . . 184

37. Radioflagellata . . . . . . . . . . . . . . 192

38. Radiolaria; Acantharia; Monopylaria; Phaeosphaeria . . . . . 196

39. Chaos Protheus . . . . . . . . . . . . . . 200

40. Sarkodina . . . . . . . . . . . . . . . 204

41. Life cycle of Goussia Sehubergi . . . . . . . . . . . 208

42. Life cycle of Plasmodium; Babesia bigemina . . . . . . . $\quad 212$

43. Life cycle of Myxoecros Blennius . . . . . . . . . . . . . 220

44. Infusoria, order Hypotricha . . . . . . . . . . . 232

45. Tokophrya Lemnarum . . . . . . . . . . . . 234 



\section{Chapter I \\ INTRODUCTION}

The purpose of this work is to persuade the community of biologists that the accepted primary classification of living things as two kingdoms, plants and animals, should be abandoned; that the kingdoms of plants and animals are to be given definite limits, and that the organisms excluded from them are to be organized as two other kingdoms. The names of the additional kingdoms, as fixed by generally accepted principles of nomenclature, appear to be respectively Mychota and Protoctista.

These ideas originated, so far as I am concerned, in the instruction of Edwin Bingham Copeland, my father, who, when I was scarcely of high school age, admitted me to his college course in elementary botany. He thought it right to teach freshmen the fundamental principles of classification. These include the following:

The kinds of organisms constitute a system of groups; the groups and the system exist in nature, and are to be discovered by man, not devised or constructed. The system is of a definite and peculiar pattern. By every feature of this pattern, we are inductively convinced that the kinds of organisms, the groups, and the system are products of evolution. It is this system that is properly designated the natural system or the natural classification of organisms. It is only by metaphor or ellipsis that these terms can be applied to systems formulated by men and published in books.

Men have developed a classification of organisms which may be called the taxonomic system. Its function-the purpose for which men have constructed it-is to serve as an index to all that is known about organisms. This system is subject to certain conventions which experience has shown to be expedient. Among natural groups, there are intergradations; taxonomic groups are conceived as sharply limited. Natural groups are not of definite grades; taxonomic groups are assigned to grades. When we say that Pisces and Filicineae are classes, we are expressing a fact of human convenience, not a fact of nature. The names assigned to groups are obviously conventional.

Since the taxonomic system represents knowledge, and since knowledge is advancing, this system is inherently subject to change. It is the right and duty of every person who thinks that the taxonomic system can be improved to propose to change it. A salutary convention requires that proposals in taxonomy be unequivocal: one proposes a change by publishing it as in effect; it comes actually into effect in the degree that the generality of students of classification accept it. The changes which are accepted are those which appear to make the taxonomic system, within its conventions, a better representation of the natural system. Different presentations of the taxonomic system are related to the natural system as pictures of a tree, by artists of different degrees of skill or of different schools, are related to the actual tree; the taxonomic system is a conventionalized representation of the natural system so far as the natural system is known.

These statements are intended to make several points. First, as a personal matter, advancement of knowledge of natural classification, and corresponding improvement of the taxonomic system, have been my purpose during the greater part of a normal lifetime. Secondly, I have pursued this purpose, and continue to pursue it, under the guidance of principles which all students of classification will accept (perhaps with variations in the words in which they are stated). In the third place, I have tried to answer the question which scientists other than students of classification, and likewise the laity, are always asking us: why can one not leave accepted classification undis- 
turbed? One proposes changes in order to express what one supposes to be improved knowledge of the kinds of organisms which belong together as facts of nature. If here I place bacteria in a different kingdom from plants, and Infusoria in a different kingdom from animals, it is because I believe that everyone will have a better understanding of each of these four groups if he does not think of any two of them as belonging to the same kingdom.

The course of evolution believed to have produced those features of the natural system to which the present work gives taxonomic expression is next to be described.

Life originated on this earth, by natural processes, under conditions other than those of the present, once only. These are the opinions of Oparin (1938) 1 , and appear sound, although some of the details which he suggested may not be. When the crust of the earth first became cool, it was covered by an atmosphere of ammonia, water vapor, and methane, and by an ocean containing the gases in the atmosphere above it and minerals dissolved from the crust. This is to state the hypotheses that organic matter in the form of methane is older than life; and that whereas conditions on the face of the earth tend now to cause oxidation, they tended originally to cause reduction. In a medium of the nature of the supposed primitive ocean, spontanous chemical changes will occur and produce organic compounds of considerable complexity: this has repeatedly been demonstrated by experiment. To convert a solution of ammonia, methane, and minerals into protoplasm, Oparin postulates a very long series of changes, producing successively more complicated compounds and mixtures, and requiring perhaps hundreds of millions of years. The changes are conceived as accidents; they are supposed to have been probable accidents, like throwing a seven at dice, not events which could only very rarely occur by accident, like throwing twenty sevens in succession. By supposing that some of these processes used up the naterials necessary for them, Oparin provides an explanation of the single origin of life: we are confident that all life is of one origin, because all protoplasm is of the same general nature, and all life consists of essentially the same processes. The course of events described would have yielded, as the original form of life, anaerobic saprophytes; this is in harmony with the fact that anaerobic energesis is in a sense the basic metabolic process. The original organisms would scarcely have possessed nuclei: Oparin's theorics indicate, as the most primitive form of life which has becn able to survive, the anaerobic bacteria. The anaerobic bacteria are indeed very far removed from any lifeless things; their protoplasm and their metabolism are fundamentally the same as ours.

Life requires energy. Under anacrobic conditions, an organism can obtain energy by converting sugars to alcohol, but it can not use alcohol as a source of energy. This example means that anacrobic energesis yields energy in strictly limited quantity and produces incompletely oxidized compounds. So long as all life was anacrobie, it was engaged in converting the organic matter upon which it depended into forms which it could not use; life under these conditions, at least if they persisted for any great period of time, was surely very sluggish. A further series of changes in the metabolic system, occurring accidentally in certain organisms and preserved by natural selection, brought plotosynthesis into existence. The purple bacteria are believed to represent stages in the evolution of photosynthesis, which exists in its fully developed form, involving the release of elemental oxygen, in the blue-green algae. Once photo-

1 Dates in parentheses are references to works which have been consulted and listed in the bibliography. 
synthesis was established in certain organisms, acrobic energesis became possible both to these and to others. This made possible a manner of life more vigorously active than before. The inconsiderable groups of autotrophic bacteria-the organisms which live by oxidizing inorganic matter-appear to be secondary developments dependent upon the existence of photosynthesis.

The organisms whose origin has been suggested thus far-the ordinary bacteria, anaerobic and acrobic, the autotrophic bacteria, the purple bacteria, and the bluegreen algae-are relatively simple in structure and function; all consist of minute physiologically independent cells. The first step in the evolution of more complex organisms was the evolution of the nucleus.

Morphologically, the nucleus is a part of a protoplast which is set apart by a membrane and which originates ordinarily by division of a pre-cxistent nucleus in the manner called mitosis. In this process, a definite number of definite chromosomes appear and undergo equal division. The nucleus exercises control over the protoplast in which it lies. Its controlling action depends upon the chromosomes which go into it, and mitosis has the effect that all nuclei which are derived from one original nucleus strictly by normal processes of mitosis are identical in the controlling effects which they exert. Thus the nucleus serves for the precise transmission of a complicated heredity. Beside mitosis, there are two other processes-two only-meiosis and karyogamy, by which nuclei may produce other normal and enduringly viable nuclei. In a sequence of generations of individuals sexually produced, these processes occur alternately, each one at one point in each cycle of sexual reproduction. Mendelian heredity is produced by changes, in the sets of chromosomes (or parts of chromosomes) in individual nuclei, which occur during meiosis and karyogamy. The role of the nucleus in sexual reproduction is one of its essential characters: the nucleus is related to sexual reproduction, including Mendelian heredity, as structure to function.

The existence of organisms without nuclei shows that the nucleus evolved after life did: it did not evolve at the same time as protoplasm. The essential uniformity of the nucleus and of its association with sexual reproduction shows that these things evolved only once, and together. There are a very few organisms, as Porphyridium and Prasiola, in which the presence or absence of nuclei is not certain; there is accordingly scant evidence for speculation as to the manner of this evolution. As to the time, we know only that microfossils representing nucleate organisms occur in the uppermost strata of the Proterozoic era.

By making possible the precise transmission of a complicated heredity, the nucleus has made possible the development of complexities of structure and function exceeding by far anything occurring in non-nucleate organisms. It appears that as soon as the nucleus was in existence, organisms provided with it entered upon evolution in many characters and gave rise to many distinguishable groups. Among these groups, those which consist respectively of the typical plants and the typical animals are the greatest. There is, however, neither any a priori rcason, nor any evidence from nature, for a belief that all groups of nucleate organisms must naturally belong to one or the other of these two. Several other groups, in general much less considerable than these, are thoroughly distinct and appear equally ancient.

E. B. Copeland understood the history of life very much as it has just been presented. In his teaching, he treated the bacteria and blue-green algae as standing entirely apart both from plants and from animals, and pointed out several other groups which are not as a matter of nature either plants or animals. It was his opinion that these groups should be treated as a series of minor kingdoms; he excused himself 
from the attempt to formulate a definite and comprehensive system. This teaching was the original stimulus which has led to the present work. I bear witness that E. B. Copeland taught these things in 1914; he did not publish them until he had ceased to teach (1927).

In the year 1926, when the teaching of elementary botany was first fully my own responsibility, I came to the conclusion that the establishment of several kingdoms of nucleate organisms in addition to plants and animals is not feasible; that all of these organisms are to be treated as one kingdom. This is one of the few points of originality which I claim for my work. It is true that the kingdom thus described is not very different from the third kingdom which various early authors proposed and which Haeckel (1866) named Protista. Haeckel, however, in his varied presentations of the kingdom Protista, included always the bacteria. By setting apart the bacteria and blue-green algae as yet another kingdorn, one meets, at least in part, the objection to the "third kingdom" that it is heterogeneous beyond what can be tolerated.

It has been necessary to meet also the objection that the "third kingdom" substitutes, for an acknowledgedly vague boundary between plants and animals, two vague boundaries: it has been necessary to recognize characters by which sharp definition can be given to plants and animals. It is my contention that these characters have long been known. The kingdom of plants, as the taxonomic representation of a natural group, is to be defined by the system of chloroplast pigments described by Willstättcr and Stoll (1913), and also by the production of certain carbohydrates which occur only sporadically elsewhere. The kingdom of animals is defined by embryonic development through the stages called blastula and gastrula, as pointed out by Hacckel (1872). It is believed that no organisms exhibit both of these sets of characters; the "third kingdom" includes the nucleate organisms which exhibit neither. The kingdoms of plants and animals as here defined are essentially those which are traditionally and popularly accepted. They include all the creatures which Linnaeus listed as plants and animals, with the exceptions of forms of which he knew little, and which he listed superficially at the ends of his treatments of the respective kingdoms.

Of course, the definitions are not warranted to describe the kingdoms without exception. For one thing, each is supposed to have come into existence by crolution through a line of organisms which exhibited its characters imperfectly. For another, evolution can erase what it has created; it is proper to include in a group organisms which have by degeneration lost its formal characters. These things are true of all taxonomic groups.

In due form, then, the system of kingrome here maintained is as follows:

Kinglom I. MYchots. Organisms without melei; the bacteria and blue-green algae.

Kingdom II. Protoctser. Nucleate ormulims not of the characters of plants and animals; the protozoa, the red and brown algae, and the fungi.

Kinglom III. Puntaf. Organisms in whose colls occur cluloroplasts, leeing plastids of a bright green color, containing the pigments chlorophyll a, chlorophyll b, carotin, and xanthophyll, and no others; and which produce sucrose, true starch, and true cellulosc.

Kingdom IV. Anmana. Multicellular organisms which pass during dicvelopment through the stages called blastula and gastrula; typically predatory, and accordingly consisting of unwalled cells and attaining high complexity of structure and function.

This system has twice been given bricf publication $(1938,19 \cdot 7)$. I an glad to say 
that Barkley (1939, 1949) and Rothmaler (1948) maintain a system of kingdoms which differs from this in a single significant detail.

Assuming that this system is tenable as a matter of reason, it will nevertheless not be accepted among taxonomists unless they have some knowledge of what it means in detail. No person is called upon to recognize the kingdoms Mychota and Protoctista until systems of their subordinate groups are available. The bulk of the present work consists of such systems. Complete systems of divisions or phyla, classes, and orders are presented. Groups of lower rank are presented in part, as examples. As a matter of facility, the groups of lower rank are presented more fully in the smaller or better known groups than in the larger or more obscure.

The preparation of this work has taken more than ten years. In the course of it I have received much help. Among those who have answered queries, or who have in various drafts scrutinized the whole work or parts of it for faults of every degree of significance, are Dr. G. M. Smith of Stanford University; Dr. A. S. Campbell of St. Mary's College; Dr. Herbert Graham, formerly of Mills College; Dr. Lee Bonar, Dr. G. L. Papenfuss, and Dr. H. L. Mason of the University of California at Berkeley; Dr. E. R. Noble of the University of California at Santa Barbara; and Dr. H. C. Day of Sacramento Junior College. The counsel of E. B. Copeland has not been withheld. It is a matter of grief that two distinguished zoologists of the University of California, Dr. S. F. Light and Dr. Harold Kirby, have passed away during the long course of this work; as have two colleagues who were my closest friends, Dr. H. J. Child and Di. C. C. Wright.

The portrait of Haeckel which is my frontispiece is used by permission of Macrae Smith Company, Philadelphia. Two figures of Chrysocapsa are used by permission of the Cambridge University Press. Numerous figures have been taken from the Archiv für Protistenkunde with the gracious permission of Prof. Dr. Max Hartmann.

We do well to realize our indebtedness to libraries and librarians. To a great extent, this work has been made possible by the unstinted hospitality of the Biology Library of the University of California at Berkeley.

Two statements appear regularly in prefaces; they are of truths which are strongly impressed upon authors. In the first place, those who have given help have made the work better; the author alone is responsible for deficiencies. The foregoing list of good friends and good scholars does not claim them as proponents of the thesis of this work.

In the second place, the work is not offered as perfect or nearly so. The scholar in a strictly limited field may become master of the available knowledge. One who attcmpts studies in a broad field realizes that he is dealing with many subjects of which otners know far more than he; that he has not wrung dry the existing literature; that some of the problems which puzzle him will be solved if he will wait a little longer. His colleagues have a right to raise these matters as criticisms. But surely, it is not desired that studies in broad fields be never attempted or indefinitely delayed.

A matter which is particularly likely to arouse criticism is that of the names which are here applied to the groups. The principles according to which this has been done are set forth in the following chapter. I beg my colleagues, in dealing with this chapter and with the names subsequently applied, not to imagine that I have acted without grave thought. I have decided, that as in classification, so also in nomenclature, I should set before the community of biologists an experiment in the application of principles; among which principles there are surely some whose strict application will be to the good of our science. 


\section{Chapter II}

\section{AN ESSAY ON NOMENCLATURE}

Whoever sets forth a system of groups finds himself under the necessity of making responsible decisions as to names. The kingdoms have received more names than one (Table 1), and so have nearly all of the major groups within them: it has here been necessary to decide as to the validity and application of the names Flagellata and Mastigophora, Rhodophyceae and Florideac, Rhizopoda and Sarcodina, and many others.

\section{Table 1. Names Applied by Various Authors to the Kingdons of Systems of Four Kingdons}

\begin{tabular}{|c|c|c|c|c|}
\hline Authors & Hacckel, 1894 & $\begin{array}{c}\text { Copeland, } \\
\text { 1938, and } \\
\text { Barkley, } 1939\end{array}$ & $\begin{array}{l}\text { Rothmaler, } \\
1948\end{array}$ & $\begin{array}{l}\text { Copeland, } \\
1947 \text { and here }\end{array}$ \\
\hline ingdoms & $\begin{array}{l}\text { I Protophyta } \\
\text { II Protozoa } \\
\text { III Metaphyta } \\
\text { IV Metazoa }\end{array}$ & $\begin{array}{l}\text { Monera } \\
\text { Protista } \\
\text { Plantae } \\
\text { Animalia }\end{array}$ & $\begin{array}{l}\text { Anucleobionta } \\
\text { Protobionta } \\
\text { Cormobionta } \\
\text { Gastrobionta }\end{array}$ & $\begin{array}{l}\text { Mychota } \\
\text { Protoctista } \\
\text { Plantae } \\
\text { Animalia }\end{array}$ \\
\hline
\end{tabular}

In dealing with plants, with animals, or with bacteria, it is necessary to observe the codes of nomenclature enacted by international congresses for the respective groups: the botanical code (Fournier, 1867; Lanjouw, 1952), with amendments enacted in 1954; the zoological code of 1889 as amended in 1948 and 1953 (issue of an edition incorporating the amendments is expected; Hemming, 1954); and the bacteriological code (Buchanan et al., 1948). Breach of the appropriate code renders an author liable to the penalty of having his work treated as nullity.

The existence of three sets of rules for one thing, and the continual amendment of the older codes, are evidence of imperfection. It will not be purely destructive to point out certain anomalies in the codes as they stand.

The zoological code pretends to overrule the principles of grammar in treating specific epithets as names. It is true that some of these words are names: the Catus in Felis Catus is a name of the cat, and the Mays in Zra May's is a name of maize. But the great majority are adjectives; the sapions in Homo sapiens is not by itself a designation of man, and the rulgare in Hordeum vulgare is not a name of barley. It is a further offense against grammar that the corle prescribes, as the names of all familics of animals, adjectives in the feminine. Applied originally to families of birds, Aves, these names were unobjectionable; but the names of the kingdom and of the overwhelming majority of its subordinate groups are neuter.

The botanical code as published with its appendages makes a book of more than two hundred pages. $A$ statement of principles, in which the last clause provides for exceptions, occupies two pages. The definite rules and recommendations occupy about thirty-five pages; one who studies them cricically will find that they prescribe more than one procedure not warranted by principle. $A$ list of mames maintained or rejected irrespective of priuciple occupies about seventy' pages. 'These things mean that current botanical nomenclature is only within limits a matter of rule; it is to a considerable extent governed by cuactments of the nature of $c x$ post facto laws and bills of attainder. 
The bacteriological code is for the most part a condensation of an earlier edition of the botanical code. It includes the odd feature that the name of a genus of bacteria is to be changed if it had previously been used either among plants or among Protozoa. Since there is an earlier Phytomonas among flagellates, bacteriologists have given a new name to the bacterium Phytomonas. The avoidance of homonyms which they desire will not, however, be attained: no zoologist will allow a new name for the flagellate Klebsiella on account of an earlier Klebsiclla among bacteria.

The grounds upon which these things are treated as wrong are provided by a passage in the botanical laws of 1867 which is believed to define the legitimate authority of congresses and codes:

"Les règles de la nomenclature ne pouvent être ni arbitraires ni imposées. Elles doivent être bassées sur des motifs assez clairs et assez forts pour que chacun les comprenne et soit disposé à les accepter."

It is implied by this statement that principles, appealing to the reason and found sound by the trial of experience, were in existence when it was written; and this is the truth. By this statement, the legitimate powers of congresses are those of courts of common law, which avoid the explicit making of law, but discover the law, interpret it, and apply it. Congresses and codes may legitimately (a) state explicitly corollaries of the principles when they are not obvious; and (b) determine arbitrarily matters which are necessarily determined arbitrarily, not being within the range of principle. One would not in theory deny a power (c) to validate breaches of principle when these are of an expedience verging on necessity; but its use by botanical congresses to produce a roll of exceptions of twice the bulk of the text of the code leads one to doubt the expedience of this admission. It has been through failure to recognize the legitimate limits of their powers - through a conception that their powers are sovereign or plenary-that international congresses have come to enact codes conflicting with each other and giving incomplete satisfaction in themselves.

Under these circumstances, a nomenclature of superior legitimacy can be applied in groups treated as removed from the jurisdiction of the codes. Not without diffidence, this assumption is extended to the bacteria; it will be agreed that the nomenclatural practice applied to the bacteria must be the same as that which is applied to the blue-green algae.

Here one attempts a brief formulation of those principles, appealing to reason and proven sound in practice, to which all nomenclature must conform.

1. Scientific names are words of the Latin language. They are not "of Latin form" or "construed as Latin"; they are Latin. This is to treat Latin as a living language and scientific names as subject to the rules of its grammar. They are not code-designations, nor words of any language or none, as chemical names are.

2. The name of a group of the kind called a genus is a proper noun in the singular. Linnaeus replaced all generic names which were adjectives; all of us his successors should do likewise.

3. The names of groups of genera are proper nouns, or adjectives used as proper nouns, in the plural.

The foregoing principles are of pre-Linnacan origin; beginning with his first significant work (1735), Linnaeus took them for granted. For the principle next to be stated, authority is the practice of Linnaeus in later works (1753 and subsequently):

4. The name of a species consists of the name of the genus to which it belongs followed by one epithet, ordinarily an adjective, occasionally a noun in apposition or in the genitive. 
A fifth principle represents Linnaean practices as subsequently modified:

5. Named taxonomic groups are necessarily of certain fixed ranks called categories, i.e., lists. There are seven principal categories, specified as follows. Every individual organism belongs to a group conceived as the single kind and called a species. Every species belongs to a genus; every genus to a family; every family to an order; cvery order to a class; every class to a division or phylum; every division or phylum to a kingdom. These conventions have the effect that the groups of each principal category embrace the entire range of the kinds of organisms.

The categories of genera and species come down from classic antiquity. Linnaeus originated orders; he originated classes in the sense of named definite groups; and it appears that he is responsible for kingdoms: the writer knows of no earlier authority for the traditional three kingdoms of nature. The category next below that of kingdoms has been variously called; originally it was embranchements (Cuvier, 1812). The history of the category of families is somewhat involved. It originated in the work of Adanson (1763); in the following year, Linnaeus (1764) treated the groups which Adanson had called families as natural orders. Botanists for a long time held that families and orders are the same thing. Zoological practice gradually made families a separate category. Authority for the list of seven principal catcgories as given is Agassiz (1857).

Nothing prevents the assignment of groups to caregories other than these, to subclasses, tribes, and the like. These may be called subordinate categories. The groups of any subordinate category embrace only fragments of the range of kinds of organisms.

The work of Linnaeus was largely innovation, and he did not have the face to declare binding the generally accepted rule of priority. Definite authority for the rule is de Candolle (1813). As currently applied, it may be stated as follows:

6 . The valid name of a group is its oldest published name, conforming to the rules, and not previously applied in the same kingdom.

As corollaries of the rule of priority, when groups are combined, the oldest name of any of them must be applied to the whole, and when a group is divided, its name must be retained for one of the parts. The part to which the original name is to be applied is determined by the methoc of types, formulated by Strickland and his associates (1843):

7. When a group is divided, its name must be applied to the portion which includes whatever part of it the original author would have regarded as typical. The part thus specified is the nomenclatural type of the group.

In the application of these principles to the naming of the groups of Mychota and Protocticta, the following practices appear expedient.

A name is applied by publication in such fashion that the community of biologists rnay reasonably be held responsible for knowing of its existence and recognizing the entity to which it is to be applied. This means that it is to be printed in a technical book or journal and defined in a language for which the generality of biologists will not require an interpreter, namely Latin, English, French, or German. Any' regulation more detailed than this is an cxcuse for breaches of priority. Definition is not necessarily by description: nearly all of the Linnacan genera of plants were cstablished by the listing of species in the Species Plantarum.

When two or more groups published in the same work at the same time are to be combined, their names are of equal priority. The choice of one of their names by the first author who combines them is binding. 
A type as specified in the original publication of a group, or as implied by the inclusion of a single subordinate group, is unchangeable. Linnaeus and his immediate successors had no conception of the device of types, and it is practically impossible to be certain of the elements which they would have regarded as typical in some of their groups. It remains necessary that the type system be applied to these groups. In some of them, it may be expedient that international authority, procecding with due caution, declare types arbitrarily. An individual scholar will do better to call what he supposes to be the type of a group by a different term, namely standard (Sprague, 1926 ) : the standard of a group is a supposed type which rcmains open to debate. The framers of codes have undertaken to make binding the choice of a type by the first author who divides a group. On various occasions, however, this action has been demonstrably mistaken.

Certain venerable names, as Vermes and Algae as used by Linnaeus, were applied to altogether miscellaneous collections of organisms among which the selection of a standard would be purely arbitrary. Such names are called nomina confusa, and are to be abandoned.

It follows from the principle of the binomial nomenclature of species that no genus is named until one or more of its species are designated by binomial names. It follows also that in works in which the nomenclature of species is not definitely binomial no names are of any standing. Hence, the point of time from which priority is effective is that of the introduction of binomial nomenclature, namely 1753 . The enactment of other starting points for the nomenclature of particular groups is pretended law which is not law, like the pretended laws of American states which attempt to regulate interstate commerce under the appearance of doing something else.

The original spelling of names, so far as it is tolerable Latin, is not to be changed. Errors of gender or number, obvious mistakes of spelling, and misprints, are to be corrected. Good Latin is written without diacritical marks: a German Umlaut in a name as published is corrected by inserting an $e$; accents, cedilles, and other barbarisms are dropped. The codes err in prescribing changes in spelling beyond those which are here admitted. If they should establish uniformity in the future, it would be at the expense of divergence from the most respected works of the past.

Specific epithets are capitalized if they are (1) names in the nominative, in apposition with the generic names; (2) names of persons, places, or organisms in the genitive; (3) adjectives derived from names of persons.

Transfer of groups from one kingdom to another docs not warrant any meddling with names. When a group is transferred from one kingdom to another, its valid name in the former-its oldest name not previously used in the kingdom in which it was originally published-has priority from the date of its original publication.

Names of groups higher than genera are in the plural. Some are proper nouns; the remainder are adjectives used as proper nouns, agreeing in gender with the names of the kingdoms in which they are included; either expressing characters of the groups which they designate, or consisting of generic names modified by terminations signifying "resembling" or "of the group of." Plurals of generic names are not tenable (de Candolle, 1813): Ericac means the species of the genus Erica; it does not mean, and can not be used to designate, the genus together with its allies. Names consisting of words other than generic names modified by terminations signifying "resembling" or "of the group of" are not tenable, because they are nonsense: the name Coniferinae, applied by Engler to a class, is an adjective with an additional adjectival termination superimposed. 
A name once applied in any principal category may not be transferred to another, unless it be of a form barred in the former and prescribed in the latter. The main clause of this statement is a consequence of the rule of priority. The exception is a concession to the practice of using names with uniform endings in certain categories.

Names of groups not of principal categorics do not have priority as against names applied in principal categories. This practice, which denies to names in subordinate categories the full sanction of priority, is justified by the fact that groups in these categories are of concern only to specialists in the groups in which they occur; one is not in reason responsible for being aware of their names in groups outside of ones own specialty.

Almost all families of plants have had names with the uniform ending -aceae from the point of time at which the category of families was distinguished from that of orders. Such names were applied to algae, liverworts, and mosses by Rabenhorst (1863) and to higher plants by Braun (in Ascherson, 1864). They are adjectives in the feminine, agreeing with the name of the kingdom Plantae. It is altogether expedient that names of this form be held obligatory throughout the kingdom of plants. A uniform termination for names of families of animals has been in use for many years, but these names are not equally positively sound both grammatically and by priority. There has been a strong tendency to apply uniform terminations to the names of groups of other categories. So far as concerns groups of subordinate categoriessuborders, subfamilics, and so forth-this practice appears expedient; these groups being of concern only to experts in the groups in which they occur, it is as well that their designations be of the nature of code designations rather than names. In attempting to put this practice into effect, some zoologists have made the mistake of applying the same adjective in different genders to different groups; they have not realized that Amoebida is the same word as Amoebidae. Meanwhile, uniform terminations for names of phyla, classes, and orders, beside involving wholesale violation of priority, is something of an insult to the intelligence.

The terminations of ordinal names in -ales and of family names in -accue, currently in use among the Mychota, are here changed to -alca and -acea to agree with the neuter name of the kingdom. A change of the gender of an adjective does not create a new word, and the original authorities for the names will stand. Accordingly:

The name of an order of Mychota, if based on that of a genus, nuust bear the termination -alea. Names of this form are valid in no other category of this kingdom, and may be reapplied to orders. They have priority and authority by publication cxplicitly as orders. Such names do not supersede older ordinal names not based on names of genera.

The name of a family of Mychota is formed of the stem of a generic name (not necessarily a valid name, but never a later homonym) by adding the termination -acca. Names of this forn are not valid in any other category, and may be reapplied to families. They have priority and authority by publication explicitly as families.

The names of families of P'rotoctista, unlike those of Mychota, of plants, and of animals, do not have by priority prevalently a uniform termination. Many of the oldest were first named in -ina. Those of flagellates and myxomycetes have double sets of names, respectively in -aceae and -idae, in current usc. It is not expedient to impose uniform terminations on the names of these groups, at least not in the present work. Accordingly:

Each group of Protoctista is called by its oldcst name of tenable form in the correct category, barring any previously used in other principal categories, irrespective 
of termination. All names which are adjectives are used in the ncuter, but ascribed to the original authors.

The practices described have resulted in the use of many names which will seem strange, producing lists which are undeniably heterogeneous. A friendly critic notes as an example of these things the list of classes, Heterokonta, Bacillariacea, Oomycetes, and Melanophycea, on page 55. It will be realized that the three among these names which are adjectives must be in the feminine if the groups are construed as Plantae, neuter if Protoctista. Taking this fact into account, these are actually the frrst names, not previously used in other principal categories, applied to these groups as classes. What other names could one use? Everyone will know what groups are intended. Would any person understand them better if new names had been created by applying a uniform termination to the old roots?

Enough about nomenclature. We should begin to deal with organisms. 


\section{Chapter III \\ KINGDOM MYCHOTA}

\section{Kingdom I. MYCHOTA Enderlein}

Stamm Moneres Haeckel Gen. Morph. 2: xxii (1866), in part.

Schizophytae Cohn in Beitr. Biol. Pfl. 1, Heft 3: 201 (1875).

Class Schizophyta or Protophyta McNab in Jour. of Bot. 15: 340 (1877); not section Protophyta nor cohors Protophyta Endlicher (1836).

Kingdoms Protophyta and Protozoa Haeckel Syst. Phylog. 1: 90 (1894), in part; not Protophyta Endlicher nor class Protozoa Goldfuss (1818).

Subdivision Schizophyta Engler in Engler and Prantl Nat. Pfanzenfam. I Teil, Abt. la: iii (1900).

Division Schizophyta Wettstein Handb. Syst. Bot. 1: 56 (1901).

Phylum Protophyta Schaffner in Ohio Naturalist 9: 446 (1909), in part.

Kingdom Mrcirota Enderlein Bakt.-Cyclog. 236 (1925).

Kingdom Monera Copeland f. in Quart. Rev. Biol. 13: 385 (1938).

Kingdom Anucleobionta Rothmaler in Biol. Zentralbl. 67 : 248 (1948).

Organisms without nuclei.

The common name of Mychota in general is bacteria, but those which contain chlorophyll together with other pigments which make the green color impure are called blue-green algae.

The cells of Mychota are always separate or physiologically independent: multicellular bodies with distinct tissues do not occur. The cells are of various shapes; most often they are cylindrical, being of diameters from a fraction of one micron to a few microns, rarely more. Except in the groups of myxobacteria and spirochaets, they are walled; the thickness of the walls is of the order of $0.02 \mu$ (Knasyi, 1944). The walls may contain cellulose, but consist chiefly of pectates, compounds of slightly oxidized polysaccharides with sulfate, calcium, and magnesium (Kylin, 1943). These compounds are readily rendered gelatinous by hydration or hydrolysis, and the cells are often imbedded in gelatinous layers called sheaths or capsules.

In describing the Mychota as lacking nuciei, one commits himself to one side of a controversy of many years duration. Because of the greater size of the cells of the blue-grcen algae, the facts are more casily ascertained in this group than in the proper bacteria.

The cells of blue-green algae (Gardner, 1906; Swellengrebel, 1910; Haupt, 1923) are clivided into outer and inner parts which are not sharply distinct. Pigments occur in a dissolved or colloidal condition in the outer part, which contains also granules of stored food. The granules are not carbohydrate, although a form of glycogen distinct from that of higher organisms has been extracted (Gardner; Kylin, 1943). The inner part contains rods and granules, some of which stain like chromatin, while others ("red granules of Bütschli") are stained red by methylene blue. Cell division is by constriction. Olive (1904) interpreted the inner part of the cell as a nucleus continually in process of mitosis, and accordingly without a membrane. It is true that in series of disk-shaped cells one may recognize series of corresponding granules. Where the cells are more elongate, the rods and granules of the interior are divided at random. Haupt expressed the impropriety of calling any part of these cells a nucleus. 
Recent studies of typical bacteria by conventional microtechnical methods (Robinow, 1942, 1949; Tulasne and Vendrely, 1947) and by the electron microscope (Hillier, Mudd, and Smith, 1949) have made it possible to recognize the essential identity of the structure of their cells with those of the blue-green algae. The protoplast consists of outer and inner parts. The outer part, considered as a substance, may be called ectoplasm (Knasyi, 1930), and the inner, considered as a body, may be called the central body (Bütschli, 1890). The ectoplasm is very thin, occupying usually less than one fifth of the radius of the cell. The spiral bands which have often been seen
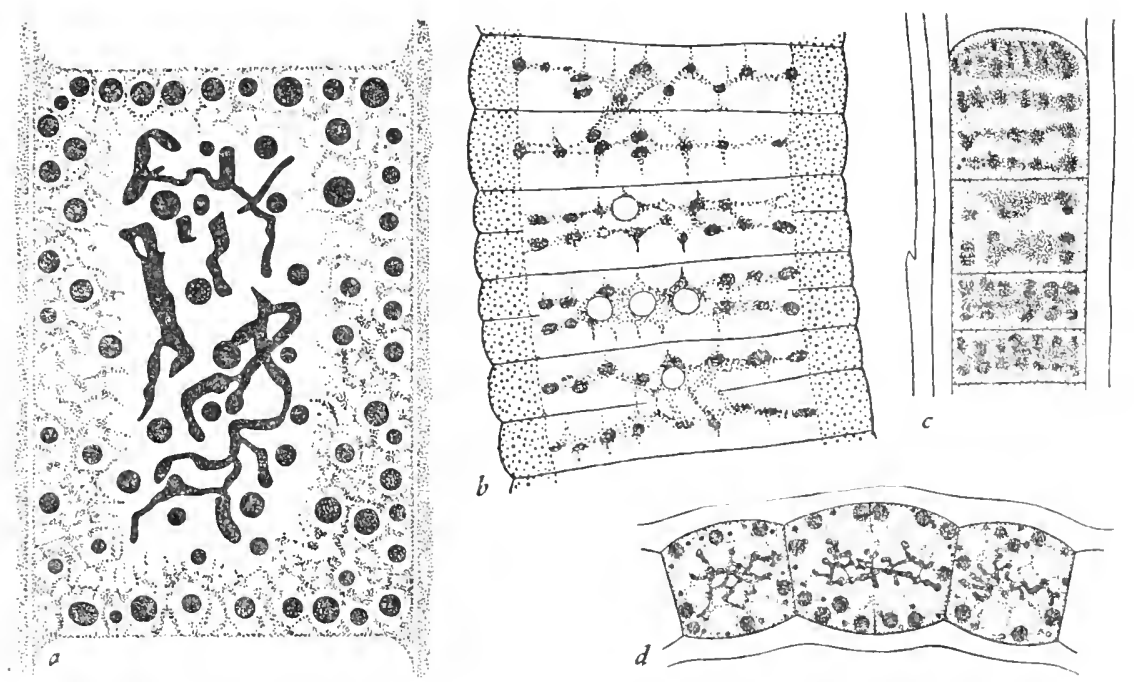

Fig. 1.- Structure of cells of blue-green algac. a, Symploca Muscorum after Gardner (1906). b, Oscillatoria Princeps after Olive (190t). c, Lyngbya sp. from a slide prepared by Dr. P. Maheshwari, x 1,000. d, Anabacna circinnalis after Haupt (1923) x 2,000.

in cells of bacteria, and which Swellengrebel (1906) mistook for a nucleus, are thickenings of the ectoplasm. Specific stains for nuclcoprotein (chromatin), as Feulgen or Giemsa, usually color uniformly the entire central body. If the cclls are exposed to hydrochloric acid, a part of the nucleoprotein, containing ribonucleic acid, dissolves. The remainder, containing desoxyribonucleic acid, persists in the form, basically, of a single fairly large granule in each cell. In rod-shaped bacteria, this granule appears usually to divide by constriction before the cell begins to divide, and may redivide, sc that the cell may contain two dumb-bell shaped bodies. De Lamater and Hunter (1951) succeeded in a partial de-staining of the dumb-bell shaped bodies and interpreted them as dividing nuclei containing centrosomes and definite numbers of chromosomes; typical chromosomes, however, are never as small as the bodies they describe, and are not imbedded in bodies of nucleoprotein from which they can be distinguished only by the most refined technique. Enderlein (1916) observed in rodshaped bacteria series of granules of which some at least are identical with the dumb- 
bell shaped bodies. He named these granules mychits. It might be held that the mychit is a chromosome, and the central body of bacteria a nucleus of a single chromosome, if it were not true that the blue-green algae contain comparable bodies of variable form and inclefinite number.

Many bacteria swim by means of flagella. The diameter of the flagella, as revealed by the electron microscope, is of the order of $0.02 \mu$. Their positions and lengths were made known, before the invention of the electron microscope, by the technique of Loeffler (1889), which consists essentially of depositing upon them a heavy layer of tannic acid. By the absence or presence and arrangement of flagella, bacteria are classified as of four types: atrichous, without flagella; monotrichous, with one flagellum at one end; lophotrichous, with a tuft of flagella at one end; peritrichous, with flagella on the sides.

Myxobacteria, spirochaets, and such blue-green algae as are sheathless filaments, are capable of bending movements (some spirochacts, observed with the electron microscope, are found also to have flagella at the ends of the cells). Spirochaets swim vigorously; in myxobacteria and blue-green algae, the bending movements are a matter of slow writhing. Filaments and cells of blue-green algae are capable also of a moderately rapid gliding movement. The mechanism of this movement has becn the subject of much speculation, reviewed by Burkholder (1934), but remains uncertain. The appearance of the movement is as though it were caused by local secretion of substances affecting surface tension.

The normal reproduction of Mychota is by constriction of the cells, each into two equal daughter cells; whence the various names in schizo- (Greek $\sigma \times i \zeta \omega$, to split). Henrici (1928) studied the changes undergone by bacteria during multiplication. As the cells become numerous, decreasing the food supply and producing substances harmful to themsclves, they begin to attain greater length before dividing. Subsequently there is a gradual transition to cnlarged and distorted forms called involution forms, which divide irregularly, cutting off minute fragments. These observations suggest the idea that the involution forms are the truc normal forms of bacteria, the so-called normal forms being a temporary stage adapted to rapid multiplication under favorable conditions.

In many rod-shaped bacteria, when conditions cease to be ideal, the protoplasts produce within themselves walled bodies of dehydrated protoplasm called spores (endospores). In general, each cell produces only one spore. No experiment has definitely shown how long these spores can remain alive; it is surely a matter of centurics, doubtfully of millenia.

Löhnis and Smith $(1916,1923)$ obscrved of Azotobacter that numbers of protoplasts might escape from their walls and unite in a common mass, which they named the symplasm. The existence of this stage has never been confirmed by other authorities. If the symplasm exists, it is a device for achicving the effect which mucleate organisms attain by sexual reproduction, that is, combination of the heredity of different lines of ancestry.

That Mychota can actually combine characters from different lines of ancestry was first demonstrated beyond question by Tatum and Leclerberg (1917). They mixec cultures of pairs of varietics of Escherichia coli, differing in two or more physiological cliaracters, and isolated from the mixtures races having characters derived from both components. Further work, reviewed by Icderberg and 'Tatum (1953), has aloundantly demonstrated phenomena analogous to typical sexual reproduction. 


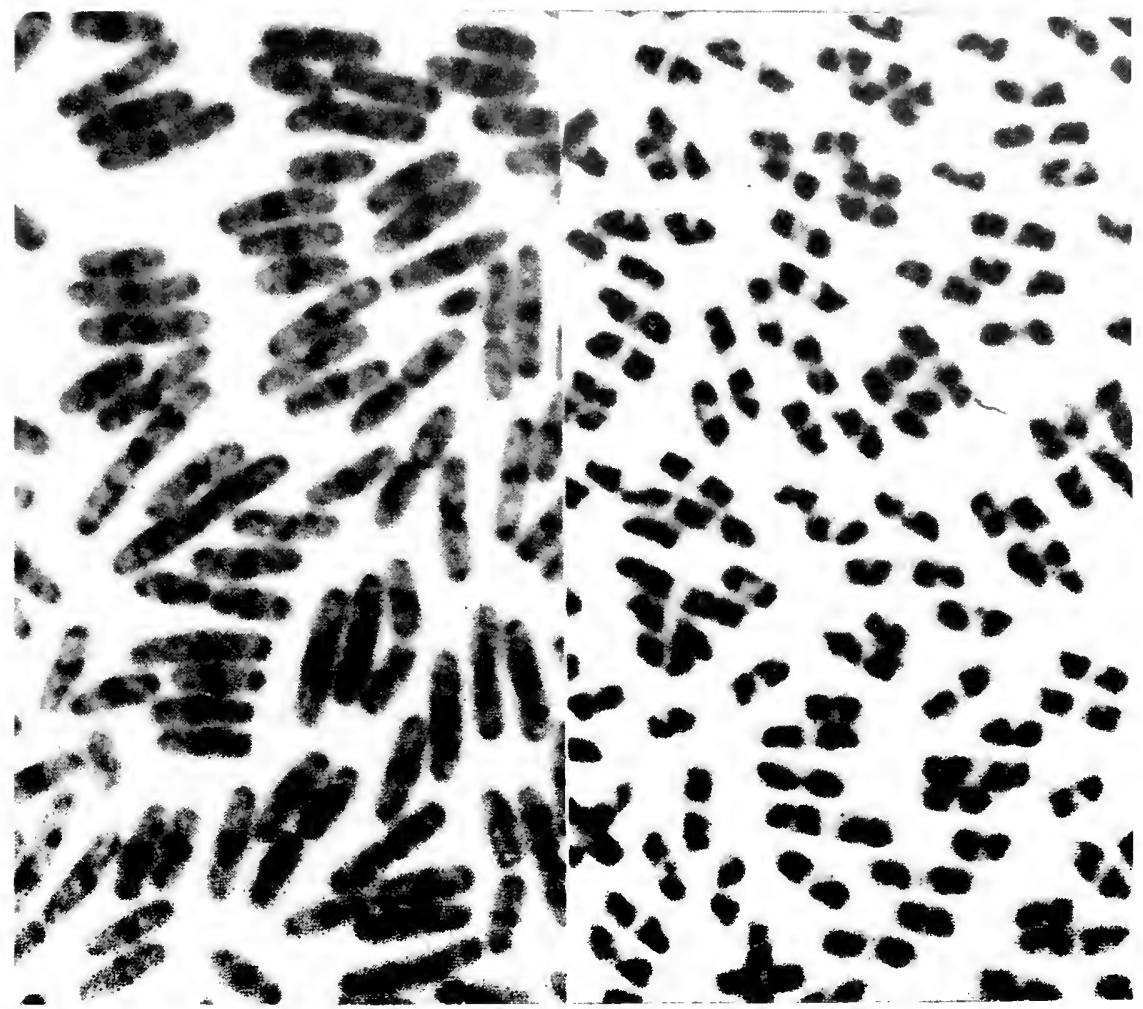

Fig. 2.-Photographs of Escherichia coli by Dr. C. F. Robinow, reproduced by Hillier, Mudd, and Smith (1919); left, stained to show the ectoplasm, in which there are thickenings which tend to be spiral; right, stained to show the large repeatedly dividing gramule in the central body. About $x 2,000$. By courtesy of Dr. Robinow and of the Society of American Bacteriologists. 

The metabolic systems of the Mychota are remarkably diverse. The most superficial list of physiological types would include the following: (a) anaerobic parasites and saprophytes; (b) facultatively acrobic parasites and saprophytes; (c) the vinegar bacteria, being apparently the only known organisms which, while requiring organic matter, are incapable of anaerobic energesis; (d) the autotrophic bacteria, the only organisms which maintain life by oxidation of inorganic matter; (e) organisms living by incomplete photosynthesis; and (f) organisms capable of typical photosynthesis.

Cecologically, the Mychota are ancient. Iron deposits and certain other formations believed to have been produced by them occur in Archeozoic rocks estimated as more than a billion years old.

More than five thousand names have been applied to species of bacteria, but in the attempt to distinguish them, only about fifteen hundred are enumerated (Bergey's Manual, 6th ed., 1948). The species of blue-green algae are probably fewer than one thousand.

The classification of this group is inescapably highly tentative. The morphology is simple and not highly varied; the physiological characters likewise appear simple, bit are highly varied, including many which are not known in other groups. The anticuity of the Mychota makes it probable that many groups which appear to belong together consist actually of parallel developments. The undoubted antiquity of the apparent main groups would lead one to place them in the category of divisions or phyla; but it is not expedient to make many divisions of a group of 2500 species: this would produce too many divisions of a single class or classes of a single order. The kingdom is accordingly treated as a single phylum, and its main divisions as classes.

\section{Phylum ARCHEZOA Haeckel}

Phyla Archephyta and ArcuezoA Haeckel Syst. Phylog. 1:90 (1894); not Phylum Archephyta Haeckel (1866).

Phylum Myxophyceae Bessey in Univ. Nebraska Studies 7: 279 (1907).

Phyla Dimychota and Monomychota Enderlein Bakt.-Cyclog. 236 (1925).

Bacteriophyta and Cyanophyta Steinecke (1931).

Stämme Cyanophyta and Schizomycophyta Pascher in Beih. bot. Centralbl. 48, Abt. 2: 330 (1931).

Divisions Cyanophyta and Schizomycetae Stanier and van Niel in Jour. Bact. 42: 464. (1941).

Characters of the kingdom.

Archezoa is Haeckel's name, at the point cited, for the bacteria. The name had been applied otherwise by Perty (1852), but not in a principal category. It will not be considered inappropriate, if it be remembered that the meaning of zoe is as much life as animal.

The conventional division of the group into two classes, bacteria and blue-green algae, is not perfectly natural. All of the recognized blue-green algae belong together; but the recognized bacteria are a wide miscellany, some of them belonging with the blue-green algae. Here three classes are recognized.

1. Cells without internal pigment, heterotrophic or living by chemosynthesis; not usually producing filaments with prominent sheaths. 
2. Cells with firm walls, non-motile or motile by means of flagella............... Glass 1. Schizophyta.

2. Gells with thin walls or none, motile by means of changes of shape, also sometimes by flagella.......................... 2. Myxoschizonycetes.

1. Cells mostly with internal pigment, living by photosynthesis or chemosynthesis, exceptionally heterotrophic; often producing filaments with prominent sheaths.

.Class 3. Arghiplastidea.

\section{Class 1. SCHIZOPHYTA (Cohn) McNab}

Schizomycetes Nägeli ex Caspary in Bot. Zeit. 15: 760 (1857).

Glass Scinzophyta or Protophyta McNab in Jour. of Bot. 15: 340 (1877).

Class Schizomycetes Winter in Rabenhorst Kryptog.-Fl. Deutschland 1, Abt. 1: 33 (1879).

Class Schizomy'cetae Schaffner in Ohio Naturalist 9: 447 (1909).

Classes Holocyelomorpha and Hemicyclomorpha Enderlein Bakt.-Gyclog. 236 (1925).

Dependent or chemosynthetic Mychota, with walled cells, without photosynthetic pigments and not producing sheathed filaments.

This class includes as orders the typical bacteria and two minor groups.

1. Cells solitary or loosely gathered into clusters or filaments, spherical, rod-shaped, or spiral, not differentiated along the axis............. Order 1. Schizosporea.

1. Consisting of branched filaments not divided

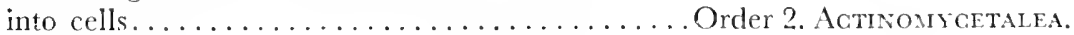

1 Cells attached by stalks, the attached and free ends differentiated.................. Order 3. Cauiobacterialea.

Order 1. Schizosporea [Schizosporeae] Cohn in Hedwigia 11: 17 (1872).

Order Schizomy'cetcs (Nägeli) McNab in Jour. of Bot. 15: 340 (1877).

Order Eubactcria Schröter 1886.

Order Haplobactcriacci Fischer in Jahrb. wiss. Bot. 27: 139 (1895).

Orders Cephalotrichinae and Peritrichinac Orla-Jensen in Centralbl. Bkt. Abt. 2,22: 33t, 344 (1909).

Order Eubacteriales Buchanan in Jour. Bact. 2: 162 (1917).

Mychota whose cells in the typical condition are without internal pigment, walled, of the form of rods, spheres, or spirals, not differentiated along the axis. As this is a numerous group, likely with advancing knowledge to require division, it will be well to provide it with a nomenclatural standard, and to suggest as such Cohn's principal discovery among bacteria, namely Bacillus subtilis.

These are the typical bacteria. As originally described by Leenwenhoeck (1677), they were taken to be a few kinds of "animacules" distinguished only by extremely small size. Only after many years were they shown to be numerous and varied, and highly important as canses of diseases and of other natural phenonena.

The natural classification of the typical bacteria has been hard to discem. The characters by which groups can be distinguished include forms of cells and of clusters of cells; absence or presence and arrangenent of flagella; non-formation or formation 
of endospores; metabolic products; and the peculiar character called Gram reaction.

The method of staining invented by Gram, 1884, consists of staining successively with gentian violet and iodine. It gives an intense blue-black color. From some bacteria, this color is washed out by alcohol; others retain it; the former are said to be Gram negative, the latter Gram positive. In practice one applies successively gentian violet, iodine, alcohol, and safranine, the last being a red dye whose function is to make the Gram negative bacteria visible. The substance stained by gentian violet plus iodine is believed to be lipoid, such as occurs in all cells. The Gram positive quality is believed to consist in a relatively low isoelectric point, a capacity, that is, to combine with anions in a relatively acid medium. This quality lies in the ectoplasm of the cells and disappears in aging cultures.

The classification given in Bergey's Manual (1923, 1925, 1930, 1934, 1939, 1948) is accepted (at least among Americans) as standard. The following system of thirteen families is a moderate rearrangement of the Bergeyan system, with certain ideas or names from Enderlein (1917, 1925), Buchanan (1925), Pribram (1929) and Stanier and van Niel (1941).

1. Gram positive, with exceptions many of which are intracellular parasites; atrichous or peritrichous.

2. Spheres dividing in more planes than one.

3. Gram positive.............. Family 1. Micrococcacea.

3. Gram negative; intracellular pathogens in animals............. Family 2. Neisseriacea.

2. Rods, or spheres dividing in one plane.

3. Not producing endospores.

4. Atrichous.

5. Not intracellular parasites. . Family 3. Cory nebacteriacea.

5. Intraccllular parasites.... . Family 4. Ricketrsiacea.

4. Peritrichous.............. Family 5. Kurthiacea .

3. Producing endospores............ Family 6. Bacillacea.

1. Gram negative.

2. Atrichous or peritrichous, requiring com-

paratively complicated organic food.

3. Not plant pathogens.

4. Not fixing nitrogen.

5. Capable of growth on ordinary media........... Family 7. Achromobacteriacea.

5. Requiring special media; minute atrichous pathogens. Family 8. Pasteurellacea.

4. Fixing nitrogen............. Family 10. Azotobacteriacea.

3. Plant pathogens............... Family 9. R hizoblacea.

2. Atrichous, monotrichous, or lophotrichous; the atrichous representatives, and many others, can survive with organic foods simpler than carbohydrates, or with none.

3. Mostly requiring at least carbohydrates.......................... 
3. Not requiring carbohydrates.

4. Oxidizing alcohol to acetic acid, and acetic acid to $\mathrm{CO}_{2}$ and $\mathrm{H}_{2} \mathrm{O} \ldots \ldots \ldots \ldots \ldots \ldots$ Family 12 . Agetobacteriacea.

4. Not as above; many examples strictly autotrophic.......... Family 13. Nitrobacterlacea.

Family 1. Micrococcacea [Micrococcaceae] Pribram in Jour. Bact. 18: 370, 385 (1929). Family Coccaceae Zopf 1884; but the genus Coccus is a scale insect. Gram positive spheres producing packets or irregular masses. Micrococcus, saprophytic or parasitic, producing irregular masses of cells; the pathogenic species have been treated as a separate genus Staphylococcus. Sarcina, saprophytic or commensal spheres producing packets.

Family 2. Neisseriacea [Neisseriaceae] Prévot ex Bergey et al. Manual ed. 5: 278 (1938). Family Neisseriacécs Prévot in Ann. Sci. Nat. Bot. sér. 10, 15: 119 (1933). Obligate parasitcs, the Gram negative spherical cells occurring chicfly in pairs within leucocytes in the lesions of disease. Neisseria gonorrhoeae, the gonococcus; N. I' eichselbaumii Trevisan ( $N$. intracellularis, $N$. meningitidis, Auctt.), the meningococcus.

Family 3. Corynebacteriacea [Corynebacteriaceae] Lehmanu and Neumann 1907. Family Corynebacteriidae Enderlein in Sitzber. Gess. naturf. Freunde Berlin (1917): 314. Family Lactobacillaceac Winslow et al. in Jour. Bact. 2: 561 (1917). Family Lactobacteriaccae Orla-Jensen 1921. Family Leptotrichaceac Pribram in Jour. Bact. 18: 372 (1929), not family Leptotrichacci Schröter 1886. Gram positive rods, or spheres dividing in one plane and producing chains, non-motile.

Streptococcus, spheres in chains; saprophytes in milk, involved in the making of butter and cheese; and commensals and serious pathogens causing, for examplc, abscesses, septicemia, erysipelas, and pneumonia.

Diplococcus, sphcres usually in pairs, encapsulated. D. pncumoniac occurs in many immunologically distinct races which are the usual causes of pneumonia.

Lactobacillus, rods, microaerophilic, producing lactic acid. In milk, involved in the making of butter and cheese; in the oral cavity, being the usual agent of dental caries (Rosebury, Linton, and Buchbinder, 1929); common in sewage.

Leptotrichia, rods which become exceptionally long before dividing. Oral cavity of man and beasts.

Corynebacterium, rods, becoming club-shaped, staining in a banded pattern. The type specics is the agent of diphthcria, $C$. diphtheriac; the genus includes also many harmless commensals important only as making diagnosis difficult. The cells divide in an exceptional fashion, by breaking violently from one side to the other near one end; the cutt-off cnd swings around besile the main body and proceeds to grow. Repeated division in this manner produces clusters of parallel cells (Park, Wiliams, and Krumweide, 1924).

Family 4. Rickettsiacea [Rickcttsiaccae] l'inkerton 1936. Familics Burtoncllaccae Gieszszykicwicz 1939 and Chlamy'dozoaccac Moshkovsky 1945. Minute obligate intracellular parasites of varied form, commonly Gram negative but with Gram positive granules.

There have been many observations of bodics of the characters stated, but a satisfactory classification of then is not yet possible. Howard Taylor Ricketts showed that Rocky Mountain spotted fever is transnitted by the tick Dermocentor, and observed, in the cells of diseased tissues, minute irregularly staining bodies; in 1910, 
in the course of further studies of the disease, he contracted it and died. Stanislas Prowazek, called into the Austrian military medical service in 1914, began to study typhus, which is transmitted by lice; observed similar intracellular bodies; contracted typhus, and died in February, 1915 (Hartmann, 1915). The cause of Rocky Mountain spotted fever is Rickettsia Rickettsii, and that of typhus is R. Prowazekii. Several other species are known. By serological methods, Anigstein (1927) showed that R. Mclophagi is closely related to Corynebacterium.

In cases of the disease of the west slope of the Andes called verruga peruana, Oroya Fever, or Carrion's disease, there occur intracellular bodies named Bartonella bacilliformis. Noguchi and thers (1928) completed the demonstration that the disease is transmitted by biting flies of the genus Phlebotomus. Good authority has construed Bartonella as a sporozoan.

Students of flagellates, Sarkodina, and Infusoria have occasionally observed in the cytoplasm or nuclei of these organisms minute bodies multiplying to form considerable masses. These parasites have generally been construed as chytrids, but have little in common with proper chytrids. The genus Caryococcus Dangeard includes at least a part of them.

Family 5. Kurthiacea, fam. nov. Gram positive peritrichous rods, not producing endospores. Kurthia, harmless; Listeria Pirie ex Murray in Bergey's Manual 6th ed. 408 (1948), pathogenic in sheep and man.

Family 6. Bacillacea [Bacillacei] Fischer in Jahrb. wiss. Bot. 27: 139 (1895). The spore-forming rods, always Gram positive, mostly peritrichous, very numerous in species, common, and important.

Bacillus Cohn 1872, is one of the oldest generic names of rod-shaped bacteria which can be definitely applied: it can be definitely applied because the type species B. subtilis was so described as to be recognizable. The genus has been used to include rods in general or at random. Defined as aerobic spore-formers, as proposed by Buchanan, 1917, it is a thoroughly natural group. As treated in the fifth edition of Bergey's Manual, it included nearly 150 duly distinguished species; in the sixth edition, this number is cut to thirty-three. The great majority are saprophytic. Exceptions, important pathogens, are B. anthracis; and B. alvei and other species causing foulbrood of bees.

The anaerobic spore-formers constitute the genus Clostridium. The type species was discovered and named three times in different connections. As an anaerobe involved in the fermentations which give butter its flavor, it is C. butyricum Prazmowskı. As an organisms whose cells contain granules staining like starch, it is Bacillus Amylobacter van Tieghem. It has the property of fixing nitrogen; discovered in this capacity by Winogradsky (1902) it was named C. Pastorianum. The species of Clostridium, as of Bacillus, are numerous. They are primarily saprophytic, but many species produce powerful toxins and are serious pathogens. Examples are C. tetani; $C$. botulinum; and C. septicum and a whole roll of other species, causing various forms of gangrene, occasion for the study and distinction of which was found during World War I.

Family 7. Achromobacteriacea [Achromobacteriaceae] Breed 1945. Family Bacteriaceae McNab in Jour. of Bot. 15: 340 (1877), based on a generic name which must be abandoned as a nomen confusum. Family Enterobacteriaceae Rahn 1937, not based on a generic name. Gram negative rods which lack the dictinctive characters of the families subsequently to be treated. 
The nine genera listed first occur normally in animals, mostly in the gut and mostly as commensals; exceptions are important pathogens. Most of them produce acid, and many of them produce gas, from sugar. These genera are the traditional colon-typhoid-dysentery group.

Escherichia coli, the colon bacillus, and Acrobacter aerogenes, the gas bacillus, are common commensals which produce acid and gas from dextrose and lactose. The standard method of testing waters for contamination is essentially a test for the presence of these organisms.

Klebsiella also produces acid and gas from sugars. It inhabits the respiratory tract. The cells are heavily capsulated and non-motile. The type species $K$. pneumoniae is an important pathogen, the pneumobacillus of Friedländer.

Proteus vulgaris (this is at least the third genus to bear the name Proteus, but the first in this kingdom) produces acid and gas from dextrose but not lactose, and liquefies gelatine. It is usually isolated from spoiled meat.

Salmonella is distinguished from Proteus by non-liquefaction of gelatine. Many of its species are harmless commensals; others cause paratyphoid fevers. Immunological study of cultures of Salmonella from cases of disease and from waters have resulted in the distinction of fully 150 races, mostly unnamed and identifiable only by immunological reactions. Eberthella includes motile rods producing acid but not gas from sugars, and belonging to the same immunological system as the various races of Salmonella. Eberthella typhi causes typhoid fever.

Shigella is distinguished from Eberthella by non-motility. The Shiga bacillus, $S$. dystenteriae, is the cause of dystentery.

Bacteroides is a numerous group of acid-producing gut bacteria, motile or nonmotile, generally harmless, distinguished from the foregoing as strictly anaerobic.

Alcaligenes fecalis, an apparently harmless organism isolated from intestinal contents, does not produce acid from sugars; grown in milk, it produces an alkaline reaction.

Numerous races of bacteria which have been isolated from soil and are capable of attacking cellulose are assigned to the genus Cellulomonas. Bacteria which produce an extracellular red pigment are Serratia (one of the oldest generic names for bacteria); those which produce yellow pigment are Flavobacterium; those which produce blue, black, or violet growths are Chromobacterium. Cultures which lack the distinctive characters of all of the above named genera (most such cultures have been isolated from water) are called Achromobacter.

Family 8. Pasteurellacea nom. nov. Family Parvobacteriaceae Rahn; there is no corresponding generic name. Minute non-motile Gram negative rods, pathogenic, requiring special media for cultivation. Pasteurella avicida is the cause of chicken cholera, upon which Pastcur made important studies. Of greater dircct importance to man is Pasteurella pestis, the causc of plague. Hemophilus includes the agents of whooping cough, soft chancre, and conjunctivitis. Brucella includes the organisms which cause Malta fever, undulant fever, Bang's clisease, contagious abortion. Pfeifferella mallei is the cause of glanders.

Family 9. Rhizobiacea [Rhizobiaceac] Conn in Jour. Bact. 36: 321 (1938). Gram negative rods, atrichous or peritrichous, parasites on plants. Cultured in the presence of sugars, these organisms produce acid; they are evident allies of the colon group.

Enwinia commemorates Iswin F. Smith, the discoverer of many bacteria pathogenic to plants. Typical species cause blights, wilts, or dry necroses. The discovery by Burrill, 1882, of Erwinia amylovora, the causc of the firc blight of peors, should 
have prevented the formulation of a theory, once entertained, that all bacteria require neutral media, and are accordingly incapable of causing diseases of plants.

The species of Pectobacterium, as P. carotovorum, cause rots. Those of Agrobacterium cause galls; A. tumefaciens causes crown gall of many plants.

Rhizobium includes the species which produce little galls ("nodules") on the roots of plants and which benefit their hosts by fixing nitrogen. The best known hosts of Rhizobium are plants of the family Leguminosae; the relationship between Leguminosae and Rhizobium is a classic example of symbiosis. There are several or many species of Rhizobium, scarcely distinguishable morphologically, but living on different groups of legumes. The race which was first recognized and isolated, $R$. Leguminosarum Frank 1890 (Schinzia Leguminosarum Frank 1879; Bacillus Radicicola Beijerinck 1888) is that which attacks plants of the pea tribe. Bewley and Hutchinson (1920) accounted for the variety of forms which Rhizobium can assume. In the roots of plants it occurs as involution forms. In culture, it is a peritrichous rod, but the flagella are often reduced to one, and it has been confused with the monotrichous bacteria (Conn and Wolfe, 1938).

Family 10. Azotobacteriacea [Azotobacteriaceae] Bergey, Breed, and Murray in Bergey's Manual 5th ed., preprint, v and 71 (1938). These are the organisms which were originally isolated by Beijerinck (1901) by inoculating with garden soil shallow layers of a nitrogen-free nutrient solution containing mannite. The commonest species, Azotobacter Chroococcum, is usually seen as ellipsoid cells, as much as $4 \mu$ thick and $7 \mu$ long, solitary, with peritrichous flagella, or forming non-motile clusters imbedded in a heavy capsule. Beijerinck observed the occurrence of globular involution forms as much as $15 \mu$ in diameter. Löhnis and Smith (1916) made a thorough study of variations in form, and reported a remarkable variety of other stages, including the symplasm.

The Pasteurellacea and Rhizobiacea are apparently reasonably close allies of the Achromobacteriacea. The Azotobacteriacea stand somewhat apart. The remaining families of the present order are more definitely distinct, being marked by monotrichous or lophotrichous flagella.

Family 11. Spirillacea [Spirillaceae] Migula 1894. Family Pseudomonadaceae Winslow et al. in Jour. Bact. 2: 555 (1917). Rods and spirals, Gram negative, monotrichous or lophotrichous; not producing much acetic acid, and mostly heterotrophic.

Pseudomonas is a numerous genus of rods which may or may not produce a fluorescent pigment soluble in water; they do not produce a yellow pigment which is insoluble in water. The original species, $P$. aeruginosa, was isolated from pus, in which it produces a blue-green discoloration; it is by itself weakly if at all pathogenic. Other species have been isolated from fresh and salt waters and brines; the bacteria which produce phosphorescence on salt fish are of this genus. Many further species ar: pathogenic to plants, producing chiefly leaf spots.

Phytomonas Bergey et al. 1923 (Xanthomonas Dowson 1948) includes numerous plant pathogens which in culture produce an insoluble yellow pigment; among them are the causes of cabbage rot, walnut blight, and leaf spots on many plants.

Pacinia Trevisan 1885 includes monotrichous curved rods. The type species $P$. cholerac-asiaticae is the cause of Asiatic cholera. Among numerous other species the majority are harmless saprophytes in waters. Recent authorities have treated the cholera organism as the type of the genus Vibrio Müller (1773); their action is an intolerable falsification of the usage of a full century preceding the discovery of the cholera organism. 
Spirillum includes the typical spirals, lophotrichous, a small number of species of harmless saprophytes in foul waters.

Thiospira includes large lophotrichous spirals, colorless, containing granules of sulfur. They are believed to live by chemosynthesis.

Family 12. Acetobacteriacea [Acetobacteriaceae] Bergey, Breed, and Murray 1938. As gross objects, growths of Acetobacter aceti Beijcrinck have been known since prehistoric times. With included yeasts they constitute mother of vinegar (the old numes Mycoderma mesentericum Persoon, Ulvina aceti Kützing, and Umbina aceti Nägeli designated the combination of bactcria and yeasts, and it seems proper to reject them). Free-swimming cells with polar flagella have been observed; ordinarily the cells appear as rods in chains, heavily encapsulated, or as involution forms. The organic food required by Acetobacter is alternatively alcohol, which is oxidized to acetic acid, or acetic acid, which is oxidized to carbon dioxide and water. These processes are strictly aerobic: to make vinegar, one exposes wine to air; to preserve it, one seals the vessels.

Family 13. Nitrobacteriacea [Nitrobacteriaceae] Buchanan in Jour. Bact. 2: 349 (1917). Organisms oxidizing the simplest organic compounds; or facultatively capable of chemosynthesis; or living strictly by chemosynthesis and strictly aerobic: mostly Gram negative monotrichous or atrichous rods.

Methanomonas is capable of oxidizing methane; Carboxidomonas of oxidizing carbon monoxide; Hydrogenomonas, of oxidizing clemental hydrogen. Thiobacillus includes organisms which oxidize hydrogen sulfide or elemental sulfur.

Winogradsky had discovered chemosynthesis in the course of studies of Beggiatoa and other sulfur-oxidizing organisms before he undertook to isolate bacteria which cause nitrification, that is, the natural production of nitrates in soil and waters. $\mathrm{He}$ achieved success (1890) by inoculating, with soil or sewage, media which contained salts of ammonia but no food; he saw the nitrifying organisms first as minute motile rods which he named Nitromonas. Further study and the use of solid media showed that nitrification takes place in two stages and is the work of several kinds of organisms. Winogradsky distinguished Nitrosomonas europaea and N. javanensis, monotrichous rods from different regions as indicated, oxidizing ammonia to nitritcs; Nitrosococcus, non-motile spheres from South Amerca, effecting the same oxidation as Nitrosomonas; and Nitrobacter, non-motile rods oxidizing nitrites to nitrates. Subsequent authors have validated Winogradsky's names by creating the combinations Nitrosococcus nitrosus and Nitrobactor Winogradskyi. Subsequently, Winogradsky discovered yet other bacteria capable of the same oxidations.

The presence of nitrifying bacteria is necessary for the normal growth of most crops. So active are the nitrifying bacteria that no more than traces of ammonia and nitrites are found in normal soils, and so avidly do plants absorb nitrates that these accumulate only in fallow fields.

Order 2. Actinomycetalea [Actinomycetales] Buchanan in Jour. Bact. 2: 162 (1917).

Organisms which consist typically of slender filaments not divided into cells, but which are capable of producing conidia, that is, minute spherical or elongate bodies cut off by constriction from the ends of the filaments, or of breaking up into cells of the form of regular or irregular rods. Non-motile; Gram positive or Gram negative; often of the staining character called acid fast.

The order may be treated as a single family. 
Family Mycobacteriacea [Mycobacteriaceae] Chester 1907. Family Actinomycetaceae Buchanan in Jour. Bact. 3: 403 (1918). Family Streptomycetaceae Waksman and Henrici 1943. Characters of the order. Three genera require discussion.

Streptomyces Waksman and Henrici 1943. The original name of this genus is Streptothrix Cohn (1875); there is an older genus Streptothrix among plants, and the numerous species of the present genus have generally been included in Actinomyces. Cultures are readily isolated from air or soil. They appear as slowly growing colonies which may at first be of various colors and have shiny surfaces. Their texture is tough; a blunt needle will more often tear a colony from the medium than penetrate it. As the colonies grow, they become truncate; the exposed surfaces become white and powdery; pigments, black, brown, red, or yellow, in various races, are produced, and discolor the medium. The toughness of the colonies is a consequence of their structure, of myriad crooked branching filaments about $1 \mu$ in diameter, without joints; the white and powdery surface is produced by myriad conidia released in basipetal succession. The cultures are of an odor which may be described as that of earth under the first rain after drouth: undoubtedly, this familiar odor is that of Streptomyces in the soil. Drechsler (1919), from careful study of several species of Streptomyces, concluded that they are fungi; their filaments are, however, much finer than those of fungi, and no definite nuclei have been seen.

Certain species of Streptomyces cause a scabbiness of potatoes. Except for this, the genus was for a long time regarded as quite unimportant. When the capacity of the fungus Penicillium notatum to inhibit the growth of bacteria had been observed, and had led to the discovery of the drug penicillin, Waksman, the leading authority on the classification of Actinomycetalea, sought comparable drugs produced by Streptomyces, and had the great success of discovering streptomycin.

Actinomyces Bovis Harz 1877 is one of several species of the same general nature as Streptothrix which are pathogenic to animals. It causes lumpy jaw of cattle.

Mycobacterium Lehmann and Neumann 1896 is typified by $M$. tuberculosis, the agent of one of the most important diseases of man, supposed originally to have attacked cattle, and to have spread around the world with European cattle. It is a chronic disease, destroying the tissues slowly and producing a nugatory sort of immunity which makes it possible to test for the disease, but does not check it. The cells are recognized in sputum and in diseased tissues by the acid fast reaction: the dye carbol fuchsin must be applied hot in order to color them; once it has done so, it does not wash out in acid alcohol. It is cultivated with difficulty. The growth is dry, powdery, wrinkled, with an odor described as sickening-sweet. It consists of branching filaments which break up readily into rod-shaped or irregular fragments.

Lesions of leprosy contain acid fast organisms named Mycobacterium leprae. Gay (1935) has discussed the results of attempts to cultivate this species. They have yielded either "diphtheroid" cells or a "streptothrix." He concludes that most of the reports are of the same organism reacting variously to various conditions.

Order 3. Caulobacterialea [Caulobacteriales] Henrici and Johnson in Jour. Bact. 29: 4 (1935).

Aquatic bacteria, the cells of most examples secreting gelatinous matter in such a manner as to produce stalks. Henrici and Johnson provided a system of four families, five genera, and nine species. Stanier and van Niel (1941) rejected the group as artificial, placing some of the genera among Eubacteria and leaving others unplaced. The order may be maintained for the accommodation of the latter and divided into two families. 


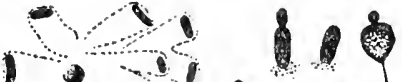

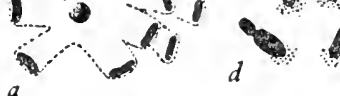
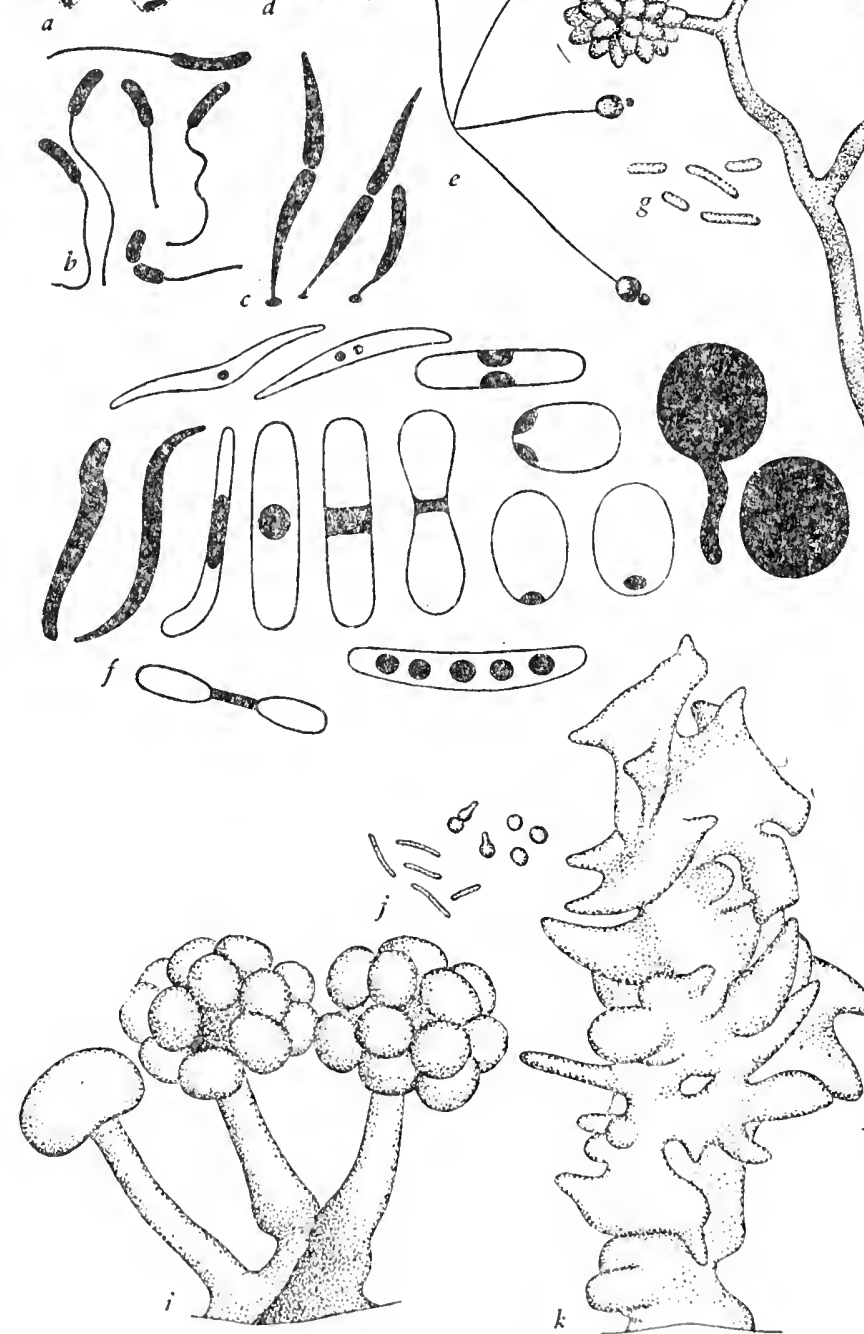

k

Fig. 3-a-e, Caulobacterialea after Henrici and Johnson (1935) x 2,000: a, Nevskia sp.; b, Caulobacter vibrioides; c, Caulobacter sp.; d, Pastcuria sp.; e, Blastocaulis sp. $\mathbf{f}$, Various stages of Cytophaga Hutchinsonii (Spirochacta cytophaga) after Hutchinson and Clayton (1919). g-k, Myxobactralea after Thaxter (1892), the cells $\times 1,000$, in the fruits $\times 200 . \mathbf{g}, \mathbf{h}$, Cells and fruit of Chondromyces crocatus; $\mathbf{i}$, fruit of C. aurantiacus; $\mathbf{j}, \mathbf{k}$, vegetative cells and spores, and fruit, of Mlyxococcus coralloi des. I, m, Dividing cells of Cristispira Veneris after Dobcll (1911) x 2,000. 
Family 1. Leptotrichacea [Leptotrichacei] Schröter 1886. The cells not elongated in the direction of the axis of the stalk.

Didymohelix ferruginea (Ehrenberg) Griffith (first named, and usually listed, under Gallionella, which is a misspelling of the name of a genus of diatoms) occurs in waters containing iron. Older authors described it as consisting of paired filaments, less than $1 \mu$ in diameter, colored bright yellow with imbedded iron oxide, and coiled about each other. In fact, the supposed paired filaments are the margins of a single twisted band, which is not itself an organism but the stalk secreted by a terminal cell. Spirophyllum Ellis is either the same species or a closely related larger one.

Leptothrix Kützing Phyc. Gen. 198 (1843) was inadequately described; the species which was first named, and which is accepted as the type, was $L$. ochracea. It is believed that this name properly designates the masses of ochraceous matter seen in iron springs. Under the microscope, this matter is seen to consist of fine yellow filaments, straight and unbranched. Ellis (1916) described them as consisting of a cylinder of protoplasm, not divided into cells, enclosed in a sheath. Almost surely, these structures, generally recognized as of the same nature as Didymohelix, are likewise stalks secreted by minute terminal cells.

Siderocapsa Molisch and Sideromonas Cholodny, described as minute spheres or rods imbedded in capsules colored by ferric oxide and attached to plants in waters containing iron, are perhaps to be interpreted as stalkless members of the present group.

Nevskia Famintzin, forming minute gelatinous colonies floating on water, does not accumulate iron.

Family 2. Caulobacteriacea [Caulobacteriaceae] Henrici and Johnson 1. c. (1935). The cells elongated in the direction of the long axes of the stalks. Caulobacter, Pasteuria, and Blastocaulis, colorless saprophytes in waters or parasites in aquatic animacules.

\section{Class 2. MYXOSCHIZOMYCETES Schaffner}

Class Myxoschizomycetae Schaffner in Ohio Naturalist 9: 447 (1909).

Clásss Polyyangidae Jahn Beitr. bot. Protistol. 1: 65 (1924).

Class Spirochaetae Stanier and van Niel in Jour. Bact. 42 : 459 (1941).

Parasitic or saprophytic Mychota, the elongate cells with thin walls or none, capable of bending movements and sluggishly or actively motile. In many examples there is a resting stage: the cell contracts generally, so as to diminish the surface, and deposits a definite wall. The structure so produced is a spore of the type called an arthrospore or chlamydospore.

The two orders Myxobactralea and Spirochaetalea have not previously been combined to form a separate class. A certain species which Hutchinson and Clayton (1919) described as a spirochact, Spirochaeta cytophaga, has subsequently been found to be a myxobacterium. The hint of relationship thus conveyed is confirmed by the whole character of both groups, as may be seen from the discussions of them by Stanier and van Niel (1941) and Knasyi (1944).

Order 1. Myxobactralea [Myxobactrales] Clements Gen. Fung. 8 (1909).

Order MYxobacteriageae Thaxter in Bot. Gaz. 17: 389 (1892).

Order Myxobacteriales Buchanan in Jour. Bact. 2: 163 (1917).

The cells not definitely of spiral form, sluggishly motile. In typical examples, the 
cells occur in swarms imbedded in slime; the entire mass moves concertedly, and is eventually converted into macroscopically visible fruiting bodies.

The group was first recognized by Thaxter. He took note that the fruiting bodies of Chondromyces had already been described by Berkeley and Curtis as those of a gasteromycete, and learned subsequently that Polyangium Link, also described as of the puffball group, is an older name for his Myxobacter. The swarms of cells live in air on damp substrata (commonly the feces of various kinds of animals), moving across them and digesting and absorbing food as they proceed. Labratory culture is fairly easy. As a reaction, apparently, to exhaustion of the available food, the cells change into chlamydospores; the masses of spores held together by dried slime are called cysts. These may be borne on simple or branched stalks built up from the slime as a preliminary to the formation of the cysts and spores. The group is of essentially no economic importance.

The accepted classification is that of Jahn (1924); to the four families which he recognized, one more has been prefixed for the accommodation of the genus Cytophaga.

Family 1. Cytophagacea [Cytophagacae] Stanier 1940. The chlamydospores formed sporadically by individual cells, not in cysts. Cytophaga Hutchinsonii Winogradsky (Spirochaeta cytophaga Hutchinson and Clayton) is one of several species discovered as active fermenters of cellulose. The slenderly spindle-shaped cells are sluggishly motile, and produce ellipsoid chlamydospores resembling yeasts.

Family 2. Archangiacea [Archangiacae] Jahn op. cit. 66. Spores elongate in irregularly extensive masses, not in cysts. Archangium, Stclangium.

Family 3. Sorangiacea [Sorangiaceae] Jahn op. cit. 73. Spores elongate, the cysts angular, in masses, not stalked. Sorangium.

Family 4. Myxobacteriacea [Myxobacteriaceae] (Thaxter) E. F. Smith 1905. Family Polyangiaccac Jahn op. cit. 75. Spores elongate, in distinct rounded cysts, clustered or solitary, sessile or borne on simple or branched stalks. Polyangium Link 1795 (Myxobacter Thaxter 1892), Stelangium, Melitangium, Podangium, Chondromyces.

Family 5. Myxococcacea [Myxococcaceac] Jahn op. cit. 83. Spores spherical; cysts indefinite or definite. Myxococcus, Chondrococcus, Angiococcus.

Order 2. Spirochaetalea [Spirochaetales] Buchanan in Jour. Bact. 2: 163 (1917).

Cells solitary, spiral in shape, actively motile.

The first known species of this group was Spirochacta plicatilis, observed in foul waters by Ehrenberg (1838). The next was the species now known as Borrelia recurrentis (Lebert) Bergey et al., observed in the blood of relapsing fever patients by Obermeier, 1873.

During the last years of the nineteenth century, many attempts to identify the agent of syphilis by standard bacteriological methods were unsuccessful. The German gevernment directed Schaudinn and Hoffmann to continue this work. Fritz Schaudinn, 1871-1906 (Stokes, 1931), had attained distinction as a student of pathogenic protozoa. Within a few weeks, by the microscopic examination of lesions, he attained success where the bacteriologists had failed, and discovered Treponema pallidum (Schaudinn and Hoffmann, 1905).

Spirochaets were first cultivated by Noguchi; few others have been successful in this difficult practice. It requires a medium of aseptic, not stcrilized, animal material, under more or less anacrobic conditions. Each species requires its peculiar variant of the conditions, to which it is quite sensitive. 
Spirochacta plicatilis and other saprophytic speries, iogether with certain species parasitic in mollusks, are fairly large. The species which are parasitic or conimensal in other animals may be extremely small. It is chiefly by study of the larger species that the structure is known. The internal structure is septate. Dobell (1911) found is Cristispira, at the margin of each septum, a whorl of granules staining like chromatin, and interpicted these granules collectively as a nucleus. Noguchi (in Jordan and Falk, 1928) saw in the interior of the smaller species no chambered structure, but a lengthwise rod. This has been interpreted as a nucleus, as a locomotor or skeletal structure, or as an artifact. The electron microscope has shown actual flagella at the ends of cells of Treponema pallidum. Reproduction is normally by transverse division into two. During division, the daughter cells may coil about one another, giving a false appearance of lengthwise division. Gross (1913) observed that Cristispira is capable of breaking up into cylindrical Stäbchen corresponding to the chambers.

The discovery of Treponema by an eminent protozoologist; the character of spirochaetal diseases, several of which are spread by biting insects, and produce only that nugatory immunity which makes diagnosis possible but does not check the disease; and the supposed lengthwise division of the cells; led to the hypothesis that the spirochaets are protozoa. Dobell was surely correct in dismissing this hypothesis, insisting that the spirochaets are neither protozoa nor typical bacteria, but a group sui generis.

The larger and smaller spirochaets are reasonably treated as separate families.

Family 1. Spirochaetacea [Spirochactaceae] Swellengrebel 1907. The cells comparatively large, 80-500u long. Spirochacta, Saprospira, Cristispira.

Family 2. Treponematacea [Treponemataceae] Robinson in Bergey Man. 6th ed. (1948). Family Treponemidae Schaudinn 1905. The cells 4-15u long.

Treponema Schaudinn. The cells comparatively loosely coiled. T. pallidum, the agent of syphillis. T. pertenue, the agent of yaws. T. macrodentium and T. microdentium, harmless commensals in the mouth.

Borrelia Swellengrebel is doubtfully distinct from the foregoing; Noguchi reduced it. B. recurrentis and other species cause relapsing fevers. B. Vincenti causes Vincent's angina (trench mouth). The fusiform cells always found associated with it and supposed to be ordinary bacteria of a genus Fusiformis or Fusobacterium may be its chlamydospores.

Leptospira Noguchi. The cells tightly coiled. L. icterohaemorrhagiae is the agent of infectious jaundice. L. icteroides, isolated by Noguchi in South America, supposedly from cases of yellow fever, is perhaps the same thing: it is now known that yellow fever is caused by a virus. It was in pursuing in Africa his study of yellow fever that Noguchi lost his life by this disease (Flexner, 1929; Eckstein, 1931).

\section{Class 3. ARCHIPLASTIDEA Bessey}

Myxophykea Wallroth 1853.

Myxophyceae Stizenberger 1860.

Division (of Class Algen) Phycochromaccae and order Gloiophyceae Rabenhorst Krytog.-Fl. Sachsen 1: 56 (1863).

Cyanophyceae Sachs Lehrb. Bot. ed. 4: 248 (1874).

Order Cyanophyceae or Phycochromaceae McNab in Jour. of Bot. 15: 340 (1877).

Schizophyceae Cohn 1879, not suborder Schizophyccae Rabenhorst Deutschland's

Kryptog.-Fl. 2, Abt. 2: 16 (1847). 
Order Schizophyceae Schenck in Strasburger et al. Lehrb. Bot. 1894.

Class Schizophyceae Engler in Engler and Prantl Nat. Pflanzenfam. I Teil, Abt. 1a: iii (1900).

Class Arghiplastideae Bessey in Univ. Nebraska Studies 7: 279 (1907).

Class Cyanophyceae Schaffner in Ohio Naturalist 9: 446 (1909).

Class Myxophyceae G. M. Smith (1918).

Subclass Myxophyceae Setchell and Gardner in Univ. California Publ. Bot. 8, part 1:3 (1919).

Cyanophyta Steinke (1931).

Stamm Cyanophyta Pascher in Beih. Bot. Centralbl. 48, Abt. 2: 330 (1931).

Mychota most of which live by phytosynthesis of primitive or typical character, many of them, and most of the saprophytic and chemosynthetic organisms included with them, being of the form of sheathed filaments.

This is primarily the group of the blue-green algae. Blue-green algae are familiar things as forming dark scums in water and on wet surfaces. Rabenhorst (1863) appears first to have recognized them as a group definitely distinct from green algae; he named most of the recognized families. Revisions by Thuret (1875), Bornet and Flahault (1886-1888), and Gomont (1892) failed to provide a satisfactory system of the group; Kirchner's revision (in Engler and Prantl, 1898) is the accepted system.

One of the important contributions of Cohn was his suggestion that the bacteria and blue-green algae belong together. He emphasized this view by mingling the genera of the two groups in two new groups, "tribes," named in effect slime-formers and thread-formers (1875). In this he went too far; but some of the arrangements which he suggested appear natural. Beggiatoa, the type of order Thiobacteria of Migula, appears to be a variant of the common blue-green alga Oscillatoria, differing from it in living by chemosynthesis. Most of the so-called iron bacteria, family Chlamydobacteriaceae of Migula, fall readily into scattered places among the bluegreen algae. Only the genus $S$ phaerotilus remains at loose ends. It is credibly reported to produce cells swimming by means of flagella; no proper blue-green algae do this.

A variety of purple bacteria-bacteria, that is, which contain a red pigmenthave been discovered from time to time. Engelmann (1888) observed that they swim toward the light, and convinced himself that they live by photosynthesis. Van Niel confirmed this, and showed that photosynthesis is in this group of a peculiar character; it requires the presence of reducing agents and does not release oxygen. This type of photosynthesis appears, in fact, to represent a stage of the evolution of typical photosynthesis; the group in which it occurs appears to represent the ancestry of the typical blue-green algae. The poorly known green bacteria appear to belong with the purple bactcria.

Various members of this class have been proved capable of fixing nitrogen (Sisler and ZoBell, 1951; Williams and Burris, 1952).

Four orders may be distinguished:

1. Possessing a red ("purple") intracellular pigment, or a green pigment not masked by others........................................ Rilonobagteria.

1. With green pigment masked by others, or colorless.

2. Producing cells with flagella; non-pigmented sheathed filaments not accumulating ferrugineous matter............... Order 2. Sphaerotilalea. 
2. Never producing cells with flagella.

3. Cells dividing in more planes than one, growing to full size before redividing; unicellular or colonial, not filamentous..................... Order 3. Coccogonea.

3. Cells dividing in one plane, and accordingly producing filaments; exceptional examples reproducing by budding (unequal division) or by repeated division into minute spores....................... Order 4. Glolophycea.

Order 1. Rhodobacteria Molisch Purpurbakterien 27 (1907).

Rods, spheres, and spirals, solitary or colonial, with red or green pigment, performing in the presence of light and reducing substances a sort of photosynthesis in which no oxygen is released.

These organisms have generally been included in Thiobacteria, but do not include Beggiatoa, the type of that order. Molisch divided them into two families, Thiorhodaceae, aerobic, accumulating granules of sulfur, and Athiorhodaceae, microaerophilic or anaerobic, not accumulating granules of sulfur. The green bacteria are to be placed as a third family. The names originally applied to the families are not tenable.

Family 1. Chromatiacea (Migula) nomen familiare novum. Subfamily Chromatiaceae Migula. Family Rhodobacteriaceae Migula; Family Thiorhodaceae Molisch; the family does not include genera with corresponding names. Purple bacteria, aerobic, accumulating granules of sulfur. Chromatium Perty includes the organism of foul waters which was originally named Monas Okenii. It is a plump rod, often bent, sometimes exceeding $10 \mu$ in length, monotrichous or lophotrichous. There are a dozen other genera, rods, spheres, and spirals (Thiospirillum, which belongs here, is to be distinguished alike from Spirillum, Thiospira, and Rhodospirillum), solitary or colonial, motile or non-motile. Most of them were discovered by Winogradsky.

Family 2. Rhodobacillacea nom. nov. Family Athiorhodaceae Molisch. Molisch named in this family a genus Rhodobacterium, but the name Rhodobacteriaceae had already been applied by Migula to the preceding family. Purple bacteria, anaerobic, not accumulating granules of sulfur. Molisch discovered all known members of the present family. The method of culture was to place a mass of organic matter, for example an egg, in the bottom of a cylinder of water (the original account specified water of the River Moldau), cover the surface with oil, place in a north window, and wait several weeks. This method yielded organisms which were assigned to seven genera. Those of spiral form are Rhodospirillum. All others are by van Niel treated as a single genus, which may be called Rhodobacillus Molisch (Rhodopscudomonas van Niel).

Family 3. Chlorobiacea nom. nov. Family Chlorobactcriaceae Geitler and Pascher ex van Niel in Bergey's Manual ed. 6: 869 (1948). Geitler and Pascher (in Pascher Süsswasserfl. Deutschland, 1925) did not place this group in a definite category and name it unequivocally: they called it Cyanochloridinae or Chlorobacteriaceae. Minute spherical or elongate cells with a green pigment different from typical chlorophyll, anaerobic, non-motile, producing irregular or regular gelatinous colonies. Chlorobium, Pelodictyon, Clathrochloris, with a half a dozen known species. Certain 


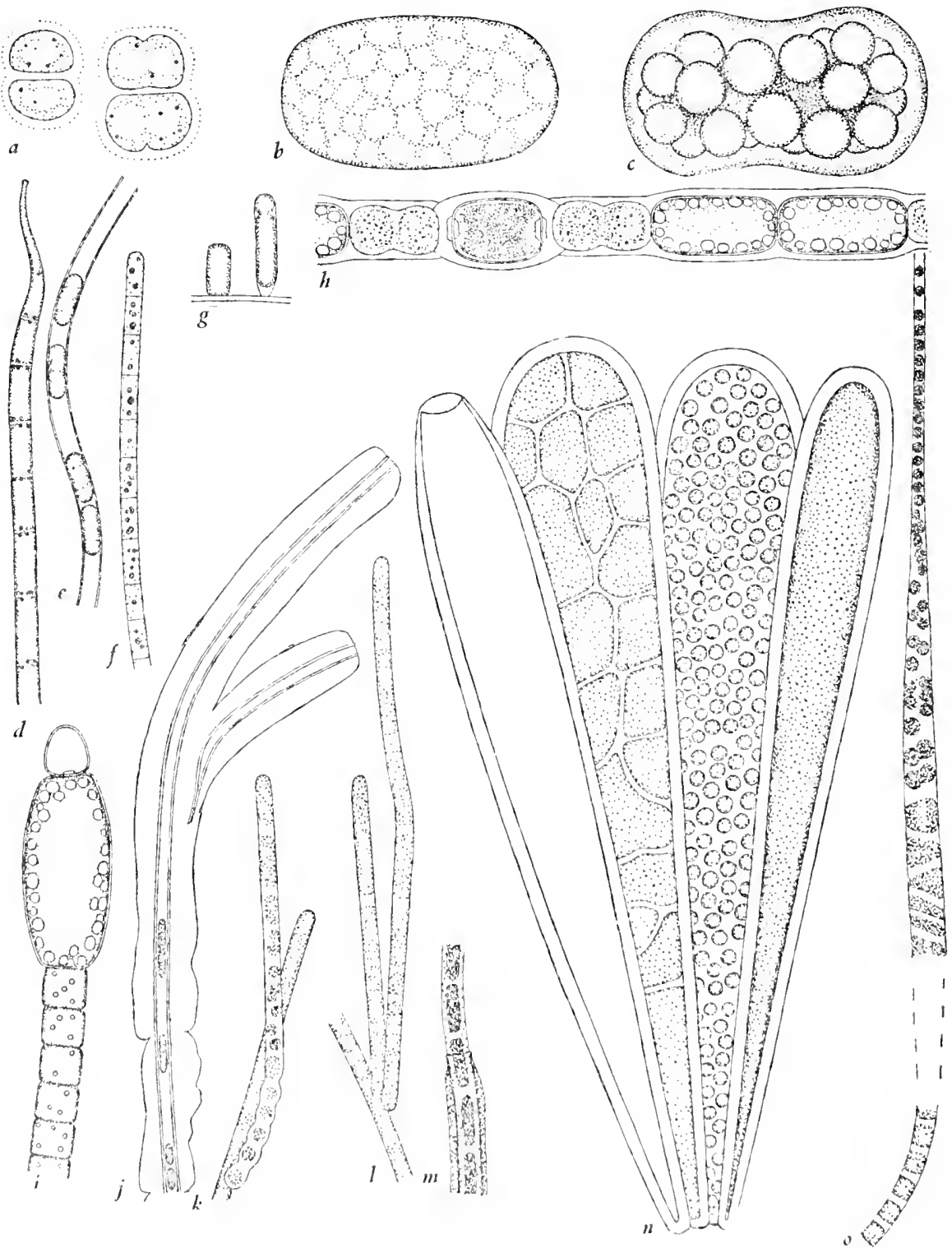

Fig. 4.-Coccogonea: a, Chroococcus sp.; b, c, Achromatium oxalifenum. GrooPHYcea: d, Oscillatoria splendida; e, Phormidium sp.; f, Beggiatoa sp.; g. Chamaesiphon incrustans; h, Anabaena inaequalis; i, Cylidrospcrmum majus; $\mathbf{j}$, Chlamydothrix ochracea; $\mathbf{k}, \mathbf{l}, \mathbf{m}$, Clonothrix fusca after Kolk (1938); n, Dermocarpa protea after Setchell and Gardner (1919); 0, Crenothrix polyspore after Kolk (1938). All $\times 1,000$. 
organisms of this group, occurring in symbiotic combinations with larger bacteria or with protozoa, have been named as additional genera; one of these is Chlorobacterium Lauterborn, but the name is a later homonym.

\section{Order 2. Sphaerotilalea nom. nov.}

Order Desmobacteriales Pribram in Jour. Bact. 18: 376 (1929); there is no corresponding generic name.

Cells colorless, elongate, in sheathed fllaments which branch freely in the manner called "false": the cells divide strictly in one plane; those at a distance from the tip may so multiply as to break the continuity of the series by pushing a growing point laterally out of the sheath. The cells may escape from the filaments, become lophotrichous, and function as swarm spores. There is a single family:

Family Sphaerotilacea [Sphaerotilaceae] Pribram 1. c. There is probably only one species, Sphaerotilus natans Kützing (Cladothrix dichotoma Cohn). It is found as minute gelatinous colonies floating on stagnant water; cells $2-4 \mu$ in diameter.

Order 3. Coccogonea [Coccogoneae] (Thuret) Campbell Univ. Textb. Bot. 84 (1902).

Tribe Chroococcaceac (Coccogoncae) Thuret in Ann. Sci. Nat. Bot. sér. 6, 1: 377 (1875).

Subclass Coccogoneac Engler in Engler and Prantl Nat. Pflanzenfam. I Teil, Abt. la: iii (1900).

Order Coccogonales Atkinson 1903.

Orders Chroococcales and Entophysalidales Geitler in Pascher et al. Süsswasserff.

Deutschland 12: 52, 120 (1925).

Cells solitary or colonial, not filamentous, never flagellate; mostly of blue-green color and living by photosynthesis.

Kirchner (in Engler and Prantl, 1898) placed here two families, Chroococcaceae and Chamaesiphonaceae, but the second belongs to the following order. A proper second family includes the colorless organisms of genus Achromatium.

Family 1. Chroococcacea [Chroococcaceae] (Nägeli) Rabenhorst Kryptog.-Fl. Sachsen 1:69 (1863). Order Chroococcaccac Nägeli Gatt. einzell. Alg. 44 (1849). Unicellular or colonial blue-green algae. Chroococcus, Glococapsa, Mcrismopedia, Coelosphaerium, Gomphosphaeria, etc., occur as plankton or as masses on damp surfaces or the bottoms of bodies of water. Certain species occur as symbionts or parasites within the cells of the green algae Glaucocystis and Gloeochaete. The resulting bodies, having the color of blue-green algae with the structure of green algae, resisted classification until Geitler (1923) explained their nature.

Family 2. Achromatiacea [Achromatiaceae] Buchanan. Cells solitary, large, ellipsoidal, without flagella, non-pigmented; protoplasm alveolar, with or without granules of sulfur in the alveoli. Half a dozen species have been described; Bersa (1920) was probably correct in reducing all to the original one, Achromatium oxaliferum Schewiakoff. It occurs on mud under still waters rich in organic matter.

Order 4. Gloiophycea [Gloiophyccae] Rabenhorst Kryptog.-Fl. Sachsen 1: 56 (1863).

Tribe Nostochincae (Hormonogoneae) Thuret in Ann. Sci. Nat. Bot. sér. 6, 1: $377(1875)$. 
Family Hormogoneae Bornet and Flahault in Ann. Sci. Nat. Bot. sér. 7, 3: 337 (1886).

Subclass Hormogoneae Engler in Engler and Prantl Nat. Pflanzenfam. I Teil, Abt. la: iii (1900).

Order Hormogoneae Campbell Univ. Textb. Bot. 84 (1902).

Order Hormogonales Atkinson 1905.

Blue-green algae whose cells divide predominantly in one plane, so that filaments are produced, together with related colorless organisms.

So far as cell division is strictly in one plane, any branching of the filaments is of the type called "false": it occurs by breaks in the continuity of the series of cells, followed by the outgrowth, beside the original series, of the newly formed tips. In some members of the group, however, the cells are not strictly confined to division in one plane, with the result that "true" branching is possible. There are a few apparently derived examples in which cell division takes place freely in all planes.

Many of these algae produce spores of the type called arthrospores by the direct conversion of normal cells into thick-walled resting spores. Many (almost but not quite exactly the same ones which produce arthrospores) produce peculiarly differentiated cells called heterocysts (the word means "different cells"). These are enlarged thick-walled cells with colorless contents; their most obvious function is to furnish breaking points for the filaments. They are believed to be variants of the arthrospores; they have been secn to germinate and give rise to normal filaments.

Ten families may be distinguished as follows:

1. Cells dividing strictly in one planc; branching none or of the "false" type.

2. The filaments not branching nor tapering nor producing spores or heterocysts.

3. Filaments elongate.

4. Pigmented, blue-green......... Family 1. Oscillatoriacea.

4. Colorless organisms accurnulating sulfur.............. Family 2 . Beggiatoacea.

3. Filaments reduced to single cells which reproduce by budding........ Family 3. Chamaesiphonacea.

2. Filaments branching or tapering, or producing spores or heterocysts, or showing several of these characters.

3. Filaments not tapering.

4. Filaments not branching....... Family 4. Nostocacea.

4. Filaments branching.

5. Blue-green algae mostly producing heterocysts..... Family 5 . Scytonematacea.

5. Minute colorless filaments without heterocysts........ Family 6. Chlianyotrichacea.

3. Filaments tapering............. Family 7. Rivelariacen.

1. Gclls dividing in more planes than one, usually after a preliminary filamentous phase.

2. Pigmented, bluc-green.

3. Producing extensive filaments with heterocysts.................. Family 8 . Sirosipironacea, 
3. Filaments more or less reduced, reproducing by minute spores (gonidia) formed by repeated division in all planes................. Family 9. Pleurocapsacea.

2. Colorless; filamentous, reproducing by

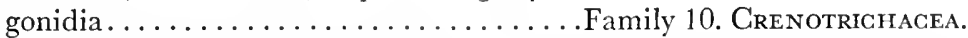

Family 1. Oscillatoriacea [Oscillatoriaceae] Harvey 1858. Blue-green algae consisting of unbranched filaments, not tapering, without spores or heterocysts; mostly actively motile by mechanisms as yet unknown. In the commonest genus, Oscillatoria, the filaments are straight and lack sheaths. Lyngbya and Phormidium produce sheathed filaments, in the latter genus very slender. Microcoleus and Hydrocoleum have more than one filament in each sheath. In Arthrospira and Spirulina the filaments are coiled; those of Spirulina are not visibly septate, and are said to be unicellular.

Family 2. Beggiatoacea [Beggiatoaceae] Migula 1895. Beggiatoa Trevisan includes slender colorless filaments, actively writhing, containing granules of sulfur, found in foul waters and sulfur springs. The species were originally included in Oscillatoria. Winogradsky (1887) showed that they live by chemosynthesis, and discovered the related genera Thiothrix and Thioploca. From the time of these discoveries, these organisms were construed as bacteria of an order Thiobacteria. Under the current hypnthesis that chemosynthesis is a derived character, we are free to believe that the position originally assigned to the species of Beggiatoa was the natural one.

Family 3. Chamaesiphonacea [Chamaesiphonaceae] Borzi 1882. Order Chamaesiphonales Smith Freshw. Alg. 74 (1933). The only genus is Chamaesiphon, minute organisms epiphytic on freshwater plants. The ellipsoid cells are attached at one end and are enclosed in tenuous sheaths. They reproduce by transverse division, which cuts loose small cells from the free ends. By the time two or three such cells are produced, the sheath is ruptured at the free end, and the small cells drift away to repinduce the organism elsewhere.

Family 4. Nostocacea [Nostocaceae] (Nägeli) Rabenhorst Kryptog.-FI. Sachsen 1: 95 (1863). Order Nostocaceae Nägeli 1847. Of this family the most familiar genus is Nostoc, seen as gelatinous bodies, usually globular, green, blue-green, yellow, or brown, of sizes from barely visible to the naked eye up to $10 \mathrm{~cm}$. or more in diameter, in fresh water or on damp earth. Under the microscope, these bodies or colonies are seen to consist of myriad crooked and tangled filaments of bead-like cells imbedded in a gelatinous matrix. Heterocysts are always, and spores usually, present.

If in water one finds filaments of much the same structure as those of Nostoc, but comparatively short, straight, and free or at least not in definite colonies, these represent the genus Anabaena. Filaments floating on water, with cylindrical spores not confined to the ends of the filaments, are Aphanizomenon. Filaments each with one heterocyst and one spore at one end are Cylindrospermum.

Family 5. Scytonematacea [Scytonemataceae] Rabenhorst op. cit. 106. Members of this family produce heavily sheathed filaments like those of Lyngbya, with the difference that heterocysts are usually present. The multiplication of the cells of a filament may produce the result that the cell next to a heterocyst is driven out of line and forced obliquely through the sheath. With further growth, the file of cells ending in one which was forced out of line may appear to be the main axis of a system of branches, while the original summit of the filament appears to be a lateral branch. The description of "false" branching thus given applies particularly to Tolypothrix. 
In Scytoncma, the pressure of multiplying cells causes waves of the filament to break laterally through the sheath and produce branches in pairs. Plectonema branches like Tolypothrix but has no heterocysts.

Family 6. Chlamydotrichacea [Chlamydotrichaceae] Pribram in Jour. Bact. 18: 377 (1929). Aquatic organisms consisting of colorless cylindrical cells in sheathed filaments, without heterocysts but exhibiting false branching, the sheaths of young filaments thin and colorless, those of older ones thick and yellow to brown. Chlamydothrix ochracea Migula was intended as a new name for Leptothrix ochracea Kützing, but the entity to which it is believed to apply is totally different from the one to which the latter name was applied above. Chlamydothrix is a filament of definite cells about $1 \mu$ in diameter. The only other definitely characterized species of this family is Clonothrix fusca Roze, the cells about $2 \mu$ in diameter, those near the tips of the filaments dividing repeatedly (always in one plane) to produce spherical non-motile gonidia (Kolk, 1938).

Family 7. Rivulariacea [Rivulariaceae] Rabenhorst op. cit. 101. The filaments include heterocysts and exhibit the false branching of Tolypothrix; the outgrowth of the filament below each heterocyst gives to the original terminal part the appearance of a branch of which the heterocyst is the basal cell. The ends of the filaments become attenuate and colorless. In Calothrix the filaments are mostly solitary; in other genera they remain together in gelatinous colonies. Rivularia is without spores; in Glocotrichia there is a large cylindrical spore next to each heterocyst.

Family 8. Sirosiphonacea [Sirosiphonaceae] Rabenhorst op. cit. 114. Family Stigonemataceae Kirchner 1898. This family takes its name from the ancient generic name Sirosiphon Kützing 1843, which turned out to be identical with Stigonema Agardh 1824. The cells divide at first in one plane and produce filaments. Presently they exhibit a capacity to divide in other planes, and may produce true branches or multiseriate filaments or both. Heterocysts and spores are generally produced.

Family 9. Pleurocapsacea [Pleurocapsaceae] Geitler in Pascher et al. SüsswasserFl. Deutschland 12: 124 (1925). This group was formeriy included in Chamaesiphonacea, but it appears probable that Chamacsiphon is related to Oscillatoria, and the present group to Stigonema. Most of the Pleurocapsacea are marine, epiphytic on seawceds. Their apparently typical behavior, as cxemplified by IIvella and Radaisia, consists of the production of branching filaments whose terminal cells become enlarged, after which their contents undergo division in many planes to produce numcrous minute spores called gonidia. In Pleurocapsa and Nenococcus there is no filamentous phase; the gonidium gives rise to a cluster of cells all of which produce gonidia. In Dermocarpa the gonidium gives rise to a single vegetative cell which divides only to produce gonidia.

Family 10. Crenotrichacea [Crenotrichaceae] Hansgirg. This family includes the single known species Crenothrix polyspora Cohn, one of the traditional iron bacteria. There is cvery appearance that it is a colorless variant of the Pleurocapsacea. A germinating gonidium gives rise to an umbranched filament of cells, about $2 \mu$ in diameter, in a sheath which is at first thin and colorless, later becoming thicker and discolored by ferric oxide. Some cells may burst from the free cud of the sheath as macrogonidia. Others may begin to divide lengthwise. These may at first grow before re-dividing, and may swell the sheath to a fusiform or trumpet-like shape. By further division they produce numerous microgoniclia, which may sift out of the sincath or be releaserl by its deray.

Such are the Mychota, the organisms which may properly he characierized as lacking mucki. 


\section{Chapter IV \\ KINGDOM PROTOCTISTA \\ Kingdom II. PROTOCTISTA Hogg}

Regne Psychodiaire, Psychodiés, Bory de Saint Vincent Dict. Class Hist. Nat. 8: 246 (1825), 14: 329 (1828).

Kingdom Protozoa Owen Palaeontology 5 (1860), not class Protozoa Goldfuss (1818).

Regnum Primigenium seu Protogtista Hogg in Edinburgh New Philos. Jour. n.s. 12: 223 (1860).

Kingdom Acrita or Protozoa Owen Palaeontology ed 2: 6 (1861).

Kingdom Primalia Wilson and Cassin in Proc. Acad. Nat. Sci. Philadelphia 1863: 117 (1864).

Kingdom Protista Haeckel Gen. Morph. 2: xix (1866).

Kingdom Protobionta Rothmaler in Biol. Centralbl. 67: 243 (1948).

Nucleate organisms other than Plantae and Animalia: the marine algae and the fungi and protozoa. Amiba diffuens may be construed as the standard.

The name Protista, of Haeckel, is the most familiar among those which have been applied to the kingdom here to be discussed, but it is not the earliest. Among followers of Cuvier, the animal kingdom consisted necessarily of four branches. Presumably, it was this tradition that induced Owen to refer the Infusoria and Amorphozoa (sponges) to a separate kingdom, which he called Protozoa. A year later, Owen published an alternative name for this kingdom; but Hogg had already published modifications of two of Owen's names, Protoctista and Amorphoctista( $\kappa \tau i \zeta \omega$, to establish, create), for the reason that names in -zoa appeared inappropriate to groups excluded from the animal kingdom.

The limits here given to the kingdom Protoctista were proposed by the present author $(1938,1947)$. They have been accepted, with exception in a single significant point, by Barkley $(1939,1949)$ and Rothmaler (1948).

It is assumed that the evolutionary origin of the Protoctista consisted of the evolutionary origin of the nucleus, and that all nuclei are essentially the same thing. Kofoid (1923) insisted that enduringly viable nuclei originate among protozoa, as among plants and animals, regularly by mitosis, never by binary or multipe fragmentation, nor by aggregation of stainable granules. He did not recognize the nucleus as essentially a device for sexual reproduction. Several considerable groups of protozoa, however, which Kofoid listed as not known to reproduce sexually, have been found to do so. Here, then, it is maintained that all nuclei, in this kingdom as among plants and animals, are the same thing; and that the nucleus is essentially a device for sexual reproduction, that is, for processes of reproduction which involve always one act of meiosis and one of karyogamy, and which produce Mendelian heredity as an effect.

Photosynthesis is believed to have evolved oniy ence. As it occurs both among nonnucleate and nucleate organisms, the nucleus is believed to hiave evolved in organisms living by this function. The closest approach between non-nucleate and nucieate organisms is believed to be between the blue-green algae and the primitive red algae (Smith, 1933; Tilden, 1933). Thus it appears that the original nucleate organisms were not capable of swimming by means of flagella. Flagella appear to have evolved in unicellular nucleate photosynthetic organisms as a device for dissemination (Bes- 
sey, 1905). The flagella of nucleate organisms are not homologous with those of bacteria; they are much larger and of much more complicated structure.

The origin of flagella was apparently associated with a simplification of the system of photosynthetic pigments, by the loss of chromoproteins, leaving systems of chlorophylls and carotinoids. The association of these two courses of evolution may have been merely coincidental; Tilden suggested the idea that the loss of chromoproteins may have been occasioned by increasing illumination of the waters of the face of the earth.

Organisms of the body type of solitary walled cells, having chlorophylls and carotinoid pigments but not chromoproteins, and producing flagellate reproductive cells, appear to have undergone radiating evolution, producing a wide variety of types of organisms, distinguished by different specific chlorophylls and carotinoids, different types of flagella, and different specific metabolic products. The types of flagella occurring in nucleate organisms are here particularly to be noted.

Loeffler (1889), in the original publication of the standard method of staining the flagella of bacteria, remarked that he had applied this method also to certain larger organisms. He found that the flagellum of Monas bears numerous lateral appendages, and that the cilia of a certain infusorian bear solitary terminal appendages. Loeffler's method is difficult, and has not been much used. Fischer (1894) used it and coined terms, Flimmergeisseln and Peitschengeisseln, designating structures of the respective types seen by Loeffler. Petersen (1929), having applied Loeffler's method to a reasonable variety of flagellates, introduced refinements of terminology. Flagella of the type of the larger flagellum of Monas (the organism bears also a minute simple flagellum) became allseitswendige Flimmergeisseln; those of Euglena, which bear a single file of appengages, became einseitswendige Flimmergeisseln.

Deflandre (1934) devised a different method for seeing the appendages on flagella, and substituted, for the Teutonisms just quoted, French terms based on Greek. These may be Anglicised as follows. (1) The acroneme flagellum bears a single terminal appendage. The flagellum without appendages is said to be simplc; so far as it appears among nucleate organisms, it appears to be a variant of the acroneme type. (2) The pantoneme flagellum bears appendages on all sides. (3) The pantacroneme flagellum bears both terminal and lateral appendages. It is a rarity, known only in the collared monads, and may be supposed to be a variant of the pantoneme type. (4) The stichoneme flagellum bears a single file of appendages.

The point in which Barkley and Rothmaler take exception to the limits here given to kingdom Protoctista is this, that they include in this kingdom the green algae. In the present work, scant attention is given to organisms whose plastids are bright green, containing chlorophylls $a$ and $b$, carotin, and xanthoplyyll, and no other pigments; whose motile stages have acroneme flagella, more than one (usually two), and equal; and which produce essentially pure ccllulose, true starch, and sucrose. Thesc organisms represent the undoubted evolutionary origin of the higher plants; a classification which attempts to represent nature includes them necessarily in the plant kingdom.

Rothmaler set up a system of only four phyla, being the red organisms, basically without flagella; those which are typically yellow to brown, having pantoneme flagella; those with acroneme flagella, including the green algae; and the euglenid group, which have stichoneme flagella. The non-pigmented Protoctista were distributcd among these groups. The system appears unsound by the fact that large blocks of non-pigmented organisms are placed where only portions of them belong. 
In the present work, a less symmetrical system of phyla is offered. Its basis is an ingenuous system of red algae, brown algae, fungi, and the four traditional groups of protozoa; this has been radically modified in view of the great accumulation of knowledge subsequent to the formulation of these groups. The phylum Pyrrhophyta as here limited is tentative; the phylum Protoplasta, marked only by negative characters, amounts to a dumping ground for groups whose relationships are altogether obscure.

1. Living by photosynthesis, which takes place in plastids containing red or blue chromoprotein pigments; never producing flagellate cells. Phylum 1. Rhodophyta.

1. Without chromoprotein pigments.

2. Typically living by photosynthesis, brown, yellow, or green in color.

3. Producing flagellate cells each with one pantoneme or pantacroneme flagellum, often with additional acroneme flagella................ Phylum 2. Phaeophyta.

3. Producing flagellate cells whose flagella are never pantoneme or pantacroneme, often stichoneme............ Phylum 3. Pyrrhophyta.

2. Dependent; motile cells with acroneme flagella or cilia, or amoeboid, or none.

3. Not producing cilia, i. e., structures of the nature of acroneme flagella, numerous and widely distributed on the surfaces of the cells.

4. Cells walled in the vegetative condition.

5. Producing motile cells with single posterior flagella; bodies mostly with tapering rhizoids............ Phylum 4. Opisthokonta.

5. Producing no motile cells; bodies filamentous.......... Phylum 5. Inophyta.

4. Cells not walled in the vegetative condition.

5. Mostly predatory, flagellate or amoeboid or with flagellate or amoeboid stages..... Phylum 6. Protoplasta.

5. Parasitic in animals, producing flagellate cells only as rare exceptions............ Phylum 7. Fungilli.

3. With cilia ...................... Phylum 8. Cilıophora. 


\section{Chapter $\mathbf{V}$}

\section{PHYLUM RHODOPHYTA}

\section{Phylum 1. RHODOPHYTA Wettstein}

Order Floridées Lamouroux in Ann. Mus. Hist. Nat. Paris 20: 115 (1813).

Florideae C. Agardh Synops. Alg. Scand. xiii (1817).

Order Florideae G. Agardh Syst. Alg. xxxiii (1824).

Division (of order Algae) Rhodospermeae Harvey in Mackay Fl. Hibern. 160 (1836).

Class Heterogarpeae Kützing Phyc. Gen. 369 (1843).

Class Florideae J. Agardh Sp. Alg. 1: v (1848).

Rhodophyceae Ruprecht in Middendorff Sibirische Reise 1, Part 2: 200 (1851).

Stamm Florideae Haeckel Gen. Morph. 2: xxxiv (1866).

Phylum Rrodophyta Wettstein Handb. syst. Bot. 1: 182 (1901).

Division Rhodophyceae Engler Syllab. ed 3: 18 (1903).

Phylum Carpophyceae Bessey in Univ. Nebraska Studies 7: 291 (1907).

Phylum Rhodophycophyta Papenfuss in Bull. Torrey Bot. Club 73: 218 (1946).

Definitely nucleate organisms (Porphyridium and Prasiola doubtfully so); with few exceptions living by photosynthetic processes involving red and blue pigments (phycocyanin and phycoerythrin) as well as green and yellow (chlorophylls $a$ and $d$ and carotinoids); not producing true starch, and producing cellulose only in small quantity, the cells walled chiefly with modified carbohydrates which tend to become gelatinous; never producing flagellum-bearing cells, but sometimes producing cells which move in water without the use of deninite organelles.

Tilden (1933) and Smith (1933) are authority for placing the red algae next to the blue-green algae, thus suggesting the inference that they include the most primitive of nucleate organisms. The resemblances between blue-green and red algae are in the following points. Both groups possess, along with the chlorophylls and carotinoids usual in photosynthetic organisms, other pigments, both blue and red. To these pigments as found in both groups, the same names, phycocyanin and phycoerythrin, are applied; they are not, however, the same chemical species (Kylin, 1930). Neither group produces true starch; carbohydrate is stored as substances of the general nature of dextrin or glycogen (occuring in the red algae as solid granules called floridcan starch). Both groups produce cellulose only in scant quantities (Miwa, 1940; Kylin, 1943); the cell walls consist chiefly of materials, of the general nature of carbohydrates, which tend to become gelatinous. They share the negative character of never producing flagella, and the positive one of producing cells which can move actively upon surfaces, without motor organelles, by a mechanism as yet unknown (Rosenvinge, 1927).

The phylum is divisible into two classes:

1. Cells of most examples each with one central plastid, withont protoplasmic interconnections, in ageregates of indefinite extent or organized as filaments or thalli with intercalary growth; zygotes producing spores directly by division. Class 1. Bangiatea. 
1. Celis with protoplasmic interconnections, containing except in the lowest examples several parietal plastids, organized as filaments with apical growth, the filaments usually massed as thalloid bodies; zygotes giving rise to spores indirectly............................... 2. Heterocarpea.

\section{Class 1. BANGIALEA (Engler) Wettstein}

Subclass Bangioideae de Toni Sylloge Algarum 4: 4 (1897).

Subclass Bangiales Engler in Engler and Prantl Nat. Pflanzenfam. I Teil, Abt. 2: ix (1897).

Glass Bangiales Wettstein Handb. syst. Bot. 1: 187 (1901).

Class Bangioideae and orders Bangiales and Rhodochaetales Bessey in Univ. Nebraska Studies 7: 291 (1907).

Class Bangieae Schaffner in Ohio Naturalist 9: 448 (1909).

Protofiorideae Rosenvinge in Mem. Acad. Roy. Sci. Lett. Danemark, sér. 7, Sciences 7: 55 (1909).

Abtheilung (of Stamm Rhodophyтa) Bangïneae Pascher in Beih. bot. Centralbl. 48, Abt. 2: 328 (1931).

Subclass Protoflorideae Smith Freshw. Algae 120 (1933).

Red algae (exceptionally green or of other colors), the cells with solitary central plastids (exceptionally with multiple parietal plastids), lacking protoplasmic interconnections, in irregular colonial masses or forming filaments or thalli with intercalary growth; the zygote produced in sexual reproduction dividing to produce spores directly.

The group is of one order, five families, about fifteen genera; the number of known species is about eighty.

Order Bangiacea [Bangiaceae] Nägeli 1847.

Characters of the class.

1. Cells forming irregular aggregates........... Family 1. Porphyridiacea.

1. Cells forming filaments or thalli.

2. Vegetative cells becoming spores without dividing.............................. Ramody 2.

2. Vegetative cells undergoing division to produce spores.

3. Organisms red, purplish, etc........ Family 3. Porphyrea.

3. Organisms green................. Family 4. Schizogonlacea.

2. Spores formed solitary in special cells.......Family 5. CoMpsopogonacea.

Family 1. Porphyridiacea [Porphyridiaceae] Kylin in Kungl. Fysiog. Sällsk. Förhandl. 7, no. 10: 4 (1937). Order Porphyridiales Kylin 1. c. The only well known species is Porphyridium cruentum (G. Agardh) Nägeli (1849). It is widely distributed in damp climates, forming extensive red patches like blood on damp earth or stone. The spherical cells are reported as varying widely in diameter $(5-24 \mu)$, and Geitler (1932) and Kylin (1937) have distinguished additional species.

Porphyridium has been classified among blue-green, red, and green algae. Lewis and Zirkle (1920) found in each cell a central red plastid, occupying most of its volume, and having rays extending to the cell membrane. Within the plastid there is 


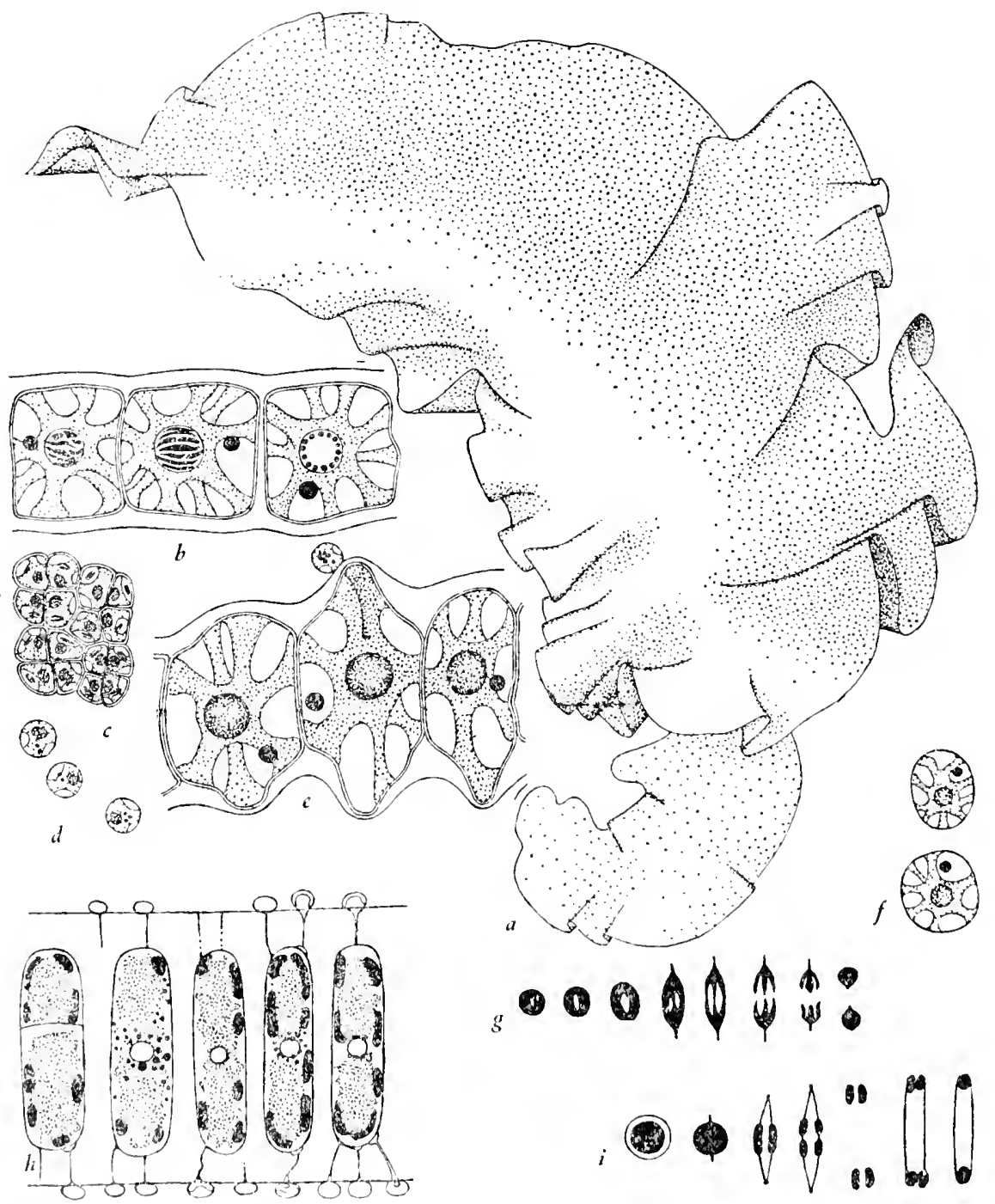

Fig. 5.-a, Porphyra laciniata, thallus $\times 1 / 2$. b-g, Porphyra tenera after Ishikawa (1921); b, cells; c, cell dividing to produce sperms; d, sperms; e, fertilization; f, "carpospores," i.e., cells produced by division of the zygote; $\mathbf{g}$, stages of nuclear division x 2,000. h, i, Porphyra umbilicaris after Dangeard (1927); h, fertilization; i, stages of nuclear division $\times 2,000$. All figures $\times 1,000$ except as noted. 
a moderately large stainable granule; outside the plastid, a single additional granule can usually be found. When a cell is to divide, the granules break up into considrable numbers of smaller ones, some of which become organized as a system of strands forming an irregular network on the surface of the plastid. The protoplast, the network, and the plastid undergo constriction; the processes by which the daughter cells return to the original structure were not clearly seen. Interpretation of these observations is difficult. It is possible that the granule outside of the plastid is a nucleus of the type of those which have been observed in Bangia and Porphyra.

Family 2. Rhodochaetacea [Rhodochaetaceae] Schmitz in Engler and Prantl Nat. Pflanzenfam. I Teil, Abt. 2: 317 (1896). Family Goniotrichaceae Smith Freshw. Algae 121 (1933). Branching filaments, sometimes becoming multiseriate by lengthwise division, the vegetative cells capable of escaping and functioning as spores. Sexual reproduction unknown. Asterocystis, uncommon, in fresh water; the remaining genera marine, epiphytic on other algae. Goniotrichum. Rhodochaete and Goniotrichopsis, the cells with numerous plastids.

Family 3. Porphyrea [Porphyreae] Kützing (1843). Family Porphyraceae Rabenhorst 1868. Family Bangiaceae (Nägeli) Schmitz (in Engler and Prantl, 1896). Filaments or thalli of a red or purple color; the cells, in producing spores, may release their protoplasts as wholes or may undergo division into many. Rosenvinge (1927) observed the active motion of these spores.

The most important genus is Porphyra; the individuals are thalli up to several centimeters in diameter, on rocks or other algae in ocean water along coasts. They are called purple lavers, $t s u^{\prime} a i$, amanori; they are used as food, for making soup or in condiments, and are extensively cultivated in Japan (Tseng, 1944). Bangia is either freshwater or marine; in structure it differs from Porphyra in having filementous bodies, uniseriate or pluriseriate.

During nuclear division in Porphyra tenera as described by Ishikawa (1921), polar appendages form at both ends of the nucleus, which becomes elongate and appears to consist of three strands. The strands break transversely, and each set of three fuses into a mass. Dangeard (1927), dealing with Porphyra umbilicaris and Bangia fuscopurpurea, observed nuclei $5 \mu$ in diameter, each consisting of a karyosome, that is, a mass of chromatin, lying in a clear space surrounded by a membrane. In mitosis, the membrane and the unstained matter disappear. Polar appendages grow out from the karyosome, and their tips become cut off as granules which may be regarded as centrosomes. The remainder of the karysome becomes organized as two masses, evidently chromosomes, connected to the centrosomes by fibers. Each chromosome divides into two; the daughter chromosomes move to the centrosomes and fuse with them to form karyosomes about which new membranes appear. This description represents a definite, if primitive, process of mitosis.

Sexual reproduction, here where we first encounter it, involves differentiated gametes. Naked sperms, indistinguishable from spores, move to the surface of other cells which function as eggs. A strand of protoplasm grows through the gelatinous wall of the egg from the sperm to the egg protoplast, and the protoplast of the sperm migrates through the passage thus formed. The zygote divides two or three times, producing spores. During the first two divisions, the two masses of chromatin which appear are somewhat different in appearance from the vegetative chromosomes (Dangeard, op. cit.); it may be supposed that these masses are tetrads and diads, and that the divisions are meiotic. Evidently, this is a life cycle of the primitive type, in which all cells except the zygotes are haploid. 
Famiiy 4. Schizogoniacea [Schizogoniaceae] Chodat. Family Prasiolaceae West. Fámily Blastosporaceae Wille. Filamentous ồ thallose algae, freshwater or marine, of the structure of Porphyrea, but of a green color; sexual reprodiuction unknown. Kylin (1930) found the pigmentation to be that of green algae rather than of red. Copeland (1955) was unable to discern nuclei. The sole genus Prasiola (Schizogonium represents a stage of development) is of about fifteen species. Setchell and Gardner (1920) and Ishikawa (1921) suggested the place in Bangiacea here given to this group.

Family 5. Compsopogonacea [Compsopogonaceae] Schmitz in Engler and Prantl Nat. Pflenzenfam. I Teil, Abt. 2: 318 (1896). Family Erythrotrichiaceae Smith Freshw. Algae 122 (1933). Filaments, unbranched or branched, uniseriate or pluriseriate, or thalli. Spore-formation is accomplished by the division of a vegetative cell, by an oblique wall, into two unequal cells; the protoplast of the smaller is released as a spore. Rosenvinge observed the spores of Erythrotrichia carnea to move as far as $140 \mu$ per minute. Sexual reproduction is much as in Porphyrea. Erythrotrichia. Erythrocladia. Compsopogon, in fresh water, the cells with numerous parietal plastids.

\section{Class 2. HETEROCARPEA Kützing}

Class Heterocarpeae Kützing Phyc. Gen. 369 (1843).

Class Florideae (C. Agardh) J. Agardh Sp. Alg. 1; v (1848).

Subclass Florideae Engler in Engler and Prantl Nat. Pflanzenfam. I Teil, Abt. 2: ix (1897).

Subclass Euflorideae de Toni Sylloge Algarum 4: 4 (1897).

Abtheilung (of Stamm Rhodophyta) Floridineae Pascher in Beih. bot. Centralbl. 48, Abt. 2: 328 (1931).

As this is the type group of phylum Rhodophyta, most of the synonymy of that name applies to this one also.

Red algae whose bodies consist essentially of filaments growing apically, the cells with protoplasmic interconnections, the plastids (except in some of the lowest examples) of the form of multiple parietal disks; the filaments commonly compacted into cylindrical or thallose bodies; zygotes not dividing to form spores directly, producing spores by luudding or indirectly by processes of growth of various degrecs of complexity.

In undertaking to describe the varied, and often highly complicated, reproductive processes of the typical red algae, one notes that these organisms occur as haploid individuals, and that the majority occur as distinct male and female liaploid individuals. Sperms (commonly caller spermatia) are minute naked protoplasts released from small cells commonly occurring in patches on the surfaces of thalli. The egg is called a carpogonium (Schmitz, 1883). It is the terminal cell of a specialized filament, the carpogonial filament, and bears a filiform terminal extension, the triclogyne (Bornet and Thuret, 1867), whose function is to receive the sperms. The cell, often differentiated, from which the carpogonial filanient grows, is the supperiing cell (Trugzelle).

In the more primitive members of the class, the zygote gives rise by budding to a mass of cells called the cystocarp. The cells of the cystocarp release their protoplasts as spores called carpospores. These on germination produce haploid individuals like the original ones. The zygote nucleus is the only cliploid nucleus in the life cycle; its first divisions are inciotic. 
In more advanced examples, the first step of development after fertilization consists of the establishment of protoplasmic contact between the zygote and other cells. These may be adjacent cells, reached directly, or distant cells, reached by the outgrowth of connecting filaments from the zygotes. In the generality of the group, the cells with which contact is made give rise to cystocarps producing carpospores; in this situation, the cells in question are called auxiliary cells. In some examples, the connecting filaments, after making contact with cells called nurse cells, themselves give rise to the cystocarps. The carpospores, in all of these more advanced examples, give rise to diploid individuals. The diploid individuals are of the same vegetative

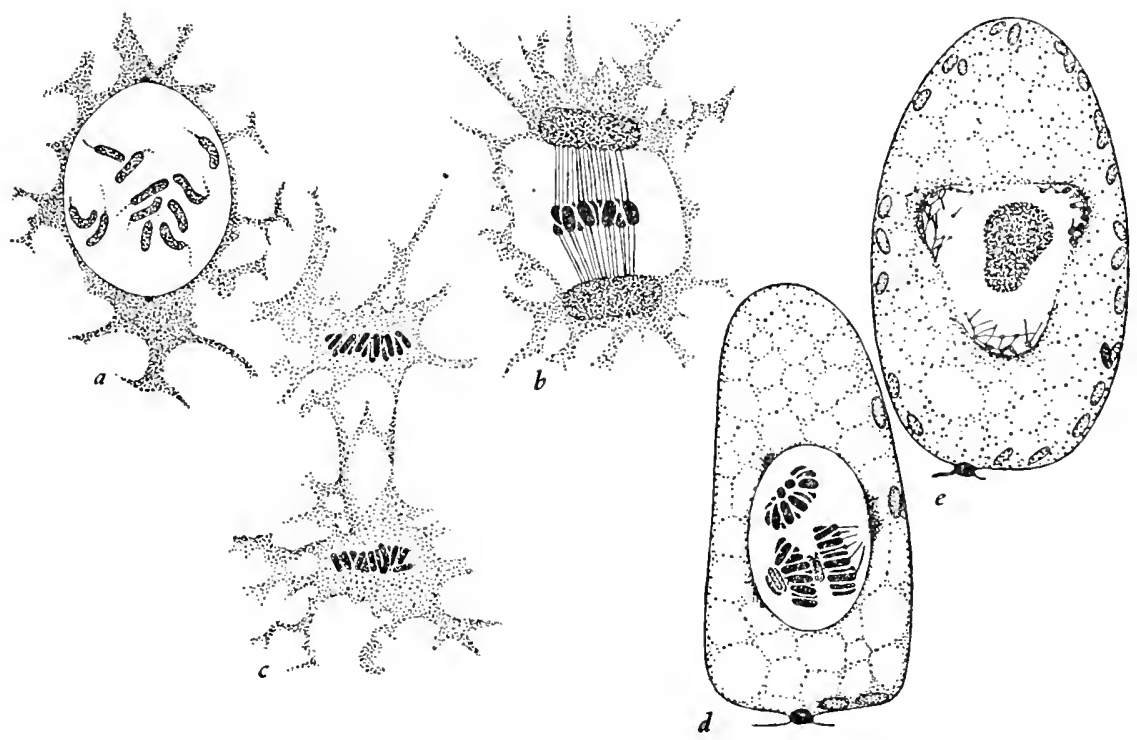

Fig. 6-Nuclear phenomena in Polysiphonia violacea after Yamanouchi (1906). a, b, c, Stages of mitosis. d, e, Stages of homeotypic division.

structure as the haploid individuals, but do not produce spermatia, carpogonia, or cystocarps. Certain cells, commonly scattered and imbedded in the body, produce sets of four spores which are accordingly called tetraspores; these give rise to haploid individuals.

This account means that these algae occur typically in somata of four types: male and female haploid individuals; cystocarps, being a preliminary, parasitic, multiplicative phase of the diploid stage (Janet named this stage the carposporophyte; Drew, 1954); and free-living diploid individuals, reproducing by tetraspores. The production of carpospores and tetraspores by different individuals of identical vegetative structure explains the oldest name applied to this class, namely Heterocarpea.

Understanding of the life cycle of typical Heterocarpea has been reached only by much labor and after a certain amount of confusion. The first significant observations were by Bornet and Thuret (1867). Schmitz (1883) showed that the zygote makes protoplasmic contact with other cells. He supposed that the contact of the zygote with an auxiliary cell is a second sexual fusion (Copulation) following upon proper 
fertilization. Oltmanns (1898) disproved this: he showed that the nuclei of auxiliary cells are inert, and that the nuclei of carpospores are derived entirely from zygote nuclei. Yamanouchi (1906) showed that the chromosome number of carposporic individuals of Polysiphonia violacea is 10 , and that that of tetrasporic individuals is 20; and reported much more of the cytology. Centrosomes appear de novo during the earlier stages of mitosis, and fade out and disappear during the later stages. The mitotic spindle is formed, and the chromosomes take their place upon it, within an intact nuclear membrane, which fades out in later stages. In meiosis, which produces the nuclei of tetraspores, the tetrads and diads divide within the original nuclear membrane, which becomes tetrahedrally lobed, and then disappears except where the haploid groups of chromosomes lie against it, with the result that the membranes of the tetraspore nuclei are partly old and partly new.

There are some 2500 species of Heterocarpea, including comparatively few in fresh water, but the majority of the marine algae. Many of them are beautiful; their variety and beauty contribute to the pleasure which people find on coasts. Experienced naturalists can identify many genera by gross structure, but the systems of orders and families based on gross structure, such as those of Kützing (1843) and J. Agardh (1851-1863), have been found artificial and abandoned. A proper respect for the principles of nomenclature makes it necessary, however, to apply many of the names used in these systems. Schmitz applied his morphological studies to a classification of the typical red algae as four groups (1889); Engler (1897) made these groups definitely orders. Subsequent scholars have found this system sound in principle, but have found it necessary, on the basis of studies of additional examples (for example, by Kylin, 1923, 1924, 1925, 1928, 1930, 1932; Papenfuss, 1944; Sjöstedt, 1926; Svedelius, 1942) radically to rearrange the families and genera. At least four orders in addition to those of Engler have been proposed but reductions have decreased the number currently recognized to six.

The following key to the orders is a rather considerable modification of those published by Kylin (1932) and Smith (1944).

1. All free-living individuals haploid; tetraspores not produced, or produced as carpospores. . Order 1. CRy ptospermea.

1. Free-living individuals of two types, the one producing gametcs (the zygotes giving rise to carpospores), the other producing tetraspores.

2. Without specialized auxiliary cells or nurse cells, the lower cells of the carpogonial filaments, or normal vegetative cells, serving as auxiliary cells............. Order 2. Spilafrococcomea.

2. With specialized nurse cells, the carpospores produced from filaments which have made contact with these........... Order 3. Geridulen.

2. With specialized auxiliary cells from which the carpogonia develop.

3. The auxiliary cells being intercalary cells in specialized filaments homologous with the carpogonial filaments... Order 4. Furgellakiea.

3. The auxiliary cells terminal in filaments which grow from the supporting cells of the carpogonial filaments before fertilization............ Order 5. Coeioblastea. 
3. The auxiliary cells originating after fertilization as branches of the supporting cells of the carpogonial filaments.................... Order 6. FLoRIDEA.

Order 1. Cryptospermea [Cryptospermeac] Kützing Phyc. Gen. 321 (1843).

Order Periblasteae Kützing op. cit. 387, in part.

Orders Helminthocladeae J. Agardh Sp. Alg. 2: 410 (1851), Chaetangieae op. cit. 456 (1851), and Wrangelieae op. cit. 701 (1863).

Order Batrachospermaceae Rabenhorst Kryptog.-Fl. Sachsen 1: 278 (1863).

Nemalioninae Schmitz in Flora 72: 438 (1889).

Order Nemalionales Engler in Engler and Prantl Nat. Pflanzenfam. I Teil, Abt. 2: ix (1897).

Heterocarpea normally without diploid bodies, the carpogonium arising from the zygote or from an adjacent cell serving as an auxiliary cell, the carpospores producing haploid bodies like the original ones. Certain genera which are exceptional to these characters are noted below. Batrachospermum may be regarded as the standard genus.

In all recent literature, this order is called Nemalionales. Eight families are recognized. The forms consisting of mere filaments, Acrochaetium, Rhodochorton, and others, are family Acrochaetiacea [Acrochaetiaceae] Fritsch (Family Chantransiaceae Auctt., but Chantransia DC. as originally published included no members of this family; Papenfuss, 1945). In the remainder of the order, the filaments are differentiated, or, with or without differentiation, organized as bodies of definite form, simply cylindrical, branched, or flattened. Fresh-water examples (the only fresh-water Heterocarpea) include Batrachospermum, Lemanea, and Thorea. These organisms are not red, but bluish, green, or brown. Marine examples include Nemalion and Cumagloia.

In Liagora tetrasporifera and certain other species tetraspores are produced in the place of carpospores. Within this genus, then, there has been a change in the time of meiosis (which could be established, presumably, by a single mutation) from immediately after fertilization to the end of the cystocarp stage.

Galaxaura is a genus of tropical marine algae which are calcified, which is to say that they deposit much calcium carbonate in the tissues; they were originally classified as corals. They have distinct sexual and tetrasporic stages. Svedelius (1942) ascertained their life cycle. Carpospore-bearing filaments arise both from the zygote and from other cells, previously undifferentiated, which serve as auxiliary cells. The genus has the structure of the present order, and is to be placed here, in spite of exhibiting in unspecialized form the life cycle of the following orders.

Order 2. Sphaerococcoidea [Sphaeroccoideae] J. Agardh Sp. Alg. 2: 577 (1852). Family Gigartineae Kützing (1843).

Orders Gigartineae and Chaetangieae J. Agardh op. cit. 229, 456 (1851).

Gigartininae Schmitz in Flora 72: 440 (1889).

Order Gigartinales Engler in Engler and Prantl Nat. Pflanzenfam. I Teil, Abt. 2: $\mathrm{x}$ (1897).

Order Nemastomatales Kylin in Kgl. Fysiog. Sällsk. Handl. n. f. 36, no. 9: 39 (1925).

Order Sphaerococcales Sjöstedt in Kgl. Fysiog. Sällsk. Handl. n. f. 37, no. 4 : 75 (1926). 


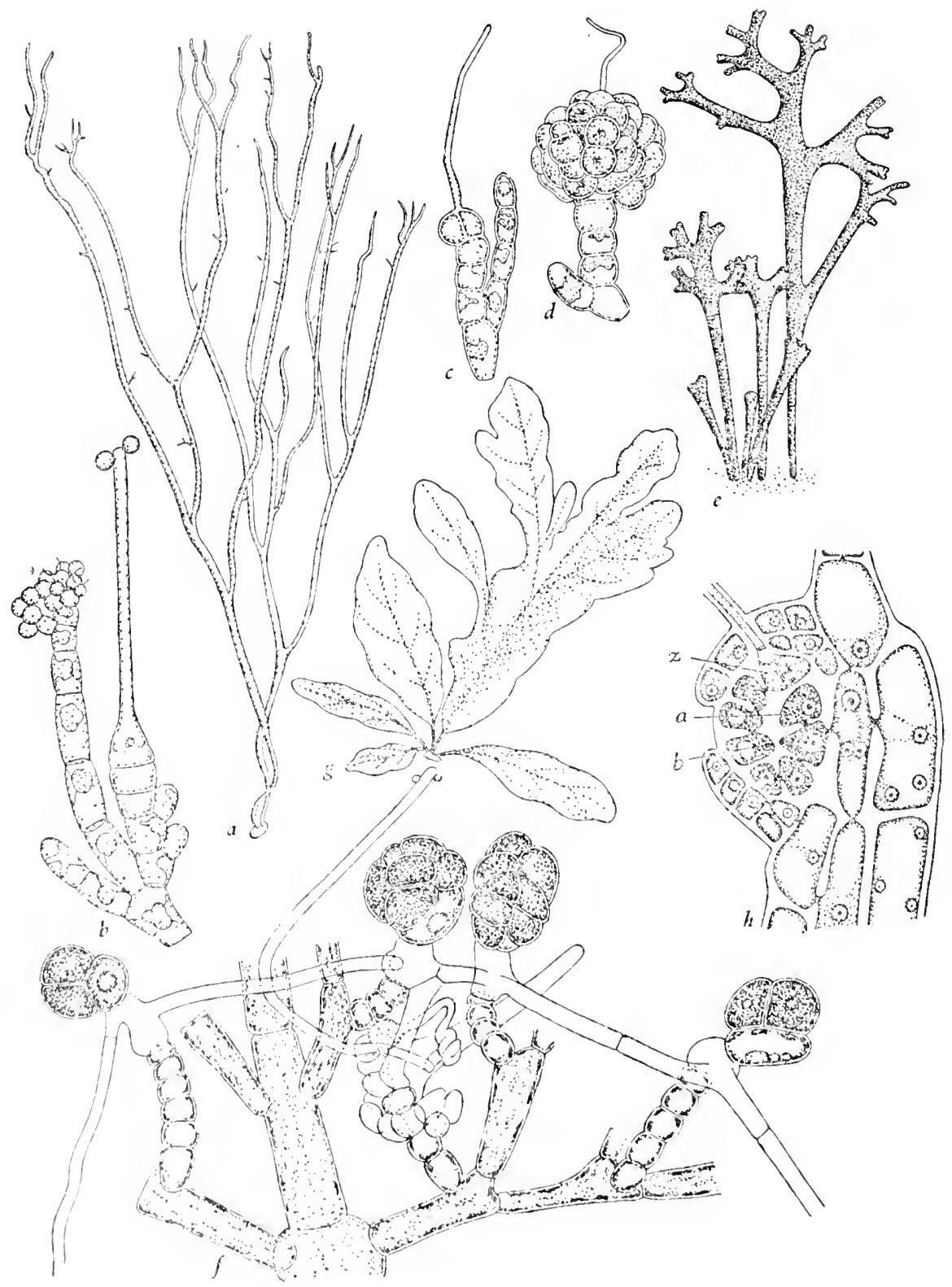

(Legend on bottom of page 49) 
This order, in all recent literature called Gigartinales, is a numerous and varied one. The bodies are generally erect; they may be cylindrical or flattened, unbranched or branched. In some examples, Haliarachnion, Rhodophyllis, Sebdenia, the zygote sends out extensive filaments, which make contact with unspecialized cells scattered in the body. In other examples, the zygote makes contact with a lower cell of the carpogonial filament. In either case, the cells with which contact is made are auxiliary cells and give rise to cystocarps; these produce carpospores, and the carpospores produce tetrasporic individuals. Certain species of Phyllophora, Gymnogongrus, and Ahnfeldtia are exceptional in producing tetraspores in the place of carpospores; these species have no free-living tetrasporic generation. In these organisms, as contrasted with Liagora tetrasporifera, it is believed that this type of life cycle has been established by reduction of a longer one.

Kylin (1932) assigned twenty families to this order. Gracilaria is a minor source of agar agar. Gigartina mammilosa and Chondrus crispus (Irish moss or carageen) are well known as yielding a jelly, carageenin, resembling but distinct from agar agar (Tseng, 1945).

Various abnormal growths on red algae have been found to be parasitic red algae, almost always on hosts closely related to themselves (Setchell, 1914). To the present order belong Gardneriella and its host Agardhiella; Plocamiocolax and its host Plocamium; Gracilariophila and its host Gracilaria (Wilson, 1910).

Order 3. Gelidialea [Gelidiales] Kylin in Kgl. Svensk. Vetensk.-Akad. Handl. 63, no. 11: 132 (1923).

Family Gelmieae Kützing (1843).

Order Gelidieae J. Agardh Sp. Alg. 2: 464 (1851).

Heterocarpea in which the zygote sends out a single elongate filament which makes contact successively with several chains of nurse cells and gives rise to carpospores; bodies consisting of branched filaments, the ultimate tips of the lateral branches compacted into a firm layer covering a branching body, cylindrical or flattened; the surface adjacent to the masses of carpospores pushed out and punctured by pores through which the spores escape.

There is a single family Gelidiea [Gelidieae] Kützing (Family Gelidiaceae Schmitz and Hauptfleisch). Such economic importance as the red algae possess lies chiefly in

Fig. 7-a, Thallus of Nemalion multifidum $\times 1$. b, c, $\mathbf{d}$, production of sperms; beginning of production of carpospores; and cluster of carpospores of Nemalion multifidum after Bornet and Thuret (1867). e, Thallus of Chondrus crispus $\times 1$. f, Reproduction of Dudresnaya purpurifera (order Furcellariea or Cryptonemiales) after Bornet and Thuret, op. cit. The trichogyne, whose free end with attached sperms is seen above, is irregularly twisted below; it leads to the egg (carpogonium); connecting filaments, growing from cells below the egg, make contact with auxiliary cells at the summits of specialized filaments; each auxiliary cell gives rise to a cluster of carpospores. $\mathrm{g}$, Thallus of Delesseria sinuosa $\times 1$. $\mathbf{h}$, Longitudinal section of conceptacle of Polysiphonia nigrescens x 500, after Kylin (1923). The zygote $z$ is the fourth and terminal cell of the carpogonial filament whose connection with the supporting cell $b$ is not shown; the auxiliary cell $a$ has grown from the supporting cell after fertilization. 
this family, and particularly in the genus Gelidium. It is the chief source of agar agar. This is the principal material of the cell walls of Gelidium. It is a jelly consisting essentially of chains of galactose units, and has the property, that having been melted by heat, it does not again become solid until cooled to a much lower temperature. Algae containing it have long been used as foods in the orient. Brought into laboratory use by Koch, it has become a necessity in routine bacteriological work. The chief source is Japan.

Kylin construed this order as relatively primitive; but its reproductive processes, involving specialized nurse cells, appear less primitive than those of the Sphaerococcoidea. The production of elongate connecting filaments is shared with certain examples both of the preceding order and of the following, and the Gelidialea are probably derived by specialization from one or the other.

Order 4. Furcellariea [Furcellarieae] Greville Alg. Brit. 66 (1830).

Orders Spongocarpeae and Gastrocarpeae Greville op. cit. 68, 157 (1830).

Order Epiblasteae Kützing Phyc. Gen. 382 (1843).

Orders Cryptonemeae, Dumontieae, Squamarieae, and Corallineae J. Agardh Sp. Alg. 2: 155, 346, 385 (1851), 506 (1852).

Cryptoneminae Schmitz in Flora 72: 452 (1889).

Order Cryptonemiales Engler in Engler and Prantl Nat. Pflanzenfam. I Teil, Abt. 2: xi (1897).

The individuals are crustose or thallose, the thalli cylindrical or flattened, unbranched or branched. On the two or three types of individuals of each species, the reproductive structures may be scattered or clustercd on the surfaces or gathered in specialized pits called conceptacles. The eggs are as usual the terminal cells of specialized filaments; other filaments, homologous with these but abortive, bear the auxiliary cells. After fertilization, the zygote may or may not establish connection with a lower cell of the same filaments. Under either circumstance, it sends out filaments which establish connection with the auxiliary cells, and these send out filaments which bear the carpospores. In less specialized examples, the filaments growing from the zygote may extend widely through the body; a single one, branching, may reach many auxiliary cells.

Kylin (1932) placed nine families here.

The family Corallinea [Corallineae] Kützing (family Corallinaceae Hauck) is one of the more specialized. The eggs, and subsequently the carpospores, are clustered in conceptacles. In each conceptacle the zygotes, the filaments from them, and the auxiliary cells, unite eventually in a single large multinucleate cell from whose margins grow the filaments which bear the carpospores. Members of this family have the property of accumulating and depositing calcareous material, and wcre originally classified as corals. In modern usage, the term coral means certain lower animals; but the coralline algae are associated with them in coral reefs, being indeed, according to Setchell (1926) and other authoritics, responsible for the building of the rcefs. Fossil coralline algac are known from the Ordovician.

The parasite Callocolax and its host Callophyllis belong to this order; Coreocolax, belonging to this order, attacks species of order Floridea.

The Furcellariea are a numerous group, rather unspecialized, varied almost to the extent of a misccllany. They are related to the Sphacrococcoidea, and are believed to represent the ancestry of the two following orders, and possibly also of the Gelidialea. 
Order 5. Coeloblastea [Coeloblasteae] Kützing Phyc. Gen. 438 (1843).

Order Rhodymenieae J. Agardh Sp. Alg. 2: 337 (1851).

Rhodymeninae Schmitz in Flora 72: 442 (1889).

Order Rhodymeniales Engler in Engler and Prantl. Nat. Pflanzenfam. I Teil, Abt. 2: x (1897).

Heterocarpea producing auxiliary cells terminally on brief filaments which grow from the supporting cells of the carpogonial filaments before fertilization; cystocarps enclosed in cup- or vase-like pericarps; the thalli (cylindrical or flattened, branched or unbranched) usually hollow. Champia may be regarded as the standard genus.

In various red algae, the germinating carpospore or tetraspore gives rise to a globe of cells which grows to produce the thallus (Kylin, 1917). In the present group the sporeling is particularly blastula-like. Its upper layer of cells becomes a ring of apical cells, of definite number, distinguishing the group from others which grow by apical cells either of a single filament or of a fascicle of indefinite number. The apical cells are indeed homologous with the apical cells of filaments, but the cells derived from them are arranged in a three-dimensional pattern as in the tissues of higher organisms; it is only in the reproductive structures that the filamentous structure remains evident.

The order thus limited by Kylin (1932) is a specialized group including only the two families Rhodymeniacea [Rhodymeniaceae] Hauck and Champiea [Champieae] Kützing. The latter family is the more specialized; the hollow thalli are partitioned by transverse septa and the supporting cells produce usually just two auxiliary cells. In many examples of this family, after fertilization and the fusion of the zygote with the auxiliary cells, the latter proceed to unite with further neighboring cells to produce a massive coenocyte from which the brief carpospore-bearing filaments arise. The resulting structure is deceptively similar to that which occurs in the Corallinea.

The parasite Faucheocolax and its host Fauchea belong to this order.

Order 6. Floridea [Florideae] C. Agardh Syst. Alg. xxxiii (1824).

Order Floridées Lamouroux in Ann. Mus. Hist. Nat. Paris 20: 115 (1813).

Section Florideae C. Agardh Synops. Alg. Scand. xiii (1817).

Orders Trichoblasteae, Axonoblasteae, and Platynoblasteae Kützing Phyc. Gen. $370,413,442(1843)$.

Orders Ceramieae, Spyridicae, Chondrieae, and Rhodomeleae J. Agardh Sp. Alg. vol. 2 (1851-1863).

Ceramiales Oltmanns Morph. u. Biol. Alg. 1: 683 (1904).

Order Ceramiales Kylin in Kgl. Svensk. Vetensk.-Akad. Handl. 63, no. 11: 132 (1923).

The Floridées of Lamouroux included the whole group of red algae organized as four genera, Chondrus Stackhouse and the new genera Claudea, Delesseria, and Gelidium. Lamouroux listed first Claudea and Delesseria, belonging to the present order, to which the name is accordingly applied.

This order is characterized by specialized strict patterns in the development of the feniale reproductive structures. The carpogonial filament is always of four cells. The supporting cell initiates, in definite patterns, brief additional filaments. After fertilization, the supporting cell cuts off one more cell adjacent to the zygote, and this becomes the auxiliary cell. The spore-bearing structures developed from it are naked in the more primitive examples; in most, they are protected by pericarps, which, in some examples, begin to devclop beforc fertilization.

There are four families, all numerous in species: Ccramiea (Harvey) Kützing, 
Dasyea Kützirig, Delesseriea Kützing, and Polysiphoniea Kützing (Rhodomelaceae Hauck). The Ceramiea are mostly filaments, uniseriate or becoming pluriseriate by lengthwise divisions. In many members of the other families the bodies are thallose, though consisting essentially of filaments produced in definite patterns. In many Delesseriea the branches of the thalli simulate leaves of higher plants.

Gonimophyllum is parasitic on Botryoglossum; both are Delesseriea. Various species of Janczereskia, a genus of Polysiphoniea, attack Laurencia, Chondria, and other members of the same family. This was the first genus of parasitic red algae to be recognized as such, by Solms-Laubach (1877).

Such are the red algae. The Bangialea appear to represent the transition between the organisms which lack nuclei and the generality of nucleate organisms. The Heterocarpea appear to be a specialized offshoot, leading to no other group. 


\section{Chapter VI \\ PHYLUM PHAEOPHYTA \\ Phylum 2. PHAEOPHYTA Wettstein}

Fucoldeae C. Agardh Synops Alg. Scand. ix (1817).

Orders Dutomeae and Fucomeae C. Agardh Syst. Alg. xii, xxxv (1824).

Stämme Diatomea and Fucoideae Haeckel Gen. Morph. 2: xxv, xxxv (1866).

Stämme Zygophyta in part and Phaeophyta Wettstein Handb. syst. Bot. 1: 71, $171(1901)$.

Divisions Zygophyccae in part and Phaeophyceae Engler Syllab. ed. 3: 8, 15 (1903).

Chysophyta, with subordinate groups Chrysophyccae, Bacillariales, and Heterokontae, Pascher in Ber. deutschen bot. Gess. 32: 158 (1914).

Stamm Chrysophyta Pascher in Süsswasserfl. Deutschland 11: 17 (1925).

Phyla Chrysophycophyta and Phaeophycophyta Papenfuss in Bull. Torrey Bot. Club 73: 218 (1946).

Organisms typically living by photosynthesis, without chromoprotein pigments, the plastids containing chlorophylls $a$ and $c$, carotin, and various xanthophylls. Lutein (the xanthophyll of typical plants) may be present but is usually exceeded in quantity by flavoxanthin, violoxanthin, isofucoxanthin, or fucoxanthin, particularly the last. The xanthophylls occur usually in quantity sufficient to give the organisms a yellow or brown color. True starch is not produced. Many examples contain granules of a white solid called leucosin, presumably a carbohydrate, which does not give a blue color with iodine. The cells are usually enclosed in walls consisting of cellulose together with larger quantities of other carbohydrates or oxidized or esterized carbohydrates. Silica or calcium carbonate may be deposited. Methanol extracts of the cells contain fucosterol, a sterol distinct from the sitosterol of typical plants. Flagellate cells are usually produced; these bear one pantoneme or pantacroneme flagellum, and usually, in addition, one acroneme or simple flagellum. Exceptional examples, non-pigmented or without flagellate stages, are rathe: numerous. The obvious standard genus of the phylum is Fucus L.

The chemical characters are stated on the authority chiefly of Carter, Heilbron, and Lythgoe (1939), Miwa (1940), and Tseng (1945). The character of the flagellation, positively known of rather few examples, is stated by authority of Petersen (1929), Vlk (1931, 1939), Couch (1938, 1941), Longest!1946), Manton (1952), and Ferris (1954).

These characters bind together an assemblage of organisms which is in some respects original here1. Engler (1897), West (1904), and Snith $(1918,1920)$ included the chrysomonad flagellates in the group of brown algae. Pascher (1914) combined as one group the chrysomonads, the diatoms, and the exceptional green algae called Heterokontae. Later $(1927,1930)$, he included also the colorless flagellates of family Monadina. He did not associate this group with the brown algae, and subsequent authors have in general followed him. Kylin (1933), however, considered the diatoms to be the closest allies of the brown algae, both groups being descended from the brown flagellates. Almost certainly, he was correct. Couch showed that the paired unlike flagella of the typical Oomycetes are respectively pantoneme and acroneme,

1Manton (1952) recognized this group, but omitted nomenclatural formalities. 


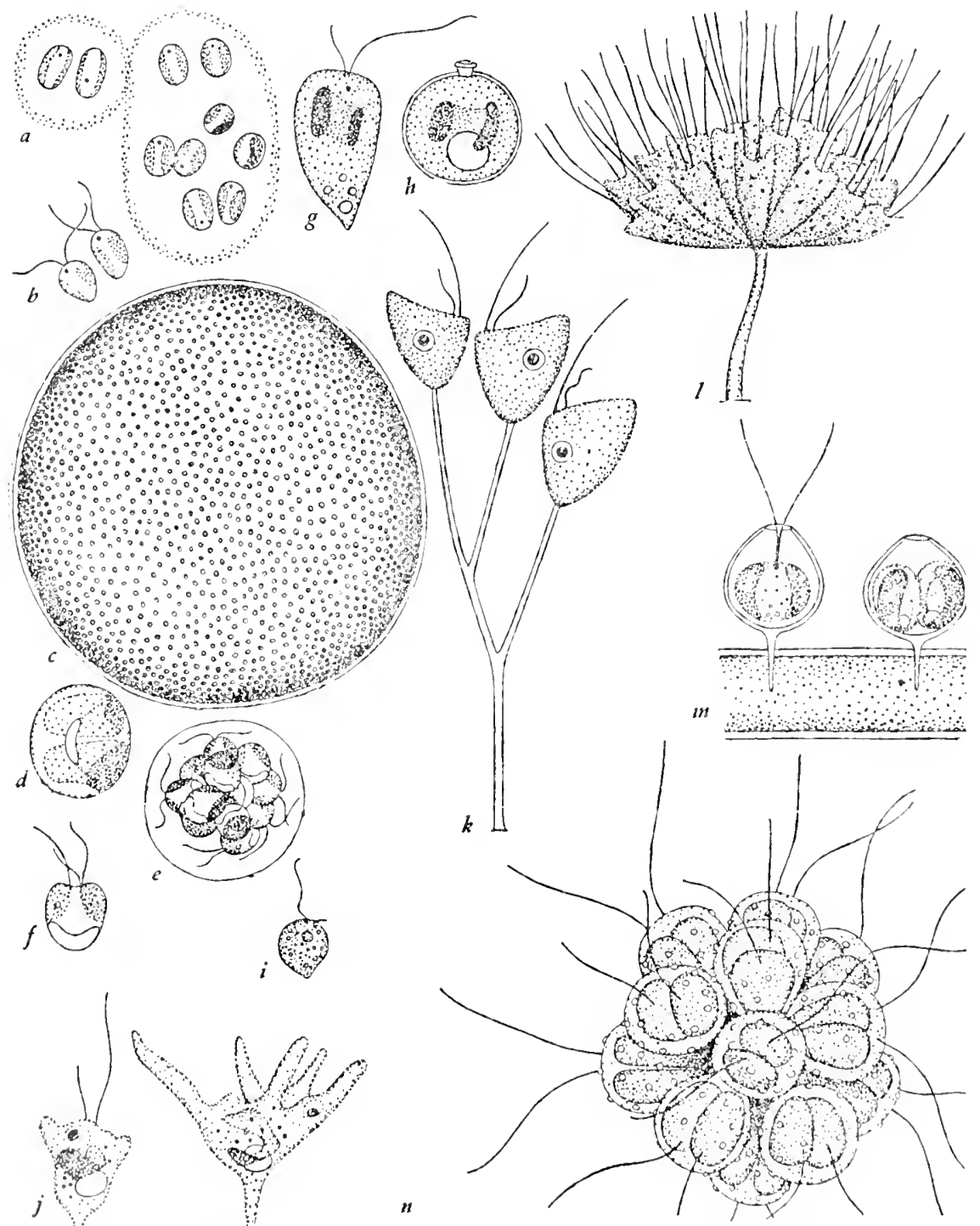

Fig. 8.-Ochromonadalisa: a, b, Chrysocapsa paludosa after West (1904); a, a colony; b, zoospores. c-f, Phacocystis globosa after Scherffcl (1900); c, a colony $\mathrm{x} 50$; d, a cell with two plastids, a mass of lcucosin forming on a mound of protoplasm projecting into the central vacuole; $\mathbf{e}$, production of zoospores; $\mathbf{f}$, a zoospore. $\mathbf{g}, \mathbf{h}$, Cell and statospore of Ochromonas granularis after Doflein (1922). i, Gell of Monas sp. j. Two cells of Brehmiclla Chrysohydra after Pascher (1928). k, A very young colony of Dendromonas virgaria after Stein (1878). 1, Colony of Cephalothamnium Cyclopum after Stein, op. cit. m, Cells of Epipyxis utriculus after Stcin, op. rit. n, Colony of Symura Uzella. x 1,000 except as noted. 
and distinguished these fungi from practically all others by the presence of cellulose in their walls.

The phylum thus assembled may be organized as four classes.

1. Miscellaneous groups, mostly small and relaatively unspecialized, of varied body type; not of the characters of the following groups............. Class 1. Heterokonta.

1. Comparatively numerous and specialized groups.

2. Unicellular brown organisms with shells of silica consisting of two parts................

2. Organisms of fungal or chytrid body types producing swimming spores with paired unlike flagella. .Class 3. Oomycetes.

2. Filamentous and thallose brown algae...........

\section{Class 1. HETEROKONTA Luther}

Class Flagellata or Mastigophora Auctt., in part.

Class Heterokontae Luther in Bihang Svensk. Vetensk.-Akad. Handl. 24, part 3, no. 13: 19 (1899).

Subclass Chrysomonadineae Engler in Engler and Prantl Nat. Pflanzenfam. I Teil, Abt. 1a: iv (1900).

Class Silicoflagellatae (Borgert) Lemmermann in Ber. deutschen bot. Gess. 19: 254 (1901).

Phylum Siphonophyceae and class Vaucherioideae Bessey in Univ. Nebraska Studies 7: 285, 286 (1907).

Chrysophyceae and Heterokontae Pascher in Ber. deutschen bot. Gess. 32: 158 (1914).

Divisions Chrysophyceae and Heterokontae, and classes Chrysomonadineae, Rhizochrysidineae, Chrysocapsineae, Chrysosphaerineae, Chrysotrichineae, Heterochloridineae, Rhizochloridineae, Heterocapsineae, Heterococcineae, Heterotrichineae, and Heterosiphoneae Pascher in Beih. bot. Centralbl. 42, Abt. 2: 323,324 (1931).

Classes Ebriaceae, Silicoflagellata, and Coccolithophoridae Deflandre, and Chrysomonadina Hollande in Grassé Traité Zool. 1, fasc. 1: 407, 425, 438, 471 (1952).

Class Phytomastigophorea Hall Protozoology 117 (1953), in part.

Phaeophyta which lack the distinctive characters of the remaining three classes. Luther named the group on the occasion of his discovery of Chlorosaccus, and this genus may be regarded as the type.

The chrysomonad flagellates are the core of this class and of the first two among the five orders into which it is divided. In the classification of these two orders, three novelties will be noted.

(a) Pascher (1913) made of the chrysomonad flagellates three orders characterized respectively by paired unequal flageila, paired equal flagella, and solitary flagella. Petersen (1929) found that the supposedly cqual flagella of Synura are actually unlike, being respectively pantoneme and acroneme. Here, accordingly, Pascher's first two orders are combined.

(b) Pascher made separate classes or orders of groups related to the chrysomonad flagellates but of distinct body type, as palmelloid, chlorococcoid, fllamentous, or 


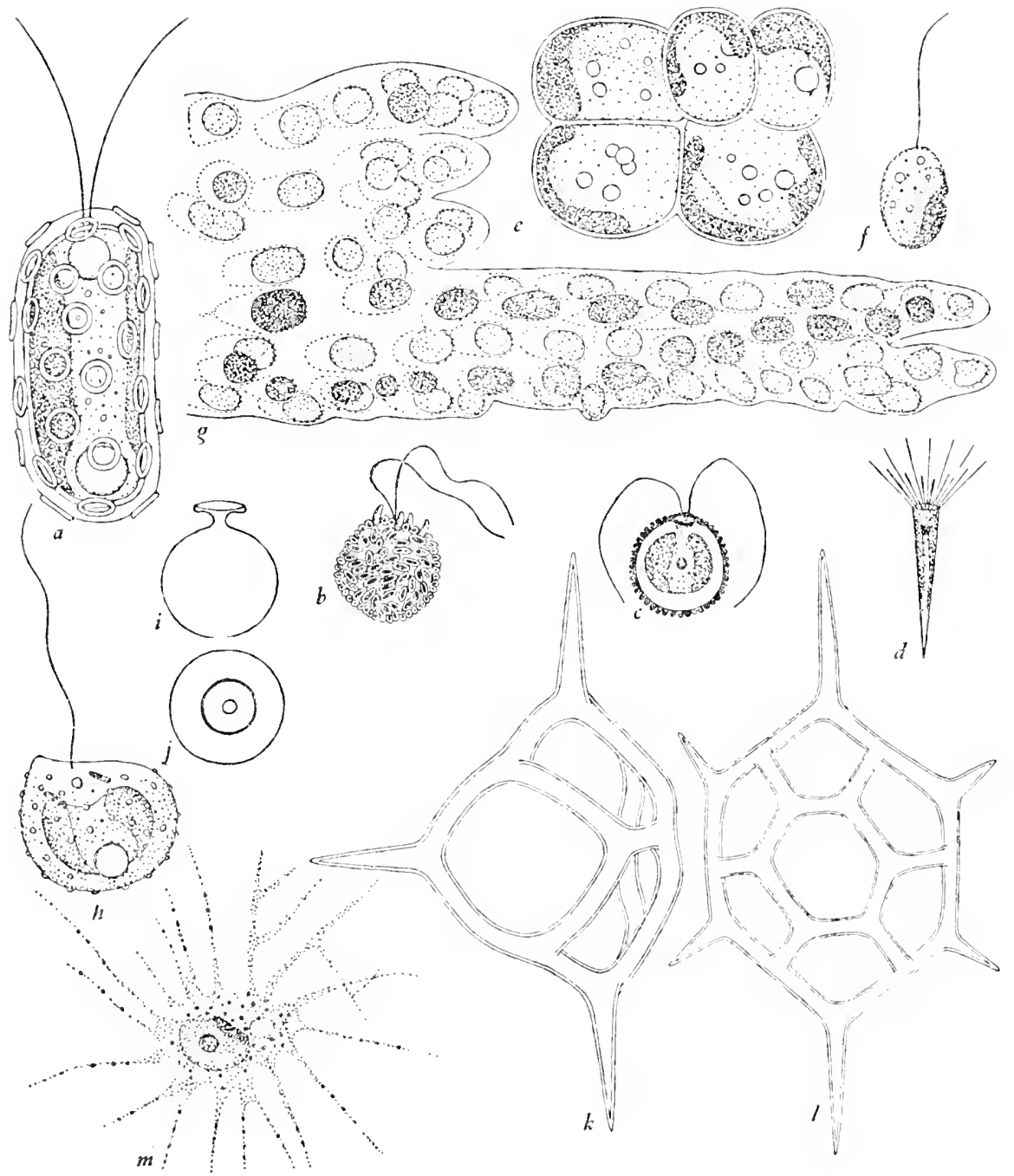

Fig. 9.-Oghiromonadales: a, Mallomonas roscola, based on Stein (1878) and Conrad (1926). b, Syracosphacra Quadricornu; c, Calyptosphacra insignis; d, Calriconus vitreus; after Schiller (1925). Silicoflageiratat e, f, Colony and zoospore of Efrichrysis after Pascher (1925). g, Part of the thallose growth of IJydrurus foctidus. h, Cell, and $\mathbf{i}, \mathbf{j}$, statospores of Chromulina Pascheri after lIofeneder (1913). k, 1, Skcletons of Dictyocha Fibula and Distcphanus Speculum from diatomaccous carth at Lompoc, California. m, Rhizochrysis Scherffeli after Doflein (1916). All $\times 1,(1000$. 
amoeboid. By Pascher's own principle of the repeated evolution of body types, these groups are surely artificial. Here most of them are broken up and their members distributed between the two chrysomonad orders according to whether the flagella of their motile stages are paired or single. It is not possible to divide by this character ameboid forms not known to produce flagellate stages; these are lumped in the second order.

(c) Since flagella appear to have evolved as a device for the dissemination of unicellular pigmented organisms, examples whose vegetative state is that of clusters of non-motile cells are placed in each order before those which are flagellate in the vegetative condition.

The two chrysomonad orders are particularly characterized by production of leucosin. They are further characterized by production of resting cells of a type called statospores. This occurs by the deposition within the protoplast of a globular shell impregnated with silica, punctured by a single pore, and oftcn marked on the outer surface by warts, spincs, or ridges, of definite pattern. The external protoplasm migrates through the pore to the interior of the shell, and the pore is then closed by deposition of a silicified plug.

The group which is treated as the third order of the present class includes the typical Heterokonta. Compared with typical green algae, these organisms give the impression of a markedly distinct class; placed next to the chrysomonads, they appear scarcely entitled to this rank. Their name is the oldest applicable to the present class, and is accordingly so applied. If it appear expedient to maintain the typical Heterokonta as a distinct class, the remainder of the present one will be called Chrysomonadinea [Chrysomonadineae] (Engler) Pascher.

Of including the choanoflagellates and anisochytrids in the present class as additional orders, one may say that it is not contrary to current knowledge.

1. Mostly pigmented; non-pigmented examples mostly producing motile cells with two flagella.

2. Brown or colorless.

3. Producing motile cells with two flagella (exceptionally more) ........ Order 1. Oghromonadalea.

3. Producing motile cells with one flagellum; or without known flagellate stages..................... Order 2. Siligof lagellata.

2. Green.............................. Vider 3. Vaugheriacea.

1. Non-pigmented, producing motile cells with one flagellum.

2. Predatory, flagellate in the vegetative condition, each cell bearing a collar-like protoplasmic ridge.................. Order 4. Choanof Lagellata.

2. Parasitic or saprophytic, the vegetative cells non-motile, walled............... Order 5 . Hyphochytrialea.

Order 1. Ochromonadalea [Ochromonadales] Pascher Süsswasserfl. Deutschland 2: 10, 51 (1913).

Suborder Monadina Büischli in Bronn Kl. u. Ord. Thierreichs 1: 810 (1884).

Order Isochrysidales Pascher op. cit. 10, 42.

Order Syracosphaerinae Schiller in Arch. Prot. 51: 108 (1925). 
Orders Heliolithac and Orthlithinae Deflandre in Grassé Traité Zool. 1, fasc. 1: 452, 457 (1952).

Brown or colorless Heterokonta, the swimming cells of typical examples with two flagella which are respectively pantoneme and acroneme. In the exceptional family Trimastigida there are a pair of equal flagella and a third flagellum shorter or longer than these; the detailed structure of the flagella of this family is unknown.

Cells of pigmented types contain usually one or two lateral band-shaped plastids. Details of nuclear division are known chiefly by the observations of Doflein (1918, 1922) on Ochromonas. The flagella spring from a granule which may be identified as a blepharoplast, near which lies the nucleus. The blepharoplast is connected through two stainable strands (rhizoplasts) to two granules, recognizable as centrosomes, on the two sides of the nucleus. The spindle forms within the intact nuclear membrane with its poles at the centrosomes. The chromosome number appears to be about 4 . The nuclear membrane presently disappears. At metaphase, the rhizoplasts are found to lead to separate blepharoplasts, each bearing two flagella. Sexual proresses are scarcely known in this group. Schiller (1926) observed in Dinobryon the division of calls into two which are released to swim and conjugate in pairs.

This order is believed to represent the direct ancestry of the two following, and also of the typical brown algae.

1. Not filamentous.

2. Flagellate stages with a pair of equal flagella and a third which is shorter or longer....................... Family 1. Trimastigida.

2. Flagellate stages with two unequal flagella.

3. Without calcareous structures attached to the cell walls.

4. Cells not enclosed in loricae, i. e., open shells.

5. Not flagellate in the vegetative condition.......... Family 2. Ghrysocapsacea.

5. Flagellate in the vegetative condition, not forming free-swimming circular or globular colonies.......... Family 3 . Monadina.

5. Free-swimming circular or globular colonies......... Family 4 . Syncry PTIDA.

4. Cells enclosed in loricae........ Family 5. Dinobritua.

3. With calcarcous structures attached to the cell walls........... Family 6. Hymenomonadacen. 1. Filamentous........................mily 7. Pinafothamangnagea.

Family 1. Trimastigida [Trimastigidae] Kent Man. Inf. 1: 307 (1880). Family Trimastigaceac Senn in Engler and Prantl. Nat. Pflanzenfam. I Teil, Abt. la: 141 (1900). Family Prymncsiidae Hall Protozoology 127 (1953). Organisms producing swimming cells with a pair of equal flagella and a third flagellum longer or shorter than these. With a vegetative stage as globular non-motile colonies as large as pinheads, of pigmented cells; marine: Phacocystis. Motile solitary cells, pigmented: Prymncsium. Chry'sochromulina; Platychrysis with an amocboid stage. Motile solitary cells, not pigmented: Dallingeria, Trimastix, Macromastix. 
Family 2. Chrysocapsacea [Chrysocapsaceae] Pascher in Süsswasserfl. Deutschland 2: 85 (1913). Family Chrysocapsidae Poche in Arch. Prot. 30: 156 (1913). Nonmotile cells with brown plastids (usually two), imbedded in gelatinous matter and forming colonial aggregates, the protoplasts sometimes escaping as zoospores with two flagella. Chrysocapsa Pascher, in fresh water, the colonies few-celled. Phaeosphaera West and West, the colonies more extensive.

Family 3. Monadina Ehrenberg Infusionsthierchen 1 (1838). Family Monades Goldfuss (1818), the mere plural of a generic name. Family Dendromonadina Stein Org. Inf. 3, I Hälfte: x (1878). Family Monadidae Kent (1880). Family Heteromonadina Bütschli in Bronn Kl. u. Ord. Thierreichs 1: 815 (1884). Family Chrysomonadaceae Engler in Engler and Prantl Nat. Pflanzenfam. I Teil, Abt. 2: 570 (1897), not family Chrysomonadina Stein. Family Ochromonadaceae Senn in Engler and Prantl Nat. Pflanzenfam. I Teil, Abt. la: 163 (1900). Family Ochromonadidae Doffein. Pigmented or colorless Ochromonadalea, flagellate in the vegetative condition, not forming circular or globular free-swimming colonies, nor loricate, nor bearing calcareous structures on the cell walls (these being the distinctions respectively of the three following families).

Ochromonas is considered to be in its normal condition when it occurs as solitary swimming cells; it occurs also as gelatinous colonies like those of Chrysocapsa. St lochrysalis consists of Ochromonas-like cells attached by a stalk at the end away from the flagella. Chrysodendron is similar but colonial, the cells attached by branched stalks. Brehmiella Pascher (1928) may occur as free-swimming Ochromonas-like cells, or these may become attached by the end away from the flagella and develop a whorl of pseudopodia at the free end. Pseudopodia are a device for predatory nutrition, here occurring in an organism which is capable also of photosynthesis. Heterochromonas includes organisms of the structure of Ochromonas but without plastids, being presumably saprophytic, and containing only a pigmented speck by which it is supposed that the direction of light is perceived. The historical generic name Monas O. F. Müller, as restricted in application by scholars up to Ehrenberg and as applied ever since, designates totally non-pigmented cells, saprophytic or predatory, freeswimming like Ochromonas or attached like Stylochrysalis (Physomonas Kent designates cells of Monas in the attached condition). 'There are believed to be several species, but the group remains poorly known. It was in some member of it that Loeffler (1889) first observed the pantoneme character of flagella. Dendromonas consists of similar cells forming colonies like those of Chrysodendron. In Cephalothamnium Stein, Monas-like cells are gathered in capitate clusters on stout stalks. Anthophysis Bory is an organism which Leeuwenhoeck had described as a microscopic water plant: it consists of Monas-like cells at the ends of branching stalks colored yellow by deposits of iron. The comparatively unfamiliar original spellings of the two generic names just mentioned were restored by Kudo (1946). The name Uvella Bory appears to represent small clusters of cells of Cephalothamnium or Anthophysis which have broken loose to swim free.

Family 3. Syncryptida [Syncryptidae] Poche in Arch. Prot. 30: 156 (1913). Family Isochrysidaceae Pascher in Süsswasserfl. Deutschland 2: 43 (1913), not based on a generic name. Family Isochrysidae Calkins Biol. Prot. 262 (1926). Families Synuraceae and Syncryptaceae Smith Freshw. Algae (1933). Ochromonas-like cells forming circular or globular free-swimming colonies. Flagella markedly unequal, colonies circular: Cyclonexis; colonies globular: Uroglena, Uroglenopsis. Flagella apparently equal: Syncrypta, Symura. 
Family 4. Dinobryina Ehrenberg Infusionsthierchen 122 (1838). Family Dinobryaceae Engler in Engler and Prantl Nat. Pflanzenfam. I Teil, Abt. 2: 570 (1897). Pigmented or colorless cells of the characters of Ochromonas or Monas, sheltered in loricac, that is, in transparent open shells, solitary or colonial. The pigmented examples have generally been referred to Ochromonadaceae (or whatever), the colorless to Monadidae (or whatever). Pigmented, solitary, flagella markedly unequal: Epipyxis, Stylopyxis; flagella apparently equal: Chrysopyxis Stein (Derep1xis Stokes). Pigmented, forming branching colonies: Dinobryon, Hyalobryon. Poteriochromonas Scherffel resembles Stylopyxis, but the protoplast can project pseudopodia from its lorica, thus supplementing photosynthesis by predatory nutrition. Non-pigmented, solitary, flagella markedly unequal: Stokesiella; flagella apprently equal: Diplomita. Non-pigmented cells in colonies quite of the character of those of Dinobryon: Stylobryon.

Family 5. Hymenomonadacea [Hymenomonadaceae] Senn in Engler and Prantl Nat. Pflanzenfam. I Teil, Abt. 1a: 159 (1900). Family Coccolithophoridae Lohman in Arch. Prot. 1: 127 (1902). Family Hymenomonadidae Doflein. Family Coccolithidac Poche in Arch. Prot. 30: 157 (1913). Order Syracosphaerinae and family Pontosphaeraceae Schiller in Arch. Prot. 51: 8 (1925). Families Syracosphacraceae, Halopappaceae, Deutschlandiaceae, and Coccolithaceae Kampter. Family Thoracosphaeracee Schiller in Rabenhorst Kryptog.-Fl. Deutschland ed. 2, 10, Abt. 2: 156 (1930). Families Syracosphaeridae, Calcisolenidae, Thoracosphaeridae, and Braadrudosphaeridae Deflandre in Grassé Traité Zool. 1, fasc. 1: 452, 457, 458 (1952). Family Discoasteridae Tan Sin Hok. Suborder Coccolithina Hall Protozoology 130 (1953). Solitary cells with one or two brown plastids, usually with two apparently equal flagella, having a thin cell wall from which project bodies of calcium carbonate (coccoliths) of definite form.

More than twenty genera and nearly 150 species have been described (Lohman; Schiller; Kamptner, 1940). Neither the number of species nor the variety of form appears to warrant making more than one family of the group. Nearly all examples are marine. In Pontosphaera, Calyptosphacra, and allied genera, the coccoliths are disks or hemispheres, sometimes umbonate and sometimes marked by one or more pits. In Syracosphacra the coccoliths, or a few of them near the insertion of the flagella, bear horn-like projections. In Najadea, Halopappus, and Calciconus, each cell bears a whorl or elongate bristles. Cells of Calcisolenia are fusiform, without flagella, with an armor of two layers of spiral bands of calcareous matter. In Hymenomonas and Coccolithus Swartz 1894 (Coccosphacra Wallich 1877, non Perty 1852; Coccolithophora Lohman 1902) the coccoliths arc punctured and accordingly ringshaped; Hymcnomonas differs from most of the group in occurring in fresh water. In Discosphacra and Rhabdosphacra the punctured calcareous bodies are drawn out to the form of tubes, spools, or trumpets.

These obscure organisms are not without importance. They occur in all oceans, being most abundant in gulfs, such as the Adriatic, where the salinity is diminished by rivers (Schiller, 1925). According to Bernard (1947) turbidity in the Mediterranean depends chiefly on this group. Coccoliths are abusidant in the ooze on the bottoms of occans. They occur as fossils as far back as the Cambrian, being particularly abundant in certain Cretaccous deposits.

Family 6. Phaeothamnionacea [Phacothamuionaccae] Pascher in Süsswasserf. Deutschland 2: 113 (1913). Family Chrysotrichaceae Pascher (1914). Family Nematochrysidaccae Pascher (1925). Brown organisms, minute, marine, epiphytic, filancn- 
tous, reproducing by zoospores bearing paired unequal flagella. Nematochrysis, the filaments unbranched; Phaeothamnion, the filaments branched. These organisms are believed to represent the transition between the Chrysocapsacea and the typical brown algae.

There is a family Amphimonadidae or Amphimonadaceae of unwalled colorless flagellates with paired supposedly equal flagella. They appear to belong to the kingdom of plants, in the neighborhood of Chlamvdomonas and Polytoma. If, however, future study shows their flagella actually to be respectively pantoneme and acroneme, they are to be placed in the present order.

Order 2. Silicoflagellata Borgert in Zeit. wiss. Zool. 51: 661 (1891).

Chromomonadina Klebs in Zeit. wiss. Zool. 55: 394 (1893).

Order Chromomonadina Blochmann Mikr. Tierwelt ed. 2. Abt. I: 57 (1895).

Subclass Chrysomonadineae Engler in Engler and Prantl Nat. Pflanzenfam. I Teil, Abt. 1a: iv (1900).

Order Chrysomonadales Engler Syllab. ed. 3: 7 (1903).

Chry'somonadinae; Euchrysomonadinae, with order Chromulinales; Chrysocapsinae; and Rhizochrysidinae Pascher in Süsswasserfl. Deutschland Heft 2 (1913).

Chrysomonadales, Chrysocapsales, Chrysosphaerales, and Chrysotrichales Pascher in Ber. deutschen bot. Gess. 32: 158 (1914).

Order Chrysomonadina Doflein Lehrb. Prot. ed. 4: 401 (1916).

Order Chrysomonadida Calkins Biol. Prot. 258 (1926).

Classes Chrysomonadineae, Rhizochrysidineae, Chrysocapsineae, Chrysosphaerineae, and Chrysotrichineae Pascher in Beih. bot. Centralbl. 48, Abt. 2: 323 (1931).

Suborders Euchrysomonadina, Silicoflagellina, Rhizochrysidina, and Chrysocapsina Hall Protozoology 125, 128, 130, 132 (1953).

Organisms of much the character of Ochromonadalea, but producing flagellate stages with a single flagellum, or not producing flagellate stages. The detailed structure of the flagella has seemingly never been determined. Statospores are known to be produced by Chromulina, Mallomonas, and (of somewhat exceptional character) by Hydrurus. Sexual reproduction has not been observed. Mitosis, with an intranuclear spindle and numerous chromosomes, was observed by Doflein (1916) in Rhizochrysis.

This order is supposed to represent the direct ancestry of orders Choanoflagellata and Hyphochytrialea.

1. Neither amoeboid nor truly filamentous.

2. Not flagellate in the vegetative condition.

3. Microscopic colonies............ Family 1. Chrysosphaeragea.

3. Macroscopic gelatinous colonies simulating filaments............ Family 2. Hydruragea.

2. Flagellate in the vegetative condition.

3. Without prominent siliceous struc-

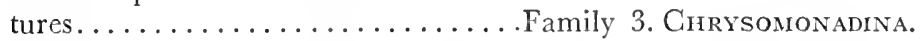

3. With siliceous scales usually bearing bristles................... Family 4. Mallomonadinea.

3. With siliceous internal skeletons..... Family 5. ActinisceA. 


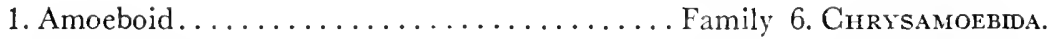

1. Filamentous............................. Thily 7 . Thallochrysidacea.

Family 1. Chrysosphaeracea [Chrysosphaeraceac] Pascher in Arch. Prot. 52: 562 (1925). Family Naegelliellaceae Pascher op. cit. 561. Family Nagelliellidae Hall Protozoology 133 (1953). Non-motile brown cells, either capable of repeated division into two, thus forming aggregates of indefinite number, or else undergoing multiple division and producing colonies of definite number of cells; mostly known to produce uniflagellate zoospores. Chrysosphacra, Epichrysis, Chrysospora, Gloeochrysis, Naegelliella, and other genera.

Family 2. Hydruracea [Hydruraceae] West British Freshw. Algae 45 (1904). Hydrurina Klebs in Zeit. wiss. Zool. 55: 420 (1893). Family Hydruridae Poche in Arch. Prot. 30: 158 (1913). Like Chrysosphaeracea, but the colonies dendroid, growing at the tips, becoming macroscopic; producing tetrahedral zoospores and spheroidal resting cells bearing a unilateral crest. Hydrurus foetidus, in mountain streams.

Family 3. Chrysomonadina Stein Org. Inf. 3, I Hälfte: x (1878). Family Chrysomonadidae Kent Man. Inf. (1880). Family Chromulinaceae Engler in Engler and Prantl Nat. Pflanzenfam. I Teil, Abt. 2: 570 (1897). Family Chromulinidae Doflein. Brown flagellates with a single anterior flagellum, sometimes producing siliceous granules but without more extensive siliceous structures. Free-swimming, walled: Chrysococcus, Microglena. Naked: Chromulina, the type genus of Chrysomonadina, the generic name Chrysomonas being a synonym. Organisms of this genus are rather freely capable of producing pseudopodia and supplementing photosynthetic nutrition by predatism, or, alternatively, of producing gelatinous aggregates of walled non-motile cells (Hofender, 1913; Gicklhorn, 1922). Chrysapsis differs from Chromulina in having in each cell a single plastid in the form of a network. Solitary attached cells, producing pseudopodia only occasionally: Lepochromulina. Bearing whorls of permanent pseudopodia: Cyrtophora, Pedinella, Palatinella (Pascher, 1928).

Family 4. Mallomonadinea Diesing in Sitzber. Akad. Wiss. Wien Math.-Nat. Cl. 52, Abt. 1: 304 (1866). Family Mallomonadidac Kent (1880). Brown uniflagellate free-swimming cells with an armor of siliceous scales usually bearing bristles. Mallomonas, solitary cells, the bristle-bearing scales circular. Conradiella, the scales of the form of rings about the body. Chrysosphaerella, spherical colonies, each cell with two long bristles.

Family 5. Actiniscea [Actinisccae] Kützing Phyc. Germ 117 (1845). Family Dictyochidae Wallich. Class Silicoflagellata (Borgert), orders Siphonotestales and Stereotestales, and families Dictyochaceae and Ebriaccae Lemmermanni in Ber. deutschen bot. Gess. 19: 254-268 (1901). Division (?) Silicoflagellatae Engler. Family Silicuflagellidae Calkins Biol. Prot. 263 (1926). Families Ebriopsidae, Ditripodiidae, Ammodochidae, and Ebriidae Deflandre in Grassé Traité Zool. 1, fasc. 1: 421, 423, 424 (1952). Solitary brown uniflagellate cells with a continuous internal skclcton of silica. Marine, commonest in colder oceans.

The skcletons are not subject to decay and are found as microfossils in chalk and diatomaccous carth. They have been reported from the Silurian and are commonest in certain Cretaccous deposits. Ehrenlorg described scveral fossil species, classifying them as diatoms. The living forms, subsequently discovered, include apparently the same species.

Gemeinhardt (in Rabenhorst, 1930) accounted for the structure of the cells. 
They are approximately of radial symmetry, the axis being shorter than the diameter. The skeleton is completely imbedded in protoplasm. It may be a mere ring; or the ring may bear radially projecting spines; or it may be the margin of a more or less complicated basket-shaped network coaxial with the cell. Numerous brown plastids lie near the surface of the protoplast. There is no cell wall. The double cells, like two cells lying face to face, which have occasionally been seen, are not stages of conjugation, but of cell division, in which one daughter cell retains the original skeleton while the other develops a new skeleton in the position of a mirror image of the original one.

Lemmermann and Gemeinhardt accounted for only six genera and twenty-four species, but Gemeinhardt recognized numerous varieties, and it is probable that the number of species has been underestimated. Mesocaena, the skeleton a mere ring, smooth or spiny; Dictyocha, Distephanus, Cannopilus, the skeleton more or less netted.

Family 6. Chrysamoebida [Chrysamoebidae] Poche in Arch. Prot. 30: 157 (1913). Families Rhizochrysidaceae, Chrysarachniaceae, and Myxochry'sidaceae Pascher in Beih. Bot. Centralbl. 48, Abt. 2: 323 (1931). Family Rhizochrysididae Hollande in Grassé Traité Zool. 1, fasc. 1: 547 (1952). Families Rhizochry'sidae and Myxochrysidae Hall Protozoology 130, 132 (1953). Amoeboid organisms with brown plastids of the form of one or two parietal films in each cell. Rhizaster, an attached organism resembling Cyrtophora and Pedinella but lacking the flagellum. Chrysocrinus, attached to algae, the protoplast covered by a dome-shaped shell punctured by many pores through which project the slender psudopodia. Chrysamoeba, a freely moving cell usually with one flagellum; Rhizochrysis, similar, without the flagellum. Myxochrysis, a large multinucleate form. Chrysarachnion, the cells clustered and linked together by strands of protoplasm. Lagynion, having an attached vase-shaped lorica from which projects usually a single slender pseudopodium. Chrysothylakion, with a retort-shaped lorica from which project many slender pseudopodia, branching and anastomosing. Only the plastids distinguish these organisms from various genera classsified as Rhizopoda, Heliozoa, or Sarkodina.

Family 7. Thallochrysidacea [Thallochrysidaceae] Pascher (1925). Brown organisms producing definite filaments of walled cells and reproducing by anteriorly uniflagellate zoospores. Thallochry'sis. Phaeodermatium.

Order 3. Vaucheriacea [Vaucheriaceae] Nägeli Gatt. einzell. Alg. 40 (1849). Class Heterokontae and orders Chloromonadales and Confervales Luther in Bihang Svensk. Vetensk.-Akad. Handl. 24, part 3, no. 13: 19 (1899). Not Chloromonadina Klebs (1893); not order Confervoidea C. Agardh (1824). Vaucheriales Bohlin Gröna Algernas 25 (1901).

Order Vaucheriales Clements Gen. Fung. 14 (1909).

Orders Heterochloridales, Heterocapsales, Heterococcales, Heterotrichales, and Heterosiphonales Pascher in Hedwigia 53: 10-21 (1912).

Division Heterokontae, Classes Heterochloridineae, Rhizochloridineae, Heterocapsineae, Heterococcineae, Heterotrichineae, and Heterosiphoneae, and orders Rhizochloridales and Botrydiales Pascher in Beih. bot. Cerıtralbl. 48, Abt. 2: 324 (1931).

Class Xanthomonadina with orders Heterochloridea and Rhizochloridea Deflandre in Grassé Traité Zool. 1, fasc. 1: 212, 217, 220 (1952).

Order Heterochlorida Hall Protozoology 133 (1953). 
Organisms producing motile cells with paired unequal flagella which Vlk (1931) found to be respectively pantoneme and acroneme, differing from Ochromonadalea in being of a green or yellow-green color, and in being mostly of algal body type, i. e., walled and non-motile. The cell wall consists usually of two parts which become separate when the cell divides; the two parts are believed to be distantly homologous with the wall and plug of the statospores of Ochromonadalea and Silicoflagellata (Pascher, 1932). The storage products are oil and sometimes leucosin.

As this is the group to which the class name Heterokontae was first applied, it is

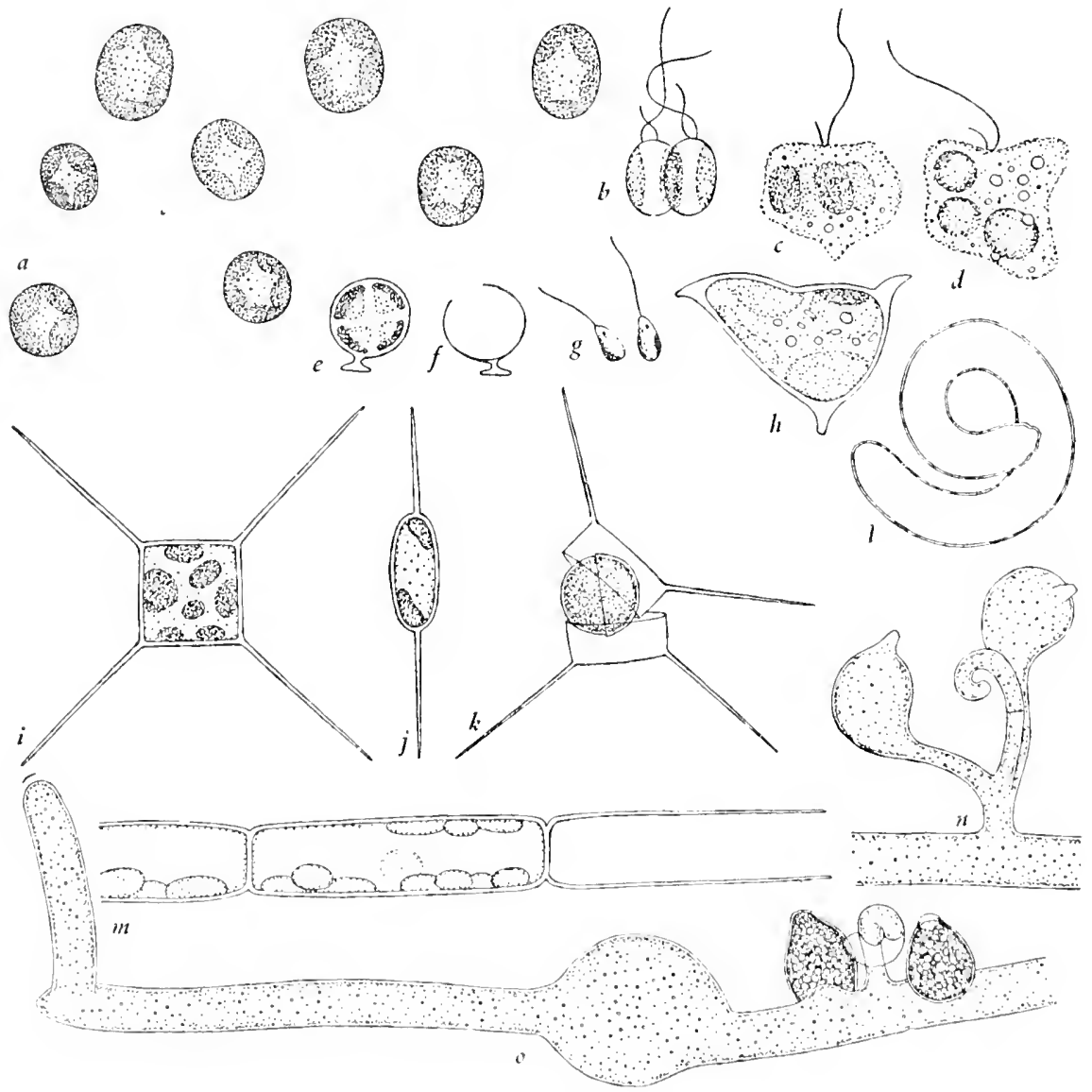

Fig. 10.-Vaugheriacen: a, b, Chlorosaccus fluidus, cells of the colony and zoosporcs, after Luther (1899). c, d, Chloramocba heteromorpha x 1,000 after Bohlin (1897). e, f, g, Ccll, empty cell, and zoospores of Characiopsis gibba $\times 1,000$ after Pascher (1912). h, Dioxys Incus after Pascher (1932). i, j, k, Cell, edge of cell, and statospore of Pscudotetracdron neglectum x 1,000 after Pascher (1912). 1, Spirodiscus fulvus $\times 1,000 . \mathbf{m}$, End of a filament of Tribonema bombycina $\times 1,000$. n. Antheridium and oogonia of V'aucheria Gardnerix 100. o, Filament of Vaucheria sessilis $\mathrm{x} 100$. 
the type group of the class. As established by Luther, the class consisted of the new genus Chlorosaccus together with a few genera of flagellates (Vacuolaria was included in error) and a few transfcrred from the group of typical green algae. From time to time, other green algae have been transferred, and it has become evident that the group is a fairly extensive one. Green organisms can be recognized as belonging here by a negative reaction to the iodine test for starch, and by the fact that they give a bluish color when heated with hydrochloric acid, instead of a yellow one, as typical green algae do: the difference depends upon differences in the complement of photosynthetic pigments. Bohlin (1901) placed Vaucheria here; most authors have not followed him, but Smith (1950) has done so. This genus brings with itself the oldest name for the group as an order.

Mitosis in Vaucheria was described by Hanatschek (1932) and Gross (1937). The spindle is intranuclear; Hanatschek saw centrosomes at the poles. The conjugation of equal free-swimming gametes was observed in Tribonema and several other genera by Scherffel (1901), and in Botrydium by Rosenberg (1930). Vaucheria was one of the organisms by study of which the nature of fertilization was discovered (Pringsheim, 1855). Hanatschek and Gross found that the first two divisions of the nucleus of the zygote are meiotic: the soma is haploid.

This order is believed to represent the direct ancestry of the two following classes, Bacillariacea and Oomycetes.

Pascher $(1912,1925)$ arranged the green Heterokonta in subordinate groups parallel to those of the typical green algae; and, as the main groups of green algae are treated as orders, he treated these groups also as orders (in 1931 as classes). They are scarcely entitled to such rank: too many of the classes or orders are of single families, and too many of the families are of one or two genera. Here, then, Pascher's classes and orders are suppressed and several of his families are reduced.

1. Not truly filamentous nor producing rhizoids.

2. The cells walled.

3. Cells regularly dividing into two, forming gelatinous colonies; occasionally producing small numbers of zoospores.

4. The colonies globular or irregular, becoming macroscopic...... Family 1. ChlorosacGaGeA.

4. The colonies dendroid, microscopic.....................mily 2. Misghococcacea.

3. Cells normally undergoing division into several.

4. Producing zoospores........... Family 3. Ghlorotheclacea.

4. Producing no motile cells........ Family 4. Botryococcacea.

2. The cells loricate........................ Stily 5. StipitococcaceA.

2. The cells amoeboid........................

1. Filaments of uninucleate cells............. Family 7. Tribonematacea.

1. Cells becoming highly multinucleate, forming filaments or at least producing rhizoids..... Family 8. Phyllosiphonacea. Family 1. Chlorosaccacea [Chlorosaccaceae] Smith Freshw. Algae 145 (1933). Family Hetcrocapsaceae Pascher in Hedwigia 53: 13 (1912); there is no corresponding generic name. Gelatinous aggregates of cells which may divide, causing the 
aggregate to grow to macroscopic dimensions; or may produce one, two, or four zoospores. Chlorosaccus Luther, the standard genus of class Heterokonta.

Family 2. Mischococcacea [Mischococcaceae] Pascher in Hedwigia 53: 14 (1912). Microscopic colonies of globular cells joined by dichotomously branching gelatinous strands. Mischococcus.

Family 3. Chlorotheciacea [Chlorotheciaceae] Luther in Bihang Svensk. VetenskAkad. Handl. 24, part 3, no. 13: 19 (1899). Families Chlorobotrydiaceae and Sciadiaceae Pascher in Hedwigia 53: 17 (1912). Family Halosphaeraceae Pascher (1925). Family Ophiocytiaccae Auctt. Cells solitary, free or attached, capable of reproduction by division to form multiple zoospores, in some examples capable alternatively of producing multiple minute non-motile cells of the same form as the parent. Large free multinucleate cells, more or less globular: Botrydiopsis, Leuvenia. Smaller cells, elongate, curved or coiled: Characiopsis, Spirodiscus. Spirodiscus fulvus Ehrenberg in Abh. Akad. Wiss. Berlin 1830: 65 (1832) (nomen nudum) and Infusionsthierchen $86(1838)$, whose identity has been a standing puzzle to bacteriological systematists, is an older name of Ophiocytium parvulum (Perty) A. Braun (Copeland, 1954). It antedates the generic name Ophiocytium Nägeli (1849); new combinations are required for the dozen additional species of this genus. The cells attached: some species of Characiopsis; Perionella; Dioxys.

Family 4. Botryococcacea [Botryococcaceae] Pascher in Hedwigia 53: 13 (1912). Solitary or colonial cells reproducing strictly by production of non-motile cells. Botryococcus. Pseudotetraedron.

Family 5. Stipitococeacea [Stipitococcaceae] Pascher in Beih. bot. Centralbl. 48, Abt. 2: 324 (1931). Family Stipitochioridae Deflandre in Grassé Traté Zool. 1, fasc. 1: 221 (1952). Amoeboid cells with green plastids, partially enclosed in loricae attached to objects in water. Stipitococcus.

Family 6. Chloramoebacea [Chloramoebaceae] Luther in Bihang Svensk. Vetcnsk.Akad. Handl. 24, part 3, no. 13: 19 (1899). Family Chloramoebidae Poche in Arch. Prot. 30: 155 (1913). Families Hetcrochloridaceae and Rhizochloridaceae Pascher Süsswasserfl. Deutschland 11: 22, 26 (1925). Families Heterochloridae, Rhizochloridae, Chlorarachnidae and My:xochloridae Deflandre in Grassé Traité Zool. 1, fasc. 1 : 217-222 (1952). Amocboid organisms with green plastids, without loricae, sometimes swimming by means of paircd unequal flagella. Chloramoeba, Chlorochromonas, Rhizochloris.

Family 7. Tribonematacea [Trilonemataceae] Pascher in Hedwigia 53: 19 (1912). Family Confervaceae Luther (1899). Jamily Monociliaceae Smith Freshw. Algac 160 (1933). Green Heterokonta producing filaments of uninuclcate cclls. The Linnacan genus Conferva included a grcat variety of growths in water. Definite groups were separated from it, one after another, until the residuc was a natural group; but this residue cannot be assumed to be the type of Conferva L.; that name is to be abandoned as a nomen confusum. The remnant in question has become two genera, Tribonema Derbes and Solier, 1858, and Bumilleria Borzi, 1895. They are unbranched filaments, common in freshwater pools. From typical green algae of similar appearance they are distinguished in the first place by the presence in each cell of several disk-shaped plastids without pyrenoids or with obscure oncs. The cell walls, when treated with sulfuric acid, can be secn to consist of two parts like a barrel sawed across the middle. $\Lambda$ broken filament cnds always with a broken half wall. Monocilia, ar. unfamiliar alga isolated from soil, differs in producing branching filaments. 
Family 8. Phyllosiphonacea [Phyllosiphonaceae] Wille in Engler and Prantl. Nat. Pflanzenfam. I Teil, Abt. 2: 125 (1890). Family Vaucheriaceae (Nügeli) Areschoug (1850), preoccupied by order Vaucheriaceae Nägeli. Family Botrydiaceae Luther (1899). Heterokonta whose bodies are highly multinucleate single cells, filamentous or anchored by filamentous rhizoids. Botrydium is found on damp soil as dark green globes, sometimes as much as $2 \mathrm{~mm}$. in diameter, anchored by much-branched colorless rhizoids. Vaucheria is a familiar alga on damp earth or in fresh water. It consists of irregularly branching filaments, green where exposed to light, colorless where growing downward and serving as rhizoids. The reproductive cells are cut off by walls. The end of an aerial filament, cut off in this fashion, may as a whole act as a spore. In water, the protoplast of such a cell may escape as an exceptionally large zoospore with as many pairs of flagella as the nuclei within it. Antheridia are brief branches, each releasing many minute sperms each with two unequal flagella. Oogonia are globular cells, multinucleate during development, but containing only one functional nucleus when mature. Phyllosiphon is of much the same structure as Vaucheria, but is parasitic in seed plants, particularly Araceae. It reproduces, apparently, only by the breaking up of the protoplast to produce minute non-flagellate spores.

\section{Order 4. Choanoflagellata [Choano-Flagellata] Kent Man. Inf. 1: 36 (1880).}

Order Bicoecidea Grassé and Deflandre in Grassé Traité Zool. 1, fasc. 1: 599 (1952).

Non-pigmented flagellates, usually attached, each cell bearing a single flagellum of the type called pantacroneme, with lateral appendages and a terminal whip-lash; the cell bearing also a protoplasmic collar, usually surrounding the base of the flagellum. The collar is a means of nutrition. Bacteria and other scraps of organic matter, driven against it by the beating of the flagellum, adhere and are carried to the interior of the cell by flow of the cytoplasm of which it consists.

It is probable that the pantacroneme flagellum is a variant of the pantoneme flagellum, and that this order belongs naturally in class Heterokonta. It may have evolved from Silicoflagellata; or it may be that the collar is a modified flagellum, and that the group evolved from order Ochromonadalea.

Most authors have recognized more than one family of choanoflagellates, but genera are not very numerous and one family seems sufficient to accommodate them.

Family Bicoekida Stein Org. Inf. 3, I Hälfte: x (1878). Family Craspedomonadina Stein 1.c. Families Bikoecidae, Codonosigidae, Salpingoecidac, and Phalansteriidae Kent op. cit. Families Codonoecina and Bikoecina Bütschli in Bronn Kl. u. Ord. Thierreichs 1: 814, 815 (1884). Families Bicoecaceae, Craspcdomonadaceae, and Phalanasteriaceae Senn in Engler and Prantl Nat. Pflanzenfam. I Teil, Abt. la: 121, 123, 129 (1900). Family Gymnocraspedidae Grassé Traité Zool. 1, fasc. 1: 590 (1952). Characters of the order. Cells naked, solitary: Monosiga; colonial: Codosiga James-Glark (Codonosiga Stein), Sphaeroeca. Cells imbedded in gelatinous matter, the collars contracted: Phalanseterium. Loricate: Salpingoeca, Bicosoeca, Poteriodendron.

The choanoflagellates were discovered by James-Clark $(1866,1868)$, who made at the same time the discovery that certain internal cavities of sponges are lined by minute cells (choanocytes) of the same structure as the choanoflagellates. From these observations he drew the conclusion that sponges are a sort of flagellates distinguished by the production of exceptionally large and elaborate colonies. Kent 
described Proterospongia Hacckeli as a colonial organism of amoeboid and choanoflagellate cells in a common matrix; he regarded it as a transitional form, important as evidence of the evolution of sponges from choanoflagellates. According to Duboscq and Tuzet (1937) it is no organism, but a stage in the development of an individual sponge from one which has been damaged. In spite of this, the hypothesis that the choanoflagellates represent the evolutionary origin of the sponges, and accordingly of the entire animal kingdom, continues to appear tenable.

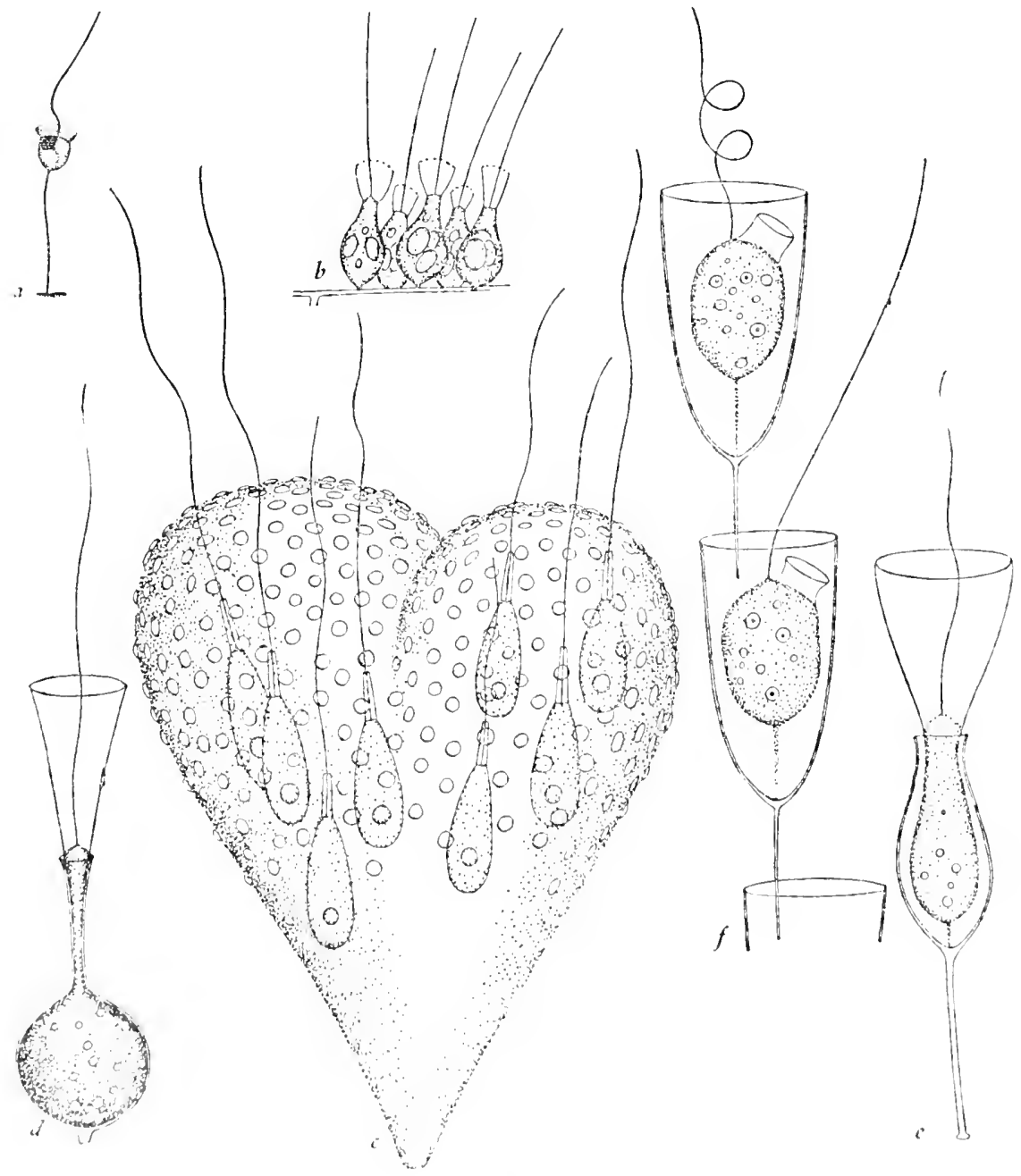

Fig. 11.-Chonnoflageldata: a, b, Monosiga spp.; c, Phalanasterium digitatum; d, Salpingocca ampullacca; e, Salpingocca Clarkii; f, I'otcriodindron petiolatum. c $\times 500$, the remainder $x 1,000$. c-f after Stcin $(1878)$. 
Order 5. Hyphochytrialea [Hyphochytriales] Bessey Morph. and Tax. Fungi 69 (1950).

Order Anisochytridiales Karling in American Jour. Bot. 30: 641 (1943), not based on a generic name.

Non-pigmented organisms with walled cells, parasitic or saprophytic, the protoplasm with numerous granules not of a shining appearance, producing zoospores with single anterior pantoneme flagella.

The naked zoospores come to rest upon appropriate hosts or substrata. Ordinarily, in parasitic species, the protoplast of the zoospore makes its way to the interior of a cell of the host. It swells and develops a thin wall. The resulting structure may be called a center. In most members of the group, the center gives rise to a system of slender rhizoids; in some species, these give rise to further centers like the original one. Karling studied the cytology particularly in Anisolpidium. There are repeated simultaneous mitoses in the growing centers. Resting nuclei contain conspicuous karyosomes. Dividing ones show about five chromosomes in an intranuclear spindle which ends sharply in centrosomes. Eventually, in the usual course of events, each center produces an exit tube to the exterior. Its contents are released by deliquescence of the tip of the exit tube. Either before this or afterward, the mass of protoplasm undergoes cleavage into uninucleate protoplasts which generate flagella. Sometimes, instead of discharging their contents, the certters are converted into resting spores by the secretion of thick walls (this has been observed in only a few of the species). The resting spores germinate by producing exit tubes and discharging zoospores as ordinary centers do.

The body type which has just been described may be called the chytrid body type; organisms of this body type were formerly assembled as a taxonomic group typified by the genus Chytridium. Couch, however, showed that these organisms form three groups distinguished by fundamental differences in type of flagellation. The present group is here given a place implying relationship to order Silicoflagellata.

Karling (1943) accounted for fourteen species. He provided three families; only one is here maintained.

Family Hyphochytriacea [Hyphochytriaceae] Fischer in Rabenhorst Kryptog.-Fl. Deutschland 1, Abt. 4: 131 (1892). Families Anisol pidiaceae and Rhizidiomycetaceae Karling in American Jour. Bot. 30: 641, 643 (1943). Characters of the order. Without rhizoids: Anisolpidium on brown algae; Roesia on Lemna; Cystochytrium on roots of Veronica. With rhizoids from a single center: Rhizidiomyces and Latrostium on green algae, aquatic fungi, and the empty exoskeletons of insects. With multiple centers: Hyphochytrium and Catenariopsis, on fungi and other hosts.

\section{Class 2. BACILLARIACEA Engler and PrantI}

Homalogonata Lyngbye Tent. Hydrog. Danicae 177 (1819).

Order Diatomeae C. Agardh Syst. Alg. xii (1824).

Division (of order Algae) Diatomaceae Harvey in Mackay Fl. Hibern. 166 (1836).

Family Bacillaria Ehrenberg Infusionsthierchen 136 (1838).

Series (of class Algae) Diatomaceae Harvey Man. British Alg. 15 (1841).

Abtheilung (of class Isocarpeae) Diatomaceae Kützing Phyc. Germ. 54 (1845).

Stamm Diatomea Haeckel Gen. Morph. 2: xxv (1866).

Division (of class Algae) Diatomaceae Rabenhorst Kryptog.-Fl. Sachsen 1: 1 (1863). 


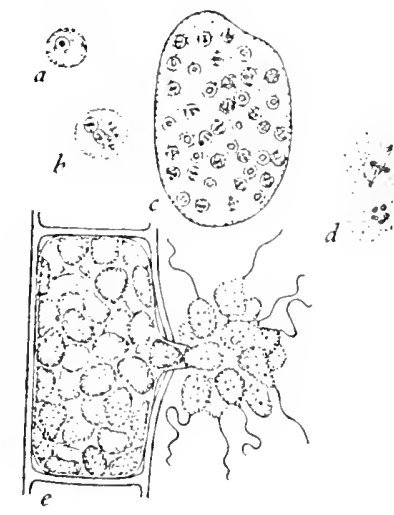

\section{(l)}

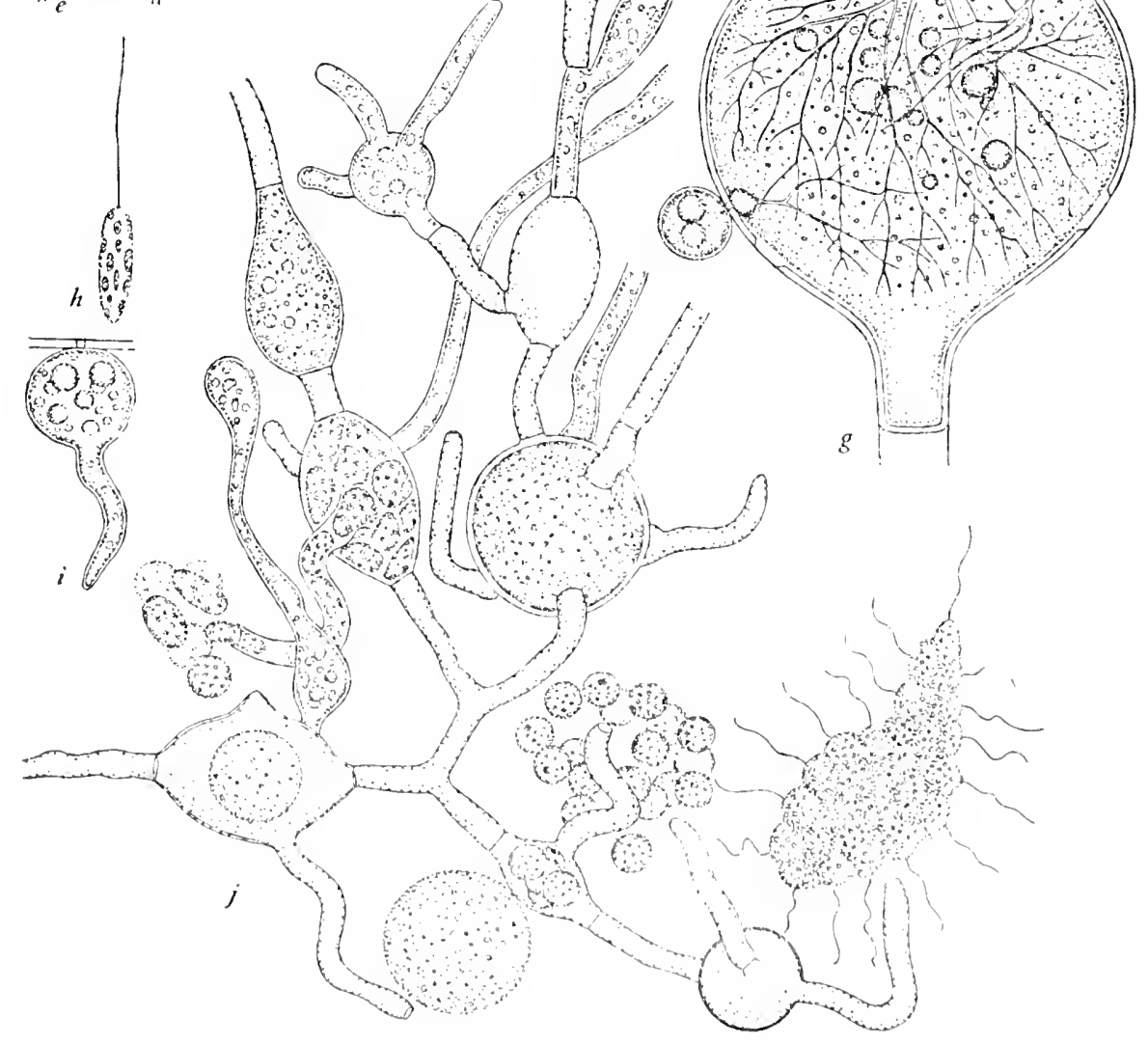

Fig. 12.--Hyphochytriales: a-e, Anisolfidizm Ectocarpii; a-c, individuals developing in cclls of Ectocarpus; d, mitotic figures x 2,000; e, cell of Ectocarpus filled by a mature individual discharging spores. $\mathbf{f}, \mathbf{g}$, Rhizidiomyces afophyatus; $\mathbf{f}$, zoospore; g, oogonium of Achlya parasitized by three individuals. h, i, j, 11 yphochytrium catcnoides; $\mathbf{h}$, zoospore; $\mathbf{i}$, young individual; $\mathbf{j}$, mature individual with filaments, sporangia, and zoospores in various stages of development. All after Karling $(1943,1944,1939) . \quad x 1,000$ except as noted. 
Class Bacillariaceae Engler and Prantl Nat. Pflanzenfam. II Teil: 1 (1889).

Subdivision and class Bacillariales Engler Syllab. 6 (1892).

Hauptclasse Diatomeae Haeckel Syst. Phylog. 1: 90 (1894).

Subclass Bacillariales Engler in Engler and Prantl Nat. Pflanzenfam. Teil I, Abt.

la: v (1900).

Class Bacillarieae Wettstein Handb. syst. Bot. 1: 74 (1901).

Class Bacillarioideae Bessey in Univ. Nebraska Studies 7: 283 (1907).

Glass Diatomeae Schaffner in Ohio Naturalist 9: 447 (1909).

Abteilung Bacillariophyta Engler.

Abteilung (of Stamm Chrysophyta) Diatomeae Pascher in Beih. bot. Centralbl. 48, Abt. 2: 324 (1931).

Class Bacillariophyceae Auctt.

Unicellular (occasionally filamentous or colonial) organisms without flagella in the vegetative condition, each cell with one, two, or more plastids, brown, varying to yellow or exceptionally to bluish or colorless, and bearing a siliceous shell of two parts. Globules of oil and granules of something called volutin (the "red granules of Bütschli," apparently protein) are present. Other granules in some examples are said to be of leucosin.

These organisms, the diatoms, are very conmon. There are some 5300 species. Microscopic examination of the bottoms of fresh water ponds reveals usually more of diatoms than of any other kind of organisms. Diatoms are frequent prey of many kinds of predators, from amoebas to whales. In using fish-liver oils as a source of vitamin $\mathrm{D}$, man adds himself to a long chain of predators of which it is believed that diatoms are the usual ultimate prey.

The shells of diatoms are not subject to decay. In certain places which were in the geologic past arms of the sea, there are enormous deposits of diatom shells in the form of a white earth. The oldest deposits are of the Cretaceous age. Thus it appears that diatoms are a modern offshoot, no more ancient than the flowering plants. Diatomaceous earth is mined for various uses. It is an effective insulating material, and was the inert material first used in connection with nitroglycerine in the manufacture of dynamite.

The two parts of the shell of a diatom are called valves. They fit one over the other "like the parts of a pill box" (ZoBell, 1941, objects to this traditional simile, on the ground that in current language a pillbox is a concrete structure with loopholes). The shells consist basically of something of the nature of pectin heavily impregnated with silica and characteristically sculptured. The cells appear markedly different in different aspects: the aspect which is in effect top or bottom view is called valve view, and that which is in effect side view is called girdle view. When a cell divides, each of the daughter cells receives one of the valves and generates an additional valve fitting within it. Diatoms in culture undergo a gradual diminution in size; there is an old hypothesis that this is caused by the fact that one of each pair of sister cells receives a slighly smaller valve than the other.

Lauterborn (1896) described mitosis in Surirella and other diatoms. He found a centrosome, with radiating strands, near the nucleus. At the beginning of mitosis, the centrosome generates a disk-shaped structure which enters the nucleus and grows in such fashion as to become a cylinder extending through it. The cylinder is recognizably a spindle, but the chromosomes, instead of appearing within it, form a ringshaped mass about its middle and divide into two ring-shaped masses which move along it to its extremities. The nuclear membrane ceases to be recognizable early in 

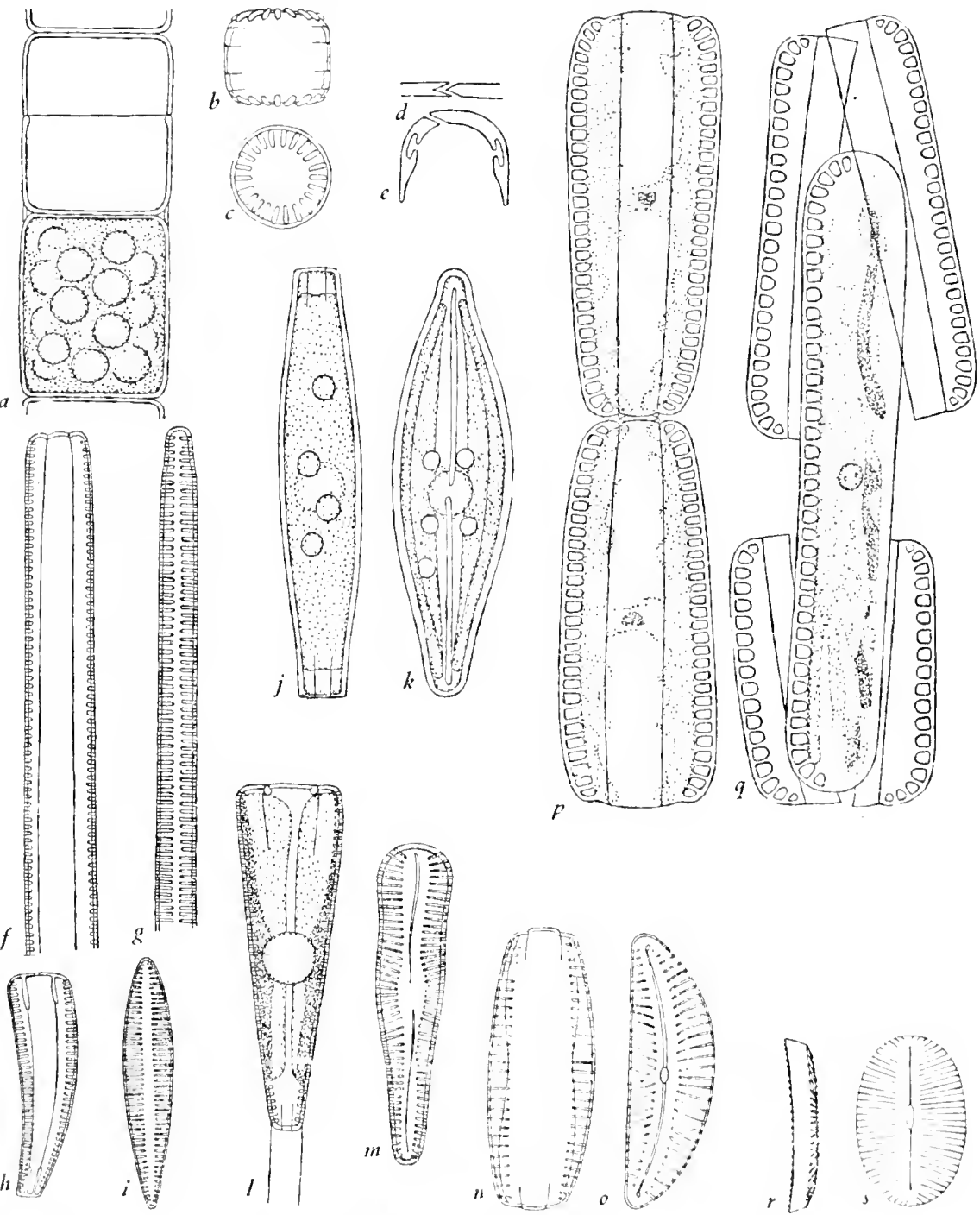

Fig. 13.-Bacillariagea: a, Melosira sp., a living cell and an empty one. b, c, Girdle and valve views of cell of Cyclotella sp. d, e, Sections of a valve of P'innularia sp., highly magnified, after Otto Müller (1896); d, about half-way between the middle and the end, e, near the cnd. $\mathbf{f}, \mathfrak{g}$, Girdle and valve views of Syncdra sp. $\mathbf{h}$, i, Girdle and valve vicws of Rhoicosphenia curvata. j, $\mathbf{k}$, Girdle and valve views of Navicula sp. 1, m, Girdle and valve views of Gomphonema sp. (the former showing the gelatinous stalk by which the cell is attached). n, o, Girdle and valve views of Cymbclla sp. p, q, Surirclla saxonica after Karsten (1900); p. two cells joined before conjugation; 1, zygote; $\mathrm{x} 250$. r, s, Girdle and valve vicws of Cocconcis sp. $\mathrm{x} 1,000$ except as noted. 
the process, but the nuclear cavity remains distinct until the chromosomes have reached the ends of the spindle. The nuclear sap and the spindle are then absorbed by the cytoplasm, but not until the spindle has budded off a new centrosome from each end.

Subsequent authors, as Karsten (1900), Geitler (1927), Iyengar and Subrahmanyan (1942, 1944), and Subrahmanyan (1947), have not seen as full a series of stages as Lauterborn did. They have found centrosomes in at least some diatoms, and have confirmed the point that the spindle is a cylinder which is surrounded by the chromosomes instead of including them.

The same authors have described sexual processes in Surirella, Cymbella, Cocconeis, Cyclotella, and Navicula. In Surirella saxonica as described by Karsten, pairs of the wedge-shaped cells become attached by little bodies of slime at the narrow ends. Each nucleus divides twice, producing four, of which three are digested by the cytoplasm. The two protoplasts then move in amoeboid fashion out of their shells and they and their nuclei unite. The zygote protoplast grows to a size much greater than that of the parent cells and secretes a membrane which becomes silicified. The resulting cell is called an auxospore.

In most kinds of diatoms, each cell produces two gametes. In some, the cells pair and proceed to produce auxospores individually, without conjugation. Karsten supsposed the latter examples to represent a stage in the evolution of sexual reproduction under some zwingender Nothwendigkeit: much more probably, they are products of degeneration. In Cyclotella, Iyengar and Subrahmanyan found the production of auxospores to involve autogamous karyogamy: the nucleus of a solitary cell undergoes meiosis; two of the haploid nuclei are digested, and the two which remain fuse with each other. It is evident that all diatoms arc diploid in the vegetative condition.

The filamentous green Heterokonta Tribonema and Bumilleria are closely similar to the diatom Melosira, and it may reasonably be supposed that they represent the evolutionary origin of the group.

Diatoms are preserved for study by violent methods which destroy the protoplasts, and the classification is based strictly on characters of the shells. So uniform is the group that Schütt (in Engler and Prantl, 1896) treated it as a single family. He provided an elaborate subsidiary classification involving two main groups. Subscquent scholars have found his system essentially sound as a representation of nature, but have raised the main groups to the rank of orders and the minor ones in corresponding degree.

Order 1. Disciformia [Disciformes] Kützing Phyc. Germ. 112 (1845).

Order Appendiculatae Kützing 1. c.

Centricae Schütt in Engler and Prantl Nat. Pflanzenfam. I Teil, Abt. 1b: 57 (1896).

Order Centricae Campbell Univ. Textb. Bot. 90 (1902).

Order Eupodiscales Bessey in Univ. Nebraska Studies 7: 284 (1907).

Diatoms basically of radial symmetry, which, however, is often distorted; not motile in the vegetative condition; plastids numerous in the cells.

These are the more primitive diatoms. The majority are marine. Three types of reproductive cells are known to be produced by them.

Occasionally, in mass catches of material from the ocean, diatoms are found whose protoplasts have undergone repeated division within the shell and produced 
numerous little naked protoplasts. These protoplasts are said to bear flagella; whether one or two, equal or unequal, is not certainly known. They are supposed to escape and function as zoospores, but Karsten (1904), on rather scant evidence, supposed them to be gametes.

A protoplast may contract and form a shell within its former shell. The new shell consists like the old one of two parts, one fitting within the other. The outer shell is usually more or less elaborately sculptured, while the inner is smooth. It is supposed that the outer shell is deposited between outer and inner masses of protoplasm, and that the entire protoplast then withdraws to the interior and deposits the inner shell in the opening. It is in this manner that the statospores of chrysomonads are formed. The resting cells of diatoms as just described are believed to be homologous with them, and are called by the same term.

As a third manner of producing a reproductive cell, a protoplast may expand, force apart the valves of its shell, and deposit an enlarged shell about itself. The resulting spore is called an auxospore. As noted, Iyengar and Subrahmanyan found the production of auxospores in Cyclotella to involve sexual processes.

Schütt divided the Centricae into three groups with names in -oideae (presumably subfamilies) and these into nine groups with names in -eae (presumably tribes). Subsequent authorities have made of Schïtt's groups a varying number of families. The minimum tenable number of families is three, corresponding to Schütt's subfamilies.

Familv 1. Coscinodiscea [Coscinodisceae] Kützing Phyc. Germ. 112 (1845). Family Melosireae Kützing op. cit. 66. Families Melosiraceae and Coscinodiscaceae West British Freshw. Alg. 274, 276 (1904). Melosira, in fresh water, the shells feebly silicified, the cells joined end to end in filaments. Cyclotclla, separate drum-shaped cells in fresh water. Coscinodiscus, the cells disk-shaped. Triceratium, cells of the form of 3-, 4-, or 5-sided prisms with abbreviated axes.

Family 2. Rhizosoleniacea [Rhizosoleniaceae] West British Freshw. Alg. 278 (1904). The cells, circular or el!iptic in cross section, becoming elongate by intercalation of ring-shaped bands of wall between the valves. Rhizosolenia. Corcthron.

Family 3. Biddulphiea [Biddulphieae] Kützing Phyc. Germ. 115 (1845). Families Biddulphiaceae and Chaetoceraceae Auctt. Cells laterally compressed, elliptic in valve view, oblong or rhombic in girdle view. Cells of Biddulphia, solitary or colonial, are familar as epiphytes on marine algae. Chaetoceros, the cells with a long spine at each corner, frequently united valve to valve in filaments, abundant in subpolar oceans.

\section{Order 2. Diatomea [Diatomeac] C. Agardh Syst. Alg. xii (1824).}

Tribe Striatae with orders Astomaticae and Stomaticae, and tribe Vittatae also with orders Astomaticae and Stomaticae, Kützing Phyc. Germ. (1845).

Pennatae Schütt in Engler and Prantl Nat. Pflanzenfam. I Teil, Abt. lb: 101 (1896).

Order Pennatae Campbell Univ. Textb. Bot. 90 (1902).

Order Naviculales Bessey in Univ. Nebraska Studics 7: 281 (1907).

Diatoms basically of isobilateral symmetry, occasionally so skewed as to be dorsiventral or asymmetric; valves usually punctured by a longitudinal cleft called the raphe, or bearing a marking of some sort, called the pseudoraplic, in the same position; cxhibiting, when possessed of a truc raphe, a gliding motion; cells usually with two plastids. 
The motion of the pennate diatoms is a gliding upon surfaces, with frequent reversal, in either direction of the long axis of the cell. It depends upon the flow of a stream of exposed protoplasm. This is the opinion of Max Schultze (1865), Otto Müller (1889, 1896), and Lauterborn (1896); there have been other hypotheses. Müller showed that the true raphe, without which the motion does not occur, is an actual opening. The raphe is not a simple crack; it enters the wall obliquely and bends at a sharp angle to come from another oblique direction to the interior. Its proportions vary along its length, and it is interrupted at the middle of the valve by a knob, the central granule, projecting inward from the valve.

The pennate diatoms do not produce flagellate cells nor statospores, but they produce auxospores, usually by sexual processes. The majority inhabit fresh water.

Eleven families are currently recognized.

\section{a. Without raphes.}

Family 1. Fragilariea [Fragilarieae] (Harvey) Kützing Phyc. Germ. 62 (1845). Family Fragilariaceae West British Freshw. Alg. 285 (1904). Cells symmetrical with respect to three planes, without internal partitions. Fragilaria. Synedra.

Family 2. Tabellariea [Tabellarieae] Kützing op. cit. 110. Family Tabellariaceae West op. cit. 281. Cells symmetrical with respect to three planes, with longitudinal internal partitions. Tabellaria.

Family 3. Bacillaria Ehrenberg Infusionsthierchen 136 (1838). Family Diatomaceae West op. cit. 284. Cells symmetrical with regard to three planes, with transverse internal partitions, solitary, or joined valve to valve in ribbons, or corner to corner in zig-zag chains. Diatoma.

Family 4. Meridiea [Meridieae] Kützing op. cit. 61. Family Meridionaceae West op. cit. 283. Cells symmetrical with regard to two planes, wedge-shaped both in valve and in girdle view, with transverse internal partitions, often joined valve to valve in fan-shaped colonies which are sometimes so extended as to produce spiral filaments. Meridion.

\section{b. With raphes, the valves of each cell alike.}

Family 5. Naviculea [Naviculeae] Kützing op. cit. 90. Family Naviculaceae Rabenhorst Kryptog.-Fl. Sachsen 1: 33 (1863). This is the most numerous family of diatoms. In most of the genera the cells are narrowly rectangular in girdle view, narrowly elliptic in valve view, being of the shape of flat-bottomed boats. Navicula, Pinnularia, etc. In other genera, as Gyrosigma and Pleurosigma, the cells are so skewed as to be sigmoid in valve view.

Family 6. Gomphonemea [Gomphonemeae] Kützing op. cit. 87. Family Gomphonemaceae West op. cit. 297. Cells wedge-shaped. Gomphonema.

Family 7. Cymbellea [Cymbelleae] (Harvey) Kützing op. cit. 84. Family Cocconemaceae West op. cit. 298. Cells with two planes of symmetry, in valve view crescentshaped or approximately so. Cymbella. Rhopalodia.

Family 8. Eunotiea [Eunotieae] Kützing op. cit. 57. Family Eunotiaceae West op. cit. 287. Cells curved as in the preceding family, the raphes reduced to brief clefts near the ends of the valves. Eunotia.

Family 9. Nitzschiacea [Nitzschiaceae] West op. cit. 301. Cells asymmetric in valve view, the raphe along one margin. Nitzschia. Hantschia.

Family 10. Surirellea [Surirelleae] Kützing op. cit. 70. Family Surirellaceae West op. cit. 303. Each cell with two marginal raphes. Surirella.

c. The two valves of each cell unlike, one with a raphe, one with a pseudoraphe. 
Family 11. Achnanthea [Achnantheae] Kützing op. cit. 81. Families Achnanthaceae and Cocconeidaceae West op. cit. 289, 290. Achnanthes, Rhoicosphenia, Cocconeis.

\section{Class 3. OOMYCETES Winter}

Class Oomycetes Winter in Rabenhorst Kryptog.-Fl. Deutschland 1, Abt. 1: 32 (1879).

Phycomyceten de Bary Vergl. Morph. Pilze 142 (1884), in part.

Class Phycomycetes Engler and Prantl Nat. Pflanzenfam. II Teil: 1 (1889), in part.

Reihe Oomycetes Fischer in Rabenhorst Kryptog.-Fl. Deutschland 1, Abt. 4: 310 (1892).

Stamm Phykomycophyta Pascher in Beih. bot. Centralbl. 48, Abt. 2: 330 (1931), in part.

Biflagellatae Sparrow Aquatic Phycomycetes 487 (1943).

Organisms of fungal or chytrid body type, that is, non-pigmented saprophytes or parasites whose bodies are walled filaments or cells with or without rhizoids; the walls consisting partially of cellulose; reproducing asexually by zoospores with paired unlike flagella which are, so far as is known, respectively pantoneme and acroneme, and usually sexually by fertilization, the eggs being distinct cells within the oogonia. The regularly cited example and evident standard genus of the group is Saprolegnia.

Conventional botanical classification recognizes within the group of Fungi a subordinate group named Phycomycetes, which is in turn divided into Oonnycetes and Zygomycetes, the former including the chytrids. This arrangement suggests an evolutionary series, originating perhaps among non-pigmented flagellates, and leading through chytrids, typical Oomycetes, and Zygomycetes to the typical fungi. It does not now appear tenable. Couch (1939) pointed out differences between Oomycetes and Zygomycetes which make any direct connection between them appear quite improbable; and his observations on flagella showed that only a small minority among organisms of chytrid body type have anything to do with the proper Oomycetes.

There is an old hypothesis (Sachs, 1874) that Vaucheria may represent the direct ancestry of Saprolegnia. This hypothesis could not be taken seriously while Saprolegnia and its allies were known to produce heterokont zoospores, while Vancheria was supposed to be a typical isokont green alga. Now it again appears probable. It implies that in the present group the fungal body type is more primitive than the chytrid.

The Oomycetes may be organized as three orders.

1. Of fungal body type, i.c., consisting of filaments.

2. Essentially aquatic........................

2. Mostly not aquatic, parasitic on higher

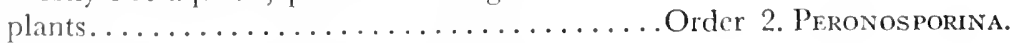

1. Of chytrid body type, i.e., the cells not clongated to filamentous form, though sometines proliferating or producing rhizoids............... Order 3. Lagenidialea. 
Order 1. Saprolegnina [Saprolengninae] Fischer in Rabenhorst Kryptog.-Fl. Deutschland 1, Abt. 4:311 (1892).

Order Eremospermeae and suborder Mycophyceae Kützing Phyc. Gen. 146 (1843), in part.

Order Oosporeae Cohn in Hedwigia 11: 18 (1872), in part.

Order Oomycetes and suborder Saprolegniineae Engler Syllab. 24 (1892).

Order Saprolegnïneae Campbell Univ. Textb. Bot. 153 (1902).

Order Siphonomycetae Bessey in Univ. Nebraska Studies 7: 286 (1907).

Order Saprolegniales Auctt.

Order Leptomitales Kanouse in American Jour. Bot. 14: 295 (1927).

Aquatic Oomycetes, filamentous, saprophytic or facultatively parasitic, the zoospores diplanetic (exhibiting two periods of swimming) or giving evidence of an ancestral diplanetic condition. The old ordinal names Eremospermeae and Oosporeae designated miscellaneous collections of groups in which this one was listed at or near the beginning. Either one, if taken up, would be applied here, but it seems better to treat them as nomina confusa.

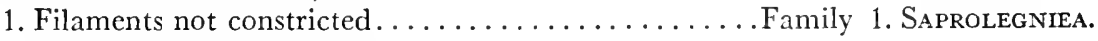

1. Filaments constricted at intervals.

2. Filaments not differentiated into basal and reproductive parts............... Family 2. Leptomitea.

2. Filaments differentiated into basal and

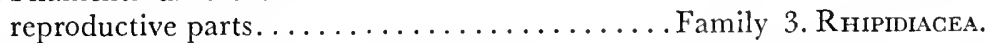

Family 1. Saprolegniea [Saprolegnieae] Kützing Phyc. Gen. 157 (1843). Family Saprolegniaceae Cohn in Hedwigia 11: 18 (1872). Aquatic Oomycetes consisting of branching filaments of essentially uniform diameter without crosswalls other than those which set apart differentiated reproductive structures.

These well-known organisms are called water molds. According to Coker (1923) there are about eighty definitely recognizable species. They may be parasitic on fishes or saprophytic on organic remains in water or soil. In almost any body of soil or of fresh water they may be found by "baiting;" in former practice with dead flies, currently with hemp seeds.

Mitosis has rarely been observed in the vegetative filaments, the nuclei being very minute. Eggs are produced in large globular multinucleate oogonia borne at the ends of filaments. The nuclei in the developing oogonia become enlarged and undergo a single flare of concurrent mitoses (Davis, 1903; Couch, 1932). The sharp-pointed spindles, ending in centrosomes, are formed within the nuclear membrane. The membrane disappears toward the end of the mitotic process, and a nucleolus, which has persisted to this stage, undergoes solution in the cytoplasm. The chromosome numbers (Ziegler, 1953) are 3, 4, 5, 6, or 7.

Within each oogonium there appear one or a few minute bodies called coenocentra. One nucleus becomes associated with each coenocentrum; all others break down and disappear. Each surviving nucleus with the cytoplasm associated with it becomes organized as an egg. When several eggs are produced, they share all of the cytoplasm of the oogonium; when only one egg is produced, some of the cytoplasm is left outside of it.

Sperms are produced in small multinucleate antheridia borne at the tips of filaments in contact with oogonia. Typically, each individual bears both oogonia and antheridia. Some species are capable of self-fertilization; others exist as two kinds of individuals, each capable of fertilizing the other; some occur as distinct male and 


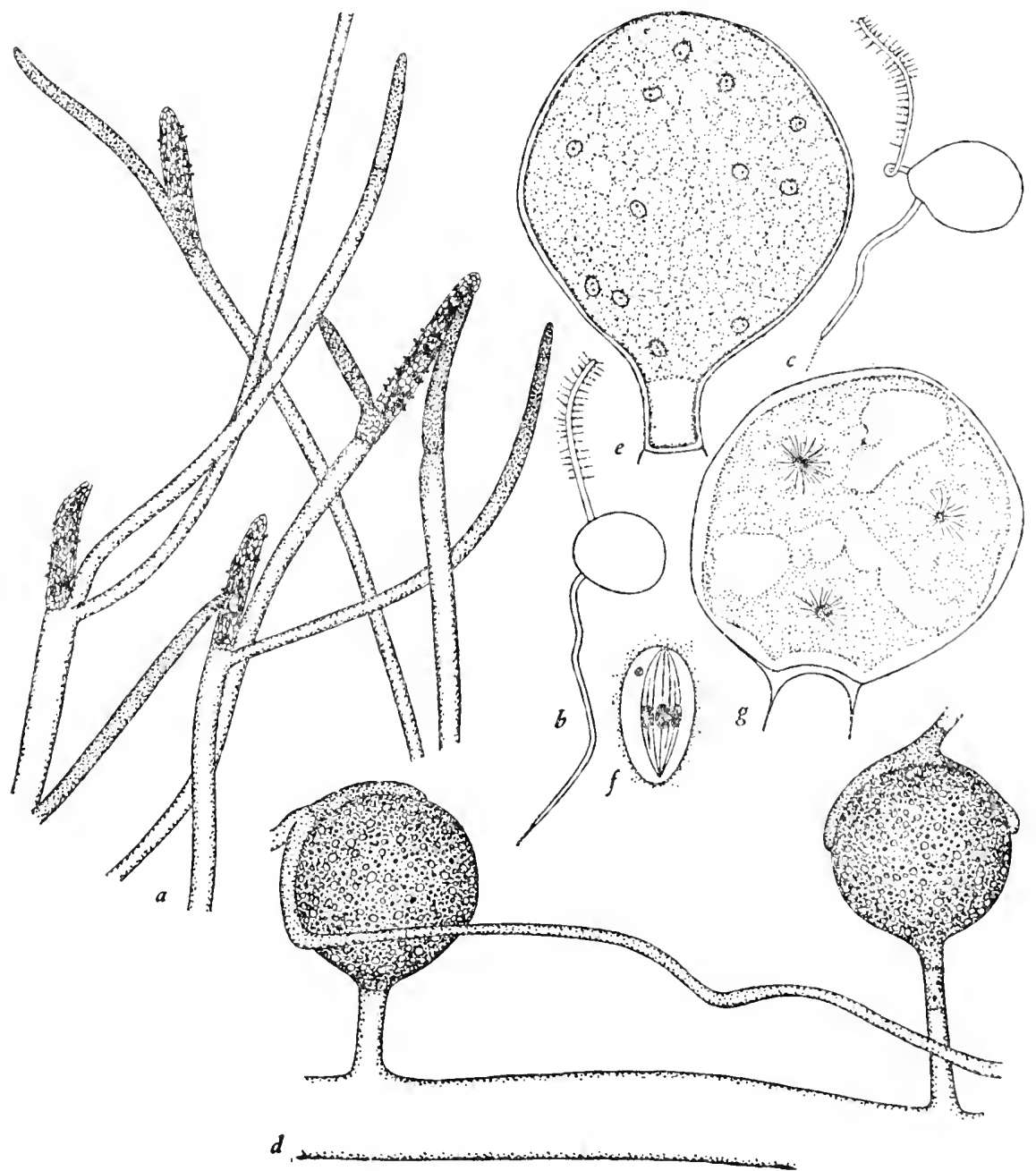

Fig. 14.-Oomscetes: a, Filaments and sporangia of Dictyuchus sp. $\mathrm{x} 50$. b, c, Zoospores of the second stage of swimming, of Achlya caroliniana and Saprolegnia ferax, after Couch (19.11) x 1,000. d, Oogonia and antheridia of Dictyuchus x 400. e, f, g, Saprolegnia mixta after Davis (1903): e, developing oogonium with numerous nuclei $\times 500 ; \mathbf{f}$, metaphase of nuclear division $\times 2,000 ; \mathbf{g}$, developing oogonium in which most of the nuclei have undergone degencration; a $\mathrm{few}$ have become associated with coenocentra, and the cytoplasm is undergoing cleavage to produce eggs about these. 
female individuals. Parthenogenesis (reproduction by eggs which have not been fertilized) is rather common in this group. There are no swimming sperms: nuclei from the antheridia reach the eggs through fertilization tubes, or by migration through the periplasm.

Ziegler found that the first nuclear divisions of the nucleus of the zygote are meiotic: all cells except the zygotes are haploid.

The organs of asexual reproduction are cylindrical sporangia terminal on the filaments. Within these the multinucleate protoplasts undergo cleavage into minute uninucleate spores. It is chiefly by details of the behavior of the sporangia and spores (the latter diplanetic, monoplanetic, or not swimming at all) that the dozen genera are distinguished. Diplanetism is the character of zoospores which are not directly infective; they undergo encystment, and the cysts release infective zoospores. During the first stage of swimming, the spores are pear-shaped, with the nucleus drawn out into a beak toward the narrow anterior end, where the flagella are attached. Spores released from cysts for a second period of swimming are bean-shaped, with the flagella attached laterally, each connected through a separate rhizoplast to the nucleus, which lies at some distance from the cell membrane (Cotner, 1930). No explanation of this behavior, whether by phylogeny, genetics, physiology, or competitive advantage, is known. The apparent trend of evolution is to eliminate it. Monoplanetic spores in the present group are usually released from the sporangia as naked protoplasts which undergo encystment and emerge subsequently as flagellate spores of the second form.

Saprolegnia releases diplanetic spores through circular pores in the tips of sporangia in which the spores are formed in several rows; new sporangia develop within empty old ones. Organisms which differ from Saprolegnia only in producing new sporangia beside, instead of within, the old ones, were formerly assigned to Achlya, but are now called Isoachlya. Leptolegnia differs from Saprolegnia and Isoachlya in forming spores in a single row. In Achlya proper, the spores are discharged without flagella, to encyst and swim only once. In Thraustotheca the monoplanetic spores are released by irregular breakdown of the distal part of the sporangium. In Dictyuchus the spores become encysted before discharge; their protoplasts escape in the form of secondary swarmers through individual pores in the wall of the sporangium. Salvin (1942) found that cultures while growing release into the medium substances which affect the type of sporangium produced, so that a given culture may be while young of the character of Achlya, and later of the character of Thraustotheca or Dictyuchus.

Family 2. Leptomitea [Leptomiteae] Kützing Phyc. Gen. 150 (1843). Family Leptomitaceae Schröter in Engler and Prantl Nat. Pflanzenfam. I Teil, Abt. 1: 101 (1893). Oomycetes consisting of filaments which are constricted at intervals, but are not differentiated into a basal cell and reproductive branches. In sewage or on organic matter decaying in water. Leptomitus, Apodachlya, Apodachlyella, with some seven known species. The numbers of species and degree of distinction of this family and the following do not appear to justify the proposed establishment of a separate order for them.

Family 3. Rhipidiacea [Rhipidiaceae] Sparrow in Mycologia 34: 116 (1942). Saprophytes resembling the Leptomitea, the body differentiated into a main part, the basal cell, rhizoids of limited growth, and slender branches bearing the reproductive structures. Sapromyces, Araiospora, Rhipidium, Mindeniella, with perhaps a dozen known species. 
Order 2. Peronosporina [Peronosporinae] Fischer in Rabenhorst Kryptog.-Fl. Deutschland 1, Abt. 4: 383 (1892).

Suborder Pcronosporineae Engler in Engler and Prantl Nat. Pflanzenfam. I Teil, Abt. 1: iv (1897).

Order Peronosporincae Campbell Univ. Textb. Bot. 155 (1902).

Order Peronosporales Auctt.

Mostly parasites on terrestrial plants, but including also aquatic parasites and a few saprophytes, the bodies filamentous, reproducing sexually by fertilization, the eggs solitary in the oogonia, reproducing asexually chiefly by conidia, that is, by airborn cells cut off from the ends of the filaments. The conidia are homologous with the sporangia of the Saprolegnina: they germinate in most examples by release of zoospores (which show no signs of diplanetism), but in the more highly evolved examples they give rise to filaments. Ferris (1954) found the zoospores of Phytophthora to bear the paired flagella, respectively pantoneme and acroneme, which are typical of Phaeophyta.

In the multinucleate oogonia of most members of the group, single flares of mitoses occur. The sharp-pointed spindles, described in some accounts as ending in centrosomes, are formed within the persistent nuclear membrane, which undergoes constriction during the final stages of mitosis. A coenocentrum appears (this structure was first described as occurring in Albugo, by Stevens, 1899); in gencral, one nucleus becomes associated with it, and is thus selected as the egg nucleus, the remaining nuclei being cast out to undergo disolution in a body of periplasm. The antheridium develops in contact with the oogonium, and fertilization is accomplished by the growth of a fertilization tube through the periplasm to the egg (Davis, 1900; Stevens, 1899, 1901, 1902).

In Albugo Bliti and A. Tragopogonis, Stevens observed two flares of simultaneous mitoses in the oogonium and antheridium. If this phenomenon were general in the group one would confidently identify it as meiosis. The single coenocentrum attracts many nuclei; the fertilization tube delivers a large number of sperm nuclei; thus multiple karyogamy occurs within a single cell. The further history of the resulting peculiar zygote, containing many nuclei which are not by any evident necessity genetically uniform, is unknown.

This order is evidently a specialized off shoot of the preceding. The family Pythiacea is a good example of a transition group; many authorities have assigned it to the preceding order.

1. Producing solitary globular sporangia or conidia at the ends of scarcely specialized filaments; mostly aquatic....................mily 1. Pутnincea.

1. Producing conidia usually in clusters at the encls of specialized filaments (conidiophores); parasites on land plants.

2. Conidiophores brief, unbranched, the conidia in chains.................. Family 2. Albuginacea.

2. Conidiophores elongate, usually branched, the conidia solitary or clustered, not

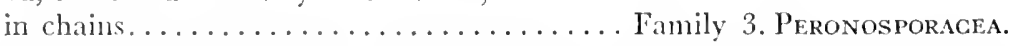

Family 1. Pythiacea [Pythiaceac] Schröter in Engler and l'rantl Nat. Pflanzenfam. I Teil, Abt. 1: 10t (1893). Aquatic parasites and saprophytes relcasing zoospores from globular reproductive structures terminal on the filaments, together with para- 
sites attacking land plants under moist conditions. The reproductive structures act as sporangia if formed in water, as conidia if formed in air. Pythium, saprophytic on plant remains in water or parasitic on algae or higher plants, includes some forty species (Matthews, 1931). The few other genera include perhaps a dozen species. Zoophagus produces specialized branches which serve as traps for rotifers which are parasitized and killed.

Family 2. Albuginacea [Albuginaceae] Schröter op. cit. 110. Parasites of higher plants, called white rusts, the masses of conidia which push up and burst through the epidermis being of a white color. Albugo.

Family 3. Peronosporacea [Peronosporaceae] Cohn in Hedwigia 11: 18 (1872). Parasites of higher plants, called downy mildews. The ovoid conidia are produced solitary or in clusters, not in chains, on elongate conidiophores, usually branched, projecting through the stomata of the hosts. This numerous group includes the agents of some of the most important diseases of cultivated plants. Plasmopara viticola, causing downy mildew of grapes. Phytophthora infestans, the cause of the blight of potatoes which produced the Irish famine of 1846 . Peronospora, the many species attacking many kinds of plants.

Order 3. Lagenidialea [Lagenidiales] Karling in American Jour. Bot. 26: 518 (1939).

Suborder Ancylistineae Engler in Engler and Prantl Nat. Pflanzenfam. I Teil, Abt. 1: iv (1897), for the most part, not as to the type genus Ancylistes.

Order Ancylistales Auctt., in part.

Oomycetes of chytrid body type, parasites consisting of walled cells which are more or less isodiametric, sometimes proliferating or producing rhizoids, but not forming extensive branched filaments. The cells become multinucleate. Mitotic figures of Olpidiopsis as described by Barrett (1912) and McLarty (1941) are quite as in the preceding orders, with sharp-pointed intranuclear spindles apparently with centrosomes at the poles. In the usual course of events, each cell develops an exit tube to the exterior of the host, and the protoplast becomes divided into uninucleate cells which escape as unequally biflagellate zoospores. Fertilization, by the migration of the protoplast of one cell into another, has been observed; the zygote becomes a thick-walled resting spore.

1. Internal parasites without rhizoids.

2. The cells not proliferating.

3. The zoospores diplanetic......... Family 1. Egtrogellagea.

3. The zoospores not diplanetic....... Family 2. Olpidiopsidacea.

2. The cells proliferating.

3. Marine.................. Family 3. Sirol pidiacea.

3. Fresh-water................ Family 4. Lagenidiagea.

1. External parasites with rhizoids.............Family 5. Thraustoghytriacea.

Family 1. Ectrogellacea [Ectrogellaceae] Scherffel in Arch. Prot. 52: 6 (1925). Ectrogella, Eurychasma, Eurychasmidium, Aphanomycopsis, with about a dozen known species, attacking diatoms and red and brown algae.

Family 2. Olpidiopsidacea [Olpidiopsidaceae] Sparrow in Mycologia 34: 116 (1942). Olpidiopsis and a few other genera, with some thirty known species, attacking water molds, green algae, red algae, and other aquatic organisms.

Family 3. Sirolpidiacea [Sirolpidiaceae] Sparrow 1. c. Sirolpidium and Pontisma, each with one species, attacking marine algae, respectively green and red. 
Family 4. Lagenidiacea [Lagenidiaceae] Schröter in Engler and Prantl Nat. Pflanzenfam. I Teil, Abt. 1:89 (1893). Lagenidium, Myzocytium, and Lagenocystis ${ }^{1}$, with some twenty known species, attacking green algae, rotifers, pollen which has fallen into water, and the roots of grasses.

Family 5. Thraustochytriacea [Thraustochytriaceae] Sparrow op. cit. 115. The single species Thraustochytrium proliferum Sparrow was found as solitary cells external on certain marine green algae and red algae which are penetrated by means of branching rhizoids. Reproduction is by release of naked protoplasts which become laterally biflagellate after a period of rest.

\section{Class 4. MELANOPHYCEA (Ruprecht) Rabenhorst}

Order Fucacées Lamouroux in Ann. Mus. Hist. Nat. Paris 20: 28 (1813).

Fucoideae C. Agardh Synops. Alg. Scand. ix (1817).

Order Fucomeae C. Agardh Syst. Alg. xxxv (1824).

Division (of order Algae) Melanospermeae Harvey in Mackay Fl. Hibern. 157 (1836).

Series (of order Algae) Melanospermeae Harvey Man. British Alg. 1 (1841).

Order Pycnospermeae and tribe Angiospermeae Kützing Phyc. Gen. 333, 349 (1843).

Class Fucoideae J. Agardh Sp. Alg. 1: 1 (1848).

Melanophyceae Ruprecht in Middendorff Sibir. Reise 1, part 2: 200 (1851).

Class Melanophyceae Rabenhorst Kryptog.-Fl. Sachsen 1: 275 (1863).

Stamm Fucoideae Haeckel Gen. Morph. 2: xxxv (1866).

Series (Reihe) Phaeophyceae Hauck in Rabenhorst Kryptog.-Fl. Deutschland 2: 282 (1885).

Class Phaeophyceae Engler and Prantl Nat. Pflanzenfam. II Teil: 1 (1889).

Class Dictyotales Engler in Engler and Prantl Nat. Pflanzenfam. I Teil, Abt. 2: ix (1897).

Classes Phaeosporeae, Tetrasporeae, and Cyclosporeae Bessey in Univ. Nebraska Studies 7: 288, 290 (1907).

Class Dictyoteae Schaffner in Ohio Naturalist 9: 448 (1909).

Subclass Melanophyceae Setchell and Gardner in Univ. California Publ. Bot. 8: 387 (1925).

Classes Isogeneratae, Heterogeneratae (with subclasses Haplostichinae and Polystichinae) and Cyclosporeae Kylin in Kungl. Fysiog. Sällsk. Handl. n. f. 44, no. 7: $91(1933)$.

Filamentous or thallose l'haeophyta, yellow to brown in color and living by photosynthesis, producing reproductive cells with paired unequal flagella.

These are the typical brown algac. Thcy are almost exclusively marine, being abundant along with red and green algac on most coasts, and particularly abundant farther toward the poles than the red and green groups. The lower brown algae are branched filaments of microscopic dimensions, commonly cpiphytic on other algac. More highly developed examples are thallose and anchored to rocks. Some of these, particularly the ones whose English name is kelp, reach grcat sizes and considerable elaboration of structure. Papenfuss (in Smith, 1951) gives the number of genera as about 240, and that of known species as about fiftecn hundred.

1 Lagenocystis nom. nov. Lagena Vanterpool and Ledingham in Canadian Jour Res. 2: 192 (1930), non Parker and Jones 1859. L. radicicola (Vanterpool and Ledingham) comb. nov. 
The cells are walled chiefly with readily hydrolyzable modified polysaccharides. Algin, the soda extract of kelps, consists of chains of oxidized mannose units. A polysaccharide of the sugar fucose, with a sulfate radicle to each sugar unit, is also present. A small percentage of cellulose is present, apparently as the immediate investment of each protoplast. A glycogen- or dextrin-like dextrosan, laminarin, is stored (Miwa, 1940; Tseng, 1945). The plastids contain chlorophylls $a$ and $c$ (Strain, in Franck and Loomis, 1949) and carotin; xanthophyll is also present in the more primitive examples. In all examples, there is an additional carotinoid called fucoxanthin, which produces the brown color. The analytic process of separating the pigments yields also a sterol, fucosterol, not found in green plants; but this substance, and fucoxanthin, are found in chrysomonads, green Heterokonta, and diatoms (Carter, Heilbron, and Lythgoe, 1939).

Cytological study of a considerable variety of brown algae (Swingle, 1897; Farmer and Williams, 1896; Mottier, 1898, 1900; Simons, 1906; Yamanouchi, 1909, 1912; McKay, 1933) has shown that the spindle and chromosomes appear within an intact nuclear membrane which disappears during the later stages of division. A centrosome, usually with radiating rays, is present outside of the membrane at each pole of the spindle. In Stypocaulon, a comparatively primitive brown alga, Swingle found the centrosome to be a permanent structure, dividing as a preliminary to each division of the nucleus. In the generality of brown algae, the centrosomes appear de novo as division begins.

Swimming cells are produced by primitive brown algae as spores and as morphologically undifferentiated gametes; in the most advanced brown algae, such cells are produced only as sperms. The flagella are attached laterally. The anterior flagellum is the longer except in order Fucoidea (Kylin, 1916). Longest (1946) found in Ectocarpus that the anterior flagellum is pantoneme, and the posterior one acroneme. The swimming cells are without walls, and contain, beside the nucleus, usually one plastid and a light-sentitive speck, the stigma or eyespot. They are quite small. No system of structures linking the nuclei, centrosomes, and flagella has been discovered.

Thuret (1850) discovered that most brown algae produce swimming cells from structures of two different sorts, which he named (1855) respectively plurilocular sporangia and unilocular sporangia. The difference between them is this. In the developing plurilocular structure, each division of the nucleus is followed by division of the protoplast and deposition of a wall, with the result that the swimming cells emerge from separate walled spaces. In the unilocular structure, the nucleus divides repeatedly before the protoplast divides; the protoplast then undergoes cleavage to produce swimming cells which emerge from a single walled space. A number of studies (Clint. 1927; Higgins, 1931; Knight, 1923, 1929) have shown that the first two nuclear divisions in the unilocular structure are normally meiotic. Unilocular structures occur normally only on diploid individuals and release haploid swimming cells. A few exceptional species, however, are known to bear unilocular structures which produce swimming cells without the intervention of meiosis.

In Ectocarpus siliculosus as studied by Berthold (1881) at Naples, the swimming cells from unilocular structures are spores which give rise to haploid individuals. In the same species as studied in the Irish Sea by Knight (1929), they were found to act as gametes, conjugating and giving rise to diploid individuals. Diploid and haploid individuals of Ectocarpus are alike, and E. siliculosus may be said to have a facultatively complete homologous life cycle. The haploid individuals produce plurilocular reproductive structures; the swarmers from these act either as spores, re- 


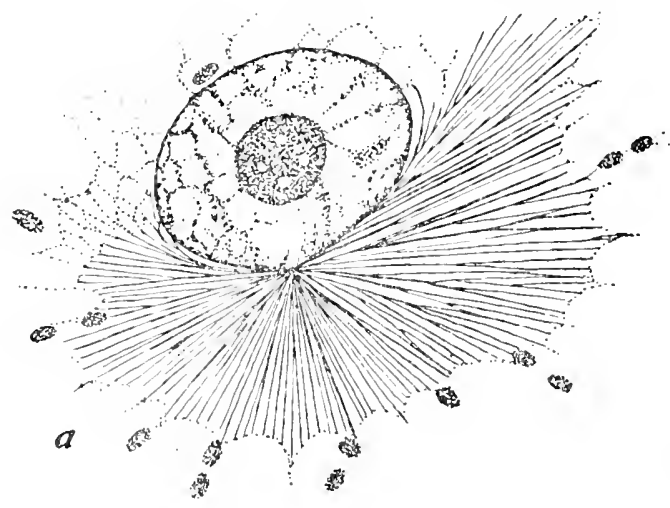

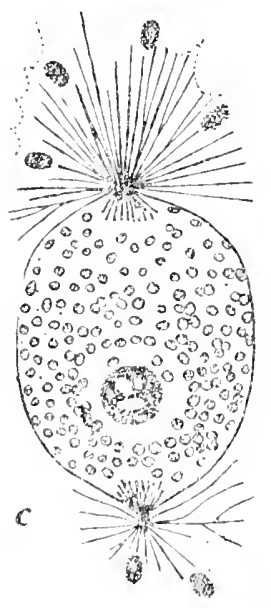

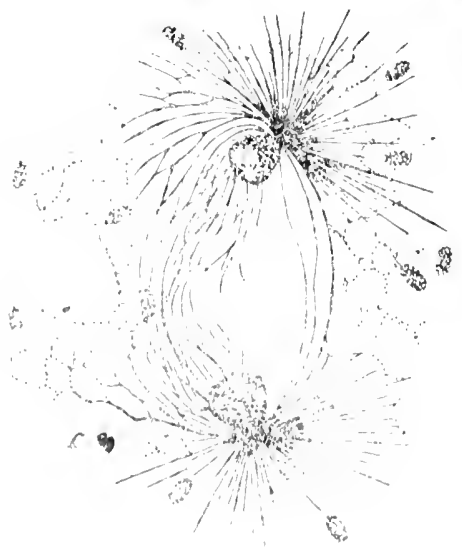

4 4. 4

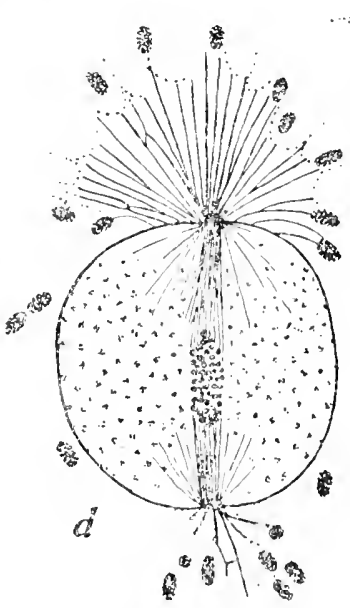

(
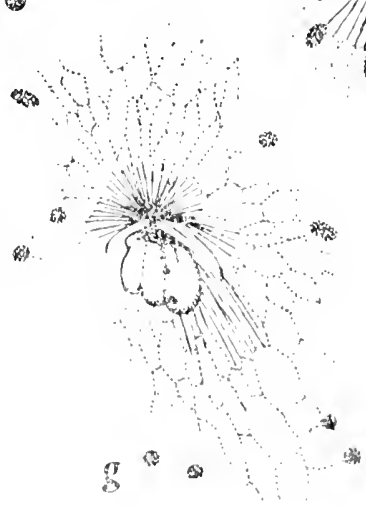
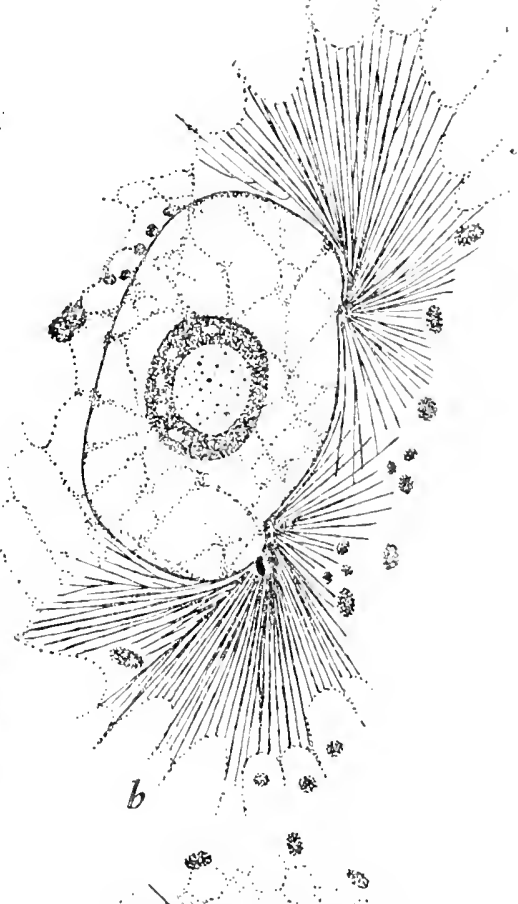
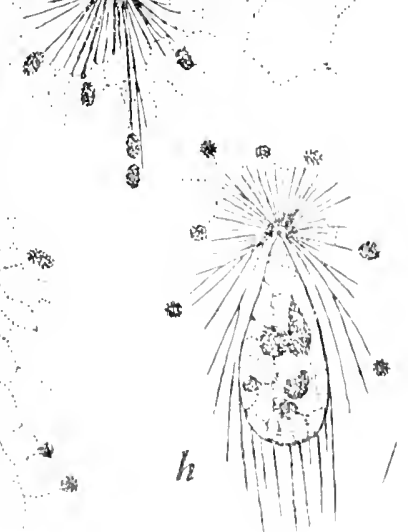

Fis. 15.-Stages of nuclear division in Stypocaulon x 1,000 after Swingle (1897). 
producing the haploid stage, or as gametes, initiating the diploid stage. The diploid individuals produce both plurilocular and unilocular reproductive structures. The swarmers from the former are spores, reproducing the diploid body. The swarmers from the latter act either as spores, giving rise to haploid individuals, or as gametes, reproducing the diploid body.

It is believed that the brown algae arose by evolution from order Ochromonadalea. Filamentous organisms with a facultatively complete homolgous life cycle, as just described, are believed to be primitive among them: such organisms appear to be the starting point of evolution in many features. The filaments have become differentiated and woven into thalli, and thalli of tridimensionally placed cells have been produced. The haploid and diploid stages have become differentiated. The plurilocular and unilocular structures have undergone specialization. Even in the most primitive brown algae, there is a physiological differentiation of gametes; this has evolved into extreme morphological differentiation. Every one of these evolutionary changes appears to have occurred in more than one line of descent; research is constantly revealing intermediate examples and rather free parallel evolution.

Conservative classification, such as that of Fritsch (1945), recognizes as orders a comparatively primitive miscellany followed by a series of small derived groups marked by distinctive specializations. Features of the life cycle, as applied to classification by Taylor (1922), Oltmanns (1922), Svedelius (1929) and Kylin (1933), are not reliable as marks of natural groups. Kylin provided three classes (one of them divided into two subclasses) and twelve orders. His system appears to provide an excessive number of subdivisions of high category within a moderately small group exhibiting no very profound evolutionary gaps. Tentatively, the seven orders distinguished as follows may be recognized.

1. Producing spores, that is, cells which germinate without syngamy.

2. All spores bearing flagella.

3. Having an alternation of haploid and diploid stages which are alike, both being filamentous; or else completely lacking one of these stages.

4. The filaments uniseriate............ Order 1. Phaeozoos porea.

4. The filaments becoming pluriseriate........................... 2 . Sphacelarialea.

3. Not as above.

4. Haploid stage thallose, not distinctly less highly developed than the diploid stage............ Order 5. Cutberialea.

4. Haploid stage filamentous, distinctly less highly developed than the diploid stage.

5. Diploid stage filamentous; or, if partially or completely thallose, the thallose part with apical growth..... Order 4. SpOROch noldea.

5. Diploid stage thallose, its growth intercalary........... Order 6. Laminariea.

2. Producing large non-motile spores............ Order 3. Dictrotea. 
1. Producing no spores; all individuals diploid and reproducing exclusively sexually........... Order 7. Fucoidea.

Order 1. Phaeozoosporea [Phaeozoosporeae] Hauck in Rabenhorst Kryptog.-Fl. Deutschland 2: 312 (1885).

Order Syntamiidae Areschoug in Act. Reg. Soc. Upsala 14: 387 (1850), in part; a nomen confusum.

Order Ectocarpeae J. Agardh Sp. Alg. 1: 6 (1848), preoccupied by family EGtocarpeae Kützing (1843).

Section (of Algae Zoosporeae) Phaeosporcae Thuret in Ann. Sci. Nat. Bot. sér. 3, 14: 233 (1850).

Order Phaeosporeae Wettstein Handb. syst. Bot. 1: 173 (1901).

Order Ectocarpales Bessey in Univ. Nebraska Studies 7: 288 (1907).

Order Phaeosporales and suborder Ectocarpineae Taylor in Bot Gaz. 74: 435, 436 (1922).

Microscopic brown algae of the form of undifferentiated uniseriate branching filaments, mostly with distinct haploid and diploid stages (exceptionally lacking the former), the stages distinguishable only by the limitation of unilocular reproductive structures to the diploid stage, the gametes morphologically uniform.

The order is typified by Ectocarpus, which is by coincidence also the theoretical ancestral type of the brown algae, the living organism which supposedly represents the evolutionary origin of the group. Recent systems of classification limit this order, formerly construed as extensive, to this genus and a few others, as Pylaiella and Streblonema, which make up the family Ectocarpea [Ectocarpeae] Kützing (family Ectocarpaceae Cohn).

Order 2. Sphacelarialea [Sphacelariales] (Oltmanns) Engler and Gilg Syllab. ed. 9 u. 10: 27 (1924).

Order Sphacelarieae J. Agardh Sp. Alg. 1: 27 (1848), preoccupied by family Sphagelarieae Kützing (1843).

Sphacelariales Oltmanns Morph. u. Biol. Alg. ed. 2, 2: 2 (1922).

Brown algae distinguished from the Ectocarpea only by features of the vegetative structure, namely that the filaments have large apical cells, and that the cells cut off from them divide lengthwise without increasing considerably in thickness, with the result that the filaments consist of tiers of cells. The life cycle is the same as in Ectocarpea. Family Sphacelariea [Sphacelarieae] Kützing (family Sphacelariaccae Cohn) includes Sphacelaria and Stypocaulon. A few other families have been segregated.

Order 3. Dictyotea [Dictyotcae] Greville Alg. Brit. 46 (1830).

Tribe Dictyoteac Harvey in Mackay Fl. Hibern. 159 (1836).

Family Dictyotcae Kützing Phyc. Gen. 337 (1843).

Order Dictyotaceae Hauck in Rabenhorst Kryptog.-Fl. Deutschland 2: 302 (1885).

Class Dictyotales Engler in Engler and Prantl Nat. Pflanzenfam. I Tcil, Abt. 2: ix (1897).

Akinetosporeae Oltmanns Morph u. Biol. Alg. 1: 473 (1904).

Order Tilopteridales and Class Tetrasporeae with order Dictyotales Bessey in Univ. Nebraska Studies 7: 290 (1907).

Scrics Aplanosporeac Setchell and Gardner in Univ. California Publ. Bot. 8: 649 (1925). 
Filamentous or thallose brown algae with haploid and diploid stages equally developed, producing large spores without flagella, solitary or few in the sporangia.

Here are placed two families, Tilopteridea and Dictyotacea.

Family Tilopteridea [Tilopterideae] Cohn is a small group, apparently known only from European coasts. They are evidently closely related to the Ectocarpea. They consist of branching filaments which may become pluriseriate. In Haplospora (poorly known; but Tilopteris and other genera are even more so), the haploid stage bears both plurilocular structures, releasing minute swimming cells of the structure usual in brown algae, and unilocular structures which release their contents as single uninucleate protoplasts without flagella. The diploid stage bears only unilocular structures which release their contents as single quadrinucleate non-motile spores. It is inferred that the swimming cells from the plurilocular structures are sperms, and that the protoplasts released from the unilocular structures on haploid bodies are eggs, capable, however, of reproducing the haploid stage if not fertilized; further, that the nuclei of the quadrinucleate spores released by diploid individuals are haploid, and become on germination the nuclei of as many cells of the haploid body.

The Tilopteridea are believed to represent the evolutionary transition between Ectocarpea and the following family.

Family Dictyotacea [Dictyotaceae] (Hauck) Kjellmann includes about twenty genera, Dictyota, Zonaria, Padina, etc., with about one hundred species which are commonest on the coasts of warmer oceans. They are thalli of moderate size, erect and dichotomously branched or appressed and fan-shaped. They grow by the division of a single apical cell or a row of apical cells in each branch. The cells multiplying behind the apical cells become differentiated into two tissues, superficial small cells rich in plastids and internal larger ones with fewer plastids, forming in different species single or multiple layers of cells.

The life cycle has been studied by Mottier (1898, 1900), Williams (1898), and Haupt (1932). There are distinct male haploid individuals, female haploid individuals, and diploid individuals, all of the same vegetative structure. The males produce sperms from clusters of densely packed plurilocular antheridia. The females produce eggs solitary in large oogonia solitary or clustered on the thalli. The eggs are without flagella. The diploid individuals produce unilocular sporangia of much the same structure as the oogonia. In Zonaria, each sporangium produces eight nonmotile spores; in Dictyota, each one produces four.

Order 4. Sporochnoidea [Sporochnoideae] Greville Alg. Brit. 36 (1830).

Order Chordarieae Greville op. cit. 44.

Order Chordariaceae Haeckel Gen. Morph. 2: xxxv (1866).

Orders Desmarestiales and Chordariales Setchell and Gardner in Univ. California Publ. Bot. 8: 554, 570 (1925).

Order Sporochnales Sauvageau in Compt. Rend. 182: 364 (1926).

Brown algae producing motile spores, the haploid stage reduced to scant undifferentiated filaments, the diploid stage filamentous or thallose, when thallose with apical growth. Ralfsia is an exception to the formal characters of the order: it has a haploid stage of the same structure as the diploid. This is a rather miscellaneous assemblage, rather arbitrarily separated from Phacozoosporea on the one hand and from Laminariea on the other.

The haploid body of the form of a short-lived body of a few undifferentiated filaments, like a reduced Ectocarpus, bearing gametangia reduced to single cells, has 
been demonstrated by Kylin $(1933,1934,1937)$ in a wide variety of genera, as Ascocyclus, Desmotrichum, Mesogloia, Eudesme, Leathesia, and Stilophora. In the more primitive examples, the gametes are not visibly differentiated; in more advanced ones, as Carpomitra and Desmarestia, different haploid bodies produce respectively smaller sperms and larger eggs, the latter non-motile.

There is a series of families, Ralfsiacea, Myrionematacea, Myriogloiacea, Mesogloiacea, and others, in which the diploid body consists of filaments differentiated into different types. In the simplest of these, the germinating zygote produces in the first place a minute thallus-like plate, generally epiphytic on other algae, one cell thick, and consisting obviously of branched filaments of limited growth. From this plate grow erect filaments. Some of thesc are simply cylindrical and appear nutritive in function; others are attenuate, and may function in protection or in absorbing materials from the water; yet others bear the reproductive structures, unilocular or plurilocular or both.

In the more advanced families, the diploid body, after passing through a Ralfsiaor Myrionema-like stage, may produce a compacted column of filaments with a terminal plate of apical cells. Besides adding cells to the column, the apical plate gives rise to a fascicle of attenuate hairs projecting forward. Members of the families Chordariacea, Sporochnea, and Desmarestiacea produce cylindrical or flattened thallose bodies of tridimensionally placed cells differentiated into an outer layer of small actively photosynthetic cells and an inner mass of nearly colorless cells. Superficial hairs, growing in intercalary fashion, may become few, and growth may become restricted to a single apical cell.

By differences in the detailed manner of growth, Setchell and Gardner distinguished two orders among the thalloid forms just mentioned. It is evident, however, that the thallose structure (and, likewise, differentiation of gametes) has developed repeatedly and independently in the present group. Knowledge which would make it possible to divide it into several recognizably natural orders is not yct available.

Order 5. Cutlerialea [Cutleriales] Bessey in Univ. Nebraska Studies 7: 289 (1907).

Brown algae producing motile spores, the haploid and diploid bodies being macroscopically visible thalli, alike or different.

This is a small group, of one family, Cutleriacea, with two genera, Zanardinia and Cutleria, known chicfly from the Mediterranean. In Zanardinia, both haploid and diploid bodies are erect and rather frecly branched. In Cutleria, the haploid bodies are of this description, while the diploid bodies are appressed and fan-shaped. The distinct diploid bodies of Cutleria were originally named as a different genus, Aglaozonia. Falkenberg (1879) first showed that Cutleria and Aglaozonia are stages of the same thing; Yamanouchi showed that they are respectively a haploid stage with 24 chromosomes and a diploid stage with 48 .

The growing margins of the thalli consist of laterally compacted filaments growing by the divisions of a band of meristematic cells which produce free hairs in the distal dircction and a continuous body of cells in the proximal direction. The latter cells are capable of further division, and produce a body scveral cells thick, with small cells rich in plastids on the surface and larger ones with fewer plastids in the interior.

Haploid individuals bear clusters of stalked plurilocular structures of two types, almost atways on different individuals, the larger ones consisting of fewer cells which release eggs, the smaller of more numerous cells which release sperms. Both kinds of 
gametes are flagellum-bearing cells of the type usual in brown algae. The eggs are capable of germination without fertilization, reproducing the haploid stage. Diploid individuals bear clusters of unilocular sporangia.

It is only in the life cycle that the Cutlerialea are decidedly different from higher Sporochnoidea such as Desmarestia. Their evolutionary origin is explicable by the hypothesis of a single mutation which enabled the haploid stage to exhibit the comparatively complicated morphology of the diploid stage, instead of being rudimentary as in all Sporochnoidea except Ralfsia (and the exceptional life cycle of Ralfsia would be explained by a similar mutation in some primitive example of Sporochnoidea, such as Myrionema).

Order 6. Laminariea [Laminarieae] Greville Alg. Brit. 24 (1830).

Order Pycnospermeae Kützing Phyc. Gen. 333 (1843).

Order Laminariaceae Haeckel Gen. Morph. 2: xxxv (1866).

Laminariales Oltmanns Morph. u. Biol. Alg. ed. 2, 2: 2 (1922).

Order Laminariales Engler and Gilg Syllab. ed. 9 u. 10: 27 (1924).

Order Dictyosiphonales Setchell and Gardner in Univ. California Publ. Bot. 8: 586 (1925).

Order Punctariales Kylin in Kungl. Fysiog. Sällsk. Handl. n. f. 44, no. 7: 93 (1933).

Brown algae with motile spores, the haploid stages reduced to microscopic dimensions, the diploid stages thallose, growing in intercalary fashion.

This numerous group, like the preceding small one, is evidently a specialized offshoot from order Sporochnoidea. The familiar examples are the kelps, whose large diploid bodies are differentiated into definite members. Kylin considered his order Punctariales to represent the transition to the kelps. They are thallose, without differentiation of members, but their microscopic and reproductive characters, as observed in Soranthera by Angst $(1926,1927)$, tend to confirm Kylin's opinion, and they are accordingly included in the same order with the kelps. Papenfuss (1947) pointed it out that the Punctariales of Kylin are essentially the same group as the Dictyosiphonales of Setchell and Gardner.

Sauvageau (1915) first showed that the reproduction of kelps is sexual. The grossly visible individuals produce zoospores; these, on germination, produce microscopic filamentous haploid individuals, generally of distinct sexes, releasing gametes from unicellular gametangia. The eggs are without flagella, and it is characteristic of them that in emerging from the oogonia they become attached at the opening (Kylin, 1916, 1933; Myers, 1928; McKay, 1933; Kanda, 1936; Hollenberg, 1939). The same things are true in Soranthera, except that the eggs, although much larger than the sperms, are also flagellate.

The visible bodies of kelps consist of three kinds of members, holdfasts (hapteres), being stout root-like growths by which the individuals are anchored to rocks, and stalks and blades comparable to stems and leaves. Growth is most active at the summits of the stalks. The histology is the same in all members (A. I. Smith, 1939). There is a superficial photosynthetic tissue of small cells rich in plastids; on the holdfasts and stalks, this tissue is meristematic, adding cells to the tissue within and increasing the thickness. Internally there is a cortex of larger cells with fewer plastids. In the center there is a medulla containing trumpet fibers, filaments whose cells are expanded where they meet and marked by pit-pairs. In the trumpet fibers of Nereocystis there are actual perforations from cell to cell. The trumpet fibers are not quite 


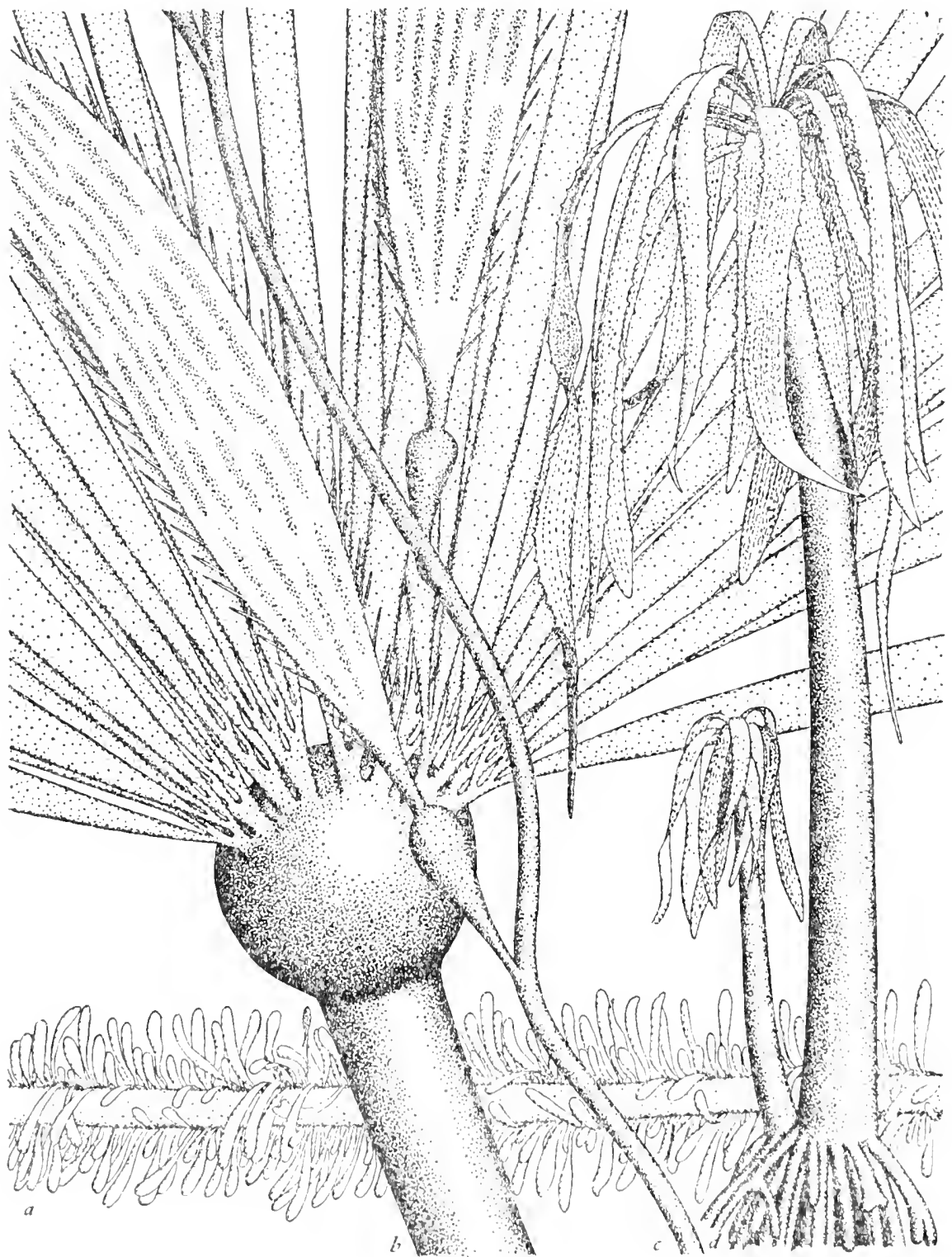

Fig. 16.- Faniliar kelps of Pacific Nortin America: a, Egresia Menziesii; b, Nereocystis Lurthana; c, Macrocystis prifera; $\mathbf{d}$, Postclsia palmacformis. Nll approximately $\times 1 / 2$. 
perfectly analogous to the sieve tubes of higher plants; the nuclei remain alive. The minute zoospores are produced in unilocular sporangia. These occur on the surface of the body in dense masses, intermingled with, and protected while young by, specialized sterile hairs.

Individuals of Laminaria consist simply of hapteres, a stalk, and one or more terminal blades. In various other genera, growth occurs in such fashion as to cause the blades to split at the base. With further growth, the splits extend to the margins of the blades and increase their number, while intercalary growth at the transitions between the stalks and the blades produces elongation and branching of the stalks. Early explorers described the stalks of Macrocystis pyrifera as reaching prodigious lengths, matters of hundreds of meters, and these accounts have been repeated in textbooks down to recent times. Frye, Rigg, and Crandall (1915) found a maximum length of somewhat less than fifty meters. The stalks are dichotomously branched to a moderate extent and bear series of blades, each with a pear-shaped pneumatocyst or float at the base. The stalks of Nereocystis Luetkeana also were said to be extremely long, but the recent observers did not find them to attain fifty meters. They are unbranched and bear a single large float from which spring several blades which may exceed four meters in length. This great organism is an annual, growing and dying within a year. Postelsia palmaeformis, called the sea palm, grows on rocks exposed to surf. It has erect stalks some $30 \mathrm{~cm}$. tall bearing many pendant linear blades. Egregia Menziesii has flattened stalks many meters long with fringes of floats and blades along the margins. Laminaria is widely distributed. Macrocystis occurs on the northwest coast of North America and in southern oceans. The other kelps which have been mentioned are confined to the northwest coast of North America.

On coasts where they occur, kelps are used as fertilizer. They have been used commercially as sources of potash, as much as $1-3 \%$ of the fresh weight being $\mathrm{K}$ as $\mathrm{K}_{2} \mathrm{O}$ (Cameron, 1915); they have been used also as sources of iodine. These uses are not economic at most times.

Setchell and Gardner divided the proper kelps, of which there are about one hundred species, into four families. The groups of less elaborate structure which appear properly to be placed in the same order are treated by Papenfuss (under Dictyosiphonales) as six families.

Order 7. Fucoidea [Fucoideae] C. Agardh Syst. Alg. xxxv (1824).

Fucomeae C. Agardh Synops. Alg. Scand. ix (1817).

Tribe Angiospermeae Kützing Phyc. Gen. 349 (1843).

Order Cyclosporeae Areschoug in Act. Roy. Soc. Upsala 13: 248 (1847).

Order Fucaceae J. Agardh Sp. Alg. 1: 180 (1848).

Order Sargassaceae Haeckel Gen. Morph. 2: xxxv (1866).

Order Fucales Bessey in Univ. Nebraska Studies 7: 290 (1907).

Order Cyclosporales and suborder Fucineae Taylor in Bot. Gaz. 74: 439 (1922).

Class Cyclosporeae Kylin in Kungl. Fysiog. Sällsk. Handl. n. f. 44, no. 7: 91 (1933).

Thallose brown algae, producing no spores, diploid in all stages except the gametes; the latter being sperms, whose posterior flagellum is longer than the anterior one, and non-motile eggs. The genus Fucus L. is to be construed as the type genus of order Fucoidea, class Melanophycea, and phylum Phaeophyta.

Two families are usually recognized (others have been segregated). In family Fucea [Fuceae] Kützing (family Fucaceae Cohn), called the rockweeds, the bodies 
are flat dichotomously branching thalli. In family Sargassea [Sargasseae] Kützing there is a differentiation of holdfasts, stalks, blades, and floats. Growth is by division of a single apical cell in each branch or member. There are the usual two tissues, a superficial photosynthetic tissue of small cells and an inner tissue of larger cells which pull apart to produce a spongy or fibrous mass.

The gametangia are borne, mixed with sterile hairs, in pits called conceptacles. These are clustered, in the Fucea near the tips of branches which have ceased to grow (these tips are swollen, and are called receptacles), in the Sargassea on special branches. Rarely, oogonia and antheridia occur in the same conceptacles; not infrequently, they occur in different conceptacles on the same individuals; commonly, they occur on different individuals. Male and female conceptacles may be distinguished by color, the male being orange-yellow, the female of the same dark color as the thalli.

Male conceptacles are full of branching hairs bearing minute antheridia. In each antheridium, the original single nucleus undergoes six successive simultaneous divisions, producing sixty-four nuclei. These become the nuclei of sperms. Female conceptacles contain fewer, larger, oogonia, in which the nuclei divide three times, pro-

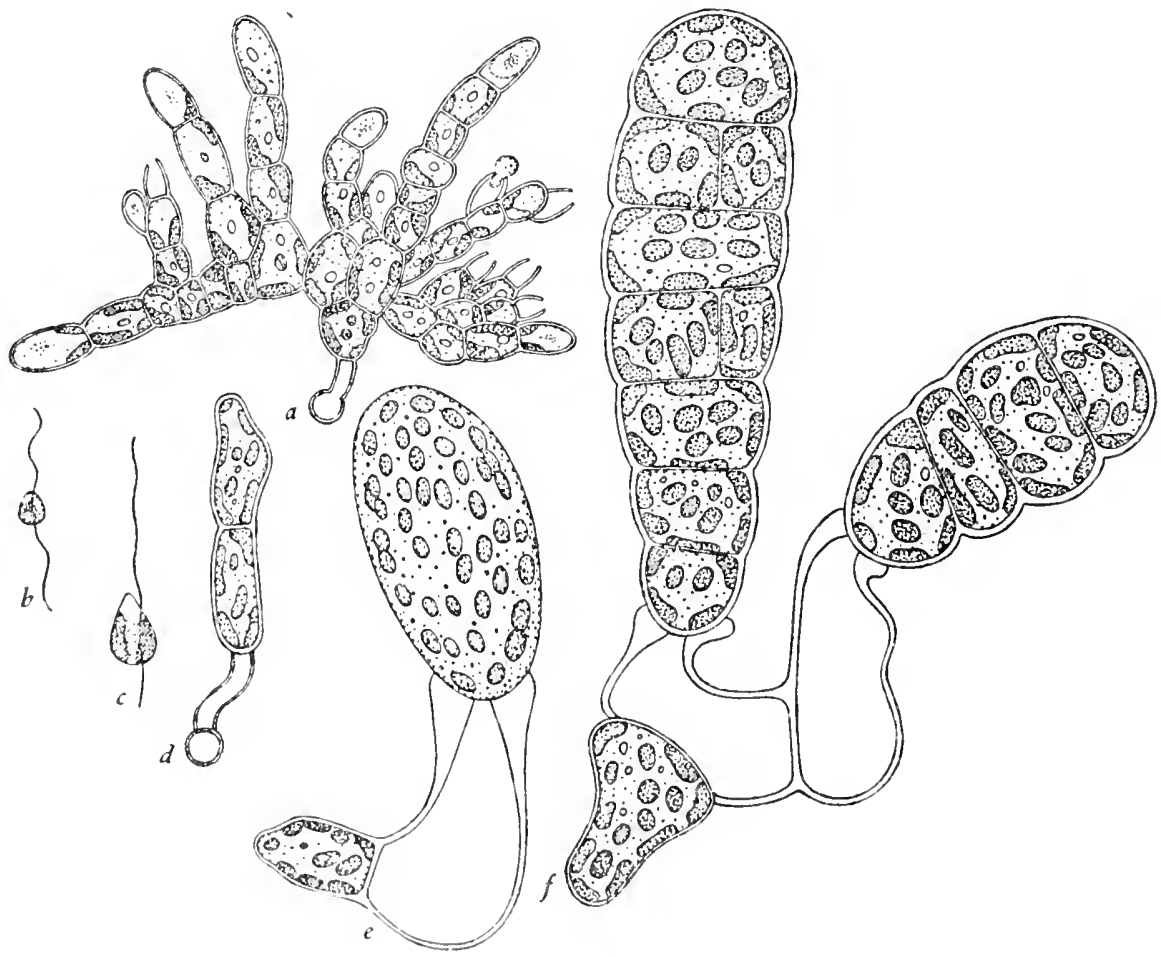

Fig. 17.-Microscopic reproductive structures of Laminaria yezocnsis after Kanda (1938) : a, malc haploid individual relcasing sperms; b, sperm; $\mathbf{c}$, zoospore; $\boldsymbol{d}$, female haploid individual of three cells; $\mathbf{e}$, female individual with an egg extrucled from the oogonium and attached in the mouth $\mathbf{f}$, female individual with two young diploid individuals attached at the mouths of oogonia. All x 1,000. 
ducing eight. In Fucus, these become the nuclei of as many eggs. In other genera, the number of functional eggs is reduced by degeneration of some of them, or of some of the nuclei before cell division. In Sargassum, Kunieda (1928) found each oogonium to produce a single egg in which seven nuclei undergo dissolution while one remains to function.

The first two nuclear divisions in each gametangium are meiotic. Farmer and Williams (1896) and Strasburger (1897) showed that the bodies are diploid; Yamanouchi (1909) first gave a full account of the meiotic process. The haploid chromosome number of Fucus vesiculosus is 32 . In Sargassum Horneri Kunieda found it to be 16 .

By a swelling of colloidal material in the conceptacles, the gametangia are forced out into the water, where they burst and release the gametes. Fucus was one of the first organisms in which syngamy was observed. Thuret (1855) saw multitudes of sperms swarm about the eggs, and showed that without sperms the eggs would not develop. This much had already been observed in frogs and certain fishes; the discovery that the essential process is the union of just one sperm with the egg was not made until later. The growing zygotes give rise directly to diploid thalli.

The gametangia of the Fucoidea appear to be homologous with the unilocular sporangia of other brown algae. In the gametangia, as in unilocular sporangia, the meiotic divisions are followed by a few divisions of the haploid nuclei: the Fucoidea are not quite perfect examples of the reduction of the haplod stage to the gametes only. As to which other brown algae may have provided their evolutionary origin, there is no very satisfactory hypothesis; Sporochnus shows certain resemblances. 


\section{Chapter VII}

\section{PHYLUM PYRRHOPHYTA}

\section{Phylum 3. PYRRHOPHYTA Pascher}

Order Astoma Siebold in Siebold and Stannius Lehrb. vergl. Anat. 1: 10 (1848).

Order Phytozoidea Perty Kennt. kleinst. Lebensf. 161 (1852).

Flagellata Cohn in Zeit. wiss. Zool. 4: 275 (1853).

Orders Flagellata and Gilro-flagellata Claparède and Lachmann Etudes Infus. 1: 73 (1858).

Suborder Mastigophora Diesing in Sitzber. Akad. Wiss. Wein Math.-Nat. Cl. 52, Abt. 1: 294 (1866).

Stämme Flagellata and Noctilucae Haeckel Gen. Morph. 2: xxv, xxvi (1866).

Class Flagellata Kent Man. Inf. 1: 27, 211 (1880).

Class Mastigophora and orders Flagellata, Dinoflagellata, and Cystoflagellata Bütschli in Bronn Kl. u. Ord. Thierreichs 1, Abt. 2, Inhalt (1887).

Class Peridineae Wettstein Handb. syst. Bot. 1: 71 (1901).

Divisions Flagellatae and Dinoflagellatae Engler Syllab. ed. 3: 6, 8 (1903).

Pyrrhophyta, Eugleninae, and Chloromonadinae Pascher in Ber. deutschen Bot. Gess. 32: 158 (1914).

Stämme Pyrrhophyta and Euglenophyta, and Abteilungen Cryptophyceae, Desmokontae, and Dinophyceae, Pascher in Beih. bot. Centralbl. 48, Abt. 2: 325, 326 (1931).

Division Pyrrhophyta G. M. Smith Freshw. Algae 10 (1933).

Protistes trichocystifères ou progastréades Chadefaud in Ann. Protistol. 5: 323 (1936).

Phyla Pyrrhophycophyta and Euglenoplyycophyta Papenfuss in Bull. Torrey Bot. Club 73: 218 (1946).

Unicellular or colonial organisms, typically with brown or green plastids, flagellate, the flagella solitary or more than one and unequal, the cells marked by grooves or pits and sometimes containing trichocysts, i. e., minute structures which lie close to the cell membrane and eject thread-like bodies when stimulated.

The organisms included here are the ones conventionally treated as four orders of pigmented flagellates, cryptomonads, dinoflagellates, euglenids, and chloromonads. These groups include organisms of the same varicd body types, algal, amocboid, and shytrid, that occur in other groups in which the flagellate body type is construed as typical. Peridinium may be considered to be the type of the phylum.

Deflandre (1934) designated as stichoneme (stichonématé) the type of flagellum which bears a single file of appendages, and which had been discovered by Fischer (1894) in Euglena. Petersen (1929) reobserved the stichoneme flagellum of Euglena, and found it also in other euglenids, Phacus and Trachelomonas. Deflandre found that one flagellum is stichoneme in varjous further euglenids (but not in all), and also in the dinoflagellate Glenodinium. This is the only report of a stichoneme flagellum ontsicle of the cuglenid group. The fine structure of the flagella of cryptomonads and chloromonads has not been determined.

In some cryptomonads, as Chilomonas, the cells contain granules which stain blue with iodine; if these are not starch, one knows not what to call them. Dinoflagellates produce a so-called starch which gives a reddlish color with iodine, and many of them have walls of a so-called cellulose which gives a redelish color with 
zinc chlor-iodide. The euglenicls store granules of a white solid believed not to be starch and called paramylum.

The plastids of cryptomonads and dinoflagellates are of various colors, off-color green, yellow, brown, bluish, or red. Those of dinoflagellates contain chlorophylls $a$ and $e$; the latter is an exceptional chlorophyll which occurs also in Tribonema. Euglenids and chloromonads are typically of the same bright green color as typical plants, and the euglenids are known to have the same chlorophylls, $a$ and $b$, as typical plants (Strain, in Franck and Loomis, 1949).

The groups here brought together exhibit family resemblances in details of the mitotic process, so far as these are known. The nuclear membrane usually persists through the process. In many examples the chromosomes appear to be present at all times, and are quite numerous, elongate, and of the appearance of strings of beads. In mitosis, quite as one would assume, they divide lengthwise; the point had been disputed, and was established by Hall $(1923,1925,1937)$ and Hall and Powell (1928). There is a neuromotor apparatus consisting of a centrosome at or near the nuclear membrane together with one or more rhizoplasts connecting it to as many blepharoplasts at the bases of the flagella. No spindle has been seen, unless the peculiar structure, seen in Noctiluca outside of and next to the dividing nucleus, is such. The centrosomes may lie at the sides of the dividing nucleus instead of at its ends. In the euglenids and some dinoflagellates the nucleus contains a nucleolus-like body which does not disappear during mitosis, but divides as the chromosomes do.

There are few reports of sexual processes in this group.

Pascher (1914) united the crytomonads and dinoflagellates in a group which he named Pyrrhophyta. He and those who follow him leave the euglenids as an isolated group. Tilden (1933) placed the four groups of flagellates with which we are here concerned in division Chrysophyceae, while leaving the Phaeophyceae as a distinct division. Her arrangement does not appear to be contrary to nature: the cryptomonads are apparently not very far removed from the chrysomonads. The different arrangement here maintained, by which the brown algae instead of the cryptomonads and so forth are placed in the same phylum with the chrysomonads, is believed to have the advantage that that phylum as least is well marked by character.

Chadefaud (1936) proposed a group consisting of the four groups of flagellates here under consideration together with the Infusoria: this on the ground that the Infusoria also have deeply indented cells containing trichocysts. He did not give to his proposed group a place in the taxonomic system by assigning it to a category and giving it a Latin name: he called it by the French common names protistes trichocystifères and progastréades. He suggested two ideas: that if a cell marked by a considerable indentation should become divided into many cells forming two layers, respectively superficial and against the indentation, the resulting structure would be a gastrula; and that the gastrula, and, in fact, the kingdom of animals, might have come into existence in this fashion. Perhaps because of novelty, these ideas seem far-fetched. So far as it concerns flagellates, Chadefaud's grouping appears sound and has been followed in giving limits to the present phylum.

The phylum is treated as a single class.

\section{Class MASTIGOPHORA (Diesing) Bütschli}

Classes Cryptomonadineae, Rhizocryptineae, Cryptocapsineae, Cryptococcineae, Desmomonadineae, Desmocapsineae, Dinoflagellatae, Rhizodininae, Dinocap- 
sineae, Dinococcincae, Dinotrichineae, Euglenineae, and Euglenocapsineae Pascher in Beih. bot. Centralbl. 48, Abt. 2: 325, 326 (1931).

Classes Chloromonadina, Euglenoidina, and Cryptomonadina Hollande in Grassé

Traité Zool. 1, fasc. 1: 227, 238, 285 (1952).

Further synonymy as of the name of the phylum.

Characters of the phylum.

There are about one thousand known species. Clearly, thirteen classes for their accommodation, as proposed by Pascher, are excessive; perhaps one goes too far in the other direction in making the entire group a single class. The type of the class is the euglenid Astasia. This is true because the family Astasiaea was listed first in the earliest appearance of the traditional group Flagellata or Mastigophora in due taxonomic form, as order Astoma Siebold. If the euglenids are set apart, taking with them the class name Mastigophora, the remaining larger class will be called Peridinea [Peridineae] Wettstein.

The traditional four orders are tenably natural; but that of dinoflagellates includes about four-fifths of the species, while the chloromonad group is very inconsiderable. The system will be more convenient if the former order is divided into three, and if the latter is included in the euglenid order. The resulting five orders are distinguished as follows:

1. Pigmentation if present brown, olive, or the like; flagella normally two.

2. Flagella at the anterior end of the cell, not moving in longitudinal and transverse grooves.

3. Not walled in the flagellate condition, flagella not markedly differentiated, or not differentiated as anterior and circumferential......... Order 1. CRy ptomonadalea.

3. Usually walled in the flagellate condition; flagella respectively anterior and circumferential........... Order 2. AdiniferideA.

2. Flagella attached laterally, respectively longitudinal and circumferential, moving in grooves impressed upon the cells.

3. Not walled in the flagellate con-

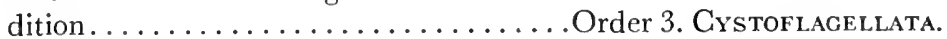

3. Flagellate cells with a wall usually of articulated plates............... Order 4. Cil.roflagellata.

1. Pigmentation if present typically bright green, flagella normally solitary, sometimes two or morc............................. Aster 5.

Order 1. Cryptomonadalea [Cryptomonadales] Engler Syllab. ed. 3: 7 (1903). Subclass Cryptomonadineae Engler in Engler and Prantl Nat. Pflanzenfam. I Teil, Abt. 1a: iv (1900).

Cryptophyceac, inchuding Phaeocapsales and Cryptococcalcs, Pascher in Ber. deutschen bot. Gess. 32: 158 (1914).

Order Cryptomonadinae Pascher Süsswasserfl. Deutschland 1: 28 (1914).

Order Cryptomonadina Doflein Lehrb. Prot. ed. 4: 417 (1916). 
Order Cryptomonadida Calkins Biol. Prot. 265 (1926).

Orders Cryptocapsales and Cryptococcales Pascher in Beih. bot. Centralbl 48, Abt. 2: 325 (1931).

Solitary (exceptionally colonial) cells, usually with one or two plastids of various colors, usually observed in the motile condition, then naked, of dorsiventral (exceptionally isobilateral) symmetry, with two anterior flagella which are not markedly differentiated or not respectively anterior and circumferential.

The resting nucleus contains a karyosome, i. e., a globule which occupies most of

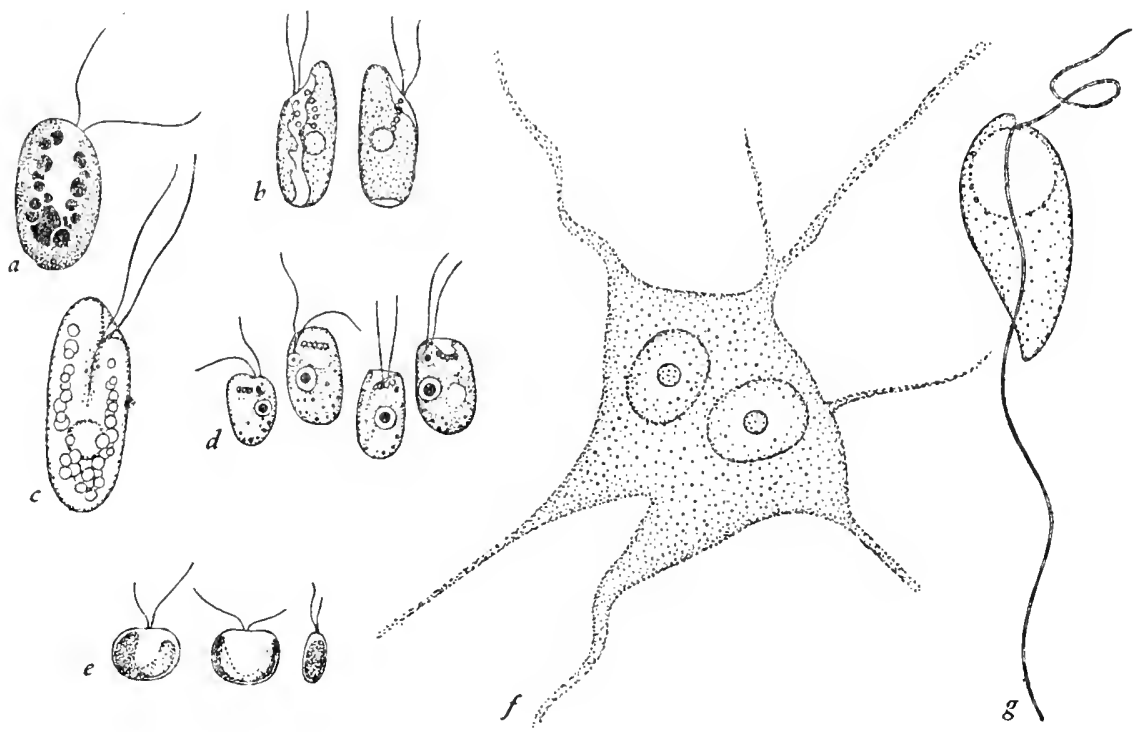

Fig. 18.--a, Cryptomonas sp. b, Rhodomonas baltica after Kylin (1935). c, Chilomonas Parmecium. d, Cyathomonas sp. e, Sennia sp. f, Vegetative cell, and g. zoospore of Paradinium Pouchetii after Chatton (1920). All x 1,000.

its volume and contains most of the chromatin. Dangeard (1910) and Bělăr (1916) have observed details of mitosis. The numerous chromosomes appear within an intact nuclear membrane and form a disk- or drum-shaped figure with its axis at right angles to the axis of the cell. No granule more massive than the chromosomes persists and divides with them.

About thirty species are known. They may be treated as five families.

1. Flagellate cells elongate, with one plane of symmetry.

2. Not parasitic, flagella not markedly differentiated.

3. Non-motile in the vegetative con-

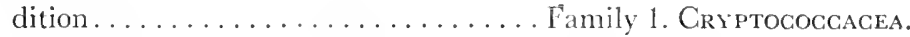

3. Flagellate in the vegetative condition....................... Family 2. Cryptomonadina. 


\section{Amoeboid in the vegetative con-} dition....................... Family 3. Paramoebida.

2. Parasitic amoeboid organisms, the flagella of swimming stages respectively anterior and trailing................... Family 4. Paradinida.

1. Flagellate cells with two planes of symmetry..... Family 5. NePhroselmidacEA.

Family 1. Cryptococcacea [Cryptococcaceae] Pascher in Beih. Bot. Centralbl. 48, Abt. 2: 325 (1931). Family Phaeocapsaceae West British Freshw. Alg. 48 (1904), in part; Phaeocapsa is a chrysomonad. Family Phaeoplakaceae Pascher 1. c. Solitary or clustered cells, non-motile in the vegetative condition, reproducing by flagellate cells of cryptomonad type. Phaeococcus, Cryptococcus, Phaeoplax. Chrysidella includes yellowish cells called zooxanthellae, internally symbiotic in Radiolaria, Rhizopoda, sponges, coelenterates, and rotifers. It is believed that the supposed zoospores of varions amoeboid organisms are actually flagellate reproductive cells of Chry'sidella escaping at certain stages of the life cycles of their hosts.

Family 2. Cryptomonadina Ehrenberg Infusionsthierchen 38 (1838). Family Chilomonadidae Kent Man. Inf. 1: 423 (1880). Family Cryptomonadaceae Engler Syllab. ed. 3: 7 (1903). Family Chilomonadaccae Lemmermann 1909. Family Cryptomonadidae Poche in Arch. Prot. 30: 159 (1913). Flagellate in the vegetative condition, the two flagella not markedly differentiated, springing from the anterior end of the cells, usually from the mouth of a pit lined by granules of some sort. Cryptomonas and Cryptochrysis have brown or yellow plastids; Chromomonas and Cy'anomonas have blue ones; Rhodomonas has red ones. Chilomonas is a colorless saprophyte familiar in infusions. The colorless Cvathomonas, also from infusions, was shown by Ulehla (1911) to be related to Chilomonas.

Family 3. Paramoebida [Paramoebidac] Poche in Arch. Prot. 30: 173 (1913). Schaudinn (1896) discovered the sole known species, Paramoeba Eilhardi, in an aquarium of sea water. It is an amoeboid organism with the peculiarity that each cell contains beside the nucleus an additional body which divides when the nucleus does. The cell may form about itself a shell of debris, and within this may undergo division into many cells which escape as pigmented swarmers resembling cells of Cryptomonas.

Family 4. Paradinida [Paradinidae] Chatton in Arch Zool. Exp. Gen. 59: 444 (1920). The sole known species, Paradinium Poucheti, is a parasite in the body cavity of copepods. The amoeboid cells are linked together by slender psendopodia so as to form a network. The reproductive cells have a shorter anterior flagcllum and a longer trailing flagellum.

Family 5. Nephroselmidacea [Nephroselmidaceae] Pascher Süsswasserfl. Dentschland 2: 110 (1913). Family Nephroselmidac Calkins Biol. Prot. 267 (1926). Cells isobilateral. Cells disk-shaped, the flagella on the margin: Scnnia. Cells laterally extended, bean- or kidney-shaped, the indentation anterior and bearing the flagella: Protochrysis, Nephrosclmis.

Order 2. Adiniferidea Kofoid and Swezy in Mem. Univ. California 5: 108 (1921).

Suborder Adinida Bïtschli in Bronn Kl. u. Ord. Thicrreichs 1: 1001 (1885). Suborder Prorocentrinea Poche in Arch. Prot. 30: 160 (1913).

Desmokontae, including Desmomonadales and Desmocapsales, Pascher in Ber. deutschen bot. Gess. 32: 158 (1914). 
Division Desmokontac; classes Desmomonadineae and Desmocapsineae; and orders Desmomonadales, Prorocentrales, and Desmocapsales Pascher in Beih. bot. Centralbl. 48, Abt. 2: 325 (1931).

Suborder Proroccntrina Hall Protozoology 142 (1953).

Solitary cells, mostly flagellate in the vegetative condition, the flagellate stages either naked or bearing a close wall of two valves, with two flagella at the anterior end, one extending forward while the other is bent circumferentially and causes the cell to whirl while swimming.

The few known organisms of this group may be treated as a single family.

Family Adinida Bergh in Morph. Jahrb. 7: 273 (1882). Family Prorocentrinen Stein Org. Inf. 3, II Hälfte: 8 (1883). Family Prorocentrina Bütschli in Bronn Kl. u. Ord. Thierreichs 1: 1002 (1885). Family Prorocentraceae Schütt in Engler and Prantl Nat. Pflanzenfam. I Teil, Abt. 1b: 6 (1896). Prorocentridae Kofoid in Bull. Mus. Comp. Zool. Harvard 50: 164 (1907). Family Prorocentridae Poche in Arch. Prot. 30: 160 (1913). Desmocapsa, Haplodinium, Desmomastix, Pleuromonas, Exuviaella, Prorocentrum; minute brown organisms, mostly marine.

Order 3. Cystoflagellata (Haeckel) Bütschli in Bronn Kl. u. Ord. Thierreichs 1, Abt. 2, Inhalt (1887).

Tribe [group of families] Gymnodinioidae Poche in Arch. Prot. 30: 161 (1913).

Classes Rhizodininae, Dinocapsineae, Dinococcineae, and Dinotrichineae; orders Gymnodiniales, Rhizodiniales, Dinocapsales, Dinococcales, and Dinotrichales Pascher in Beih. bot. Centralbl. 48, Abt. 2: 326 (1931).

Suborders Gymnodinina, Dinocapsina, and Dinococcina Hall Protozoology 143, 147, 149 (1953).

Haeckel (1866) made of Noctiluca alone a phylum under the name of Noctilucae. He had the carelessness, as it appears, to publish in the same work the synonymous phylar name Myxocystoda as a label in a phylogenetic diagram. In 1873 he used a third name, Cystoflagellata, and Bütschli took this up; in the text of the Klassen und Ordnungen ambiguously as an Unterabtheilung or Ordnung, in the table of contents definitely as an order. Allman (1872) had shown that Noctiluca belongs to the present group. Bütschli did not agree with this opinion, but it is evidently correct, and Haeckel's name becomes the valid one for the order to which Noctiluca belongs

Typical members of the present order are naked motile cells with brown plastids. The two flagella are attached near the equator of the cell. One of them extends in a posterior direction, in a groove called the sulcus. The other extends horizontally about the cell (generally to the right, in the reversed image seen in the microscope), lying in a groove called the girdle. The part of the cell anterior to the girdle is called the epicone, the part posterior to it, the hypocone. From the typical structure as thus described, there are, as will be seen, many deviations.

The species, of which more than three hundred are known, may be treated as nine families.

1. Relatively unspecialized; having stages freely propelled by two flagella, with a single girdle, no tentacles, and unspecialized eyespots or none; not parasitic; commonly pigmented.

2. Walled and non-motile in the vegeta-

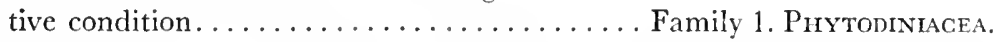

2. Flagellate in the vegetative condition.......Family 2. GrMNODN1ACEA. 
1. Not as above, always without photosynthetic pigments.

2. Amoeboid

2. Flagellate or free-floating. Family 3. Dinamoebidina.

3. With multiplied girdles, without tentacles or specialized light-sensitive organelles.................. Family 4. Polykrikma.

3. With one girdle or none.

4. Cells more or less isodiametric.

5. With prominent light-sensitive organelles, sometimes with tentacles........... Family 5 . Pouchetuda.

5. Without light-sensitive organelles, with tentacles.

6. Not exceptionally large............... Family 6 . Protodiniferida.

6. Reaching exceptional sizes, to $1 \mathrm{~mm}$. in $\mathrm{dj}-$ ameter.................. Family 7. NoctrLucida. 4. Cells dome-shaped..............Family 8. Lepodiscida.

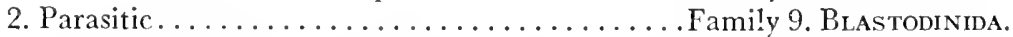

Family 1 . Phytodiniacea [Phytodiniaceae] Schilling in Pascher Süsswasserf. Deutschland 3: 61 (1913). Family Phytodinidae Calkins Biol. Prot. 277 (1926). Dinocapsales, Dinocapsaceae, Dinococcales, Dinotrichales, and Dinotrichaceae Pascher in Ber. deutschen bot. Gess. 32: 158 (1914). Orders Dinocapsales, Dinococcales, and Dinotrichales, and families Glocodiniaceae, Hypnodiniaceae, Dinotrichaceae, and Dinocloniaceae Pascher in Beih. bot. Centralbl. 48, Abt. 2: 326 (1931). Organisms with numerous yellow to brown plastids, walled and non-motile in the vegetative condition, reproducing by gymnodinioid zoospores. Some fifty species are known; it is only recently that Thompson (1949) has found several of these in America. Cells multiplying in a gelatinous matrix: Gloeodinium. Cells solitary, dividing into several which escape usually in the flagellate condition; with smooth ellipsoid walls: Phytodinium, Stylodinium; anvil-shaped, stalked and with two horns: Raciborskya; tetrahedral, with horns at each corner: Tetradinium; with a ring of about six horns: Dinastridium. Tending to produce filaments; marinc: Dinothrix, Dinoclonium.

Family 2. Gymnodiniacea [Gymnodiniaccae] Schütt in Engler and Prantl Nat. Pflanzenfam. I Teil, Abt. 1b: 2 (1896). Subfamily Gymnodinida Bergh in Morph. Jahrb. 7: 274 (1882). Gymnodinidae Kofoid in Bull. Mus. Comp. Zool. Harvard 50: 164 (1907). Family Gymnodiniidae Poche in Arch. Prot. 30: 162 (1913). The typical unarmorcd dinoflagellates, free-swimming, with sulcus and girdle, without tentacles or a conspicuous light-sensitive organelle, commonly with photosynthetic pigments.

The genus which is most numerous in species is Gymnodinium Stcin. It includes both pigmented and non-pigmented species, mostly marine, occasional in fresh water, the girclles nearly equatorial and forming nearly complete circles. The cells readily become encysted, and the cysts may grow to large sizes, reaching diameters of $0.5 \mathrm{~mm}$. These cysts have been taken for a distinct genus Pyrocystis. Observed in darkness, 
the protoplasm in the cysts is seen to become luminous in response to disturbance of the medium; they are among the agents of phosphorescence at sea. In Gymnodinium Lunula the protoplast of each large globular cyst undergoes division into several protoplasts which do not immediately become flagellate; each of them becomes crescent-shaped, deposits a cell wall, and is released by dissolution of the wall of the parent cyst. In the crescent-shaped cysts, the protoplasts divide into several which develop flagella and escape as typical gymnodinioid cells.

In Hemidinium the girdle forms less than a complete circle; in Amphidinium, the girdle is close to the anterior end of the cell; in Gyrodinium, it forms a steep left spiral; in Cochliodinium it forms a left spiral of more than one and one half turns.

Family 3. Dinamoebidina nom. nov. Order Rhizodiniales and family Amoebodiniaceae Pascher (1931), not based on generic names. Non-pigmented amoeboid organisms producing crescent-shaped cysts which germinate by releasing gymnodininid zoospores. Dinamoebidium varians Pascher (1916; originally Dinamoeba, but there is an earlier genus of this name, and the author changed it).

Family 4. Polykrikida [Polykrikidae] Kofoid and Swezy in Mem. Univ. California 5: 395 (1921). Family Polydinida Bütschli (1885), not based on a generic name. There is a single genus Polykrikos, of only three known species. They are colorless predatory organisms of such a structure as might be produced if a cell of Gymnodinium were repeatedly to enter upon division and fail to complete it. Each elongate cell bears a single extended sulcus and a series of girdles; with each girdle are associated the usual two differentiated flagella. Of nuclei there are usually half as many as of girdles. The cells contain structures called nematocysts, whose development and structure was studied by Chatton (1914). Each nematocyst consists of a conical wall, with a peculiar operculum at the broad end, surrounding a minute cavity containing fluid and a coiled thread. Nematocysts are supposed to be homologous with trichocysts, and to contribute to protection, or to the capture of prey; the points seem not fully established. They occur only in this family and the following.

Family 5. Pouchetiida [Pouchetiidae] Kofoid and Swezy in Mem. Univ. of Califcrnia 5: 414 (1921). Each of the gymnodinioid cells contains a light-sensitive apparatus, the ocellus, consisting of a pigmented area and of one or more transparent globes, of unknown composition, serving as lenses. Most species have nematocysts. Protopsis, Pouchctia, etc.; Erythropsis, in warm seas, with a prominent tentacle.

Family 6. Protodiniferida [Protodiniferidae] Kofoid and Swezy in Mem. Univ. California 5: 111 (1921). Family Pronoctilucidae Lebour Dinofl. Northern Seas 10 (1925). Predatory organisms, the cells subglobular, without ocellus or nematocysts, but with a tentacle. Pronoctiluca Fabre-Domergue 1889 (Protodinifer Kofoid and Swezy 1921); Oxyrrhis Dujardin.

Description of the neuromotor apparatus and process of division in Oxyrrhis marina by Hall (1925) provides part of the authority for, and is in good conformity to, the remarks on mitosis included above in the description of the phylum. The nucleus contains a prominent internal body (endosome) which does not contain the material of the chromosomes and does not disappear during mitosis. A centrosome, close outside the nuclear membrane, is connected by two rhizoplasts to blepharoplasts at the bases of the flagella. When a cell is to divide, the centrosome divides; the daughter centrosomes do not necessarily lie at the poles of the nucleus where the chromosomes assemble. Each daughter centrosome appears to generate one rhizoplast, blepharoplast, and flagellum to complete the neuromotor apparatus of a celi. In due course, the endosome, nucleus, and cell undergo constriction. 
Family 7. Noctilucida [Noctilucidae] Kent Man. Inf. 1: 396 (1880). The single species Noctiluca scintillans (Mackartney) Kofoid and Swezy (1921; usually known as $N$. miliaris Suriray) is a predatory marine organism, the subglobular cells reaching dimensions exceeding $1 \mathrm{~mm}$., luminescent when stimulated and accordingly contributing to phosphorescence at sea. Each cell is marked by an extensive depression representing the sulcus; the girdle is obsolete. A part of the area of the sulcus functions as a cytostome. A tooth in the sulcus represents the transverse flagellum. Present are a longitudinal flagellum, minute in proportion to the cell, and a prominent tentacle.

Mitosis in Noctiluca has been studied by Calkins (1899), van Goor (1918), and Pratje (1921). Adjacent to the nucleus there is a body of differentiated cytoplasm, as large as the nucleus, called by Calkins the attraction sphere. Before mitosis, the tentacle and flagellum are absorbed. The attraction sphere becomes elongate and its central part becomes converted into fibers. The nucleus becomes appressed to, and curved about, the bundle of fibers, and the numerous elongate chromosomes assemble against this. The two curved margins of the nucleus draw apart along the bundle of fibers, appearing to draw the daughter chromosomes with them. Division is completed by constriction of the nucleus and disappearance of the fibers, leaving a daughter attraction sphere in association with each daughter nucleus. This peculiar mitotic process is probably of no phylogenetic significance, being, like the organism in which it occurs, an aberrant by-product of evolution.

Nuclear division may be followed by division of the cell into two, the entire process requiring from twelve to twenty-four hours. Alternatively, the nucleus may divide repeatedly, each division requiring from three to four hours; the numerous nuclei produced are budded off from the cell in small uniflagellate spores. Ischikawa (1891) saw conjugation of pairs of cells, and van Goor stated that this is a preliminary to the production of spores; Pratje, on the other hand, could find no evidence of conjugation. The spores are believed to give rise by direct growth to cells like the original one.

Family 8. Leptodiscida [Leptodiscidae] Kofoid 1905. Large dome-shaped predatory marine organisms with small flagella or none. Leptodiscus R. Hertwig (1877) was placed by Bütschli in order Cystoflagellata as the sole genus in addition to Noctiluca; Craspedotella is a comparatively recent discovery of Kofoid.

Family 9. Blastodinida [Blastodinidae] Chatton in Arch. Zool. Exp. Gen. 59: 442 (1920). Ordre Blastodinides Chatton in Compt. Rend. 143: 981 (1906). Families Apodinidae, Haplozoonidae, Oodinidae, and Syndinidae Chatton op. cit (1920). Dinoflagellates which are parasitic chiefly in copepods and tunicates, also in other animals and in diatoms. As a general rule, after the parasite has grown to a certain size, and a multiplication of nuclei has taken place, a part of the protoplast undergoes division to form gymnodinioid zoospores, while the remainder resumes growth in the host. Schizodinium, Blastodinium, Apodinium, Chytriodinium, ctc.

Order 4. Cilioflagellata Claparède and Lachman Etudes Inf. 1: 394 (1858). lamily P'sidinaea Ehrenberg Infusionsthierchen 2.49 (1838).

Family Dinifera Bergh in Morph. Jahrb. 7: 273 (1882).

Order Dinoflagellata Bütschli in Bronn Kl. u. Ord. Thierrcichs 1, Abt. 2: Inhalt (1887).

Subclass Peridiniales Engler in Engler and Prantl Nat. Pflanzenfan. I Teil, Abt. 1b: v (1896). 
Class Peridineae Wettstein Handb. syst. Bot. 1: 71 (1901).

Division Dinoflagellata Engler Syllab. ed. 3: 8 (1903).

Dinophyceae and Dinoflagellatae Pascher in Ber. deutschen bot. Gess. 32: 158 (1914).

Order Diniferidea and tribe [group of families] Peridinioidae Kofoid and Swezy in Mem. Univ. California 5: 106, 107 (1921).

Order Dinoflagellida Calkins Biol. Prot. 267 (1926).

Division Dinophyceae, Class Dinoflagellatac, and order Peridiniales Pascher in Beih. bot. Centralbl. 48. Abt. 2: 326(1931).

Suborder Peridinina Hall Protozoology 144 (1953).

This order is very close to the preceding; its members are distinguished only by the presence, while the cells are in the flagellate condition, of cell walls, consisting in most examples of separable plates. The name Cilioflagellata is evidence of an early error of observation: the circumferential flagellum was mistaken for a whorl of cilia. This name and most of its synonyms were published as applying both to the preceding order and this. For almost all of these names the type or obvious standard example is Peridinium, with the effect that the names belong to the present order.

There are about five hundred species, prevalently marine. Five families may be recognized.

Family 1. Peridinaea Ehrenberg Infusionsthierchen 249 (1838). Family Peridinidae Kent Man. Inf. 1: 441 (1880). Family Peridiniaceae Schütt in Engler and Prantl Nat. Pflanzenfam. I Teil, Abt. 1b: 9 (1896). Ceratiidae Kofoid in Bull. Mus. Comp. Zool. Harvard 50: 164 (1907). The typical dinoflagellates, of numerous genera and species. The distinctions among them are largely matters of the detailed arrangement of the plates making up the walls. Glenodinium, the plates scarcely distinguishable. Peridinium, Goniodoma, Goniaulax, Geratium, Oxytocum, etc. The cells of certain species in various genera are ornamented with prominent horns; in Ceratium especially the epitheca is drawn out into one long horn, and the hypotheca intc one, two, or three. Goniaulax becomes abundant at certain seasons, is eaten by shellfish, and renders them poisonous.

The neuromotor apparatus (much as in Menoidium) and the process of nuclear and cell division in Ceratium Hirundinella were described by Entz (1921) and Hall (1925). Many nuclei lack the endosome; if present, it disappears during mitosis, as does also the nuclear membrane. The daughter centrosomes lic at the sides of the blunt-ended mitotic figure. When nuclear division is complete, the protoplast expands and then becomes constricted in such fashion that each daughter cell receives certain plates of the wall; each daughter cell then secretes the plates which it lacks.

Zederbauer (1904) reported conjugation in Ceratium. He saw an elongate protoplast with each of its ends covered by a complete cell wall. Dividing cells are of quite different appearance.

Families Ptychodiscida, Cladopyxida, and Amphilothida of Kofoid (1907, the names in the feminine; explicitly made families by Poche, 1913) are minor segregates from Peridinaea.

Family 5. Dinophysida (Bergh) Bütschli in Bronn Kl. u. Ord. Thierreichs 1: 1009 (1885). Subfamily Dinophysida Bergh in Morph. Jahrb. 7: 273 (1882). The limits of the plates obscure; girdle near the anterior end; sulcus and girdle bordered by prominent flanges. Strictly marine, mostly in warmer oceans. Dinophysis, Oxyphysis, Amphisolenia, Triposolenia, etc. 


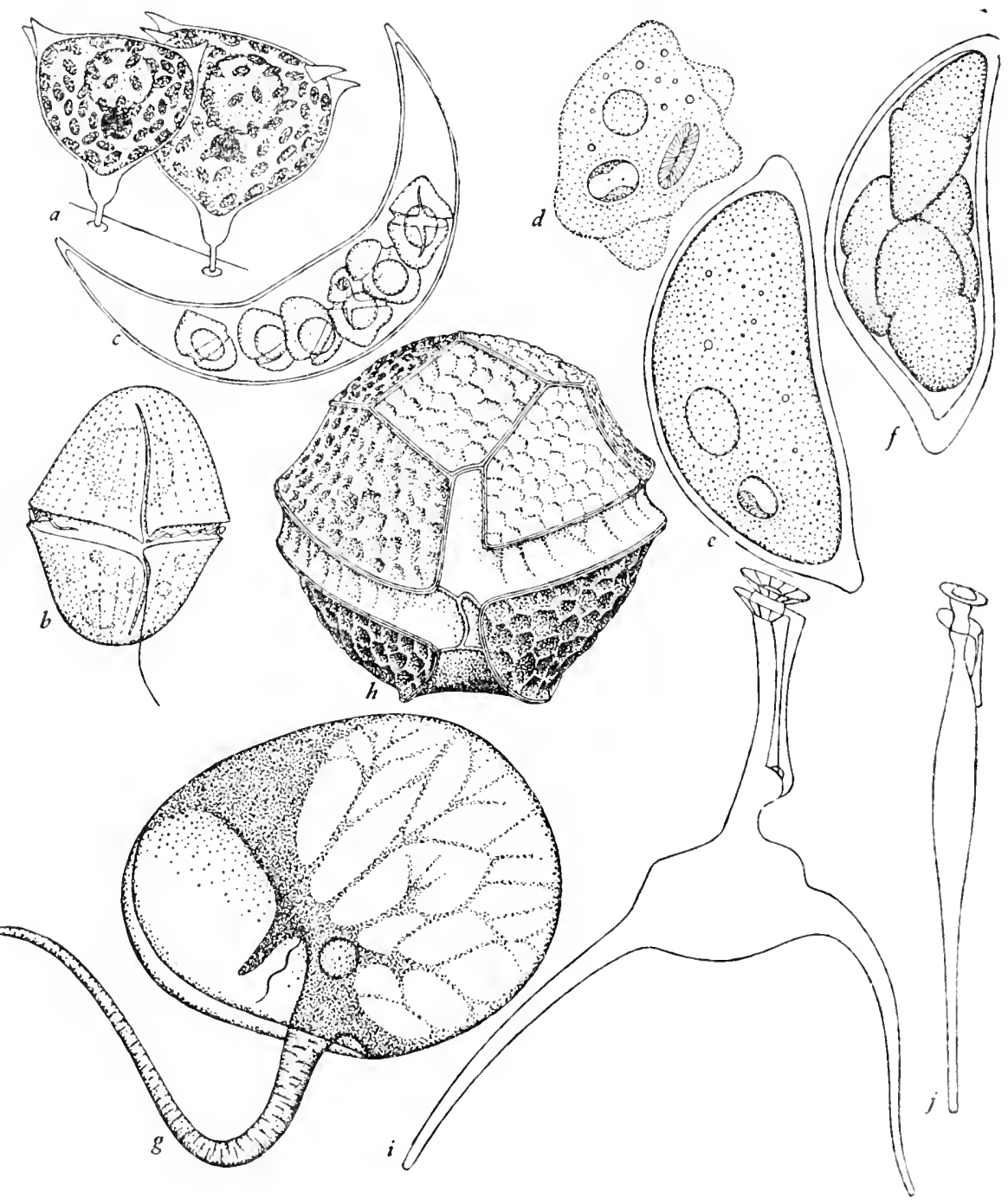

Fig. 19.-a, Tetradinium javanicum x 1,000 after Thompson (1919). b, Gymnodinium striatum $\times 500$ after Kofoid \& Swezy (1921). c, Gymnodininm Lunula, flagellate cells forming in a cyst $x$ 500, after Kofoid \& Swezy op. cit. d, e, f, Dinamocbidium varians; amocboid vegetative cell, cyst, and production of gymnodinioid zoospores x 1,000 after Pascher (1916). g, Noctiluca scintillans $\times 100$ after Allman (1872). h, Peridinium cinctum $\times 1,000$. i. Triposolenia Ambulatrix $\mathrm{x} 500$ ) after Kofoid (1907). j, Amphisolcnia laticincta after Kofoid, op. cit. 
Order 5. Astoma Siebold in Siebold and Stannius Lehrb. vergl. Anat. 1: 10 (1848). Order Phytozoidea Perty Kennt. kleinst. Lebensf. 161 (1852), in part.

Order Flagellata Claparède and Lachmann Etudes Inf. 1: 73 (1858), in part. Order Flagellato-Eustomata Kent Man. Inf. 1: 36 (1880).

Suborder Euglenoidina Bütschli in Bronn Kl. u. Ord. Thierreichs 1: 818 (1884). Abtheilung (suborder) Chloromonadina Klebs in Zeit. wiss. Zool. 55: 391 (1893).

Order Euglenoidina Blochmann Mikr. Tierwelt 1, ed. 2: 50 (1895).

Subclasses Chloromonadineae and Euglenineae Engler in Engler and Prantl Nat. Pflanzenfam. I Teil, Abt. 1a: v, vi (1900).

Orders Euglenales and Chloromonadales Engler Syllab. ed. 3: 7 (1903).

Orders Eugleninae and Chloromonadinae Pascher Süsswasserf. Deutschland 1: 29 (1914).

Orders Euglenida and Chloromonadida Calkins Biol. Prot. 283, 285 (1926).

Mostly solitary flagellate cells of fresh water, unwalled and capable of contraction and writhing movement; the anterior end of each cell (in the flagellate condition) penetrated by a pit, the reservoir or cytopharynx, into which contractile vacuoles open; having one flagellum, or two, usually unequal, or more, one flagellum of each cell usually being stichoneme; mostly producing a solid storage product, not staining blue with iodine, called paramylum.

Jahn (1946) reviewed this group. He recognized four families, to which one more, to include the chloromonads, is to be added.

1. Producing paramylum.

2. Flagellum with a swelling near the base, usually single but formed of two parts which join below the swelling; cells mostly pigmented.

3. Non-motile and walled in the vegetative condition.................. Family 1. Colaciacea.

3. Flagellate in the vegetative condition....................... Family 2. Euglenida.

2. Flagellum not swollen and usually not forked near the base; cells not pigmented.

3. Cells without internal rod-shaped structures; flagella stichoneme..........Family 3. Astasiaea.

3. Cells with internal rod-shaped structures; flagella acroneme or simple....... Family 4. Anisonemida.

1. Not producing paramylum, storing oil............ Family 5 . Coelomonadina.

Family 1. Colaciacea [Colaciaceae] Smith Freshw. Alg. 617 (1933). Family Colaciidae Jahn in Quart. Rev. Biol. 21: 264 (1946). Euglenoid organisms which are walled and non-motile in the vegetative condition. There is a single genus Colacium, producing dendroid colonies.

Family 2. Euglenida Stein Org. Inf. 3, I Hälfte: x (1878). Family Euglenina Bütschli in Bronn Kl. u. Ord. Thierreichs 1: 820 (1884). Family Euglenaceae Engler in Engler and Prantl Nat. Pflanzenfam. I Teil, Abt. 2: 570 (1897). Solitary motile cells, mostly with abundant green plastids, the flagella with swellings near the base, mostly solitary and forked below the swelling. Jahn recognized twelve genera. Eutreptia has two flagella; Euglenamorpha has three. Members of the latter genus 


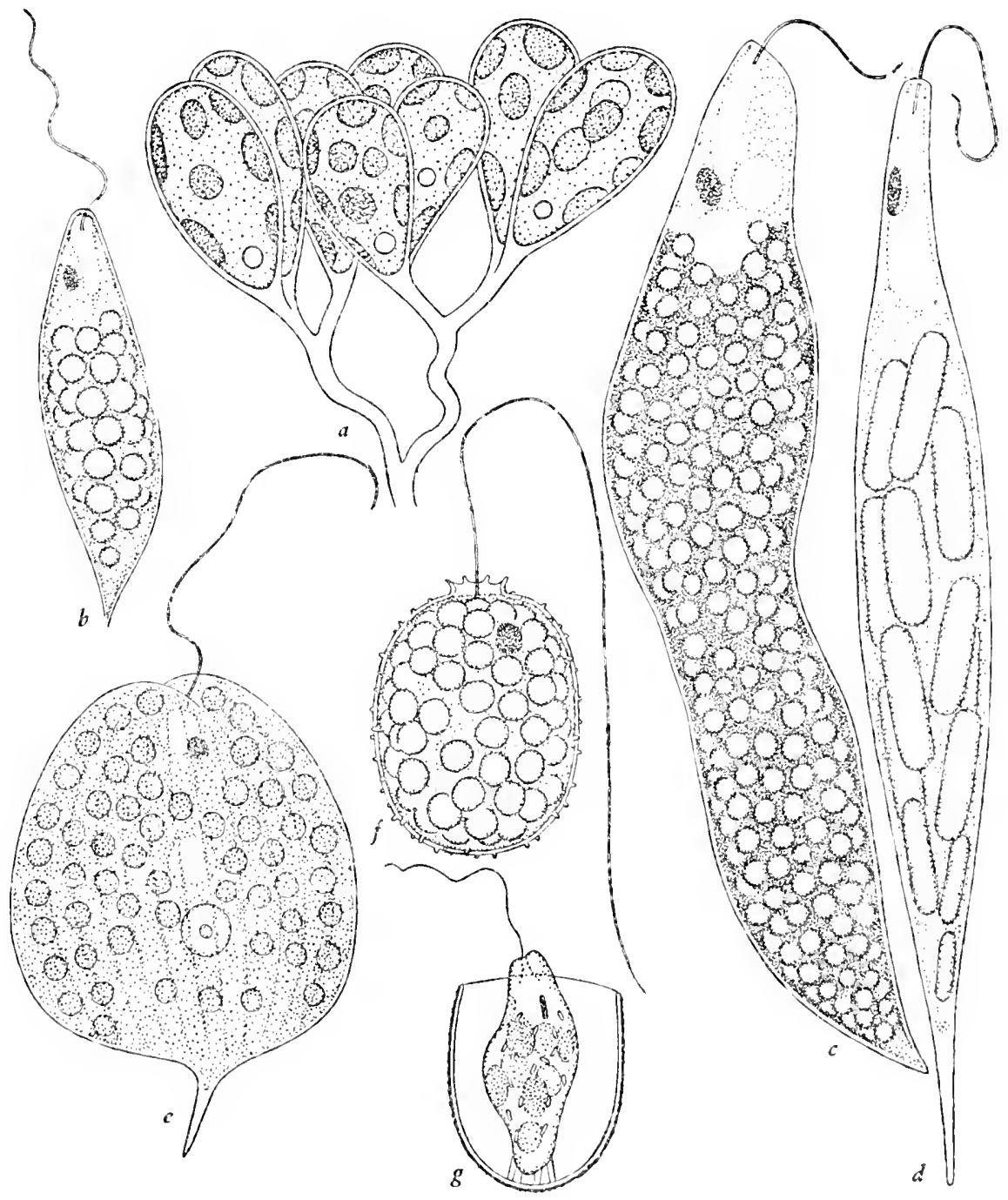

Fig. 20.--a, Colacium Arbuscula after Stein (1878). b, Euglena viridis. c, Euglena Spirogyra. di, Euglena acus. e, Phacus sp. f, Trachclomonas sp. g, Klcbsiclla alligata after Pascher (1931). All x 1,000. 
are entozoic in frog tadpoles; some of them are non-pigmented. Three genera having the typical single flagella are among the most familiar of flagellates. Euglena has fusiform to cylindrical cells freely capable of writhing changes in shape. Phacus has flattened cells with a rigid membrane. In Trachelomonas, the protoplast lies loose in a rigid lorica which is often ornamented with spines; variations in the form and ornamentation of the lorica have made it possible to distinguish a large number of species.

There are accounts of mitosis in Euglena by Keuten (1895), Baker (1926), Ratcliffe (1927) and Hall and Jahn (1929). All observers have seen within the nucleus a large globule which divides as the nucleus does and appears to guide the separating chromosomes. Keuten applied to it the term nucleolo-centrosome; the implications of this term are not confidently to be accepted, and the body will better be called by the neutral term endosome. Ratcliffe's account of mitosis in Euglena Spirogyra is the most detailed. It appears that division is initiated when the endosome buds off a small granule which migrates to a position just within the nuclear membrane and divides. The resulting granules may be regarded as centrosomes. The nucleus moves forward within the cell and comes into contact with the cell membrane at the bottom of the reservoir. Each centrosome appears to generate, just within the cell membrane, a granule recognizable as a blepharoplast; the nucleus then withdraws from the cell membrane, but the centrosomes remain connected to the blepharoplasts by rhizoplasts. The flagellum, already split at the base, divides throughout its length into two; a new flagellum-base grows out from each blepharoplast and becomes fused to one of the halves of the old one not far from the base of the latter. Meanwhile, within the intact nuclear membrane, the chromosomes and endosome are dividing. The centrosomes are at the sides of the dividing nucleus. No spindle has been recognized. Nuclear division is completed by constriction of the membrane. The cell divides by constriction which proceeds longitudinally from the anterior end. The centrosomes and rhizoplasts disappear, to be replaced during the next division by new ones.

Hall and Hall and Schoenborn (in several papers, 1938, 1939) have reported experiments on nutrition in Euglena. All species are capable of photosynthesis. Some of them, surprisingly, have lost the capacity to synthesize amino acids which usually accompanies photosynthesis; and there are transitional species in which some individuals possess the capacity to make amino acids and others do not, evidently as heritable characters.

Family 3. Astasiaea Ehrenberg Infusionsthierchen 100 (1838). Family Astasiidae Kent Man. Inf. 1: 375 (1880). Family Astasiina Bütschli in Bronn. Kl. u. Ord. Thierreichs 1: 826 (1884). Family Astasiaceae Senn in Engler and Prantl Nat. Pflanzenfam. I Teil, Abt. 1a: 177 (1900). Colorless organisms. Deflandre found the flagella stichoneme, as to the single flagella of Astasia and Menoidium, and as to one of the two flagella of Distigma. Hall and Jahn (1929) found the flagella not swollen near the base. The internal rod-shaped structures which characterize the following family are absent.

Bělăr (1915) described mitosis in Astasia, and Hall (1923) described it in Menoidium. There is a blepharoplast at the base of the flagellum, and some preparaticns show a rhizoplast connecting this to a centrosome immediately outside the nnclear membrane. The blepharoplast divides during the early stages of mitosis, and the flagellum appears to divide lengthwise. The daughter centrosomes mark the loci toward which the dividing chromosomes move. The chromosome number appears to be 12. A dividing endosome like that of Euglena is present. 
Scytomonas pusilla Stein (Copromonas subtilis Dobell) occurs in the intestines of frogs and toads. When cast out with the feces, it exhibits conjugation as a preliminary to encystment (Dobell, 1908).

Family 4. Anisonemida [Anisonemidae] Kent Man. Inf. 1: 429 (1880). Families Pernamina and Anisonemina Bütschli in Bronn Kl. u. Ord. Thierreichs 1: 824, 828 (1884). Family Peranemaceae Senn in Engler and Prantl Nat. Pflanzenfam. I Teil, Abt. 1a: 178 (1900). Family Heteronemidae Calkins Biol. Prot. 285 (1926). Each cell of these colorless organisms bears one conspicuous anterior flagellum; most of them bear also a less conspicuous trailing flagellum. The trailing flagellum of Peranema is grown fast to the cell membrane, and is detected only with difficulty (Hall,

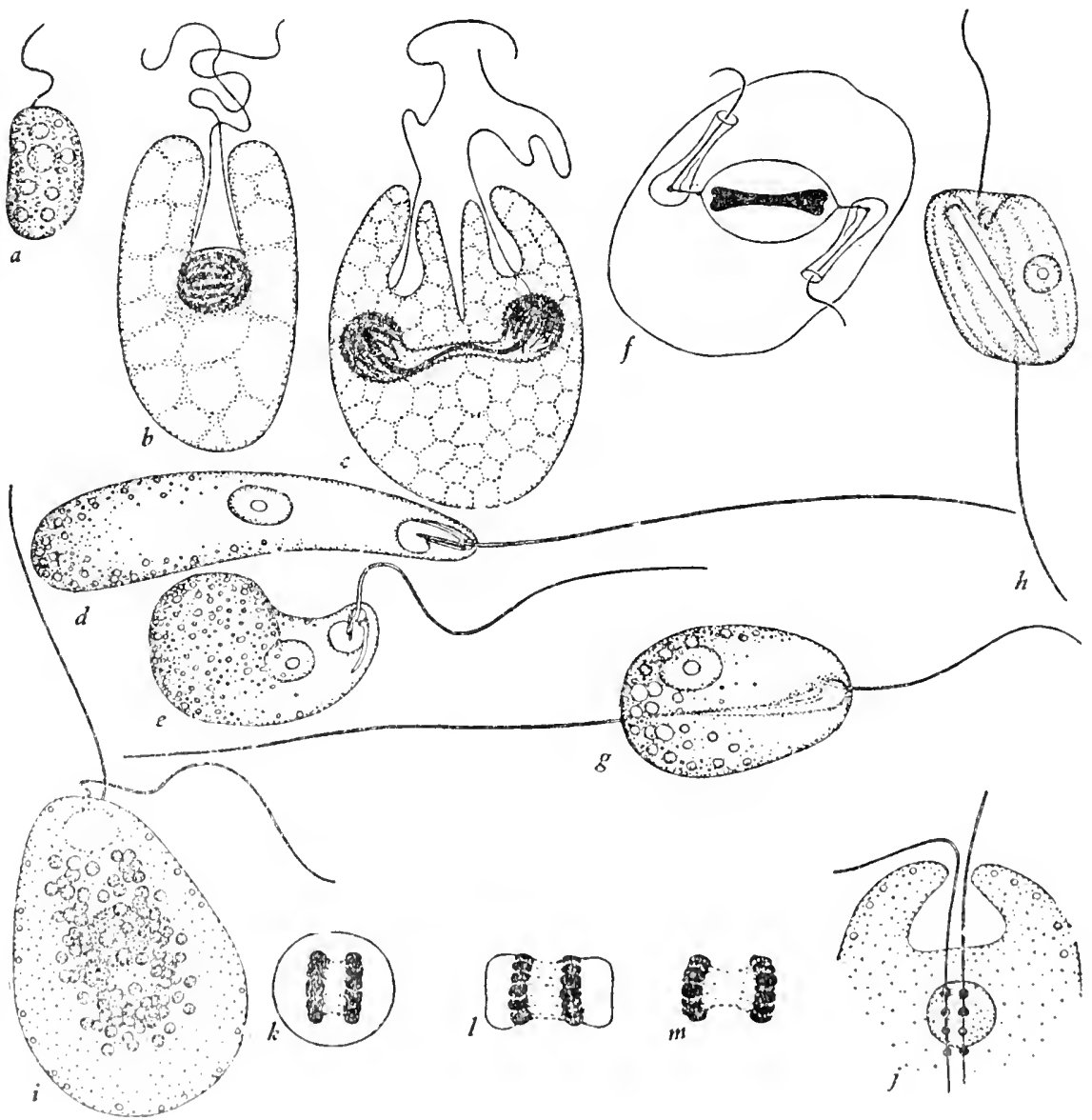

F1G. 21.-a, Mcnoidium incurvum. b, c, Stages of mitosis in Menoidium incurvum x 2,000 after Hall (1923). d, e, Perancma trichophorum. f, Stage of division in Peranema trichophorum after Hall (1934). g, Anisonema truncatum. h, Entosipon sulcatum. i-m, Vacuolaria viridis: $\mathbf{i}$, cell; $\mathbf{j}$, neuromotor apparatus after Fott (1935); k-m, stages of mitosis x 2,000 after Fott, op cit. x 1,000 except as noted. 
1934). Deflandre was unable to find appendages on the flagella of members of this family. As in other members of the order, the flagella spring from a deep anterior pit in the cell; in this family, the pit is a functional cytopharynx (Hall, 1933). The cytoplasm of Peranema contains three brief rods, the pharyngeal rods or Staborgane, lying near the cytopharynx; their function is unknown. Each cell of Urceolus, of Anisonema, and of Heteronema contains a single conspicuous rod extending the length of the body. Hall and Powell (1928) and Hall (1934) described the mitotic process in Peranema, which is much as in Menoidium.

Family Coelomonadina Bütschli in Bronn Kl. u. Ord. Thierreachs 1: 819 (1884). Family Vacuolariaceae Luther in Bihang Svensk. Vetensk-Akad. Handl. 24, part 3, no. 13: 19 (1889). Family Chloromonadaceae Engler Syllab. ed 3: 7 (1903). Family Thaumatonemidae Poche in Arch. Prot. 30: 155 (1913). Family Chloromonadidae Hollande in Grassé Traitè Zool. 1, fasc. 1: 235 (1952); family Thaumatomonadidae Hollande op. cit. 686. Unicellular organisms, mostly green, with two differentiated flagella springing from a large reservoir, producing globules of oil but no solid storage product. Klebs apologized for erecting the grössere Abtheilung Chloromonadina for the single genus Vacuolaria, and in fact, this genus differs from other members of the present order only in one conspicuous character, the failure to produce paramylum. Fott (1935) studied the cytology of Vacuolaria. From the base of each flagellum, a rhizoplast extends into the cytoplasm, but fails to come into contact with the nucleus. Several granules or swellings, not definitely identifiable as blepharoplasts or centrosomes, are distributed along the length of each rhizoplast. In mitosis, which takes place within an intact nuclear membrane, the numerous subglobular chromosomes form a blunt-ended figure much as in Chilomonas. Genera believed to be allied to Vacuolaria include the green flagellate Goniostomum; Chysophacum Lewis and Bryan (1941), a marine organism forming non-motile yellow dendroid colonies of macroscopic dimensions; and the colorless flagellate Thaumatomastix Lauterborn (originally named Thaumatonema, but there is among plants an older genus of this name). 


\section{Chapter VIII}

\section{PHYLUM OPISTHOKONTA}

\section{Phylum 4. OPISTHOKONTA, phylum novum}

Chytridieae de Bary in Bot. Zeit. 16, Beil. 96 (1958).

Family Chytridieen de Bary and Woronin (1864).

Family Chytridiaceae Cohn in Hedwigia 11: 18 (1872).

Ghytridineae Schröter in Engler and Prantl Nat. Pflanzenfam. I Teil, Abt. 1: $62(1892)$.

Series (Reihe) Archinycetes (Ghytridinae) A. Fischer in Rabenhorst Kryptog.-Fl. Deutschland 1, Abt. 4: 11 (1892).

Suborders Chrytidiineae and Monoblepharidineae Engler in Engler and Prantl

Nat. Pflanzenfam. I Teil, Abt. 1: iii, iv (1897).

Order Ghytridineae Campbell Univ. Textb. Bot. 152 (1902).

Classes Arghimygetae and Monoblepharideae Schaffner in Ohio Naturalist 9: 447,449 (1909).

Class Archimycetes Gaümann Vergl. Morph. Pilze 15 (1926).

Uniflagellatae Sparrow Aq. Phyc. 21 (1943).

Parasites and saprophytes of simple structure (filamentous, of uniform diameter or tapering; or unicellular, with or without rhizoids, i. e. tapering filamentous outgrowths), with cell walls of chitin, containing no cellulose; producing motile cells with solitary posterior acroneme flagella. Type, Chytridium Olla Braun. From ótíöı૮s, rearward, and kovtós, oar.

Chytrid is the English form of the generic name Chytridium, from Greek xutpís, a jug. Braun (1856) applied this name to a colorless unicellular organism found attached to green algae whose cells are penetrated by rhizoids which draw food from them and kill them. By chytrids we mean organisms of body types of the general nature of that of Chytridium. All such organisms were formerly treated as a single taxonomic group. Couch $(1938,1941)$ showed that the organisms of chytrid body type form three markedly distinct groups distinguished by types of flagellation. The proper chytrids, those which legitimately constitute a taxonomic group, are marked by swimming cells with solitary posterior acroneme flagella, and further by lack of cellulose in the ccll walls. The group thus marked includes, beside organisms of chytrid body type, a few organisms of the filamentous body type of the typical fungi.

The cytoplasm of members of this group is described as peculiarly lustrous and as containing shining globulcs. In mitosis (seen repeatedly, as by Dangeard, 1900, Stevens and Stevens, 1903, Wager, 1913, and Karling, 1937), the sharp-pointed spindle forms within the intact nuclear membrane. Some obscrvers have secn centrosomes at the poles. The nuclear membrane clisappears toward the end of the process.

The formation of motile cells (zoospores and sometimes gametes) occurs in enlarged cells. In these cells there are repeated simultancous unclear divisions. After the last of these, uninucleate protoplasts, cach one containing, ordinarily, one of the above-mentioned shining globules, are separated by cleavage. On each of these protoplasts a flagellum grows from the cell membrane at the point nearest that part of the nucleus which represents a pole of the previous mitotic spindle. Among the Blastocladiacea, the nucleus lies against the cell membrane and the flagellum appears to spring from a granule within it (Cotner, 1930; Hatch, 1935). Sinilarly, in Clado- 
chytrium, it appeared to Karling (1937) that the nucleolus generates the flagellum. Within the developing swimming cell a body of granules assembles and produces a "cap," prominent in stained material, on the anterior side of the nucleus, that is, on the side away from the flagellum.

Nowakowski (1876) observed sexual processes in Polyphagus, and Scherffel (1925) observed them in many other chytrids. Sexual processes were known in Monoblepharis from the discovery of this genus, and have been studied in detail in Allomyces by Emerson $(1939,1941)$ and Emerson and Wilson (1949).

The group thus characterized is of fewer than three hundred known species. One takes no satisfaction in making it a phylum, but feels constrained to do so by its isolation. Note has been taken that other groups including organisms of chytrid body type, as Hyphochytrialea, Lagenidialea, and Phytomyxida, have nothing to do with the proper chytrids. Furthermore, it will not do to thrust the proper chytrids in with the groups of colorless flagellate and amoeboid organisms treated below as phylum Protoplasta. One does not trust that group as natural, but it has a morpological continuity which would be defaced by the addition of this one.

Vischer, 1945, coined the name Opistokonten for organisms whose motile cells have posterior flagella. Gams (1947) listed as such the green organisms Pedilomonas and Chlorochytridion; the choanoflagellates; the proper chytrids; the Sporozoa (the whole group by virtue of such examples as have flagellate stages); and the proper animals. He inferred that these groups make up a major natural group derived from the lowest green algae. This interesting hypothesis must as yet be treated as far-fetched. Pedilomonas is scarcely known; it was described by Korschikoff, 1923, as a green flagellate of somewhat the appearance of a Chlamydomonas lacking one of its flagella. The flagella of the choanoflagellates are pantacroneme instead of acroneme. There remains a striking resemblance between the motile cells of the proper chytrids and the sperms of animals. The nuclear cap of the former is quite similar, in development and structure, to the beak of the latter.

The Opisthokonta are reasonably treated as a single class.

\section{Class ARCHIMYCETES (A. Fischer) Schaffner}

Synonymy of the phylum.

Characters of the phylum.

Previous authors have arranged these organisms in a sequence from strictly unicellular forms to typically filamentous forms. In the following treatment, this sequence is reversed. The course of the evolution of the group is unknown, and it seems reasonable to place the body types in the same sequence as among the Oomycetes. The class is treated as two orders, Monoblepharidalea, essentially filamentous, and Chytridinea, unicellular or producing filaments which taper or are swollen at intervals.

Order 1. Monoblepharidalea [Monoblepharidales] Sparrow in Mycologia 34: 115 (1942).

Suborder Monoblepharidineae Engler and Prantl Nat. Pflanzenfam. I Teil, Abt. 1: iv (1897).

Blastocladiincae Petersen in Bot. Tidsskr. 29: 357 (1909).

Order Blastocladiales Sparrow 1. c.

Opisthokonta whose bodies consist of filaments of uniform diameter, or are of types apparently immediately derived from this. Saprophytes in fresh water or soil, chiefly on vegetable remains. There are two families. 
Family 1. Monoblepharidacea [Monoblepharidaceae] A. Fischer in Rabenhorst Kryptog.-Fl. Deutschland 1, Abt. 4: 378 (1892). Gonapodiineae and Gonapodiaceae Petersen in Bot. Tidsskr. 29: 357 (1909). Producing extensive coenocytic filaments, non-septate but with false septa of cytoplasm, anchored by rhizoids, reproducing asexually by zoospores produced in sporangia which are usually terminal on the filaments, the gametes produced in smaller antheridia and larger oogonia which are in the more familiar forms terminal and subterminal on the filaments, the branches commonly proliferating below them, the eggs without flagella.

The species, about a dozen, form three genera. In Monoblepharis, the zygote, being the entire protoplast of the oogonium, moves out of the oogonium through a terminal pore, becomes attached in the opening, and develops a thick wall. In Monoblepharclla the zygote, retaining the fiagellum of the sperm, swims for a time bcfore becoming encysted. Gonapodya resembles Monoblepharella (Johns and Benjamin, 1954). Myrioblepharis Thaxter is believed not to be an organism; it is described as something which might be produced if sporangia of Monoblepharis were parasitized by an infusorian.

Family 2. Blastocladiacea [Blastocladiaceae] Petersen in Bot. Tidsskr. 29: 357 (1909). Cocnocytic filaments, in some examples of a false appearance of septation, of the body type of the Rhipidiacea, i. e., differentiated into a basal cell anchored by rhizoids and distal branches bearing reproductive structures, sometimes so reduced that the basal cell bears, or is itself, the reproductive structure; the reproductive structures including thin-walled zoosporangia, thick-walled resting spores which germinate by releasing zoospores, and gametangia; the gametes morphologically uniform or larger and smaller, all bearing flagella.

These organisms are not familiar, although they are readily isolated by baiting pond water, or tap water to which soil has been added, with hemp seeds or pieces of fruit. There are four genera, Allomyces, Blastocladia, Blastocladiella, and Sphaerocladia, with about twenty-five known species. Allomyces is of interest for varied life cycles, and Blastocladia for a peculiar type of metabolism.

The first known species of Allomyees, A. Arbuscula, was discovered by Butler (1911) on dead flies in water in India. The individuals are of the appearance of minuscule shrubs, the branches divided by pseudosepta punctured in the middle and ending in scries of varicolored reproductive structures. Ordinary sporangia are colorless, resting spores arc brown, mature antheridia are pink, and mature oogonia dull gray. Kniep (1929), in discovering the second species, A. javanicus, found that the indivicluals are of two types, one bearing sporangia and resting spores, the other oogonia and antheridia. Thus this organism has a complete life cycle of morphologically homologous haploid and diploid individuals. Kniep supposed that meiosis occurs in the resting spores, and Emcrson and Wilson (1949) cstablished the point. The chromosome number $(n)$ of $A$. Arbuscula is 7 ; that of $A$. javanicus var. macrogynus and of $A$. eystogenes is 14 .

The life cycle of $A$. Arbuscula is the same as that of $A$. javanieus. In A. cystogenes, the haploid stage consists mercly of the zoospores from the resting spores; these become encysted and germinate by releasing isogametes. Thus this species has a life cycle essentially of the advanced type characteristic of animals. There are further species of Allomyces in which a scxual cycle is belicred not to occur.

In Blastocladia the basal cell bears directly multiple reproductive structures. Organisms of this genus are less easily cultured than Allomyces; they require several vitamins of the B group (Cantino, 1918). They tolerate oxygen, but do not require it. 
They convert sugars to lactic and succinic acids, producing no $\mathrm{CO}_{2}$; the acids, if not neutralized, check the growth of cultures (Emerson and Cantino, 1948; Cantino, 1949). Blastocladia appears to have lost the capacity to carry on the acrobic stages of energesis, thus reverting to the type of metabolism characteristic of the supposedly most primitive bacteria.

In Blastocladiella, the basal cell bears a single reproductive structure. Different species have the same three types of life cycle which occur in Allomyces (Couch and Whiffen, 1942). In Sphacrocladia the vegetative body is reduced to the unicellular condition which is characteristic of the following order rather than of this. The life cycle is of the complete homologous type.

\section{Order 2. Chytridinea [Chytridineae] (Schröter) Campbell Univ. Textb. Bot.} 152 (1902).

Orders Myxochytridinae and Mycochytridinae A. Fischer in Rabenhorst Kryptog. Fl. Deutschland 1, Abt. 4: 20, 72 (1892), not based on generic names. Order Chytridiales Auctt.

Further synonymy as of the name of the phylum.

Opisthokonta which consist entirely or largely of more or less isodiametric bodies called centers: the centers may send out filaments more slender than themselves, generating at their ends further centers; or may be capable only of producing rhizoids, i. e., tapering absorptive filaments; or may be by themselves complete individuals.

The chytrids are commonly thought of as prevalently parasitic on algae and higher plants. They attack also rotifers, insects, nematodes, and other minute animals; some parasitize other chytrids (Karling, 1942, 1948). It is probable, however, that the majority of the group are saprophytic on organic remains. Some have been cultured with no other organic food than cellulose (Haskins, 1939); new forms have been discovered by baiting with, and culturing on, chitin (Karling, 1945; Hanson, 1946) or keratin (Karling, 1946, 1947).

The following varieties of vegetative structurc may be noted. (a) A zoospore, settling upon the surface of an appropriate host or substratum, may penetrate this by means of a walled filament which develops a terminal center; the center then sends out rhizoids, and also filaments which generate further centers. (b) Development may be as above except that only one center is formed. The body thus described is of the Entophlyctis type of Sparrow (1943). (c) The zoospore may itself become the single center, penetrating its host or substratum only by rhizoids. The resulting body is of the Chytridium type if the center is in contact with the host or substratum, of the Rhizidium type if it is not. (d) The protoplast of the zoospore may migrate into the protoplast of the host and there become a center without rhizoids; the resulting body is of the Olpidium type. To the varied bodies thus described, the following terminology is applicable:

Pluricentric, with more centers than one; monocentric, with a single center.

Intramatrical, the center developing within the substratum or host; alternatively, in a host, endobiotic.

Extramatrical or epibiotic, contrary to the foregoing.

Eucarpic, the center not constituting the entire body; holocarpic, the center constituting the entire body.

The center regularly remains uninucleate during the vegetative phases and then becomes the seat of successive simultaneous nuclear division, of cleavage, and of the maturation of zoospores. Thus it is converted into a sporangium. In many forms, the 


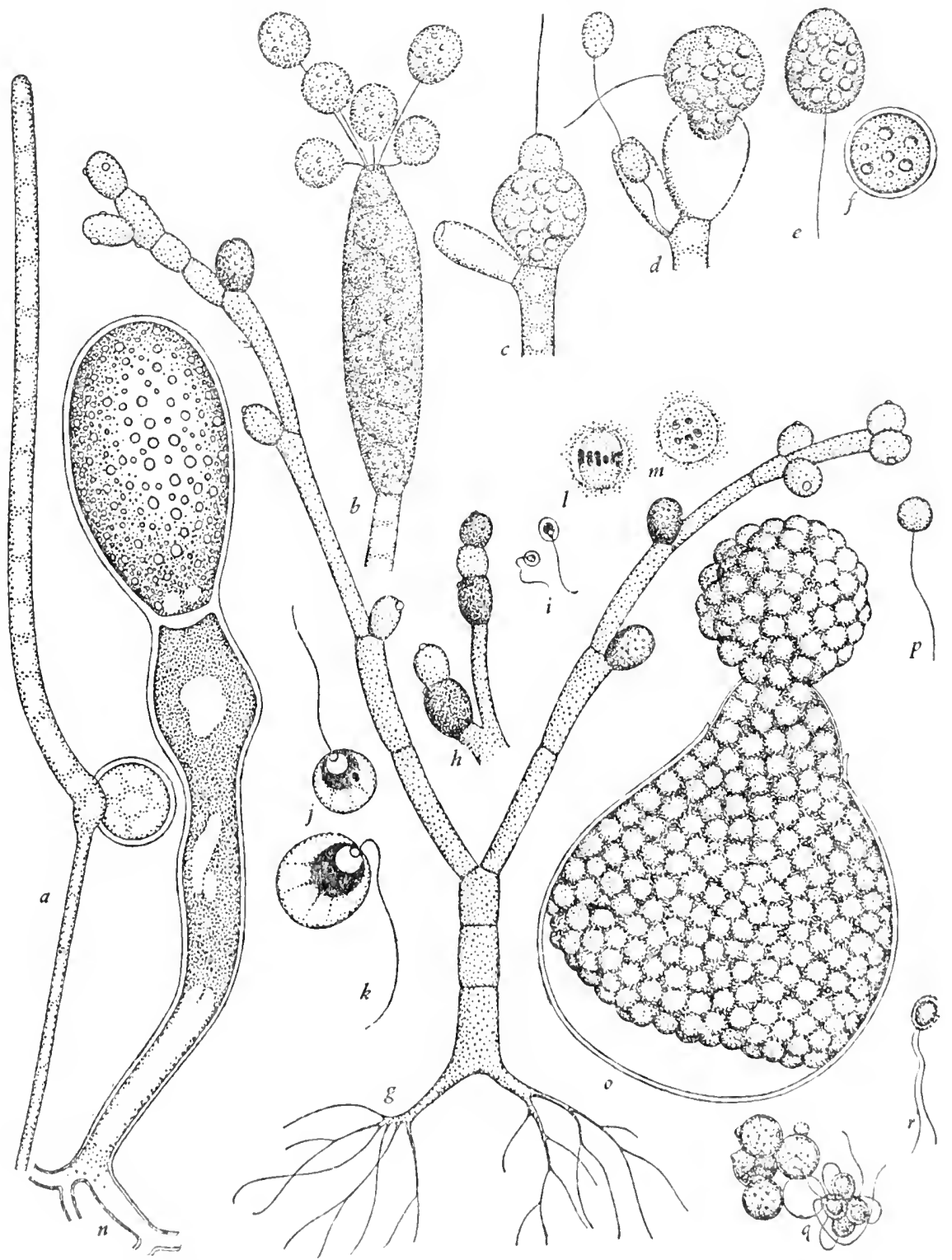

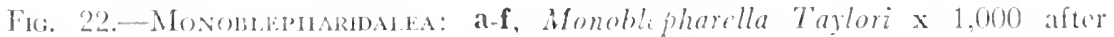
Springer (1945); a. germinating spore producing a filmont and a rhizoid; b, sporangium relcasing spores; comply antheridiun and sperm uniting with ege; d, spems rscaping from antheridium and zygotc escaping from ongonium; e. swimming zygote; f. encysted zygote. g-i, Allomyers jazanicus x 100 after Kniep (1929); g, asexual 
proximal part of the system of rhizoids develops a large swelling called the apophysis. In other forms, the center generates the sporangium as an outgrowth. In these circumstances, the center is sometimes called an apophysis, but were better called a presporangium. The sporangium discharges its spores, usually, through one or more tubes which grow forth from it. The tube may open through a differentiated cap, the operculum; the production of opercula appears to mark a natural subordinate group.

Syngamy occurs in different chytrids in most of the possible fashions, by union of like or unlike swimming cells, by the union of a swimming cell with a stationary one, or by the establishment of contact by growth. The zygote regularly becomes a thickwalled resting spore (asexual resting spores are also of frequent occurrence). Resting spores germinate by producing zoospores. Meiosis has not been observed, but is believed to occur during the first nuclear divisions in the germinating zygote; the life cycle is apparently of the primitive type, in which all cells except the zygote are haploid (Physoderma, or at least some of its species, is believed to be exceptional).

Sparrow (1943) recognized nine families. One of these does not appear tenable; the remainder are distinguished as follows:

1. Sporangia not opening through opercula.

2. Eucarpic, i. e., producing rhizoids and sometimes other filaments, the centers not constituting the entire body.

3. Pluricentric ............... Family 1. Cladochytriagea.

3. Monocentric.

4. Germinating spores generating the center as a distinct body.................... Family 2. Phlyctidiacea.

4. Zoospores themselves becoming centers, and subsequently sporangia or presporangia...... Family 3 . RHIzIDIACEA.

2. Holocarpic, i. e., without rhizoids, the individual consisting entirely of one or more centers.

3. Centers becoming presporangia, each one generating a cluster of sporangia................. Family 4 . Synchytriacea.

3. Centers proliferating, giving rise to linear series of sporangia.......... Family 5 . AghlyogetonaceA.

3. Each center becoming one sporangium..................... Family 6. Olpidiacea.

individual with light sporangia and dark resting cells with pitted walls; $\mathbf{h}$, branch of scxual individual, the oogonia larger and darker than the antheridia; $\mathbf{i}$, gametes. $\mathbf{j}-\mathbf{m}$, Allomyces Arbuscula after Hatch $(1935) ; \mathbf{j}$, k, gametes, x 1,000; $\mathbf{l}, \mathbf{m}$, mitotic figures in the gametangia, $\times 2,000$. n-r, Blastocladiella cystogena, $x 500$, after Couch and Whiffen (1942); n, individual producing a resting spore; o, resting spore germinating by release of numerous naked protoplasts; these become flagellate zoospores, p. which subsequently encyst; $\boldsymbol{\alpha}$, the protoplast of each cyst divides to produce four gametes; $\mathbf{r}$, young zygote with the flagella of both gametes. 


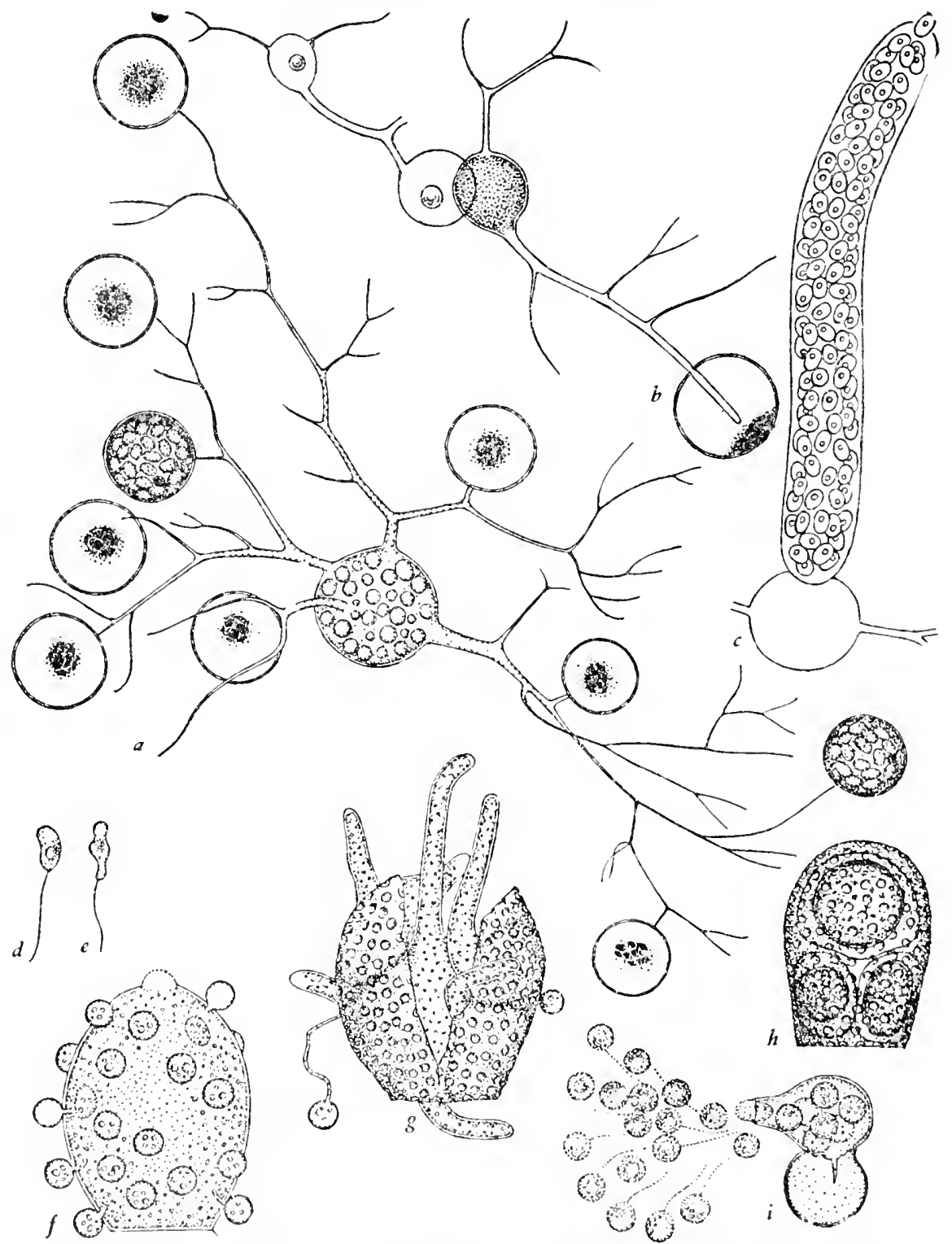

Fig. 23.-Cirrtrimnas: a-c, Polyphagus Euglenae attacking cells of Euglena, x 400, after Nowakowski (1876); in figure b, two individuals have made contact and a zygote is developing at the point of junction; c, sporangium. d-i, Olpidium Allomycetos attacking Alomyces anomalus, x 1,000, after Karling (1948); d, e, zoospores; $\mathbf{f}$, sporangium of the host beset with many parasites; $\mathbf{g}$, $\mathbf{h}$, resting cells of the host containing respectively sporangia and resting cells of the parasite; $\mathbf{i}$, germinatien of resting cell. 
1. Sporangia opening through opercula.

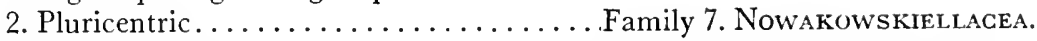

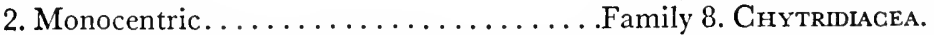

Family 1. Cladochytriacea [Cladochytriaceae] Schröter in Engler and Prantl Nat. Pflanzenfam. I Teil, Abt. 1: 80 (1892). Family Hyphochytriaceae (Cladochytriaceae) A. Fischer in Rabenhorst Kryptog.-Fl. Deutschland 1, Abt. 4: 131 (1892), in part. Family Physodcrmataceae Sparrow Aq. Phyc. 304 (1943). Pluricentric chytrids, the sporangia not operculate. The members of this family are of the same body type (designated by Karling, 1931, the rhizomycelium) as the anisochytrid Hyphochytrium and the Nowakowskiellacea of the present order. In most Cladochytriacea the rhizomycelium includes pairs of swollen cells ("turbinate organs") which give a false appearance of conjugation. There are some forty known species, mostly of two genera, Cladochytrium, saprophytic in vegetable remains, and Physoderma (including Urophlyctis), parasitic in higher plants. Sparrow $(1946,1947)$ discovered in certain species of Physodcrma an alternation of morphologically distinguishable generations, bcth on the same hosts; the generations are presumably haploid and diploid, but this has not been established by observation of syngamy and meiosis. Polychytrium grows well only on chitin (Ajello, 1948).

Family 2. Phlyctidiacea [Phlyctidiaceae] Sparrow in Mycologia 34: 114 (1942). Family Sporochytriaceae (Rhizidiaceae, Polyphagaceae) subfamily Metasporeae A. Fischer in Rabenhorst Kryptog.-Fl. Deutschland 1, Abt. 4: 85 (1892). Monocentric eucarpic chytrids, the centers developed at the ends of filaments which grow from the zoospores, sporangia without opercula.

These are the most familiar chytrids. There are more than one hundred species. Many are parasitic, on blue-green and green algae, diatoms, pollen grains, nematodes, and other minute fresh-water life; others are saprophytic, on cellulose, chitin, or keratin. Rhizophidium, the most numerous genus; Phlyctidium, Phlyctorhiza, Entophlyctis, Diplophlyctis, Loborhiza, etc.

Family 3. Rhizidiacea [Rhizidiaceae] Schröter in Engler and Prantl Nat. Pflanzenfam. I Teil, Abt. 1: 75 (1892). Family Sporochytriaccae (Rhizidiaccae, Poly'phagaceae) A. Fischer in Rabenhorst Kryptog.-Fl. Deutschland 1, Abt. 4: 85 (1892) and subfamily Orthosporeae op. cit. 124. Monocentric cucarpic chytrids, the zoospores enlarging and becoming centers, which in turn become sporangia or presporangia; the sporangia without opercula. A moderate number of species, parasitic on blue-green or green algae, flagellates, or diatoms; or chitinophilous, saprophytic in the shed exoskeletons of insects. Rhizidium, Siphonaria, Asterophlyctis, Polyphagus, etc. Polyphargus Euglenae Nowakowski (1876) is a classic example. The centers lie free in the water, parasitizing cysts of Euglena through freely branching and widely spreading rhizoids. Most centers act as presporangia. Syngamy occurs when a rhizoid from one center makes contact with another center. The protoplasm of the latter migrates into the tip of the rhizoid, which swells and becomes a resting spore.

Family 4. Synchytriacea [Synchytriaceae] Schröter op. cit. 71. Family Merolpidiaccae (Synchytriaceae) A. Fischer op. cit. 45. Holocarpic chytrids, the intramatrical cell unwalled in the vegetative condition, becoming a presporangium or a resting spore, either of which gives rise to a cluster of sporangia. Synchytrium, parasitic on higher plants; Micromy'copsis on Conjugatae.

Family 5. Achlyogetonacea [Achlyogetonaceae] Sparrow in Mycologia 34: 114 (1942). Chytrids without rhizoids, the intramatrical center proliferating and producing a linear series of centers, each of which becomes a sporangium without an 
operculum. Achlyogeton, in green algae, diatoms, and nematodes; of very much the appearance of certain Lagenidialea.

Family 6. Olpidiacea [Olpidiaceae] Schröter op. cit. 67. Family Monolpidiaceae (Olpidiaceae) A. Fischer op. cit. 20. Holocarpic chytrids, each individual a single intramatrical parasitic center, naked until the reproductive phase, when it becomes a sporangium without an operculum. Olpidium, attacking blue-green and green algae, diatoms, flagellates, Allomyces, Vampyrella, rotifers, and nematodes. Rozella, attacking Oomycetes and producing spiny resting spores, has been confused with certain Lagenidialea. The genera Sphaerita and Nucleophaga of Dangeard, including intracellular parasites of amoebas and Infusoria, have been placed in this family; it seems more probable that they should be placed among bacteria of family Rickettsiacea.

Family 7. Nowakowskiellacea [Nowakowskiellaceae] Sparrow in Mycologia 34: 115 (1942). Family Megachytriaccae Sparrow Aq. Phyc. 378 (1943). Pluricentric chytrids, the sporangia with opercula. A moderate number of saprophytes on material of green algae and higher plants. Nowakowskiella, Mcgachytrium, etc. Zygochytrium was described by Sorokin, 1874, as living on decaying insects, producing multiple operculate sporangia, and exhibiting a conjugation of filaments to produce zygotes much like those of Zygomycetes. It has apparently not been reobserved.

Family 8. Chytridiacea [Chytridiaceae] Cohn in Hedwigia 11: 18 (1872). Family Chytridieen de Bary and Woronin in Berichte Verhandl. Naturf. Gess. Freiburg 3 (Heft 2) : 46 (1864). Monocentric eucarpic chytrids, the sporangia operculate. Some fifty species, the majority parasitic on fresh water algae. Chytridium, etc. Catenochytridium, saprophytic in cast-off exoskeletons of insects. 


\section{Chapter IX \\ PHYLUM INOPHYTA}

\section{Phylum 5. INOPHYTA Haeckel}

Order Fungr L. Sp. Pl. 1171 (1753).

Hysterophyta Link, 1808.

Classes Fungi and Lichenes Bartling Ord. Nat. 4 (1830).

Regnum Mycetoideum Fries Syst. Myc. 1: lvi (1832).

Class Lichenes and section Hysterophyta with class Fungi Endlicher Gen. Pl. 11, 16 (1836).

Stamm Inophyta Haeckel Gen. Morph. 2: xxxvi (1866).

Subdivision Fungi Engler and Prantl Nat. Pflanzenfam. II Teil: 1 (1889).

Division Eumycetes Engler Syllab. ed. 3: 25 (1903).

Phylum Carpomycctcae Bessey in Univ. Nebraska Studies 7: 249 (1907).

Stamm Mycophyta Pascher in Beih. bot. Centralbl. 48, Abt. 2: 330 (1931).

Kingdom Mycetalia Conard Plants of Iowa iv (1939).

Phylum Eumycophyta Tippo in Chron. Bot. 7: 205 (1942).

Parasites and saprophytes without flagellate stages, the bodies filamentous, the wills containing no cellulose.

This group represents the conventional division or subdivision Fungi of the kingdom of plants, excluding, of course, the bacteria, Oomycetes, chytrids, and Mycetozoa. The name Fungi, used as a scientific name, is properly to be applied, by authority of Linnaeus, to an order. Agaricus campestris L. will be recognized as the standard species of the phylum and of the order.

Those who study Inophyta are accustomed to use, for soma and filament respectively, the terms mycelium and hypha. The walls of the hyphae are believed to consist of pectic material. A small percentage of chitin is usually present (Schmidt, 1936); cellulose is totally absent (Thomas, 1928; Nabel, 1939; Castle, 1945). The organism Basidiobolus, having hyphae walled with cellulose, is tentatively retained among Inophyta as an exception.

The multiplication and dissemination of those organisms is by spores, of various types, scattered in the air. Most Inophyta produce two or more kinds of spores, some of them asexually, others as features of a sexual cycle. Spores produced within cases are called endospores, and the cases sporangia. Other spores are produced externally, commonly by constriction of the ends of hyphae. Spores thus produced are called conidia, and the hyphae or other structures which bear them, conidiophores. Spores are commonly produced not directly on the mycelium but on macroscopic structures of various types, all of which may be called by the familiar term fruit. The common mushroom as we see it is a fruit; it is the temporary spore-producing structure of an organism whose soma consists of filaments living saprophytically in the soil below.

It is expedient to mention at this point the growths called lichens, which are traditionally treated as a taxonomic group, either subordinate to Fungi or of the same rank. Lichens are gelatinous or thallose growths, usually of an impure green color, common everywhere, terrestrial or epiphytic, as on stones, trees, or fence posts. The microscope, in the hands of de Bary and others, showed that they consist of cells of two types, colorless filaments like those of Inophyta, and pigmented 
cells of quite the character of those of certain algae. De Bary (in Hofmeister, 1866) concluded that some lichens are not organisms but combinations of totally diverse organisms. Presently (1868) he was convinced by the work of Schwendener, soon (1868) published under his own name, ". . . dass die Flechten sammt und sonders keine selbstständigen Pflanzen seien, sondern Pilze aus der Abtheilung der Ascomyceten, denen die fraglichen Algen-deren Selbstständigkeit ich also nicht bezweifleals Nährpflanzen dienen." In 1879 de Bary coined the term symbiosis to designate the association of different kinds of organisms. In de Bary's usage the term included parasitism; in general usage, it means association to mutual advantage. The lichens are a classic example of symbiosis.

Clearly, the group of lichens is not to be maintained; the algal components are known to have natural places among algae, and the inophyte components are to be assigned to their natural places among Inophyta, almost all in various orders of class Ascomycetes. This has already been done by Clements (1909) and Clements and Shear (1931). The numerous names which students of lichens have given to them are to be applied to the inophyte components.

Another common example of symbiosis involving inophytes is furnished by at least some of those which live on or in the tissues of higher plants without killing them (Kelley, 1950). They occur mostly on roots. Frank (1885) coined the term mycorhiza to designate the combination of roots and inophytes; it will be more convenient to hold that this term designates the inophyte component of the combination. Such mycorhizae as cover the growing tips of roots are helpful to their hosts by serving as agents of absorption.

Jones (1951) estimated the number of species of Inophyta as 40,000. This is surely an extreme underestimate. Martin (1951) gives reason for believing the number to be about as great as that of flowering plants, of the order of 300,000 .

The early classifications of "fungi," as by Persoon (1801) and Fries (1821-1832), were based on gross characters. They presented, along with recognizable groups whose names arc to be applied in order of priority, others which were mere random assemblages, and whose names are to be abandoned as nomina confusa. De Bary (in Hofmeister, 1866; 1884), having applied comparatively modem methods, cstablished a dozen groups (under German names). These, so far as they are retained in the present phylum, have bcen assembled as three classes distinguished by details of the sexual cycle. A fourth class, acknowledgedly artificial, is maintained for the accomodation of the numerous and important fungi whose sexual cycles are unknown. The termination -mycetes, of the names of the classes and also of various subordinate

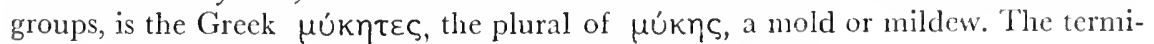
nation -mycetae which some authors have used is a solecism.

1. Reproducing sexually, or by apomictic processes clcarly of sexual origin.

2. The zygote becoming a thick-walled resting cell; fruits none or inconsiderable...... Class 1. Zygonycetes.

2. The zygote not becoming a thick-walled resting cell; mostly producing fruits.

3. The zygotes giving rise, usually indirectly, to sporangia called asci, cach typically containing cight spores called ascospores.............. Chass 2. Ascomycetes. 
3. The zygotes giving rise indirectly to conidiophores called basidia, each bearing typically four conidia

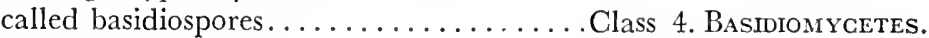

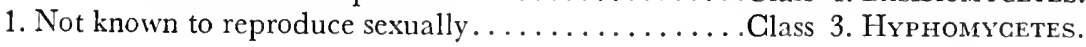

\section{Class 1. ZYGOMYCETES (Sachs ex Bennett and Thistleton-Dyer) Winter}

Zygomyceten Sachs Lehrb. Bot. ed. 4: 248 (1874).

Zrgomycetes Bennett and Thistleton-Dyer in Sachs Textb. Bot. English ed. 847 (1875).

Class Zygomycetes Winter in Rabenhorst Kryptog.-Fl. Deutschland 1, Abt. 1: $32(1879)$.

Order Zygomycetes Engler Syllab. 23 (1892).

Class Zygomyceteae Schaffner in Ohio Naturalist 9: 449 (1909).

Inophyta whose zygotes are thick-walled resting cells, in germination giving rise to spores indistinguishable from those produced asexually; hyphac usually without crosswalls; mostly not producing fruits. The standard species is Mucor Mucedo L.

Among the Inophyta as here limited, the Zygomycetes appear to be primitive (an alternative hypothesis, that certain Ascomycetes are primitive, will be discussed below). Traditionally, the Zygomycetes are associated with the Oomycetes. The association is probably mistaken, being based merely on similarity of body form: the Zygomycetes are terrestrial instead of aquatic, produce no flagellate cells, have no cellulose in their cell walls (except in Basidiobolus), and do not produce female gametes by the cutting out of cells within a cell. In later editions of Engler's Syllabus (1924), one finds most of the chytrids included among the Zygomycetes, instead of in their conventional place among the Oomycetes. The hypothesis thus suggested, that the Opisthokonta may represent the ancestry of the Inophyta, is attractive, but not to present knowledge supported by convincing evidence. Class Zygomycetes and phylum Inophyta must as yet be regarded as of unknown origin and treated as isolated.

There are some 500 known species of Zygomycetes. They form two orders. The bulk of the group, and the typical examples, are order Mucorina. A minority, distinguished by parasitism and by explosively discharged conidia, are order Entomophthorinea.

Order 1. Mucorina [Mucorini] Fries Syst. Myc. 3: 296 (1832).

Suborder Mucorineae Engler in Engler and Prantl Nat. Pflanzenfam. I Teil, Abt. 1: iv (1897).

Order Mucorineae Campbell Univ. Textb. Bot. 158 (1902).

Order Spirogyrales (presumably in part only) Clements Gen. Fung. 12 (1909). Order Mucorales Smith Crypt. Bot. 1: 405 (1938).

Order Zoopagales Bessey Morph. and Tax. Fungi 117 (1950).

The typical Zygomycetes, mostly saprophytic, not producing explosively discharged conidia (Pilobolus produces explosively discharged sporangia).

The asexual reproductive structures of the supposedly primitive Mucorina, as Mucor and Rhizopus, are solitary globular sporangia terminal on erect hyphae. In the developing sporangium, a dome-shaped basal sterile area, the columella, is set apart by cleavage followed by deposition of a wall. The protoplasm above the 


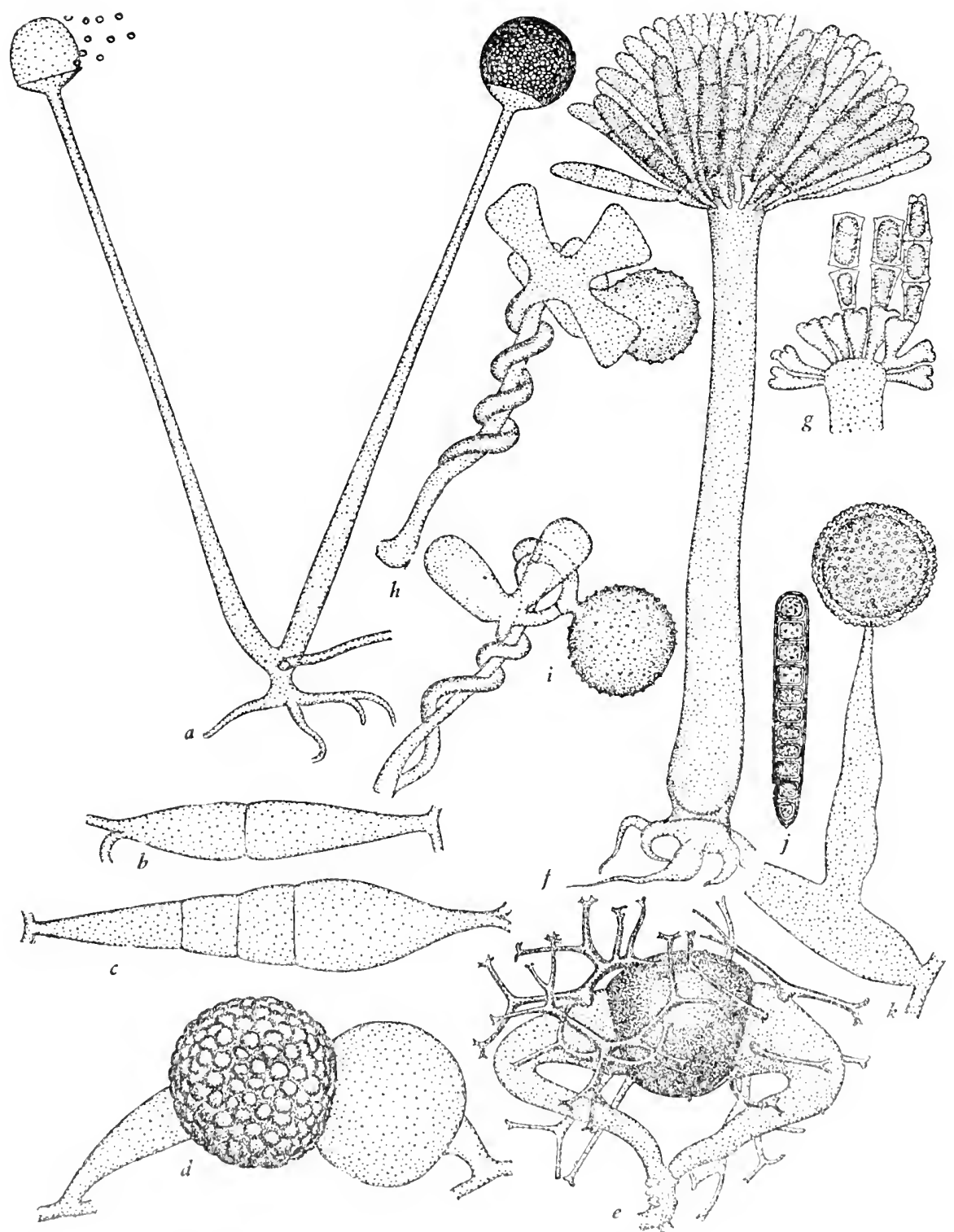

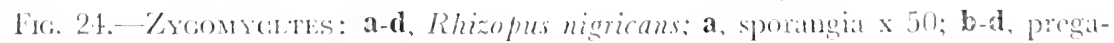

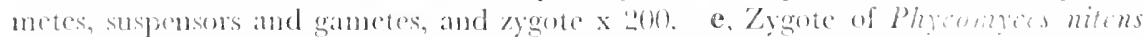
after Bbakestere $(1901)$. f, ge, Conidiophore with soung contiat, and mature conidia, of Syncethalis pycnosperma after Thaxter (1897). h, i. Comjugation of Syncethatis nodosa after thaxter, of. cit. j. Sposangium of sincephatestrum ras mosum after Thaxter, of cit. $\mathbf{k}$, Sporanginum of Haptosporengium lignicold after Martin $(1937), \times 1,(000)$. 
columella undergoes cleavage to form spores, which may remain plurinucleate (Swingle, 1903). Other members of the order exhibit transitions (apparently two distinct series of transitions) from sporangia as just described to typical conidia.

Syngamy occurs when the tips of pairs of hyphae meet and are cut off by crosswalls to act as multinucleate gametes. The process is regarded as conjugation, although the gametes of a pair are usually not of the same size. Conjugation does not occur at random, but, in most Zygomycetes, between branches from hyphae of two mating types, designated plus and minus (the distinction of mating types is not identical with the differentiation of sexes). Zygomycetes were the first group reproducing by conjugation in which a distinction of mating types was discovered; the discovery was by Blakeslee (1904).

Syngamy is preceded by a flare of mitoses in the gametes. The mitotic figures are sharp-pointed, as though centrosomes were present; the haploid chromosome number appears to be 2. The process is not meiotic (Moreau, 1913). After these divisions, the walls between the gametes break down and the nuclei unite in pairs. Unpaired nuclei, presumably contributed in excess by one gamete or the other, undergo dissolution (Keene, 1914, 1919). Ordinarily, the zygote enlarges and becomes a thickwalled resting spore; in some cxamples, the resting spore forms as an outgrowth on what was one of the gametes. In Phycomyces, Absidia, and Syncephalis, the hyphae which have produced the gametes, and to which the zygote remains attached, send out branches which form a layer about the zygote. These branches might be interpreted as making up fruits. Endogone produces definite fruits of considerable size.

A zygote germinates by production of a hypha bearing a sporangium (Blakeslee, 1906). Meiosis is believed to occur in the course of germination.

While Mucorina in general are saprophytic, some of them are parasitic on others, Piptocephalis and Chaetocladium on Mucor, and Parasitella on Absidia. Drechsler (1935, 1937) discovered a number of organisms apparently of this group parasitizing amoebas and nematodes in the soil.

The Mucorina may be treated as five families.

1. Not producing macroscopic fruits.

2. Not parasitic on amoebas or nematodes.

3. All spores produced in sporangia with columellae.............. Family 1. Mucoracea.

3. Not as above.

4. Producing sporangia or else conidia as outgrowths from a knob, homologous with a sporangium, solitary on an unbranched stalk............ Family 2. Piptocephalidacea.

4. Sporangia or conidia solitary and terminal on branches of a branched sporangiophore or conidiophore; sporangia, if produced, without columellae.... Family 3. Mortierellacea.

2. Parasitic on amocbas or nematodes........ Family 4. Zoopagacea.

1. Producing macroscopic fruits............ Family 5. Endogonacea.

Family 1. Mucoracea [Mucoraccae] Cohn in Hedwigia 11: 17 (1872). Mucorina whose spores are produced exclusivcly in sporangia with columellae solitary on unbranched sporangiophores. Mucor L., typified by M. Mucedo, is now limited to a 
small group mostly saprophytic on manure. Pilobolus, another coprophilous genus, is distinguished by sporangiophores which become swollen at the summit, bend toward the light, and discharge the sporangia violently to a distance of several meters. Rhizopus nigricans, the common black bread mold; Phycomyces, Absidia, Sporodinia, Zygorhynchus.

Family 2. Piptocephalidacea [Piptocephalidaceae] Schröter in Engler and Prantl Nat. Pflanzenfam. I Teil, Abt. 1: 132 (1893). Family Choanephoraceae Schröter op. cit. 131. Mucorina producing sporangia without columellae, or conidia, in compact clusters terminal on unbranched stalks. Blakesleea, transitional between the preceding family and this, may produce solitary sporangia with columellae, or else, as outgrowths from the primordia of sporangia, clusters of minuscule sporangia without columcllae. Cunninghamella, producing heads of globular conidia; Syncephalastrum, with clustered cylindrical sporangia; Syncephalis and Piptocephalis, producing clustered chains of conidia.

Family 3. Mortierellacea [Mortierellaceac] Schröter op. cit. 130. Family Chaetocladiaceae Schröter op. cit. 131. Mucorina whose sporangiophores or conidiophores are branched, the sporangia (without columellae) or conidia solitary and terminal on the branches. Thamnidium, Chaetocladium, Mortierclla, Haplosporangium.

Family 4. Zoopagacea [Zoopagaceac] Drechsler in Mycologia 27: 37 (1935). Mucorina parasitic in amoebas or nematodes, producing conidia. The hosts of Zoopagacea inhabit the soil and are infected by contact with hyphae or conidia. From the point of contact, a hypha grows into the host and gives rise to a mycelium; this is in some examples reduced to a single coiled cell. The host being killed, the parasite sends out hyphae which may produce conidia, usually in chains, or else may conjugatc and produce zygotes. Endocochlus, Cochlonema, Bdellospora, Zoopage, Acaulopage, Stylopage.

Family 5. Endogonacea [Endogonaceac] Paoletti in Saccardo Sylloge Fungorum 8: 905 (1889). Endogonei Fries. Mucorina saprophytic in soil or wood, producing macroscopic subterrancan fruits. The fruits may reach a diameter of $2 \mathrm{~cm}$. Within them, the tips of hyphae are cut off by crosswalls, and develop either into sporangia without columellae or into gametes.

\section{Order 2. Entomophthorinea [Entomophthorineae] (Engler) Campbell Univ.} Textb. Bot 161 (1902).

Suborder Entomopitthorineae Engler in Engler and Prantl Nat. Pflanzenfam. I Teil, Abt. 1: iv (1897).

Order Entomophthorales Smith Crypt. Bot. 1: 408 (1938).

Zygomycetes, mostly parasitic, producing cxplosively discharged conidia (Massostora, while clcarly belonging to the group, is an exception to the stated character).

These organisms, although of the gencral nature of ordinary Inophyta, exhibit cytological characters markeclly distinguishing the two familics from the generality of Inophyta and from each other. The position here given to them is the customary onc; it is cloubtful that it is natural.

Family 1. Entomophthoracea [Entomophthoraceac] Berlese and de Toni in Saccarclo Sylloge 7: 280 (1888). Most species are parasitic in the bodics of insects, whose tissues they replace. The hyphae become divided by crosswalls, and the multinucleate cells thus produced tend to round up and become separate. $A$ well-nourished ccll may send forth a hypha which reaches the outer air and whose tip is cut off and discharged in the direction of the light. Martin (1925) and Couch (1939) described 
the mechanism of discharge. The conidiophore ends in a columella projecting into the base of the conidium. The columella develops a double wall. Increasing pressure within the conidium causes a sudden eversion of the wall on the side of the conidium, and this movement throws the conidium forth to a distance of perhaps $1 \mathrm{~mm}$. Conidia which come down on unfavorable substrata may form and discharge secondary conidia.

Adjacent cells may conjugate, the thick-walled zygote forming either in one of them or as an outgrowth from one of them. Many examples produce thick-walled resting spores without conjugation.

Olive (1906) described the nuclei and the process of mitosis in Empusa. The resting nuclei are fairly large, $7-9 \mu$ in diameter. In the course of division, two stainresistant granules are seen, with strands of chromatin radiating from them. These move apart, while the nucleus becomes dumb-bell shaped. The nuclear membrane remains intact and division is completed by its constriction. As Olive remarked, the process is much as in Euglena.

Entomophthora, Empusa, and Massospora attack insects; the first produces zygotes, while the other two produce asexual resting spores; Massospora does not discharge the conidia violently. Conidiobolus and Delacroixia are saprophytic. Completoria attacks the prothallia of ferns. Ancylistes, a parasite in the green alga Closterium, was formerly included among chytrids or Oomycetes. Berdan (1938) showed that it belongs here: it produces conidia and zygotes quite of the character of the present group, and does not produce zoospores.

Family 2. Basidiobolacea [Basidiobolaceae] Engler and Gilg Syllab. ed. 9 u. 10: 45 (1924). Basidiobolus ranarum Eidam (1886) occurs in the intestinal contents of frogs and toads as uninucleate cells, solitary or in brief filaments, walled with cellulose. In manure the filaments develop into a scant branching mycelium. The protoplasm gathers in the ends of erect hyphae which are cut off as conidia and discharged. Conjugation occurs between adjacent cells of a filament. It is preceded by a single nuclear division in each gamete (Fairchild, 1897). In this process, the nuclear membrane disappears and the numerous minute chromosomes are found in a blunt-ended spindle without centrosomes. Each gamete form a papilla; one of the two nuclei enters the papilla, whose contents, after being cut off by a wall, die and disappear. The gametes and their nuclei unite and the zygote secretes a thick wall.

\section{Class 2. ASCOMYCETES (Sachs ex Bennett and Thistleton-Dyer) Winter}

Order Ascosporeae Cohn in Hedwigia 11: 17 (1872).

Ascomyceten Sachs Lehrb. Bot. ed. 4: 249 (1874).

Ascomycetes Bennett and Thistleton-Dyer in Sachs Textb. Bot. English ed. 847 (1875).

Class Ascomycetes Winter in Rabenhorst Kryptog.-Fl. Deutschland 1, Abt. $1: 32$ (1879).

Class Ascosporeae Bessey in Univ. Nebraska Studies 7: 295 (1907).

Class Ascomycetae Schaffner in Ohio Naturalist 9: 449 (1909).

Inophyta which produce, as a feature of the sexual cycle, sporangia called asci, in which the spores, called ascospores, typically eight in number, are delimited by the manner of cell division called free cell formation, i.e., in such fashion as to exclude a part of the cytoplasm. 
The hyphae of Ascomycetes are septate and the cells most often uninucleate.

Most Ascomycetes produce, beside the ascospores, conidia of one type or another. A mycelium may produce a mass of densely woven hyphae with conidia on the surface; such a mass is called an acervulus or sporodochium. Either a mycelium or an acervulus or sporodochium may send up spore-bearing columns called coremia.

Many Ascomycetes produce, either directly from the mycelium or from special structures consisting of interwoven hyphae, globular or flask-shaped structures which produce conidia internally and release them through a pore. These structures are called pycnidia, and the spores pycniospores. In many examples, the pycniospores are capable of functioning as sperms; so far as this is true, the pycnidia may alternatively be called spermagonia, and the pycniospores spermatia.

Hyphae woven into a mass may go into a resting condition, becoming thick-walled, hard, and usually dark in color. The resulting structure is a sclerotium. If a structure of the general nature of an acervulus, sporodochium, or sclerotium gives rise either to pycnidia or to fruits bearing asci, it is called a stroma.

As to asci and ascospores, Dangeard $(1893,1894,1907)$ reached definitely the conclusion that they are essentially sexual products. There had been earlier observations, beginning with de Bary, 1863, that there are meetings, coilings together, and fusions of hyphae as a preliminary to the production of asci. Many ascomycetes are of two mating types; this was first discovered of Glomerella, by Edgerton (1914). As Dodge (1939) remarks, the mating types are not sexes; in forms producing recognizable male and female reproductive structures, cach mating type may produce both.

In Ascomyeetes which may be regarded as primitive, differentiated male and female cells are produced. The male cell or antheridium is ordinarily terminal on a hypha. The female cell (constituting, together with other differentiated cells of the same hypha, if any are present, the ascogonium) mav be terminal; more often it bears an elongate cell, or a chain of cells, called the trichogyne, and having the function of reaching the antheridium. In some Ascomycetes, antheridia are produced, but syngamy does not take place; the egg is binucleate or multinucleate, and the nuclei within it take the part of gamete nuclei in further development. There are others in which no antheridia are produced. Hansen and Snyder (19.3) found, in Hypomyes Solani var. Cucurbitae, that "any part of the living thallus, ascospores, conidia or bits of the mycelium could act as the male fertilizing agent." There are forms in which fusions take place between undifferentiated hyphal cells; and yet others in which it appears that the paired nuclei involved in sexual processes arise by divisions of a single nucleus originally present in a spore.

In some Ascomycetes, syngamy is followed immediately by karyogamy, and the zygote develops directly into a single ascus. In the overwhelming majority of the group, asci are produced indirectly, and there is no fusion of nuclei until this takes place. The zygote sends out hyphac called ascogenous hyphae, recognizably different from the vegetative ones. The cells of the ascogenous hyphae are bimucleate; or, arising from a multimucleate zygote, become binucleate by the establishment of crosswalls. The two nuclei of each cell divide concurrently and the cell walls are so placed that each cell receives muclei of different origin. This effect is achieved in the final cell division before ascus formation by a peculiar process called crozier formation. The terminal cell of the ascogenous hypha beromes bent to the form of a hook; the nuclej divide concurrently, and cell walls appear between the daugliter nuclei of each pair; the midelle cell of the row of three thus produced remains binucleate and becomes an ascus. The uninucleate terminal and basal cells lie side by side, and may 
fuse to form a binucleate cell which may become an additional ascus, or else may grow forth and give rise to more asci than one.

The stage consisting of cells with two nuclei of different origin is called the dikaryophase. It is characteristic of Ascomycetes, and also of Basdiomycetes: among Inophyta, it is a normal and familiar thing. To a concept of cytology founded on studies overlooking the Inophyta, it would appear an extreme anomaly, almost an impossibility. It has the appearance of a rather awkward device for making cells genetically and physiologically diploid while the nuclei remain haploid. In most Ascomycetes it is a brief stage, but there are some, as Taphrina, whose mycelium consists prevalently of binucleate cells.

The detailed behavior of nuclei in the ascus was first described by Harper (1895, 1897, 1900) from studies of Peziza, Sphaerotheca, Erysiphe, and Pyronema. The two nuclei in the primordium of the ascus unite into one. The fusion nucleus divides three times, each time in much the same manner. A centrosome with astral rays is present at the nuclear membrane, apparcntly outside. It divides, and a spindle forms, irside the intact nuclear membrane, between the daughter centrosomes. The chromosomes appear and divide. As they move toward the poles of the spindle, the nuclear membrane collapses or dissolves, leaving the spindle free in the cytoplasm. The mass of chromatin at each pole of the spindle shreds out into a nuclear network, duly surrounded by a nuclear membrane and usually containing a nucleolus.

Haploid chromosome numbers of Ascomycetes (all of which have been observed in the ascus) include the following:

Ascoidea rubescens, fide Walker (1935) . . . . . . . . 2

Eremascus albus, fide De Lamater et al. (1953) . . . . . . 6

Glomerclla, fide Lucas (1946) . . . . . . . . . . . 4

Hyomyces Solani var. Cucurbitae, fide Hirsch (1949) . . . . 4

Lachnca scutellata, fide Brown (1911) . . . . . . . . . 5

Neurospora crassa, fide McClintock (1945) . . . . . . 7

Peziza domiciliana, fide Schultz (1927) . . . . . . . . 8

Phyllactinia corylea, fide Colson (1938) . . . . . . . 10

Pyronema confluens var. igneum, fide Brown (1915) . . . . . 5

Taphrina deformans, fide Martin (1940) . . . . . . . 4

According to Harper, when the third division in the ascus is complete, each of the eight nuclei produced by it thrusts forths its centrosome upon a beak. The astral rays of the centrosomes become recurved in the cytoplasm about the nucleus, and grow and multiply until they are converted into a smooth membrane, outside of which a wall is deposited. Most observers have not seen so much detail. Brown (1911) and Dodge (1937) describe the cell membrane of the ascus, apparently under the influence of the centrosome of each nucleus, as cutting into the cytoplasm in an ellipsoid pattern. In Taphrina (Martin, 1940), the cytoplasm of the spores is delimited simply by accumulation about the nuclei. By whatever process the ascospores are cut out. some of the cytoplasm of the ascus is excluded and left without nuclei. Harper (1899) proposed to limit the older term free cell formation to processes which have this effect; he observed that the occurrence of such processes distinguishes asci from the sporangia of Oomycetes and Zygomycetes, in which spores are cut out by cleavage.

Harper believed that a fusion of nuclei follows immediately the fusion of gametes; that the karyogamy observed in the ascus is a uniting of diploid nuclei, producing tetraploid nuclei; and that the characteristic three nuclear divisions in the ascus are necessary for reduction of the chromosome number from tetraploid to haploid. These 
hypotheses, long accepted as possible, were disproved by genetic studies by Betts and Meyer (1939) and Keitt and Langford (1941). In the asci of many species, the spores lie in a single series in which their order is determined by the divisions which produce their nuclei. By refined technique, the spores from a single ascus may be identified, separated, and cultivated. It is then observed that the mycelia grown from the first four spores may differ in some particular character from those grown from the second four spores; those from the first pair of spores may differ from those from the second; but those from two members of any of the pairs, first, second, third or fourth, are always alike. These observations mean that the first two divisions in the ascus constitute the meiotic process, the third being mitotic. Lucas (1946) obtained cytological evidence refined enough to confirm this conclusion.

Asci are almost always produced in fruits, which may be called ascocarps. The ascocarp aside from the asci arises usually from vegetative hyphae; in the Ascomycetes regarded as primitive, it does not begin to develop until after fertilization, but in the higher ones it may develop in advance of fertilization and become the seat of this process.

There are several types of ascocarps, among which three are most familiar. A small ascocarp completely enclosing the asci is a cleistothecium. Cleistothecia were formerly included under the term perithecium; that term will better be limited to small fruits which are globular or vase-like, opening through a single pore, the ostiole, and differing from the pycnidia already described in producing ascospores instead of conidia. A fruit in which the asci form a broad layer which is typically fully cxposed at maturity, the whole being ordinarily of the form of a disk or cup, larger than a cleistothecium or perithecium, is an apothecium.

Asci produced in perithecia or apothecia usually discharge the ascospores violently. The mechanism of discharge is apparently simply turgidity. Some asci show no visible adaptations for the discharge of spores; others have lids (opercula) whose position determines the direction of discharge. Certain large apothecia can throw the spores to a distance of $10-20 \mathrm{~cm}$; the discharge is so governed by temperature and humidity as to occur in gently moving rather than in still air. By blowing across these apothecia one can make them throw out a visible cloud of spores. Heald and Walton (1914) reviewed many older observations of violent discharge by perithecia, the oldest by Pringshcim on Sphacria Scirpi, 1858. Rankin, 1913, found that each ascus in turn breaks loose, comes up to the ostiole, projects through it, throws out its spores, and collapses to make room for another. Weimer (1920) found that the perithecia of Pleurage curvicolla bend toward the light and throw the spores to a maximum distance of $45 \mathrm{~cm}$., which is apparently the record.

There is a widcly entertained hypothesis that the Ascomycetes evolved from the red algae. It appears to have developed from a picce of classification by Sachs (1874), who proposed a class Carposporeen, to consist of the red algae, certain higher green algac, and the Ascomycetes and Basidiomycetes. A number of rescmblances support it. Both red algae and Ascomycetes include many parasites; both lack flagellate cells; both have differentiated gametes, the egg bearing a trichogync; in both, fertilization leads to further development before spores are produced. In addition to these genuine resemblances, an imaginary one was influential, namely the double fertilization ascribed to the red algac by Schmitz and to the Ascomycetes by Harpcr. Numerous as these rescmblances are, they are not now believed to indicate relationship. Atkinson (1915) formulated the counter-argument. The Ascomycetes rescmble the Mucorina in nutrition, in producing no flagellate cclls, and in multi- 
nucleate gametes. The germination of the zygote of the Mucorina, by the production of a hypha bearing a sporangium, rescmbles the prorluction of ascogenous hyphae by the zygotes of Ascomycetes. Two principal changes would convert Mucorina into Ascomycetes: the zygote should cease to be a resting spore, and cell division within the sporangium should be by frec cell formation. This could happen if the centrosomes of the ultimate nuclei of the sporangia were in control of cleavage, and if these nuclei were so far separated that considerable areas of cell membrane would lie beyond the influence of the centrosomes, with the effect that the cell membrane, furrowing in to delimit a spore around each nucleus, would leave some of the cytoplasm outside of all of the spores. The organisms listed below as the first order of Ascomycetes, Endomycetalea, are but poorly known, yet seem genuinely to represent the transition from Mucorina to typical Ascomycetes.

It is not yet possible to formulate a system of orders of Ascomycetes with the expectation that it will not be found to require much amendment ${ }^{1}$. The following will serve tentatively; excellent contemporary authority makes several orders each of the ones listed fourth, fifth, and seventh.

1. Ascus developed directly from the zygote (or apomictically from an unfertilized cell); not producing fruits......................... Order 1. Endomycetalea.

1. The zygote giving rise to filaments of cells with more than one nucleus, these producing the asci.

2. Producing fruits.

3. The fruits cleistothecia.

4. Asci scattered in the fruits; mostly saprophytes with branched conidiophores........... Order 2. Mucedines.

4. Asci in one cluster, or solitary, in the fruits; mostly parasites with unbranched conidiophores....... Order 3. Peris poriacea.

3 . The fruits, originally closed, opening by irregular pores or regular or irregular clefts.................. Order 4. Phiacidialea.

3. The fruits apothecia.............. Order 5. Cupulata.

3. The fruits perithecia.

4. Producing a normal mycelium....... Order 7. Sclerocarpa.

4. Parasitic on insects, the mycelium reduced................. Order 8 . Laboulbenialea.

2. Not producing fruits, the asci arising directly from the mycelium................. Order 6 . Exoascalea.

Order 1. Endomycetalea [Endomycetales] Gäumann Vergl. Morph. Pilze 135 (1926).

Subclass Hemiasci Engler Syllab. 26 (1892).

1Luttrell (1951) has presented a complete reorganization of the class. He sets apart as a major subordinate group Bituricatae five orders in which the ripe ascus exudes a vesicle and discharges the spores from this. 
Subclass Hemiasci or Hemiasccae, with suborder (Unterreihe) Hemiascineae. and suborder Protoascineac of subclass Euasci, Engler in Engler and Prantl Nat. Pflanzelfam. I Teil, Abt. 1: iv (1897), the names not based on those of gencra.

Order Protoascineae Campbell Univ. Textb. Bot. 165 (1902).

Order Hemiascales Engler Syllab. ed. 3: 28 (1903).

Ascomycetes whose asci develop directly from the zygotes. Two families may be recognized.

Family 1. Endomycetacea [Endomycetaceae] Schröter in Engler and Prantl Nat. Pflanzenfam. I Teil, Abt. 1: 154 (1894). Family Ascoideaceae Schröter op. cit. 145. Mostly saprophytes, the uninucleate or multinucleate cells of the filaments tending to round up, bccome separate, and function as conidia; the zygotes, produced by syngamy of scarcely differentiated cells, enlarging and becoming asci of 4, 3, or many spores cut out by free cell formation. Dipodascus, Eremascus, Endomyces, Ascoidca. The asci of the last are apparently produced asexually (Walker, 1935).

The genus Protomyees requires mention. It is a parasite on higher plants, producing walled resting spores which germinate by producing a sporangium of many spores. It is chytrid-like, but its spores are non-motile. Its proper place in classification has for a long time been a puzzle.

Family 2. Saccharomycetacea [Saccharomycctaceac] (Rees) Schröter op. cit. 153. Class and family Saccharomycetes Winter in Rabenhorst Kryptog.-Fl. Deutschland 1, Abt. 1: (1879). Unicellular, reproducing by budding, i.e., by production upon the cells of outpocketings which are pinched off as additional cells, or by a sexual cycle in which endospores are produced, usually by fours.

These are the organisms which are in English called yeasts. The common breadand beer-yeast called Saccharomyees cercvisiac has a good claim to be considered, economically, the most important of all "fungi." Its metabolism, in which dextrose is converted to alcohol and carbon dioxide, gives a superficial appearance of simplicity, and has attracted much study, contributing much to an mderstanding of the genuine intricacy of energesis.

In addition to agents of fermentation, this family includes pathogens causing chronic infections of animals. These have been treated as a genus Torula, Torulopsis, Blastodema, or Cry'ptocoecus. They have not been observed to produce cndospores.

Order 2. Mucedines Fries Syst. Myc. 3: 380 (1832).

Order Gimnoascaceae Winter in Rabenhorst Kryptog-Fl. Deutschland 1, Abt. 2: $3(1887)$.

Suborder Plectascineae Engler in Engler and !rantl Nat. Pfamzenfam. I Teil, Abt. 1: v (1897).

Order Plectascincae Campbell Univ. Textb. Bot. 169 (1902).

Order Aspergilliales Bessey in Univ. Nebraska Sudies 7: 301 (1907).

Order Cimmaseales Cilemens Cien. Fung. 93 (1909).

Order Plectaseales Gämmann V'erol. Morph. l’ilze 16t (1926).

Ascomycetes producing cleistothecia in which the asci are scattered; mostly saprophytic and producing branched conidiophores.

The name Mucedines means molels. Under this mame Fries listed twelve genera, with Asfergillus link and l'enicillium link first. The former is the cvident standard gemus of the order. Both genera are very common and numerous in species. They are readily recognized muer the microseope by the forms of their clusters of conidia. 
The conidiophore of Aspergillus ends in a globular swelling from which spring many radiating rows of conidia, with the effect that the entire mass, ycllow, brown, black, pink, or red in color, is globular. Penicillium has a branching conidiophore bearing rows of conidia in a broom-like mass. The masses are usually blue or green, and are familiar on cheese, jam, bread, cardboard, oranges, or almost any organic material.

Particular species of Penicillium are involved in the making of genuine Camembert and Roquefort cheeses. The genus has become best known for the production by P. notatum of the drug penicillin. In 1929, Dr. Alexander Fleming of London noticed that a mycelium of this species, growing as a contaminant on a plate of bacteria, interfered with the growth of the latter. This observation led to the discovery of a substance clinically useful against actinomycetes, spheres, and Gram positive rods, but not against Gram negative rods. Production was for several years very scant, and the drug expensive accordingly; in the early 1940's, as a war measure, the United States financed large scale production along with the appropriate scientific study (Elder, 1914: Committee on Medical Research, Washington, and the Medical Research Council, London, 1945). Several forms of penicillin have been recognized; they differ in the radicle $\mathrm{R}$ in the formula $\mathrm{G}_{9} \mathrm{H}_{11} \mathrm{O}_{4} \mathrm{SN}_{2} \mathrm{R}$. The structural formula is believed to be as follows (Editorial Board of the Monograph on the Chemistry of Penicillin, 1947):

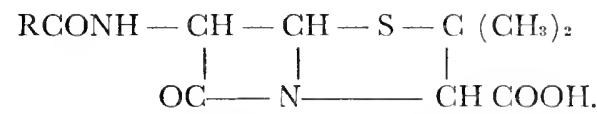

The sexual reproduction of Aspergillus and Penicillium involves the syngamy of differentiated cells. The zygote sends out ascogenous hyphae which bud off scattered asci; the neighboring cells send out hyphae which become woven into a minute firm-walled cleistothecium enclosing them.

Link, who named Aspergillus and Penicillium, gave to the ascocarp-producing stage of Aspergillus the name Eurotium. There is a rule of botanical nomenclature which allows only a tentative status to names given to the conidium-producing stages of inophytes. Thom and his associates $(1926,1945)$, in presenting a workable system of the species of Aspergillus, remarked that "It is better to forget Eurotium along with the technicality."

This order includes a variety of other molds: Gymnoascus, producing only a loose weft of hyphae about the asci; Ctenomyces, on feathers, recognized by comblike outgrowths from the loosely woven ascocarps; Monascus, its name a misnomer, the minute fruit containing many asci; Onygena, saprophytic on horns and hoofs, producing puffball-like fruits as much as $1 \mathrm{~cm}$. high; Elaphomyces, forming a mycorrhiza on roots of conifers and producing hypogaeous fruits as large as walnuts.

Order 3. Perisporiacea [Perisporiaceae] Fries Syst. Myc. 3: 220 (1829).

Order Perisporia Fries op. cit. 1: xlviii (1832).

Suborder Perisporiaccae Winter in Rabenhorst Kryptog.-Fl. Deutschland 1, Abt. 2: 21 (1887).

Subsuborder (Underordnung) Perisporiales Engler in Engler and Prantl Nat. Pflanzenfam. I Teil, 1: v (1897).

Order Perisporiales Bessey in Univ. Nebraska Studies 7: 295 (1907).

Ascomycetes producing cleistothecia containing a compact cluster of asci or a solitary ascus; mostly parasites producing unbranched conidiophores. 


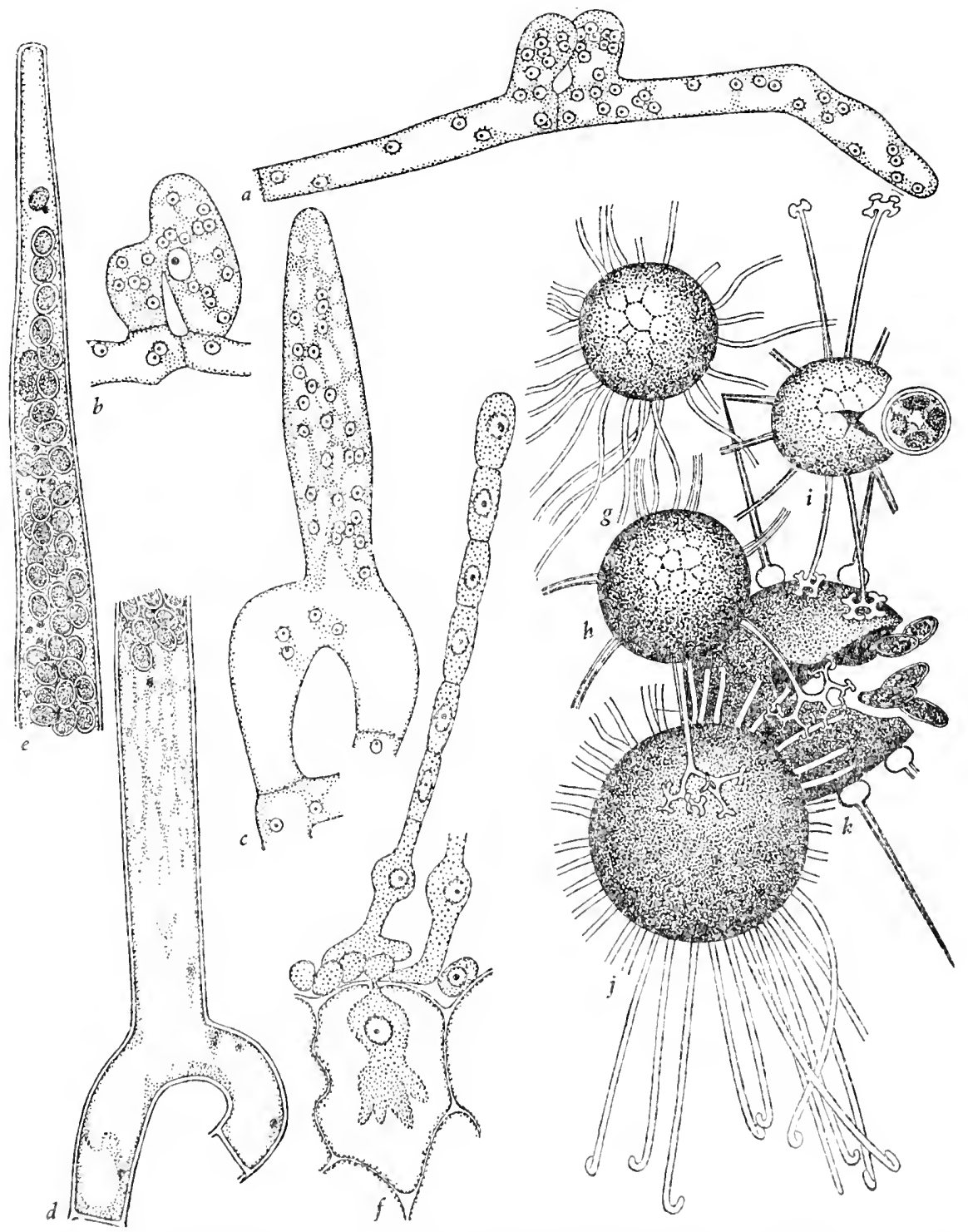

Fig. 25.-Ascomycetes: a-e, Dipodascus albidus after Juel (1902). x 1,000; $\mathbf{a}$, gametes; b, syngamy; $\mathbf{c}$, development of ascus; $\mathbf{d}, \mathbf{e}$, lower and upper parts of a mature ascus. f, Erysiphe graminis, haustorium penetrating an cpidermal cell of a grass and conidiophore bearing a chain of conidia $\times 500 . \mathrm{g}-\mathbf{k}$, Clcistothecia of Perisporiacea x 100: g, of Erysiphe sp.; $\mathbf{h}$, of Microsphaera sp.; i, of Podosphacra sp.; $\mathbf{j}$, of Uncinula sp.; $\mathbf{k}$, of Phyllactinia sp. 
The more familiar Perisporiacea are those of family Erysiphea [Erysipheae] Winter. They are parasites on plants, mostly producing a white mycelium on the surface and sending brief haustoria into the epidermal cells. They produce abundant conidia in erect unbranched chains; this habit explains the common name of powdery mildews. Harper's important studies of the morphology of Ascomycetes were in large part made on powdery mildews. The gametes are uninucleate and unite directly, the egg bearing no trichogyne; the ascogenous hyphae are brief; each minute black globular cleistothecium bears an equatorial whorl of appendages of a form characteristic of the genus. In Erysiphe and Sphaerotheca ( $S$. pannosa is the common rose mildew), the fruits bear unbranched sinuous appendages like vegetative hyphae; the fruit of Erysiphe contains several asci, while that of Sphaerotheca contains one. In Microsphaera (M. Alni is the powdery mildew of lilac) and Podosphaera, the appendages are dichotomously forked near the tip; the fruit of Microsphaera contains several asci, that of Podosphacra only one. The appendages of Uncinula are hooked at the tip. Those of Phyllactinia are like sharp spikes with bulbous bases.

Other Perisporiacea, parasitic or saprophytic on plant material, are comparatively poorly known. The fruits may bear appendages of other characters than those of the Erysiphea, or none, and may be characteristically clustered or borne in stromata. In some examples the fruits have no definite dehiscence mechanism; in others they open by deliquescence or by a separation of plates. Some open by a single pore, and appear transitional to those of order Sclerocarpa; some open by a cleft, or by lobes separated by radiating clefts, and appear transitional to those of order Phacidialea.

Order 4. Phacidialea [Phacidiales] Bessey in Univ. Nebraska Studies 7: 298 (1907).

Phacidiacei Fries Syst. Myc. 1: li (1832).

Order Hysteriaceae and suborders (of order Discomycetes) Phacidiaceae, Stictideac, and Tryblidieae Rehm in Rabenhorst Kryptog.-Fl. Deutschland 1, Abt. 3: 1, 60, 112, 191 (1896); the ordinal name preoccupied by family Hysteriaceae Saccardo.

Suborders Phacidiineae and Hysteriincae Engier in Engler and Prantl Nat. Pflanzenfam. I Teil, Abt. 1: v (1897).

Orders Graphidiales and Hysteriales Bessey op. cit. 298, 303.

Order Hemisphaeriales Theissen in Ann. Myc. 11: 468 (1913).

Order Microthyriales Clements and Shear Gen. Fung. ed. 2: 94 (1931).

Ascomycetes producing fruits which are not typical cleistothecia, apothecia, or perithecia.

This group is here used as a catch-all for three or more distinct groups, which appear to form cross-connections among orders Perisporiacea, Cupulata, and Sclerocarpa. This appearance suggests the probability that the present group, and the usually accepted orders assembled under it, are not natural, but represent parallel developments from several sources. The present groups include moderately numerous ordinary parasites and saprophytes, together with great numbers of lichen-formers. Only the latter are common and familiar in temperate countries. There has been little study of the morphology.

The families which appear tenable are distinguished as follows:

a. Fruits minute and flattened, usually releasing the spores through one or more pores or clefts (Order Hemisphaeriales Theissen, Microthyriales Clements and Shear). 
Family Microthyriacea [Microthyriaceae] Lindau (in Engler and Prantl, 1897). Parasitic on plants, surfaces of the fruits marked by radiating ridges.

Family Micropeltidacea [Micropeltidaceae] Clements and Shear (1931). Family Hemisphaeriaceae Theissen (1913), not based on a generic name. Like the foregoing, but the surface of the fruit not radiate or radiate only at the margin.

Family Trichothyriacea [Trichothyriaceae] Thessen and Sydow. Parasitic on inophytes, the mycelium a pseudoparenchymatous layer, asci pendant within the fruits from the apparent summit.

b. Fruits elongate, hard, dark, opening by a narrow cleft (suborder HysterineaE Engler).

Family Hysteriacea [Hysteriaceae] Saccardo Sylloge 2: 721 (1883). Parasitic on higher plants or saprophytic.

Family Graphidiacea [Graphidiaceae] Clements (1909). An enormous group of lichens or parasites on lichens, largely tropical and chiefly crustose, the opcnings of the fruits forming dark lines.

c. Fruits not as above, mostly with a roundish area of asci exposed by the irregular or stellate shattering of a superficial layer; if long and narrow, not hard and dark (Suborder Phacidineae Engler).

Family Phacidiea [Phacidieae] Saccardo Sylloge 8: 705 (1889). Phacidiaceae Saccardo (1889). Family Phacidiaceae Lindau (in Engler and Prantl, 1896). The dark fruits thin and weak laterally and below.

Family Tryblidacea [Tryblidaceae] Rehm (in Rabenhorst, 1896). The dark fruits hard and thick laterally and below.

Family Stictea [Sticteae] Saccardo Sylloge 8: 647 (1889). Stictaccae Saccardo (1889). Family Stictidaceae Lindau (1896). Fruits light-colored or white. Higgins (1914) found that the agents of the shot-hole disease of plums and cherries, which, on the basis of non-fruiting stages, have been called Cylindrosporium Pruni, produce on fallen leaves ascocarps distinguishable as three species of the genus Coccomyces of the present family.

\section{Order 5. Cupulata [Cupulati] Fries Syst. Myc. 1: 2 (1821).}

Order Mitrati Fries 1. c.; order Uterini Fries op. cit. 1: liii (1832).

Family Discomycetes Fries Epicrisis 1 (1836).

Orders Discomycetes and Tuberaccae Winter in Rabenhorst Kryptog.-Fl. Deutschland 1, Abt. 2: 3 (1887).

Suborders Helcuellineac, Pezizincac, and Tuberincae Engler in Engler and Prantl Nat. l'flanzcnfam. I Teil, Abt. 1: v (1897).

Orders Helevellineae, Pezizineae, and Tuberincae Campbell Univ: Textb. Bot. $166,167,168$ (1902).

Orders Pezizales, Discolichenes, Helvellales, and Tubcrales Bessey in Univ. Nebraska Studies 7: 299, 300, 303, 301 (1907).

This order includes primarily the cup fungi, the inophytes which produce cupor elisk-shaped fruits beatring a single layer of closcly packed asci on the inner or upper surface. There has been much study of some of them, notably of Pyronema, by Harper, Dangeard, Clanssen, and Brown. The disk-chaped flesh-colored apothecia of Pyronema, 1-3 $\mathrm{mm}$. in cliancter, are found particularly on damp charcoal. The mycelinm produces differentiated multinucleate antheridia and ascogonia, the latter bearing one-eclled multinucleate trichogynes. After syngamy, or sometimes without it, but always to the best of our knowledge without any fusion of nuclei, the ascogonia 
send out branching filaments which become septate in such fashion that the ultimate cells are binucleate. These cells form croziers and produce asci. During the development of the ascogenous hyphae, other hyphae, more slender, grow up from the vegetative mycelium; these produce a disk of undifferentiated cells below the layer of asci, and send up sterile hairs (paraphyses) among them.

Gäumann (1926) divided the families of this group into two series by the presence or absence of a differentiated operculum at the summit of the ascus. The names being put into neuter form, and family Tuberacea being added, the lists are as follows:

Inoperculata: Patellariacea, Dermateacea, Bulgariacea, Cyttariacea, Mollisiacea, Helotiacea, Geoglossacea, Tuberacea.

Operculata: Rhizinacea, Pyronemacea, Ascobolacea, Pezizacea, Helvellacea.

Along with these, Clements and Shear (1931) list eight families of lichen-formers, some of them very numerous.

Families Pezizacea and Ascobolacea include the ordinary cup fungi. They are mostly saprophytes in soil or on manure, and do not usually produce conidia. Peziza was listed by Fries first in order Cupulata; it is the evident standard genus of the order.

Families Dermateacea and Helotiacea include many parasites on plants. One of the Helotiacea is Sclerotinia cinerea, the agent of the brown rot of stone fruits. As an active parasite it produces conidia of a type which, if the fruits were unknown, would place it in the genus Monilia. These spread the disease rapidly. The killed fruits fall and the organism lives in them as a saprophyte, replacing their tissues with a hard black mass of hyphae, a sclerotium. This survives the winter and in spring sends up stalked white apothecia.

The Helvellacea have been treated as a separate order, but are not sufficiently numerous and distinct to justify this treatment. They are saprophytes in soil, producing large stalked apothecia bearing an extensive layer of asci which is everted and wrinkled. The most familiar genera are Elvella and Morchella. The fruits are edible, indeed delicious; they should be boiled briefly, then creamed and served on toast. When found in abundance they should be preserved by drying for use throughout the year.

The Tuberacea, the truffles, also usually treated as a distinct order, produce underground fruits which appear to be apothecia distorted and rolled into balls. They are associated with particular species of trees on which the mycelia are believed to live as mycorhizae (Dangeard, 1894). The asci commonly contain reduced numbers of spores. The fruits are prized by gourmands.

The relationships of the Cupulata are a puzzle. Pyronema could be interpreted as representing an evolutionary transition from the order Mucedines to this. Certain parasitic cup fungi produce minute apothecia, hard, dark, and nearly closed, suggesting a transition to order Sclerocarpa. Some species, particularly among the parasites and lichen-formers, seem to intergrade with order Phacidialea, and thence again both to Mucedines and Sclerocarpa. The operculate asci which mark a part of the group occur also in other orders. Thus there is among Ascomycetes an appearance of reticulate relationships, such as reputable naturalists of the past supposed to exist in many groups. The appearance is of course lllusory; sufficient study of other groups has made it possible to distinguish the resemblances among them which indicate relationship from those which are results of parallel evolution. The study of the Ascomycetes has not yet been carricd this far. 


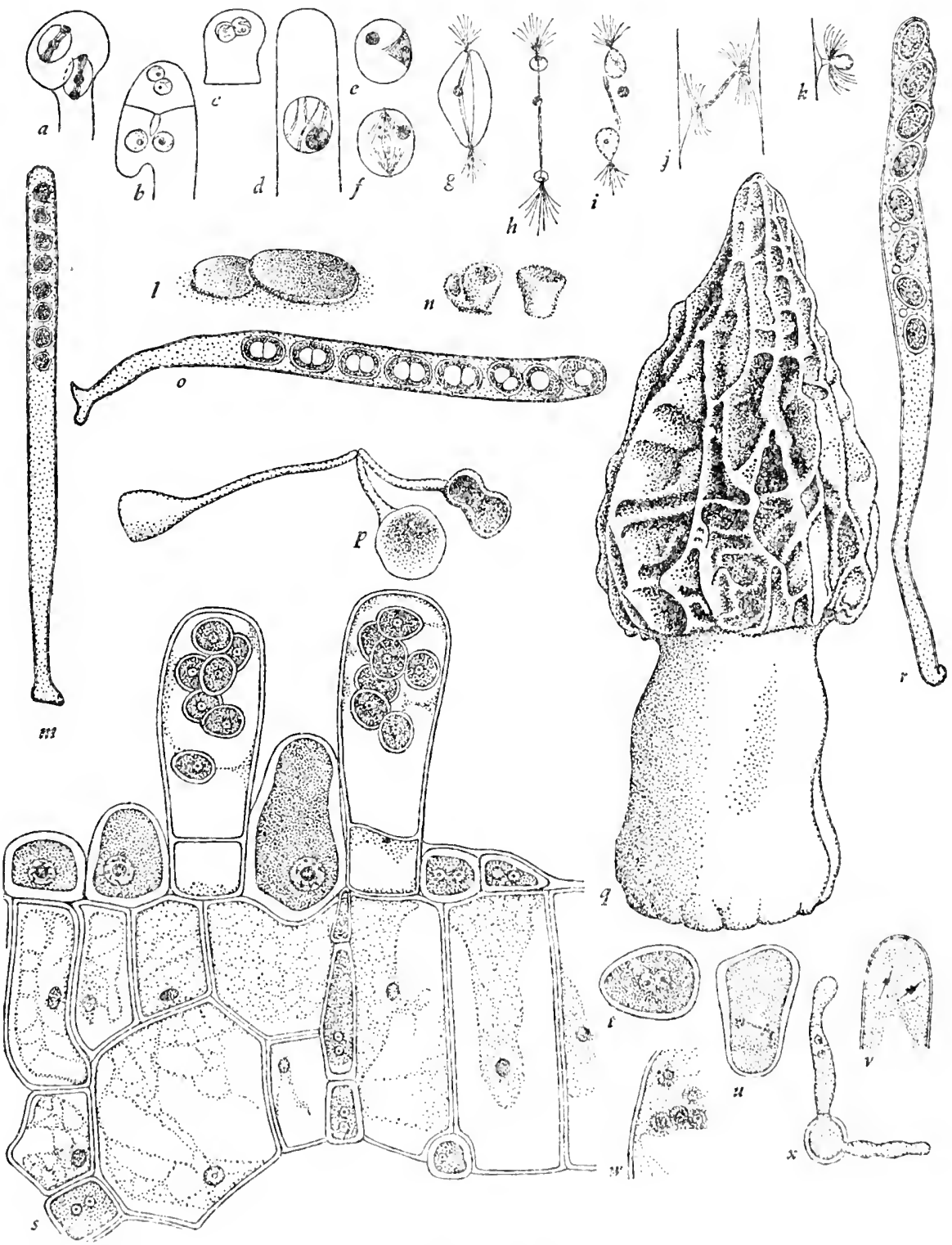

Fig. 26.-Asconycetes: a-k, Lachnca scutcllata after Brown (1911) x 1,000; $\mathbf{a}, \mathbf{b}$, formation of crozicr; $\mathbf{c}$, karyogany; $\mathbf{d}$, fusion mucleus; e-i, stages of meiosis; $\mathbf{j}$, $\mathbf{k}$, carly stages of free cell formation. $\mathbf{l}, \Lambda$ pothecia $\times 2$, and $\mathbf{m}$, ascus $\times 250$, of Lamprospora lciocarpa. $\mathbf{n}$, Apothecia $\times 2$, and $\mathbf{0}$, ascus $\times 250$, of Aleuria rutilans. $\mathbf{p}$, Apothecia of Sclerotinia cinerea $\times 2$. q, Fruit $\times 1$, and $\mathbf{r}$, ascus $\times 250$, of Morchella conica. S-x, Taphrina deformans after Martin (1940) x 1,000; s, growth on surface of an infected leaf; $\mathbf{t}$, karyog:mny; $\mathbf{u}$, mitosis; $\mathbf{v}$, homcotypic anaphase in the ascus; $\mathbf{w}$, development of ascospores; $\mathbf{x}$, germination. 
Order 6. Exoascalea [Exoascales] Bessey in Univ. Nebraska Studies 7: 305 (1907).

Suborder Protodiscineae Engler in Engler and Prantl Nat. Pflanzenfam. I Teil, Abt. 1: v (1897), not based on a generic name.

Order Protodiscineae Campbell Univ. Textb. Bot. 166 (1902).

Order Agyriales Clements and Shear Gen. Fung. ed. 2: 141 (1931), in part.

Ascomycetes parasitic on plants, producing no fruits but a broad layer of asci directly on the mycelium.

The leaves of the hosts of these parasites become swollen and distorted; the diseases recognized by these symptoms are called curly-leaf diseases. The most familiar is the curly-leaf of peaches, caused by Taphrina (Exoascus) deformans. Many others are known. The agents of all of these diseases may be regarded as a single family Exoascacea [Exoascaceae] Schröter (in Engler and Prantl, 1894), and all are commonly treated as a single genus, Taphrina Fries, typified by $T$. aurea on poplar trees; there are differences among them which might well be treated as of generic rank.

Clements and Shear associated the curly-leaf parasites with a collection of saprophytes producing small and undifferentiated disk-like or indefinite fruits, as Pyronema, Ascocorticium, and Agyrium; and offended against the principles of nomenclature by re-naming the order Agyriales. It is probable that something of the nature of Agyrium may represent the transition from order Cupulata to this one.

Martin (1940) described the cytology of Taphrina deformans. The mycelium grows between the cells of the host, not penetrating them. It is a dikaryophase mycelium, the cells binucleate, the nuclei dividing concurrently, cell division occurring in such fashion as to separate the daughter nuclei of each pair. In preparation for reproduction, hyphae of short round cells form a single layer between the epidermis and the cuticle of the host. In each cell of these hyphae, the nuclei unite and then divide. The division is mitotic, the fusion nuclei and the daughter nuclei having each eight chromosomes. The ccll divides, by a wall parallel to the surface of the leaf, into two. The daughter cell which lies against the tissues of the host dies, and its wall becomes empty; the other cell grows and bursts through the cuticle of the host and becomes an ascus. Its nucleus divides three times; the first two divisions are the meiotic process, and the chromosome number is reduced to four. Cytoplasm accumulates around each of the resulting eight nuclei and is presently cut out by a membrane and a wall. No centrosome is evident at any stage of the process. The spores germinate by sending out buds, as yeasts form buds; sometimes they do this before being discharged from the ascus. So far as Martin could determine, the binucleate condition of the mycelium is established by division of the nucleus of the spore from which it grows.

Order 7. Sclerocarpa [Sclerocarpi] Persoon Syst. Meth. Fung. xii (1801).

Order Pyrenomycctes Fries Syst. Myc. 2:312 (1822); order Uterini, suborder Pyrenomycetes Fries op. cit. 1: li (1832).

Family Pyrenomycetes Fries Epicrisis 1 (1836).

Order Pyrenomycetes, suborders Hypocreaceae, Sphaeriaceac, and Dothideaceae, Winter in Rabenhorst Kryptog.-Fl. Deutschland 1, Abt. 2: 18, 82, 152, 893 (1887).

Suborder (Unterreihe) Pyrenomycetineae, sub-suborders (Untcrordnungen) Hypocreales, Dothideales, and Sphaeriales Engler in Engler and Prantl Nat. Pflanzenfam. I Teil, Abt. 1: v, vi (1897). 
Order Pyrenomycetales Bessey in Univ. Nebraska Studies 7: 295 (1907).

Orders Hyocreales, Sphacriales, and Dothidcales Gäumann Vergl. Morph.

Pilze 222, 253, 284 (1926).

Ascomycetes producing, from a normal mycelium, perithecia, i. e., small fruits of the shape of a small globe or flask opening through a single pore, the ostiole. Sphaeria, which Persoon and Fries listed first under the names which they respectively used, is the evident standard genus; but this genus has become broken up and lost in the work of subsequent scholars.

This order includes very many species and is by the generality of authority divided into three. Forms whose perithecia are borne directly on the mycelium, together with those whose perithecia are borne in or on but distinct from a dark

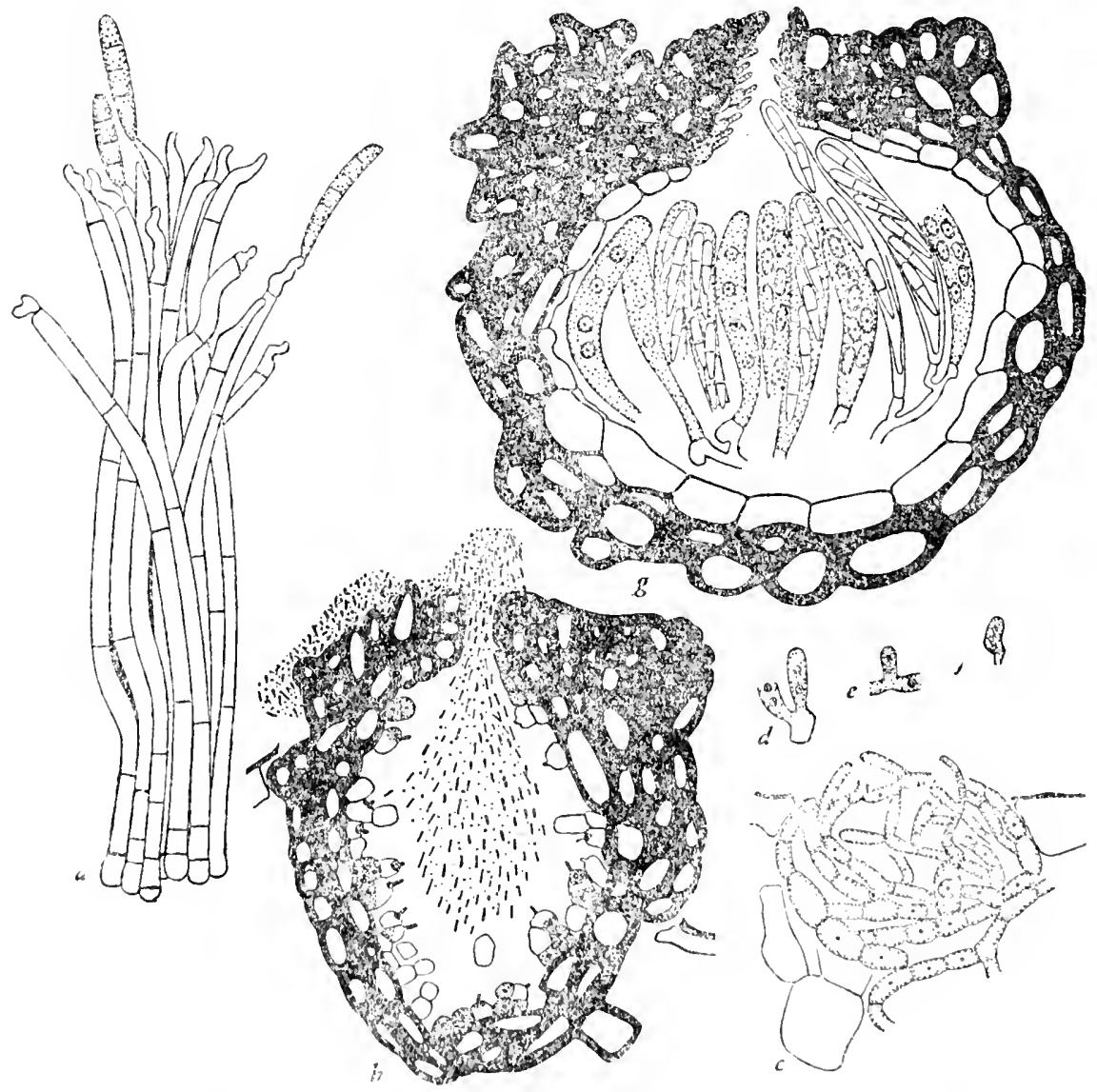

Fig. 27.-Myeosphaerella personata after I higgins (1929), x 1,000; a, conidiophores and conidia of Cereospora type. b, longitudinal section of pycnidium: c, primordium of perithecium with ascogonoium bearing a trichogync; d, e, ascogenous hyphae; $\mathbf{f}$, crozier formation; g, longitudinal section of mature peritliecium. 
stroma, are assigned to order Sphaeriales. Forms with perithecia in or on a brightly cclored stroma are Hypocreales. Those whose perithecia are cavities with a wall indistinguishable from a dark stroma are Dothideales. These groups are not confidently acceptable as natural: the stromatic Sphaeriales (Wehmeyer, 1926), the Hypocreales, and the Dothideales appear each to include more than one line of descent from Sphaeriales with solitary perithecia.

As a general rule, each perithecium develops in consequence of a separate act of fertilization, of a differentiated ascogonium, either by an antheridium, a spermatium, or otherwise.

Gäumann recognized fourteen families in the present group or groups. To these are to be added a great number of lichen-formers, properly Sphaeriales and Hypocreales, but construed as a single family Verrucariacea; and a smaller number, representing the Dothideales, and called Mycoporacea.

Exmples include the following:

Among Sphaeriales with solitary perithecia, Mycosphaerella is a genus of more than one thousand parasites on plants, mostly inconspicuous, causing leaf spots. Their conidia are of various types, Septoria, Phleospora, Ramularia, Cercospora. $V$ enturia, another numerous genus, includes $V$. inaequalis, causing apple scab; its conidia are of a type called Fusicladium.

Four species of Neurospora were discovered by Shear and Dodge (1927) as the fruiting stages of a red mold on bread called Monilia sitophila. Genetic study of this genus particularly by Tatum, Beadle, and their associates (Ryan, Beadle, and Tatum, 1943; McClintock, 1945; Beadle and Tatum, 1945; Tatum and Bell, 1946; Mitchell and Houlahan, 1946; Tatum, Barratt, Fries, and Bonner, 1950) has yielded results of the highest theoretical significance. Normal cultures require no other food than minerals, carbohydrate, and a single vitamin, biotin (Butler, Robbins, and Dodge, 1941). Either spontaneously or under violent treatment (with x-rays, ultra-violet radiations, or mustard gas) the cultures give rise to many mutations, behaving as Mendelian recessives, each consisting of the inability to synthesize some one vitamin or amino acid. These observations mean that life in its aspect of metabolism consists of unit chemical processes, each controlled by a specific enzyme, each enzyme being dependent upon a specific area in a specific chromosome.

Among stromatic Sphaeriales, Glomerella, with conidial stages identified as Gloeosporium or Colletotrichum, attacks many plants; $G$. cingulata causes the bitter rot of apples. Valsa, Diatrype, and Diaporthe are numerous in species. Endothia parasitica causes the chestnut blight, destructive in the eastern United States. $X$ laria, Daldinia, and other genera are saprophytic on wood; the former produces black fruits, club-shaped or branched; the latter, fruits of the form of black knobs which may reach the size of golf balls.

Among Hypocreales, Nectria cinnabarina is common as a saprophyte on dead twigs of poplar. It produces small wart-like red stromata which bear first conidia, then perithecia. Claviceps purpurea causes a disease of rye; it produces conidia of various types, and converts the grains of rye into sclerotia. These bodies are called ergot; they are extremely poisonous, sometimes dangerously so, because they may be ground with the grain. They are used in medicine. After lying in the earth through the winter, the sclerotia send up fruits of the form of a stalk bearing a knob consisting of radiating perithecia. Cordyceps kills subterranean larvae or pupae of insects and then sends up a stalk bearing an elongate head of many perithecia. 
The Dothideales include Plowrightia morbosa, the agent of the black knot of plums. Diseased twigs become swollen and covered with a black stroma which bears, according to the scason, conidia of various types or else perithecia.

Order 8. Laboulbenialea [Laboulbeniales] Engler Syllab. ed. 3: 42 (1903).

Order Laboulbeniaceae Thaxter, the name (ascribed to Pcyritsch) preoccupied by family Laboulbeniaceae Berlese in Saccardo Sylloge 8: 909 (1889).

Suborder Laboulbenïneae Engler in Engler and Prantl Nat. Pflanzenfam. I Teil, Abt. 1: vi (1897).

Class Laboulbeniomyectes Engler Syllab. 1. c.

Class Laboulbenieae Schaffner in Ohio Naturalist 9: 450 (1909).

Parasites on insects, the mycclium scant or reduced to a single cell, producing antheridia which discharge spermatia into the air and small numbers of perithecia.

These organisms have the appearance of exceptional setae on their hosts, which are not usually seriously injured by them. They were first mentioned in a note by the entomologist Rouget, 1850; Montagne and Robin, in Robin's book on parasitic plants, 1853, gave the first names, Laboulbenia Rougetii and L. Gucrinii, the generic name honoring the entomologist Laboulbène. Only a few scholars, notably Thaxter $(1896,1908,1924,1926,1931)$ have given much attention to this group; they have distinguished well over a thousand species, forming three families and about fifty genera.

Many Laboulbenialea occur as two forms, male and hermaphrodite. A male individual produces a series of flask-shaped antheridia, each of which discharges into the air, one at a time, a series of globular naked sperms. A hermaphrodite individual produces first a series of antheridia as described and then one or more perithecia. A perithecium consists of a wall, of a definite number of cells produced in definite order and pattern, surrounding an egg which bears a trichogyne; the trichogyne protrudes from the perithecium and receives the sperms. The zygote gives rise to a fascicle of asci which crowd aside and destroy the inner cells of the wall and discharge the ascospores (usually eight in the ascus, and divided into two cells) through the ostiole.

Those who would link the Ascomycetes with the red algae entertain the hypothesis that the Laboulbenialea represent the transition. This hypothesis is surely mistaken. The Laboulbenialea are a highly specialized group, not a link between others. They appear to have evolved from Sphaeriales with solitary perithecia.

\section{Class 3. HYPHOMYCETES Fries}

Classes Hyphomycetes and Coniomycetes Fries Syst. Myc. 3: 261, 455 (1832).

Families Hyphomycetes and Coniomycetes Fries Epicrisis 1 (1836).

Fungi imperfecti or Deuteromycetes Auctt.

Inophyta of which the structures involved in sexual reproduction are unknown.

It has been noted that a partirular genus of $\Lambda$ scomycetes may produce conidia of more types than one, as Sclerotinia produces types called Monilia and Botrytis, and Glomerella produces types called Gloeosporium and Collctotrichum. The same type may be produced by many genera; the Monilia type recurs in Neurospora, which cloes not belong to the same order as Sclerotinia. Collecting naturalists, and plant pathologists in the pursuit of their cluties, are constantly encountering conidial stages whose assignment to an order of Ascomycetes is impossible. It is an obvious 
practical necessity that a register of these observations be kept. The register is provided by the present group, one which is named, defined, and assigned to the category of classes, and divided into named orders, families, and genera under which specimens may be identified as of species old or new. Class, orders, families, and genera are known not to be valid taxonomic groups; many of the ostensible species are known, and most of the rest are believed, to be stages of organisms which would in other stages have other names. Almost all of them are Ascomycetes; Zygomycetes and Basidiomycetes do not usually occur in unidentifiable stages.

The ascus-bearing stages are constantly being discovered. When this happens, the species is re-named in its proper place among Ascomycetes. Theoretically, it loses its place in the list of imperfect fungi; practically, it retains it, because the next collector or plant pathologst is most likely to try to find it there.

The system of Hyphomycetes is as follows:

Order 1. Phomatalea [Phomatales] Clements Gen. Fung. 121 (1909).

Sphaeropsideae Saccardo Sylloge 8: xvi (1889).

Order Sphaeropsidales Engler in Engler and Prantl Nat. Pflanzenfam. I Teil Abt. $1^{* *}$ : v (1900), not based on a generic name.

Order Phomales Clements and Shear Gen. Fung. ed. 2: 175 (1931).

Producing pycnidia. The four families correspond with as many groups of Ascomycetes.

Family 1. Phomatacea [Phomataceae] Clements Gen. Fung. 121 (1909). Family Sphaerioideae or Sphaerioidaceae Saccardo; but Sphaeria belongs to order Sclerocarpa. Family Phomaceae Clements and Shear (1931). Pycnidia hard and black as in Sphaeriales and Dothideales. Phoma, Ascochyta, Diplodia, Septoria, each of many species.

Family 2. Zythiacea [Zythiaceae] Clements Gen. Fung. 128 (1909). Family Nectrioideae or Nectrioidaceae Saccardo; but Nectria belongs to order Sclerocarpa. Pycnidia in brightly colored stromata as of Hysteriales.

Family 3. Leptostromatacea [Leptostromataceae] Saccardo Sylloge 3: 625 (1884). Pycnidia in shield-like stromata, like the fruits of Microthyriacea.

Family 4. Discellacea [Discellaceae] Clements and Shear Gen. Fung. ed. 2: 192 (1931). Family Excipulaceae Saccardo; but Excipula is a cup fungus. Pycnidia wide open like the fruits of Phacidiea.

Order 2. Melanconialea [Melanconiales] Engler in Engler and Prantl Nat. Pflanzenfam. I Teil, Abt. $1^{* *}$ : v (1900).

The conidia borne on a stroma but not in pycnidia.

Family Melanconiacea [Melanconiaceae] (Saccardo, without category) Lindau in Engler and Prantl op. cit. 398, the single very numerous family: Gloeosporium; Coryneum, C. Beijerinckii, the shot-hole of almonds; Pestallozia.

Order 3. Nematothecia [Nematothecii] Persoon Synops. Meth. Fung. xix (1801). Orders Dematiei, Sepedoniei, Tubercularini, and Stilbosporci Fries Syst. Myc. Order Hyphomycetes (Fries) Auctt. Order Moniliales Clements Gen. Fung. 138 (1909). Conidia directly on the mycelium, or none.

Family 1. Tuberculariea [Tubercularieae] Saccardo Sylloge 4: 635 (1886). Tuberculariaceae Saccardo (1889). Family Tuberculariaceae Lindau (1900). Scarcely distinct from Melanconiacea, the conidia on a mass of interwoven hyphae 
less compact than a stroma. Fusarium, an enormous number of species producing as conidia crescent-shaped rows of cells. Snyder and Hansen (1941, 1945) find that the fruiting stages are species of Hypomyces, Nectria, Gibberella, or Caloncctria, all Hypocreales.

Family 2. Stilbellacea [Stilbellaceae] Bessey Morph. and Tax. Fungi 584 (1950). Family Stilbeae Saccardo Sylloge 4: 563 (1886). Stilbaceae Saccardo (1889). Family Stilbaceae Lindau (1900); Bessey observed that the type of the genus Stilbum does not belong to this family. Mostly molds producing coremia.

Family 3. Dematiea [Dematieac] Saccardo Sylloge 4: 235 (1886). Demałiaceae Saccardo (1889). Family Dematiaccae Lindau (1900). Dark-colored parasites, as Helminthosporium, Cladosporium, and Cercospora, or molds, as Alternaria.

Family 4. Moniliacea [Moniliaceae] Clements Gen. Fung. 138 (1909). Mucedineae Persoon, family Mucedincae or Mucedinaceae Saccardo, not based on a generic name. White or brightly colored parasites or molds, as Oidium, with colorless spores in chains, Monilia, Botrytis, etc. The parasites on animals which have bcen referred to Monilia are currently called Candida.

Family (?') 5. Sterile mycelia. Many mycorhizae must be left here. Rhizoctonia, dark net-like masses of hyphae occurring as parasites or saprophytes. Trichophyton, parasitic on the skins of man and animals, causing ringworm, athlete's foot, etc.

\section{Class 4. BASIDIOMYCETES (Sachs ex Bennett and Thistleton-Dyer) Winter}

Order Basidiosporeae and subordinate group Basidiomycetae Cohn in Hedwigia 11: 17 (1872).

Basidiomyceten Sachs Lehrb. Bot. ed. 4: 249 (1874).

Basidiomycetes Bennett and Thistleton-Dyer in Sachs Textb. Bot. English ed. 847 (1875).

Class Basidiomyaetes Winter in Rabenhorst Kryptog.-Fl. Deutschland 1, Abt. 1: 72 (1884).

Classes Teliosporeae and Basidiosporcae Bessey in Univ. Nebraska Studies 7: 305, 306 (1907).

Classes Teliosporeae and Basidiomyctae Schaffner in Ohio Naturalist 9: 450 (1909).

Inophyta which produce, as a feature of the sexual cycle, conidiophores called basidia, cach producing typically four conidia called basidiospores.

Creminating basidiospores give rise to mycelia of cells with solitary haploid nuclei. Syngamy occurs among cells of these mycclia, usually simply by contact of undifferentiated cells; the rusts produce differentiated sperms in spermagonia resembling the pycnidia of Ascomycetes. In some species any haploid lypha may conjugate with any; in some there are two mating types, and in some four. Raper (1953) has studied the interesting genetics of the mating types.

The cell produced by syngany remains undifferentiated, but gives rise, by concarrent division of its nuclei, to a dikaryote mycelium. The nuclei are minute, and mitosis has raredy been seen. The nuclear divisions are often followed by a peculiar mamner of cell division, comparable to the crozicr formation of Ascomycetes, and producing structures called clamp comnections.

Either the origimal haploid mycelium or the dikaryophase may produce conidia witlout nuclear cliange. Such reproduction is familiar among the rusts, rather unfamiliar among otler Basidionyeetes. 
Only the dikaryophase produces the specialized conidiophores called basidia, which are regularly the seat of karyogamy and meiosis. There is a considerable variety of types of basidia. Van Tieghem (1893) originated the terminology applicable to these; Martin (1938) has attempted to refine it, and Linder (1940) to simplify it.

Frequently, the seat of meiosis is a thick-walled resting spore or an otherwise differentiated cell called a probasidium, upon which the proper basidium develops, after meiosis, as an outgrowth. A basidium arising in this fashion is commonly elongate and divided into four cells each of which produces a basidiospore. Such a hypha-like basidium may be called a promycelium or a phragmobasidium; the latter term is applicable also to an clongate four-celled basidium which does not arise from a probasidium. In a few Basidiomycetes, the basidium is divided into four cells by longitudinal walls; such basidia are called cruciate basidia. In the familiar Basidiomycetes the basidium does not become divided by walls and is called a holobasidium or autobasidium. Gäumann (1926) distinguished two types of holobasidia: the stichobasidium, in which the spindles of the dividing nuclei lie at various levels and in various directions, and which frequently produces more than four nuclei; and the chiastobasidium, in which the spindles lie transversely near the summit, and which regularly produces just four nuclei. Dodge, translating Gäumann (1928), denies much importance to this distinction.

The meiotic divisions have repeatedly been studied. Apparent centrosomes have been seen at the poles of the spindles (Lewis, 1906; Lander, 1933), but not by most microtechnical methods (Savile, 1939; Ritchie, 1941). The chromosomes gather as usual at the middle of the spindle and divide. The nuclear membrane becomes indistinct, but the nuclear sap remains distinct from the cytoplasm nearly until the completion of division; it then disappears, leaving the groups of daughter chromosomes connected by a spindle of the appearance of a dark streak in the cytoplasm.

Observed haploid chromosome numbers include the following:

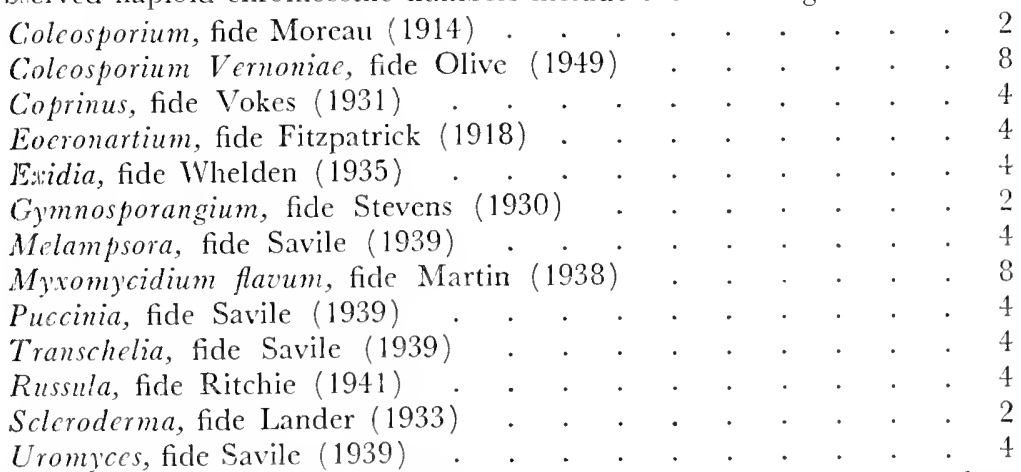

Savile suggests that some at least of the reports of a chromosome number of 2 may have resulted from misinterpreted observations of one pair of choromosomes behind another.

Normally, only the two meiotic divisions, producing four nuclei, occur in the basidium; exceptionally, there are further, mitotic, divisions, resulting in more than four spores on the basidium. The basidiospores are usually borne on slender stalks called sterigmata. Sterigmata and spores are formed by evagination of the wall of the basidium; the nuclei migrate through the sterigmata into the spores. 


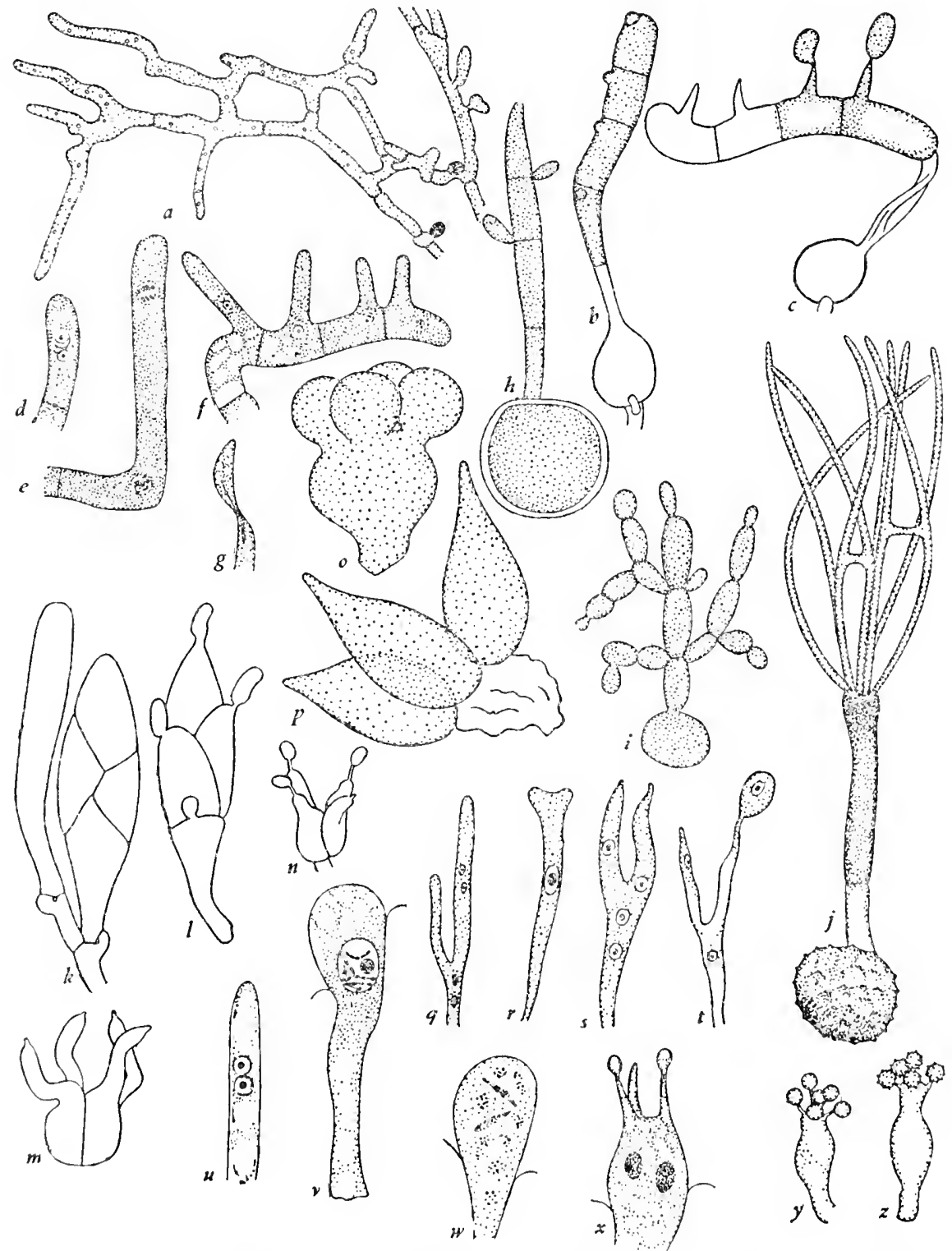

Fig. 28.-BAsidiomýcetes: a, Two germinating basidiospores of Agaricus campestris produce mycelia which anastomose frecly, the cells becoming plurinucleate, after llein (1930), x 500. b, c, Young and older basidia of Cystobasidium scbaceum, after Martin (1939). d-g, Eocronartium muscicola after Fitzpatrick (1918); d, fusion nuclens; e, homeotypic division in the basidium; $\mathbf{f}$, four-celled basidium; $\mathbf{g}$, production of basidiospore. $\mathbf{h}, \mathbf{i}, \mathbf{j}$, Basidia of I'stilago Heufteri. U. Hordei, and Tille- 
Most basidia discharge the spores actively, to a distance of a fraction of a millimeter. Buller (1929) observed that just before a spore is cast off a minute droplet of liquid appears at the summit of the sterigma. This occurs in precisely the same fashion in mushrooms, rusts, certain smuts, and the yeast-like organism Sporobolomyccs. Buller inferred that the force which discharges the spore is surface tension in the droplet. The fruits of Basidiomycetes are evidently adapted to the feebleness of the mechanism by which the spores are discharged. If the fruits are cup-like, they open laterally or downward. The basidia of mushrooms stand horizontally on gills which are commonly less than one millimeter apart, allowing the spores to fall from between them without touching them.

The groups of Ascomycetes and Basidiomycetes are evidently related. Morels and mushrooms, truffles and puffballs, taste alike. The technical scholar will be convinced that the groups are related by the occurrence in both of a dikaryophase stage, a character too strongly in contrast with those of the generality of organisms to be a probable product of parallel evolution. Gäumann quotes an old opinion of Vuillemin (1893), "qu'une baside est un asque dont chaque cellule-fille avant de passer à l'état de spore, fait saillie au dehors et se transforme en une sorte de conidie pour mieux s'adapter au transport par la vent." In dealing with the Zygomycetes, Gäumann emphasized the apparent evolution of conidia from endospores by evagination of the walls of the sporangia. Largely, as it seems, by Gäumann's influence, Vuillemin's hypothesis has become generally accepted.

Gäumann was disposed to derive the Basidiomycetes from something like Ascocorticium, and began his account of several of the groups of Basidiomycetes with ferms having scant flat fruits, or having basidia which spring directly from the sutstratum or host. Linder (1940) suggested a derivation from Cupulata or Sclerocarpa having operculate asci. He took note that many such asci open by producing a vescicle, bounded by the stretched inner wall of the ascus, into which the ascospores pass. This led to the conclusion that the Basidiomycetes producing probasidia are the lowest, and to this extent his reasoning appears cogent. He went on to identify the rusts as the lowest Basidiomycetes, which seems far-fetched, the rusts being distinctly a specialized group.

The generally accepted groups of Basidiomycetes are those which were set forth by Engler $(1897,1900)$, as follows:

Subclass HenibasidI, having basidia bearing indefinite numbers of spores; the smuts.

Subclass Eubasmin, the basidia bearing definite numbers of spores.

Order (Reihe) Protobasidomycetes, the basidia divided into cells.

Suborder (Unterreihe or Ordnung) Aurigularineae, the basidia divided by transverse walls.

Sub-suborder (Untcrordnung) UREDINALES, the rusts.

tia Tritici, after Sartoris (1924). k, 1, Basidia of Patouillardina cinerea after Martin (1935). m, Basidium of Scbacina sublilacina after Martin (1934). n, Basidium of Protodontia Uda after Martin (1932). o, p, younger and older basidia of Tulasnella phaerospora, after Martin (1939). q-t, Development of the basidium of Guepinia Spathularia, after Bodman (1938). u-x, Russula emetica after Ritchie (1941); binucleate primordium of basidium, fusion nucleus, homeotypic division, development of basidiospores. $\mathbf{y}, \mathbf{z}$, Basidia of Lycogalopsis Solmsii after Martin (1939). x 1,000 except as noted. 
Sub-suborder Auriculariales.

Suborder Tremelineae, the basidia divided by longitudinal walls.

(At this point should appear Reihe Autobasidomycetes, to include eight Unterreihen of ordinary Basidiomycetes. The name Autobasidiomycetes does not appear in the table of contents, the text, or the index of the Natürlichen Pflanzenfamilien; it was published in Engler's Syllabus, 1892).

Rearranging these groups according to current opinion, and suppressing the subsidiary categories, one arrives at the following system of orders:

1. Producing probasidia or transversely divided basidia, usually both.

2. Probasidia, if formed, terminal on the hyphae.

3. Mostly saprophytic and producing gelatinous fruits............... Order 1. Protobasidiomycetes.

3. Parasitic, mostly not producing fruits; the rusts............ Order 2. Hy ponermia.

2. Probasidia produced by rounding up and deposition of thick walls by the generality of the cells of the mycelium....... Order 3. Ustilaginea.

1. Without probasidia, the basidia divided longitudinally..................... Order 4. Tremellina.

1. Without probasidia, the basidia undivided.

2. Fruits gelatinous, basidia producing only two spores on stout sterigmata......... Order 5. Dacryomycetalea.

2. Not as above.

3. Basidia in a layer which forms without protection or becomes exposed. . Orcler 6. Fungr.

3. Basidia formed in closed fruits which do not open to expose them as a single layer............... Order 7. DERniatocarpa.

Order 1. Protobasidiomycetes Engler in Engler and Prantl Nat. Pflanzenfam. I Teil, Abt $1^{*}$ : iii (1900).

Suborder Auricularïnac and sub-suborder Auriculariales Engler 1. c.

Order Auricularincac Campbell Univ. Textb. Bot. 175 (1902).

Order Auriculariales bessey in Univ. Nebraska Studies 7: 309 (1907).

Basidionycetes mostly producing probasidia, thi' basidia divided by transwerse walls, mostly saprophytic and producing gelatinous fruits.

This order includes the fanily Auriculariacea [Auriculariaccac] Lindau in lingler and Prantl Nat. Pllanzenfam. I Tril, Abt. $1^{* *}: 83(1900)$, from which two or threc others have been segregated; about fifteen genera and about 125 species.

Martin (19t3) has cliscossed the name of the genus Auricularia and of its type species. The organism in question is surely the Jew's ear, Tromclla Aluricula L.; the genus Auricularia Bulliard 1795 can have nothing else as a type. The right name of the species is Auricularia Auricula (L.) Underwood 1902. It is a saprophyte on logs and sticks, producing flattened brown gelatinous fruits a fow centincters in diameter, vagucly resembling human cars. There are no probasidia. Hyphac growing toward the surfaces of the fruits produce a palisade of elongate basidia. Eath basidium becomes divided by tramsverse walls into four cells, ant each of these sends out 
to the surface an elongate sterigma which bears a curved basidiospore. The organism produces also conidia, either from the mycelium, the fruits, or directly from the basidiospores.

A series of unfamiliar other genera, Platygloca, Cystobasidium, Septobasidium, etc., have been studied notably by Martin (1934, 1937, 1939, 1942). Jola and Eocronartium are parasites on mosses. All of these genera produce probasidia, from which four-celled phragmobasidia arise, as a layer near the surfaces of the fruits. Most of them produce also conidia.

\section{Order 2. Hypodermia [Hypodermii] Fries Syst. Myc. 3: 460 (1832).}

Urédinées Brongniart in Bory de Saint Vincent Dict. Class. Hist. Nat. 16: 471 (1830).

Order Uredineae Winter in Rabenhorst Kryptog.-Fl. Deutschland 1, Abt. 1: 74. (1884).

Sub-suborder Uredinales Engler in Engler and Prantl Nat. Pflanzenfam. I Teil, Abt. $1^{* *}$ : iii (1900).

Order Uredinales Bessey in Univ. Nebraska Studies 7: 306 (1907).

Order Pucciniales Clements and Shear Gen. Fung. ed. 2: 147 (1931).

The rusts: parasitic Basidiomycetes, the haploid and dikaryote mycelia usually attacking different hosts; the dikaryote mycelium producing probasidia, these not usually compacted into fruits, usually heavily walled and serving as resting spores, becoming or giving rise to four-celled phragmobasidia.

The typical reproductive structure of the haploid stage is the aecium, a cup-shaped structure which releases spores called aeciospores; this stage is accordingly called the aecial stage, and its host the aecial host. In addition to aecia, this stage usually produces pycnidia or spermagonia. The typical reproductive structures of the dikaryote mycelium are clusters (telia) of spores called teliospores or teleutospores; this stage, then, is the telial stage, and its host the telial host. The telial stage usually produces, beside the teliospores, others called uredospores. The teliospore, or rather (since the teliospore commonly consists of two or more cells) each cell of the teliospore, is a probasidium, producing a promycelium which bears four basidiospores. These statements mean that a normal rust produces spores of five kinds. Rusts producing different kinds of spores were formerly supposed to be different genera; such were the Aecidium, Uredo, and Puccinia of Persoon, who, however, remarked of Uredo linearis, "vereor, ne junior plantula Pucciniae graminis modo sit." De Bary first proved that Aecidium Berberis is yet another stage of Puccinia graminis.

The dikaryophase is initiated, of course, by syngamy among cells of the aecial stage. In Phragmidium violaceum, Blackman observed this to take place between different cells of the same hypha. Christman (1905) and Moreau (1911), studying other species of Phragmidium, observed fusion to take place between tips of different hyphae. Craigie, 1927, showed that Puccinia graminis occurs in two mating types, and that the fertilizing elements are pycniospores or spermatia. De Bary (1884) had suggested that this is the truth; his suggestion waited some forty years to be confirmed. Allen (1930) has described much of the detail. The pycniospores are carried out of the pycnidium in exuding fluid, and are carried by insects; they make protoplasmic connection with paraphyses growing from pycnidia of the opposte mating type. The binucleate uredospores arise from a dikaryote mycelium, but the cup-shaped wall of the accium is produced by the haploid mycelium. 
The first-formed reproductive structures of the dikaryote mycelium on the telial host are usually uredospores, which remain binucleate and have the function of spreading the infection of the telial host.

Teliospores may be compacted into palisade-like masses which break through the epidermis of the host; the masses may be gelatinous and yellow, like fruits of Auriculariacea. In other genera, the teliospores are gathered into hard, microscopically stout columns, and in yet others they break throngh the epidcrmis in masses not compacted, each teliospore on a separate stalk. The teliospores of Phragmidium are chains of several probasidia; those of the many species of Puccinia are chains reduced to two probasidia; those of Ravenelia are globular clusters of probasidia. Almost always, the tcliospores are thick-walled; outside of the tropics, they have the function of overwintering. Each probasidium contains two nuclei. These unite as a preliminary to germination: this was first observed by Sappin-Trouffy (in Dangeard and SappinTrouffy, 1893). Thereafter the probasidium gives rise to the four-celled promycelium.

The life cycle thus described is not perfectly stable. Aeciospores, uredospores, and young teliospores are alike dikaryote, and are genetically identical. Spores of the structure and behavior of any of these types may be produced by processes which normally lead to another. Thus in Puccinia Malvacearum, the hollyhock rust, syngamy leads directly to the production of teliospores on the host of the haploid mycelium; spermagonia, aecia, and uredosori are not produced.

Four families of rusts may be recognized (various authorities make fewer or more). There are about five thousand species.

Family 1. Melampsoracea [Melampsoraceae] Dietel in Engler and Prantl Nat. Pflanzenfam. I Teil, Abt. $1^{* *}: 38$ (1900). Teliospores forming a single compact layer and germinating by producing promycelia. The aecial stages are mostly on conifers. Some have telial stages on ferns, and Faull (1929) regards these as most primitive; others attack a variety of flowering plants.

Family 2. Coleosporiacea [Coleosporiaceae] Auctt. The teliospores thenselves becoming basidia by transverse division. In some examples, as Galloway'a, they are thin-walled.

Family 3. Cronartiacea [Cronartiaceae] Auctt. The teliospores compacted into columns. Cronartium, with aecial stages on pines; $C$. ribicola, the important whitc pine blister rust, its telial stage on gooseberries and currants.

Family 4. Uredinacea [Uredinaceac] Cohn in Hedwigia 11: 17 (1872). Family Pucciniaceae Dietel op. cit. 48. The bulk of the rusts, producing teliospores on individual stalks. Hemileia vastatrix, the coffee rust; Phragmidium spp., autoecious (attacking a single host) on Rosaceae; Gymnosporangium, the aecial stagc on junipers, the telial (with no uredospores) on plants of the apple tribe; Puccinia, a great numbcr of species. The races which attack barberry and grasses are all called Puccinia graminis; but there are morphologically distinguishable strains on wheat, rye, oats, timothy, Agrostis, and blue grass. Leading an active scxual life and capable of nutation, these strains are subdivisible into large numbers of races distinguished by capacity to attack different races of hosts. Given a specimen of rust on wheat, one detcrmincs by trial upon seedlings of ten varicties of wheat to which of $189 \mathrm{numbercd}$ races it belongs. The races occur characteristically in different wheat-growing arcas. If one brecels wheat for resistance to rust, there is good probability of success against the races occurring locally; but some other race is likely to move into the area (Stakman, 1947). 
Order 3. Ustilaginea [Ustilagineae] (Tulasne and Tulasne) Winter in Rabenhorst Kryptog.-Fl. Deutschland 1, Abt. 1: 73 (1884).

Ustilagineae Tulasne and Tulasne in Ann. Sci. Nat. Bot. sér. 3, 7: 73 (1847).

Subclass Hemibasidii Engler Syllab. 26 (1892).

Order Ustilaginales Bessey in Univ. Nebraska Studies 7: 306 (1907).

The smuts: parasitic Basidiomycetes completing their development on a single host, the dikaryophase mycelium breaking up into thick-walled black spores, these functioning as probasidia, the basidia usually bearing more than four basidiospores.

In the apparently more primitive smuts, the promycelia are four-celled phragmobasidia. The haploid nuclei divide before passing into the basidiospores, with the effect that each cell of the promycelium buds off a series of basidiospores. In other examples the promycelia do not become divided by walls, but are of the character of holobasidia. The basidiospores of some species are capable of budding like yeasts. In some species, they are capable of syngamy with each other, and in some they send out hyphae which bear conidia of characteristic form. In many species, syngamy has not been observed, but is believed to take place between vegetative hyphae. Hybridization, and mutation, particularly in the capacity to attack particular races of hosts, take place freely in smuts, which are accordingly well fitted to cope with the efforts of plant breeders.

The smuts are believed to be somewhat degenerate descendants of the rusts.

There are two families, about thirty genera, about six hundred species.

Family 1. Ustilaginacea [Ustilaginaceae] Cohn in Hedwigia 11: 17 (1872). The basidia divided by transverse walls. Ustilago, on grasses and other plants.

Family 2. Tilletiacea [Tilletiaceae] Dietel in Engler and Prantl Nat. Pflanzenfam. I Teil, Abt. $1^{* *}: 15$ (1900). The basidia not divided by walls. Tilletia, on grains, etc. Tuburcinia, Doassansia, the resting spores produced in globular masses.

Order 4. Tremellina [Tremellinae] Fries Syst. Myc. 1: 2 (1821); 2: 207 (1822). Order Tremellinei Fries Hymen. Eur. 1 (1874).

Order Tremellineae Winter in Rabenhorst Kryptog.-Fl. Deutschland 1, Abt. 1 : 74 (1884).

Suborder Tremellineae Engler in Engler and Prantl Nat. Pflanzenfam. I Teil, Abt. $1^{* *}$ : iii (1900).

Order Tremellales Bessey in Univ. Nebraska Studies 7: 309 (1907).

Order Tulasncllales Gäumann Vergl. Morph. Pilze 487 (1926).

Saprophytic Basidiomycetes producing gelatinous fruits bearing a layer of basidia which typically become divided into four cells by longitudinal walls. Each cell produces a long stout sterigma which reaches the surface of the fruit and bears a spore. The mycelia, the young fruits, or the basidiospores may bear conidia.

The number of species is perhaps one hundred. Nearly all belong to family Tremellacea [Tremellaceae] Cohn in Hedwigia 11: 17 (1872). Martin (1935, 1937, 1939) has given much study to this group. It is clearly related to the Protobasidiomycetes; Patouillardina, having basidia divided by oblique walls, is clearly transitional. Tremella, Sebacina, Tremellodendron, Hyaloria.

Tulasnella differs from the generality of Tremellina in producing holobasidia of a peculiar type, with bulbous sterigmata (Lindau interpreted the sterigmata as basidiospores borne without sterigmata and not released, but producing conidia; it may $\mathrm{be}$ that this interpretation is more sound than the obvious one). It is supposed that the holobasidia of this genus are derived from the cruciate basidia of proper Tremel- 
lina by a line of descent separate from those which have produced the holobasidia of other groups. By leaving Tulasnella in order Tremellina, we spare ourselves the recognition of one more insignificant order.

Order 5. Dacryomycetalea [Dacryomycetales] Gäumann Vergl. Morph. Pilze 490 (1926).

Suborder Dacryomycetineae Engler in Engler and Prantl Nat. Pflanzenfam. I Teil, Abt. $1^{* *}$ : iv (1900).

Saprophytic Basidiomycetes producing small gelatinous fruits bearing holobasidia in which two of the nuclei produced by meiosis undergo degeneration, while two pass into the basidiospores by way of stout sterigmata which give the basidium the form of a Y. Conidia are produced either from the mycelium, from the young fruits, or from the basidiospores.

There is a single family Dacryomycetacea [Dacryomycetaceae] Hennings in Engler and Prantl Nat. Pflanzenfam. I Teil, Abt. 1**: 96 (1900). Dacryomyces, Dacryomitra, Guepinia. Bodman (1938) observed the details of the cytological processes in the basidia.

This insignificant order, like Tulasnella and the two great orders next to be considered, is evidently derived from Protobasidiomycetes, through Tremellina, by loss of septa in the basidia; the peculiarities of its basidia suggest an independent origin.

Order 6. Fungi L. Sp. Pl. 1171 (1753).

Order Hymenothecii Persoon Syst. Meth. Fung. xvi (1801).

Class Hymenomycetes and orders Pileati and Clavati Fries Syst. Myc. 1: 1, 2 (1821).

Fanily Hymenomycetes Fries Espicrisis 1 (1836).

Family Agaricaceae Cohn in Hedwigia 11: 17 (1872).

Order Hymenomycetes Winter in Rabenhorst Kryptog.-Fl. Deutschland 1, Abt. 1: $74(1884)$.

Suborders Exobasidiineae and Hymenomycetineae Engler in Engler and Prantl Nat. Pflanzenfam. I Teil, Abt. $1^{* *}$ : iv (1900).

Orders Hymenomycetales and Exobasidiales Bessey in Univ. Nchraska Studies 7: 307, 308 (1907).

Order Agaricales Clements Gen. Fung. 102 (1909).

Orders Cantharellales, Polyporales, and Agaricales Gäumann Vergl. Morph. Pilze 495, 503, 519 (1926).

Basidiomycetes producing holobasidia in a layer which is or becomes exposed to the air, usually on fruits which are woody, leathery, or fleshy, rather than waxy or gelatinous.

The layer of basidia is called the hymenium. In the lowest members of the group, the hymenium is formed directly on the mycelium, on the surface of the host or substratum; in higher examples, it is formed on the surfare of more or less complicater fruits; in the highest, it is formed in closed fruits which open to expose it. The area of the bymenium, and the number of basidia it can bear, is increased when it is not smonth, but thrown into teeth, ridges, plates, or other projections. Families have been distinguished chiefly on the basis of the form of the hymenium. The system is not relialbly entircly natural; Overholts (1929) pointed out various microscopic details which promise to contribute to a more natural system. Among these are cystidia, swollen cells imbedded in the hymenium and projecting from it; in some examples at 
least, they are sterile basidia and serve to hold apart the ridges bearing the hymenium. Other microscopic features are setae, similar to cystidia but hard, dark, and pointed; slender hairs called paraphyses; latex ducts; and crystalline inclusions.

There are some fifteen thousand species. The following families are for the most part the conventionally accepted ones.

Family 1. Exobasidiacea [Exobasidiaceae] Hennings in Engler and Prantl Nat. Pflanzenfam. I Teil, Abt. $1 *$ : 103 (1900). The basidia directly on the mycelium. A small group, mostly parasitic on plants. Exobasidium.

Family 2. Thelephoracea [Thelephoraceae] (Saccardo) Hennings (1900). Order Thele phore i Fries Hymen. Eur. 1 (1874). Family Thele phorei Winter (1884). Thelephoraceae Saccardo Sylloge 8: xiii (1889). Fruits of various form, gelatinous, fleshy or leathery, the hymenium covering the surface generally except where it faces upward. Corticium, saprophytic, the fruit a mere appressed layer; Stereum, leathery shelf-like extensions from decaying sticks and logs: these genera seem to lead into family Polyporacea. Cora, a tropical variant of Stereum, is the only lichen-forming basidiomycete. Thelephora, Craterellus, the fruits club-, funnel-, or cup-like.

Family 3. Clavariacea [Clavariaceae] (Saccardo) Hennings (1900). Order Clavariei Fries (1874). Family Clavariei Winter (1884). Clavariaceae Saccardo (1889). Fruits fleshy, club-like or branched; stag-horn fungi. Clavaria, generally edible.

Family 4. Hydnacea [Hydnaceae] (Saccardo) Hennings (1900). Order Hydnei Fries (1874). Family Hydnei Winter (1884). Hydnaceae Saccardo (1889). Hymenium on the surface of downward-pointing teeth. Fruits assigned to the genus Hydnum may be massive or variously branched or mushroom-shaped, leathery or fleshy; the fleshy examples are edible. Fruits of Irpex are little leathery brackets projecting from sticks and logs, distinguished from Stereum or Polystictus by the masses of fine teeth projecting below.

Family 5. Polyporacea [Polyporaceae] (Saccardo) Hennings (1900). Order Polyporei Fries (1874). Family Polyporei Winter (1884). Polyporaceae Saccardo (1889). The hymenium lining vertical tubes open below. These are mostly woody or leathery shelf fungi, mostly saprophytic on wood, numerous and varied in detail. Cooke (1940) recognized forty-six genera in North America. Polyporus, Fomes, Polystictus. In Daedalea, the pores are not cylinders but slits; this genus leads into Lenzites, in which the hymenium is borne on radiating plates, and which is conventionally stationed in Agaricacea. Boletus has stout fleshy mushroom-shaped fruits, yellow to brown, turning green when bruised. These fruits are unattractive, but some species are eaten; others are supposed to be poisonous.

Family 6. Agaricacea [Agaricaceae] Cohn in Hedwigia 11: 17 (1872). Order Agaricini Fries (1874). Family Agaricini Winter (1884). The hymenium on vertical plates, radiating from a center, called gills.

These are the Fungi whose fruits are called mushrooms or toadstools. The fruits are mostly mushroom-shaped, sometimes shelf-like; the texture is usually fleshy, varying to leathery on the one hand, and on the other to deliquescent, i.e., becoming converted after maturity into black fluid. There has been much study of the development of the fruits (Levine (1922) and Hein (1930) give extensive bibliographies). This occurs in any of several different fashions, leading to recognizable differences in the mature structure. For the identification of agarics, many mushroom books are available. Any interested person, noting the details of structure which result from the different courses of development, together with the color of the spores (of one 
of five classes, white, pink to red, light brown to rust color, dark brown or purple, or black), will find identification reasonably easy. Popular interest in agarics is concerned, of course, with the edible and poisonous. Many amatcur mycophagists need to be convinced that there is no single test for poisonous agarics except the final one. One who encounters an unfamiliar species may chew and eat a small scrap of it; if it is tasty and without bad after-effects, one may collect and eat the same species when one again recognizes it by its technical characters. At the present point, it is cxpedient to mention only a few examples.

Deliquescent agarics with black spores are called inky caps and constitute the genus Coprinus. All are edible; they should be fried in butter and served on toast.

Fruits of Agaricus campestris, the field mushroom, are rather large, white or gray on top, the stalk marked by a ring but no cup, the gills pink when young, dark brown to nearly black when mature. Anything of this character is safely edible.

Fruits of Pleurotus have an excentric or lateral stalk, or none, being shelf- or bracket-like, fleshy, with white spores. All species are edible. The most familiar is the oyster mushroom, $P$. ostrcatus, producing large white to gray fruits on dead trees, commonly on poplars.

Fruits of Amanita are marked by cup and ring, and bear white spores. Some species are known to be ediblc; others, as the fly agaric, A. muscaria, recognized by a red cap flecked with white, are extremely poisonous.

Family 7. Podaxacea [Podaxaceae] Fischer in Engler and Prantl Nat. Pflanzenfam. I Teil, Abt. $1^{* *}: 332$ (1900). Gyrophragmium produces fruits much like those of Agaricus, but coming up only to ground level, and drying and shattering irregularly instead of opening like mushrooms. The gills are quite evident in immature fruits. Podaxon is similar, but does not form definite gills. These organisms arc conventionally stationed in the next order, but their obvious natural position is next to Agaricacea.

\section{Order 7. Dermatocarpa [Dermatocarpi] Persoon Syst. Meth. Fung. xiii (1801).}

Order Lytothecii Persoon op. cit. xv.

Class Gasteromycetes and orders Angiogastres and Trichospermi Fries Syst. Myc. 2: 275,276 (1822).

Family Gasteromycetes Fries Epicrisis 1 (1836)

Order Gasteromycetes Winter in Rabenhorst Kryptog.-Fl. Deutschland 1, Abt. 1: 864 (1884).

Suborders Phallineae, Hymenogastrineae, Lycoperdineae, Nidulariineae, and Plectobasidiineae Engler in Engler and Pranti Nat. Pflanznfam. I Tcil, Abt. $1^{* *}$ : iv (1900).

Orders Phallineae, Lycoperdineae, and Nidularineae Campbell Univ. Textb. Bot. 186, 187, 188 (1902).

Orders Iymenogastrales, Phallales, Lycoperdales, Nidulariales, and Sclerodermatales Bessey in Univ. Nebraska Studics 7: 306-307 (1907).

Orders Plectobasidiales and Gasteromycetes Gäumann Vergl. Morph. Pilze 537, 544 (1926).

Basidiomycetes producing holobasidia enclosed in fruits, not forming a continuous layer or not exposed as such, not discharging the spores directly into the air, sterigmata more or Iess suppressecl.

Distinguished by negative characters, this order may be suspected of being artificial; but Engler's attempt to correct this produced orders which were small and numerous 


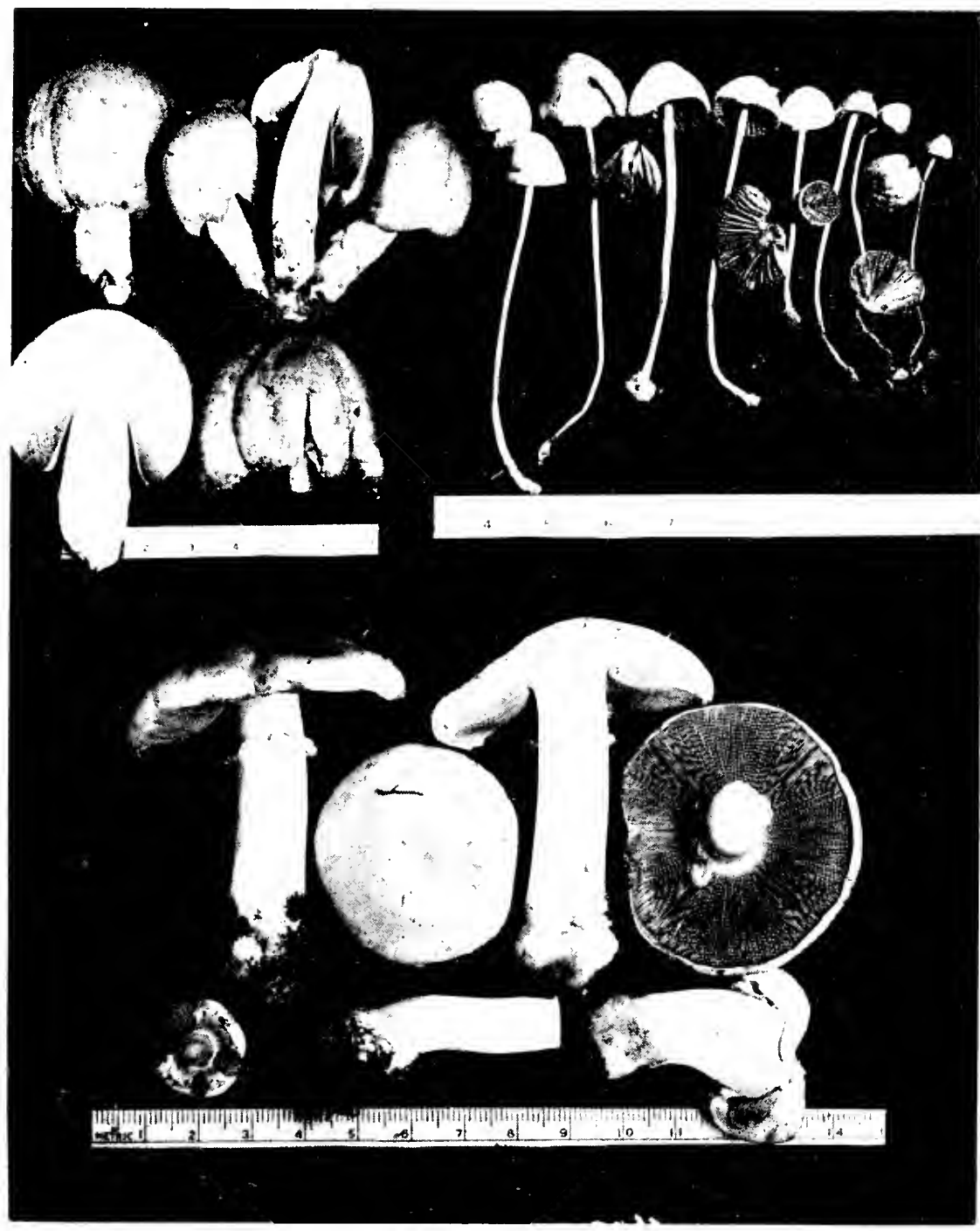

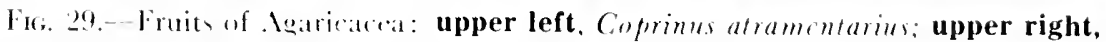
Galera tenera: below, fearieu campestris. Photengaph by the late Dr. J. J. Mr Cabe. by rourtes of the Inepartment of Botany. Cuiversity of Califormia. 

to an unsatisfactory degree, and to some of which the suspicion of artificiality continued to attach.

Dodge, translating Gäumann (1928), took account of the course of development of the fruits in rearranging those families whose fruits are characteristically produced underground. The roll of families which appear tenable is as follows.

A. Fruits typically formed underground.

Family 1. Rhizopogonacea [Rhizopogonaceae] Dodge in Gäumann Comp. Morph. Fungi 469 (1928).

Family 2. Sclerodermea [Sclerodermei] Winter in Rabenhorst Kryptog.-Fl. Deutschland 1, Abt. 1: 865 (1884). Family Sclerodermataceae Fischer in Engler and Prantl Nat. Pflanzenfam. I Teil, Abt. $1^{* *}: 334$ (1900).

Family 3. Hydnangiacea [Hydnangiaceae] Dodge in Gäumann op. cit. 485.

Family 4. Hymenogastrea [Hymenogastrei] Winter in Rabenhorst op. cit. 865. Family Hymenogastraccac de Toni in Saccardo Sylloge 7: 154 (1888).

Family 5. Hysterangiacea [Hysterangiaceae] Fischer in Engler and Prantl op. cit. 304.

B. Fruits appearing on the surface of the ground.

Family 6. Lycoperdacea [Lycoperdaceae] Cohn in Hedwigia 11: 17 (1872). These are the common puffballs, Lycoperdon, Bovista, Calvatia, Lycogalopsis, etc. The contents of the more or less globular fruits become disorganized, leaving a mass of spores mixed with fibers (modified hyphae constituting a capillitium), enclosed in one or more continuous layers of tissue (peridia) which open usually through one stellate pore at the summit. Geaster has a double peridium. The outer peridium becomes split by meridional clefts from the apex nearly to the base, and the lobes curl back in damp weather, exposing the inner peridium with its terminal pore. The appearance of the fruit in the damp condition explains the common name, earth star, and the scentific name of the same meaning.

Family 7. Tulostomea [Tulostomei] Winter in Rabenhorst op. cit. 866. Family Tulostomataceae Fischer in Engler and Prantl op. cit. 342. Tulostoma produces at ground level puffball-like fruits which are found to stand upon buried stalks some centimeters long. The basidia bear the spores scattered along the sides instead of in a crown at the summit. This is probably a minor deviation from the condition in ordinary puffballs, and not a token of independent origin.

Family 8. Nidulariea [Nidulariei] Winter in Rabenhorst 1. c. Family Nidulariaceae de Toni in Saccardo Sylloge 7: 28 (1888). The bird's nest fungi, Nidularia, Cyathus, etc., with small fruits growing on sticks or earth, the outer peridium opening and exposing several peridioles.

Family 9. Sphaerobolacea [Sphaerobolaceae] Fischer in Engler and Prantl op. cit. 346. Sphaerobolus, a saprophyte on wood, produces minute puffball-like fruits which discharge mechanically a globular mass of spores.

Family 10. Clathracea [Clathraceae] Fischer in Engler and Prantl op. cit. 280. Closely related and transitional to the following family.

Family 11. Phalloidea [Phalloidei] Winter in Rabenhorst 1. c. Family Phallaceae Fischer in Engler and Prantl op. cit. 289. The stinkhorns, Phallus, Dictyophora, Mutinus, etc. These organisms produce highly specialized fruits. A fruit is first seen as a white globe, as large as a marble or a golf-ball, at ground level. It has a leathery peridium containing certain structures imbedded in gelatinous matter: there is a firm thimble-shaped structure upon whose surface the basidia develop; below or within this there is a body of the form of a hollow cylinder of spongy structure. When 
the spores are ripe, the spongy body grows, so to speak, by unfolding, and becomes, it may be within an hour, a stalk as much as $15 \mathrm{~cm}$. tall. This happens usually during the night or at dawn, and is not commonly observed. The growing stalk carries the basidium-bearing structure into the air, bursting the peridium, which remains as a cup about the base, and exposing the spores in a mass of jelly which is of an odor repulsive to man but attractive to carrion-seeking insects. The latter are used as agents of dissemination. 


\section{Chapter X \\ PHYLUM PROTOPLASTA \\ Phylum 6. PROTOPLASTA Haeckel}

Stämme Protoplasta and Myxomycetes Haeckel Gen. Morph. 2: xxiv, xxvi (1866).

Subphylum Plasmodroma Doflein Protozoen 13 (1901), in part.

Subphylum Rhizoflagellata Grassé Traité Zool. 1, fasc. 1: 133 (1952), not order Rhizoflagellata Kent (1880).

Further names for the myxomycetes as a phylum are cited below under class Mycetozoa.

Organisms without photosynthetic pigments, mostly with flagellate stages, the flagella simple or acroneme, not paired and equal nor solitary and posterior; commonly occurring also in amoeboid stages. By Haeckel's original publication, the type or standard is Amoeba, i.e., Amiba diffuens.

Amoeboid organisms are those whose protoplasts lack walls or shells, or are only incompletely covered by them, and which thrust forth temporary bodies of protoplasm, called pseudopodia, functional in motion and in predatory nutrition. Pseudopodia are of several types. If massive and blunt they are lobopodia. If fine and straight, not anastomosing and usually not branching, they are filopodia; or, if they contain inner filaments, axopodia. If fine, branching, and anastomosing, they are rhizopodia.

The characters of the pseudopodia distinguish the accepted primary groups of amoeboid organisms. Variations in this character tend to run parallel to variations in the structure and composition of shells and skeletons: to a considerable extent, the accepted groups appear natural. This applies to the second, third, and fourth among the classes treated below. The phylum, on the other hand, is acknowledgedly artificial. Some of its groups appear to have had their origins (presumably more origins than one) among the chrysomorads; others are of unguessed origin.

1. Flagellate in the vegetative condition.............. Class 1. Zoomastigoda.

1. Amoeboid in the vegetative condition.

2. Producing rhizopodia; with shells, these

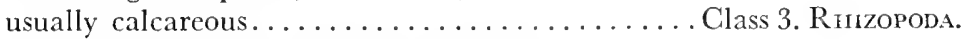

2. Producing filopodia or axopodia; mostly with skeletons, these usually siliceous......... Class 4. HelozoA.

2. Producing lobopodia.

3. Producing flagellate reproductive cells; mostly macroscopic, subaerial........ Class 2. Mycetozoa.

3. Not as above; without flagellate

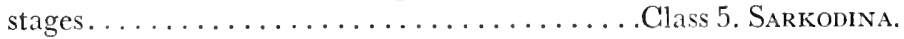

\section{Class 1. ZOOMASTIGODA Calkins}

Subclass Zoomastigina Doflein Lehrb. Prot. ed. 4: 462 (1916).

Class Zoomastigoda Calkins Biol. Prot. 285 (1926).

Class Zooflagellata Grassé Traité Zool. 1, fasc. 1: 574 (1952).

Class Zoomastigophorea Hall Protozoology 170 (1953). 
Non-pigmented flagellates having acroneme or simple flagella; amoeboid stages, if they occur, having lobopodia. The standard is Bodo. Four orders are to be recognized.

1. Flagella one or two.................... Order 1. Rhizoflagellata.

1. Flagella four to eight (in each neuromotor system, if these are more than one).

2. Axostyles, if present, homologous with flagella; parabasal body commonly absent.......................... Order 2. Polymastigida.

2. Axostyles present, not homologous with flagella; parabasal body present, disappearing during mitosis................... Trder 3. TRICHOMONADINA. 1. Flagella of indefinite large numbers........... Order 4. Hy permastigina.

Order 1. Rhizoflagellata [Rhizo-Flagellata] Kent Man. Inf. 1: 220 (1880). Orders Trypanosomata (the mere plural of a generic name) and FlagellatoPantostomata in part Kent op. cit. 218, 229.

Suborders Monadina in part and Heteromastigoda Bütschli in Bronn Kl. u. Ord. Thierreichs 1: 810, 827 (1884).

Protomastigina Klebs in Zeit. wiss. Zool. 55: 293 (1893).

Order Protomonadina Blochmann Mikr. Tierwelt ed. 2, 1: 39 (1895).

Subclasses Pantostomatineae and Protomastigineae Engler in Engler and Prantl Nat. Pflanzenfam. I Teil, Abt. 1a: iv (1900).

Orders Pantostomatales and Protomastigales Engler Syllab. ed. 3: 7 (1903).

Orders Cercomonadinea and Monadidea in part Poche in Arch. Prot. 30: 139, 140 (1913).

Orders Pantostomatineae and Protomastigineae Lemmermann in Pascher Süsswasserfl. Deutschland 1: 30, 52 (1914).

Order Rhizomastigina Doflein Lehrb. Prot. ed. 4: 704 (1916).

Orders Pantostomatida and Protomastigida Calkins Biol. Prot. 286, 288 (1926).

Orders Trypanosomidea Grassé, Bodonidea Hollande, and Proteromonadina Grassé in Grassé Traité Zool. 1, fasc. 1: 602, 669, 694 (1952).

Orders Rhizomastigida and Protomastigida Hall Protozoology 171, 173 (1953). Non-pigmented flagellates with one flagellum or two unequal flagella, these simple or acroneme; commonly with amoeboid stages, or amoeboid while bearing flagella. The type, being the solc genus of Rhizo-Flagellata as originally published, is Mastigamoeba, i. e., Chaetoproteus Stcin.

As the synonymy shows, most authorities have made these organisms two orders, Pantostomatales (or some such name), amoeboid in the vegetative condition, and Protomastigina (or the like), not definitely so. Monas, and the choanoflagellates and Amphimonadaceac, usually included in the latter order, have in the present work been given places elsewhere. The residue of the Protomastigina are not sharply different in character from the original Rhizoflagellata, and are accordingly placed in the same order. The resulting group is not a very numerous one. Some examples appear to occur naturally as predators in uncontaminated waters; the majority have been found in foul or contaminated waters, or in feces, and are believed to be naturally entozoic, cither commensal or parasitic. Further examples are parasites in blood. $A$ cytological character marking the majority of the goup, but not confined to it, is the parabasal body (better, perhaps, the kinetoplast; Kirby, 1944). This is a 
rather massive extranuclear body regularly present in the cell and distinct both from the centrosome and the blepharoplast. In the present group, it divides when the nucleus does. Thus this group, although marked chiefly by characters which are negative or derived, appears possibly to be natural.

1. Flagella two.

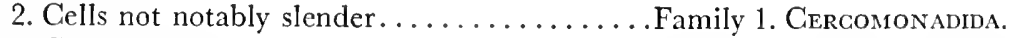

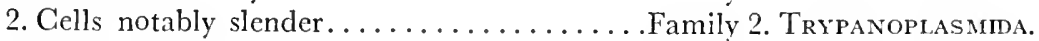
1. Flagellum one.

2. Not regularly markedly amoeboid..........Family 3. Orcomonadacea.

2. Conspicuously amoeboid............. Family 4. Chaetoprotema.

Family 1. Cercomonadida [Cercomonadidae] Kent Man. Inf. 1: 249 (1880). Family Bodonina Bütschli in Bronn Kl. u. Ord. Thierreichs 1: 827 (1884). Family Bodonaceae Senn in Engler and Prantl Nat. Pflanzenfam. I Teil, Abt. 1a: 133 (1900). Family Bodonidae Doflein Protozoen 73 (1901). Family Cercobodonidae Hollande 1942. Family Proteromonadidae Grassé Traité Zool. 1, fasc. 1: 694 (1952). Nonpigmented flagellates, the bodies not notably slender, with two flagella, one directed anteriorly, the other trailing. Fischer (1894) found both of the flagella of Bodo to be acroneme.

In Bodo both flagella are free of the body. There are numerous species, in infusions or foul or polluted waters, or entozoic in a wide variety of animals, from insects to men. Prowazekia, Proteromonas, and Pleuromonas are doubtfully distinct. Rhynchomonas, from fresh or foul waters, is distingished by a protoplasmic beak in which the anterior flagellum is imbedded. Cercomonas, of like habitats, has the trailing flagellum grown fast to the cell membrane; the cel1; exhilit a considerable capacity to send out lobopodia.

Biflagellate organisms which can lose their flagclia and take on the appearance of ordinary amoebas have repeatedly been discovered and variously named. So far as the pseudopodia are lobopodia and the flagella are unequal, these organisms belong in this family; but many accounts fail to establish the equality or inequality of the flagella, with the result that the names used in them cannot be applied with confidence. This is true of various organisms originally named under Pseudospora, Dimastigamoeba, and Naegleria. The earliest generic name definitely applicaple to organisms as described in Cercobodo Senn, 1910.

Bělăr (1914, 1916, 1920, 1921), Kühn (1915), and others have described mitosis in various examples of this family; the most detailcd account is of Bodo Lacertae in Bělăr's paper of 1921. The flagella spring from a blepharoplast from which a rhizoplast extends into the nucleus. The chromatin is reticulate, not massed in a karyosome, but no centrosome has been recognized in it when it is not dividing. The rhizoplast, where it passes through the cytoplasm, is surrounded by stainable Ringkörper. The parabasal body, located on the posterior side of the nucleus, is massive and often irregular. In division, the blepharoplast divides, each part retaining one flagellum and generating an additional one. The rhizoplast appears to begin to split, but presently it and the Ringkörper become invisible. Within the intact nuclear membrane there appears a spindle with evident centrosomes at the poles. The centrosomes come presently to the inner surface of the nuclear membrane, while the blepharoplasts move to adjacent positions on the outside. Chromosomes duly assemble at the equator of the spindle and undergo division. Division of the nucleus is completed by constriction of the nuclear membrane; the parabasal body undergoes constriction; the cell divides by constriction lengthwise. The Ringkörfer and the rhizoplast are apparently regenerated by the blepharoplast. 


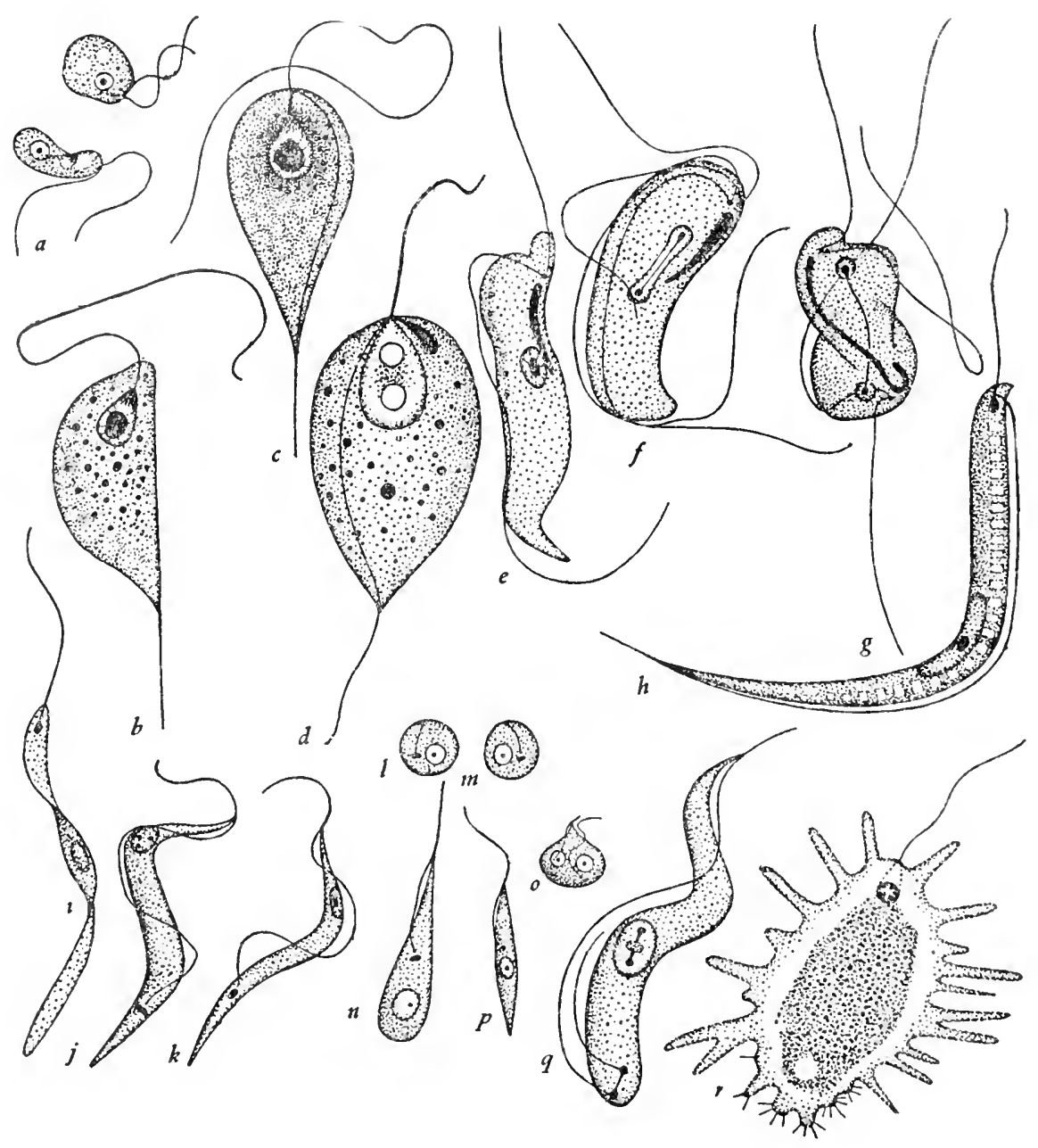

Fig. 30.-Rhizoflageliata: a, Bodo sp. x 1,000. b, c, Cercomonas longicauda as identified by Wenyon (1910) in material from a cholera patient; $\mathbf{d}$, the same as identified by Hovasse (1937) in swamp water. e-h, Cryptobia spp.; e-g, cell and division stages of a species from the conger eel after Martin (1910); h, a species from siphonophores after Keysselitz (1904) x 1,000. i, Phytomonas Donovani after França (1914). j-p, Trypanosoma Lewisi; j, k, forms from the rat after Minchin (1909); 1-p, forms from the flea Ceratophyllus fasciatus after Minchin \& Thompson (1915). q, Division stage of Trypanosoma Brucii after Kühn \& Schuckmann (1911). r, Chactoproteus (Mastigamocba aspera) after Schulze (1875) x 100. $\mathbf{x} 2,000$ except as noted. 
Alexeieff (1924) described fusions of pairs of cells of Bodo edax.

Family 2. Trypanoplasmida [Trypanoplasmidae] Hartmann and Jollos 1910. Family Cryptobiidae Poche in Arch. Prot. 30: 148 (1913). Family Trypanophidae Hollande in Grassé Traité Zool. 1, fasc. 1: 680 (1952). Organisms of essentially the structure of Cercomonas, but notably slender in adaptation to parasitic life, the trailing flagellum forming the margin of an undulating membrane on the body. Parasitic in various invertebrates and in the gut and blood of fishes.

The numerous species may be included in a single genus Cryptobia Leidy (Trypanoplasma Laveran and Mesnil; Trypanophis Keysselitz).

According to Martin's (1910) description of a species from the eel Conger niger, both flagella spring from a blepharoplast ("basal granule") at the anterior end. As preliminary to division, the blepharoplast and flagella divide, and one blepharoplast migrates to the posterior end of the cell. The nucleus divides by constriction of the nuclear membrane. There is a prominent parabasal body ("kinetonucleus") which divides by constriction, as does the cell, transversely.

Bělăr (1916) described sexual fusions of differentiated individuals of a species parasitic in snails.

Family 3. Oicomonadacea [Oicomonadaceae] Senn in Engler and Prantl Nat. Pflanzenfam. I Teil, Abt. 1a: 118 (1900). Family Trypanosomidae Doflein Protozoen 55 (1901). Family Trypanosomatidae Grobben 1904. Family Oicomonadidae Hartog. Non-pigmented anteriorly uniflagellate organisms, not markedly amoeboid while in the flagellate condition.

Oikomonas includes organisms of the character of the family without particular specialization, occurring in contaminated water or soil, and as commensals in the intestine of animals.

The bulk of the family consists of the slender-celled parasites which may be celled trypanosomes in the broad sense of the word. From the viewpoint of man, these are the most important flagellates, and they have been the most intensely studied. Some are known only from the guts of insects; some occur alternatively in insects and plants; some in insects and vertebrates; and some in vertebrates and in invertebrates other than insects, as ticks and leeches. The range of parasitization is as though the group had evolved as parasites in insects, and had been carried to other hosts by the activity of insects and other biting or sucking invertebrates.

Most trypanosomes occur in varied forms. The forms are designated by words which originated as names of genera and remain in use as such. (1) The leptomonas form has an anterior flagellum but no undulating membrane; it resembles a cell of Oikomonas but is notably slender. (2) The leishmania form has no flagellum; the cell is rounded up and lives attached to, or inside of, cells of the host. (3) In the crithidia form, the base of the flagellum is continued as an undulating membrane more or less to the middle of the cell. (4) In the trypanosoma form, the base of the flagellum is continued as an undulating membrane to the posterior end of the cell.

The accepted genera are distinguished (artificially, as one may suspect) by stages produced and groups of hosts attacked, as follows:

1. With leptomonas stages in insects and in

Euphorbiaceae, Ascelepiadaceae, and other plants with milky juice................................

1. Confined to invertebrate animals.

2. Trypanosoma stage known......................... Herpetomonas.

2. Trypanosoma stage unknown; crithidia 


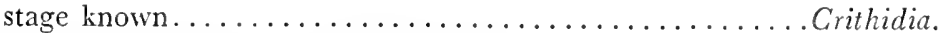

2. Trypanosoma and crithidia stages un-

known

1. Attacking vertebrate animals.

2. Trypanosoma stage known.................. Trypanosoma.

2. Trypanosoma stage unknown.................. Leishmania.

Man has been concerned particularly with Trypanosoma gambiense, the agent of African sleeping sickness; T. Cruzi, the cause of Chagas' disease; T. Brucii, T. Evansi, $T$. equinum, and T. equiperdum, which cause in domestic animals the diseases, respectively, nagana, surra, mal de caderas, and dourine; Leishmania Donovani and $L$. tropica, causing kala azar and oriental sore; and L. brasiliensis, causing espundia, ferida brava, or chicleros' ulcer, usually appearing as a grievous disfigurement of the features.

Schaudinn (1903), having studied a trypanosome occurring in mosquitoes and in the owl Athene noctua, described the nucleus as undergoing repeated unequal divisions. It appeared to him that when a cell is to produce a flagellum, one of the minor nuclei produced by unequal division generates it. Prowazek (1903) described similar phenomena in a Herpetomonas occurring in flies. These reports led Woodcock (1906) to apply to the proper nucleus of trypanosomes the term trophonucleus, and to the large granule near the base of the flagellum the term kinetonucleus.

There has been much other study of the cytology of trypanosomes (as by Minchin, 1908, 1909; Robertson, 1909; Woodcock, 1910; Minchin and Woodcock, 1910, 1911; Kühn and Schuckmann, 1911; Minchin and Thomson, 1915; Schuurmans Stekhoven, 1919). This has not confirmed the foregoing accounts and conclusions, but appears to have established the following points.

The base of the flagellum is slightly swollen and may be construed as a blepharoplast. Separated from the blepharoplast by a distance of one or two microns there is a conspicuous parabasal body (the kinetonucleus of Woodcock). Fine strands connecting the blepharoplast, parabasal body, and nucleus, have been observed. Most of the stainable material in the resting nucleus is aggregated in a globular karyosome. In mitosis, the karyosome breaks up to form a moderate number of chromosomes and a central granule, evidently a centrosome, which stains more heavily than the chromo. somes. It divides before the chromosomes, the daughter centrosomes remaining connected by a fine fiber, the centrodesmosc. An obscure spindle forms about the centrodesmose; the chromosomes undergo division within the spindle, and the daughter chromosome; assemble about the centrosomes. Mitosis is completed by constriction of the nuclear membrane.

The blepharoplast divides at the same time as the nucleus. The flagellum splits to a short distance and one of the branches breaks loose; one daughter blepharoplast retains essentially the whole of the original flagellum wlile the other generates one which is almost entirely new. The parabasal body undergoes constriction. The cell membrane cuts in in such fashion as to divide the cell longitudinally. The blepharoplast and the parabasal body persist through the non-flagellate lcishmania stage. Reports that the nucleus may generate these structures, or that one of them may gencrate another, were apparently mistaken.

Schaudinn described complicated processes by which a trypanosome generates differentiated male and female gametes which duly undergo syngany. His account is believed to have resulted from mistaking stages of a sporozoan for those of a trypanosome. Still, the occurrence of syngamy among trypanosomes is inherently probable. 
Family 4. Chaetoproteida [Chaetoproteidae] Poche in Arch. Prot. 30: 172 (1913). Family Rhizomastigina Bütschli in Bronn Kl. u. Ord. Thierreichs 1: 810 (1884). Family Rhizomastigaceae Senn in Engler and Prantl Nat. Pflanzenfam. I Teil, Abt. la: 113 (1900). Family Mastigamoebidae Kudo Protozoology ed. 3: 263 (1946). Amoeboid organisms bearing one anterior flagellum, either permanently or temporarily. In polluted soil or water, or commensal or pathogenic in animals.

The oldest genus, Chaetoproteus Stein (Mastigamoeba F. E. Schulze, 1875; Dinamoeba Leidy ?) remains poorly known. This organism and Mastigella are described as fairly large; Craigia is much smaller. Rhizomastix is doubtfully distinct from Craigia. Early names of this family appear to refer to Rhizomastix as the type, but the family is much older than the genus, and the names are not valid.

Order 2. Polymastigida Calkins Biol. Prot. 292 (1926).

Family Polymastigina Bütschli in Bronn Kl. u. Ord. Thierreichs 1: 842 (1884). Order Polymastigina Blochmann Mikr. Tierwelt ed. 2, 1: 47 (1895).

Subclass Distomatineae Engler in Engler and Prantl Nat. Pflanzenfam. I Teil, Abt. la: iv (1900).

Order Distomatinales Engler Syllab. ed. 3: 7 (1903), not based on a generic name.

Orders Pyrsonymphina, Oxymonadina, Retortomonadina, and Distomata Grassé Traité Zool. 1: fasc. 1: 788, 801, 824, 963 (1952).

Non-pigmented flagellates with simple or acroneme flagella of definite number, from four to eight (two in Retortomonas), in the individual neuromotor system, and accordingly on the individual cell, except when the neuromotor systems are multiplied; not of the definite characters of the following order. Free-living, chicfly in foul waters, or commensal or parasitic in animals. Polymastix is presumably the type of the group. It was listed with a query in Bütschli's original publication of family Polymastigina.

In the generality of Polymastigida, the cells are dorsiventral and have single nuclei and neuromotor systems. There are derived examples in which the cells are spirally twisted. There is a group in which the cells are double, having two nuclei and neuromotor systems. In another group there are two or more neuromotor systems, usually with more than one nucleus; the cells consist of units in a whorled or spiral arrangement, so that as wholes they are of radial symmetry.

The neuromotor system consists primarily of (1) the flagella; (2) one or more blepharoplasts from which the flagella spring; (3) one or more rhizoplasts linking together the parts of the system; and (4) a centrosome located just outside the nuclear membrane. Furthermore, (5) a parabasal body may be present. (6) An axostyle is a rod imbedded in the cytoplasm. In Hexamita the axostyles are the proximal ends of backwardly directed flagella; axostyles occurring in various other genera of the order appear also to be homologous with flagella.

Nuclear and cell division have been observed in various genera, as in Hexamita by Swezy (1915); in Streblomastix by Kidder (1929); in Giardia by Kofoid and Christianson (1915) and Kofoid and Swezy (1922); and in Oxymonas by Connell (1930).

Cleveland (1947) observed in Saccinobaculus a multiplication of nuclei followed by their fusion in pairs, and by meiosis in the fusion nuclei: thus there is a sexual cycle without fusion of cells. It is not probable that sexual reproduction does not occur in the generality of the group, but it has not been observed in any others. 

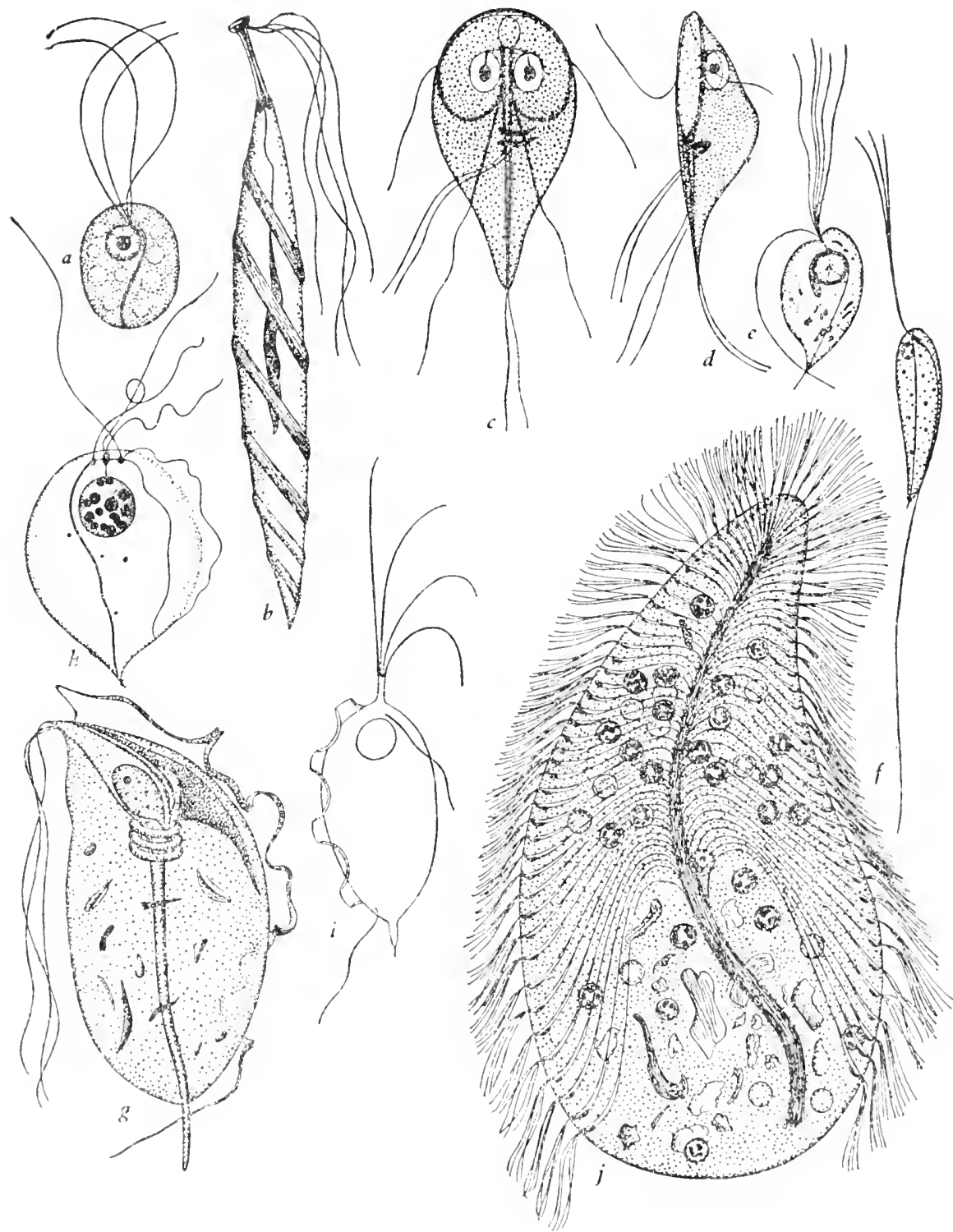

Fig. 31.-Polymastagida: a, Polymastix Melolonthae after Swezy (1916). b, Streblomastix Strix x 1,000 after Kidder (1929). c, d, Giardia cntcrica after Kofoid \& Swezy (1922). Trichomonamina: e, Hexamastix Termopsidis after Kirby (1930). f. Triccrcomitus Termopsidis after Kirby (1930). g, Hacrotrichomonas pulchra after Kirby (1938). h, Trichomonas tenax $\times$ 4,000 after Ilinshaw (1926). i, Pentatrichomonas obliqua after Kirby (1943). j, Snyderella Tabogae x 500 after Kirby (1929). x 2,000 except as noted. 
In making the clearly natural group of trichomonads a separate order, Kirby (1947) removed the majority of the species formerly assigned to this order, and left a miscellany of small isolated families. It seems not expedient to make them several small orders, as Grassé has done; rather they are to be held together until their respective relationships become evident. A hint of Hall has led in the present work to the transfer of family Trimastigida to order Ochromonadalea.

1. With a single nucleus and neuromotor system.

2. Cells not spirally twisted, at least not as wholes and not conspicuously.......... Family 1. Tetramitida.

2. Entire cells conspicuously spirally twisted.

3. With four free flagella............ Family 2. Streblomastigida.

3. With four or eight flagella whose proximal ends are grown fast to the cell membrane......................... Damily 3. Dinenymphida.

1. With one or several nuclei and two or more

neuromotor systems.........................

1. With two nuclei and neuromotor systems....... Family 5. Trepomonadida.

Family 1. Tetramitida [Tetramitidae] Kent Man. Inf. 1: 312 (1880). Families Tetramitina and Polymastigina Bütschli in Bronn Kl. u. Ord. Thierreichs 1: 841, 842 (1884). Family Tetramitaceae Senn in Engler and Prantl Nat. Pflanzenfam. I Teil, Abt. la: 143 (1900). Family Polymastigidae Doflein Protozoen 83 (1901). Family Chilomastigidae Wenyon (1926). Family Costiidae Kudo Handb. Prot. 153 (1931). Family Retortomonadidae Wenrich 1932. Gells mostly dorsiventral and with four flagella; these uniform or differentiated; when differentiated, one or two may trail behind the cell. Axostyles present or absent, parabasal bodies not reported. Like the order, the family is a miscellany; good authority has made as many as four families of the few genera. Tetramitus, free-living, unfamiliar. Costia, occurring usually as sessile parasites on fishes. Polymastix, in insects. Monocercomonoides, in insects and vertebrates. Chilomastix, in insects and vertebrates, cells marked by a cytostomal groove into which one of the flagella, shorter than the others, is recurved. The species which occurs in man (usually, as it appears, as a harmless commensal) is in most works called C. Mesnili; the correct name is apparently Chilomastix Hominis (Davaine) n. comb ${ }^{1}$. Current authority places next to Chilomonas the biflagellate Retortomonas, also in insects and vertebrates, and having cells of essentially the same structure.

1Kofoid (1920) gave the history involved in this combination. Davaine, 1860, described the flagellates Cercomonas Hominis var. A and var. B. The two forms are not of the same species, and Moquin-Tandon, in the same year, re-named them respectively $C$. Davaine $i$ and $C$. obliqua. They are not of the same genus, being respectively a Chilomastix and a Pentatrichomonas, under which genera they have various names. Kofoid named them respectively Chilomastix davainei and Trichomonas hominis. In so doing, he may be held to have exercised his right to choose a type in a group in which no type has been designated; but it is arguable on the contrary that an author who designates a var. A designates the type in doing so. It is on the basis of this argument that the new combination here published is applied to the Cercomonas Hominis var. A of Davaine. 
Family 2. Streblomastigida [Streblomastigidae] Kofoid and Swezy in Univ. California Publ. Zool. 20: 15 (1919). The only known species is Streblomastix Strix, a slender spirally twisted organism with four anterior flagella, free-swimming or attached in the gut of the termite Termopsis. The significance of the epithet Strix (a Greek noun meaning screech owl) as applied to this species is not clear.

Family 3. Dinenymphida [Dinenymphidae] Grassi in Atti Accad. Lincei ser. 5. Rendiconti Cl. Sci. 20, $1^{\circ}$ Semestre: 730 (1911). Elongate flagellates, the four or eight anterior flagella adherent to the body and spirally twisted with it, free at their distal ends. Often beset with spirochaets, which have been mistaken for additional flagella; the family has been misplaced in order Hypermastigina. Dinenympha and Pyrsonympha in termites; Saccinobaculus in the wood roach Cryptocercus.

Family 4. Oxymonadida [Oxymonadidae] Kirby in Quart Jour. Micr. Sci. n. s. 72: 380 (1928). Flagellates with radially symmetrical bodies including two or more neuromotor systems, entozoic in termites of subfamily Kalotermitinae. Each pear-shaped cell of Oxymonas has one nucleus and two neuromotor systems (Kofoid and Swezy, 1926). In Microrhopalodina (Proboscoidella) each cell contains a whorl of nuclei, each with its separate neuromotor system (Kofoid and Swezy, 1926; Kirby, 1928). These organisms are superficially closely similar to the Calonymphida, from which Kirby distinguished them.

Family 5. Trepomonadida [Trepomonadidae] Kent Man. Inf. 1: 300 (1880). Family Hexamitidae Kent op. cit. 318. Distomata Klebs in Zeit. wiss. Zool. 55: 329 (1893). Family Distomataccae Senn in Engler and Prantl Nat. Pflanzenfam. I Teil, Abt. 1a: 148 (1900). Flagellates each with two nuclei and two neuromotor systems. In most examples, each half-cell is dorsiventral, and the whole isobilateral, with two cytostomes. Most of the genera, Trepomonas, Gyromonas, Trigonomonas, are freeliving in fresh or foul waters and have been little studied. Hexamita occurs both freeliving and entozoic, in roaches and in all classes of vertebrates; the cells have eight flagella (Octomitus Prowazek and Urophagus Moroff are synonyms). In Giardia the half-cells are asymmetric, and the whole cells dorsiventral, with one cytostome. There are several species, serious pathogens in mammals. The valici name of the species in man, usually known as G. Lamblia, appears to be G. enterica (Grassi) Kofoid (1920).

\section{Order 3. Trichomonadina Grassé Traité Zool. 1, fasc. 1: 704 (1952).}

Order Trichomonadida Kirby in Jour. Parasitol. 33: 215, 224 (1947), preoccupied by family Tricilomonadidae Wenyon (1926).

Flagellates of the general nature of the Polymastigida having in each neuromotor system one trailing flagellum; axostyle present, rigid, apparently not homologous with the flagella; parabasal body present, disappearing during mitosis. Entozoic, the majority of the species, to the number of fully 150 , occurring in termites.

The base of the trailing flagellum may be underlain by a cresta, a more or less prominent body distinct both from parabasal body and from axostyle. The trailing flagellum may be grown fast to the cell membrane and converted into an undulating membrane; in this case it is underlain by a rod called the costa, apparently homologous with the cresta (Kirby, 1931).

Nuclear and cell division have becn described in Trichomonas by Kuczynski (1914), Kofoid and Swezy $(1915,1919$; the Trichomitus described in the latter year is a Trichomonas) and Iinshaw (1926). The centrosome (or a combined centrosome and blepharoplast, the centroblepharoplast of Kofoid and Swezy, 1919) lies 
outside the nuclear membrane. This structure divides and the daughter structures move apart along the nuclear membrane. They remain connected, usually until mitosis is complete, by a stainable strand, the paradesmose. Definite chromosomes, usually few in number, and an intranuclear spindle, are formed. Mitosis is completed by constriction of the nuclear membrane. In what appears to be the typical course of cell division, the rhizoplast and blepharoplast divide when the centrosome does. Of other parts of the neuromotor system, some may remain connected to one blepharoplast and some to the other; some may disappear. The parts needed to complete a neuromotor system are regenerated in each daughter cell.

1. With a single nucleus and neuromotor system.

2. Lacking a cresta, costa, or undulating membrane............................ Manily 1. Mogercomonadida.

2. With a trailing flagellum whose base is underlain by a cresta.............. Family 2. Devescovinida.

2. With a trailing flagellum grown fast to the cell membrane, forming an undulating membrane underlain by a costa..... Family 3. Trichomonadida.

1. With several nuclei and neuromotor systems. Family 4. CalonymphidA.

Family 1. Monocercomonadida [Monocercomonadidae] Kirby in Jour. Parasitol. 33: 225 (1947). Minute flagellates of the appearance of certain Tetramitida, but having a firm axostyle, the parabasal body disappearing and a paradesmose forming between the daughter centrosomes during mitosis; lacking a cresta, costa, or undulating membrane; entozoic in termites and other insects, and in all classes of vertebrates. Monocercomonas, Hexamastix, Tricercomitus.

Family 2. Devescovinida [Devescovinidae] Doflein Lehrb. Prot. ed. 3: 537 (1911). Subfamily Devescovininae Kirby in Univ. California Publ. Zool. 36: 215 (1931). Organisms with three anterior flagella and a larger trailing flagellum underlain by a cresta; confined to termites of the families Mastotermitidae, Hodotermitidae, and Kalotermitidae, being most abundant in the last. The cells, usually fairly large, ingest scraps of wood and are presumed to contribute to the lives of their hosts by digesting it. Devescovina, Gigantomonas, Macrotrichomonas, Foaina, Parajoenia, Metadevescovina. Spirochaets which share the habitat of these organisms are commonly found adhering to their cell membranes, and were mistaken for additional flagella in the original descriptions of some of the genera.

Family 3. Trichomonadida [Trichomonadidac] Wenyon Protozoology 1: 646 (1926). Flagellates with three or more flagella directed forward and one trailing, the proximal part of the latter grown fast to the cell membrane and forming an undulating membrane underlain by a costa. Entozoic in a wide variety of animals. Trichomonas, normally with four anterior flagella, is the most numerous genus. It occurs in termites, including those of the advanced family Termitidae, in which scarcely any other flagellates occur; it does not ingest wood, and is not believed to be beneficial to its hosts. It occurs also in all classes of vertebrates. Man harbors Trichomonas tenax as a commensal in the mouth. T. vaginalis may be a serious pathogen. Pentatrichomonas obliqua (Moquin-Tandon) comb. nov.,1 commensal (or pathogenic?') in the gut has at the anterior end a fifth flagellum separate from the other four (Kirby, 1943).

${ }^{1} \mathrm{cf}$. footnote, p. 165. 
Family 4. Calonymphida [Calonymphidae] Grassi in Atti Accad. Lincei ser. 5, Rendiconti Cl. Sci. 20, $1^{\circ}$ Semestre: 730 (1911). Flagellates with radially symmetrical bodies including more than two nuclei and neuromotor systems, the latter of trichomonad type; entozoic in termites of subfamily Kalotermitinae. These flagellates ingest scraps of wood and are believed to contribute to the nutrition of their hosts. In Coronympha each cell contains one whorl of nuclei each with its separate neuromotor system (Kirby, 1929). In Stephanonympha, the nuclei and neuromotor systems are so numerous as to form a spiral band of several cycles in the anterior part of the cell. In Calonympha, besides numerous neuromotor systems associated with nuclei, there are others free of any nucleus; in Snyderella, the two types of structures are independently multiplied.

Order 4. Hypermastigina Grassi in Atti Accad. Lincei ser. 5, Rendiconti Cl. Sci. 20, $1^{\circ}$ Semestre: 727 (1911).

Order Trichonymphidea Poche in Arch. Prot. 30: 149 (1913).

Order Hypermastigida Calkins Biol. Prot. $2 \overline{95}$ (1926).

Order Lophomonadida Light in Univ. California Publ. Zool. 29: 486 (1927).

Orders Joeniidca, Lophomonadina, Trichonymphina, and Spiratrichonymphina, Grassé Traité Zool. 1, fasc. 1: 837, 851, 862, 916 (1952).

Flagellates, mostly large and of radial symmetry, with single nuclei and indefinitely numerous flagella. Entozoic in roaches and in termites excluding those of family Termitidae. Lophomonas is to be regarded as the type.

Cleveland $(1925,1926)$ found it possible, by starvation or by exposure to high pressures of oxygen or high temperatures, to rid insects of all of their intestinal flagellates or of some of the kinds. When completely frced of flagellates, wood roaches and termites of the lower families are able to remain alive only for a few wecks. The life of Termopsis is not prolonged by the presence of Streblomastix, and it is prolonged only moderately by the presence of Trichomonas Termopsidis. But if infested with either Trichonympha Campanula or T. sphaerica, it can survive indefinitely on a diet of pure cellulose. Both species ingest the ground scraps of wood which reach the part of the intestine in which they occur; it is evident that they serve their hosts as agents of digestion. Cleveland's observations raise unanswered questions as to the occurrence of fixation of nitrogen; it is known only that termites are quite economical in their use of nitrogenous compounds available to them.

The Hypermastigina have elaborate neuromotor systems. There is regularly a large centroblcpharoplast. In what appears to be the relatively primitive type of ccll division, as in Trichonympha (Kofoid and Swczy, 1919), the neuromotor system of the mother cell is divided between the daughter cells. In Spirotrichonympha (Cupp, 1930), only the centroblepharoplast divides; the neuromotor system of the motiner cell remains attached to one of the daughter centroblcpharoplasts, while the other generates the remaining parts of a complete system. In Lophomonas (Kudo, 1926), and Kofoidia (Light, 1927), the ncuromotor system of a dividing cell is absorbed or discarled, with the exception of the centroblepharoplasts, from which new systems develop.

In Trichonympha and Spirotrichonympha the details of nuclear division have much the appcarance of meiosis. A double set of chromosomes appears, and the chromosomes form pairs which are divided in the spindle. It is supposed that this appearance is produced by a precocious splitting of the chromosomes. 
In species of Trichonympha, Leptospironympha, and Eucomonympha from the wood roach Cryptocercus, Cleveland $(1947,1948)$ observed the syngamy of undifferentiated or differentiated gametes; the appearance of the process is as though the egg ingested the sperm. Syngamy is followed immediately by meiosis. This means that vegetative individuals are haploid. Barbulanympha achieves without syngamy an alternation of haploid and diploid stages. Diploid cells are produced when a centroblepharoplast fails to divide, with the result that the nucleus remains intact, while chromosomes appear and divide. Reduction division, by the separation of undivided chromosomes, occurs when a centroblepharoplast divides at an exceptionally early stage. Cleveland concluded that the early division of the central body is the event which primarily distinguishes meiosis from mitosis. It is possible that he has recognized an essential feature of the evolution of the sexual cycle. His words suggest the idea that the sexual cycle may have originated within the present group. This is an impossibility; the sexual cycle is a normal character of nucleate organisms, and is fully established in nucleate organisms far more primitive than these.

There are fewer than one hundred known species of Hypermastigina. They are treated as seven families.

1. Body without segmented appearance.

2. Flagella distributed generally over the surface of the body or its anterior part.... Family 1. TRTCHONYMPHIDA.

2. Flagella in spiral bands............ Family 2. Holomastigotoidida.

2. Flagella in tufts.

3. Flagella in a single tuft........... Family 3. LopHomonadida.

3. Flagella in two tufts............. Family 4. HoplonympHida.

3. Flagella in four tufts............... Family 5. Staurojoentida.

3. Flagella in many tufts........... Family 6. KofordmDA.

1. Body with segmented appearance........... Family 7. Teratony MPHida.

Family 1. Trichonymphida [Trichonymphidae] Leidy ex Doflein Lehrb. Prot. ed. 3: 537 (1911). The numerous flagella distributed generally over the surface of the body or its anterior part. Trichonympha (Leidyopsis), Eucomonympha, etc.

Family 2. Holomastigotoidida [Holomastigotoididae] Janicki in Zeit. wiss. Zool. 112: 644 (1915). Family Spirotrichonymphidae Grassi in Mem. Accad. Lincei Cl. Sci. ser. 5, 12: 333 (1917). The numerous flagella arranged in spiral bands. Holomastigotoides, Spirotrichonympha, etc.

Family 3. Lophomonadida [Lophomonadidae] Kent Man. Inf. 1: 321 (1880). Family Joeniidae Janicki in Zeit wiss. Zool. 112: 644 (1915). The numerous flagella assembled in a single anterior tuft. Lophomonas, in cockroaches, all of the flagella directed forward. Joenia, Joenina, Joenopsis, etc., in termites, the outer flagella directed backward.

Family 4. Hoplonymphida [Hoplonymphidae] Light in Univ. California Publ. Zool. 29: 138 (1926). The flagella assembled in two anterior tufts. Hoplonympha, Barbulanympha, etc.

Family 5. Staurojoeninda [Staurojoenindae] Grassi in Mem. Accad. Lincei Cl. Sci. ser. 5, 12: 333 (1917). The flagella assembled in four anterior tufts. Staurojoenina.

Family 6. Kofoidiida [Kofoidiidae] Light in Univ. California Publ. Zool. 29: 485 (1927). The flagella fused at their bases into several bundles. Kofoidia, a single known species in Kalotermes.

Family 7. Teratonymphida [Teratonymphidae] Koidzumi in Parasitology 13: 303 (1921). Family Cyclonymphidae Reichenow. Elongate and segmented, with a single 


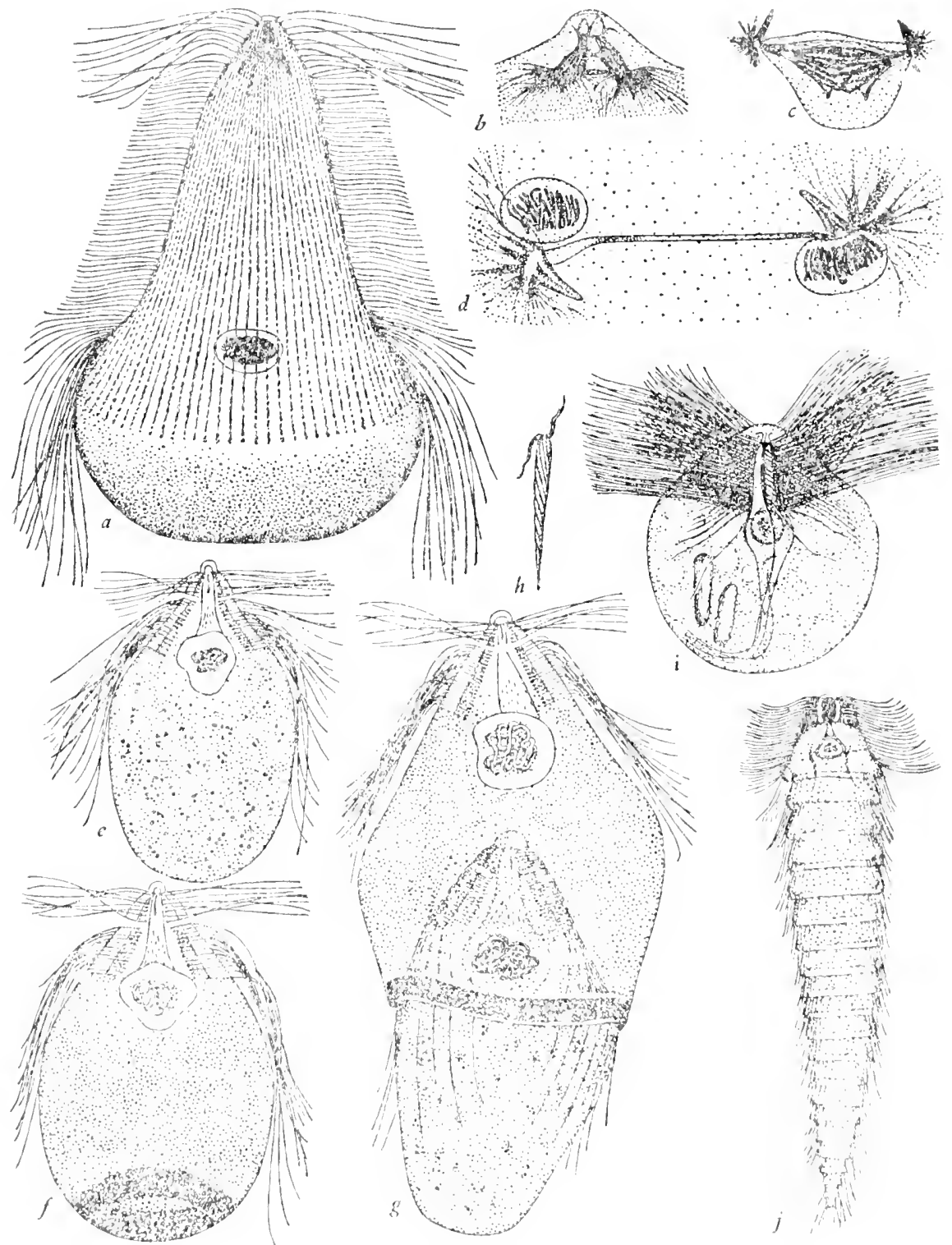

Fig. 32.-IIypermastigina: a-d, Trichonympha Campanula after hofoid \& Swezy (1919); a, cell x 250; b, division of centroblepharoplast and formation of paradesmose, and $\mathbf{c}$ and $\mathbf{d}$, earlicr and later stages of mitosis x 500. e, f, g. Sperm, egg, and fertilization of Trichonympha sp. from the roach Cryptoccreus after Cleveland (1948). h, IIoplonympha Natator x 250 after Light (1926). i, Staurojocnina assimilis $\times 250$ after Kirby (1926). j. Toratonym tha mirabilis after Koidzumi (1921). 
nucleus in the anterior segment; flagella distributed generally on the surface, most abundant on an anterior beak. Teratonympha Koidzumi (Cyclonympha Dogiel), a single known species in Reticulitermes.

\section{Class 2. MYCETOZOA de Bary}

Order Dermatocarpi Persoon Syst. Meth. Fung. xiii (1801), in part.

Suborder Myxogastres Fries Syst. Myc. 3 : 3 (1829); suborder Trichospermi Fries op. cit. 1: xlix (1832), in part.

Suborder Myxomycetes Link 1833.

Mycetozoen de Bary in Bot. Zeit. 16: 369 (1858); Zeit. wiss. Zool. 10: 88 (1859).

Stamm Myxomycetes Haeckel Gen. Morph. 2: xxvi (1866).

Class Mycetozoa de Bary ex Rostafinski Versuch Systems Mycetozoen 1 (1873).

Division Mycetozoa and classes Myxogasteres and Phytomyxini Engler and Prantl Nat. Pflanzenfam. II Teil: 1 (1888).

Division Myxothallophyta Engler in Engler and Prantl Nat. Pflanzenfam. I Teil, Abt. 1: iii (1897).

Stamm Myxophyta Wettstein Handb. syst. Bot. 1: 49 (1901).

Division Phytosarcodina, Myxothallophyta, or Myxomycetes Engler Syllab. ed. 3: 1 (1903).

Division Myxomycophyta Tippo in Chron. Bot. 7: 205 (1942).

Order Mycetozoida Hall Protozoology 227 (1953).

Organisms whose walled resting cells produce in germination anteriorly uncqually biflagellate cells; these giving rise to bodies called plasmodia, being multinucleate bodies of amoeboid character.

1. Predatory, subaerial, producing macroscopic spore-bearing fruits.

2. Spores produced within the fruits........... Order 1. EntermieA.

2. Spores produced on the surfaces of the

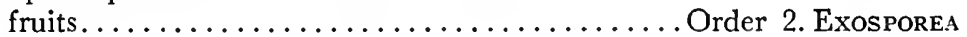

1. Parasitic, not producing definite fruits.......... Order 3. Рнутомухиа.

Order 1. Enteridiea [Enteridieae] Rostafinski Vers. 3 (1873).

Cohort Endosporeae and orders Anemeae, Heterodermeae, Reticularieae, Anaurochaeteae, Calcareae, and Calonemeae Rostafinski op. cit.

Order Endosporea Lankester in Enc. Brit. ed. 9, 19: 840 (1885).

Orders Protodermieae and Columniferae Rostafinski ex Berlese in Saccard., Sylloge 7: 328, 417 (1888).

Cohorts Amaurosporales and Lamprosporales, with numerous orders with names in -aceae, Lister Monog. Mycetozoa 21-23 (1894).

Subclass Myxogastres and orders Physaraceae, Stemonitaceae, Cribrariaceae, Lycogalaceae, and Trichiaceae Macbride North American Slime Molds 20 (1899).

Subsuborder (!) Endosporinei Poche in Arch. Prot. 30: 200 (1913).

Orders Physarales, Stemcnitales, Cribrariales, Lycogalales, and Trichiales Macbride op. cit. ed. ? (1922).

Order Liceales Ma, bride and Martin (1934).

Suborder Eumycetızoina Hall Protozoology 230 (1953). 
Predatory Mycetozoa producing macroscopic fruits, these producing internal uninucleate spores. The type is Lycogala, the sole genus of the order as originally published.

The fruits of many examples are of the appearance of minute puffballs, and Persoon and Fries classified them as puffballs; Fries took note that they are primitus mucilaginosi and made them a suborder distinct from the proper puffballs. De Bary studied the non-reproductive stages; concluded "dass die Myxomyceten nicht dem Pflanzenreiche angehören, sondern dass sie Thiere, und zwar der Abtheilung der Rhizopoden angehörig, sind"; and renamed the group Mycetozoen. This name was apparently first published in Latin form, in the category of classes, by de Bary's student Rostafinski. Conventional botany continues to list Myxomycetes as a class of Fungi; conventional zoology unakes the group an order of Rhizopoda or Sarcodina.

The spores germinate readily in water or appropriate solutions (Jahn, 1905; Gilbert, 1929; Smith, 1929). Their nuclei usually divide once or twice, during or just after germination; thus each spore produces from one to four naked cells.

It is in germinating spores that mitosis is most easily observed. Mitosis takes place in a clear area, about which some observers have found a persistent nuclear membrane. The spindle is sharp-pointed. Only a few observers (as Skupienski, 1927) have discerned definite centrosomes. When the onc or two divisions associated with germination are complete, the flagella grow forth from the areas of the poles of the mitotic spindle. All earlicr observers described the spores as uniflagellate, but Ellison (1945) and Elliott (1949) found them biflagellate. The flagella may be apparently equal or moderatcly unequal; or one of them may be very brief. Each nucleus remains connected to the base of the flagella by a conical body of clear protoplasm, the Geisselglocke of Jahn (Jahn, 1904; Howard, 1931).

The flagellate cells are not spores, but gametcs; they fuse with each other. Skupienski (1917) affirms that they are of two mating types. Fusion is at first by pairs, and Howard (1931) found that each zygote develops into a plasmodium by itself. All other observers (de Bary, 1858, 1859; Cicnkowski, 1863; Skupienski, 1917, 1927; Schünemann, 1930) have found the zygotes to fuse with each other and with further gametes. The flagella are lost. The nuclei fuse in pairs; those which fail to find partners are digested.

The cell formed by the fusion of zygotes and gametes is a young plasmodium. The term was coined by Cienkowski (1863, p. 326): "Das Protoplasmanetz der Myxonyceten werde ich mit den Namen Plasmodium bezeichnen." The plasmodium nourishes itself in predatory fashion, on fungus spores, bacteria, and other cligestible objects, and grows accordingly. Mitosis occurs simultancously in all nuclei of the plasmodium, and takes 20 to 40 minutes; it has accordingly only rarely been observed (Lister, 1893; Iloward, 1932). Plasmodia do not ordinarily divide, but grow to great sizes. They are not very familiar objects because during most of their life they keep to dark and moist places, chicfly among vegetable remains. Drouth does not kill them; they can become dry and hard while retaining the capacity to resume activity upon the return of moisture. When an active plasmodium reaches a certain stage, its reactions change; it moves out into the light and to dry places. A plasmodium in this stage is conspicuons, being of the form of a network which may be many centimeters in diameter, in some species brilliantly colored. The whole is a single naked protoplast.

Each plasmodium procecds to produce a fruit or fruits. The entire mass may heap itsclf up, or it may break up into portions, large or minutc. In specics whose plasmodia break up into small fragments, each of these may secrete a column of lifeless 
material, a millimeter or more in height, and ascend upon it. Each separate body of protoplasm secretes an external wall and begins to undergo cleavage within it. Harper (1900) described the details of the process. All authorities agree that the nuclei undergo a flare of divisions at this time (Strasburger, 1884; Harper, 1900, 1914; Bisby, 1914). It is almost ccrtain that there arc two flares of division, constituting the meiotic process, but few authoritics have positively affirmed this (Schünemann, 1930 $)^{1}$. Cleavage is carried to the point of producing uninucleate protoplasts. While this is taking place, many species secrete a network of hollow tubes or a system of hollow fibers, called the capillitium, by deposition of lifeless material outside the cell membranes. In species which produce a truc capillitium, all of the uninucleate protoplasts secrete walls and become spores. Strasburger found the capillitium and the walls of the spores to consist of impure cellulose; others have found no cellulose. In many species which do not produce a true capillitium, an analogous structure called a pseudocapillitium, consisting of solid bodies of various forms, is modelled from a part of the nucleate protoplasin which is deprived of its reproductive function and killed. In many species, much calcium carbonate is deposited in the wall, or both in the wall and in the capillitium or pseudocapillitium.

A small separate fruit is called a sporangium. A fruit of the form of a large mass, or of many sporangia not completely separate, is an aethalium. The spores are released by collapse of the outer wall.

These organisms are of no known economic importance. There are some forty genera, between four and five hundred species. As Lister remarked, the same species occur everywhere: collections from Colombia (Martin, 1938) and from Mount Shasta (Cooke, 1949) consist entirely of familiar species.

Rostafinski (1873) arranged the genera in two cohorts, seven orders, and nineteen tribes, the last with names in -aceae. His subsequent monograph of the group (1875) was regrettably published in a barbarous language, and is for nomenclatural purposes a nullity. All later systems are based on Rostafinski's original system. The group being essentially uniform, it is properly treated as a single order.

Definite families were first established by Lankester, mostly under names which Rostafinski had applied to tribes. Berlese (in Saccardo, 1888) provided a complete set of names in -aceae, valid under botanical rules; Poche provided a complete set in -idae, valid under zoological rules. Authorities have differed moderately as to the list of families; here, somewhat arbitrarily, fourteen are maintained.

1. Capillitium none (order Cribrariales Macbride).

2. Producing separate sporangia, pseudocapillitium none.

3. Sporangia shattering irregularly or opening through a terminal operculum.................. Family 1. Ligeacea.

3. Sporangia opening through numerous pores, the walls becoming sieve-

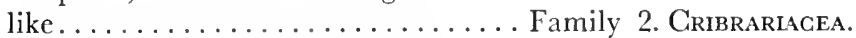

2. Fruits acthalioid, pseudocapillitium present.

1While the present work was in proof, Wilson and Ross (1955) established the point that meiosis occurs immediately before the formation of spores. 
3. Aethalia consisting of more or less separate sporangia.

4. Sporangia tubular, opening through terminal pores......... Family 3. TubifERIDA.

4. Sporangia indistinct, their walls becoming freely punctured and converted into a reticulate pseudocapillitium............ Family 4. Reticulariacea.

3. Aethalia not consisting of distinguishable sporangia.............. Family 5. Lycogalactida.

\section{Gapillitium present.}

2. Fruits without considerable deposits of calcium carbonate.

3. Spores black or dark, capillitial hairs smooth (order Stemonitales Macbride).

4. Fruits aethalioid, capillitium poorly defined, without a central axis................ Family 6. Amaurochaetacea.

4. Fruits of separate sporangia with a definite capillitium including a central axis (columella).

5. Capillitium spreading horizontally from the columella................ Family 7. Stemontea.

5. Capillitium spreading chiefly from the summit of the columella.............Family 8. Enerthenemea.

3. Spores pallid or yellow (order Trichiales Macbride).

4. Capillitial hairs smooth, unbranched or sparsely branched.

5. Capillitial threads horizontal, attached at both ends...................Family 9. Margaritida.

5. Capillitial threads running at random, not attached at the cnds......... Family 10. Perichaenacea.

4. Capillitium reticulate, sculptured, but not with spiral bands. . Family 11. Arcririces.

4. Capillitial threads unbranched or sparsely branched, sculptured with spiral bands..........Family 12. Trichiacea.

2. Fruits containing considerable deposits of calcium carbonate (order Physarales Macbride).

3. Calcium carbonate both in walls and in capillitium............... Family 13. Physarea. 
3. Calcium carbonate in walls but not in capillitium................. Family 14 . Didymacea.

Family 1. Liceacea [Liceaceac] (Rostafinski) Lankester in Enc. Brit. ed. 9, 19: 841 (1885). Tribe Liceaceae Rostafinski Vers. 4 (1873). Order Liceaceae Lister Monog. Mycetozoa 149 (1894). Family Liccidae Doflein 1909. Family Orcadellidae Poche in Arch. Prot. 30: 200 (1913). Family Orcadellaceae Macbride N. Am. Slime Molds ed. 2: 203 (1922). Sporangia separate, sessile or stalked, without capillitium or pseudocapillitium, the walls shattering irregularly or opening by means of a terminal operculum. Licea, Orcadella.

Family 2. Cribrariacea [Cribrariaceae] (Rostafinski) Lankester 1. c. Tribe Cribrariaccae Rostafinski op. cit. 5. Order Cribrariaceae Macbride N. Am. Slime Molds 20 (1899). Order Heterodermaceae Lister op. cit. 136. Family Cribrariidae Poche 1. c. The wall of the stalked fruit becoming sieve-like. Cribraria. Dictydium.

Family 3. Tubiferida [Tubiferidae] Poche in Arch. Prot. 30: 200 (1913). Order Tubulinaceae Lister op. cit. 152 (1894). Family Tubulinidae Doflein 1909. Family Tubiferaceae Macbride in N. Am. Slime Molds ed. 2: 203 (1922). Aethalia consisting of tubular sporangia opening through terminal pores. Tubifer (its older name Tubulina preoccupied), Lindbladia, Alwisia.

Family 4. Reticulariacea [Reticulariaceae] (Rostafinski) Lankester 1. c. Tribes Dictydiaethaliaceae and Reticulariaceae Rostafinski op. cit. 5, 6. Order Reticulariaceae Lister op. cit. 156. Family Dictydiaethaliidae Poche 1.c. Aethalia of indistinct sporangia whose walls become porous and are converted into a reticulate pseudocapillitium. Reticularia, Dictydiaethallium, etc.

Family 5. Lycogalactida [Lycogalactidae] Poche in Arch. Prot. 30: 201 (1913). Tribe Lycogalaceae de Bary. Order Lycogalaceae Macbride N. Am. Slime Molds 20 (1899). Family Lycogalaceae Macbride and Martin Myxomycetes (1934). Aethalia with a pseudocapillitium, not divided into sporangia. Lycogala, the brownish fruits a $\mathrm{few}$ millimeters in diameter clustered on wood, of much the appearance of small puffballs.

Family 6. Amaurochactacea [Amaurochaetaceae] (Rostafinski) Berlese in Saccardo Sylloge 7: 401 (1888). Tribe Amaurochaetaceae Rostafinski op. cit. 8. Order Amaurochactaceae Lister op. cit. 134. Family Amaurochactidae Doflein 1909. Fruits aethalioid with dark spores and a poorly defined capillitium without a central axis. Amaurochaete.

Family 7. Stemonitea Lankester in Enc. Brit. ed. 9, 19: 841 (1885). Tribes Stemonitaceae and Brefeldiaceae Rostafinski op. cit. 6, 8. Families Stemonitaceae and Brefeldiaceae Berlese in Saccardo op. cit. 390, 402. Order Stemonitaceae Macbride N. Am. Slime Molds 20 (1899). Family Stemonitidae Doflein 1909. Families Brefeldiidae and Stemonitidae Poche op. cit. 202. Sporangia with dark spores and a capillitium of smooth threads spreading from a central axis, the columella. Stemonitis, common, the clustered stalked fruits of the appearance of minuscule dark bottle-brushes. Brefeldia, Comatricha; Diachca, exceptional in containing much lime in the stalk and wall.

Family 8. Enerthenemea Lankester 1. c. Tribes Echinosteliaceae and Enerthenemaceae Rostafinski op. cit. 7, 8. Families Echinosteliaceae and Enerthenemaceae Berlese in Saccardo op. cit. 389, 402. Family Lamprodermacece Macbride N. Am. Slime Molds ed. 2: 189 (1922). Like Stemonitea, in which this family has usually been included, but the capillitium attached chiefly at the summit of the columella. Enerthenema, Clastoderma, Lamproderma, Echinostelium. 
Family 9. Margaritida [Margaritidae] Doflein 1909. Order Margaritaccae Lister op. cit. 202. Family Dianemaceae Macbride N. Am. Slime Molds ed. 2: 237 (1922). Sporangia with pale or yellow spores and a capillitium of smooth threads attached at both ends. Dianema, Margarita.

Family 10. Perichaenacea [Perichaenaceae] (Rostafinski) Lankester 1. c. Tribe Perichacnaceae Rostafinski op. cit. 15. Sporangia with pale or yellow spores and a capillitium of unattached smooth threads. Perichaena, Ophiotheca.

Family 11. Arcyriacea [Arcyriaccae] (Rostafinski) Lankester 1. c. Tribe Arcyriaceae Rostafinski op. cit. 15. Order Arcyriaceae Lister op. cit. 182. Family Arcyriidae Doflein 1909. Sporangia with pale or yellow spores and a reticulate capillitium, usually sculptured, but not with spiral bands. Arcyria, Lachnobolus.

Family 12. Trichiacea [Trichiaceae] (Rostafinski) Berlese in Saccardo Sylloge 7: 437 (1888). Tribe Trichiaceae Rostafinski op. cit. 14. Family Trichinaceac Lankes-

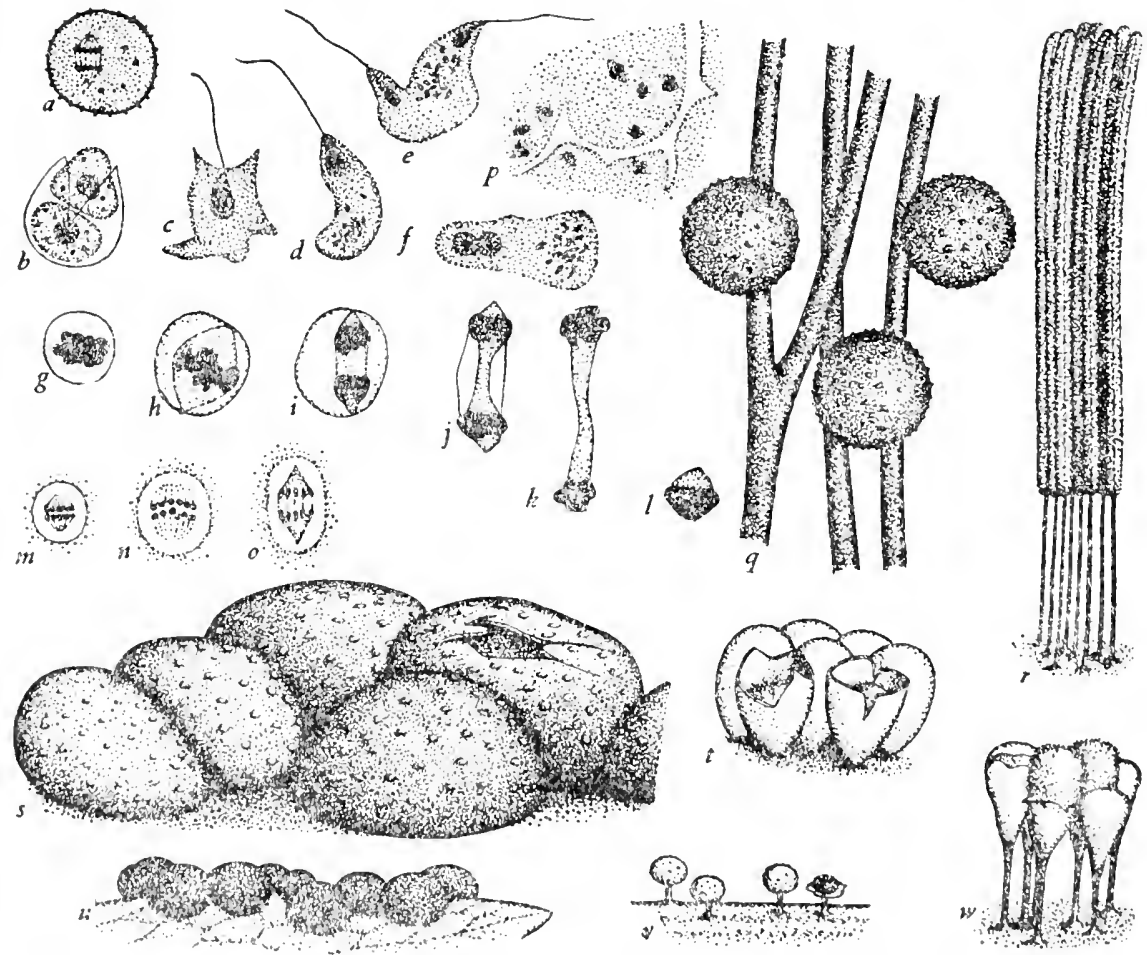

Fig. 33.-MrcetozoA. a-f, Spore, germination, gametes, syngamy, and zygote of Physarum polycephalum after Iloward (1931) x 1,000. g-I, Stages of mitosis in the plasmodium of Physarum polycephalum after Howard (1932) x 2,000. m-o, Stages of mitosis in the plasmodium of Trichia after lister (1893) x 1,000. p, Cleavage in the developing fruit of Physarum polyccphalum after Howard (1931) x 1,000. q, Capillitium and spores of Lepidoderma Chailletii x 1,000. r-w, fruits of Myceteza x 5; r, Stemonitis splendens; $\mathbf{s}$, Lycogala cpidendrum; $\mathbf{t}$, Leocarpus fragilis; u, Le fidoderma Chaillettii; v, Physarum notabile; w, Hemitrichia intorta. 
ter 1. c.; the genus Trichina does not belong to this family! Order Trichiaceac Macbride N. Am. Slime Molds 20 (1899). Family Trichiidae Doflein 1909. Sporangia with pale or yellow spores, the capillitium of free threads, unbranched or sparsely branched, marked with spiral bands. Trichia, Hemitrichia, Oligonema, Calonema.

Family 13. Physarea Lankester 1. c. Tribes Cienkowskiaceae, Physaraccae, and Spumariaceac Rostafinski op. cit. 9, 13. Families Cienkowskiaceae, Physaraceae, and Spumariaceae Berlese in Saccardo op. cit. 328, 329, 387. Order Physaraceac Macbride N. Am. Slime Molds 20 (1899). Family Physaridae Doflein 1909. Fruits sporangial or aethalioid, with capillitium, both wall and capillitium containing considerable deposits of calcium carbonate. Physarum, with some seventy-five species, is the most numerous genus of Mycetozoa; the little gray sporangia may be spherical or irregular, sessile or stalked. Fuligo septica produces dirty yellow aethalia reaching several centimeters in diameter on vegetable trash; observed on spent tan bark, it has the common name of flowers of tan. Badhamia, Craterium, Leocarpus, Chondrioderma, Spumaria, etc.

Family 14. Didymiacea [Didymiaceae] (Rostafinski) Lankester 1. c. Tribe Didymiaceae Rostafinski op cit. 12. Order Didymiaceae Lister op. cit. 93. Family Didymidae Doflein 1909. Family Didymiidae Poche op. cit. 202. Family Collodermataceae Macbride and Martin Myxomycetes 145 (1934). Sporangia with deposits of calcium carbonate in the wall and a simple capillitium free of mineral deposits. Didymium, Leangium, Lepidoderma, Colloderma.

Order 2. Exosporea (Rostafinski) Lankester in Enc. Brit. ed. 9, 19: 841 (1885).

Cohors Exosporcae Rostafinski Vers. 2 (1873).

Order Ectosporcae Engler Syllab. 2 (1892).

Order Ceratiomyxaceae (Schröter) Lister Monog. Mycetozoa 25 (1894).

Subsuborder (!) Exosporinei Poche in Arch. Prot. 30: 200 (1913).

Organisms of much the character of the Enteridiea, but the spores forming a single layer on the surface of the fruits. There is a single family with only one well-marked species.

Family Ceratiomyxacea [Ceratiomyxaceae] Schröter (in Engler and Prantl, 1889). Ceratiomyxa Schröter (Ceratium Albertini and Schweinitz, 1805, non Schrank, 1793); C. fruticulosa (O. F. Müller) Macbride. The fruits are white pillars, sometimes branched, 1-2 mm. tall, of secreted material. Each spore of the single superficial layer generates a microscopic stalk and ascends upon it before becoming walled. Meiosis then takes place, making the spores 4-nucleate; the chromosome number is cut from 16 to 8 (Gilbert, 1935). In germination, the contents of the spore are released as a single amoeboid protoplast, whose nuclei divide once; the cell then divides into eight, and these generate flagella (Rostafinski, 1873; Jahn, 1905; Gilbert, 1935).

Order 3. Phytomyxida Calkins Biol. Prot. 330 (1926).

Class Phytomyxini Engler and Prantl Nat. Pflanzenfam. II Teil: 1 (1889); class Phytomyxinac op. cit. I Teil, Abt. 1: iii (1897).

Order Phytomyxinae Campbell Univ. Textb. Bot. 71 (1902).

Class Plasmodiophorales Engler Syllab. ed. 3: 1 (1903).

Order Plasmodiophorales Sparrow in Mycologia 34: 115 (1942).

Suborder Plasmodiophorina Hall Protozoology 228 (1953).

Intracellular parasites chiefly of higher plants, attacking also algae, Oomycetes, and beetles, being naked multicellular plasmodia producing walled resting cells, 
the walls containing no cellulose; these releasing naked infective cells with paired unequal simple flagclla.

This inconsiderable group was made known by the discovery of Plasmodiophora Brassicae, the agcint of the clubroot disease of cabbage, by Woronin (1878). The proper place of the group in classification has been a puzzle; some students treat it as a class of myxomycetes, others as an order of chytrids. The known characterspaired uncqual simple flagella; cells naked in the vegetative condition; and non-production of cellulose-assure us that this group has nothing to do with proper chytrids, ror with Oomycetes of chytrid body type. The traditional association with myxomycetes is tenable. Alternatively, the group would not be out of place next to order Rhizoflagellata (anyone who chooses to put it there should take note that the class name Phytomyxini is older than Zoomastigoda).

The plasmodium causes often much hypertrophy of the host tissue. In some forms the mature plasmodium becomes walled; the protoplast undergoes cleavage into uninucleate portions; these become swimming cells and are released through a discharge tube. These forms are of much the appearance of Lagenidialea. In the majority of the group the naked plasmodium undergocs cleavagc; the resulting protoplasts bccome walled; the resulting sporcs or cysts, released by decay of the host, discharge their contents as one or two swimming cells. Ledingham (1939) and Sparrow (1947) report both types of development as occurring in Polymyxa. Karling (1944) found the walls to contain no cellulose. Ellison (1945) found the flagella to be simple.

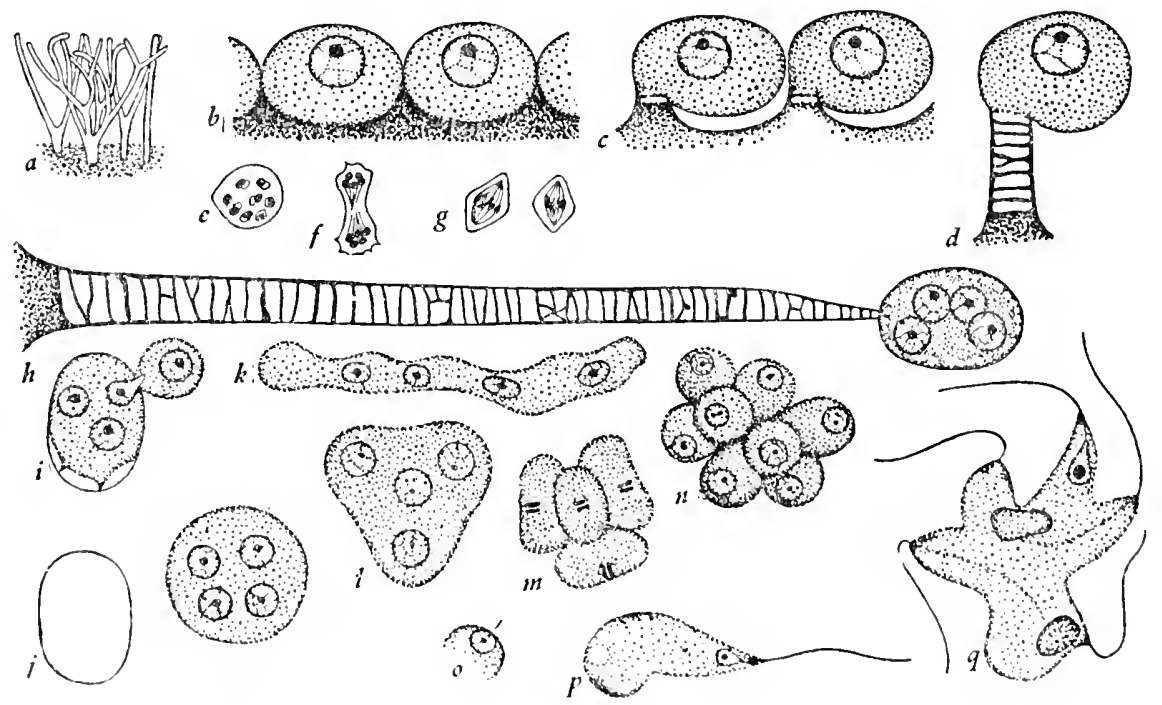

Fig. 34.-Ceratiomyxa fruticulosa. a, Fruits $\times 5$. b-q, reproductive processes after Gilbert (1935); b, young spores on the surfaces of the fruit; $\mathbf{c}$, $\mathbf{d}$, the same raised on stalks; $\mathbf{e , ~} \mathbf{f}$, hetcrotypic division; $\mathbf{g}$, homeotypic division; $\mathbf{h}$, the mature spore on its stalk; i-n, germination and subsequent processes: the amocboid protoplast pas"es through a "threarl stage" before rounding up and dividing into four and then into eight; $\boldsymbol{\theta}$, production of Hagellum; $\mathbf{p}$, "zoospore" (gamcte); $\mathbf{q}$, ganctes fusing to initiate the plasmodium. All $\times 1,000$ except Fig. a. 
In the growing plasmodium, a nucleus which is not dividing contains an endosome ("nucleolus"). During mitosis, which occurs within the intact nuclear membrane, the endosome becomes elongate, and a ring of chromatin, within which separate chromosomes have not been distinguished, forms about its middle. The resulting "cruciform" figure resembles some which have been seen in trypanosomes. The nuclear divisions which occur immediately before cleavage are of a different character: no endosome is seen, but there is a spindle with centrosomes at the poles, and definite chromosomes are present. The occurrence of these two types of nuclear division has been noted by every careful observer, Schwartz (1914), Horne (1930), Cook (1933), Ledingham (1939), and Karling (1944). Horne was probably correct in supposing the divisions which precede cleavage to be meiotic. Conjugation of the flagellate cells of Spongospora has been observed.

There are monographic accounts of the Phytomyxida by Cook (1933) and Karling (1942). The group may be treated as a single family with a dozen genera and about twenty-five species.

Family Plasmodiophorea [Plasmodiophoreae] Berlese in Saccardo Sylloge 7: 464 (1888). Family Plasmodiophorcen Zopf Pilzthiere 129 (1885). Family Plasmodiophoraceae Engler Syllab. 1 (1892). Family Wroroninaceae Minden 1911. Families Phytomyxidae and Woroninidae Poche in Arch Prot. 30: 198 (1913). Plasmodiophora, Polymyxa, Spongospora, and Sorosphaera attack land plants; Tetramyxa, Ligniera, and Sorodiscus, chiefly aquatic seed plants; Woronina and Octomyxa, Oomycetes; Phagomyxa, brown algae; Sporomyxa (Léger, 1908) and Mycetosporidium, beetles.

\section{Class 3. RHIZOPODA Siebold}

Order Foraminifères d' Orbigny in Ann. Sci. Nat. 7: 128, 245 (1826).

Order Foraminifera Zborewski 1834.

Rhizopodes Dujardin in Compt. Rend. 1: 338 (1835).

Class Foraminifera d'Orbigny in de la Sagra Hist. Cuba vol. 8 (1839).

Order Polythalamia Ehrenberg in Abh. Akad. Wiss. Berlin (1838): table 1 (1839).

Class Rhizopoda and orders Monosomatia and Polysomata Siebold in Siebold and Stannius Lehrb. vergl. Anat. 1: 3, 11 (1848).

Reticulosa Carpenter 1862.

Stamm Rhizopoda and Class Acyttaria Haeckel Gen. Morph. 2: xxvii (1866).

Thalamophora R. Hertwig Hist. Radiolar. 82 (1876).

Class Reticularia Lankester in Enc. Brit. ed. 9, 19: 845 (1885).

Order Reticulosa Poche in Arch. Prot. 30: 203 (1913).

Order Granuloreticulosa de Saedeleer in Mem. Mus. Roy. Hist. Nat. Belgique 60: 7 (1934).

Order Foraminiferida Hall Protozoology 250 (1953).

Amoeboid organisms, the pseudopodia of the character of rhizopodia, i.e., fine, fieely branching and anastomosing; producing shells, these usually calcareous; commonly reaching macroscopic dimensions; mostly marine.

The first examples of rhizopodes mentioned by Dujardin were milioles, vorticiales, and le gromia: the genus Miliola is to be construed as the type. These organisms, the proper rhizopods, are in general usage called Foraminifera, but that name was originally applied in the category of orders. 


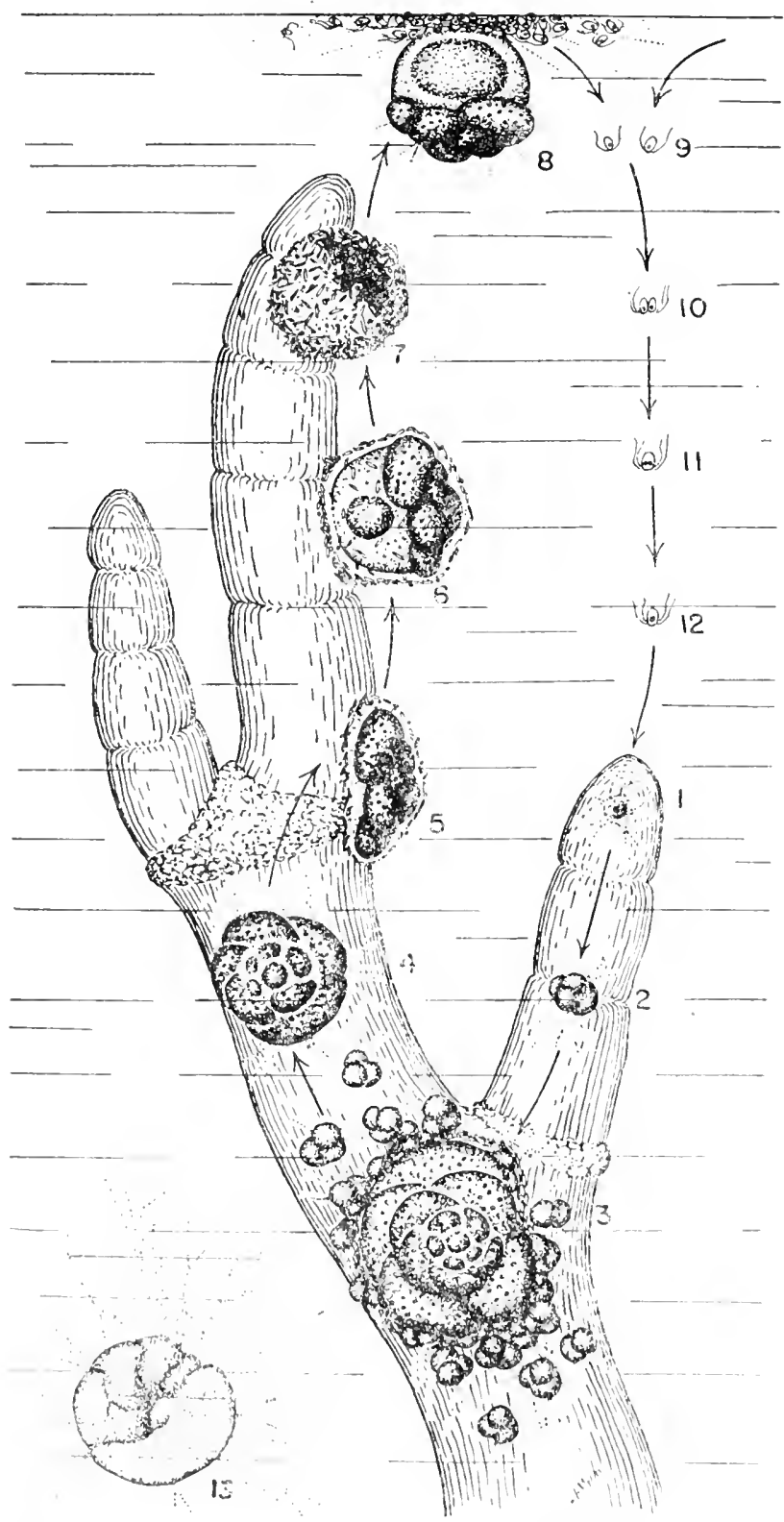

Fig. 35.- Life cycle of "Tretomphalus," i.e., Discorbis or Cymbalopora, from Myers (1913); 1-3, microspheric indivicluals, in 3 releasing young megalospheric individuals; 4-8 megalospheric individuals; 9-12, gametes and syngamy. 
The individual rhizopod originates as a minute amoeboid cell which secretes a shell from which the pseudopodia project. In the fresh-water forms, each protoplast, after moderate growth, divides into two, one of which retains the original shell while the other secretes a new one. In some of the marine forms, the original protoplast, having a cylindrical or irregular shell, enlarges this as it grows. In the great majority of the group, the original shell, called the proloculus, is of definite size and form and has a constricted orifice. When the protoplast reaches a certain stage, it expands, protrudes from the orifice, and secretes an extension of the shell in the form of a second chamber. In some few examples, the second chamber is the final one, being capable of indefinite extension. But again in the great majority, the second chamber, although different from the proloculus, resembles it in being definite in form and in having a constricted orifice. After further development, the protoplast again protrudes through the orifice and secretes a third chamber, generally of the same form as the second, though often larger. Repetition of this process produces macroscopically visible bodies. Even though becoming a centimeter or more in diameter, the individuals continue to be single cells.

As a result of different patterns of growth, the developed shells are of highly varied forms, linear, globular, or coiled in one plane; trochoid or rotaloid, that is, helical, of the form of a low cone; of the form of high cones; or screw-like, with the chambers in fixed longitudinal rows. The growth pattern may change during the life of the individual. There are apparently degenerate forms, simple or irregular. It is highly probable that some of the forms have evolvcd repeatedly.

The shells may be of gelatinous material or of chitin, without or with imbedded grains of sand. Exceptionally, they are siliceous. They are sometimes of crystallized calcium carbonate with imbedded grains of sand. In the bulk of the group they consist of crystallized calcium carbonate without foreign matter, and are of either of two types of texture: vitreous, that is, hyaline, and punctured by numerous pores a few microns in diameter; or porcellanous, white by reflected light and amber by transmitted light, and with no perforations except the proper orifices. In fossil shells, other textures than these may occur; it is supposed that these are products of modification during preservation. Some of the textures, like some of the forms, are believed to have evolved repeatedly.

Most rhizopods occur in two forms which are most readily distinguished by the size of the proloculi. This was first pointed out by Munier-Calmas, 1880; who, jointly with Schlumberger, 1885, designated the smaller and larger proloculi respectively microspères and mégasphères. Lister (1895), by study in culture of Elphidium crispum (Polystomella crispa Lamarck), showed that the two forms are alternate generations. He observed that the microspheric cells become multinucleate during growth, while the megalospheric cells remain uninucleate until just before reproduction. The reproduction of the megalospheric cells is by release of numerous minute biflagellate cells.

Schaudinn (1902) confirmed much of what Lister had observed. He was mistaken in describing nuclear division (except just before the production of the swimming rells) as non-mitotic; and correct in identifying the swimming cells as gametes. Winter (1907) observed a similar life cycle in Peneroplis, but described the gametes as having solitary flagella.

Myers (1934, 1935, 1936), dealing with Patellina and Spirillina, described the details of mitosis. This takes place within an intact nuclear membrane, and is completed by its constriction. The spindle is blunt-ended; there is no evidence of centro- 
somes. The chromosomes are numerous, long, and slender; the mitotic figures resemble those of Pyrrhopliyta. Reduction of the chromosome number is said to be effected by a single nuclear division, the last one before the formation of gametes, which cuts the chromosome number of Patellina from 24 to 12, and that of Spirillina from 12 to 6 . Before they reach this stage, the megalospheric individuals have gathered themselves in clusters of two or more within cyst walls consisting of secreted gelatinous matter and scraps from the neighborhood. Gametes from one individual are unable to unite with cach other. The gametes are amoeboid, positively without flagella. In Discorbis and Cymbalopora, however, Myers (1943) observed the production of biflagellate gametes.

Le Calvez (1950) has cleared up various questions raised by earlier studies. Some forms, as Discorbis orbicularis, appear to lack a sexual cycle. Patellina and Spirillina produce amoeboid gametes $40-50 \mu$ in diametcr. Most rhizopods produce biflagellate gametes 1.5-4 $\mu$ long. Le Calvez found the flagella definitely unequal. In Discorbis mediterrancnsis he showed that the megalospheric individuals are of two mating types. Earlier zoologists, apparently misled by familiarity with the normal life cycle of animals, had identified meiosis as occurring at the time of gametogenesis; it is the fact, on the contrary, that it occurs in the last two nuclear divisions in the microspheric individuals. The inegalospheric and microspheric stages of rhizopods are respectively haploid and diploid, like the gametophytes and sporophytes of plants.

With the possible exception of some of the one-chambered fresh water forms, the rhizopods are clearly a natural group. The fresh water forms appear to intergrade with organisms which Pascher identified as chrysomonads.

The shells of dead rhizopods may under appropriate conditions be preserved through geologic ages. Natural chalk consists of shells of Tcxtularia mixed with coccoliths. Certain forms of limestone consist chiefly of shells of Miliola. Certain fossil rhizopods have long been known as indicators of division of geologic time. Since about 1917, it has been found that the whole group offers one of the beautiful illustrations of evolution as related to geologic time: the shells of rhizopods found under magnification in a particular stratum serve promptly and precisely to identify it. The services of experts on "Foraminifera" have acquired a high economic value in the petroleum industry: these experts have found themselves promoted from the status of pure biologists to that of cconomic geologists.

Among some eleven hundred genera which have been published, Galloway (1933) maintains 542. Of the number of species one can only say that it is a matter of thousands, but probably not many tens of thousands. Economic micropalcontologists find themselves dealing with great numbers of forms which are slightly, yet significantly, distinct. They find it expedient not to name these, but to identify them by comparison with available collections.

Some of the marine and fossil forms are similar, on a small seale, to the animal Nautilus, and Linnacus placed some of them in that genus. Montfort and Lamarck treated them as several genera of mollusks. In first distinguishing these organisms as the order Foraminifères of class Céphlalopodes, d'Orbigny intended to contrast them with Nautilus, in whose shells a series of chambers are connected, not by holes (foramina) but by cylindrical tubes. Dujardin (1835) found that his Rhizo podes are without definite organs. Their shells enclose a clear semiliquid substance; their apparent tentacles are merely temporary structures, formed of this substance, thrust forward in the direction of the movement of the shell and withdrawn as it advances. Dujardin named this substance surcode; it is, of course, the same which has since becn called 
protoplasm. The effect of his discoveries was to show that the rhizopods or Foraminifera are not mollusks, but one-celled organisms.

Very much taxonomic study has been given to this interesting group. The standard system, in the modern period of practical concern with the group, has been that of Cushman (1928).

Galloway (1933), attempting to recognize phylogeny and concluding that certain types of form and texture of shells have evolved repeatedly, has radically revised Cushman's system and set up a system of thirty-five families. The following survey of the group is based on Galloway's system. The names applied to the families are those which he has cited as the oldest, and the groups treated as orders are the blocks of families which to him appeared natural.

1. Shell one-chambered, or of a proloculus followed by one other chamber, not of a series of similar chambers..................... Order 1. Monosonratia.

1. Shell a series of similar chambers.

2. Shell porcellanous, imperforate............ Order 2. Minjolidea.

2. Not as above.

3. Not specialized as in the following orders....................... Order 3. Foraminifera.

3. Shell hyaline, perforate, typically trochoid, i.e., having the successively larger chambers helically arranged so that all may be seen from one side and only the last whorl from the other.................... Order 4. GlobigerinideA.

3. Chambers of the fundamentally planispiral shell with specialized walls containing channels or produeing chamberlets................. Order 5. Numaulitinidea.

Order 1. Monosomatia (Ehrenberg) Siebold in Siebold and Stannius Lehrb. vergl. Anat. 1: 11 (1848).

Monosomatia Ehrenberg in Abh. Akad. Wiss. Berlin (1838): table 1 (1839).

Order Astrorhizidea Lankester in Enc. Brit. ed. 9. 19: 846 (1885).

Order Imperforida Delage and Hérouard Traité Zool. 1: 107 (1896).

Order Archi-Monothalamia Calkins Biol. Prot. 354 (1926).

Rhizopoda consisting of a single chamber, or of a proloculus followed by one other chamber; exceptionally, after passing through a stage of this character, producing a series of similar chambers.

Family 1. Allogromiida [Allogromiidae] Cash and Wailes. Minute, with onechambered chitinous or gelatinous shells, usually subglobular; large in fresh water. Allogromia Rhumbler; Mikrogromia Hertwig, the pseudopods of sister cells retaining contact so that small colonies are formed; etc.

Family 2. Astrorhizida [Astorhizidae] Brady (1881). Family Astrorhizina Lankester (1885). Family Astrorhizidaceae Lister. Families Rhizamminidae, Saccamminidae, and Hyperamminidae Cushman. Shell of agglutinated foreign material, usually elongate, often branched, but not coiled. In Astrorhiza there is a central chamber from which grow elongate arms. In Rhizammina, the shell is tubular, open at both ends; in Bathysiphon it is a tube closed at one end; in Hyperammina a proloculus is formed before the extended tubr. 


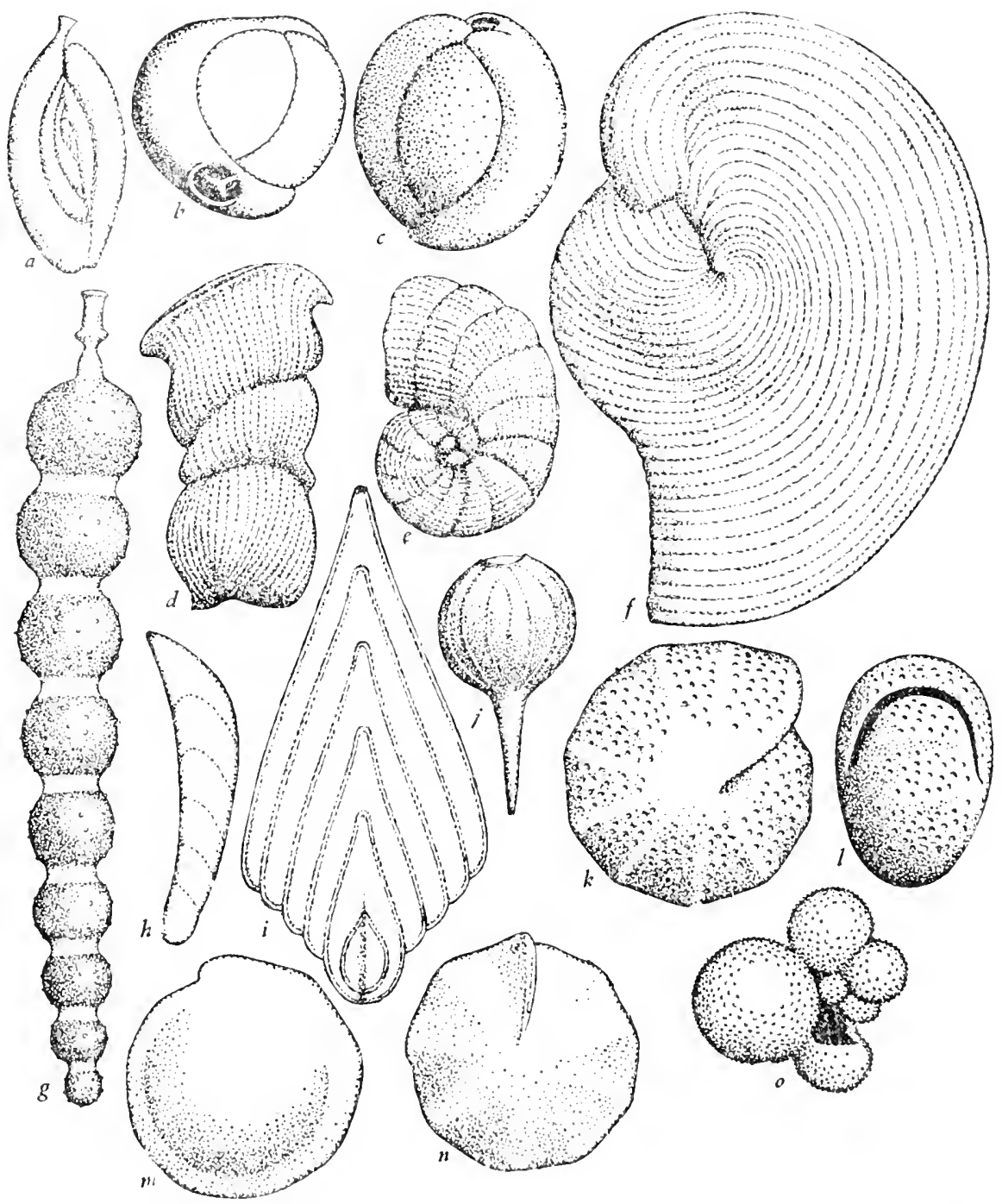

Fig. 36-Shells of Rhizopoda. a, Ophthalimidium. b, c, Triloculina. d, Vertebralina. e, Peneroplis. f, Archaias x 25. g, Nodosaria. h, Dentilina. i, Flabellina. j, Lagena. $\mathbf{k}, \mathbf{1}$, Nonion. $\mathbf{m}$, n, Rotalia. o, Globigerina. x 50 except as noted. 
Family 3. Spirillinidea Reuss 1861. Family Spirillinina Lankester (1885). Family Silicinidae Cushman. In Spirillina, the perforate hyaline one-chambered shell is planispirally coiled; the family is distinguished by a shell of this form in the young stages if not throughout life. Silicina is a Jurassic fossil whose shell is silicified. In Patellina the spirally coiled first chamber is followed by others arranged in a helix.

Family 4. Ammodiscida [Ammodiscidae] Rhumbler 1895. Like the preceding family, but the shell consisting of agglutinated foreign matter. Ammodiscus etc.

\section{Order 2. Miliolidea Lankester in Enc. Brit. ed. 9, 19: 846 (1885).}

Order Flcxostylida Calkins Biol. Prot. 355 (1926).

Rhizopoda with imperforate porcellanous shells, a numerous and important group.

Family 1. Miliolida [Miliolidae] d'Orbigny (1839). Families Nubecularina, Miliolina, and Hauerinina Lankester (1885). Fisherinidae Cushman. The genus Cornuspira, known from the carboniferous, differs from Spirillina only in the texture. Evidently evolved from this are genera of planispirally coiled tubes divided into chambers, and from these others in which the series of chambers becomes straight or irregular, as in Vertebralina and Tubinella. There is an important block of genera in which each cycle of chambers is of two members, the second opening at the opposite end of the body from the first. In Ophthalmidium and Pyrgo alternate chambers lie regularly on opposite sides of a body whose form is that of an elliptic flake. In other genera of this group successive chambers are not opposite each other, but separated by less than $180^{\circ}$, so that more than two appear on the outside. In Triloculina three chambers are externally visible. In Miliola Lamarck (Miliolina Lamarck, the latter name applied to fossil representatives of the same genus) the chambers are $144^{\circ}$ apart, so that five appear on the outside. In many members of the family the apertures are partially blocked by teeth, single, double, or multiple, or extended as bars clear across.

Family 2. Soritina Ehrenberg (1839). Family Helicosorina Ehrenberg op. cit. Family Pcneroplidea Reuss 1861. Family Peneroplidina Lankester (1885). Family Pcneroplidae Gushman. Family Soritidae Galloway (1933). Specialized derivatives of the lower Miliolida: planispiral shells in which the chambers become successively larger, as in Peneroplis, and, by a further development, divided into large numbers of secondary chambers, as in Archaias, Sorites, and Orbitolites. Spirolina, the shell coiled in the oldest part, straight in the remainder.

Family 3. Alveolinea Ehrenberg (1839). Family Alveolinida Schultze 1854. Families Alveolinina and Keramosphaerina Lankester, Alveolinellidae and Keramosphaeridae Cushman. Another group of specialized derivatives, the planispirally coiling chambers broadened and divided into many chamberlets with separate apertures, the entire body more or less globular. Borelis; Fasciolites Parkinson 1811 (Alveolina d'Orbigny 1826); Alveolinella; Keramosphaera Brody, a rare antarctic form. The organisms of these last two families resemble, as a parallel development, those of order Nummulitinidea, from which they are distinguished by the texture.

\section{Order 3. Foraminifera Zborewski 1834.}

Order Polythalamia and subordinate group Polysomatia Ehrenberg in Abh. Akad. Wiss. Berlin (1838): table 1 (1839).

Order Polysomatia Siebold in Siebold and Stannius Lehrb. vergl. Anat. 1: 11 (1848).

Orders Lituolidea, Textularidea, and Lagenidea Lankester in Enc. Brit. ed. 9, $19: 847(1885)$. 
Order Perforida Delage and Hérouard Traité Zool. 1: 107 (1896).

Orders Nodosalida and Textulinida Calkins Biol. Prot. 355, 356 (1926).

Comparatively unspecialized Rhizopoda, the shells of various textures, not porcellanous; not usually of trochoid form, and if so, usually not vitreous.

Early students, Montfort, Lamarck, and d'Orbigny, were much concerned with organisms which they called Geophonus, Vorticialis, or Polystomella. These names represent organisms of much the appearance of Nautilus; all are synonyms of Elphidium Montfort, which is to be considered the type or standard genus of Foraminifera.

Family 1. Endothyrina Lankester (1885). Family Endothyridae Rhumbler 1895. Fossils, pre-Cambrian to Carboniferous, the calcareous shells granular or fibrous, not porcellanous or vitreous. Cayeuxina Galloway (1933) includes minute globular shells solitary or irregularly clustered, described by Cayeux, 1894, from the pre-Cambrian of Brittany; Matthewina Galloway includes Cambrian fossils of similar character. Endothyra and Cribrospira are Carboniferous forms, planispirally coiled; Tetrataxis produced trochoid shells.

Family 2. Nodosinellida [Nodosinellidae] Rhumbler 1895. Shells like those of the Endothyrina or containing imbedded grains of sand, one-chambered or forming straight or curved, not coiled, rows. Mostly Carboniferous, rare as late as the Eocene. Archaelagena, Nodosinclla, Nodosaroum, Pedangia, etc.

Family 3. Reophacida [Reophacidae] Cushman 1827. A small group of forms apparently degenerate from the foregoing, the chambers in straight, curved, or irregular series, walls chitinous or sandy; sometimes parasitic in other rhizopods. Reophax, etc., surviving to the present in cold deep water.

Family 4. Trochamminida [Trochamminidae] Schwager 1877. Family Trochamminina Lankester (1885). Family Plocapsilinidae Cushman. Gells planispiral or trochoid, becoming evolute or irregular; walls with imbedded grains of sand. Pennsylvanian to recent, abundant only in the Cretaceous. Trochammina, Plocapsilina, etc.

Family 5. Lituolidea Reuss 1861. Family Lituolidae Brady (1881). Familics Lituolina and Loftusiina Lankester. Family Lituolidaceae Lister. Families Loftusiidae and Neusinidae Cushman. Shells spiral or beconing evolute or irregular, with walls of agglutinated siliceous or calcareous matter, the chambers subdivided as in order Nummulitinidea. Cyclammina, Lituola, Loftusia, Neusina, etc.; Mississippian to recent, most abundant in the Cretaceous and at present.

Family 6. Orbitolinida [Orbitolinidae] Martin 1890. Specialized derivatives of the preceding family, walls agglutinated as in that group, the numcrous chambers forming a conical or nearly circular body. Dictyoconus, Orbitolina, etc. Mesozoic and Eoccne.

Family 7. Ataxophragmidea Schwager 1877. Familics Talvulinidae and I'trneulinidae Gushman 1927. Family Ataxophragmidae Galloway (1933). Having walls of agglutinated material and allied to the preceding families; chambers of the shell tending to form an clongate, screw-like spiral. I'alvulina, Ataxophragmium, I'emculina, ctc.; since carly Mesozoic, abundant in the present.

Family 8. Textularina Ehrenberg (1339). Family Textularidae d'Orbigny (1839). Family Textulariaceae lister. Walls more or less agglutinated, the chambers usually in an clongate spiral with two members to a cycle, so that they form two series, the body as a whole tending to be wedge-shaped. Tcxtularia, Cuneolina, I'ulinlina, etc.; Ordovician to the present.

Family 9. Nodosarina Ehrenberg (1839). Family Nodosarida Schultze 1854. Family Lagenidac Brady (1881). Family Lagenina Lankester (1885). Family Nodo- 
saridae Rhumbler. Family Lagenaceae Lister. Walls calcareous, hyaline, perforate; chambers planispiral in the earliest forms, becoming curved or straight in the majority; orifice ordinarily of radiating slits, becoming reduced to a single slit. A numerous group, Triassic to the present. Lenticulina Lamarck (Lenticulites Lamarck and Cristellaria Lamarck are synonyms) is Nautilus-like. Hemicristellaria and Vaginulina resemble the sheath of a dagger; Flabellina and Frondicularia resemble fans; Glandulina is shaped like a jug. Nodosaria is like a row of enlarging beads. Lagena is a onechambered form connected to Nodosaria by transitions, and evidently reduced, not primitive.

Family 10. Polymorphinida [Polymorphinidae] d'Orbigny. Families Polymorphinina and Ramulinina Lankester (1885). Specialized irregular forms related to the preceding, as indicated by orifices of the same character. Polymorphina, etc., present in the Mesozoic, abundant in the Cenozoic to the present.

Family 11. Nonionidea [Noninideae] Reuss 1860. Family Polystomellina Lankester (1885). Family Hantkeninidae Cushman. Shells mostly nautiloid, that is, planispiral with successively larger chambers, a few of the highest trochoid; walls hyaline, perforate; aperture generally a transverse slit. Nonion Montfort (Nonionina d'Orbigny) and Elphidium Montfort (Geophonus Montfort, Vorticialis Lamarck, Polystomella Lamarck, the apparent type of Foraminifera) are simply nautiloid; Hantkenina is ornamented with spines. Jurassic to the present.

\section{Order 4. Globigerinidea Lankester in Enc. Brit. ed. 9, 19: 847 (1885).}

Orders Rotalidea and Chilostomellida Lankester l. c., both names having previous use in the category of families.

Order Rotalida Calkins Biol. Prot. 356 (1926).

The main body of Rhizopoda with perforate hyaline shells, many-chambered, the chambers primitively of the trochoid arrangement.

Family 1. Rotalina Ehrenberg (1839). Family Rotalidea Reuss 1861. Family Rotalidae Brady (1861). Family Rotalina Lankester. Family Rotaliaceae Lister. Families Globorotaliidae, Anomalinidae, and Planorbulinidae Cushman. A numerous family, including unspecialized forms, Globorotalia, Rotalia, etc., as well as degenerate and irregular forms, Planopulvinulina, etc., and moderately specialized ones with conical or disk-shaped bodies of numerous chambers, Cymbalopora, Planorbulina, etc. Triassic, rare; Jurassic to the present, common.

Family 2. Acervulinida Schultze 1854. Family Rupertiidae Cushman. A small group of degenerate derivatives of the foregoing, the bodies attached, irregular, sometimes reduced to one chamber, Rupertia, Acervulina, etc., Gretaceous to the present.

Family 3. Tinoporidea Schwager 1877. Family Calcarinidae Cushman. Another small group derived from Rotalina, the disk-shaped cells with a whorl of prominent spines. Calcarina, Tinoporus, etc. Cenozoic, to the present.

Family 4. Asterigerinida [Asterigerinidae] d'Orbigny (1839). Two genera, Asterigerina and Amphistegina, diverging from Rotalina in having each chamber divided into two by an oblique wall. Doubtfully in the Cretaccous; Eocene to the present.

Family 5. Chapmaniida [Chapmaniidae] Galloway (1933). The numerous chambers arranged in a low cone whose inside is filled with deposited solid material. Chapmania, Halkyardia, Dictyoconoides. Eocene and Oligocene.

Family 6. Chilostomellida [Chilostomellidae] Brady (1881). Family Chilostomellaccae Lister. A few genera of reduced derivatives of Rotalina with few chambers. Allomorphina, Chilostomella, Sphaeroidina, etc. Jurassic to the present. 
Family 7. Orbulinida Schultze 1854. Family Globigerinida Carpenter 1862. A few genera with the chambers mostly few, subglobular, clustered rather than arranged in a definite pattern. Orbulina. Globigerina, abundant, pelagic in all oceans, the shells abundant in the ooze on the bottom. Pennsylvanian, doubtful; Jurassic, rare; Cretaceous to the present, common.

Family 8. Pegidiida [Pegidiidae] Heron-Allen and Earland 1928. A few genera much like the Orbulinida but with thinner walls. Pegidia, etc. Oligocene to the present.

Family 9. Heterohelicida [Heterohelicidae] Gushman 1927. A numerous group, the shells screw-like, biseriate, uniseriate, sheath-like or fan-like, the walls often with exterior ornamentation; paralleling the Nodosarina, but without the radiate orifices. Hctcrohclix, Sagrina, Eouvigerina, Pavonina, Plectofrondicularia, Bolivina, Mucronina. Common, Jurassic to the present.

Family 10. Buliminida Jones 1876. Family Uvellina Ehrenberg (1839), not based on a generic name. Family Buliminina Lankester (1885). Shells mostly high spirals, screw-like, often with spines or other external ornamentation, the orifices various, commonly comma-shaped. Turrilina, Bulimina, Virgulina, etc. Triassic to the present.

Family 11. Cassidulinida [Cassidulinidae] d'Orbigny (1839). A small group with high-spiralled shells and comma-shaped orifices, evidently derived from the foregoing family. Cassidulina, etc. Eocene to the present.

Family 12 Uvigerinida [Uvigerinidae] Galloway and Wissler, 1927. Further variants from Heterohelicida, the high-spiralled shells with chambers in three rows at first, varying to biseriate and uniseriate. Uvigerina, Siphonogenerina, etc. Jurassic to the present, common since the Miocene.

Family 13. Pleurostomellida [Pleurostomellidae] Reuss 1860. An additional rather small family of the same general character as the few preceding. Pleurosiomella, Nodosarella, Daucina, Ellipsoidina, etc. Cretaceous to the present, commonest in upper Cretaceous and Eocene.

Order 5. Nummulitinidea Lankester in Enc. Brit. ed. 9, 19: 848 (1885).

Rhizopoda with large specialized shells, the walls hyaline, perforate, generally thickened and traversed by channels and thrown into internal ridges which subdivide the chambers.

Family 1. Fusulinida [Fusulinidae] Möller 1878. Carboniferous fossils, the chambers short and broad, numerous, in a planispiral coil, forming bodics which are usually fusiform or globular. Orobias, Fusulina, Triticina, Verbcekina, ctc.

Family 2. Nummulitisla [Nummulitidae] Rcuss 1861. Family Camcrinidae Merk and Hayden 1865. Family Nummulinidae Brady (1881). Family Nummulitina Lankester (1885). Family Nummulitaceae Lister. Mostly disk-shaped, planispiral, the walls not highly specialized. Camerina Bruguière 1792 (Nummulites Lamarck 1801), Operculina, Heterostcgina, etc. Jurassic to the present, most abundant in the Eocene.

Family 3. Orbitoidida [Orbitoididae? Schubert 1920. Similar to the foregoing, the numerous chambers divided into numerous chamberlets. A considerable group of Mesozoic and Cenozoic fossils. Orbitoides, Cyclosiphon, cte.

Family 4. Cycloclypeina Lankester (1885). Family Cycloclypeidae Galloway (1933). Similar to the preceding. A number of Mesezoic and Cenozoic genera, most numerous in the Eocenc. Asterocyclina. The only living species is Cycloclypeus Carpenteri Brady. 


\section{Class 4. HELIOZOA Haeckel}

Family Polycystina Ehrenberg in Abh. Akad. Wiss. Berlin 1838: 128 (1839).

Rhizopoda radiaria seu Radiolaria J. Müller in Abh. Akad. Wiss. Berlin (1858): 16 (1859).

Echinocystida Claparède.

Order Radiolaria Haeckel Radiolarien 243 (1862).

Stamm Moneres for the most part, and classes HeliozoA and Radiolaria, Haeckel Gen. Morph. 2: xxii, xxviii, xxix (1866).

Subclasses Heliozoa and Radiolaria Bütschli in Brown Kl. u. Ord. Thierreichs 1, 1 Teil: Inhalt (1882).

Class Protcomyxa Lankester in Enc. Brit. ed. 9, 19: 839 (1885).

Subclasses Proteomyxiae, Heliozoariae, and Radiolariae Delage and Hérouard Traité Zool. 1: 66, 156, 169 (1896).

Class Actinopoda Calkins Biol. Prot. 318 (1926).

Class Actinopodea and orders Helioflagellida, Heliozoida, Radiolarida, and Proteomyxida Hall Protozoology 202, 203, 212, 220 (1953).

Subphylum Actinopoda Grassé and Deflandre, and classes Acantharia, Radiolaria, and HeliozoA Trégouboff in Grassé Traité Zool. 1, fasc. 2: 267, 270, 321, 437 (1953).

Organisms having pseudopodia of the character of filopodia, stiffly radiating, or of axopodia, stiffly radiating and having inner fibers; often with siliceous skeletons.

Here, not without authority, one combines in one class the three groups which have been treated as the classes Proteomyxa, Heliozoa, and Radiolaria; and adds further two families of shelled amoebas.

Cienkowski (1865) listed as "Monaden" the new species or genera Monas amyli, Colpodella (apparently a chytrid), Pseudospora, and Vampyrella. They are minute fresh-water amoeboid organisms, in part having flagellate stages. Haeckel (1866) placed most of them (the Monas under the new generic name Protomonas), together with his own discoveries Protamoeba and Protogenes, and also the bacteria, in his Stamm Moneres, i.e., his group of Protista without nuclei. Later (1868) he omitted the bacteria. Zopf (1885) found several of Haeckel's Moneres to possess nuclei, and Lankester renamed the group Proteomyxa. Publication of subsequent original observations of these organisms has been scant and scattered; they remain poorly known.

The Heliozoa as conventionally construed are also mostly inhabitants of fresh water. Ehrenberg observed some of them and took them for Infusoria with immobile cilia. There are only a few dozen species of Heliozoa sensu stricto (Schaudinn, 1896) : the whole group is no more than a reasonable order.

The Radiolaria (this name also used at this point in its conventional sense) are marine. Examples were first observed as floating gelatinous bodies. These were taken for fragments and remained unnamed until 1834, when Mayen named Physematium and Sphaerozoum. Fossil skeletons of many examples were described by Ehrenberg (1839). Huxley (1851) named Thalassicolla and gave an accurate account of its structure. It was by work on organisms of this group that Haeckel first distinguished himself (1862).

Haeckel dealt further with this group in four important papers $(1879,1882,1887$, 1887-1888). In the last of these, the Radiolaria are a class of four legions, eight sublegions, twenty orders, 85 families, 739 genera, and more than four thousand species. The categories, Haeckel explained, are purely relative: Radiolaria would as well be 
a phylum, the legions classes, and so forth. This idea scrved him as license for confounding the application of many names, by shifting them among the categories, or by substituting new names for old. All subsequent authors have followed Haeckel's system of Radiolaria, applying names as best they might.

The class Heliozoa in the extended sense here proposed may be organized as five orders distinguished as follows:

1. Cells without a central capsule, i.e., without a firm membrane surrounding the inner part of the protoplast....................... Order 1. Radioflagellata.

1. Cells with a central capsule.

2. Central capsule of spherical symmetry or with three planes of symmetry at right angles, punctured by many pores.

3. Pores of the central capsule evenly distributed; skeleton absent or present, without spicules which cross the central capsule or meet in its center...... Order 2. Radiolaria.

3 . Pores of the central capsule clustered; skeleton including spicules which cross the central capsule or meet in its middle................. Order 3. Acantharia.

2. Central capsule of radial symmetry, with one opening......................... Monder 4.

2. Central capsule of isobilateral symmetry, with one main opening and two minor ones...................................... Phaeosphaeria.

Order 1. Radioflagellata Kent Man. Inf. 1: 225 (1880).

Subdivision or subclass Heliozoa (Haeckel), and orders Aphrothoraca (Hertwig), Chlamydophora (Archer), Desmothoraca (Hertwig and Lesser), and Chalarothoraca (Hertwig and Lesser) Büschli in Bronn Kl. u. Ord. Thierreichs 1: 261, 320, et seq. (1881, 1882).

Suborder Protoplasta Filosa Leidy in Rept. U.S. Geol. Survey Territories 12: 189 (1879).

Class Proteomyxa Lankester (1885).

Subclass Proteomyxiae and orders Acystosporidia, Azoosporidia, and Zoosporidia; subclass Heliozoariae and orders Aphrothoracida, Chlamydophorida, Chalarothoracida, and Desmothoracida Delage and Hérouard Traité Zool. 1: 66-72, 156-168 (1896).

Order Heliozoa Doflein Protozoen 13 (1901).

Orders Vampyrellidea and Chlamydomyxidea Poche in Arch. Prot. 30: 182, $193(1913)$.

The proper Heliozoa together with the Protcomyxa: organisms of the character of the class, lacking central capsules, that is, firm membranes about the inner part of the protoplasts. Mostly fresh water organisms of spherical symmetry, commonly withnut skeletons. The type, being the only genus assigned to the order by Kent, is Actinomonas.

1. Pseudopodia unspecialized; amoeboid organisms with or without flagellate stages. 
2. Without shells.................. Family 1. Pseudos Porea.

2. With shells; without known flagellate stages.

3. Shells chitinous, without siliceous scales..................... Family 2. Lagy NidA.

3. Shells bearing circular siliceous scales...................... Family 3. EugLYPhida.

1. Pseudopodia slender, with apical knobs......... Family 4. Vampyrellacea.

1. Pseudopodia of the character of typical axopodia, without apical knobs; the cells or their main bodies usually regularly spherical.

2. Bearing flagella as well as axopodia in the vegetative condition............... Family 5. Actinomonadida.

2. Without flagella in the vegetative condition.

3. Cells without a lifeless outer coat...... Family 6. Actinophryma.

3. Cells having a gelatinous outer coat without siliceous spicules.............Family 7. Нетеrophritda.

3. Cells having a gelatinous outer coat with siliceous spicuies. . . . . . . . . . Family 8. Aganthocystida.

3. Cells with a hard shell punctured by pores......................... Family 9. Clathrulinida.

Family 1. Pseudosporea [Pseudosporeae] Berlese in Saccardo Sylloge 7: 460 (1888). Monadincae Zoosporcae Cienkowski in Arch. mikr. Anat. 1: 213 (1865). Family Pseudosporeen Zopf Pilzthicre 115 (1885). Orders Azoosporidea for the most part and Zoosporidea Delage and Hérouard (1896). Azoosporidae for the most part and Zoosporidae Doflein Protozoen 40, 41 (1901). Family Pscudosporidae Poche in Arch. Prot. 30: 197 (1913). Amoeboid organisms without shells or skeletons, the pseudopodia tapering from a broad base to a filamentous termination. Flagellate stages (with one flagellum or two unequal flagella) occur in Protomonas, Pseudosporn, and Diplophysalis. In other genera, as Arachnula and Chlamydomyxa, no flagellate stages are known.

Family 2. Lagynida Schultze 1854. Order Gromida Claparède and Lachmann 1859. Family Gromida Carpenter 1862. Family Gromiidae Brady (1881). Families Monostomina and Amphistomina Lankester (1885). Amoeboid organisms having chitinous shells without siliceous scales with a broad orifice through which project pseudopodia of the character of filopodia. Gromia, Lagynis, etc.

Family 3. Euglyphida [Euglyphidae] Wallich 1874. Amoeboid organisms with a chitinous shell beset with circular siliceous scales, the filopodia projecting through a broad orifice. Euglypha, Cyphoderia, Campuscus, Trinema, etc.

Family 4. Vampyrellacea [Vampyrellaceae] Zopf Pilzthiere 99 (1885). Monadineae Tetraplasteae Cienkowski op. cit. 218. Family Vampyrelleae Berlese in Saccardo Sylloge 7: 454 (1888). Family Vampyrellidae Poche in Arch. Prot. 30: 182 (1913). Cells subglobular, slowly creeping, with slender pseudopodia, numerous, densely packed and stiffly radiating on mature individuals, bearing terminal knobs. Vampyrella, the cells colored faintly pink by some metabolic by-product, is not unfamiliar as a predator on freshwater algae cultured under unfavorable conditions.

Family 5. Actinomonadida [Actinomonadidae] Kent Man. Inf. 1: 226 (1880). Family Ciliophryidae Poche in Arch Prot. 30: 187 (1913) Family Helioflagellidae 


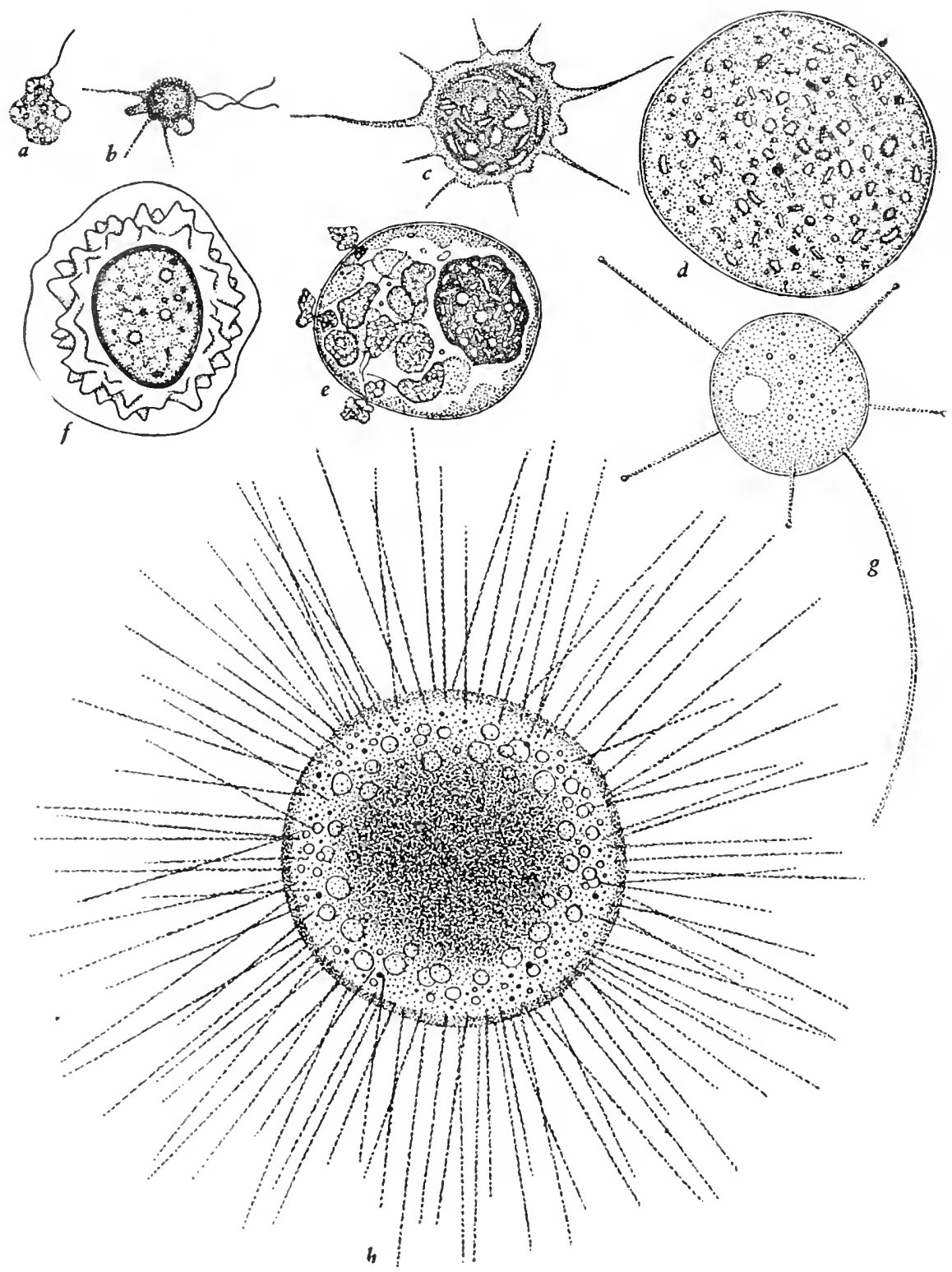

Fig. 37.-Radioflageliata: a-f, Diplophysalis stagnalis after Karling (1930); $\mathbf{a}, \mathbf{b}$, young cells with one or two flagella; $\mathbf{c}$, active amoeboid form; $\mathbf{d}$, walled cell; e, same releasing flagellate cells; $\mathbf{f}$, resting cell. g, Young cell of Vampyrella $\times 1,000$. h, Actinosphaerium Eichhornii x 1,000. 
Doflein. Organisms bearing at the same time flagella and typical axopodia. Dimorpha, free-swimming, with two unequal flagella. Actinomonas, Pteridomonas, Ciliopirys, with one flagellum, either free-swimming or attached by a protoplasmic stalk.

Family 6. Actinophryida [Actinophryidae] Claus 1874. Askcleta Hertwig and Lesser in Arch. mikr. Anat. 10 Suppl. 164. (1874). A phrothoraca seu Actinophryidae Hertwig Org. Radiolar. 142 (1879). Order A phrothoraca Bütschli (1881). Suborder Abhrothoraca Minchin (1912). Family Camptonematidae Poche in Arch. Prot. 30: 187 (1913). Cells typically spherical, with typical axopodia, having no flagella nor shells nor skeletons. Actinophrys Sol Ehrenberg and Actinosphacrium Eichhornii (Ehrenberg) Stein arc common in fresh water among algae, living as predators largely on diatoms; Actinophrys is uninucleate, the cells to $50 \mu$ in diameter; Actonospaerium is multinucleate, the cells to $1000 \mu$ in diameter. Camptonema is marine.

Mitosis in Actinophrys as described by Schaudinn (1896) occurs within an intact nuclear membrane which undergoes constriction; the dividing nucleus lies within a spindle-like body of cytoplasm. Schaudinn and Bělăr (1923) observed conjugation. Pairs of gametes, which are usually sister cells but may sometimes be random pairs, lie within a cyst wall of secreted material. The nucleus of each gamete undergoes meiosis; at the end of each meiotic division, one of the daughter nuclei is digested; thus each gamete comes to possess a single haploid nucleus. Syngamy and karyogamy follow in due course and the zygote becomes walled. An old account of the cytology of Actinosphaerium by Hertwig is defaced by descriptions of the origin of nuclei from fragments of nuclei (chromidia), and of nuclear fusions at two separate stages of development.

Family 7. Heterophryida [Heterophryidae] Poche in Arch. Prot. 30: 189 (1913). Heliozoa Chlamydophora Archer in Quart. Jour. Micr. Sci. n.s. 16: 348 (1876). Order Chlamydophora Bütschli (1882). Suborder Chlamydophora Minchin (1912). Family Lithocollidae Poche l.c. The cells or their main bodies spherical with axopodia projecting through a gelatinous envelope. Heterophrys and Astrodisculus are simply globular cells. Elaeorhanis and Lithocolla are similar but with grains of sand or diatom shells imbedded in the envelope. Actinolophus is stalked. Sphacrastrum becomes colonial by incomplete division of the cells.

Family 8. Acanthocystida [Acanthocystidae] Claus 1874. Chalarothoraca Hertwig and Lesser in Arch. mikr. Anat. 10 Suppl. 193 (1874). Chalarothoraca seu Acanthocystidae Hertwig Org. Radiolar. 142. (1879). Order Chalarothoraca Bütschli in Bronn K1. u. Ord. Thierreichs 1: 325 (1882). Suborder Chalarothoraca Minchin (1912). Resembling the preceding family, but the gelatinous envelope containing hard bodies, supposedly usually siliceous, of definite form. In Raphidophrys, these bodies are curved needles; in Pinacocystis, small plates; in Acanthocystis and Pinaciophora, disks bearing a central spine which is in some species forked. The cell of $\mathrm{W}$ agnerella (a marine form, on rocks in bays) consists of a globular head with spines and axopodia, borne on a protoplasmic stalk attached by a foot; the nucleus lies in the foot.

In these forms the axial filaments of the pseudopodia radiate from a central granule located outside the nucleus (in W'agnerella, in the head). Schaudinn (1896) reported nuclear division in Acanthocystis as being either amitotic or mitotic: the report of amitosis is of course not to be taken seriously. In the mitotic process, the central granule acts as a centrosome; the chromosomes are numerous and minute; the nuclear membrane disappears during the middle stages. Nuclear division may be followed by division of the cell into two, or may be repeated and followed by production of buds. The buds may lose their pseudopodia and develop paired flagella. It is 
suspected that the flagellate cells may be gametes. The central granule is said to originate by extrusion from the nucleus of a bud.

Zuelzer (1909) found in Wagnerella two types of individuals, slender and stout, supposedly respectively haploid and diploid. In either type the nuclei may become numerous (and it is said that they sometimes develop from chromidia). The nuclei may migrate to the head and be released in buds, or they may become distributed throughout the protoplast, which then breaks up into biflagellate cells. It is supposed that these may be gametes, but a fusion of the heads of individuals of the slender type was observed.

Family 9. Clathrulinida [Clathrulinidae] Claus 1874. Desmothoraca Hertwig and Lesser op. cit. 225. Desmothoraca seu Clathrulinidae Hertwig Org. Radiolar. 142 (1879). Order Desmothoraca Bütschli in Bronn Kl. u. Ord. Thierreichs 1: 328 (1882). Family Choanocystidae Poche in Arch. Prot. 30: 192 (1913). Protoplasts lying within globular shells, apparently of chitin, usually stalked, punctured by numerous pores through which the axopodia project. In reproduction, the protoplast may divide into two, one of which escapes from the shell and secretes a new one; or it may divide into many which become unequally biflagellate. Clathrulina, Hedriocystis, Choanocystis.

Order 2. Radiolaria (J. Müller) Haeckel Radiolarien 243 (1862).

Rhizopoda radiaria seu Radiolaria J. Müller in Abh. Akad. Wiss. Berlin 1858: 16 (1859).

Orders Thalassicollen, Sphacrozoen, and Peripyleen Hertwig Org. Radiolar. 133 (1879).

Orders Peripylaria, Collodaria, Symbelaria, and Syncollaria Haeckel in Jenaische Zeitschr. 15: 447, 469, 471, 472 (1882).

Legion Spumellaria or Peripylea, with orders Callodaria and Sphacrellaria and seven suborders, Haeckel in Rept. Voy. Challenger Zool. 18: 5, 9 (1887).

Legion Spumcllaria, sublegions Collodaria and Sphaerellaria, and six orders, Haeckel Radiolarien 2: 87 (1887).

Order Peripylida Delage and Hérouard Traité Zool. 1: 176 (1896).

Suborder Peripylaria Minchin Protozoa 225 (1912).

Order Sphacridea Poche in Arch. Prot. 30: 206 (1913).

Order Peripylea Calkins Biol. Prot. 343 (1926).

Suborder Peripylea Kudo I Iandb. Protozool. 259 (1931).

Suborder Peripylina Hall Protozoology 218 (1953).

This order and the three which follow, being the Radiolaria as conventionally construed, are unicelhular marine organisms with axopodia, having within the protoplast a layer of organic material, varionsly punctured and of various types of symmetry, which separates the inner protoplasm from the outer. The central capsule consists of this layer (the central capsule membrane) and its contents, including the one or more nuclei of the cell. Imbedded in the protoplasm there is usually a skeleton, usually siliceous, various in structure and sometimes highly complicated. The outer cytoplasm is commonly inhabited by symbiotic cryptomonads in the resting condition (yellow cells, zooxanthellar), and sometimes contains masses of dark material, apparently debris extruded from the central capsule. The type of Radiolaria is evidently Thalassicolla; this genus was the first one described from living material, and was listed first by J. Miiller in the original publication of the name.

The order which includes Thalassicolla, and to which the name Radiolaria is here restricted, is distinguished by uniformly distributed small punctures in the central 
capsule membrane and by the absence of skeletal spicules extending across the central capsule or meeting in its middle. Except during reproduction, each central capsule contains a single nucleus, but the cells of many examples are coenocytic, containing several or many central capsules.

Brandt $(1885,1905)$ observed reproduction particularly as it occurs by the production of swimming cells by some of the coenocytic forms. The nucleus divides to produce very many, and the intracapsular cytoplasm divides to produce uninucleate flagellate cells. In Collosphaera, all the nuclei are included in these cells. The cells are of two sizes, produced by different individuals, and are supposed to be gametes. In Sphaerozoum and its allics. some of the muclei degenerate instead of being included in the swimming cells, of which two sizes are produced by single individuals. It appears that the swimming cells have characteristically two unequal flagella, though many are found to have only one, and some produce a third appendage by which they can attach themselves.

Haeckel listed thirty-two families in his legion Spumellaria. Other authors recognize about a dozen, including the following.

Family Thalassicollida Haeckel (1882). Thalassicollen J. Müller (1859). Family Collida Haeckel (1862); there is no corresponding generic name. Order Collida Hacckel (1887). Globular forms with a single central capsule, skeleton none or of numerous small spicules. Thalassicolla, Phy'sematium, Lampoxanthium, etc.

Family Sphaerozoida Haeckel (1882). Family Collozoida Haeckel op. cit. Family Sphaeroidina Haeckel (1862); there is no corresponding generic name. Coenocytic, each cell with several nuclei in separate central capsules; skeleton none or of numerous small spicules. Shaerozoum, the cells globular, to $1 \mathrm{~mm}$. in diancter; Raphidozoum, the cells elongate.

Family Collosphaerida Haeckel (1862). Coenocytic, the spherical cell to $1 \mathrm{~mm}$. in diameter, with several central capsules, each with an individual lattice-like skeleton. Collosphaera.

Family Haliommatina Ehrenberg 1847. Families Ethmosphaerida, Ommatida, and Cladococcida Haeckel (1862). Family Sphacrida Haeckel (1882). Order Sphaeroidea, with six families, Haeckel (1887). Globular, with small numbers of radiating main spicules, the main spicules bearing tangential branches which form a globular network of definite pattern, or, often, two or more concentric networks. Haliomma, Actinomma, Hexacontium, Cladococcus, and many other genera.

Further families are of the character of the Haliommatina, but with the spherical symmetry modified by abbreviation or elongation of one or more axes:

Family Spongurida Haeckel (1862). Order Prunoidea, with seven families, Haeckel (1887). Having one axis elongate. Spongurus, Pipetta, etc.

Family Lithocyclidina Ehrenberg 1847. Family Discida Haeckel (1862). Order Discoidca, with six families, Hacckel (1887). Having one axis shorter than the others. Lithocyclia, Staurocyclia, Heliodiscus, etc.

Family Larcarida Hackel (1887). Order Larcoidea, with this and seven other families, Haeckel (1887). The skeleton with three unequal axes, or spiral. Cenolarcus, etc.

\section{Order 3. Acantharia Haeckel in Jenaische Zeitschr. 15: 465 (1882).}

Order Actipyleen Hertwig Org. Radiolar. 133 (1879).

Legion Acantharia or Actipylea, orders Acanthometra and Acanthophracta, and seven suborders, Haeckel in Rept. Voy. Challenger Zool. vol. 18 (1887). 


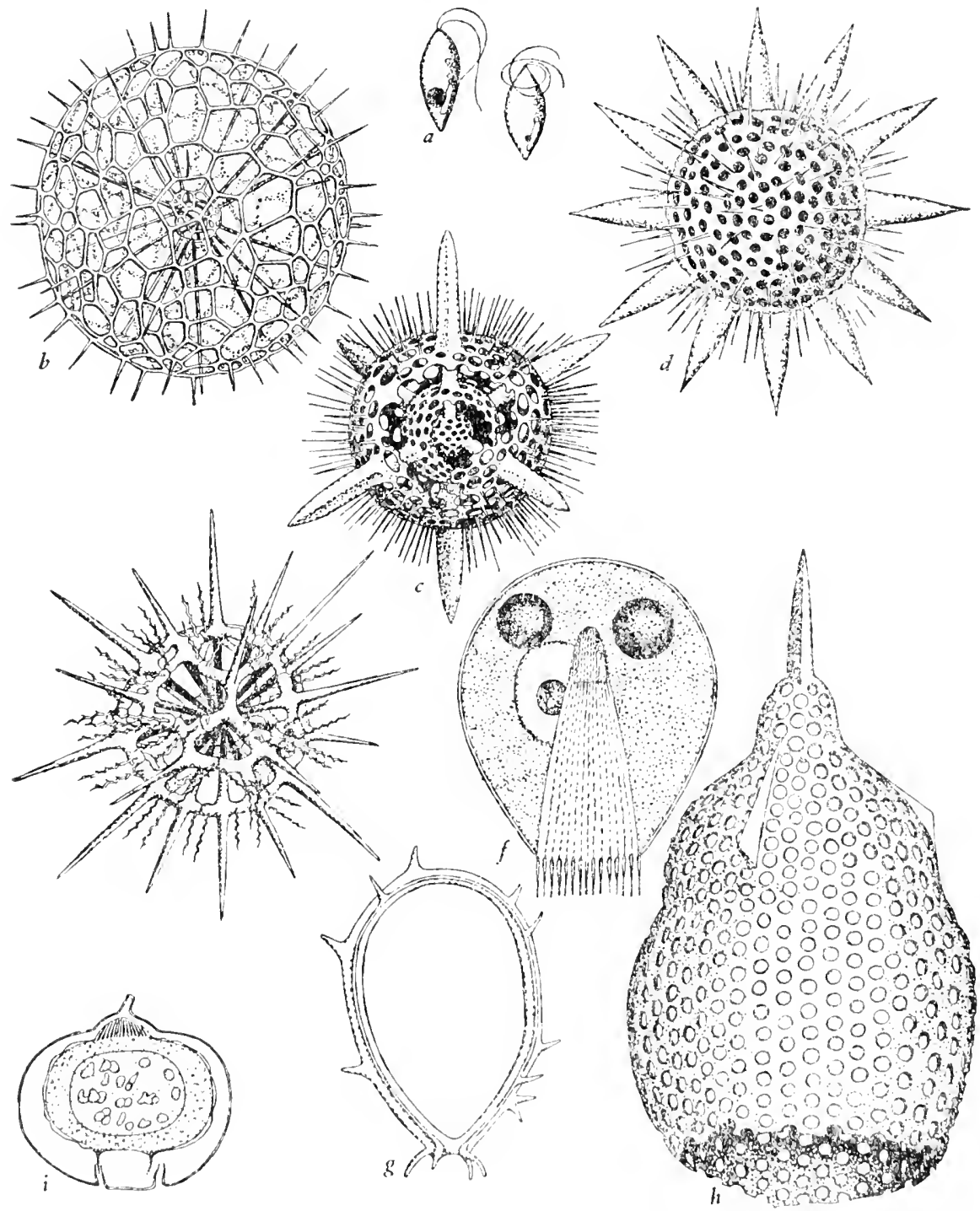

Fig. 38.-RAdiolaria: a, motile cells of Collosphacra Huxleyi after Brandt (1885). b, Skeleton of Haliomma capillaris after Hacckel (1862). c, Skeleton of Actinomma Asteracanthion after Haeckel (1862). d, Skeleton of Hcliodiscus Phacodiscus after Hacckel (1887). Acantharia: e, Skeleton of Doralaspis costata after Hacckel (1987). Monopylaria: f, Central capsule of Tridictyopus elegans after R. Hertwig (1879). g, Skeleton of Lithocircus productus after R. Hertwig, op. cit. h, Skeleton of Eucyrtidium carinatum after Hacckel (1862). Pinaeosphaeria: i, Typical central capsule after $\mathrm{R}$. Hertwig, op. cit. 
Legion Actipyca or Acantharia, sublegions Acanthometra and Acanthophracta, and orders Actinellida, Acanthonida, Sphaerophracta, and Prunophracta Haeckel Radiolarien II Teil (1887).

Order Actipylida Delage and Hérouard Traité Zool. 1: 204 (1896).

Suborder Acantharia Minchin Protozoa 256 (1912).

Order Acanthometrida Poche in Arch. Prot. 30: 212 (1913).

Order Actipylea Calkins Biol. Prot. 345 (1926).

Suborder Actipylea Kudo Handb. Protozool. 216 (1931).

Suborder Actipylina Hall Protozoology 216 (1953).

In this group the central capsule membrane has many punctures arranged in clusters. The skeleton includes radiating spicules; in some examples these extend through the cell from side to side, passing through the central capsule; in the majority, their proximal ends meet in the center of the central capsule. In the latter forms, the number of radiating spicules is twenty, and they are arranged according to a pattern discovered by Johannes Müller and called Müller's law; they form five parallel whorls of four. Usually they bear tangential branches of definite, often highly elaborate, patterns: these may form a globular frame, or two or more concentric frames.

Haeckel, Hertwig, and Brandt found the spicules not to consist of silica. They are soluble in acids and alkalis, and were reported to be destroyed by heat. They were supposed, accordingly, to consist of some organic substance; Haeckel named it acanthin. Schewiakoff found them resistant to heat, and Bütschli (1906) analyzed them and found them to consist of strontium sulfate. This surprising fact has recently been confirmed by Odum (1951).

The cytoplasm at each point where a spicule passes through the surface is attached to the spicule by a whorl of minute fibers called myophrisks. The myophrisks are believed to be contractile, and to have the function of changing the volume, and hence the density, of the cells, enabling them to sink or float.

Young cells contain a single nucleus, eccentric in the central capsule; older ones have several to many nuclei.

Haeckel listed twenty families in his legion Acantharia. Other authors recognize about a half dozen, including the following.

Family Litholophida Haeckel (1882). Family Astrolophida Haeckel (1887). Spicules numerous, radiating, not arranged according to Müller's law. Litholophus, Astrolophus, Actinelius, etc.

Family Chiastolida Haeckel (1887). Spicules ten to twenty, extending clear through the body. Chiastolus, Acanthochiasma.

Family Acanthometrida Haeckel (1862). Acanthometren J. Müller (1859). Family Acanthonida Haeckel (1882). With twenty spicules arranged according to Müller's law; they may be branched, but do not form a continuous network. In most examples, as Acanthometron, Xiphacantha, etc., they are equal; in others, as Amphilonche, two of the spicules of the equatorial whorl are much longer than the others.

Family Sphaerocapsida Haeckel (1882). Family Dorataspida Haeckel l.c. Order Sphaerophracta Haeckel (1887). Like the foregoing, but the branches of the radiating spicules forming a globular network, or two or more concentric networks. Dorataspis, Sphacrocapsa, Lychnaspis.

Family Diploconida Haeckel (1862). Order Prunophracta Haeckel (1887). Again like the foregoing, but with the eight spicules of the two polar whorls either extended or abbreviated. Diploconus, Hexaconus. 
Order 4. Monopylaria Haeckel in Jenaische Zeitschr. 15: 422 (1882)

Order Monopyleen Hertwig Org. Radiolar. 133 (1879).

Legion Nassellaria with orders Plectellaria and Cyrtellaria, and six suborders, Haeckel in Rept. Voy. Challenger Zool. vol. 18 (1887).

Legion Nasscllaria with sublegions Plectcllaria and Cyrtellaria and orders Nassoidea, Plcctoidea, Stephoidea, and Cyrtoidea, Haeckel Radiolarien II Teil (1887).

Order Monopylida Delage and Hérouard Traité Zool. 1: 215 (1896).

Suborder Nassellaria Doflein.

Suborder Monopylaria Minchin Protozoa 256 (1912).

Order Monopylea Poche in Arch. Prot. 30: 218 (1913).

Suborder Monopylea Kudo Handb. Protozool. 261 (1931).

Suborder Monopylina Hall Protozoology 218 (1953).

This order is distinguished by a central membrane with one opening, or with a single circular field of pores. From this opening or field as a base, there extends into the central capsule a large conical body (apparently a bundle of protoplasmic fibers) called the porocone. The skeleton varies from none to highly elaborate; it does not in any form consist of separate spicules. Its symmetry is dorsiventral, not radial. These skeletons are well known as microfossils.

In this group, under the name of legion Nassellaria, Haeckel placed twenty-six families. Other authors recognize about a half dozen.

Family Nassellida Haeckel (1887). Skcleton none. Cy'stidium.

Family Plectonida Haeckel (1887). Family Plectida Haeckel (1882), not based on a generic name. Skelcton consisting of three arms radiating from a point opposite the mouth of the central capsule; sometimes with a fouth forming a caltrop. Triplagia.

Family Stephanida Haeckel (1887). Family Stephida Hacckel (1882), not based on a generic name. Skeleton including a ring in the sagittal plane, often with a basal tripod and with branches and crossbars. Lithocircus, Zygostcphanus. This family is well represented by microfossils as far back as the Cambrian.

Family Eucyrtidina Ehrenberg 1847. Family Polycystina Ehrenberg in Abh. Akad. Wiss. Berlin (1838): 128 (1839), not based on a generic name. Families Halicrytina and Lithochytridina Ehrenberg 1817. Family Cyrtida Hacckel (1862). Order Cirtoidea, with twelve families, Haeckel (1887). Skeleton a more or lcss bas-

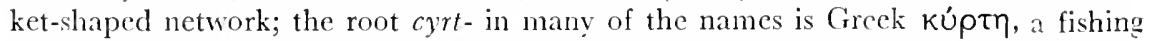
basket. Lithocampe, Cryptocalpis, Encyrtidium, Theoconus, Dictyoconus, and many other gencra. This group is common as Mesozoic and Cenozoic microfossils, occurring mixed with diatoms and silicoflagellates.

Family Spyridina Ehrenberg 1847. Family Sprrida Ilacckel (1882). Order Spyroidea, with four families, Hacckel (1887). The skcleton divided by sagittal grooves into two lobes.

Family Cannobotryida Hackel (1887). Family Botrida Hacckel (1882), not based on a generic name. Order Botryoidca, with three families, Haeckel (1887). The skeleton divided by three or more longitudinal grooves into as many lobes.

Order 5. Phacosphaeria Ilacekel in Sitzber. Jenaische Gess. Med. Naturw. 1879: $156(1879)$.

Phacodariae, with orders Phacocystia, Phacogromia, Pninospineria, and Phacoconchia llacckel op. cit. 
Order Tripyleen Hertwig Org. Radiolar, 133 (1879).

Order Phacodaria Haeckel in Jenaisehe Zeitschr. 15: 470 (1882).

Legion Phaeodaria and orders Phaeocystina, Phaeosphaeria, Phaeogromia, and Phaeoconchia Haeckel in Rept. Voy. Challenger Zool. vol. 18 (1887).

Order Tripylea Doflein.

Suborder Tripylaria Minchin Protozoa 256 (1912).

Suborder Tripylea Kudo Handb. Protozool. 263 (1931).

Suborder Tripylina Hall Protozoology 218 (1953).

In this order, the central capsule is of isobilateral symmetry, having a rather small main opening (astropyle) at one end and two smaller openings (parapyles) at the other. The openings are located on projections of the central capsule membrane; inside of each, the protoplasm is so differentiated as to appear to be a conical bundle of fibers with the apex at the opening (in contrast to the preceding order, in which the base of the conieal structure is at the opening). A mass of variously colored bodies, supposedly exereted from the eentral capsule, lies in the extracapsular cytoplasm about the astroplyle. The skeletons consist in part of organic matter and are not well preserved as fossils.

Borgert $(1896,1900)$ deseribed nuclear division in Aulacantha. A very large number of chromosomes, a matter of several hundred, form a plate which splits into two; the two plates move apart in a body of differentiated cytoplasm, but no definite spindle, and no eentrosomes, were seen. The margins of the plates draw apart faster than the middles, with the effect that the plates beeome saucer-shaped, then bowlshaped, and finally globular, after which nuclear membrancs form about them. While the nucleus divides, the eentral capsule membrane becomes constricted by longitudinal grooves so placed that cach daughter central eapsule membrane receives one parapyle and an astropyle formed from half of the original astropyle. The rudiments of additional parapyles are first seen as granules in the intracapsular cytoplasm. Each granule grows slightly and becomes "hat-shaped," and migrates so as to eome into contaet with the eentral eapsule membrane at the point appropriate for the development of its second parapyle.

Later, Borgert (1909) described a process in which the nucleus divides repeatedly, producing many. The divisions are mitotie, with small numbers of chromosomes, perhaps twenty; the eventual produets become the nuelei of gametes. There are reports, in part illustrated with photographs, of similar processes in family Thalassicollida (Häcker, 1907; Huth, 1913). Aceording to Hollande (in Grassé, 1953) the small nuclei are those of a parasitic dinoflagellate, Solenodinium. Le Calvez (1935) found Coclodendrum to produce zoospores with a pair of unequal simple flagella. They resemble cells of Cryptomonas or of Bodo.

Haeckel's legion Phaeodaria was of fifteen families. These have been maintained by the generality of authors.

A. Skeleton none or of distinet spicules; cells usually nearly spherical.

Family Aulacanthida [Aulacanthidae] Hacckel (1879). Aulacantha.

Family Astracanthida [Astracanthidae] Häekcr. Spicules more or less thorny at the distal ends. Aulactinium.

B. Skeleton spherieal or of two concentric spheres, with no main opening.

Family Aulosphaerida Haeckel (1862). Aulosphaera.

Family Cannosphaerida [Cannosphaeridae] Haeekel (1879). Cromodromys.

Family Sagosphaerida Haeckel (1887).

C. Skeleton with a distinet main opening, either nearly spherical, radially symmetrical, or distinctly dorsiventral. 
Family Castanellida [Castanellidae] Haeckel (1879). Skeleton nearly globular with numerous pores. Castanidium.

Family Circoporida [Circoporidae] Haeckel (1879). Like the foregoing, but with the pores gathered about the bases of radiating spines. Circoporus.

Family Tuscarorida Haeckel (1887). The main pore on an extended neck, the skeleton accordingly flask-shaped. Tuscarora. Tuscarilla.

D. Shell strongly dorsiventral.

Family Challengerida [Challengeridae] J. Murray. Shell finely pitted. Challengeron.

Family Medusettida Hacckel (1887). Shell smooth or with small spines. Medusetta.

E. Shell bilaterally divided into two parts.

Family Concharida [Concharidae] Haeckel (1879).

Family Coelodendrida Haeckel (1862). The shell bearing extensive branched appendages. Coelodendrum.

\section{Class 5. SARKODINA (Hertwig and Lesser) Bütschli}

Sarkodina Hertwig and Lesser in Arch. mikr. Anat. 10 Suppl. 43 (1874).

Class SARKodina Bütschli in Bronn Kl. u. Ord. Thierreichs 1, I Teil: Inhalt (1882).

Class, subclass, etc., Rhizopoda Auctt.; class, subclass, etc. Sarcodina Auctt.

Amoeboid organisms without flagellate stages, the pseudopodia of the character of lobopodia; without skeletons, without or with shells of various materials.

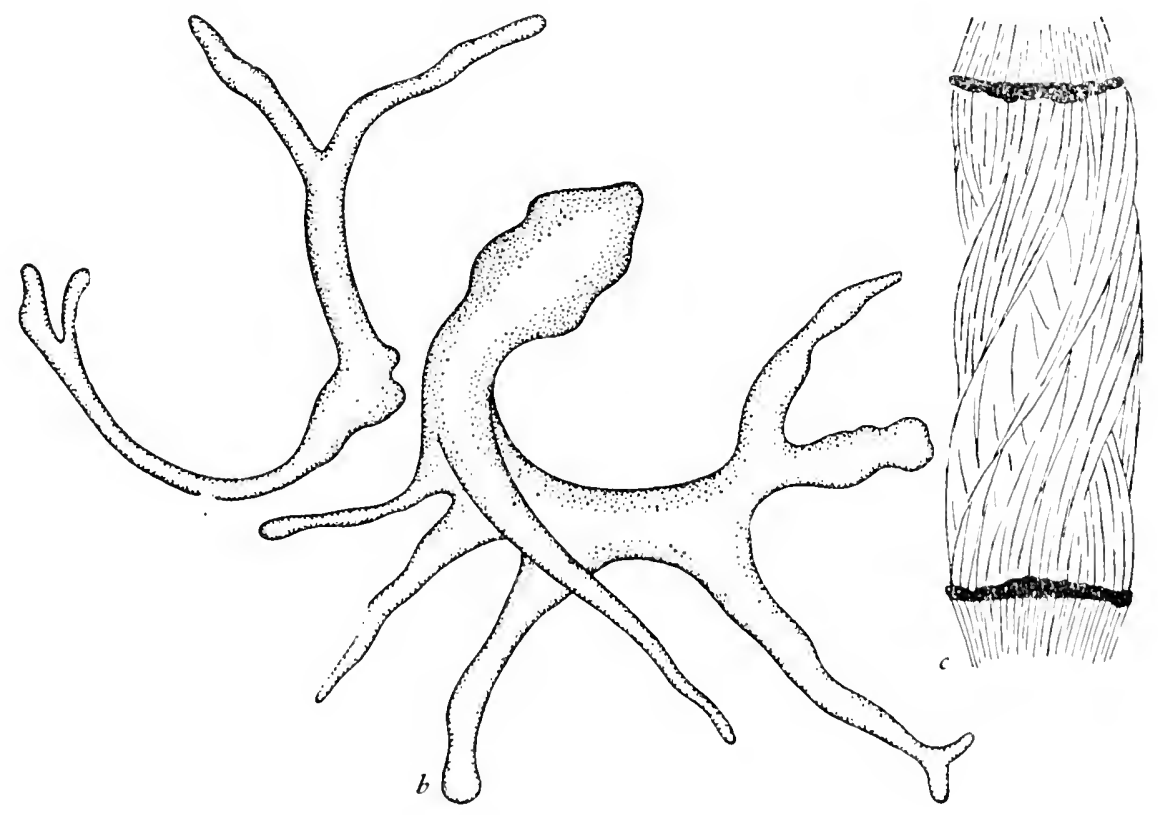

Fig. 39-Chaos Protheus: a, b, cells $\mathrm{x}$ 25, after the original figures of Pelomyxa carolinensis by Wilson (1900); c, mitotic figure x 2,000 after Short (1945). 
Hertwig and Lesser took note that the name Rhizopoda was originally applied to organisms such as Miliola, which have rhizopodia; they proposed the name Sarkodina for all amoeboid organisms, with Rhizopoda as a subordinate group. Among examples of Sarkodina which are not Rhizopoda, they listed first Diffugia, which may accordingly be considered the standard genus.

The Sarkodina as here presented are not assumed to be a natural group. Their common characters are probably the outcome of degeneration, by which organisms of diverse evolutionary origins have lost their distinctions.

This assemblage is obviously and superficially divisible into two by the absence or presence of shells. The resulting groups are construed as orders.

\section{Order 1. Nuda Schultze 1854.}

Family Amoebaea Ehrenberg Infusionthierchen 125 (1838).

Order Lobosa Carpenter 1861.

Order Gymnamoebae Haeckel Gen. Morph. 2: xxiv (1866).

Order Amoebina Kent Man. Inf. 1: 27 (1880).

Suborder Amocbaca Bütschli in Bronn. Kl. u. Ord. Thierreichs 1: $176(1880)$. Order Gymnamoebida Delage and Hérouard (1896).

Order Chaidea Poche in Arch. Prot. 30: 170 (1913).

Subclass Amoebaea and order Amoebida Calkins Biol. Prot. 335, 337 (1926).

Order Amoebaca Kudo Handb. Protozool. 204 (1931).

Sarkodina without shells. The type is the common amoeba, Amiba diffluens.

1 Protoplasts not tending to form pseudoplas-

modial communities.

2. Free-living. .................. Family 1. Amroebaea.

Family 2. Mayorellida.

Family 3. Thecamoebida.

Family 4. HYalodiscida.

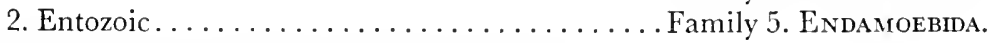

1. Protoplasts assembling and acting in unison

in pseudoplasmodial communities.

2. Parasitic in plants............... Family 6. LABYRInthulma.

2. Predatory on bacteria, in air on moist

surfaces; mostly producing complicated

fructifications. ............... Family 7. Guttulinacea.

Family 1. Amoebaea Ehrenberg Infusionsthierchen 125 (1838). Family Amoebidae Bronn 1859. Family Chaidae Poche in Arch. Prot. 30: 171 (1913). Family Chaosidae Chatton in Grassé Traité Zool. 1, fasc. 2: 58 (1953). The ordinary freeliving amoebas. Schaeffer (1926) limited the family to forms which produce numerous indefinite granular pseudopodia. There has been much confusion as to the identity of the species. There are apparently two species of common large amoebas:

1. Chaos Protheus L. Syst. Nat. ed. 12: 1326 (1767) (Volvox Chaos L. Syst. Nat. ed. 10: 821. 1758. Vibrio Protheus O. F. Müller Verm. Terr. et Fluv. 1: 45. 1773. Pelomyxa carolinensis Wilson in American Nat. 34: 535. 1900. Chaos chaos Stiles). Schaeffer identified Pelomy:xa carolinensis as the original Chaos Protheus L. It is exceptionally large, being macroscopically visible, and is multinucleate. Surely, sound nomenclature will apply to this species the name which Linnaeus gave it.

2. Amiba [Amoeba] diffuens (O. F. Müller) Ehrenberg Infusionsthierchen 127 (1838) (Protcus diffluens O. F. Müller Animac. Infus. 9. 1786; there is an older genus 
Proteus; Amiba divergens Bory Dict. Class. Hist. Nat. 1: 261. 1822; Amoeba Proteus Leidy). It appears that Müller intended to rename the Chaos Protheus of Linnaeus; that in 1773 he actually did so; but that in 1786 he applied another new name to a different organism. Ehrenberg's amended spelling Amocba, although in general use, is not valid as that of a generic name; as Schaeffer suggests, the word may be used as a common noun. Amiba diffucns is uninucleate; large, but not visible to the naked eye.

In nuclear division in the common amoebas the nuclear membrane disappears. There are many chromosomes in a blunt-ended spindle. Short (1945) noted a peculiar twisting of the spindle of Chaos Protheus.

Schaeffer included in the present family thrce further genera, Trichamocba Fromentel, Polychaos Schaeffer, and Mctachaos Schaeffer. Here, in ignorance of its relationships, another well-known genus is assigned to this family.

Pelomyxa, typified by P. palustris Greeff (1874), resembles Chaos Protheus in being exceptionally large, macroscopically visible, and multinucleate. It is definitely different from Chaos Protheus in manner of movement (King and Jahn, 1948) and in chemical characters (Andressen and Holter, 1949).

Minute amoebas moving by means of a single pseudopodium are called Vahlkampfia. They are believed to have swimming stages with paired equal flagella. If so, they do not belong to the present group, but perhaps to the plant kingdom.

Family 2. Mayorellida [Mayorellidae] Schacffer in Publ. Carnegie Inst. 345: 47 (1926). Producing numerous brief conical pseudopodia, but moving by a single large clear one. Mayorella, Pontifex, and several other genera proposed by Schaeffer; Dactylosphacrium Hertwig and Lesser; Dinamoeba Leidy? The last may be the nonflagellate stage of Chactoproteus Stein.

Family 3. Thecamoebida [Thecamocbidac] Schacffer op. cit. 83. Amocbas with a tough pellicle simulating a shell, moving by the outflow of clcar protoplasm at the anterior margin. Thecamocba Fromentel. Rugipes Schacffer.

Family 4. Hyalodiscida [Hyalodiscidae] Poche in Arch. Prot. 30: 182 (1913). Family Cochliopodïdae de Sacdelecr in Mém. Mus. Roy. Hist. Nat. Belgique 60: 5 (1934). Similar to the foregoing but without the tough pellicle. Commonly domeshaped, with a row of small pscudopodia projecting from the margin. Hyalodiscus and Cochliopodinm of Hertwig and Lesser, together with certain genera of Schaeffer.

Family 5. Endamoebida [Endamorbidac] Calkins. Entozoic amoebas.

Endamoeba Leidy is found in cockroaches and termites. The nucleus contains no karyosome, but many separate granules; in mitosis, definite chromosomes are forned (twelve in E. disficatia), but there is apparently no centrosome; at least, no intradesmose is seen (Kirby, 1927).

Entamoeba Casagrandi and Barbagello, named at nearly the same time as the foregoing and regrettably similarly, is widely distributed in invertebrate and vertebrate hosts. E. dysenteriae (Councilman and Lafleur) Craig (Endamocba histolytica Schaudinn) is a serious pathogen to man, the canse of amocbic dysentery. $E$. coli and $E$. gingivalis are believed to be harmless commensals. The fully mitotic character of nuclear division in these organisms was cstablished by Kofoid and Swezy (1921, 1922, 1925). The nucleus contains a small karyosome and an intranuclear centrosonc. Mitosis begins with division of the centrosome into two, which remain connected, as they draw apart, by a stainable strand, the intradesmose (the term is of Kofoid and Swezy, 1921). The karyosome breaks up into chromosomes, six in the species mentioned. Spindle fibers comnecting these to the centrosomes have been seen; Child (1926) 
found that the two halves of the spindle swing apart as the centrosomes move apart like the legs of a compass being extended. There is no doubt that Endamoeba and Entamoeba are generically distinct.

Endolimax, Iodamoeba, and Councilmania occur chiefly in vertebrates and include species commensal in man. A refined technique is required to discern the characters by which they are distinguished from Entamoeba. Karyamoebina Kofoid and Swezy (1924, 1925,) another commensal in man, resembles Vahlkampfia in details of the mitotic process, and probably does not belong to the present group. Hydramoeba, usually listed in the present family, is not an entozoic organism, but a predator on Hydra.

Family 6. Labyrinthulida [Labyrinthulidae] Haeckel ex Doflein Protozoen 47 (1901). There is a single genus Labyrinthula Gienkowski, and probably only one species, L. macrocystis, parasitic in green and brown algae and in the marine seed plant Zostera. The uninucleate cells are spindle-shaped. These cells send out from one or both ends fine filaments which writhe in the water. The filaments from different cells coil together and produce "tracks" along which the cells glide. The tracks form a network on which the cells may be scattered or gathered into clusters; or the cells may abandon their tracks and generate new ones. The nature of the tracks is not clear. Possibly they are pseudopodia, on which the cells move by absorbing them at one end while generating them at the other. Young (1943) found Labyrinthula remarkably indifferent to variations in temperature, reaction, and salinity.

Family 8. Guttulinacea [Guttulinaceae] Berlese in Saccardo Sylloge 7: 325 (1888) Tribe Dictyosteliaceae Rostafinski Vers. 4 (1873). Sorophoreen with families Guttulineen and Dictyostcliaceen Zopf Pilzthiere 131-134 (1885). Families Guttulineae and Dictyosteliaccae Berlese op. cit. 451. Sappiniaceac Olive in Proc. American Acad. 37: 334 (1901). Families Sappinïdae, Guttulinidae, and Dictyostelidae Doflein 1909. Family Acrasidae Poche in Arch. Prot. 30: 177 (1913). Suborder Acrasina Hall Protozoology 228 (1953). Amoeboid cells predatory on bacteria and other scraps of organic matter, in air on moist surfaces, commonly on dung. The cells are capable of assembling and moving and going into a resting stage in unison. These organisms have generally been included among the Mycetozoa; the resemblance is superficial.

More recently than Olive, Raper (1940) and Bonner (1944) have surveyed the group and studied the behavior. Three families have been maintained, but one appears sufficient to accommodate the seven genera and approximately twenty species.

Cells of Sappinia are binucleate. They do not necessarily assemble in clusters; a single cell may secrete a stalk, by which it is raised into the air, where it rounds up and becomes dry. Alternatively, small numbers of cells may assemble and secrete a common stalk. The dry cells are "pseudospores": they are capable of resuming activity without casting off a wall. Hartmann and Nägler (1908) described a peculiar sexual process in Sappinia diploidca.

Guttulina and Guttulinopsis produce larger clusters of resting cells than Sappinia does; in Guttulina the resting cells are said to be walled spores.

Acrasis produces fruits, solitary or clustered, of the form of uniseriate rows of spores terminal on stalks consisting of rows of dead cells.

Distyostelium produces fruits consisting of a column of dead cells bearing a globular cluster of spores; Polysphondylium and Coenenia produce slightly more elaborate fruits of the same general nature. In Dictyostclium, Raper and Bonner saw that the amoeboid active cells, having devoured the available food, gather into a disk-shaped mass which may exceed a millimeter in diameter. Wilson (1953) found syngamy, 


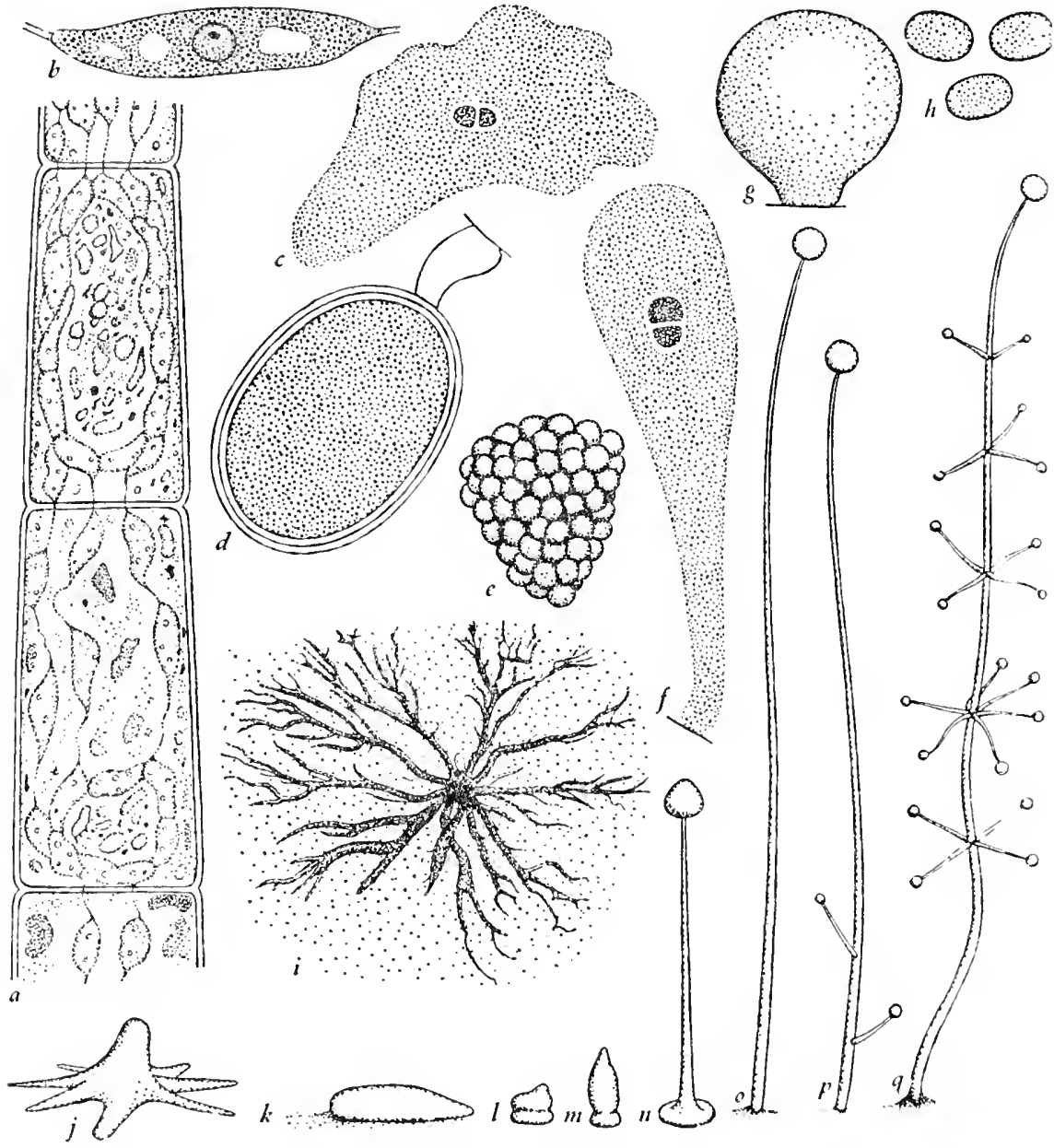

FIG. 40.-a, Labyrinthula as a parasite in cells of Ectocarpus Mitchelliae $\times 1,000$ after Karling (1944). b, Cell of Labyrinthula x 2,000 after Young (19:3). c, d, Sappinia pedata, active cell and cyst, x 1,000 after Dangeard (1896). e, f, Sappinia pedata, cluster of pseudospores $\times 100$ and single pseudospore $\times 1,000$ after Olive (1902). g, h, Guttulina sessilis, cluster of pseudospores $\mathrm{x} 100$ and individual pscudospores x 1,000 after Olive (1902). i-n, Dictyostclium discoideum x 10 after Bonner (1944): $\mathbf{i}$, the pseudoplasmodium; $\mathbf{j}$, it heaps itself up; $\mathbf{k}$, falls toward the light and creeps; $\mathbf{1}, \mathbf{m}$, again heaps itself up and becomes a fruit, $\mathbf{n} . \mathbf{0}, \mathbf{p}$, Fruits of Dictyostclium mucoroides; $\mathbf{q}$, of Polysphondylium violaccum; $\mathrm{x} 10$, after Bonner, op. cit. 
karyogamy, and meiosis to occur at this point; the chromosome number $(n)$ is 7 . The disk changes into a column which bends, and then falls, toward the light, and afterward creeps some distance in the same direction. When this has happened, the foremost cells, being those which were originally in the middle of the disk-shaped mass, pile up again to form a sterile stalk perhaps one millimeter tall; the cells behind them crawl up the stalk to form the globular mass of spores; the hindmost, being those which were last to arrive at the disk-shaped mass, remain behind to form a flange about the base of the stalk.

Order 2. Lampramoebae Haeckel Gen. Morph. 2: xxiv (1866).

Order Testacea Schultze 1854, non L. (1758).

Order Thecamoebae Haeckel.

Order Conchulina Cash and Hopkinson British Freshw. Rhizop. 1: 37 (1905). Suborder Testaceolobosa de Saedeleer in Mém. Mus. Roy. Hist. Nat. Belgique 60: 5 (1934).

Order Testacida Hall Protozoology 241 (1953).

Order Testaceolobosa Deflandre in Grassé Traité Zool. 1, fasc. 2: 97 (1953).

Amoeboid organisms without known flagellate stages, bearing shells and producing lobopodia. Various organisms producing rhizopodia or filopodia, traditionally associated with these, have here been placed among Rhizopoda or Heliozoa, as suggested by de Saedeleer (1934) and Grassé (1953). Deflandre (in Grassé, op. cit.) distinguishes several families beside the following:

1. Shell without secreted scales of silica.

2. Shell of uniform secreted material............ Family 1. Arcellina.

2. Shell with imbedded grains of sand ........... Family 2. Difflugima.

1. Shell with secreted scales of silica............. Family 3 . Nebelida.

Family 1. Arcellina Ehrenberg Infusionsthierchen 129 (1838). Family Arcellidae Schultze 1876. Arcella, etc.

Family 2. Difflugiida [Difflugiidae] Taránek 1881. Difflugia, etc.

Family 3. Nebelida [Nebelidae] Schouteden 1906. Nebela, the shell beset with circular siliceous scales; Quadrula, the scales square; etc. 


\section{Chapter XI}

\section{PHYLUM FUNGILLI}

\section{Phylum 7. FUNGILLI Haeckel}

Order Gregarinae Haeckel Gen. Morph. 2: xxv (1866).

Class Sporozod Leuckart Parasiten der Menschen 1, part 1: 241 (1879).

Phylum Fungilli Haeckel Syst. Phylog. 1: 90 (1894).

Class Sporozoaria Delage and Hérouard Traité Zool. 1: 254 (1896).

Subphylum Sporozoa Calkins Biol. Prot. 249 (1926).

Essentially unicellular organisms (the cells sometimes becoming multinucleate or multiple, but remaining undifferentiated except in connection with reproduction); commonly with a writhing motion; reproduction usually involving complicated sexual processes and the production of walled cysts (spores); flagella absent except sometimes on the sperms; parasitic in animals.

The class Sporozoa as originally published by Leuckart included the following groups: (a) the gregarines, first described by Dufour (1826) as worms parasitic in beetles: the generic name Gregarina Dufour (1828) refers to their occurrence in crowds; ( $b, c$ ) coccidians and psorosperms, different sorts of parasites discovered in fishes by J. Müller and Retzius (1842); and, doubtfully, (d) Micscher's tubes (Mieschersche Schläuche), being certain abnormal growths in muscles. The cause of the pébrine disease of silkworms, which Nägcli (in Caspary, 1857) had named Nosema Bombycis, belongs to this group but was not originally included, presumably: because Nägcli had concidered it to be a schizomycete.

It has subsequently become known that almost every species of the animal kingdom is parasitized by one or more species of Fungilli. Not all of these parasites, but many. are serious pathogens. Thus the Fungilli are a very important group and sery numerous. The number of species duly registered by name and description is apparently some two or three thousand; this is surely a small fraction of the number which exist.

The transmission of discase by biting arthrnpods was first demonstrated when Theobald Smith (1893) showed that the Texas fever of cattle, cansed by Babesia bigemina, is transmitted by ticks.

All who have classified the Sporozoa or Fungilli have recognized two prime subordinate groups, the first including the gregarines and coccidians, the second including the organisms which were formerly called psorosperms (Myxosporidia or Neosporidia). In addition to the main bodies of these groups, there are certain organisms which have resisted definite placement and have been assigned sometimes to one of the main groups, sonetimes to the other, and sometimes to additional main groups. In the present work the two main groups are treated as classes and the groups of uncertain relationship are included in the first. Clearly, this class is to bear the name of Sporozoa Lcuckart. Schaudinn's famous paper on parasites in the owl (1903) is apparently authority for the widely entertained opinion that this class is artificial, representing at least two lines of desecnt. In fact, the class appears natural with the possible exception of some of the poorly known groups. The second class is marked by positive specialized characters and is clearly natural; it is not clearly certain that the second class is related to the first, and it is accordingly not certain that the phylum is natural. The elasses are distinguisherl as follows: 
1. Producing resting cells protected by cell walls and not containing polar capsules; or not producing resting cells......................... SPorozoA.

1. Producing resting cells whose walls consist (at least usually) of modified cells, and which contain "polar capsules" enclosing coiled threads........................ Class 2. Neosporidia.

\section{Class 1. SPOROZOA Leuckart}

Class SporozoA Leuckart Parasiten der Menschen 1, Abt. 1: 241 (1879).

Subclass Gregarinida Bütschli in Bronn Kl. u. Ord. Thierreichs 1, Abt. 1: Inhalt (1882).

Class Sporozoaria and subclass Rhabdogcniae Delage and Hérouard Traité Zool. 1: 254,255 (1896).

Legion Cytosporidia Labbé in Thierreich 5: 3 (1899).

Subclass Telosporidia Schaudinn in Zool. Jahrb. Anat. 13: 281 (1900).

Class Telosporidia Calkins Biol. Prot. 421 (1926).

Class Telosporidca with subclasses Gregarinidia, Coccidia, and Haemosporidia; and class Acnidosporidea Hall Protozoology 270, 271, 290, 301, 323 (1953).

Sous-cmbranchement des Sporozoaires, with classes Grcgarinomorpha, Coccidiomorpha, and Sarcosporidia Grassé Traité Zool. 1, fasc. 2: 545 et seq. (1953).

Fungilli which produce resting cells protected by cell walls and not containing polar capsules; or else do not produce resting cells.

The nature of the organisms included in this class may be made clear by an example, Goussia Schubergi (Schaudinn) comb. nov. (Coccidium Schubergi Schaudinn, 1900).

Goussia is parasitic in centipedes. Infection is by certain spindle-shaped cells which have a certain power of movement, and which make their way to the interior of cells of the epithelium of the gut of the host. Each parasitic cell grows and becomes globular; it becomes multinucleate; when the host cell dies and breaks up, the parasitic cell divides into many spindle-shaped cells which infect other cells of the gut epithelium.

Alternatively, a sexual process takes place. Some of the parasites emerge into the gut and do not divide but function as eggs. Others produce numerous cells which are more slender than the usual infective cells. These become flagellate, each producing two unequal flagella, and function as sperms.

The zygote becomes walled. Its nucleus divides twice. Each of the four resulting nuclei becomes the nucleus of a walled cyst. The cysts are apparently formed by a process of free cell formation: not all of the cytoplasm of the zygote is included in them. In each cyst, two of the spindle-shaped infective cells are produced, again apparently by free cell formation, excluding a part of the cytoplasm. The zygotes, with their included cysts and infective cells, pass out with the feces of the host. If a centipede eats one of them with its food, the infective cells are released to perform their function.

No feature of the life cycle described is peculiar to the Sporozoa as contracted with other nucleate organisms. Nevertheless, largely by the authority of Schaudinn, specialists in Sporozoa use an extensive system of special terms. A familiarity with these is necessary to anyone reading about Sporozoa. They include the following: 
Sporozoite, the original infective cell.

Trophozoite, the vegetative individual.

Nucleogony, the multiplication of nuclei.

Plasmotomy, multiplication of cells.

Meront or schizont, the individual in process of dividing to produce further infective cells.

Schizogony or agamogony, the process of dividing to produce infective cells.

Merozoite or agamete, the infective cell produced from a trophozoite.

Gamogony, the production of gametes.

Macrogamete and microgamete mean, of course, egg and sperm; macrogametocyte and microgametocyte mean the cells which produce them.

Sporoblast or sporont, the zygote or other cell inside of which walled cysts are produced.

Sporogony, the sexual cycle which produces walled cysts.

Sporulation, the production of walled cysts by asexual processes.

Spore, the walled cyst.

Trophozoite (or schizont) and sporont are regarded as the alternating main stages in the life cycle of Sporozoa. The point at which meiosis occurs is uncertain. In the

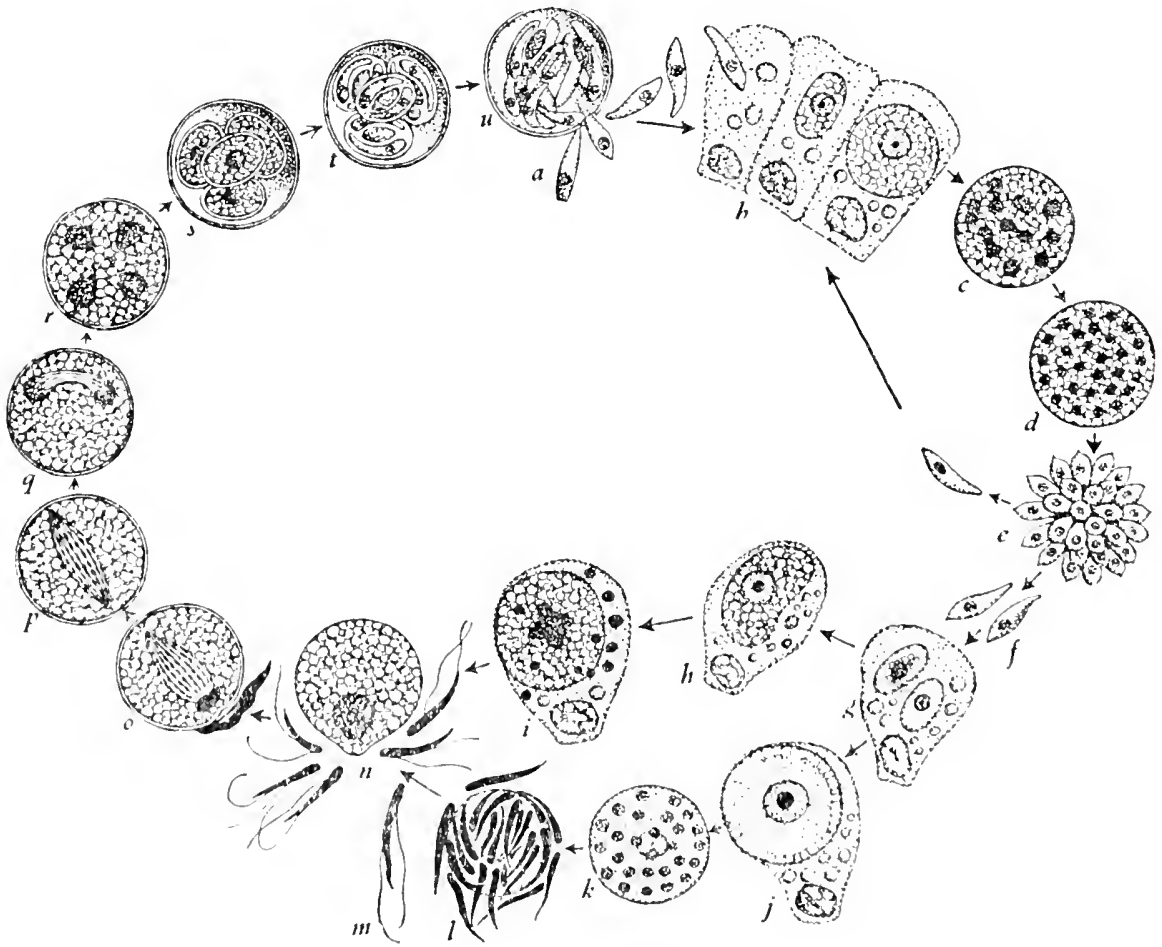

Fig. 41.-Life cycle of Coussia Schubergi after Schaudimn (1900): a, sporozoites; b-d, developing trophozoitcs; e, schizogony; f, merozoites; g, young gametocytes; $\mathbf{h} \mathbf{i}$, development of egg; $\mathbf{j}-\mathbf{m}$, development of sperms; $\mathbf{n}$, fertilization; $\mathbf{0}$, zygote (sporoblast); p-t, clevelopment of spores; $\mathbf{u}$, germination of spores. 
monocystid gregarines, Muslow (1911) and Calkins and Bowling (1926) described a reduction of the chromosome number immediately before gametogenesis, quite as in typical animals. They described reduction as accomplished by a single process of nuclear division; to current cytological theory, this is an impossibility. Dobell and Jameson (1915), Jameson (1920), and Dobell (1925), dealing with organisms of the same group and also with the coccodian Aggregata, found meiosis to occur immediately after karyogamy. They conclude that all nuclei except those of zygotes are haploid, as among most of the lower plants.

The coccidian group, to which Goussia belongs, is here treated as primitive among Sporozoa because the sperms of this group are flagellate. The detailed structure of the flagella is unknown; they appear to resemble those of Bodo and Cryptobia. This fact conveys the best available hint as to what may have been the evolutionary origin of the Sporozoa. The majority of Sporozoa, having gametes which are alike or scarcely differentiated, appear to be derived from forms with markedly differentiated gametes.

The Sporozoa are classified primarily by whether or not the trophozoites are intracellular; by the occurrence or non-occurrence of asexual reproduction; and by the production or non-production of spores in the sense in which the term is used in dealing with this group, that is, of walled cysts.

1. Sexual reproduction, so far as it is known, involving oocytes which produce single large eggs and spermatocytes which produce from few to many sperms; the organisms multiplying also asexually.

2. The gametocytes not attached in pairs.

3. Producing walled spores............ Order 1. Oligosporea.

3. Not producing walled spores.

4. Intracellular in erythrocytes....... Order 3. Gy M Nos PORIDIDA.

4. Producing macroscopic bodies in muscle................... Order 4. Dolichocystida.

2. The gametocytes pairing before gametogenesis; sperms few; with or without walled spores..................... Order 2. Polýsporea.

1. Gametes slightly differentiated or undifferentiated, produced by the gametocytes in more or less equal, usually large, numbers.

2. The organisms multiplying also asexually.

3. Spores producing several sporozoites.... Order 5. Schizogregarinida.

3. Each spore producing one sporozoite.... Order 8. HaplosporidideA.

2. The organisms not multiplying asexually.

3. Cells not elongate and divided into two parts....................... Order 6. Monocystiden.

3. Gells elongate and divided into two parts........................ Order 7. Polycystidea.

Order 1. Oligosporea Lankester in Enc. Brit. ed. 9, 19: 855 (1885).

Tribe Monosporées and groups Disporées and Tetrasporées Schneider in Arch. Zool. Exp. Gen. 9: 387 (1881). 
Coccididae, with tribes Monosporea and Olıosporea, Bütschli in Bronn Kl. u. Ord. Thierreichs 1: 574, 575 (1882).

Order Monosporea Lankester op. cit. 854.

Suborder Coccididae Delage and Hérouard Traité Zool. 1 : 278 (1896).

Order Coccidiidia Labbé in Thierreich 5: 51 (1899).

Order Coccidiomorpha Doflein Protozoen 95 (1901).

Order, suborder, or tribe Eimeridea Léger in Arch. Prot. 22: 80 (1911).

Order Eimeriidea, suborders Selenococcidinea and Eimeriinea, and tribe Eimerioidae, Poche in Arch. Prot. 30: 237, 238 (1913).

Subclass Coccidiomorpha and order Coccidia Calkins Biol. Prot. 435, 436 (1926).

Suborder Eimeridea Reichenow in Doflein Lehrb. Prot. ed. 5, $3: 921$ (1929).

Order Eimcriida Hall Protozoology 297 (1953).

Sporozoa living mostly within epithelial cells of their hosts, multiplying asexually, the gametocytes not pairing before gametogenesis, the macrogametocytes producing single eggs and the microgametocytes numcrous flagellate sperms, the zygotes usually producing definite walled spores.

The organisms of the present order and the following are called coccidians. Schneider (1881) classified them by the number of spores produced in each sporoblast (i.e., zygote), either one, two, four, or many. Bütschli and Lankester gave due form to Schneider's system. As between their names Monosporea and Oligosporea, the one which included the typical example Eimeria is here chosen in preference to the one which had page priority. Léger classified these organisms primarily by the number of sporozoites per zygote, and distinguished eight familics. Here, with the authority, for example, of Reichcnow (1929) and Kudo (1931), these are reassembled as one family to which are appended three others including markedly exceptional or poorly known forms.

Family 1. Eimerida [Eimeridae] Minchin 1903. The typical coccidians. In Eimeria Schneider (Coccidium Leuckart) the zygote produces four firmly-walled spores each with two sporozoites. The spores are symmetrically ellipsoid and relcase the sporozoites through a terminal pore. Species of this genus parasitize many vertebrate hosts, rabbits, sheep, goats, swine, dogs, cats, chickens, turkeys, frogs, and fishes. Some of the other gencra differ from this as follows: Jarrina, attacking birds, is distinguished by spores bearing the pore at the end of a brief neck. Goussia, in centipedes, has spores whose walls split lengthwise into two valves. The zygote of Isospora, in mammals, including man, produces two spores each with four sporozoites; that of Caryospora, in snakes, produces one spore with cight sporozoites. Barrouxia, in various invertebrates, produces from each zygote numerous bivalved spores each containing one sporozoitc.

Family 2. Dobelliida [Dobelliidae] Ikeda. The single known species, Dobellia bimucleata, occurs in a siphunculid worm. It exhibits an exception to the characters of the order: the male and female gametocytes becounc attached to each other; the male gametocyte, however, produces many sperms, as in the generality of the order.

Fanily 3. Aggregatida [Aggregatidae] Labbé in Thicreich 5: 6 (1899). This family is distinguished by heteroecism. In Ageregata Eherthi, vegetative growth and multiplication take place in crabs. When these are eaten by squids, the cells either develop into single eggs or else divide to produce many sperms. The zygote produces abont twenty bivalved spores which pass ont with the feces and infect crabs. The number of sporozoites per spore is variable. "There are several other species of $A g-$ 
gregata. Various other genera, Merocystis, Hyaloklossia, Myriospora, Caryotropha, etc., attacking mussels, polychaet worms, and other marine invertebrates, are assigned to this family although their life cycles are not fully known.

Family 4. Selenococcidiida [Selenococcidiidae] Poche in Arch. Prot. 30: 238 (1913) includes the single species Selenococcidium intermedium Léger and Dubosq (1910) in the lobster. The vegetative cell is long and slender, and asexual reproduction is regularly by transverse division into eight.

\section{Order 2. Polysporea Lankester in Enc. Brit. ed. 9, 19: 855 (1885).}

Tribe Polysporea Bütschli in Bronn Kl. u. Ord. Thierreichs 1: 576 (1882).

Suborder Haemosporidae Delage and Hérouard Traité Zool. 1 : 284 (1896).

Order Haemosporidiida Labbé in Thierreich 5: 73 (1899).

Order, suborder, or tribe Adeleidea Léger in Arch. Prot. 22: 81 (1911).

Tribe Adeleoidae Poche in Arch. Prot. 30: 239 (1913).

Order Adeleida with suborders Adeleina and Haemogregarinina Hall Protozoology 296 (1953).

It is characteristic of this order that pairs of reproductive cells, essentially merozoites, which are to become gametocytes, become attached to each other. The macrogametocyte becomes converted into a single egg; the microgametocyte produces, at least usually, four sperms.

Family 1. Adeleida [Adeleidae] Mesnil in Bull. Inst. Pasteur 1: 480 (1903). Chiefly in invertebrates, either in the gut epithelium or in the kidneys, testes, or other organs. Zygote usually producing definite spores, these numerous (commonly twenty or more), thin-walled, without definite dehiscence mechanism, with two or four sporozoites. Adelea and Adelina chiefly in centipedes; Klossia and Orcheobius in snails; Klossiella in the kidney of the mouse; Legerella in various arthropods, the zygote not producing spores but numerous sporozoites.

Family 2. Haemogregarinida [Haemogregarinidae] Lühe in Mense Handb. Tropenkrankheiten 3: 205 (1906). Heteroecious, with vegetative multiplication in the tissues of a vertebrate host. The infection spreads to the erythrocytes of the host, and blood-sucking invertebrates are infected by these. Sexual reproduction occurs in the invertebrate host. Production of spores is suppressed; the zygote produces numerous sporozoites. Haemogregarina Danilewski (1885; Drepanidium Lankester 1882, non Ehrenberg 1861) in turtles, frogs, fishes, transmitted by leeches; Hepatozoon in rodents, Karyolysus in lizards, transmitted by mites.

\section{Order 3. Gymnosporidiida Labbé in Thierreich 5: 77 (1899).}

Suborder Gymnosporidae Delage and Mérouard Traité Zool. 1: 284 (1896).

Suborder Haemosporidia Doflein Protozoen 121 (1901).

Order Hacmosporidia Calkins Biol. Prot. 441 (1926).

Subclass Haemosporidia with orders Plasmodiida and Babesiida Hall Protozoology 301, 302, 306 (1953).

In this order the vegetative cclls occur in vertebrates and infect the erythrocytes. Sexual reproduction, so far as it has been discovered, occurs in blood-sucking arthropods. The gametocytes do not become associated in pairs; the male gametocytes produce numerous spirochact-like sperms by a process of budding. In the zygote, the nucleus undergoes a series of divisions, after which numerous naked uninucleate sporozoites are budded off from the surface. There are no walled spores. 
The name Haemosporidia, commonly applied to this order, appears to belong by priority to the preceding.

Schaudinn (1903) was disposed to connect this order with the trypanosomes, while connecting the coccidians with Bodo and Cryptobia. This view has been entertained by Lühe (in Mense, 1906), Woodcock (1909), and Léger (1910). In spite of authority thus good, it appears far-fetched. The Gymnosporidiida are of the same general nature as the Aggregatida, Adeleida, and Haemogregarinida.

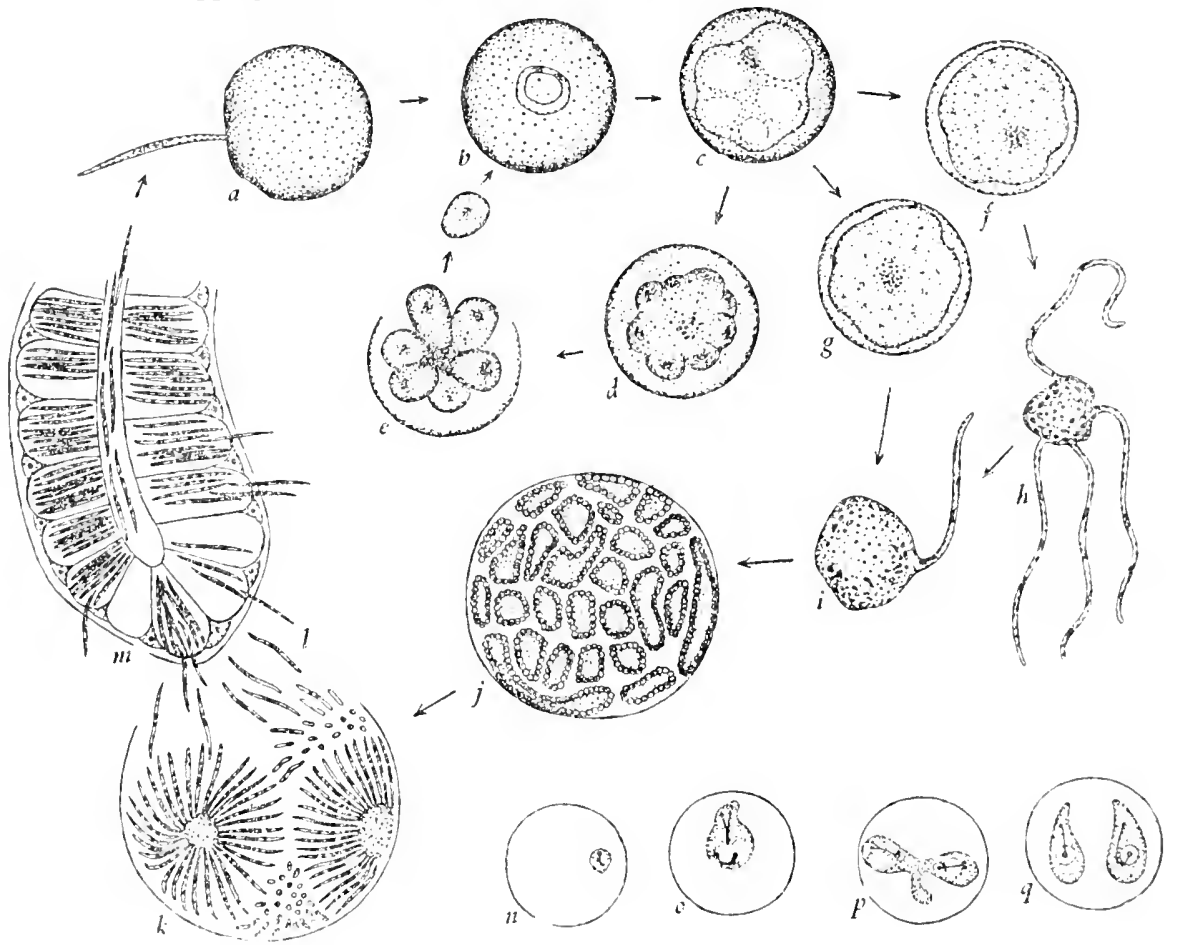

Fig. 42.- a-m, Life cycle of Plasmodium compiled from various sources: a, infection of an crythrocyte by a sporozoite; b-e, trophozoites, plasmotony, and merozoites; $\mathbf{f}$, spermatocyte; $\mathbf{g}$, oocyte; $\mathbf{h}$, production of sperms; $\mathbf{i}$, fertilization; $\mathbf{j}, \mathbf{k}$, production of sporozoites in cells of the gut epithelium of the mosquito; $\mathbf{1}$, sporozoites; niz sporozoites cntering the salivary gland of the mosquito. n-q, Stages of division of cells of Babesia bigemina in erythrocytes of cattle x 2,000 after Dennis (1930).

The Gymnosporidiida are organized, somewhat arbitrarily, as three families.

Family 1. Iralteridiida [Halterididac]Hartmann and Jollos 1910. Family Leucocytozoidae Hartmann and Jollos. Family Hacmoproteidae Doflein. Haemoproteus Kruse (Halteridium Iabbé) occurs in reptiles and birds. Vegetative growth and reprocluction oceur in tissue eclls. Some of the merozoites infect erythrocytes, and are belicved to become gametocytes, and to develop no further unless swallowed by some blood-sucking arthropod. In the best known example, H. Columbac of pigeons 
(Argao, 1908), the alternate host is a fly. In the gut of the fly, the spermatocytes produce the elongate sperms as outgrowths. The zygotes make their way into the wall of the gut of the fly, grow, and produce very numerous sporozoites. These migrate to the salivary gland, from which they are injected into pigeons.

Leucocytozoon attacks birds; its cells become fairly large in certain blood cells which become colorless and spindle-shaped.

Family 2. Plasmodida [Plasmodidae] Mesnil in Bull. Inst. Pasteur 1: 480 (1903). The malaria organisms, differing from Haemoproteus in that they multiply in the erythrocytes of their hosts. With a few obscurc exceptions, the species are construed as a single genus Plasmodium. Three species attack man; they have perhaps done mankind more injury than any comparable group of living creatures. Several comparatively poorly known species attack apes and monkeys. The alternate hosts of all species are mosquitoes of the genus Anopheles.

The vegetative individuals complete their growth within erythrocytes of their hosts in more or less definite periods of time, and undergo multiple division; the erythrocytes then break up and release the merozoites. The chill and fever of malaria are associated with the destruction of erythrocytes. In the ordinary form of malaria, called tertian malaria, development requires forty-eight hours, and the chill and fever occur every other day. Another form, called malignant tertian or tropical malaria, exhibits the same rhythm; it is distinguished by details of the appearance of the infected erythrocytes. In the third form of malaria in man, called quartan, development requires 72 hours, and the chill and fever occur every third day.

The course of development in the mosquito is quite like that of Haemoproteus Columbae in the fly. Some of the parasites inside the erythrocytes are gametocytes; each female gametocyte in an erythrocyte swallowed by a mosquito develops into a single egg, while each male gametocyte buds off several spirochaet-like sperms. The fertilized eggs are able to move. They break into the epithelium of the gut of the mosquito, grow into large globes, and become multinucleate; their protoplasts divide into numerous masses of protoplasm each of which buds off large numbers of sporozoites. The sporozoites are released into the body cavity of the mosquito, migrate to the salivary gland, and are injected into whatever animal the mosquito may bite.

The scientific names usually applied to the three species which cause human malaria are not valid by priority. Extensive synonymy is given by Sabrosky and Usinger, in their application to the International Commission on Zoological Nomenclature for action arbitrarily maintaining the current names (1944), and in the report by Hemming (1950) of the action of the Commission.

Certain structures in the erythrocytes of malaria patients were first recognized as parasites by Laveran, 1880, who, in 1881, named them Oscillaria malariae. The organism is believed to have been that of malignant tertian or tropical malaria. The word plasmodium, properly designating a certain type of body, was applied by Marchiafava and Celli 1885, in the combination Plasmodium malariae, believed also originally to have designated the agent of malignant tertian malaria. Feletti and Grassi, 1889, introduced the generic name Haemamoeba, with two species, $H$. vivax, the agent of tertian malaria, and $H$. malariae, that of quartan malaria; it is believed that the latter epithet was applied under the misapprehension that this was the organism which Marchiafava and Celli had named. It appears that Lühe, 1900, is responsible for the currently used names:

Plasmodium vivax, the organism of tertian malaria;

P. malariae, that of quartan malaria; 
$P$. falciparum, that of malignant tertian.

In order that a great mass of literature may be read without confusion, it is expedient that these names be arbitrarily maintained. The International Commission of Zoological Nomenclature has duly taken action to this effect.

Family 3. Babesiida [Babesiidae] Poche in Arch. Prot. 30: 241 (1913). Family Theileridae du Toit in Arch. Prot. 39: 94 (1918). Minute intracellular parasites transmitted by arthropods; sexual reproduction unknown. Theileria Bettencourt et al. causes a fever of cattle in Africa; the parasites multiply in the tissue cells and spread to the erythrocytes, by which ticks are infected. Babcsia Stercovici (Piroplasma Patton) is similar, but the parasites multiply in the erythrocytes. B. bigcmina causes the Texas fever of cattle.

The minute nucleus of Babcsia bigemina is largely filled by a single granule, a karyosome. This is connected by a rhizoplast to an cxtranuclear granule which has been identified as a blepharoplast, although no flagellum is present. In nuclcar division, as described by Dennis (1930), the blepharoplast divides; the rhizoplast splits; the nucleus widens, the karyosome becoming a rod; karyosome, nucleus, and cell undergo constriction. No chromosomes are seen.

If Bartonella bacilliformis, the agent of the disease variously known as verruga peruana, Oroya fever, or Carrion's disease, is not a bacterium, perhaps it may be placed in or near this family.

Order 4. Dolichocystida Delage and Hérouard Traité Zool. 1: 289 (1896). Sarcosporidia Balbiani 1882.

Class Sarcosporidia Bütschli in Bronn Kl. 11. Ord. Thierreichs 1, Abt. 1: Inhalt (1882).

Subclass Sarcocystidea Lankester in Enc. Brit. ed. 9, 19: 855 (1885).

Order Sarcosporidia Doflein Protozoen 214 (1901).

Order Sarcocystidea Poche in Arch. Prot. 30: 245 (1913).

Subclass Sarcosporidia Calkins Biol. Prot. 461 (1926).

The characters are those of the single family and genus:

Family Sarcocystida [Sarcocystidae] Poche in Arch. Prot. 30: 245 (1913).

Sarcocystis Lankester produces the Mieschersche Schläuche, macroscopically visible bodies, globular, fusiform, or filiform, of dimensions up to several millimetcrs, in muscles of animals. The several supposed species, from mice, shecp, swine, deer, etc., are not morphologically distinguishable. Miescher observed these things in mice, in which they are called Sarcocystis Muris; material from swine is called S. Micscheriana.

The visible body is a mass of cells, the whole walled by modified muscle of the host. The mass originates as a single cell which divides repeatedly; the ultimate division products are crescent-shaped uninucleate reproductive cells. Erdmann (1910) observed the infection of cpithelial cells of the gut of mice. Each infective cell srew and divided into scveral, which made their way, or were carried, to the muscles, where they gave risc to the Mieschersche Schläuche. Crawley (1914, 1916), on the other hand, found the infective cells to be gametocytes. In cells of the gut epithelium of the host, they may be converted as wholes into eggs, or else may give rise to mumerous (.)ongate sperms. These conflicting observations could be explained by an alcmation of sexual and ascxual generations, but the point is not established. 
Order 5. Schizogregarinida Calkins Biol. Prot. 433 (1926).

Amocbosporidies Schneider.

Amocbosporidia Labbé in Thierreich 5: 120 (1899).

Suborder Amocbosporidia Doflein Protozoen 171 (1901).

Suborder Schizocystinea Poche in Arch. Prot. 30: 233 (1913).

Suborder Schizogregarinaria Rcichenow in Doflein Lehrb. Prot. ed. 5, 3: 872 (1929).

Orders Archcgregarina and Neogregarina Grassé Traité Zool. 1, fasc. 2: 622, 665 (1953).

The Sporozoa previously considered, particularly those of the first two orders, are called coccidians; those of the present order and the two which follow are called gregarines. The latter are characterized (not without exceptions) by inter- instead of intra-cellular active stages, and by the production of numerous gametes, alike or not strongly difierentiated, from paired scarcely differentiated gametocytes. The present order includes the gregarines which exhibit asexual reproduction. They are a rather miscellaneous assemblage.

Family 1. Schizocystida [Schizocystidae] Léger and Duboscq in Arch. Prot. 12: 102 (1908). Family Monoschizae Weiser in Jour. Protozool. 2: 10 (1955), including the two following families. In marine worms and other invertebrates. The sporozoites enlarge in the host and become multinucleate individuals which reproduce frcely by producing uninucleate buds. Some of these buds continue the infection directly; others become attached in pairs, each pair secreting a common cyst wall. Each of the individuals in the cyst become multinucleate and buds off numerous uninucleate gamctes. The zygotes become walled spores which are cast out with the feces of the host, to infect others which ingest them. Each produces eight sporozoites. Schizocystis, Siedleckia.

Family 2. Seleniida [Seleniidae] Brasil in Arch. Prot. 8: 394 (1907). In marine worms. Vegetative individuals notably long and slender; spores spiny, with four sporozoites. Selcnidium, Meroselenidium.

Family 3. Merogregarinida [Merogregarinidae] Fantham 1908. Family Caulleryellidae Keilin. Merogregarina, Caulleryella, Tipulocystis.

Family 4. Spirocystida [Spirocystidae] Calkins Biol. Prot. 435 (1925). Family Spirocystidées Léger and Duboscq in Arch. Prot. 25: 210 (1915). In earthworms. Spores containing a solitary sporozoite which escapes through a pore. Spirocystis.

Family 5. Ophryocystida [Ophryocystidae] Léger and Duboscq in Arch. Prot. 12: 102 (1908). Family Amoebosporidiidae Brasil (1907), not based on a generic name. Family Dischizac Weiser in Jour. Protozool 2: 10 (1955). In Ophryocystis Schneider (Léger, 1907), the vegetative individuals, attached to the walls of the Malpighian tubules of beetles, grow and become multinucleate and send out branches whose ends develop into additional individuals. Eventually, different individuals become attached in pairs. Each of these individuals buds off a single uninucleate gamete. The remaining protoplasm of the gametocytes forms a protective sheath around the zygote, which becomes a single spore with eight sporozoites.

Order 6. Monocystidea Bütschli in Bronn Kl. u. Ord. Thierreichs 1: 574 (1882). Order Haplocyta Lankester in Enc. Brit. ed. 9, 19: 853 (1885).

Suborder Acephalina Labbé in Thierreich 5: 37 (1899).

Organisms of the character of gregarines, not multiplying asexually, the vegetative individuals not elongate and divided into serial parts. 
The genus which is best known is Monocystis Stein, including several species which are common in earthworms. The cells grow within epithelial cells of the seminal funnels; they and their nuclei reach considerable sizes without dividing. At maturity, they escape into the seminal vescicles, where they form pairs, each pair secreting a common cyst wall. The pairing and encystment were observed, more definitely of the related genus Zygocystis than of Monocystis, by Stein (1848). The nuclei of the paired cells divide. Several observers, as Brasil (1905) and Mulsow (1911); also, as to related genera, Jameson (1920) and Noble (1938); have observed peculiarities in the first nuclear division. The peculiarities amount to this, that the large nucleus breaks up and, for the most part, undergoes dissolution, leaving a small number of definite chromosomes to undergo normal mitosis in a spindle. Repeated subsequent divisions are of normal character. The numerous nuclei thus produced become those of gametes which are budded off from the surfaces of the gametocytes. This was first observed by Wolters (1891). The gametes from the respective paired cells are presumably always of different mating types, and are usually visibly differentiated, larger and smaller. Each zygote becomes a spindle-shaped walled spore; the enucleate remainder of the gametocytes provides nourishment during their development. Each spore produces eight sporozoites.

The number of known species of Monocystidea is of the order of 150 . The majority occur in annelid worms; others attack flatworms, echinoderms, insects, tunicates, and other invertebrates. Bhatia (1930) distinguished twelve families which are here merely listed.

1. The two ends of the spore alike.

Family 1. Monocystida [Monocystidae] (Bütschli) Poche in Arch. Prot. 30: 236 (1913). Family Monocystiden Stein in Arch. Anat. Phys. 1848: 187 (1848). Movocystidae Bütschli (1882). Monocystis, etc.

Family 2. Rhynchocystida [Rhynchocystidae] Bhatia in Parasitology 22: 158 (1930). Rhynchocystis.

Family 3. Stomatophorida [Stomatophoridae] Bhatia op. cit. 159. Stomatophora, Choanocystis, etc.

Family 4. Zygocystida [Zygocystidae] Bhatia op. cit. 160. Zygocystis, Pleurocystis.

Family 5. Akinetocystida [Akinetocystidae] Bhatia op. cit. 160. Akinetocystis.

Family 6. Syncystida [Syncystidae] Bhatia op. cit. 161. Syncystis.

Family 7. Diplocystida [Diplocystidac] Bhatia op. cit. 161. Diplocystis, Lankestcria.

Family 8. Schaudinellida [Schaudinellidae] Poche in Arch. Prot. 30: 236 (1913). Schaudinella.

B. The ends of the spores differentiated.

Family 9. Doliocystida [Doliocystidac] Labbé in Thierreich 5: 33 (1899). Family: Iecudinidae Kamm. Lecudina Mingazzini (Doliocystis Léger).

Family 10. Urosporida [Urosporidac] Woodcock 1906. Family Choanosporidae Dogicl. Conosfora; Lithocystis; Urospora, the spores with long tails; Ccratospora; Pterospora, the spores with longitudinal flanges.

I'anily 11. Ganymedida [Ganymedidae] J. S. I Iuxley in Quart. Jour. Micr. Sci. n.s. 55: $169(1910)$. Cranymcdes.

Family 12. Allantocystidae [Allantocystidac] Bhatia op. cit. 163. Allantocystis.

Order 7. Polycystidea Bütschli in Bronn K1. u. Ord. Thierreichs 1: 578 (1882). Order Gregarinae Ilacekel Gen. Morph. 2: xxv (1866). the mere plural of a generic name. 
Subclass Gregarinida Bütschli op. cit. Inhalt (1882).

Order Septata Lankester in Enc. Brit. ed. 9, 19: 853 (1885).

Order Brachycystida, suborder Gregarinidae, and tribe Cephalina or Polycystina Delage and Hérouard Traité Zool. 1: 255, 256, 269 (1896).

Order Gregarinida Labbé in Thicrreich 5: 4 (1899).

Suborder Eugregarinaria Doflein Protozoen 160 (1901).

Order Gregarinoidea Minchin (1912).

Suborder Gregarininea and tribe Gregarinoidae Poche in Arch. Prot. 30: 234 (1913).

Subclass Gregarinida, order Eugrcgarinida, and suborder Cephalina Calkins Biol. Prot. 422, 428 (1926).

The typical gregarines, the vegetative cells elongate and divided by more or less definite constrictions into two (or, occasionally, more than two) parts; not reproducing asexually.

Typical gregarines occur chiefly in insects. The vegetative cell consists of an anterior portion (protomerite) serving for attachment and a posterior portion (deutomerite), containing the nucleus, lying in the gut cavity of the host. Both parts have a thick outer layer, commonly differentiated upon the protomerite into a more or less elaborate knob, the epimerite. Longitudinal fibrils, presumably contractile, are present. The cells writhe actively.

The individuals are commonly found in pairs, one member attached to the epithelium of the gut, the other to the posterior end of the first. This arrangement is produced by active self-placement on the part of the second member. When both are mature, they take common action to produce a globular cyst. The protoplasts remain distinct until both have become multinucleate, after which they produce numerous gametes. In some forms, as Nina, studied by Goodrich (1938), all of the gametes migrate from one cell, recognizably male, into the other, the female cell; the male cell is left empty and is compressed or crushed by the growth of the zygotes in the female cell. The zygotes are spores, usually fusiform, and usually producing sporozoites by eights. In Gregarina and Gamocystis, an inner layer of the cyst wall is so modelled as to form tubes (sporoducts) running from the surface to the interior. When the spores are ripe, the sporoducts become extroverted and the spores are extruded through them in uniseriate rows. In connection with this behavior, the spores have flat ends like barrels.

Family 1. Stenophorida [Stenophoridae] Crawley 1903. Protomerite a mere knob. Stenophora.

Family 2. Gregarinida [Gregariniclae] Greene 1859. Family Gregarinarien Stein in Arch. Anat. Phys. 1948: 187 (1848). Gregarines which are without epimerites and are not notably elongate. There are about a dozen genera. Cysts without sporoducts: Hirmocystis, Hyalospora, Cnemidospora. Cysts with sporoducts, the spores barrel-shaped: Gregarina, Gamocystis. The earliest observations of Sporozoa were by Dufour (1826), who, studying the anatomy of insects, found them in the gut of beetles. He took them for worms and illustrated an individual with an epimerite, which he took for a sucker. Later (1828) he applied names, Gregarina conica to the form first seen, G. ovata to a form without an epimerite found in the forficule, i.e., in an orthopteran. The former does not belong to the genus Gregarina as subsequently construed; it appears to be a member of the family Actinocephalida. Gregarina ovata should be regarded as the type of Gregarina, but the genus has usually been interpreted by $G$. cuneata, which Stein observed in cockroaches. 
Family 3. Didymophyida [Didymophyidae] Wasilewski 1896. Family Didymophyiden Stein (1848). Like the foregoing, but the cells extremely elongate. Didymophyes.

Family 4. Acanthosporida [Acanthosporidae] Labbé in Thierreich 5: 27 (1899). The spores with polar or equatorial bristles. Acanthospora.

Family 5. Stylocephalida [Stylocephalidae] Ellis 1912. Family Stylorhynchidae Labbé op. cit. 30, based on a generic name which is a later homonym. Epimerite elongate with a small terminal knob. Stylocephalus.

Family 6. Actinocephalida [Actinocephalidae] Wasilewski 1896. Epimerite with thorns. Numerous genera, Sciadophora, Acanthorhynchus, Actinocephalus, Hoplorhynchus, Pileocephalus, etc.

Family 7. Menosporida [Menosporidae] Labbé op. cit. 29. Epimerite with a long stalk, distally branched and bearing appendages. Menospora.

Family 8. Dactylophorida [Dactylophoridae] Wasilewski 1896. Epimerite distally broadened, clinging to the host epithelium by means of numerous filiform processes. Dactylophorus, Nina (Pterocephalus), etc.

Family 9. Porosporida [Porosporidae] Labbé op. cit. 7. Heteroecious: in Porospora, the gregarinoid stage occurs in crabs and the production of spores occurs in mussels. The spores contain a single sporozoite and open through a pore.

\section{Order 8. Haplosporidiidea Poche in Arch. Prot. 30: 178 (1913).}

Order Aplosporidies Caullery and Mesnil 1899.

Order Haplosporidies Caullery and Mesnil in Arch. Zool. Exp. Gen. sér. 4, 4: 104 (1905).

Order Haplosporidia Auctt., the mere plural of a generic name.

Subclass Haplosporidia Hall Protozoology 326 (1953).

Unicellular intracellular parasites, the cells becoming multinucleate and multiplying by fragmentation, producing walled spores which germinate by releasing the protoplasts as single sporozoites.

The vegetative body is of the type properly called a plasmodium. The nuclei and the process of division, described by Granata (1914) are characteristic. The resting nucleus contains an "axial rod" as well as a nucleolus-like body. In mitosis the axial rod becomes converted into an intranuclear spindle. Individual chromosomes have not been seen; the chromatin gathers in a mass about the middle of the spindle (the figures are curiously diatom-like). The mass of chromatin, the nucleolus-like body, and the entire nucleus, divide by constriction; the ends of the spindle persist as the axial rods of the daughter nuclei. Eventually, the plasmodium secretes a thin wall and the protoplast divides into uninucleate naked cells. Granata found that these cells are gametes, and that conjugation takes place among gametes produced by the sane plasmodium. The zygotes become walled spores which germinate by casting off a circular operculum and releasing the contents. If the life cycle is correctly understood, we may suppose that these organisms are degenerate gregarines.

In the present state of knowledge, it will be as well to treat the typical haplosporidians as a single family:

Family Haplosporidiida [Haplosporidiidae] Caullery and Mesnil in Arch. Zool. Exp. Gen. sér. 4, 4: 106 (1905). Families Bartramïdae and Coelosporidiidae Caullery and Mesnil op. cit. 107. Characters of the order. Haplosporidium (spores with appendages at both ends) and Urosporidium (spores with a single appendage) attack 
chiefly annelid worms. Bartramia attacks rotifers; Ichthyosporidium is a serious parasite of fishes; Coelosporidium attacks cockroaches.

The following fanily, of uncertain position, may tentatively be associated with the Haplosporidiidea:

Family Metchnikovellida [Metchnikovellidae] Caullery and Mesnil in Compt. Rend. Soc. Biol. 77: 527 (1914), Ann. Inst. Pasteur 33: 214 (1919). Secondary parasites, intracellular in gregarines; cells naked at first, with very minute nuclei, which become numerous, later converted into walled cysts of characteristic form, the protoplasts undergoing division into uninucleate infective cells. Mctchnikovella, Amphiamblys, Amphiacantha.

\section{Class 2. NEOSPORIDIA (Schaudinn) Calkins}

Myxosporidia Bütschli in Zool. Jahresber. 1880: 162 (1881).

Subclass Myxosporidia Bütschli in Bronn Kl. u. Ord. Thierreichs 1, Abt. 1: Inhalt (1882).

Subclass Amoebogeniae Delage and Hérouard Traité Zool. 1: 291 (1896).

Subclass Neosporidia Schaudinn in Zool. Jahrb. Anat. 13: 281 (1900).

Order Cnidosporidia Doflein Protozoen 177 (1901).

Class Cnidosporidia Poche in Arch. Prot. 30: 224 (1913).

Class Neosporidia and subclass Cnidosporidia Calkins Biol. Prot. 445, 448 (1926).

Subphylum Cnidosporidia Grassé Traité Zool. 1, fasc. 1: 129 (1952).

Class Cnidosporidea Hall Protozoology 311 (1953).

Fungilli whose resting cells contain polar capsules; are walled, at least usually, by a layer of modified cells; and, in most examples, release a single infective cell.

As a general rule, the vegetative bodies of Neosporidia are plasmodia, i.e., naked multinucleate bodies, usually freely capable of asexual reproduction by internal or external budding. An entire small plasmodium may become converted into one or two spores, or the spores may be cut out internally and produced continually. The spores, at least in the two better-known orders, are structures formed from several cells; they are not homologous with the spores of the proper Sporozoa. In most examples, only one of the cells involved in the formation of a spore is fertile, and only one infective protoplast is released on germination. Of the sterile cells, one or more become converted into the structures called polar capsules. These resemble the nematocysts of coelenterates: they contain a coiled hollow thread capable of swift extroversion. Extroversion occurs during germination. Its significance is unknown. The presence of polar capsules marks the class as a natural group.

Three orders are recognized:

1. Spores covered by two valves formed from

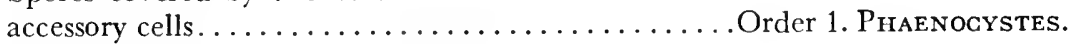

1. Spores covered by three valves formed from

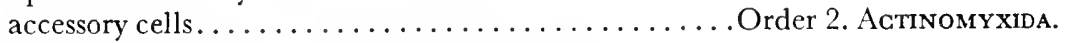

1. Spores very minute, with a continuous membrane. . . . Order 3. Cryptocystes.

Order 1. Phaenocytes Gurley in Bull. U. S. Fish Comm. 11: 410 (1893). Order Nematocystida Delage and Hérouard Traité Zool. 1: 291 (1896). Order Phaenocystida Labbé in Thierreich 5: 85 (1899). 
Order Cnidosporidia Doflein Protozoen 177 (1901).

Order Myxosporidia Calkins Biol. Prot. 449 (1926).

Most species of this order parasitize fishes, living cither in internal cavities or in the tissue cells; fewer than a dozen species are known from miscellaneous other animals, amphibia, reptiles, insects, and worms. Most of these parasites are not extremely injurious.

The infective protoplast which issues from a spore is, at least usually, binucleate. The nuclei fuse and the fusion nucleus divides repeatedly as the plasmodium grows.

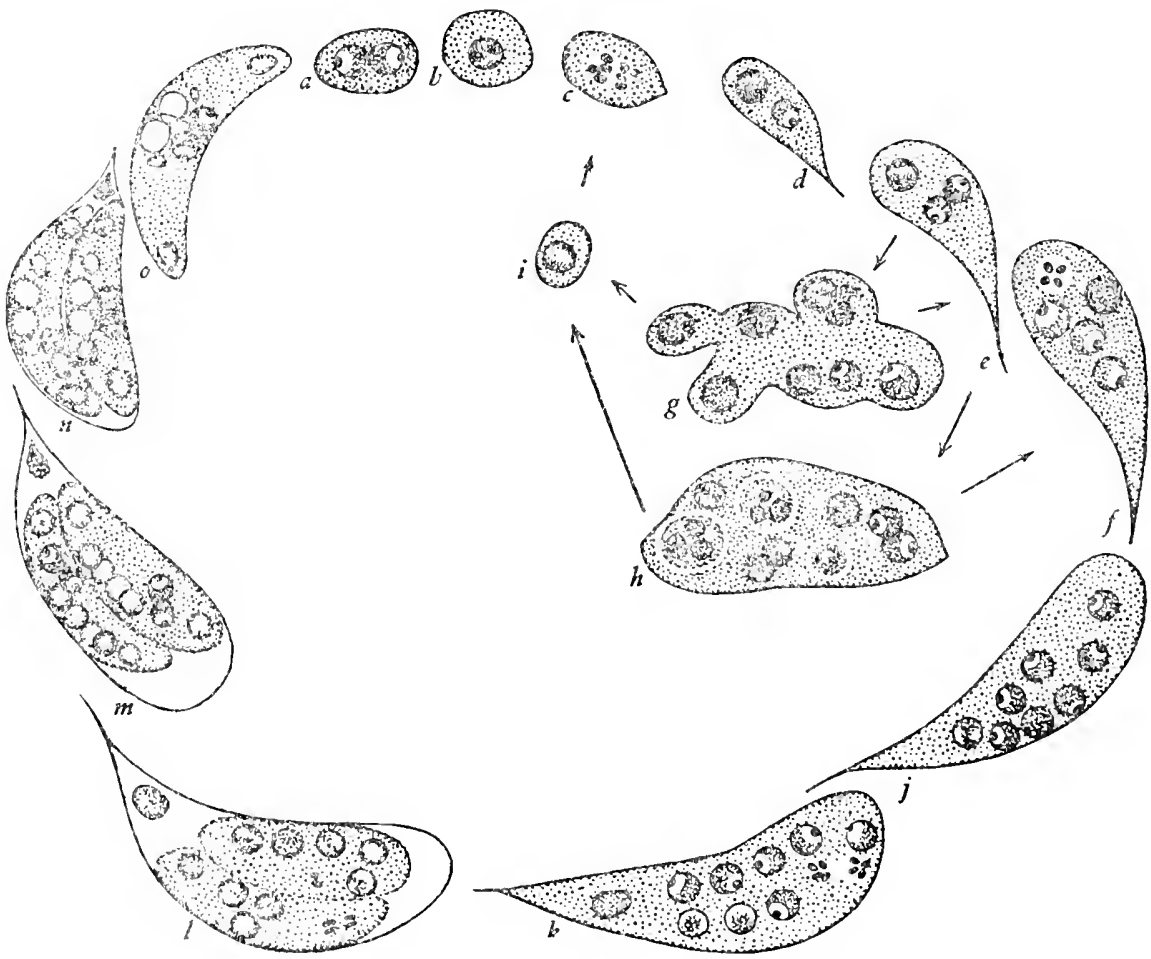

Fig. 43.-Diagran of the life cycle of Myxoceros Blennius after E. Noble (1941).

In the examples which are belicved to be more primitive, the plasmodia are frcely capable of budding, and the mature plasmodia are rather small and are converted as wholes into single or paired spores. In the remaining examples, the plasmodia do not nultiply by budding, but produce spores continually.

Noble (1941) described the mitotic process. There is a rather large intranuclear centrosome, which divides, the daughter centrosomes moving to opposite sides of the nuclear cavity. Four chromosomes appear; this is apparcutly constant throughout the order. The nuclear membrane and the centrosomes disappear. No spindle has been seen. The chromosomes divide, and the daughter chromosomes move apart and melt into two masses. The masses swell, a nuclear membrane appears about cach, and a centrosome appcars inside of each. 
The spore-forming structure (sporoblast) is a protoplast with several nuclei; it is either a whole small plasmodium, or half of one, or a protoplast cut out endogenously within a plasmodium. Two of the nuclei are set apart in cells which become converted into the valves of the spore. Two or four are set apart in cells which become converted into polar capsules. Two, of which it is established that they have two chromosomes each, are the nuclei of the infective protoplast.

In a review of the literature as to life cycles, Noble (1944) remarks as follows. "A survey of the literature reveals that there is little agreement on the details of nuclear changes in the Myxosporidia. Some authors maintain that the cycle is mainly haploid, others have described a diploid cycle. Some reports indicate that there are tivo reduction divisions and two zygotes in one cycle. When only one zygote is reported the reduction division in one case occurs just before fertilization, in another case it occurs just after fertilization. Some authors have maintained that there is no sexual process." Noble's own conclusions include the following. The organisms are diploid at most stages. The meiotic divisions are among those by which the sporoblast becomes multinucleate. The two haploid nuclei of the spore, which unite after germination, are derived from a single diploid nucleus. Authors who have described fusions of protoplasts, or transfers of nuclei from one protoplast to another, have had no evidence beyond an understandable unwillingness to accept fusions of sister nuclei.

Nearly two hundred species of the present order are listed in the monograph of Kudo (1920), who established three suborders.

A. Valves conical, spores biconic (suborder Eurysporea Kudo).

Family 1. Myxoceratida nom. nov. Family Ceratomyxidae Doflein Protozoen 182 (1901), based on a generic name which is a later homonym. Characters of the suborder. Myxoceros nom. nov. (Ceratomyxa Thélohan 1892, non Ceratiomyxa Schröter 1889; if ever names are homonymous without being absolutely identical, these are.) Some thirty-five species; the type is $\mathbf{M}$. sphaerulosa (Thélohan) comb. nov.; Noble studied mitosis in M. BIennius (Noble) comb. nov. Leptotheca, Myxoproteus, Wardia, Mitraspora.

B. Valves hemispherical, spores spherical (suborder Sphaerosporea Kudo).

Family 2. Chloromyxida [Chloromyxidae] Gurley in Bull. U. S. Fish Comm. 11 : 418 (1893). Chloromyxées Thélohan in Bull. Soc. Philomath. Paris sér. 8, 4: 176 (1892). Chloromyxea Braun in Centralbl. Bakt. 14: 739 (1893). With four polar capsules. Chloromyxum.

Family 3.Sphaerosporida [Sphaerosporidae] Davis 1917. With two polar capsules. Sphaerospora, Sinuolinea.

C. Valves saucer- or boat-shaped, spores disk-shaped or fusiform (suborder Platysporea Kudo).

Family 4. Myxidiida [Myxidiidae] Gurley op. cit. 420. Myxidiées Thélohan op. cit. 175. Myxidiea Braun l.c. Myxidium, Sphaeromyxa, Zschokkella.

Family 5. Coccomyxida [Coccomyxidae] Léger and Hesse 1907. Coccomyxa.

Family 6. Myxosomatida [Myxosomatidae] Poche in Arch. Prot. 30: 230 (1913). Myxosoma, Lentospora.

Family 7. Myxobolida [Myxobolidae] Gurley op. cit. 413. Myxobolées Thélohan op. cit. 176. Myxobolea Braun 1.c. Myxobolus, Henneguya, Hoferellus.

Order 2. Actinomyxida Stolc 1911.

This order includes about a dozen parasites in annelid worms. A plasmodial stage and asexual reproduction are believed not to occur; the infective protoplast grows 
into an individual whose one or two nuclei remain undivided until the commencement of the ill-understood process by which the complicated spores, with three valves and three polar capsules, are produced.

Family 1. Tetractinomyxida [Tetractinomyxidae] Poche in Arch. Prot. 30: 231 (1913). Family Haploactinomyxidae Granata in Arch. Prot. 50: 205 (1925). Spores subglobular, with a single binucleate sporozoite. Tetractinomyxon.

Family 2. Synactinomyxida [Synactinomyxidae] Poche 1.c. Family Euactinomyxidae Granata 1.c. Family Triactinomyxidae Kudo Handb. Protozool. 314 (1931). Spores producing eight or more sporozoites. Sphaeractinomyxon and Neactinomyxon, the spores subglobular. Synactinomyxon, with two of the valves protruding as considerable horns, the whole horse-shoe shaped. Triactinomyxon and Hexactinomy:xon, all three valves drawn out into long horns, the whole caltrop- or anchor-shaped.

Order 3. Cryptocystes Gurley in Bull. U. S. Fish Comm. 11: 409 (1893).

Microsporidies Balbiani 1882.

Order Microsporidiida Labbé in Thierreich 5: 104 (1899).

The parasites of this order attack chiefly arthropods and fishes. They multiply asexually and produce serious epizootics. The spores are very minute, and the details of the processes by which they are formed are unknown. A polar capsule is present in each spore (those of Telomyxa have two polar capsules). The polar capsules are not visible in living material, but are revealed by treatment with alkali.

In Kudo's monograph of this order (1924), more than 150 species are treated. They form four families.

Family 1. Glugeida [Glugeidae] Gurley op. cit. 409. Glugeidées Thélohan op. cit. 174. Glugeidea Braun 1.c. Family Nosematidae Labbé in Thierreich 5: 10t (1899). Family Plistophoridae Doflein Protozoen 205 (1901). Spores oval, ovoid, or pyriform. Nosema Bombycis Nägeli causes the pébrinc disease of silkworms; another species of Nosema causes an epizootic of honeybees. Glugea attacks several species of fishcs. Gurleya, Thelohania, Duboscquia, Plistophora, etc.

Family 2. Coccosporida [Coccosporidae] Kudo Handb. Protozool. 323 (1931). Family Cocconemidae Léger and Hesse 1922, based on a generic name which is a later homonym. Spores globular. Coccospora Slavinae (Léger and Hesse) Kudo, in the oligochaet worm Slavina.

Family 3. Mrazekiida [Mrazekiidae] Léger and Hesse 1922. Spores elongate, exceedingly minute, resembling bacteria. Mrazekia, Octospora, Spironema, Toxonema.

Family 4. Telomyxida [Telomyxidae] Léger and Hesse 1910. Telomyxa glugeiformis, in the fat body of the larva of Ephemera vulgata, producing cllipsoid spores with a polar capsule at each end. 


\section{Chapter XII \\ PHYLUM CILIOPHORA}

\section{Phylum 8. CILIOPHORA (Doflein) nomen phylare novum}

Class Infusoires Lamarck Phil. Zool. 1: 127 (1809).

Glass Infusoria Lamarck Anim. sans Verteb. 1: 392 (1815).

Class Protozoa Goldfuss in Isis 1818: 1008 (1818).

Class Polygastrica Ehrenberg Infusionsthierchen p.* (1838).

Hauptgruppe Protozoa, class Infusoria, and order Stromatoda Siebold in Siebold and Stannius Lehrb. vergl. Anat. 1: 3, 10 (1848).

Subkingdom Archczoa Perty Kennt. kl. Lebensf. 22 (1852), not phylum Archezoa Haeckel (1894).

Order Ciliata Perty op. cit. 137.

Subphylum Infusoria Haeckel Gen. Morph. 2: lxxviii (1866).

Phylum Infusoria Haeckel Syst. Phylog. 1: 90 (1894).

Subphylum Giliophora Doflein Protozoen 227 (1901).

Dependent organisms, mostly predatory, unicellular but mostly of complicated structure; swimming by means of cilia at least at some stage of life; mostly with nuclei of two types in each cell. Vorticella, the only genus named by Linnaeus, is to be considered the type.

These organisms are the typical examples of the accepted groups Infusoria and Protozoa. The name Infusoria, referring to creatures which appear in infusions, is said to have been introduced by Ledermïller, 1763, or Wrisberg, 1764. As a scientific name it has status from its application to a class by Lamarck (1815). The name Protozoa, applied to a class in its original publication by Goldfuss, is a later synonym of Infusoria. In treating the group as a phylum, one finds it necessary to apply a new name, and takes up as such the name which Doflein applicd to it as a subphylum.

The essential point in the definition of the phylun is the word cilia. Cilia are cellorgans of the same nature as flagclla, differing in being smaller in proportion to the cell which bears them, more numerous, and distributed generally on the surface. In Loeffler's classic investigation (1889), they were found to bear solitary terminal appendages; by subsequent terminology, they are acroneme. Doflein appears to have been mistaken in emphasizing the difference between flagella and cilia; there is no fundamental difference. A verbal distinction, nevertheless, is expedient: the application of the term cilium is to be restricted to two things, (a) the swimming organelles of the Ciliophora, and (b) moving fibrils protruding abundantly from certain epithelial cells of animals. Botanical usage, which treats cilium and flagellum as synonyms, is unsound. The structures which in botany have been called cilia are definitely flagella.

The cells of Ciliophora reach moderately large sizes; those of the classroom example Paramaecium attain a length of $0.25 \mathrm{~mm}$. and are perceptible to the naked eye. The cells of some of the Ciliophora are the most highly complicated of all individual cells. In addition to the cilia, the cell organs which require discussion are the pellicle, neuromotor fibrils, trichocysts, structures involved in nutrition, contractile vacuoles, and nuclei.

The cell has a firm ectoplasm or pellicle which gives it a definite form. The cilia spring from basal granules imbedded in the pellicle. In simpler examples, the cilia 
are essentially uniform and uniformly distributed on the surface. Other examples are without separate cilia upon part or all of the surface, but bear a variety of structures which consist of coalescent cilia. Membranelles are triangular appendages consisting of brief rows of cilia; undulating membranes represent long rows; cirri rcpresent tufts. The organisms of class Tentaculifera bear cilia only in the juvenile condition. At maturity they bear extensible tubular structures called tentacles, by means of which they capture free-swimming ciliates and absorb their contents.

The basal granules of the cilia are linked together by a system of fibrils; the cilia and fibrils make up the neuromotor apparatus. This term was coined by Sharp, in his study of Diplodinium (1914). The neuromotor fibrils form a highly elaborate network, not connected with the nucleus, as in flagellates, but to a central structure, apparently regulative, called the motorium. The motorium of Diplodinium is a massive body near the anterior end; that of the tintinnids is fairly large in proportion to the cells (Campbell, 1926, 1927); that of Paramaccium, presumably a comparatively primitive organism, is a minute body lying near the dorsal side of the cytopharynx (Lund, 1933).

Imbedded in the pellicle, in addition to the neuromotor fibrils, there are certain minute ellipsoid bodies called trichocysts. These, when the cell is irritated, discharge their contents in the form of elongate rods or threads. Their mechanism and effect are not understood.

In most Ciliophora, each cell has a month and gullet; or better, since these structures are not homologous with those of animals, a cytostome and cytopharynx. The cytopharynx is a more or less funnel-shaped impression in the cell. It is bounded laterally by ciliate pclliclc; its outer opening is the cytostome; it is closed at the inner end by a layer of cell membrane directly over fluid cytoplasm. Prey, chiefly bacteria and small algae, encountered by the organism as it swims, is swept into the cytopharynx by the action of the cilia. When a certain mass of prey has accunulated, the cell membrane at the inner end of the cytopharynx becomcs impressed and undergoes constriction, enclosing the prcy in a food vacuole. The matcrial in the food vacuole undergoes digestion; while this is taking place, movement of the cytoplasm carrics the vacuole along a definite circuitous course through the interior of the cell. After some time, the vacuole arrives at a certain point on the pellicle, the anus or cytoproct, where it discharges its contents and disappears by bursting through the pellicle.

In freshwater species, each cell contains one or more contractile vacuoles which appear at definite points and disappear periodically by discharge of their contents to the exterior. Associated with the proper contractile vacuoles, there may be systems of "canals" which are in fact additional contractile vacuoles. These structures have been much studied; there are notable accounts by Day (1930) and Mac Lennan (1933). When a vacuole has disappeared by discharge, it reappears as one or more minute vacuoles in the same area: minute bodics of gelled protoplasm turn into sol, and then become lifeless liquid. The discharge of a "canal" into the proper contractile vacuole occurs by dissolution of the bounding membranes of gelled protoplasm where the two are in contact, followed by contraction of the membrane of the canal. The proper contractile vacuole discharges by essentially the same mechanism. Its membrane meets and becomes fused with the bounding membrane of the cell, gencrally at the end of a brief channel through the pellicle; the combined membrane breaks, and the membrane of the vacuole contracts. 
Earlier biologists supposed that the contractile vacuole is an cxcretory mechanism. More probably, its function is purely hydrostatic, to rid the cell of the water which is constantly entering by osmosis. Marine Ciliophora have no contractile vacuoles.

In many members of the family Opalinoea each cell has many similar nuclei. These divide, from time to time, by mitosis. Cell division takes place independently of nuclear division, by transverse constriction, when a certain size has been reached.

In the generality of Ciliophora, each cell has one or more nuclei of each of two types, macronuclei, which are conspicuous, and micronuclei, discerned with difficulty.

Cell division occurs by transverse constriction and is necessarily associated with nuclear division. The macronucleus becomes elongate and divides by constriction without any formation of chromosomes; in other words, amitotically. The micronucleus also becomes elongate and divides by constriction. Early observers supposed this process also to be amitotic. Actually, there appear within the intact nuclear membrane a spindle and a definite number of chromosomes. Reichenow (editing Doflein, 1927) compiled the following diploid counts:

Stentor coeruleus

Didinium nasutum

Chilodon uncinatus

Carchesium polypinum

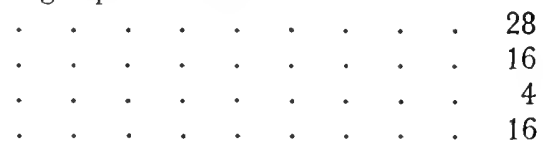

Turner (1930) found 8 in Euplotes Patella. Thus the chromosome numbers of Ciliophora appear usually to be small powers of 2 .

The chromosomes duly undergo division, the daughter chromosomes going to different ends of the nuclear cavity. The nucleus becomes greatly elongate and its membrane presses in from the sides and cuts it in two. Turner observed in the axis of the spindle of Euplotes a rather small endosome which becomes elongate and undergoes constriction while the chromosomes are forming.

Opalina has a sexual process in which the multinucleate cells divide into many uninucleate gametes. These are sexually differentiated, larger and smaller; they duly unite in pairs and the zygotes grow and become ordinary multinucleate individuals.

In the generality of Ciliophora, early observers discovered a sexual process in which the cells, apparently undifferentiated, join in pairs but maintain their individuality. The uniting cells become attached to each other in definite positions: in Paramaecium, by their ventral or mouth-bearing surfaces; in Euplotes, by the left halves of their broad ventral surfaces; in the ophryoscolecids and various other groups, by their anterior ends. They remain attached, while continuing to swim, for several hours, during which an exchange of nuclei takes place, and then resume their separate life. Calkins (1926) was disposed, contrary to historical usage, to confine application of the term conjugation to this exceptional form of syngamy.

The nuclear details of conjugation were described by Maupas (1889) and Richard Hertwig (1889), whose observations have repeatedly been confirmed. When a pair have joined, their macronuclei divide several times; the ultimate fragments are digested and disappear. The micronuclei also divide, concurrently in both conjugants, a fixed number of times, in Paramaecium three, in Euplotes four. These divisions include a meiotic process. Most of the haploid nuclei produced are digested; as a general rule, only one survives to undergo the final division, which is mitotic, producing in each conjugant two genetically identical haploid nuclei. By this time a cytoplasmic connection has been established between the conjugants. In Paramaecium, the spindles of the mitotic final nuclear divisions extend through this connection, 
so that when mitosis is complete each protoplast contains two haploid nuclei of different origin. In other ciliates the same result is attained, apparently, by the migration of one nucleus of each pair. Karyogamy takes place in each conjugant. The cytoplasmic connection is broken and the conjugants separate from each other. During several subsequent hours, the zygote nucleus undergoes a characteristic number of divisions, three in Paramaecium. Among the nuclei produced, one usually enlarges and becomes a macronucleus; others, of the number characteristic of the form, survive as micronuclei; the remainder are digested.

In Vorticella and its allies, syngamy consists of the complete fusion of a smaller swimming individual with a larger one attached by a stalk. The nuclear processes are believed to be essentially as in other ciliates. The reproduction of the Tentaculifera has not been much studied, but here also the nuclear changes are as in the generality of ciliates (Noble, 1932).

The possibility of conjugation is limited by the occurrence of mating types. Certain early observations had suggested the existence of these; the definite discovery was by Sonneborn, in Paramaecium Aurelia (1937). Results of further study are available in a symposium edited by Jennings (1940) and in a review by Kimball (1943). To current knowledge, then:

Paramaecium caudatum includes four mating types divided into two grolips; types I and II conjugate with each other, and types III and IV with each other, but the two groups are mutually sterile.

Paramaecium Aurelia includes eight mutually sterile groups, each of two mutually fertile mating types.

Paramaecium Bursaria includes three mutually sterile groups. The first group is of four types, each self-sterile but able to conjugate with any other; the second group is of eight such types, and the third again of four.

Paramaecium multimicronucleatum is without mating types; any race can conjugate with any other

Euplotes Patella includes six mating types all in one group; each can conjugate with any other.

The heredity of mating types is not understood. It is not a matter of simple Mendelian heredity. In Paramaecium Bursaria group I, the progeny of a cell of a given mating type may include after conjugation either two or all four of the mating types. The mating type of a line becomes fixed in connection with the first or second cell division after conjugation, at the time that macronuclei are being differentiated; it is accordingly believed that something in the macronuclei fixes the mating types.

So far as mating types are present, pure lines of ciliates cannot conjugate. Early attempts to maintain pure cultures failed by death after intervals of some months. These observations led to speculations that the vitality of protoplasm is linited, and that sexual reproduction restores it. Woodruff, however, proved it possible to maintain Paramaecium Aurelia indefinitely without conjugation: he reported (1926) a culture so maintained for sixteen years, an estimated eleven thousand gencrations.

The cultures are not thus persistent without nuclear change. $\Lambda$ t intervals, the macronuclei break up and dissolve, and are replaced by new ones formed by division of the micronuclei. Woodruff and Erdmann (1914) applied to this process of replacement of nuclei the term endomixis. It is not possible that this process is the genetic equivalent of karyogamy. It is, presumably, the physiological cquivalent of conjugation in its feature of providing new macronuclei. 
Diller (1936) observed in P. Aurelia a different manner of replacement of nuclei, by autogamy. In this process, the nuclei of a solitary cell go through the preliminaries of conjugation; two haploid nuclei, sister products of one act of mitosis, unite to form a zygote nucleus; and this divides in the usual manner to produce micronuclei and macronuclei. Wichtermann $(1939,1940)$ observed that two cells, joined as in conjugation, may simultaneously undergo autogamy instead of exchanging nuclei.

In the normal conjugation of ciliates, the gamete nuclei produced in each cell, being sister products of mitosis, are genetically identical; and the zygote nuclei produced after interchange are also genetically identical with each other. Autogamy is believed to produce diploid nuclei which are completely homozygous. Thus the sexual processes of the ciliates tend strongly to limit the variability of the progeny. This is a peculiar and surprising feature of the group.

The ciliates have attracted experimental study, beyond what has already been implied, of various functions, including nutrition, inheritance of acquired characters, and regeneration after injury.

Hall and his associates (1940-1945) have shown that Colpidium campylum and Tetraphymena Gelcii (the latter is in their earlier papers called Glaucoma piriformis) require thiamin and probably riboflavin. Nutritional requirements, rather than such an entity as vitality, are presumably responsible for the limited life of early attempted pure cultures. As to minerals, the same scholars demonstrated the necessity of $\mathrm{Ca}$ and Fe: others have demonstrated the necessity of $\mathrm{K}, \mathrm{Mg}$, and $\mathrm{P}$.

It has been observed of certain cultures in which the rate of division has been increased by exposure to high temperature that they would continue to divide abnormally rapidly when returned to normal temperatures. The peculiarity disappeared in individuals which conjugated. By refrigeration or by application of chemicals, there have been produced "monsters," individuals of abnormal structure, which have reproduced themselves through many gencrations, and have proved capable eventually of giving rise to normal individuals. Jollos (1913) designated as Dauermodifikationen, that is, enduring changes, modifications of the type described. They are actually acquired characters which can be inherited within limits. It is evident that they are determined by macronuclei or by cytoplasm, and that they are not in conflict with the principle that the truly enduring heredity of nucleate organisms lies in nuclei which divide mitotically.

Balamuth (1940) revicwed the literature of experimental mutilation of Protozoa and gave a bibliography of 173 titles. Most of the experiments have been performed on ciliates. The conclusions from them include these, that regeneration of parts artificially cut away takes place with different degrees of facility in differcnt groups, and that it is effected, if at all, by the same mechanism by which the parts are produced after division or excystment. The less elaborate ciliates, as Opalina and Paramaecium, are usually killed by mutilation, since this allows the fluid inner cytoplasm to escape. In Stentor, injury to the crown of membranelles results in the appearance of a new crown of membranelles on the side of the body, followed by its migration to the injured area. In Stylonychia and Euplotes, destruction of one cirrus is followed by the appearance, in a certain area of the surface, of the primordia of a complete set of cirri; the original cirri are absorbed, and the new ones migrate along the surface to their proper stations. The regulation of regeneration is explained, as are various other phenomena, in a review by Weisz (1954).

Micronuclei are neccssary for unlimited life and for sexual reproduction, but not for regeneration and a long period of life. Schwartz kept a culture of Stentor alive 
without micronuclei for more than a year. Macronuclear material is necessary for regeneration, but any fragment of a macronucleus is sufficient. This is a very significant observation. It means that all the factors controlling the vegetative structure and behavior of a cell can be spread out and intermingled in all parts of a body of considerable size; it furnishes an analogy to the state of affairs which may be supposed to exist in bacteria.

The Ciliophora are treated as two classes, Infusoria and Tentaculifera. Hartog (1909) estimated the number of known species of the former as about five hundred. This number would have included practically all of the fresh-water species known up to the present. Entozoic and marine species were known, but hundreds of species of these ecological groups have subsequently been discovered. Including some two hundred species of Tentaculifera, the phylum Ciliophora appears to be of about twelve hundred known species.

\section{Class 1. INFUSORIA Lamarck}

Class Ciliata Haeckel Gen. Morph. 2: lxxviii (1866).

Class Ciliatea Hall Protozoology 333 (1953).

Further synonymy essentially as of the name of the phylum.

Ciliophora lacking tentacles, bearing cilia or modified cilia in the mature condition.

Stein (1867) provided four orders of Infusoria. These orders are surely natural. Subsequent authors have proposed many modifications of Stein's system, and many of these are surely sound; but anong groups proposed as additional orders, only the opalinids are positively entitled to this status.

1. Nuclei all alike, commonly numerous............ Order 1. Opalinalea.

1. Nuclei differentiated into macronuclei and micronuclei.

2. Without a spiral band of membranelles or cilia about the cytostome.............. Order 2. Hoiotricha.

2. With a spiral band of membranelles or cilia about the cytostome.

3. The spiral sinistrorse.

4. Not of the character of the following order.................. Order 3. Heterotricha.

4. Flattened, cirri and most cilia confined to the ventral surface....... Order 4. Hypotricina.

3. The spiral dextrorse .................. Order 5. Stomatona.

\section{Order 1. Opalinalea nom. nov.}

Suborder Opalininca Poche in Arch. Prot. 30: 250 (1913).

Protociliata Metcalf in Anat. Record 11: 89 (1918) and Jour. Washington Acad. Sci. 8: 431 (1918).

Subclass Protociliata Kudo Handb. Protozool. 335 (1931).

Order Opalinida Hall Protozoology 113 (1953), preoccupied by family Opalinidae Claus.

Nuclei not differentiated into two types; cilia abundant, undifferentiated; sexual reproduction by the complete union of differentiated minute uninucleate gametes. Commensal in the gut of amphibia and fishes.

The group has been treated monographically by Metcalf (1923). A single family is usually recognized. 
Family Opalinoea Pritchard 1842. Family Opalinaea Siebold in Siebold and Stannius Lchrb. vergl. Anat 1: 10 (1848). Family Opalinina Stcin Org. Inf. 2: 169 (1867). Family Opalinidae Claus 1874. Family Protoopalinidae Metcalf 1940. There are about 150 known species of four approximately equally numerous genera: Protoopalina Metcalf, cylindrical, with one or two nuclei which are always found in a stage of mitosis; Zelleriella Metcalf, similar, the cells flattened; Cepedia Metcalf, cylindrical, with many nuclei; Opalina Purkinje and Valentin, flattened and multinucleate.

\section{Order 2. Holotricha Stein Org. Inf. 2: 169 (1867).}

Orders Gymnostomata and Trichostomata, and suborder Aspirotricha Bütschli in Bronn Kl. u. Ord. Thierreichs 1: 1674 (1889).

Suborder Hymenostomata Hickson 1903.

Orders Gymnostomataceae and Aspirotrichaceae Hartog in Cambridge Nat. Hist. 1: 137 (1909).

Order Holotricha with suborders Anoplophryinea, Gymnostomata, and Hymenostomata Poche in Arch. Prot. 30: 250-255 (1913).

Order Holotrichida Calkins Biol. Prot. 376 (1926).

Infusoria with differentiated macronuclei and micronuclei, with simple cilia distributed generally over the surface of the body, not having membranelles in a spiral band about the cytostome.

This group is the mass of the more primitive typical Infusoria, of numerous families, not all of which are to be listed here. Arrangements of the families in other groups than the three here maintained have been proposed and are presumably more nearly natural.

a. Cytostome anterior. Suborder Gymnostomata (Bütschli) Poche. Suborder Gymnostomina Hall.

Family Enchelia Ehrenberg Infusionsthierchen 298 (1838). Family Enchelina Stein Org. Inf. 2: 169 (1867). Family Enchelyidae Kent. Families Holophryidae and Cyclodinidae Schouteden. Family Didiniidae Poche. Comparatively unspecialized forms, radially symmetrical or nearly so. Enchelis O. F. Müller; Holophrya, Chaenia, Prorodon; Ichthiophthirius, becoming parasitic in the skins of fishes; Lacrymaria, the cytostome at the end of an extensible proboscis; Didinium, barrel-shaped, with the cilia confined to two belts, having an extensible proboscis by means of which it seizes other Infusoria and through which it swallows them.

Family Colepina Ehrenberg op. cit. 316 includes the single genus Coleps. The cells look like hand grenades of World War I: they are approximately barrel-shaped (the axis more or less curved), the pellicle forming hardened quadrangular plates between which the cilia project. The anterior cytostome can be opened widely to ingest other Infusoria.

b. Gytostome lateral. Suborder Aspirotricha Bütschli.

Family Parameciina Perty (1852). Family Paramoecidae Grobben. Paramaecium [Hill] O. F. Müller Verm. Terr. Fluv. 1: 54 (1773). The name is variously spelled; the spelling here used is Müller's in what is believed to be the first publication under binomial nomenclature.

Family Colpodaea Ehrenberg Infusionsthierchen 345 (1838). Family Colpodidae Glaus 1879. Family Ophryoglcnidae Kent 1882. Small forms, oval, bean-shaped, or fiattened. Ophryoglena, Glaucoma, Colpoda, Tetrahymena, and many others. 
Family Cyclidina Ehrenberg op. cit. 244. Family Pleuronemidae Kent. Family Plcuronemina Bütschli (1889). Similar, with a conspicuous undulating membrane a!ong one side. Cyclidium and many other genera.

Family Urocentrina Claparède and Lachmann Etudes Inf. 1: 134 (1858). Family Uroccntridae Schouteden. Urocentrum, the single genus, top-shaped, with cilia confined to two belts and a tail-like tuft, constantly whirling in the water.

Family Trachelina Ehrenberg op. cit. 319. Family Tracheliidae Kent. Having an anterior proboscis, the mouth at the base of this. Trachelius, Dileptus, Lionotus, Loxodes, etc.

Family Chlamydodontida [Chlamydodontidae] Claus 1874. Family Chlamydodonta Stein, the mere plural of a generic name. Family Chilodontida Biitschli. Family Nassulidae Schouteden. Flattened. The cytopharynx surrounded by longitudinal rods, apparently of hardened protein, collectively forming a conical basket, enclosed except when the cytostome is open for ingestion. Chilodon, Chlamydodon, Nassula.

c. Cytostome lacking; parasitic, mostly in invertebrates. Suborder ANoplopirRyinEA Poche; suborder Astomina Hall.

Family Anoplophryida [Anoplophryidae] and seven other families, all named by Cépède, 1910.

\section{Order 3. Heterotricha Stcin Org. Inf. 2: 169 (1867).}

Suborder Spirotricha, sections Hctcrotricha and Oligotricha Bütschli in Bronn Kl. u. Ord. Thierreichs 1: 1674 (1889).

Section Chonotricha Wallengren in Acta Univ. Lund 31, part 2, no. 7: 48 (1895). Order Oligotricha Doflein Protozoen 240 (1901).

Orders Heterotrichaccae and Oligotrichaceae Hartog in Cambridge Nat. Hist. 1: 137 (1909).

Orders Heterotrichida and Oligotrichida Calkins Biol. Prot. 386, 388 (1926).

Suborder Entodiniomorpha Reichenow in Doflein Lchrb. Prot. ed. 5, 3: 1195 (1929); Order Chonotricha Reichenow op. cit. 1211; suborder Ctcnostomata Kahl ex Reichenow op. cit. 1024.

Orders Spirotrichida and Chonotrichida Hall Protozoology 380, 411 (1953).

Infusoria having a sinistrorse spiral band of cilia about the cytostome, these cilia united (except in family Spirochonina) in triangular-attenuate membranelles; not having the body flattened and the cilia or cirri confined to the ventral surface.

The peristomal apparatus of this order is an evidently derived character, so peculiar as to appear to have evolved only once: in short, the order appears natural. There are numerous subordinate groups. Several of these, of many species or of exceptional character, have been segregated as additional orders; it is by an arbitrary decision that they are here treated as suborders.

a. Comparatively unspecialized examples. Suborder SPIRotriona Bütschli. Suborders Hctcrotrichina and Olisotrichina Iall.

Family Plagiolomina Pütschli op. cit. 1719 (1889). Family Plagiotomidae Poche (1913). Peristomal area narrow and elongate, extending from the anterior end to a cylectome located mear the middle of one side. Blcpharisma. Spirostomum.

F.tmily Bursarina Stein Org. Inf. 2: 169, 295 (1867). Family Bursariidae Kent. Cytostome scated in a deep pit in one side of the body. Bursaria. Balantidium, parasitic in the gut of Amphibia and mammals; $b$. coli, a serious pathogen in man.

Family Stentorina Stein op. cit. 169, 217. Family Stcntoridac Clans. Peristomal area anterior, nore or less transverse. Stentor, sessile and obronic, familiar. Follicu- 
lina, the posterior end seated in a chitinous lorica, the peristomal area broadly expanded as two wings.

Family Halterina Claparède and Lachmann Etudes Inf. 1: 367 (1858). Family Halteriidae Claus. Halteria, subglobular, with a single whorl of long cilia; familiar in infusions, recognizable by the motion of the cells, alternately revolving slowly and snapping violently from place to place.

b. Loricate, free-swimming. Suborder Trntrnnornea Kofoid and Campbell. Suborder Tintinnina Hall.

Family Tintinnodea Claparède and Lachmann Etudes Inf. 1: (1858). Family Tintinnidae Glaus. Peristomal membranclles elongate and ciliate, the cylindrical or conical body attached in and retractile into the lorica; characteristically with two macronuclei and two micronuclei. Mostly marine. Kofoid and Campbell, who monographed the group (1929), found it possible to distinguish the natural and subordinate groups entirely by the structure of the lorica. They divided the former single family into twelve and recognized more than three hundred species.

c. Laterally flattened, with a tough membrane and few cilia and membranelles.

Suborder Ctenostomata Kahl. Suborder Ctenostomina Hall.

Family Ctenostomida [Ctenostomidae] Lauterborn in Zeit. wiss. Zool. 90: 665 (1908). Kahl (1932) monographed the group and found twenty-five species, which he arranged in six genera and three families.

d. Cylindrical, entozoic, with no ciliation except the membranelles. Suborder

Entodniomorpha Reichenow. Suborder Entodiniomorphina Hall.

Family Ophryoscolecina Stein Org. Inf. 2: 168 (1867). Family Ophryoscolecidae Claus. Becker (1932) reviewed previous studies of this group, examples of which were first mentioned by Gruby and Delafond, 1843. He noted 71 species, of the genera Entodinium, Diplodinium, Ophryoscolex, Epidinium, etc. (the genera were first named by Stein) in the domestic ox; and 52 (Didesmis, Paraisotricha, Spirodinium, Cycloposthinm, etc.) in the horse. Dogiel (1927) monographed the family, but it is certain that large numbers of species remain to be discovered in wild animals, oxen and others.

The barrel-shaped cells are about 0.1-0.25 $\mathrm{mm}$. long. The cytostome is anterior, surrounded by the usual spiral band of membranelles; this may be broken up into several partial files, and there may be belts or clusters of membranelles on other parts of the body. The posterior end is drawn out into processes, one, few, or many, obscure or prominent, horn-like or fringe-like. Internally, beside contractile vacuoles and a neuromotor apparatus including a large motorium, there are characteristic skeletal plates. These consist of minute cylindrical bodies imbedded in an amorphous matrix, the whole staining with iodine and consisting supposedly of some polysaccharide carbohydrate.

Animals are infected by cating food contaminated with the saliva of others. The ciliates may be present in the rumen in numbers from one thousand to three million per cc. It has been supposed that they are symbiotic, benefitting their hosts by carrying on useful syntheses, or perhaps merely by controlling numbers of bacteria in the rumen. There is no good evidence for these ideas: the probability is, that they are harmless commensals.

e. Cylindrical or obconic, sessile, cilia of the peristomal band separate, body otherwise naked. Suborder Chonotricha (Wallengren) subordo novus.

Family Spirochonina Stein Org. Inf. 2: 168 (1867). Family Spirochonidae Grob- 


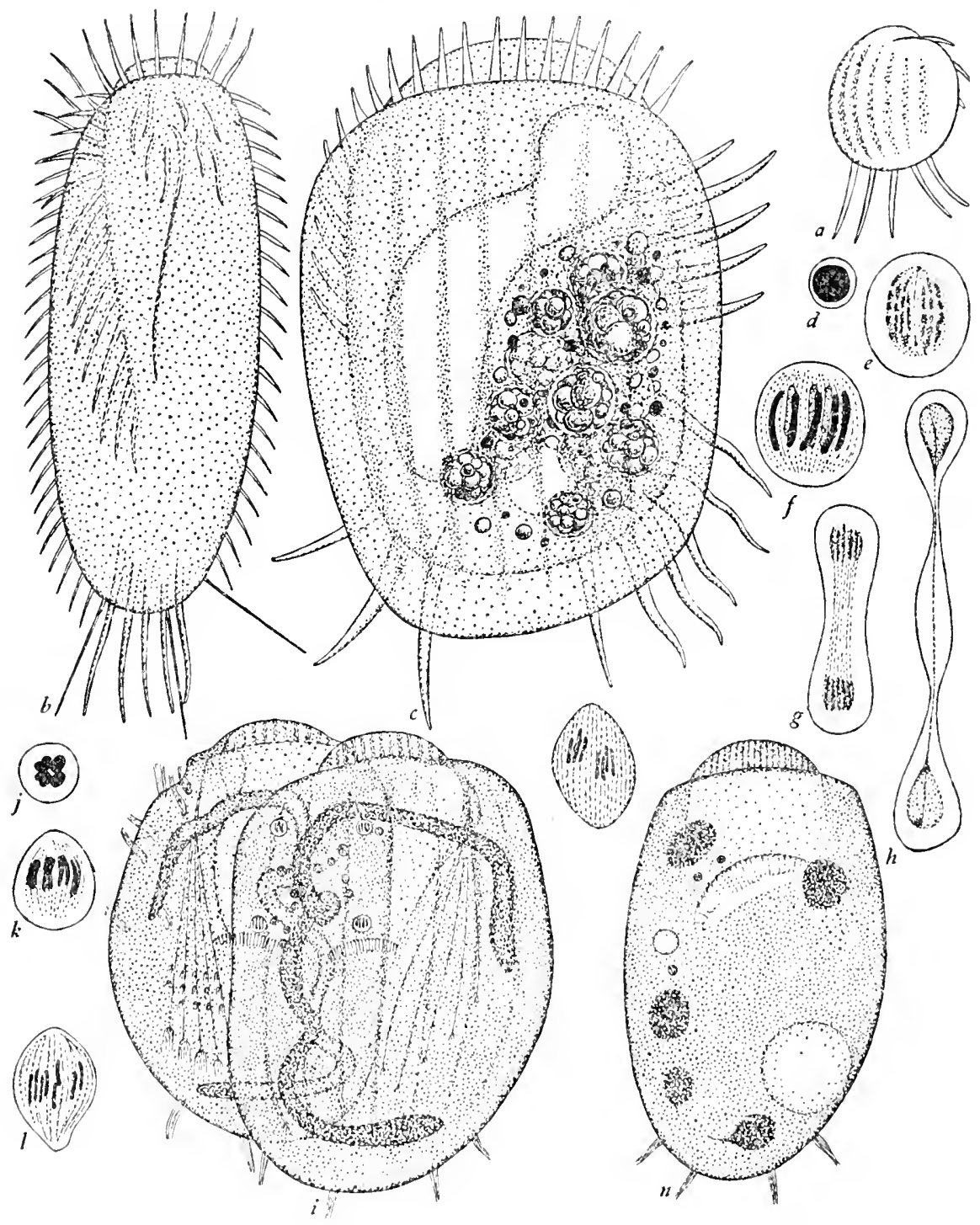

Fig. 44.-Infusoria, order Hypotrigha: a, Aspidisca x 800 . b, Stylonychia x 400. c, Euplotes x 400. d-n, Euplotes Patella after Turner (1930); d-h, stages of mitosis $\times 2,000, \mathbf{i}$, conjugating cells $\times 400 ; \mathbf{j}, \mathbf{k}$, polar and equatorial view's of the heterotypic division in a conjugant $\times 2,000 ; \mathbf{l}$, carly anaphase of the homeotypic division $\times 2,000 ; \mathbf{m}$, first division of the zygote nucleus $\mathrm{x} 2,000 ; \mathbf{n}$, a cell after conjugation $\mathrm{x} 400$, the macronucleus breaking up, the zygote nucleus divided into four, of which one is to become a macronucleus, one a micronucleus, and two are to undergo dissolution. 
ben. Spirochona and a few other genera, attached to aquatic animals, fresh-water or marine, best known from the crustaccan Gammarus.

\section{Order 4. Hypotricha Stein Org. Inf. 2: 168 (1867).}

Section Hypotricha Bütschli in Bronn K1. u. Ord. Thierreichs 1: 1674 (1889).

Order Hypotrichaceae Hartog in Cambridge Nat. Hist. 1: 137 (1909).

Order Hypotrichida Calkins Biol. Prot. 389 (1926).

Suborder Hypotricha Kudo Man. Protozool. ed. 3: 668 (1946).

Suborder Hypotrichina Hall Protozoology 381 (1953).

Flattened Infusoria bearing a band of membranelles crossing the upper surface near the anterior end from right to left and continued rearward on the lower surface beside the cytostome, along which lie also undulating membranes; mostly bearing cirri, which are confined to the lower surface, as are most free cilia, if these are present.

This group is evidently natural, and evidently a specialized offshoot from the preceding order. It might reasonably be treated as a subordinate group of the preceding order; Bütschli, Kudo, and Hall have done so. There are comparatively few species. Several are familiar in infusions and have been much studied.

Family 1. Peritromina Stein Org. Inf. 2: 168 (1867). Family Peritromidae Kent. Cilia abundant on the lower surface, cirri none. Pcritromus.

Family 2. Urostylida [Urostylidae] Calkins Biol. Prot. 390 (1926). As above, but with frontal and sometimes also anal cirri. Numerous genera, Urostyla, Uroleptus, Epiclintes, Stilotricha; Kerona O. F. Müller, an ectoparasite on the animal Hydra.

Family 3. Oxytrichina Ehrenberg Infusionsthierchen 362 (1838). Family Oxytrichidae Kent. Family Pleurotrichidae Bütschli. Cirri present; cilia in one or two marginal rows, few or absent on the ventral surface. Oxtricha, Stylonychia, Pleurotricha, Euplotes, etc.

Order 5. Stomatoda Siebold in Siebold and Stannius Lehrb. vergl. Anat. 1: 10 (1848).

Order Ciliata Perty Kennt. kl. Lebensf. 137 (1852).

Order Peritricha Stein Org. Inf. 2: 168 (1867).

Section Peritricha Bütschli in Bronn Kl. u. Ord. Thierreichs 1: 1674 (1889).

Order Peritrichaceae Hartog in Cambridge Nat. Hist. 1: 138 (1909).

Order Peritrichida Calkins Biol. Prot. 395 (1926).

Infusoria having a dextrorse spiral band of membranelles about the cytostome, which can in most examples be concealed and protected by contraction of the body; free-swimming only in the immature condition, at maturity attached and without separate cilia; syngamy occurring by the complete union of a smaller swimming individual with a larger attached one. Vorticella is the apparent type of the old ordinal names Stomatoda and Ciliata, which are accordingly held to belong to this order.

Family Vorticellina Ehrenberg Infusionsthierchen 259 (1838). Family Vaginifera Perty (1852). Family Vorticellidae Fromentel 1874. Vorticella L., a familiar microscopic organism in material from ponds and ditches, consists of solitary bell-shaped cells on contractile stalks. Carchesium and Zoothamnium are similar organisms in colonies. Ophrydium, Epistylis, etc., consist of similar colonies of non-contractile cells. Cothurnia and Vaginicola are solitary stalkless cells having conical loricae into which they can withdraw themselves. 


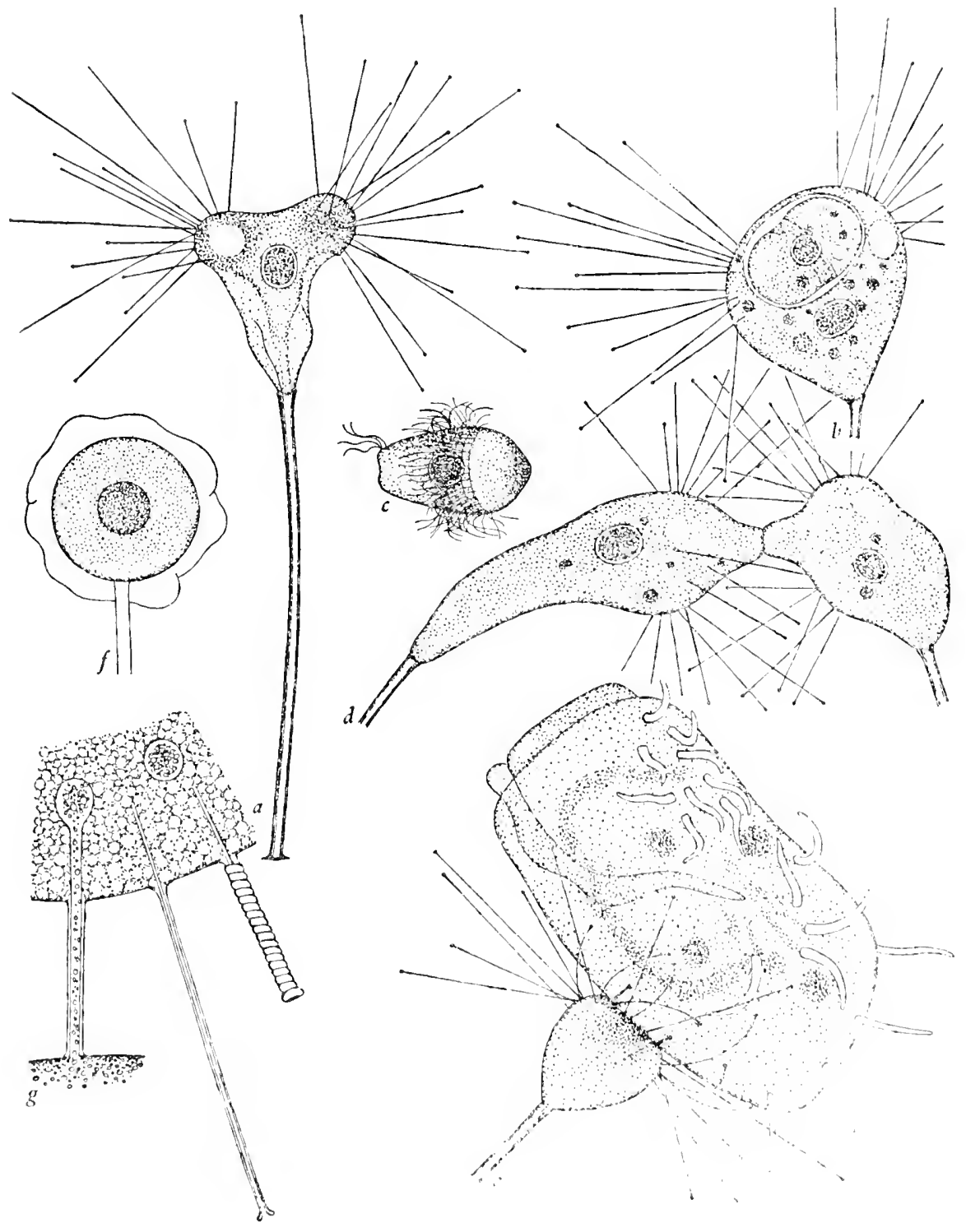

FIG. 45-Tokophyra Lemnarum after A. Noble (1932): a, representative individual; b, budding; c, swimming bud; d, conjugation; e, feeding on a cell of Euplotes; f, cyst; $g$, tentacles, feeding, expanded, and contracted. $\mathrm{g} \times 2,000$, all others $\mathrm{x} 400$. 
Family Urceolarina Perty (1852). Family Trichodinidae Glaus. Family Urccolaridae Kudo. Urceolaria, Trichodina, etc., disk- or barrel-shaped cells attached on or in aquatic animals by means of a whorl of hard hooks.

\section{Class 2. TENTACULIFERA (Huxley) Kent}

Order Iufusoires suceurs and group Acinctina Claparède and Lachmann Etudes Inf. 1: 377,381 (1858).

Class Acinetae Haeckel Gen. Morph. 2: lxxix (1866), the mere plural of a generic name.

Tentaculifera Huxley Man. Anat. Invert. 100 (1877).

Class Tentaculifera with orders Suctoria and Acinetaria Kent Man. Inf. 1: 36 (1880).

Class Acinetaria and order Suctoria Lankester in Enc. Brit. ed. 9, 19: 865 (1885).

Subclass Suctoria Bütschli in Bronn K1. u. Ord. Thierreichs 1: 1842 (1889).

Class Acinctoidea Poche in Arch. Prot. 30: 263 (1913).

Class Suctorea Hall Protozoology 413 (1953).

Organisms swimming by means of cilia while immature, at maturity lacking cilia and usually attached, provided with tentacles by which they capture and paralyze their prey and absorb food. Acineta is the type genus.

These organisms are rather unfamiliar. They occur both in fresh water and in salt, and prey chiefly upon Infusoria. There are differentiated macronuclei and micronuclei; in branching or colonial individuals, a single macronucleus may extend to all parts. Asexual reproduction is by budding, often endogenous. Conjugation occurs either between attached individuals or between an attached individual and a swimming bud. The fact that one individual may bend past another to conjugate with a third indicates the presence of mating types. Conjugating individuals exhibit pregamic and postgamic nuclear divisions quite as among Infusoria (Noble, 1932). The group is undoubtedly derived from Infusoria; whether from something of the nature of Didinium, Vorticella, or Spirochona remains uncertain.

Collin (1912) accounted for about 170 species and recognized eight families. One of these families has subsequently been transferred to order Holotricha. The remainder may be construed as a single order:

Order Suctoria Kent (1880). Lankester chose this as between two ordinal names which Kent published at the same time.

a. Individuals subglobular, usually stalked, their tentacles essentially uniform.

Family 1. Podophryina Bütschli in Bronn Kl. u. Ord. Thierreichs 1: 1926 (1889). Family Podophryidae, Rousseau and Schouteden 1907. Buds produced exogenously. Podophrya, Sphaerophrya, naked; Urnula, loricate.

Family 2. Acinetida [Acinetidae] Claus 1874. Acinetina Claparède and Lachmann (1858). Family Acinetina Bütschli (1889). Bodies with a thin pellicle, with or without loricae; budding endogenous. Acineta, Tokophrya, etc.

Family 3. Discophryida [Discophryidae] Collin in Arch. Zool. Exp. Gen. 51: 364 (1912). Body with a firm pellicle, budding endogenous. Discophrya, etc.

b. Individuals branching or colonial.

Family 4. Dendrosomida [Dendrosomidae] Kent Man. Inf. 2: 215 (1882). Family Dendrosomina Bütschli (1889). Family Dendrosomatidae Poche (1913). Dendrosoma, etc. 
Family 5. Ophryodendrida [Ophryodendridae] Kent 1.c. Family Ophryodendrina Bütschli (1889). Ophryodendron, etc.

Family 6. Dendrocometida [Dendrocometidae] Kent l.c. Family Dendrocometina Pü̈schli (1889). Dendrocometes, Stylocometes.

c. With differentiated tentacles for piercing and sucking.

Family 7. Ephelotida [Ephelotidae] Kent. l.c. Family Ephelotina Sand 1899. Marine, individuals subglobular, stalked. Ephelota, naked; Podocyathus, loricate.

With this peculiar and highly evolved group, the here-proposed classification of organisms which lack the distinctive characters both of plants and of animals is concluded. 


\section{LIST OF NOMENCLATURAL NOVELTIES}

Family Kurthiacea fam. nov. . . . . . . . . . . . . 21

Family Pasteurellacea nom. nov. . . . . . . . . . . . $\quad$. 22

Family Chromatiacea nomen familiare novum . . . . . . . . 31

Family Rhodobacillacea nom. nov. . . . . . . . . . . . 31

Family Chlorobiacea nom. nov. . . . . . . . . . . . 31

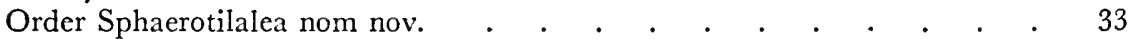

Lagenocystis, nom. nov., and L. radicicola, comb. nov. . . . . . . $\quad$. 82

Family Dinamoebidina nom nov. . . . . . . . . . . . 101

Phylum Opisthokonta phylum novum . . . . . . . . . . 110

Chilomastix hominis comb. nov. . . . . . . . . . . . 165

Pentatrichomonas obliqua comb. nov. . . . . . . . . . . 167

Goussia Schubergi comb. nov. . . . . . . . . . . . 207

Family Myxoceratida and Myxoceros, nomina nova; $M$. sphaerulosa and

M. Blennius, combinationes novae . . . . . . . . . 221

Phylum Ciliophora nomen phylare novum . . . . . . . . . 223

Order Opalinalea nom. nov. . . . . . . . . . . . . . 228

Suborder Chonotricha subordo novus . . . . . . . . . 231 


\section{BIBLIOGRAPHY}

Adanson, Michel. Familles des plantes. Paris. 1763.

Agardh. Carolus A. Synopsis algarum Scandinaviae, adjecta dispositione universali algarum. Lund. 1817.

-... Systema algarum. Lund. 1824.

Agardh, Jacob Georg. Species genera et ordines algarum . . . 3 vols. Lund. 1848-1901. Agassiz, Louis. Contributions to the natural history of the United States of America. 4 vols. Boston. 1857-1862.

Ajello, Libero. A cytological and nutritional study of Polychytrium aggregatum. I. Gytology. American Jour. Bot. 35: 1-11. 1948.

Alexcieff, A. Notes sur quelques protistes copricoles. Arch. Prot. 50: 27-49. 1924.

Allen, Ruth F. A cytological study of heterothallism in Puccinia graminis. Jour. Agr. Res. 40: 585-614. 1930.

Allman, Gcorge. Notes on Noctiluca. Quart. Jour. Micr. Sci. n. s. 12: 326-332. 1872. Andresen, N., and H. Holter. The genera of amocbae. Science 110: 114-115. 1949. Angst, Laura. The gametophyte of Soranthera ulvoidea. Publ. Puget Sound Biol. Sta. 5: 159-163. 1926.

. The holdfast of Soranthera ulvoidea. Publ. Puget Sound Biol. Sta. 5: 267-275. 1927.

Anigstcin, Ludwik. Untersuchungen über dic Morphologie und Biologic der Rickettsia Melophagi Noller. Arch. Prot. 57: 209-246. 1927.

Archer, William. Résumé of recent contributions to our knowledge of "Freshwater Rhizopoda." Part I. Hcliozoa. Quart. Jour. Micr. Sci. n. s. 16: 283-309, 347-376. 1876.

Areschoug, John Erh. Enumeratio phycearum in maribus Scandinaviae crescentium. Act. Reg. Soc. Sci. Upsala ser. 2, 13: 223-382. 1847; 14: 385-454. 1850.

Argao, Henrique de Bcaurepaire. Uber den Entwicklungsgang und die Uberträgung von Hacmoproteus columbae. Arch. Prot. 12: 154-167. 1908.

Ascherson, Paul. Flora der Provinz Brandenburg der Altmark und des Herzogthums Magdeburg. Berlin. 1864.

Atkinson, George F. Phylogeny and relationships in the Ascomycetes. Ann. Missouri Bot. Gard. 2: 315-376. 1915.

Baker, Woolford B. Studies in the life history of Euglena. I. Euglena agilis, Carter. Bioi. Bull. 51: 321-362. 1926.

Balamuth, William. Regeneration in Protozoa: a problem in morphogenesis. Quart. Rev. Biol. 15: 290-337. 1940.

Barkley, Fred A. Keys to the phyla of organisms. Missoula, Montana. 1939.

. Un Esbozo de clasificatión de los organismos. Rev. Fac. Nal. Agron. Medellín 10: 83-103. 1949.

Barrett, J. T. Development and sexuality in some species of Olpidiopsis, (Cornu) Fischer. Anu. Pot. 26: 209-238. 1912.

Bartling, Fr. Th. Ordines naturales plantarum . . Göttingen. 1830.

de Bary, Anton. Ueber die Myxomyceten. Bot. 7cit. 16: 357-358, 361-361, 365-369. 1858.

Bericht ïbor die Fortschritte der Algenkunde in den Jahren 1855, 1856, und 1857. Bot. Zcit. 16, Beilagen 55-99. 1858.

Die Mycetozonn. Zcit. wiss. Zool. 10: 88-175. 1859.

and M. Woronin. Beitrag zor Kemtniss der Chytridicen. Berichte Verhandl. naturf. Gess. Freiburg 3, Heft 2: 22-55. 1864. 
Review of Baranetsky, J. Beitrag zur Kenntniss des selbstständigen Lebens der Flechtengonidien. Bot. Zeit. 26: 196-198. 1868. Bacterien. Leipzig. 1884.

Beadle, G. W., and E. L. Tatum. Neurospora. II. Methods of producing and detecting mutations concerned with nutritional requirements. American Jour. Bot. 32: 678-686. 1945.

Becker, Elery Ronald. The present status of problems relating to the ciliates of ruminants and Equidae. Quart. Rev. Biol. 7: 282-297. 1932.

Beijerinck, Martinus W. Die Bacterien der Papilionaceen-Knollchen. Bot. Zeit. 46: 725-735, 741-750, 757-771, 781-790, 797-804. 1888. 1901.

Bělăr, Karl. Bau und Vermehrung von Prowazekia josephi n. sp. Arch. Prot. 35 : 103-118. 1914.

-. Protozoenstudien I. Arch. Prot. 36: 13-51. 1915.

- Protozoenstudien II. Arch. Prot. 36: 241-302. 1916.

- Die Kernteilung von Prowazekia. Arch. Prot. 41: 308-320. 1920.

-. Protozoenstudien III. Arch. Prot. 43: 431-462. 1921.

Formwechsels. Arch. Prot. 46: 1-96. 1923.

Berdan, Helen. Revision of the genus Ancylistes. Mycologia 30: 396-415. 1938.

Bergey, David H., and others. Bergey's manual of determinative bacteriology. Baltimore. 1923. Second edition, 1925; third edition, 1930; fourth edition, 1934; fifth edition, 1938-1939; sixth edition, 1948.

Bergh, R. S. Der Organismus der Cilioflagellaten. Morph. Jahrb. 7: 177-288. 1882. Bernard, Francis. Rôle des flagellées dans la transparence marine en Mediteranée. Bull. Soc. Hist. Nat. Afrique du Nord 38: 74-79. 1947.

Bersa, Egon. Über das Vorkommen von kohlensaurem Kalk in einer Gruppe von Schwefelbakterien. Sitzber. Akad. Wiss. Wien Math.-nat. Kl., Abt. I, 129: 231-259. 1920.

Berthold, G. Die Geschlechtliche Fortpflanzung der eigentlichen Phaeosporeen. Mittheil. zool. Stat. Neapel 2: 401-413. 1881.

Bessey, Charles E. The structure and classification of the lower green algae. Trans. American Micr. Soc. 36: 121-136. 1905.

Bessey, Ernst A. Morphology and taxonomy of the Fungi. Philadelphia and Toronto. 1950.

Betts, Edwin M., and Samuel L. Meyer. Heterothallism and segregation of sexes in Ascobolus geophilus. American Jour. Bot. 26: 617-619. 1939.

Bewley, W. F., and H. B. Hutchinson. On the changes through which the nodule organism (Ps. radicicola) passes under cultural conditions. Jour. Agr. Sci. 10: 144-162. 1920.

Bhatia, B. L. Synopsis of the genera and classification of haplocyte gregarines. Parasitology 22: 156-167. 1930.

Bisby, Guy R. Some observations on the formation of the capillitium and the development of Physarella mirabilis Peck and Stemonitis fusca Roth. American Jour. Bot. 1: 274-288. 1914. 
Blakeslee, Albert Francis. Zygospore formation a sexual process. Science n. s. 19: 864-866. 1904.

205-319. 1904.

Zygospore germinations in the Mucorineae. Ann. Myc. 4: 1-28. 1906.

Blochmann, F. Die mikroskopische Tierwelt des Süsswassers. Abt. I. Protozoa. 2d ed. Hamburg. 1895.

Bodman, Sister Mary Cecilia. Morphology and cytology of Guepinia Spathularia. Mycologia 30: 635-652. 1938.

Bohlin, Knut. Zur Morphologie und Biologie einzelliger Algen. Öfvers kgl. vetensk.Akad. Förhandl. 54: 507-529. 1897.

- Utkast till de gröna algernas och arkegoniaternas fylogeni. Upsala. 1901. Bölsche, Wilhelm. Haeckel, his life and work. Translated by Joseph McCabe. Philadelphia. 1906.

Bonner, John T. A descriptive study of the development of the slime mold Dictyostelium discoideum. American Jour. Bot. 31: 175-182. 1944.

Borgert, Adolf. Uber die Dictyochiden, insbesondere über Distephanus speculum; sowie Studien an Phaeodarien. Zeit. wiss. Zool. 51: 629-676. 1891.

- Fortpflanzungsverhältnisse bei tripyleen Radiolarien (Phaeodarien). Verhandl. deutschen zool. Gess. 1896: 192-195.

- Untersuchungen über die Fortpflanzung der tripyleen Radiolarien, speciell von Aulacantha scolymantha H. I. Theil. Zool. Jahrb. Anat. 14: 203-276. 1900.

- Untersuchungen über die Fortpflanzung der tripyleen Radiolarien, speziell von Aulacantha scolymantha H. II. Teil. Arch. Prot. 14: 134-263. i909.

Bornet, Ed., and Gustave Thuret. Recherches sur la fécondation des floridées. Ann. Sci. Nat. Bot. sér. 5, 7: 137-166. 1867.

. and Cr. Flahault. Revision des nostocacées heterocystes. Ann. Sci. Nat. Bot. sér. 7, 3: 323-381. 1886; 4: 343-373. 1886; 5: 51-129. 1887; 7: 177-262. 1888.

Bory de Saint-Vincent (editor). Dictionnaire classique d'histoire naturelle. 17 vols. Paris. 1822-1831.

Brady, Henry B. Notes on some of the reticularian Rhizopoda of the "Challenger" expedition. Part III. Quart. Jour. Micr. Sci. n. s. 21: 31-71. 1881.

- Report on the Foraminifera dredged by H. M. S. Challenger, during the years 1873-1876. Rep. Sci. Results Voy. Challenger Zool. 9: i-xxi, 1-814. 1884.

Brandt, K. Die kolonienbildenden Radiolarien ... Flora und Fauna des Golfes von Neapel 13: i-viii, 1-276. 1885.

\section{8: 311-352. 1905 .}

Brasil, Louis. Recherches sur la reproduction des grégarines monocystidées. Arch. Zool. Exp. Gen. sér. 4, 3: 17-38. 1905.

Arch. Zool. Exp. Gen. sér. 4, 4: 69-99. 1905.

- Recherches sur le cycle ćvolutif des Sclcniidae, grégarines parasites d'annélides polychètes. Arch. Prot. 8: 370-397. 1907.

Braun, NIexander. Über Chytridium, eine Gattung einzelliger Schmarotzergewächse auf Algen und Infusoricn. Abl. Akad. Wiss. Berlin 1855: 21-83. 1856.

Braun, M. Review of Thélohan (1892). Centralbl. Bakt. 14: 737-739. 1893. 
Brown, William H. The development of the ascocarp of Lachnea scutellata. Bot. Gaz. 52: 275-305. 1911. Bot. 2: 289-298. 1915.

Buchanan, R. E. Studies in the nomenclature and classification of bacteria II. The primary subdivisions of the Schizomycetes. Jour. Bact. 2: 155-164. 1917.

350. 1917.

III. The families of the Eubacteriales. Jour. Bact. 2: 347-

Jour. Bact. 3: 403-406. 1918.

VIII. The subgroups and genera of the Actinomycetales.

General systematic bacteriology. Baltimore. 1925.

Ralph St. John-Brooks, and Robert S. Breed. International bacteriological code of nomenclature. Jour. Bact. 55: 287-306. 1948.

Buller, A. H. R. Some observations on the spore discharge of the higher fungi. Proc. Internat. Congr. Pl. Sci. Ithaca 2: 1627-1628. 1929.

Burkholder, P. R. Movement in the Cyanophyceae. Quart. Rev. Biol. 9: 438-459. 1934.

Butler, E. J. On Allomyces, a new aquatic fungus. Ann. Bot. 25: 1023-1035. 1911.

Butler, Ellys T., William J. Robbins, and B. O. Dodge. Biotin and the growth of Neurospora. Science 94: 262-263. 1941.

Bütschli, O. Protozoa. Zool. Jahresber. 1880, Abt. 1: 122-173. 1881.

. Protozoa. in Dr. H. G. Bronn's Klassen und Ordnungen des ThierReichs 1: i-xviii, 1-2035. 1880-1889.

1890.

. Ueber den Bau der Bacterien und verwandter Organismen. Leipzig.

Ueber die chemische Natur der Skeletsubstanz der Acantharia. Zool. Anz. 30: 784-789. 1906.

Calkins, Gary N. Mitosis in Noctiluca miliaris and its bearing on the nuclear relations of the Protozoa and Metazoa. Jour. Morph. 15: 711-772. 1899.

- The biology of the Protozoa. Philadelphia and New York. 1926.

and Rachel C. Bowling. Gametic meiosis in Monocystis. Biol. Bull. 51 :

385-399. 1926.

le Calvez, J. Flagellispores du radiolaire Coelodendrum ramosissimum (Haeckel). Arch. Zool. Exp. Gen. 77, notes 99-103. 1935.

- Recherches sur les foraminifères II. Place de la méiose et sexualité. Arch. Zool. Exp. Gen. 87: 211-243. 1950.

Cameron, Frank. Potash from kelp. United States Dept. Agr. Office of the Secretary Rept. 100: 1-122. 1915.

Campbell, Arthur Shackleton. The cytology of Tintinnopsis nucula (Fol) Laackmann ... Univ. Galifornia Publ. Zool. 29: 179-236. 1926.

Publ. Zool. 29: 429-452. 1927.

Campbell, Douglas H. A university text-book of botany, New York. 1902.

de Candolle, Augustin Pyrame. Théorie élémentaire de la botanique . . . Paris. 1813. Cantino, Edward C. The vitamin nutrition of an isolate of Blastocladia Pringsheimii. American Jour. Bot. 35: 238-242. 1948.

. The physiology of the aquatic phycomycete, Blastocladia Pringsheimii, with emphasis on its nutrition and metabolism. American Jour Bot. 36: 95-112. 1949. 
Carter, P. W., I. M. Heilbron, and B. Lythgoe. The lipochromes and sterols of the algal classes. Proc. Roy. Soc. London B 128: 82-109. 1939.

Cash, James, and others. The British freshwater Rhizopoda and Heliozoa. 5 vols. London. 1905-1921.

Caspary, Rob. Bericht über die Verhandlungen der botanischen Sektion der 33 . Versammlung deutscher Naturforscher und Aerzte, gehalten in Bom vom 18. bis 24. September 1857. Bot. Zeit. 15: 749-776, 784-792. 1857.

Castle, Edward S. The structure of the cell walls of Aspergillus and the theory of cellulose particles. American Jour. Bot. 32: 148-151. 1945.

Caullery, Maurice, and Félix Mesnil. Recherches sur les haplosporidies. Arch. Zool. Exp. Gen. sér. 4, 4: 101-181. 1905.

and - Sur les Metchnikovellidae et autres protistes parasites des grégarines d'annélides. Compt. Rend. Soc. Biol. 77: 527-532. 1914. and - Metchnikovellidae et autres protistes parasites des grégarines d'annélides. Ann. Inst. Pasteur 33: 209-240. 1919.

Chadefaud, M. Les protistes trichocytifères ou progastréades. Ann. Protistol. 5: 323-343. 1936.

Chatton, Edouard. Les blastodinides, ordre nouveau de dinoflagelées parasites. Compt. Rend. 143: 981-985. 1906.

- Les cnidocystes du péridinien Polykrikos schwartzi Bütschli. Arch. Zool. Exp. Gen. 54: 157-194. 1914.

\section{Zool. Exp. Gen. 59: 1-475. 1920.}

Child, Horace J. Studies on the ingestion of leucocytes, and on mitosis, in Endamoeba gingivalis. Univ. California Publ. Zool. 28: 251-284. 1926.

Christman, A. H. Sexual reproduction in the rusts. Bot. Gaz. 39: 267-275. 1905.

Cienkowski, L. Zur Entwickelungsgeschichte der Myxomyceten. Jahrb. wiss. Bot 3: 325-337. 1863.

- Das Plasmodium. Jahrb. wiss. Bot. 3: 400-441. 1863.

1865.

Claparède, Edouard, and Johammes Lachmann, Études sur les infusoires et les rhizopodes. 2 vols. Geneva. 1858-1861.

Clements, Frederic E. The genera of Fungi. Minneapolis. 1909.

and Cornelius L. Shear. The genera of Fungi. New York. 1931.

Cleveland, L. R. The method by which Trichonymplia campanula, a protozoön in the intestine of termites, ingests solid particles of wood for food. Biol. Bull. 48: 282-288. 1925.

. The ability of termites to live perhaps indefinitely on a diet of pure cellulose. Biol. Bull. 48: 289-293. 1925.

- The effects of oxygenation and starvation on the symbiosis between the termite, Termopsis, and its intestinal flagellates. Biol. Bull. 48: 309-326. 1925. - Symbiosis among animals with special reference to termites and their intestinal flagellatcs. Quart. Rev. Biol. 1: 51-60. 1926.

16-17. 1947.

Sex produced in the protozoa of Cryptocercus by molting. Science 105:

The origin and evolution of meiosis. Science 105: 287-289. 1947.

An ideal partnership. Sci. Mouth. 67: 173-177. 1918.

Clint, Hilda B. The life history and cytology of Sphacelaria bipinnata Sauv. Unir. Liverpool Publ. Hartley Bot. Lab. 3: 1-23. 1927. 
Gohn, Ferdinand. Beiträge zur Entwickelungsgeschichte der Infusorien II. Ueber den Encystirungsprocess der Infusorien. Zeit. wiss. Zool. 4: 253-281. 1953.

Conspectus familiarum Cryptogamarum secundum methodum naturalem dispositarum. Hedwigia 11: 17-20. 1872.

1872. 1875 .

Coker, William Chambers. The Saprolegniaccae with notes on other water molds. Chapel Hill, North Carolina. 1923.

Collin, Bernard. Etude monographique sur les acinétiens II. Morphologie, physiologie, systematique. Arch. Zool. Exp. Gen. 51: 1-457. 1912.

Colson, Barbara. The cytology and development of Phyllactinia corylea Lév. Ann. Bot. n.s. 2: 381-402. 1938.

Committce on Medical Research, Washington, and the Medical Research Council, London. Chemistry of penicillin. Science 102: 627-629. 1945.

Conard, Henry S. Plants of Iowa, being a fifth edition of the Grinnell Flora ... Grinnell, Iowa. 1939.

Conn, H. J., and Gladys E. Wolfe. The flagellation of bacteria. Science 87: 283-284. 1938. Bact. 36: 320-321. 1938.

Connell, Frank H. The morphology and life cycle of Oxymonas dimorpha sp. nov., from Neotermes simplicicornis (Banks). Univ. California Publ. Zool. 36: 51-66. 1930.

Conrad. Walter. Recherches sur les flagellates de nos eaux saumatres. Arch. Prot. 56: 167-231. 1926.

Cook, W. R. Ivimey. A monograph of the Plasmodiophorales. Arch. Prot. 80: 179254. 1933.

Cooke, $\mathrm{Wm}$. Bridge. A nomenclatorial survey of the genera of pore fungi. Lloydia 3 : 81-104. 1940.

Copeland, Edwin Bingham. What is a plant? Science n. s. 65: 388-390. 1927.

Copeland, Herbert F. The kingdoms of organisms. Quart. Rev. Biol. 13: 384-420. 1938.

Progress report on basic classification. American Nat. 81: 340-361. 1947. . Spirodiscus Ehrenberg identified as Ophiocytium Nägeli. Science 119: 338. 1954.

Observations on Prasiola mexicana .... Madroño 13: 138-140. 1955.

Cotner, F. B. The development of the zoospores in the Oömycetes at optimum temperatures and the cytology of their active stages. American Jour. Bot. 17: 511546. 1930. 309. 1930 .

Couch, John N. The development of the sexual organs of Leptolegnia caudata. American Jour. Bot. 19: 584-599. 1932.

- Observations on cilia of aquatic Phycomycetes. Science 88: 476. 1938.

A new Conidiobolus w ith sexual reproduction. American Jour. Bot. 26:

119-130. 1939. 
American Jour. Bot. 28: 704-713. 1941.

. The structure and action of the cilia in some aquatic Phycomycetes. and Alma J. Whiffen. Observations on the genus Blastocladiella. American Jour. Bot. 29: 582-591. 1942.

Crawley, Howard. The evolution of Sarcocystis muris in the intestinal cells of the mouse (preliminary note). Proc. Acad. Nat. Sci. Philadelphia 66: 432-436. 1914. The sexual evolution of Sarcocystis muris. Proc. Acad. Nat. Sci. Philadelphia 68: 2-43. 1916.

Cupp, Easter E. Spirotrichonympha polygyra sp. nov. from Neotermes simplicicornis Banks. Univ. California Publ. Zool. 33: 351-378. 1930.

Cushman, Joseph A. Foraminifera. Their classification and cconomic use. Sharon, Massachussetts. 1928.

Cuvier, Georges. Sur un nouveau rapprochement à établir entre les classes qui composent le règne animal. Ann. Mus. Hist. Nat. Paris 19: 73-34. 1812.

Dangeard, P.-A., et Sappin-Trouffy. Urédinées. Le Botaniste 3: 119-125. 1893.

-. Recherches sur la reproduction sexuelle des champignons. Le Botaniste 3: 221-281. 1893.

- La reproduction sexulelle des ascomycètes. Le Botaniste 4: 21-58. 1894.

- La truffe. Recherches sur son développement, sa structure, sa reproduction sexuelle. Le Botaniste 4: 63-87. 1894.

Contributions à l'étude des acrasiées. Le Botaniste 5: 1-20. 1896.

- Recherches sur la structure du Polyphagus Euglenae Nowak. Le Botaniste 7: 213-261. 1900.

1907.

- L'origine du périthèse chez les ascomycètes. Le Botaniste 10: 1-385.

- Études sur le développement et la stracture des organismes inférieurs. Le Botaniste 11: 1-311. 1910.

Dangeard, Pierre. Recherches sur les Bangia et les Porphyra. Le Botaniste 18: 183244. 1927.

Danilewski, B. Die Hämatozoen der Kaltblüter. Arch. mikr. Anat. 24: 588-598. 1885.

Davis, Bradley Moore. The fertilization of Albugo candida. Bot. Gaz. 29: 297-311. 1900.

- Oogenesis in Saprolegnia. Bot. Gaz. 35: 233-249, 320-349. 1903.

Day, Howard Calvin. Studies on the contractile vacuole in Spirostomum and Paramecium. Physiol. Zool. 3: 56-71. 1930.

Deflandre, Gcorges. Sur la structure des flagelles. Ann. Protistol. 4: 31-54. 1934.

Delage, Yves, and Edgard Hérouard. Traité de zoologie concrète. vols. 1, 2, 5, 8. Paris. 1896-1901.

DeLamater, Edward D., and Mary Elizabeth Hunter. Preliminary report of true mitosis in the vegetative cell of Bacillus megathorium. American Jour. Bot. 38: 659662. 1951.

Sidney Yaverbaum, and Lucille Schwartz. The nuclear cytology of Eremascus albus. American Jour. Bot. 40: 475-492. 1953.

Dennis, Enery Westervelt. The morphology and linary fission of Babesia bigemina of Trxas cattle fever. Univ. Galifornia Publ. \%ool. 33: 179-192. 1930.

Diesing, K. M. Revision der Prothelmintlen. Abtheilung: Mastigophorcu. Sitzber. Akacl. Wiss. Wien Math.-nat. Cl. 52, Abt. I: 287-401. 1866.

Diller, William F. Nuclear reorganization processes in Paramecium aurclia, with descriptions of autogamy and 'hemixis.' Jour. Morph. 59: 11-67. 1936. 
Dobell, Clifford. The structure and life history of Copromonas subtilis nov. gen. et nov. spec.: a contribution to our knowledge of flagellates. Quart. Jour. Micr. Sci. n. s. 52: 75-120. 1908.

On Cristispira veneris nov. spec., and the affinities and classification of the spirochaets. Quart. Jour. Micr. Sci. n. s. 56: 507-541. 1911.

and A. Pringle Jameson. The chromosome cycle in coccidia and gregarines. Proc. Roy. Soc. London B 89: 83-94. 1915.

- The life-history and chromosome cycle of Aggregata eberthi [Protozoa: Sporozoa: Coccidia]. Parasitology 17: 1-136. 1925.

Dodge, B. O. Nuclear phenomena associated with heterothallism and homothallism in the ascomycete Neurospora. Jour. Agr. Res. 35: 289-305, 1937.

Doflein, Franz. Die Protozoen als Parasiten und Krankheitserreger . . Jena. 1901.

- Lehrbuch der Protozoenkunde. [The work of 1901 is construed as the first edition.] Jena. Third edition, 1911; fourth edition, 1916; fifth edition, revised by Eduard Reichenow, 1927-1929.

. Rhizochrysis. Zool. Anz. 47: 153-158. 1916.

. Beiträge zur Kenntnis von Bau und Teilung der Protozoenkerne. Zool. Anz. 49: 289-306. 1918.

Dogiel, V. A. Monographie der Familie Ophryoscolecidae Teil I. Arch. Prot. 59: 1-288. 1927.

Drechsler, Charles. Morphology of the genus Actinomyces. Bot. Gaz. 67: 65-83, 147-168. 1919.

- Some conidial Phycomycetes destructive to terricolous amoebae. Mycologia 27: 6-40. 1935.

- Some non-catenulate conidial Phycomycetes preying on terricolous amoebae. Mycologia 27: 176-205. 1935.

249. 1937.

Drew, Kathleen M. The organization and inter-relationships of the carposporophytes of living Florideae. Phytomorphology 4: 55-69. 1954.

Duboscq, O., and O. Tuzet. L'ovogénèse, la fécondation et les premiers stades du développement des éponges calcaires. Arch. Zool. Exp. Gen. 79: 157-316. 1937.

Dufour, Léon. Recherches anatomiques sur les carabiques et sur plusieurs autres insectes coléoptères. Ann. Sci. Nat. 8: 5-54. 1826.

intestins de divers insectes. Ann. Sci. Nat. 13: 366-368. 1828.

Dujardin, Félix. Observations sur les rhizopodes et les infusoires. Compt. Rend. 1: 338-340. 1835.

343-377. 1835.

- Histoire naturelle des zoophytes. Infusoires. Paris. 1841.

Eckstein, Gustav. Noguchi. New York and London. 1931.

Edgerton, C W. Plus and minus strains in the genus Glomerella. American Jour. Bot. 1: 244-254. 1914.

Editorial Board of the monograph on the chemistry of penicillin. The chemical study of penicillin: a brief history. Science 105: 653-659. 1947. 
Ehrenberg, Christian Gottfried. Beiträge zur Kenntniss der Organisation der Infusorien und ihrer geographischen Verbreitung, besonders in Siberien. Abh. Akad. Wiss. Berlin 1830: 1-88. 1832.

. Die Infusionsthierchen als volkommene Organismen. Ein Blick in das tiefe organische Leben der Natur. Leipzig. 1838.

sichtbare Organismen. Abh. Akad. Wiss. Berlin 1838: 59-147. 1939.

Eidam, Eduard. Basidiobolus, eine neue Gattung der Entomophthoraceen. Beitr. Biol. Pf. 4: 181-251. 1886.

Elder, Albert L. Penicillin. Sci. Month. 58: 405-409. 1944.

Elliott, Eugene W. The swarm-cells of Myxomycetes. Mycologia 41: 141-170. 1949. Ellis, David. Iron bacteria. New York. 1916.

Ellison, Bernard R. Flagellar studies on zoospores of some members of the Mycetozoa, Plasmodiophorales, and Chytridiales. Mycologia 37: 444-459. 1945.

Emerson, Ralph. Life cycles in the Blastocladiales. Trans. British Myc. Soc. 23: 123. 1939.

An experimental study of the life cycles and taxonomy of Allomyces. Lloydia 4: 77-144. 1941.

and Edward C. Cantino. The isolation, growth, and metabolism of Blastocladia in pure culture. American Jour. Bot. 35: 157-171. 1948.

and Charles M. Wilson. The significance of meiosis in Allomyces. Science 110: 86-88. 1949.

Enderlein, Günther. Grundelemente der vergleichenden Morphologie und Biologie der Bakterien. Sitzber. Gess. naturf. Freunde Berlin 1916: 403-406. 1916.

. Ein neues Bakteriensystem auf vergleichend morphologischer Grundlage. Sitzber. Gess. naturf. Freunde Berlin 1917: 309-319. 1917.

_. Bakterien-Cyklogenie . . Berlin and Leipzig. 1925.

Endlicher, S. Genera plantarum secundum ordines naturales disposita. Vienna. 18361840.

Engelmann, Th. W. Die Purpurbacterien und ihre Beziehungen zum Licht. Bot. Zeit. 46: 661-669, 677-689, 693-701, 709-720. 1888.

Engler, Adolf, and K. Prantl. Die Natürlichen Pflanzenfanilien. 20 vols. Lcipzig. 1889-1909.

- Syllabus der Vorlesungen über specielle und medicinisch-pharmaceutisch Botanik ... Berlin. 1892.

. Übersicht über die Gliederung des "Pflanzcnreich" ... Das Pflanzenreich Heft 1: v-vii. 1900.

. Syllabus der Pflanzenfamilien . . . [The syllabus of 1892 is construed as the first edition.] Third edition, 1903; ninth and tenth edition, with E. Gilg, 1924.

Entz, Géza. Über die mitotische Tielung von Geratium himundinclla. Arch. Prot. 43: 415-430. 1921.

Erdmann, Rhoda. Die Entwicklung der Sarcocystis muris in der Muskulatur. Sitzber. Gess. naturf. l'reunde Berlin 1910: 377-387. 1910.

Fairchild, David G. Ueber Kerntheilung und Befruchtung bei Basidiobolus ranarum Eidam. Jahrl,. wiss. Bot. 30: 285-296. 1897.

Falkenberg, P. Dic Befruchtung und der Generationsweclisel von Cutleria. Mittheil. zool. Stat. Neapel 1: 420-447. 1879. 
Farmer, J. Bretland, and J. Ll. Williams. On fertilization and segmentation of the spore in Fucus. Ann. Bot. 10: 479-487. 1896.

Faull, J. H. The morphology, biology and phylogeny of the Pucciniastreae. Proc. Internat. Congr. Pl. Sci. Ithaca 2: 1735-1745. 1929.

Ferris, Virginia Rogers. A note on the flagellation of Phytophthora infestans (Mont.) de Bary. Science 120: 71-72. 1954.

Fischer, Alfred. Ueber die Geisseln einiger Flagellaten. Jahrb. wiss. Bot. 26: 187235. 1894.

- Untersuchungen über Bakterien. Jahrb. wiss. Bot. 27: 1-163. 1895.

Fitzpatrick, Harry M. The cytology of Eocronartium muscicola. American Jour. Bot. 5: 397-419. 1918.

Flexner, Simon. Hideo Noguchi. A biographical sketch. Science 69: 653-660. 1929.

Fott, Bohuslav. Uber den inneren Bau von Vacuolaria viridis (Dangeard) Senn. Arch. Prot. 84: 242-250. 1935.

Fournier, Eugène (editor). Actes du Congrès International de Botanique tenu à Paris en août 1867. Paris. 1867.

França, Carlos. La flagellose des euphorbes. Arch. Prot. 34: 108-132. 1914.

Franck, James, and Walter E. Loomis. Photosynthesis in plants. Ames, Iowa. 1949.

Frank, B. Ueber die Parasiten in den Wurzelanschwellungen der Papilionaceen. Bot. Zeit. 37: 377-388, 393-400. 1879.

. Ueber die auf Wurzelsymbiose beruhende Ernährung gewisser Bäume durch unterirdische Pilze. Ber. deutschen bot. Gess. 3: 128-145. 1885.

Fries, Elias. Systema mycologicum, sistens Fungorum ordines, genera et species, huc usque cognitas . . . 3 vols. Lund. 1821-1832.

1836-1838.

- Hymenomycetes europaei sive epicriseos systematis mycologici editio altera. Upsala. 1874.

Fritsch, F. E. The structure and reproduction of the algae. 2 vols. Cambridge. 1935, 1945.

Frye, T. C., G. B. Rigg, and W. C. Crandall. The size of kelps on the Pacific Coast of North America. Bot. Gaz. 60: 473-482. 1915.

Galloway, J. J. A manual of Foraminifera. Bloomington, Indiana. 1933.

Gams, Helmut. Die Protochlorinae als autotrophe Vorfahren von Pilzen and Tieren ? Mikroscopie 2: 383-387. 1947.

Gardner, Nathaniel Lyon. Cytological studies in Cyanophyceae. Univ. California Publ. Bot. 2: 237-296. 1906.

Gäumann, Ernst. Vergleichende Morphologie der Pilze. Jena. 1926. English translation by C. W. Dodge. New York and London. 1928.

Gay, Frederick P. The unsolved problems of leprosy. Science 81: 283-285. 1935.

Geitler, Lothar. Der Zcllbau von Glaucocystis Nostochinearum und Gloeochaete Wittrockiana und die Chromatophoren-symbiosetheorie von Mereschkowsky. Arch. Prot. 47: 1-24. 1923.

Prot. 58: $465-507.1927$.

. Somatische Teilung, Reduktionsteilung, Copulation und Parthenogenese bei Cocconeis placentula. Arch. Prot. 59: 506-549. 1927.

76: 595-604. 1932. 
Gicklhorn, Josef. Notiz über den durch Chromulina smaragdina nov. spec. bedingten Smaragdglanz des Wasserspiegels. Arch. Prot. 44: 219-226. 1922.

Gilbert, Frank A. Factors influencing the germination of myxomycetous spores. American Jour. Bot. 16: 280-286. 1929.

germination by families. American Jour. Bot. 16: 421-432. 1929.

Gilbert, Henry C. Critical events in the life history of Cerationyxa. American Jour. Bot. 22: 52-74. 1935 .

Goldfuss, August. Ueber die Classification der Zoophyten. Isis 1818: 1008-1013. 1818.

Gomont, Maurice. Monographie des oscillariées (nostochacées homocytées). Ann. Sci. Bot. sér. 7, 15: 263-368. 1892.

Goodrich, Helen Pixell. Nina: a remarkable gregarine. Quart. Jour. Micr. Sci. n. s. 81: 107-126. 1938.

van Goor, A. G. J. Die Cytologie von Noctiluca miliaris im Lichte der neueren Theorien über den Kernbau der Protisten. Arch. Prot. 39: 147-208. 1918.

Granata, Leopoldo. Richerche sul ciclo evolutivo di Haplosporidium limnodrili Granata. Arch. Prot. 35: 47-79. 1914.

Gli attinomissidi. Morphologia-sviluppo-sistematica. Arch. Prot. 50: 139-212. 1925.

Grassé, Pierre P. (Editor). 'Traité de Zoologic. Anatomic, systematique, biologie. Paris. vols. 1 - . 1952 -

Grassi, B., and A Foà. Intorno ai protozoi dei termitidi. Atti Accad. Lincei ser. 5, Rendiconti Cl. Sci. 20, $1^{\circ}$ Semestre: 725-741. 1911. $231-39+.1917$.

Greeff, Richard. Pelomyxa palustris (Pelobius), ein amöbenartiger Organismus des sïssen Wassers. Arch. mikr. Anat. 10: 51-73. 1874.

Greville, Robert Kaye. Algae Britannicae, or descriptions of the marine and other inarticulated plants of the British Islands belonging to the order Algae . . . Edinburgh and London. 1830.

Gross, J. Sporenbildung bei Cristispira. Arch. Prot. 29: 279-292. 1913.

Gross, Catherine. The cytology of Vaucheria. Bull. Torrey Bot. Club 6t: 1-15. 1937.

Gurley, R. R. On the classification of the Myxosporidia, a group of protozoan parasites infesting fishes. Bull. United States Fish Comm. 11: 407-420. 1893.

Haeckel, Ernst Meinrich. Dic Radiolaricn (Rhizopoda radiaria). Ein Monographie. 4 vols. Berlin. 1862-1888.

- Gencrelle Morphologic. 2 vols. Berlin. 1866.

Monographic der Moneren. Jenaische Zeitschr. 4: 61-137. 1868.

- Die Kalkschwämme. Eine Monographie . . . 3 vols. Bcrlin. 1872.

- Ueber die Phaeodarien, cine neue Gruppe kiesclschaliger mariner Rhiz-

opoden. Sitzber. Jenaische Gess. Mcd. u. Naturw. 1879: 151-157. 1879.

- Entwurf eines Radiolarien-Systems auf Grund von Studien der Chal-

lenger-Radiolarien. Jenaische Zeitschr. 15: 418-472. 1882.

- Report on the Radiolaria collected by H. M. S. Challenerer during the years 1873-1876. Rept. Voy. Challenger Zool. 18: i-viii, 1-1803, plates 1-140. 1887.

Systematische Phylogenie. 3 vols. Berlin. 1894-1896.

Iäcker, V. Uber Chromosomen- und Sporenbildung bei Radiolarien. Verhandl. deutschen zool. Gess. 1907: 7t-8t. 1907. 
Hall, Richard P. Morphology and binary fission of Menoidium incurvum (Frcs.) Klebs. Univ. California Publ. Zool. 20: 447-476. 1923.

26: 281-324. 1925.

- Mitosis in Ceratium hirundinella O. F. M., with notes on nuclear phenomena in encysted forms and the question of sexual reproduction. Univ. California Publ. Zool. 28: 29-64. 1925.

- _ a and William N. Powell. Morphology and binary fission of Peranema trichophorum (Ehrbg.) Stein. Biol. Bull. 54: 36-64. 1928.

- - and Theodore Louis Jahn. On the comparative cytology of certain euglenid flagellates and the systematic position of the families Euglenidae Stein and Astasiidae Bütschli. Trans. American Micr. Soc. 48: 388-405. 1929.

- - The method of ingestion in Peranema trichophorum and its bearing on the pharyngeal-rod ("Staborgan") problem in the Euglenida. Arch. Prot. 81: 308-317, 1933.

. A note on the flagellar apparatus of Peranema trichophorum and the status of the family Peranemidae Stein. Trans. American Micr. Soc. 53: 237-244. 1934.

. A note on behavior of chromosomes in Euglena. Trans. American Micr. Soc. 56: 288-290. 1937.

and H. W. Schoenborn. Studics on the question of autotrophic nutrition in Chlorogonium euchlorum, Euglena anabaena, and Euglena deses. Arch. Prot. 90: 259-271. 1938.

1-12. 1939 .

- The trophic nature of Euglena viridis. Arch. Zool. Exp. Gen. 80: notes 61-67. 1939.

and H. W. Schoenborn. Selective effects of inorganic culture media on bacteria-free strains of Euglena. Arch. Prot. 93: 72-80. 1939.

and The question of autotrophic nutrition in Euglena gracilis. Physiol. Zool. 12: 76-84. 1939.

grat and J. B. Loefer. Effects of culture filtrates and old medium on growth of the ciliate, Colpidium campylum. Proc. Soc. Exp. Biol. Med. 43: 128-133. 1940.

- Vitamin deficiency as one explanation for inhibition of protozoan growth by conditioned medium. Proc. Soc. Exp. Biol. Med. 47: 306-308. 1941. and A. Schottenfeld. Maximal density and phases of death in populations of Glaucoma piriformis. Physiol. Zool. 14: 384-393. 1941.

- Incomplete proteins as nitrogen sources, and their relation to vitamin requirements in Colpidium campylum. Physiol. Zool. 15: 95-107. 1942.

and W. B. Cosgrove. The question of the synthesis of thiamin by the ciliate, Glaucoma piriformis. Biol. Bull. 86: 31-40. 1944.

Comparative effects of certain vitamins on populations of Glaucoma piriformis. Physiol. Zool. 17: 200-209. 1944.

the ciliate Tetrahymena geleii. Physiol. Zool. 18: 425-430. 1945.

- Protozoology. New York. 1953.

Hanatschek, Hcrta. Der Phasenwechsel bei der Gattung Vaucheria. Arch. Prot. 78: 497-513. 1932. 
Hansen, H. N., and William C. Snyder. The dual phenomenon and sex in Hypomyces solani f. cucurbitae. American Jour. Bot. 30: 419-422. 1943.

Hanson, Anne Marie. A morphological, developmental, and cytological study of four saprophytic chytrids. IV. Phlyctorhiza endogena gen. nov., sp. nov. American Jour. Bot. 33: 732-739. 1946.

Harper, Robert A. Beitrag zur Kenntnis der Kerntheilung und Sporenbildung im Ascus. Ber. deutschen bot. Gess. 13: (67) - (78). 1895.

- Die Entwicklung des Peritheciums bei Sphaerotheca Castagnei. Ber deutschen bot. Gess. 13: 475-481. 1895. 249-284. 1897.

- Cell division in sporangia and asci. Ann. Bot. 13: 467-525. 1899.

- Sexual reproduction in Pyronema confluens and the morphology of the ascocarp. Ann. Bot. 14: 321-400. 1900.

- Cell and nuclear division in Fuligo varians. Bot. Gaz. 30: 217-251. 1900. . Cleavage in Didymium melanospermum (Pers.) Macbr. American Jour. Bot. 1: 127-144. 1914.

Hartmann, Max, and K. Nägler. Copulation bei Amoeba diploidea n. sp. mit Selbstständigbleiben der Gametenkerne während des ganzen Lebenszyklus. Sitzber. Gess. naturf. Freunde Berlin 1908: 112-125. 1908.

\section{S. von Prowazek. Arch. Prot. 36: i-xii. 1915.}

Hartog, Marcus. Protozoa. in Harmer, S. F., and A. E. Shipley. The Cambridge Natural History 1: 3-162. 1909.

Harvey, William Henry. A manual of the British algae ... London. 1841.

Haskins, R. H. Cellulose as a substratum for saprophytic chytrids. American Jour. Bot. 26: 635-639. 1939.

Hatch, Winslow R. Gametogencsis in Allomyces arbuscula. Ann. Bot. 49: 623-649. 1935.

Haupt, Arthur W. Cell structure and cell division in the Cyanophyceae. Bot. Gaz. 75: 170-190. 1923. 19: 239-254. 1932

Healcl, F. D., and R. C. Walton. The expulsion of ascospores from the perithecia of the chestnut blight fungus, Endothia parasitica (Murr.) And. American Jour. Bot. 1: 499-521. 1914.

Hein, Illo. Studies on the mycelium of Psalliota campestris. American Jour. Bot. 17: 197-211. 1930. Jour. Bot. 17: 882-915. 1930.

Hemming, Francis. The official record of the proceedings of the International Commission on Zoological Nomenclature at their session held in Paris in July, 1948. Bull. Zool. Nomencl. 4: 1-648. 1950.

- Zoological nomenclature: decisions taken by the Fourtenth International Congress of Zoology, Copenhagen, August, 1953. Science 119: 131-133. 1954.

Henrici, Arthur T. Morphologic variation and the rate of growth of bacteria. Springfield and Baltimore. 1928.

and Delia Johnson. Stalked bacteria, a new order of Schizomycetes. Jour. Bact. 29: 3-4. 1935. a new order of Schizomycetes. Jour. Bact. 30: 61-94. 1935. 
Hertwig, Richard, and E. Lesser. Ueber Rhizopoden und denselben nahestandende Organismen. Morphologische Studien. Arch. mikr. Anat. 10, Suppl. 35-243. 1874. Zur Histologie der Radiolarien. Leipzig. 1876.

- Ueber Leptodiscus medusoides, eine neue den Noctiluceen verwandte Flagellate. Jenaische Zeitschr. 11: 307-323. 1877.

Der organismus der Radiolarien. Jena. 1879.

Ueber die Conjugation der Infusorien. Abh. Kgl. Bayerischen Akad. Wiss. Math.-phys CI. 17: 151-233. 1889.

Higgins, Bascombe Britt. Contribution to the life history and physiology of Cylindrosporium on stone fruits. Amcrican Jour. Bot. 1: 145-173. 1914.

Morphology and life history of some Ascomycetes with special reference to the presence and function of spermatia II. American Jour. Bot. 16: 287-296. 1929.

Higgins, E. Marion. A cytological investigation of Stypocaulon scoparium (L.) Kütz., with especial reference to the unilocular sporangia. Ann. Bot. 45: 345-353. 1931.

Hillier, James, Stuart Mudd, and Andrew G. Smith. Internal structure and nuclei in cells of Escherichia coli as shown by improved electron microscopic techniques. Jour. Bact. 57: 319-338. 1949.

Hinshaw, H. Corwin. On the morphology and mitosis of Trichomonas buccalis (Goodey) Kofoid. Univ. California Publ. Zool. 29: 159-174. 1926.

Hirsch, Hilde E. The cytogenetics of sex in Hypomyces solani var. cucurbitae. American Jour. Bot. 36: 113-121. 1949.

Hofeneder, Heinrich. Uber eine neue kolonienbildende Chrysomonadine. Arch. Prot. 29: 293-307. 1913.

Hofmeister, Wilhelm, Anton de Bary, Th. Irmisch, and Julius Sachs. Handbuch der physiologischen Botanik. 4 vols. Leipzig. 1865-1877.

Hogg, Joln. On the distinction of a plant and an animal, and on a fourth kingdom of nature. Edinburgh New Philos. Jour. n. s. 12: 216-225. 1860.

Hollenberg, George J. Culture studies of marine algae. I. Eisenia arborea. American Jour. Bot. 26: 34-41. 1939.

Horne, A. S. Nuclear division in the Plasmodiophorales. Ann. Bot. 44: 199-231. 1930. Hovasse, Raymond. Contribution à l'étude de l'appareil de Golgi des flagellés libres: l'existence d'un corps parabasal chez Cercomonas longicauda Duj. Arch. Zool. Exp. Gen. 79, notes 43-46. 1937.

Howard, Frank L. The life history of Physarum polycephalum. American Jour. Bot. 18: 116-133. 1931.

1932.

Hutchinson, Henry Brougham, and James Clayton. On the decomposition of cellulose by an aerobic organism (Spirochaeta cytophaga, n. sp.). Jour. Agr. Sci. 9: 143173. 1919.

Huth, Walther. Zur Entwicklungsgeschichte der Thalassicollen. Arch. Prot. 30: 1124. 1913.

Huxley, Julian S. On Ganymedes anaspidis (nov. gen., nov. sp.): a gregarine from the digestive tract of Anaspides tasmaniae (Thompson). Quart. Jour. Micr. Sci. n. s. $55: 155-175.1910$.

Huxley, Thomas Henry. Zoological notes and observations made on board H. M. S. Rattlesnake. II. Upon Thalassicolla, a new zoophyte. Ann. Mag. Nat. Hist. ser. 2, 8: 433-442. 1851. 
A manual of the anatomy of invertebrated animals. London. 1877.

Ischikawa, C. Vorläufige Mittheilungen über die Conjugationserscheinungen bei den Noctiluceen. Zool. Anz. 14: 12-14. 1891.

Ishikawa, Matsuharu. Cytological studies on Porphyra tenera Kjellm. I. Bot. Mag. Tokyo 35: 206-218. 1921.

Iyengar, M. O. P., and R. Subrahmanyan. On reduction division and auxospore formation in Cyclotella Meneghiniana Kütz. Jour. Indian Bot. Soc. 21: 231-237. $19+2$.

and On reduction division and auxospore formation in Cyclotella Meneghiniana Kütz. Jour. Indian Bot. Soc. 23: 125-152. 1944.

Jahn, Eduard. Myxomycetenstudien. 3. Kernteilung und Geisselbildung bei den Schwärmern von Stemonitis flaccida Lister. Ber. deutschen bot. Gess. 22: 84-92. 1904.

Myxomycetenstudien. 4. Die Keimung der Sporen. Ber. deutschen bot. Gess. 23: 489-497. 1905. 1924.

Jahn, Theodore Louis. The cuglenoid flagellates. Quart. Rev. Biol. 21: 246-274. 1946.

James-Clark, H. [Preliminary abstract of the following.] Proc. Boston Soc. Nat. Hist. 11: 16. 1866.

-. On the Spongiae Ciliatae as Infusoria Flagellata; or, observations on the structure, animality, and relationship of Leucosolenia botryoides, Bowerbank. Mcn. Boston Soc. Nat. Hist. 1: 305-340. 1868.

Jameson, A. Pringle. The chromosome cycle of gregarines, with special reference to Diplocystis schneideri Kuunstler. Quart. Jour. Micr. Sci. n. s. 64: 207-266. 1920. Janicki, C. Zur Kenntnis des Parabasalapparats bei parasitischen Flagellaten. Biol. Centralbl. 31: 321-330. 1911.

. Untersuchungen an parasitischen Flagellaten. II. Teil. Die Gattungen Devescovina, Parajocnia, Stephanonympha, Calonympha.-Uber den Parabasalapparat.-U Uber Kernkonstitution und Kernteilung. Zeit. wiss. Zool. 112: 573691.1915.

Jennings, H. S. (editor), T. M. Sonneborn, A. G. Giese, L. C. Gilman, and R. F, Kimball. Mating types and their interactions in the ciliate infusoria. Biol. Symp. 1: 117-188. 1940.

Johns, Robert M., and R. K. Benjanin. Sexual reproduction in Gonapodya. Mycologia 46: 201-208. 1954.

Jollos, Victor. Experimentelle Unterschungen an Infusorien. Biol. Centralbl. 33: 222-236. 1913.

Jones, Gcorge Neville. On the number of species of plants. Sci. Month. 72: 289-294. 1951.

Jordan, Edwin O., and I. S. Falk (editors). The newer knowledge of bacteriology and immunology. Chicago. 1928.

Juel, H. O. Ucber Zellinhalt, Befruchtung und Sporenbildung bei Dipodascus. Flora 91: 47-55. 1902.

Kahl, A. Ctenostomata (Lauterborn) n. subordo. Vierte Unterordnung der Iteterotricha. Arch. Prot. 77: 231-304. 1932.

Kampter, Erwin. Die Coccolithincen der Südwestküste von Istrien. Ann. Naturhist. Staatsmus. Wien 51: 54-149. 1940. 
Kanda, Tiyoiti. On the gametophytes of some Japanese species of Laminariales. Sci. Papers Inst. Alg. Res. Hokkaido Imp. Univ. 1: 221-260. 1936; 2: 87-111. 1938. Kanouse, Bessie Bernice. A monographic study of special groups of the water molds I. Blastocladiaceae. American Jour. Bot. 14: 278-306. 1927.

A monographic study of special groups of the water molds II. Leptomitaceae and Pythiomorphaceae. American Jour Bot. 14: 335-357. 1927.

Karling, John S. A preliminary descriptive study of a parasitic monad in cells of American Characeae. American Jour. Bot. 17: 928-937. 1930.

- Studies in the Chytridiales VI. The occurrence and life history of a new species of Cladochytrium in cells of Eriocaulon septangulare. American Jour. Bot. 18: 526-557. 1931.

-._. The cytology of the Chytridiales with special reference to Cladochytrium replicatum. Mem. Torrey Bot. Club 19, no. 1: 1-92. 1937.

. A new fungus with antcriorly uniciliate zoospores: Hyphochytrium catenoides. American Jour. Bot. 26: 512-519. 1939.

- The Plasmodiophorales ... New York. 1942.

- Parasitism among the chytrids. American Jour. Bot. 29: 24-35. 1942.

. The life history of Anisolpidium Ectocarpii gen. nov. et sp. nov., and a synopsis and classification of other fungi with anteriorly uniflagellate zoospores. American Jour. Bot. 30: 637-648. 1943.

. Phagomyxa algarum n. gen., n. sp., an unusual parasite with plasmodiophoralean and proteomyxean characteristics. American Jour. Bot. 31: 38-52. 1944.

- Brazilian anisochytrids. American Jour. Bot. 31: 391-397. 1944.

- Brazilian chytrids. VI. Rhopalophlyctis and Chytriomyces, two new chitinophyllic operculate genera. American Jour. Bot. 32: 362-369. 1945.

- Keratinophilic chytrids. I. Rhizophidium keratinophilum n. sp., a saprophyte isolated on human hair, and its parasite, Phlyctidium mycetophagum n. sp. American Jour. Bot. 33: 751-757. 1946.

Keratinophilic chytrids. II. Phlyctorhiza variabilis n. sp. American Jour. Bot. 34: 27-32. 1947.

1948.

Karsten, G. Die Auxosporenbildung der Gattungen Cocconeis, Surirella, und Cymatopleura. Flora 87: 253-283. 1900.

. Die sogenannte "Mikrosporen" der Planktondiatomeen und ihre weitere Entwicklung, beobachtet an Corethron Valdiviae n. sp. Ber. deutschen bot. Gess. 22: 544-554. 1904.

Keene, Mary Lucille. Cytological studics of the zygospores of Sporodinia grandis. Ann. Bot. 28: 455-470. 1914.

- Studies of zygospore formation in Phycomyces nitens Kunze. Trans. Wisconsin Acad. 19: 1195-1220. 1919.

Keitt, G. W., and M. H. Langford. Venturia inaequalis (Cke.) Wint. I. A groundwork for genetic studies. American Jour. Bot. 28: 805-820. 1911.

Kelley, Arthur P. Mycotrophy in plants. Waltham, Massachussetts. 1950.

Kent, William Saville. A manual of the Infusoria: including a description of all known flagellate, ciliate, and tentaculiferous Protozoa, British and foreign, and an account of the organization and affinities of the sponges. 3 vols. London. $1880-1882$.

Keuten, Jacob. Die Kerntheilung von Euglena viridis Ehrenberg. Zeitfl wiss. Zool. 60: 215-235. 1895. 
Keysselitz, G. Uber Trypanophis grobbeni (Trypanosoma grobbeni Poche). Arch. Prot. 3: 367-375. 1904.

Kidder, George W. Streblomastix strix, morphology and mitosis. Univ. California Publ. Zool. 33: 109-124. 1929.

Kimball, Richard F. Mating types in the ciliate Infusoria. Quart. Rev. Biol, 18: 30-45. 1943.

King, Robert L., and Theodore Louis Jahn. Concerning the genera of amebas. Science 107: 293-294. 1948.

Kirby, Harold, Jr. The intestinal flagellates of the termite, Cryptotermes hermsi Kirby. Univ. Calif. Publ. Zool, 29: 103-120. 1926.

- - Studies on some amoebae from the termite Mirotermes, with notes on some other Protozoa from the Termitidae. Quart. Jour. Micr. Sci. n. s. 71: 189222. 1927.

A species of Proboscoidella from Kalotermes (Cryptotermes) dudleyi Banks, a termite of Central America, with remarks on the oxymonad flagellates. Quart. Jour. Micr. Sci. n. s. 72: 355-386. 1928.

Snyderella and Coronympha, two new genera of multinucleate flagellates from termites. Univ. California Publ. Zool. 31: 417-432. 1929.

- Trichomonad flagellates from termites I. Tricercomitus gen. nov., and Hexamastix Alexeieff. Univ. California Publ. Zool. 33: 393-444. 1930.

Trichomonad flagellates from termites II. Eutrichomastix, and the subfamily Trichomonadinae. Univ. California Publ. Zool. 36: 171-262. 1931.

Univ. California Publ. Zool. 41: 189-212. 1937.

- The devescovinid flagellates Caduceia theobromae França, Pseudodevescovina ramosa new species, and Macrotrichomonas pulchra Grassi. Univ. California Publ. Zool. 43: 1-40. 1939.

Observations on a trichomonad from the intestine of man. Jour. Parasitol. 29: 422-\$23. 1943.

- Some obscrvations on cytology and morphogenesis in flagellate protozoa. Jour. Morph. 75: 361-421. 1944.

- Flagellate and host relationships of trichomonad flagellates. Jour. Parasitol. 33: 214-228. 1947.

Klebs, Georg. Flagellatenstudien. Zeit. wiss. Zool. 55: 265-351, 353-445. 1893.

Knasyi, Georges. The cell structure and cell division of Bacillus subtilis. Jour. Bact.

19: 113-115. 1930.

- Elements of bacterial cytology. Ithaca, New York, 1944.

Kniep, H. Allomyces javanicus n. sp., ein anisogamer Phycomycet mit Planogameten. Ber. deutschen bot. Gess. 47: 199-212. 1929.

Knight, Margery. Studies in the Ectocarpaceae. I. The life-listory and cytology of l'hylaiella litoralis, Kjellm. Trans. Roy. Soc. Edinburgh 53: 343-360. 1923. - Studies in the Ectocarpaceac. II. The life-history and cytology of Ectocarpus siliculosus, Dillw. Trans. Roy. Soc. Eslinburgh 56: 307-332. 1929. Kofoid, Charles Atwood. New species of dinoflagellates. Bull. Mus. Comp. Zool. Harvard 50: 163-207. 1907.

and Elizabeth Bohn Christianson. On binary and multiple fission in

Giardia muris (Grassi). Univ. California Publ. Zool. 16: 30-54. 1915. and Olive Swezy. Mitosis in Trichomonas. Proc. Nat. Acad. Sci. 1: 315 321.1915. 
and

Studies on the parasites of the termites I. On Streblomastix strix, a polymastigote flagellate with a linear plasmodial phase. Univ. California Publ. Zool. 20: 1-20. 1919.

and $\longrightarrow$ Studies on the parasites of the termites II. On Trichomitus termitidis, a polymastigote flagellate with a highly developed neuromotor system. Univ. California Publ. Zool. 20: 21-40. 1919.

and- Studies on the parasites of the termites III. On Trichonympha campanula sp. nov. Univ. California Publ. Zool. 20: 41-98. 1919.

Leidyopsis sphaerica gen nov., Studies on the parasites of the termites IV. On 1919.

. A critical review of the nomenclature of human intestinal flagellates, Cercomonas, Chilomastix, Trichomonas, Tetratrichomonas, and Giardia. Univ. California Publ. Zool. 20: 145-168. 1920.

and Olive Swezy. On the free, encysted, and budding stages of Councilmania lafleuri, a parasitic amoeba of the human intestine. Univ. California Publ. Zool. 20: 169-198. 1921.

Univ. California 5: i-viii, 1-562. 1921.

and - Mitosis and fission in the active and encysted phases of Giardia enterica (Grassi) of man, with a discussion of the method of origin of bilateral symmetry in the polymastigote flagellates. Univ. California Publ. Zool. 20: 199-234. 1922.

and Mitosis in Endamoeba dysenteriae in the bone marrow in arthritis deformans. Univ. California Publ. Zool. 20: 301-307. 1922.

The life cycle of the Protozoa. Science n. s. 57: 397-408. 1923.

and Olive Swezy. Karyamoeba falcata, a new amoeba from the human intestinal tract. Univ. California Publ. Zool. 26: 221-242. 1924.

and - On the number of chromosomes and type of mitosis in Endamoeba dystenteriae. Univ. California Publ. Zool. 26: 331-352. 1925. and - Karyamoebina substituted for Karyamoeba, with a note on its occurrence in man. Univ. California Publ. Zool. 26: 435-436. 1925. and - On Oxymonas, a flagellate with an extensile and retractile proboscis from Kalotermes from British Guiana. Univ. California Publ. Zool. 28: 285-300. 1926.

and Arthur Shackleton Campbell. A conspectus of the marine and freshwater ciliata belonging to the suborder Tintinnoinea, with descriptions of new species principally from the Agassiz expedition to the eastern tropical Pacific 1904-1905. Univ. California Publ. Zool. 34: 1-403. 1929.

Koidzumi, Makoto. Studies on the intestinal Protozoa found in the termites of Japan. Parasitiology 13: 235-309. 1921.

Kolk, Laura A. A comparison of the filamentous iron organisms, Clonothrix fusca Roze and Crenthrix polyspora Cohn. American Jour. Bot. 25: 11-17. 1938.

Kukzynski, Max H. Untersuchungen an Trichomonaden. Arch. Prot. 33: 119-204. 1914.

Kudo, Richard R. Studies on Myxosporidia. Illinois Biol. Monogr. 5: 239-506. 1920. . A biological and taxonomic study of the Microsporidia. Illinois Biol. Monogr. 9: 77-344. 1924. 
- Observations on Lophomonas blattarum, a flagellate inhabiting the colon of the cockroach, Blatta orientalis. Arch. Prot. 53: 191-214. 1926. edition. 1946.

Kühn, Alfred, and W. von Schuckmann. Über den Bau und die Teilungserschinungen von Trypanosoma brucei (Plimmer u. Bradford). Sitzber. heidelberger Akad. Wiss., Math.-nat. K1., 1911, Abh. 11: 1-21.1911.

- Utber Bau, Teilung und Encystierung von Bobo edax Klebs. Arch. Prot. 35: 212-255. 1915.

Kunieda, Hiroshi. On the development of the sexual organs and embryogeny in Sargassum Horneri Ag. Jour. Coll. Agr. Tokyo Imp. Univ. 9: 383-396. 1928.

Kützing, Friedrich Traugott. Phycologia generalis oder Anatomie, Physiologie und Systemkunde der Tange. Leipzig. 1843.

—. Phycologia germanica, d. i. Deutschland's Algen ... Nordhausen. 1845. Kylin, Harald. Úber den Bau der Spermatozoiden der Fucaceen. Ber. deutschen bot. Gess. 34: 194-201. 1916.

. Uber den Generationswechsel bei Laminaria digitata. Svensk Bot. Tidskr. 10: 551-561. 1916.

1917.

- Uber die Keimung der Florideensporen. Arkiv för Bot. 14, no. 22: 1-25.

- Studien über die Entwicklungsgeschichte der Florideen. Kgl. Svenska Vetensk.-Akad. Handl. 63, no. 11: 1-139. 1923.

1-111. 1924.

Studien über Delesseriaceen. Kgl. Fysiog. Sällsk. Handl. n. f. 35, no. 6:

- The marine red algae in the vicinity of the biological station at Friday Harbor, Wash. Kgl. Fysiog. SäIlsk. Handl, n. f. 36, no. 9: 1-87. 1925.

Handl. n. f. 39, no. 4: 1-127. 1928.

. Some physiological remarks on the relationship of the Bangiales. Bot.

Notiser 1930: 417-420. 1930.

43, no. 8: 1-88. 1932.

- Ucber die Entwicklungsgeschichte der Phaeophyceen. Kgl. Fysiog. SälIsk. Handl. n. f. 44, no. 7: 1-102. 1933.

Zur Kenntniss der Entwicklungsgeschichte einiger Phaeophyceen. Kgl.

Fysiog. Sällsk. Handl. n. f. 45, no. 9: 1-18. 1934.

- Uber Rhodomonas, Platymonas, und Prasinocladus. Kgl. Fysiog. Sällsk. Förhandl. 5, no. 22: 1-13. 1935.

no. $10: 1-5.1937$.

- Bermerkungen über die Entwicklungsgeschichte einiger Phaeophyceen. Kgl. Fysiog. Sällsk. Handl. n. f. 48, no. 1: 1-34. 1937.

- Zur Biochemie der Rhodophyceen. Kgl. Fysiog. Sällsk. Förhandl. 13, no. 6: 1-13. 1943.

Zur Biochemie der Cyanophycecn. Kgl. Fysiog. Sällsk. Förhandl. 13, no. 7: 1-14. 1943. 
Labbé, Alphonse. Sporozoa. Thierreich Lief. 5: i-xx, 1-180. 1899.

de Lamarck, J.-B.-P.-A. Philosophie Zoologique . . . 2 vols. Paris. 1809.

Histoire naturelle des animaux sans vertèbres. 7 vols. Paris. 1815-1822.

Lamouroux, J. V. F. Essai sur les genres de la famille des thalassiophytes non articulées. Ann. Mus. Hist. Nat. Paris 20: 21-47, 115-139, 267-293. 1813.

Lander, Caroline A. Spore formation in Scleroderma lycoperdoides. Bot. Gaz. 95: 330-337. 1933.

Lanjouw, J., and others. International code of botanical nomanclature. Utrecht. 1952.

Lankester, E. Ray. On Drepanidium ranarum, the cell-parasite of the frog's blood and spleen (Gaule's Würmschen). Quart. Jour. Micr. Sci. n. s. 22: 53-65. 1882.

- Protozoa. in Encyclopedia Britannica ed. 9, 19: 830-866. 1885.

Lauterborn, Robert. Untersuchungen über Bau, Kernteilung, und Bewegung der Diatomen. Leipzig. 1896.

sorien aus dem Gebiete des Oberrheins. Zeit. wiss. Zool. 90: 645-669. 1908.

Lebour, Marie V. The dinoflagellates of northern seas. Plymouth, England. 1925.

Lederberg, Joshua, and E. L. Tatum. Sex in bacteria: genetic studies, 1945-1952. Science 118: 169-175. 1953.

Ledingham, G. A. Studies on Polymyxa graminis, n. gen. n. sp., a plasmodiophoraceous parasite on wheat. Canadian Jour. Res. 17 C: 38-51. 1939.

van Leeuwenhoeck, Antony. Observations communicated to the publisher in a Dutch letter of the 9th of Octob. 1676. here English'd: Concerning little animals by him observed in rain, well, sea, and snow-water; as also in water wherein pepper hath lain infused. Phil. Trans. Roy. Soc. London 12: 821-831. 1677.

Léger, Louis. Les schizogrégarines des trachéates. I. Le genre Ophryocystis. Arch. Prot. 8: 159-202. 1907.

and O. Duboscq. L'évolution schizogonique de Aggregata (Eucoccidium) eberthi (Labbé). Arch. Prot. 12: 44-108. 1908.

- Mycétozoairs endoparasites des insectes. I. Sporomyxa scauri nov. gen. nov. spec. Arch. Prot. 12: 109-130. 1908.

and O. Duboscq. Selenococcidium intermedium Lég. et Dub. et la systématique des sporozoaires. Arch. Zool. Exp. Gen. sér. 5, 5: 187-238. 1910. cidies. Arch. Prot. 22: 71-88. 1911.

and O. Duboscq. Etude sur Spirocystis nidula Lég. et Dub. schizogrégarine du Lumbriculus variegatus Müll. Arch. Prot. 35: 199-211. 1915.

Leidy, Joseph. Fresh-water rhizopods of North America. Rept. U. S. Geol. Surv. Territories, vol. 12. 1879.

Lemmermann, E. Silicoflagellatae. Ber. deutschen bot. Gess. 19: 247-271. 1901.

Leuckart, Rudolf. Die Parasiten der Menschen und die von ihnen herrührenden Krankheiten. vol. 1. [no more were issued]. Leipzig and Heidelberg. 1879-1901.

Levine, Michael. The origin and development of lamellae in Agaricus campestris and in certain species of Coprinus. American Jour. Bot. 9: 509-533. 1922.

Lewis, Charles E. The basidium of Amanita bisporigera. Bot. Gaz. 41: 348-352. 1906. Lewis, Ivey F., and Conway Zirkle. Cytology and systematic position of Porphyridium cruentum Naegeli. American Jour. Bot. 7: 333-340. 1920.

and Hilah F. Bryan. A new protophyte from the Dry Tortugas. American Jour. Bot. 28: 343-348. 1941. 
Light, Sol F. On Hoplonympha natator gen. nov. sp. nov. a non-xylophagous hypermastigote from the termite, Kalotermes simplicicornis Banks, characterized by biradial symmetry and a highly developed pellicle. Univ. California Publ. Zool. 29: 123-140. 1926.

. Kofoidia, a new flagellate, from a California termite. Univ. California Publ. Zool. 29: 467-492. 1927.

Linder, David H. Evolution of the Basidiomycetes and its relation to the terminology of the basidium. Mycologia 32: 419-447. 1940.

Linnaeus, Carolus. Systema naturae sive regna tria naturae systematice proposita per classes, ordines, genera, \& species. Leyden. 1735 [Facsimile reprint. Stockholm. 1907]. Tenth edition. 2 vols. Stockholm. 1758. Twelfth edition. 3 vols. Stockholm. 1766-1768.

. Species plantarum . . 2 vols. Stockholm. 1753.

. Genera plantarum ... 6th ed. Stockholm. 1764.

Lister, Arthur. On the division of nuclei in the Mycctozoa. Jour. Linnacan Soc. Bot. 29: 529-542. 1893.

A monograph of the Mycetozoa being a descriptive catalogue of the species in the herbarium of the British Museum. London. 1894.

Lister, J. J. Contributions to the life-history of the Foraminifera. Phil. Trans. Roy. Soc. London B 186: 401-453. 1895.

Loeffler, F. Eine neue Methode zum Färbung der Mikroorganismen, in besonderen ihrer Wimperhaare und Geisseln. Centralbl. Bakt. 6: 209-224. 1889.

Lohman, H. Die Coccolithophoridae, eine Monographie der Coccolithen bildenden Flagellaten. Arch. Prot. 1: 89-165. 1902.

Löhnis, F., and N. R. Smith. Life cycles of the bacteria. Jour. Agr. Res. 6: 675-702. 1916.

life history of Azotobacter. Jour. Agr. Res. 23: 401-432. 1923.

Longest, Pauline Moser. Structure of the cilia in Ectocarpus Mitchelliae and Codium decorticatum. Jour. Elisha Mitchell Soc. 62: 249-252. 1946.

Lucas, George Blanchard. Genetics of Glomerella. IV. Nuclear phenomena in the ascus. American Jour. Bot. 33: 802-806. 1946.

Lund, Everett Eugene. A correlation of the silverline and neuromotor systems of Paramoecium. Univ. California Publ. Zool. 39: 35-76. 1933.

Luther, A. Ueber Chlorosaccus, cine neue Gattung der Süsswasseralgen, ncbst cinigen Bemerkungen zur Systematik verwandter Algen. Bihang till kgl. Svenska Vetensk.-Akad. Iandl. 24, Afd. III, no. 13: 1-22. 1899. ,

Luttrell, E. S. Taxonomy of the Pyrcnomycetes. Univ. Missouri Studies 24 (no. 3): 1-120. 1951.

Lyngloye, IIans Christian. Tentamen hydrographiae Danicac . . Copenhagen. 1819. Macbride, Thomas H. The North American slime-molds. New York and London. 1899. Second cdition. 1922. and G. W. Martin. The Myxomycetes. New York. 1934.

MacLennan, Ronald I. The pulsatory cycle of the contractile vacuoles in the Ophryoscolecidac, ciliates from the stomach of cattle. Univ. California Publ. Zool. 39: 205-250. 1933.

Mackay, James Townsend. Flora IIibernica ... Dublin. 1836.

Manton, I. The fine structure of plant cilia. Symp. Soc. Exp. Biol. 6: 306-319. 1952.

Martin, C. H. Observations on Trypanoplasma congeri. Part I.-The division of the active form. Quart. Jour. Micr. Sci. n. s. 55: 485-496. 1910. 
Martin, Ella M. The morphology and cytology of Taphrina deformans. American Jour. Bot. 27: 743-751. 1940.

Martin, G. W. Morphology of Conidiobolus villosus. Bot. Gaz. 80: 311-318. 1925.

- The genus Protodontia. Mycologia 24: 508-511. 1932.

- Three new heterobasidiomycetes. Mycologia 26: 261-265. 1934.

- Atractobasidium, a new genus of Tremellaceac. Bull. Torrey Bot. Club 62: 339-343. 1935.

112-114. 1937.

- New or noteworthy Fungi from Panama and Colombia. I. Mycologia 29: 618-625. 1937. 30: 431-441. 1938.

1938.

1938.

- Myxomycetes from Colombia. Trans. American Micr. Soc. 57: 123-126.

- The morphology of the basidium. American Jour. Bot. 25: 682-685.

. New or noteworthy Fungi from Panama and Colombia. III. Mycologia

31: 239-249. 1939.

$31: 507-518.1939$.

- Notes on Iowa Fungi. VIII. Proc. Iowa Acad. Sci. 46: 89-95. 1939.

- The genus "Lycogalopsis." De Lilloa 4: 69-73. 1939.

- Notes on Iowa Fungi. IX. Proc. Iowa Acad. Sci. 49: 145-152. 1942.

- New or noteworthy tropical Fungi II. Lloydia 5: 158-164. 1942.

- The generic name Auricularia. American Midl. Nat. 30: 77-82. 1943.

. The numbers of Fungi. Proc. Iowa Acad. Sci. 58: 175-178. 1951.

Matthews, Velma Dare. Studies on the genus Pythium. Chapel Hill, North Carolina. 1931.

Maupas, E. La rajeunissement karyogamique ches les ciliés. Arch. Zool. Exp. Gen. sér. 2, 7: 149-517. 1889.

McClintock, Barbara. Neurospora. I. Preliminary observations of the chromosomes of Neurospora crassa. American Jour. Bot. 32: 671-678. 1945.

McKay, Hazel IIayden. The life history of Pterygophora califonica Ruprecht. Univ. California Publ. Bot. 17: 111-148. 1933.

McLarty, D. A. Studies in the Woroninaceac-II. The cytology of Olpidiopsis Achlyae sp. nov. (ad int.). Bull. Torrey Bot. Club 68: 75-99. 1941.

McNab, W. R. On the classification of the vegetable kingdom. Jour. of Bot. 15: 340344.1877.

Mense, Carl (editor). Handbuch der Tropenkrankheiten. 3 vols. Leipzig. 1905-1906.

Mesnil, Félix. Les travaux récents sur les coccidies. Bull. Inst. Pasteur 1: 473-480. 1903.

Metcalf, Maynard M. Opalina and the origin of the Ciliata. Anat. Rec. 14: 88-89. 1918. Sci. 8: 427-431. 1919. i-vii, 1-484. 1923.

Minchin, Edward Alfred. Investigations on the development of trypanosomes in the tsetse-flies and other Diptera. Quart. Jour. Micr. Sci. n. s. 52: 159-260. 1908. 
. The structure of Trypanosoma lewisi in relation to microscopical technique. Quart. Jour. Micr. Sci. n. s. 53: 755-808. 1909.

and H. M. Woodcock. Observations on certain blood-parasites of fishes occurring at Rovigno. Quart. Jour. Micr. Sci. n. s. 55: 113-154. 1910.

and - Observations on the trypanosome of the little owl

(Athene noctua) with remarks on the other protozoan parasites occurring in this bird. Quart. Jour. Micr. Sci. n. s. 57: 141-185. 1911.

. An introduction to the study of the Protozoa ... London. 1912.

and J. D. Thomson. The rat-trypanosome, Trypanosoma lewisi, in relation to the rat-flea, Ceratophyllus fasciatus. Quart. Jour. Micr. Sci. n. s. 60: 463-692. 1915.

Mitchell, Herschel K., and Mary B. Houlahan. Neurospora. IV. A temperature-sensitive riboflavineless mutant. American Jour. Bot. 33: 31-35. 1946.

Miwa, Tomoo. Biochemische Studien über die Zellmembran von Braun- und Rotalgen. Japanese Jour. Bot. 11: 41-127. 1940.

Molisch, Hans. Die Purpurbakterien nach neuen Untersuchungen. Jena. 1907.

Moreau, Fernand. Recherches sur la reproduction des Mucorinées et de quelques autres Thallophytes. Le Botaniste 13: 1-136. 1913.

Moreau, Mme. F. Les phénomènes de la sexualité chez les uredinées. Le Botaniste 13: 145-284. 1914.

Mottier, David M. Das Gentrosom bei Dictyota. Ber. deutschen bot. Gess. 16: 123128. 1898. 192. 1900 .

Müller. Johannes, and A. Retzius. Ueber parasitische Bildung. Arch. Anat. Physiol. 1842: 193-212. 1842.

Uber die Thalassicollen, Polycystinen und Acanthometren des Mittelmeeres. Abh. Akad. Wiss. Berlin 1858: 1-62. 1859.

Miiller, Otho Fredericus. Vermium terrestrium et fluviatilım seu animalium infusorium helminthicorum et testaceorum, non marinorum, succincta historia. 2 vols. Copenhagen and Leipzig. 1773, 1774.

-_. Animacula infusoria fluviatilia et marina . . Copenhagen. 1786.

Müller, Otto. Durchbrechung der Zellwand in ihren Beziehungen zur Ortsbewegung der Bacillariaceen. Ber. deutschen bot. Gess. 7: 169-180. 1889.

54-64. 1896.

Mulsow, Karl. Uber Fortpflanzungserscheinungen bei Monocystis rostrata n. sp. Arch. Prot. 22: 20-55. 1911.

Myers, Earl II. The life cycle of Patellina corrugata, a foraminifera. Science 79: 436-437. 1934.

. The life history of Patellina corrugata Williamson a foraminifer. Bull. Scrips Inst., Tech. ser. 3: 355-392. 1935.

. The life cycle of Spirillina vivipara Ehrenberg, with notes on morphogenesis, systematics and distribution of the Foraminifera. Jour. Roy. Micr. Soc. scr. 3, 56: 120-146. 1936.

. Biology, ecology, and morphogenesis of a pelagic foraminifer. Stanford Univ. Publ. Biol. Sci. 9: 1-40. 1943.

Mycrs, Margret E. The life history of the brown alga, Egregia Menziesii. Univ. California Publ. Bot. 14: 225-246. 1928. 
Nabel, Kurt. Über die Membran der niederer Pilze, besonders von Rhizidiomyces bivellatus nov. spez. Arch. Mikrobiol. 10: 515-541. 1939.

Nägeli, Garl. Gattungen einzelliger Algen physiologisch und systematisch bearbeitet. Zurich. 1849.

Noble, Alden E. On Tokophrya lemnarum Stein (Suctoria) with an account of its budding and conjugation. Univ. California Publ. Zool. 37: 477-520. 1932.

Noble, Elmer R. The life cycle of Zygosoma globosum sp. nov. a gregarine parasite of Urechis caupo. Univ. California Publ. Zool. 43: 41-66. 1938.

. Nuclear cycles in the life history of the protozoan genus Ceratomyxa. Jour. Morph. 69: 455-479. 1941.

- Life cycles in the Myxosporidia. Quart. Rev. Biol. 19: 213-235. 1944.

Noguchi, Hideo, Raymond C. Shanor, Evelyn B. Tilden, and Joseph R. Tyler. Phlebotomus and Oroya fever and verruga peruana. Science 68: 493-496. 1928.

Nowakowski, Leon. Beitrag zur Kenntniss der Chytridiaceen. II. Polyphagus Euglenae, eine Chytridiacee mit geschlechtlicher Fortpflanzung. Beitr. Biol. Pfl. 2: 201-219. 1876.

Odum, Howard T. Notes on the strontium content of sea water, celestite radiolaria, and strontianite snail shells. Science 114: 211-213. 1951.

Olive, Edgar W. A preliminary enumeration of the Sorophoreae. Proc. American Acad. 37: 333-344. 1901. 1902.

Monograph of the Acrasieae. Proc. Boston Soc. Nat. Hist. 30: 451-513.

. Mitotic division of the nuclei of the Cyanophyceae. Beih. bot. Centralbl. 18: 9-44. 1904.

. Cytological studies on the Entomophthoreae. Bot. Gaz. 41: 192-208, 229-261. 1906.

Olive, Lindsay S. Karyogamy and meiosis in the rust Coleosporium Vernoniae. American Jour. Bot. 36: 41-54. 1949.

Oltmanns, Friedrich. Zur Entwicklungsgeschichte der Florideen. Bot. Zeit. 56: 99140. 1898.

-_. Morphologie und Biologie der Algen. 2 vols. Jena, 1904, 1905. Second edition. 3 vols. 1922, 1923.

Oparin, Alexander Ivanovitch. The origin of life. Translated by Sergius Morgulis. New York. 1938.

d'Orbigny, Alcide Dessalines. Tableau methodique de la classe des céphalopodes. Ann. Sci. Nat. 7: 96-169, 245-314. 1826.

Foraminifères. in R. de la Sagra. Histoire . . . de l'ile de Cuba, vol. 8. Paris. 1839.

Orla-Jensen, S. Die Hauptlinien des natïrlichen Bakteriensystems. Centralbl. Bakt. Abt. 2, 22: 305-346. 1909.

Overholts, L. O. Research methods in the taxonomy of the Hymenomycetes. Proc. Internat. Congr. Pl. Sci. Ithaca 2: 1688-1712. 1929.

Owen, Richard. Palaeontology, or a systematic summary of extinct animals and their geological relations. Edinburgh. 1860. Second cdition. 1861.

Papenfuss, George F. Structure and taxonomy of Taenioma, including a discussion of the phylogeny of the Ceramiales. Madroño 7: 193-214. 1944.

Univ. California Publ. Bot. 18: 299-334. 1945. 
218. 1946.

Proposed names for the phyla of algae. Bull. Torrey Bot. Club 73: 217.

Extension of the brown algal order Dictyosiphonales to include the Punctariales. Bull. Torrey Bot. Club. 74: 398-402. 1947.

Park, William Hallock, Anne Wessels Williams, and Charles Krumweide. Pathogenic microorganisms ... 8th ed. Philadelphia and New York. 1924.

Pascher, Adolf. Zur Gliederung der Heterokonten. Hedwigia 53: 6-22. 1912.

and others. Die Süsswasser-Flora Deutschlands, Österreichs und der Schweiz. 15 Hefte. Jena. 1913-1936.

1914.

- Uber Flagellaten und Algen. Ber. deutschen bot. Gess. 32: 136-160.

. Über eine neue Amöbe-Dinamoeba (varians)-mit dinoflagellatenartigen Schwärmern. Arch. Prot. 36: 118-136. 1916.

. Fusionsplasmodien bei Flagellaten und ihre Bedeutung für die Ablei-

tung der Rhizopoden von den Flagellaten. Arch. Prot. 37: 31-64. 1916.

- Die braune Algenreihe Chrysophyceen. Arch. Prot. 52: 489-564. 1925.

. Eine Chrysomonade mit gestielten und verzweigten Kolonien. Arch.

Prot. 57: 319-330. 1927.

. Eine eigenartige rhizopodiale Flagellate. Arch. Prot. 63: 227-240. 1928.

Zur Verwandtschaft der Monadaceae mit den Chrysomonaden: eine

gehäusebewohnende, farblose Chrysomonade. Ann. Protistol. 2: 157-168. 1930.

. Uber die Verfestigung des Propoplasten im Gehäuse einer neuen Euglenine (Klebsiella). Arch. Prot. 73: 315-322. 1931.

Systematische Utbersicht über die mit Flagellaten in Zusammenhang stehenden Algenreihen und Versuch einer Einrichtung dieser Algenstämme in die Stämme des Pflanzenreiches. Beih. bot. Cebtralbl. 48, Abt. 2: 317-332. 1931. - Uber die Verbreitung endogener bezw. endoplasmatisch gebildeter Sporen bei den Algen. Beil. bot. Centralbl. 49, Abt. 1: 293-308. 1932.

- Über drei auffallend konvergente zu verschicdenen Algenreihen gehörende epiphytische Gattungen. Beih. bot. Centralbl. 49, Abt. 1: 549-568. 1932. Persoon, Christiaan Hendrik. Synopsis methodica Fungorum . . Göttingen. 1801. Perty, Maximilian. Zur Kenntniss kleinster Lebensformen . . B Bern. 1852.

Petersen, Hennig Eiler. Studien over Ferskvands-Phycomyceter. Bot. Tidsskr. 29: 345-440. 1909.

Petersen, Johs. Boye. Beiträgc zur Kenntnis der Flageliatengeisseln. Bot. Tidsskr. 40: 373-389. 1929.

Poche, Franz. Das System der Protozoa. Arch. Prot. 30: 125-321. 1913.

Pratje, Andre. Noctiluca miliaris Suriray. Beiträge zur Morphologie, Physiologie und

Cytologie. I. Morphologie und Physiologie (Bcobachtungen an der lebenden Zelle). Arch. Prot. 42: 1-98. 1921.

Prévot, André-Romain. Titudes de systématique bactérienne. Ann. Sci. Nat. Bot. sćr. 10, 15: 23-260. 1933.

Pribram, Emst. A contribution to the classification of microorganisms. Jour. Bact. 18: 361-394. 1929.

Pringsheim, N. Uber die Befruchtung der Algen. Monatsber. Akad. Wiss. Berlin 1855: 133-165. 1855.

Prowazek, Stanislas. Die Entwicklung von Herpetomonas. Arb. kaiserl. Gesundheitsante 20: 440-452. 1903.

Rabenhorst, Ludwig. Deutschland's Kryptogamen-Flora . . . 2 vols. Leipzig. 1844, 1847. 
Kryptogamen-Flora von Sachsen, der Ober Lausik, Thüringen und Nordböhmen . . . 2 vols. Leipzig. 1863, 1870.

and others. Dr. L. Rabenhorst's Kryptogamen-Flora von Deutschland,

Oesterreich und der Schweiz ... [ [construed as second edition of the work of 1844-1847.] 14 vols. Leipzig. 1879-1944.

Raper, John R. Tetrapolar sexuality. Quart. Rev. Biol. 28: 233-259. 1953.

Raper, Kenneth B. The communal nature of the fruiting process in the Acrasieae. American Jour. Bot. 27: 436-448. 1940.

Ratcliffe, H. L. Mitosis and cell division in Euglena spirogyra Ehrenberg. Biol. Bull. 53: 109-122. 1927.

Ritchie, Don. A fixation study of Russula emetica. American Jour. Bot. 28: 582-588. 1941.

Robertson, Muriel. Further notes on a trypanosome found in the alimentary tract of Pontobdella muricata. Quart. Jour. Micr. Sci. n. s. 54: 119-139. 1909.

Robinow, C. F. A study of the nuclear apparatus of bacteria. Proc. Roy. Soc. London B 130: 299-324. 1942.

- Cytological observations on bacteria. Proc. 6th Internat. Congr. Exp. Cytol. 204-207. 1949.

Rosenberg, Marie. Die geschlechtliche Fortpflanzung von Botrydium granulatum Grev. Oesterreichische Bot. Zeit. 79: 289-296. 1930.

Rosebury, Theodor, Richard W. Linton, and Leon Buchbinder. A comparative study of dental aciduric organisms and Lactobacillus acidophilus. Jour. Bact. 18: 395412. 1929.

Rosenvinge, L. Kolderup. The marine algae of Denmark. Vol. 1. Rhodophyceae. Mem. Acad. Roy. Sci. Lett. Danemark sér. 7, Sciences vol. 7. 1909-1931.

skr. $40: 72-80.1927$.

von Rostafinski, Joseph Thomas. Versuch eines Systems der Mycetozoen. Strassburg. 1873.

Rothmaler, Werner. Über das natürliche System der Organismen. Biol. Zentralbl. 67: 242-250. 1948.

Ruprecht, F. J. Tange des ochotskischen Meeres. in A. T. von Middendorf. Sibirische Reise, vol. 1, part 2: 193-435. 1851.

Ryan, Francis J., G. W. Beadle, and E. L. Tatum. The tube method of measuring the growth rate of Neurospora. American Jour. Bot. 30: 784-799. 1943.

Sabrosky, Curtis W., and Robert L. Usinger. Nomenclature of the human malaria parasites. Science 100: 190-192. 1944.

Saccardo, P. A. Sylloge Fungorum omnium hucusque cognitorum . . 25 vols. Padua. 1882-1931.

Sachs, Julius. Lehrbuch der Botanik. 4th ed. Leipzig. 1874. English translation by Alfred W. Bennett and W. T. Thistleton-Dyer. Oxford. 1875.

de Saedeleer, Henri. Beitrag zur Kenntnis der Rhizopoden . . Mém. Mus. Roy. Hist. Nat. Belgique 60: 1-112. 1934.

Salvin, S. B. Factors controlling sporangial type in Thraustotheca Primoachlya and Dictyuchus. American Jour. Bot. 29: 97-104. 1942.

Sartoris, George B. Studies in the life history and physiology of certain smuts. American Jour. Bot. 11: 617-647. 1924. 
Sauvageau, M. C. Sur le développement et la biologie d'une laminaire (Saccorhiza bulbosa). Compt. Rend. 160: 445-448. 1915.

Compt. Rend. 161: 796-799. 1915.

- Sur un nouveau type d'alternance de générations chez les algues brunes; les Sporochnales. Compt. Rend. 182: 361-364. 1926.

Savile, D. B. O. Nuclear structure and behavior in species of the Uredinales. American Jour. Bot. 26: 585-609. 1939.

Schaeffer, Asa Arthur. Taxonomy of the amebas with descriptions of thirty-nine new marine and freshwater species. Carnegie Inst. Publ. 345: 1-116. 1926.

Schaffner, John H. The classification of plants. IV. Ohio Naturalist 9: 446-455. 1909. Schaudinn, Fritz. Heliozoa. Thierreich Probelief.: 1-24. 1896.

Akad. Wiss. Berlin 1896: 31-41. 1896.

. Uber die Copulation von Actinophrys sol Ehrbg. Sitzber. Akad. Wiss. Berlin 1896: 83-89. 1896.

- Ueber das Centralkorn der Heliozoen, ein Beitrag zur Centrosomenfrage. Verhandl. deutscher zool. Gess. 1896: 113-130. 1896.

Jahrb. Abt. Anat. 13: 197-292. 1900.

Untersuchungen über die Fortpflanzung einiger Rhizopoden. Arb.

kaiserl. Gesundheitsamte 19: 547-576. 1902.

. Generations- und Wirtswechsel bei Trypanosoma und Spirochaete. Arb.

kaiserl. Gersundheitsamte 20: 387-439. 1903.

and Erich Hoffmann. Vorläufiger Bericht über das Vorkommen von

Spirochaeten in syphilitischen Krankheitsprodukten und bei Papillomen. Arb.

kaiserl. Gesundheitsamte 22: 527-534. 1905.

Scherffel, A. Phaeocystis globosa nov. spec. nebst einigen Beobachtungen über die

Phylogenie niederer, insbesonderer brauner Organismen. Wiss. Meeresunters.

n. f. 4, Abt. Heligoland: 1-29. 1900.

. Kleiner Beitrag zur Phylogenie einiger Gruppen niederer Organismen.

Bot. Zeit. 59: 143-158, 1901.

. Endophytische Phycomyceten-Parasiten der Bacillariaceen und einige

neue Monaden. Arch. Prot. 52: 1-141. 1925.

. Zur Sexualität der Chytridineen. Arch. Prot. 53: 1-58. 1925.

Schiller, Jos. Die planktonischen Vegetationen des adriatischen Meeres. A. Die Coccolithophoriden-Vegetationen in den Jahren 1911-14. Arch. Prot. 51: 1-130. 1925.

- Uber Fortpflanzung, geissellosse Gattungen und die Nomenklatur der Coccolithophoraceen nebst Mitteilung über Copulation bei Dinobryon. Arch. Prot. 53: 326-342. 1926.

Schmidt, Matthias. Makrochemische Untersuchungen ïber das Vorkonmen von

Chitin bei Mikroorganismen. Arch. Mikrobiol. 7: 241-260. 1936.

Schmitz, Fr. Untersuchungen über die Befruchtung der Florideen. Sitzber. kgl. preussischen $\Lambda$ kad. Wiss. 1883: 215-258. 1883.

- Systematische Ubersicht der bisher bekannten Gattungen der Floridecn.

Flora 72: 435-456. 1889.

Schneider, Aimć. Sur les psorospermes oviformes ou coccidies. Arch. Zool. Exp. Gen. 9: 387-404. 1881 . 
Schultz, E. S. Nuclear division and spore-formation in the ascus of Peziza domiciliana. American Jour. Bot. 14: 307-322. 1927.

Schultze, Max. Die Bewegung der Diatomen. Arch. mikr. Anat. 1: 376-402. 1865.

Schulze, Franz Eilhard. Rhizopodenstudien V. Arch. mikr. Anat. 11: 583-596. 1875.

Schünemann, Erich. Untersuchungen über die Sexualität der Myxomyceten. Planta 9: 644-672. 1930.

Schuurmans Stekhoven, J. H. Jr. Die Teilung der Trypanosoma brucei Plimmer u. Bradford. Arch. Prot. 40: 158-180. 1919.

Schwartz, E. J. The Plasmodiophoraceae and their relationship to the Mycetozoa and Chytridieae. Ann. Bot. 28: 227-240. 1914.

Schwendener, S. Ueber die Beziehung zwischen Algen und Flechtengonidien. Bot. Zeit. 26: 289-292. 1868.

Setchell, William Albert. Parasitic Florideae, I. Univ. California Publ. Bot. 6: 1-34. 1914.

and Nathaniel Lyon Gardner. The marine algae of the Pacific Coast of North America. Univ. California Publ. Bot. 8, parts 1-3. 1919-1925.

Bot. 7: 279-324. 1920.

Tokyo 323-329. 1926.

Sharp, Robert G. Diplodinium ecaudatum with an account of its neuromotor apparatus. Univ. California Publ. Zool. 13: 43-122. 1914.

Shear, C. L., and B. O. Dodge. Life histories and heterothallism of the red breadmold fungi of the Monilia sitophila group. Jour. Agr. Res. 34: 1019-1042. 1927.

Short, Robert B. Spindle twisting in the giant Amoeba. Science 102: 484. 1945.

von Siebold. C. Th., and H. Stannius. Lehrbuch der vergleichenden Anatomie. Berlin. vol. 1. 1848. vol. 2. 1846.

Simons, Etoile B. A morphological study of Sargassum filipendula. Bot. Gaz. 41: 161-182. 1906.

Sisler, Frederick D., and Claude E. ZoBell. Nitrogen fixation by sulfate-reducing bacteria indicated by nitrogen/argon ratios. Science 113: 511-512. 1951.

Sjöstedt, L. G. Floridean studies. Kgl. Fysiog. Sällsk. Handl. n. f. 37, no. 4: 1-95. 1926.

Skupienski, François-Xavier. Sur la sexualité chez les champignons myxomycètes. Compt. Rend. 165: 118-121. 1917.

- Sur le cycle évolutif chez un espèce de myxomycète endosporé, Didymium difforme (Duby). Etude cytologique. Compt. Rend. 184: 1341-1344. 1927.

Smith, Arlo I. The comparative histology of some of the Laminariales. American Jour. Bot. 26: 571-585. 1939.

Smith, Ernest C. Some phases of spore germination of Myxomycetes. American Jour. Bot. 16: 645-650. 1929.

Smith, Gilbert Morgan. A preliminary list of algae found in Wisconsin lakes. Trans. Wisconsin Acad. 18: 531-565. 1916.

19: 614-653. 1918.

. Phytoplankton of the inland lakes of Wisconsin. Wisconsin Geol. and Nat. Hist. Survey Bull. 57, part 1: 1-243. 1920; part 2: 1-227. 1924.

. The fresh-water algae of the United States. New York and London. 1933. Second edition. 1950. 
- Gryptogamic botany. 2 vols. New York and London. 1938.

- Marine algae of the Monterey Peninsula, California. Stanford University. 1944.

- (editor). Manual of phycology. Waltham, Massachusetts. 1951.

Smith, Theobald. Investigation of infectious diseases of domesticated animals. United States Dept. Agr. Bur. Anim. Ind. Ann. Reports 8 and 9: 45-70. 1893.

Snyder, William C., and H. N. Hansen. The species concept in Fusarium with reference to section Martiella. American Jour. Bot. 28: 738-742. 1941.

- The species concept in Fusarium with reference to Discolor and other sections. American Jour. Bot. 32: 657-666. 1945.

Solms-Laubach, Herman. Note sur le Janczewskia, nouvelle floridée parasite du Chondria obtusa. Mém. Soc. Nat. Sci. Nat. Cherbourg 21: 209-224. 1877.

Sonneborn, T. M. Sex, sex inheritance and sex determination in Paramecium aurelia. Proc. Nat. Acad. Sci. 23: 378-395. 1937.

Sparrow, Frederick K., Jr. A classification of aquatic Phycomycetes. Mycologia 34: 113-116. 1942.

Aquatic Phycomycetes. Ann Arbor. 1943.

Observations on chytridiaccous parasites of phanerogams. I. Physoderma Menyanthis de Bary. American Jour. Bot. 33: 112-118. 1946.

- Observations on chytridiaceous parasites of phanerogams. II. A preliminary study of the occurrence of ephemeral sporangia in the Physoderma disease of maize. American Jour. Bot. 34: 94-97. 1947.

- Obscrvations on chytridiaceous parasites of phanerogams. III. Physoderma Claytoniana and an associated parasite. Amcrican Jour. Bot. 34: 32.5-329. 1947.

Sprague, T. A. Standard-species. Kew Bull. 1926: 96-100. 1926.

Springer, Martha E. A morphologic study of the genus Monobiepharella. Imerican Jour. Bot. 32: 259-269. 1945.

Stakman, Elvin C. The nature and importance of physiologic specialization in phytopathogenic fungi. Science 105: 627-632. 1947.

_. Plant diseases are shifty enemies. American Scientist 35: 321-350. 1947.

Stanier, Roger Y., and C. B. van Niel. The main outlines of bacterial classification. Jour. Bact. 42: 437-466. 1941.

Stein, Friedrich. Ueber die Natur der Gregarinen. Arch. Anat. Phys. 1848: 182-223. 1848.

- Der Organismus der Infusionsthicre. 3 vols. Lcipzig. 1859-1883.

Steinccke, Fritz. Die Phylogenie der Algophyten. Schr. königsberger Gelehrt. Gcss. 8: 127-297. 1931 .

Stcvens, Edith. Cytological features of the life history of Gymnosporangium Junipcrivirginianac. Bot. Gaz. 89: 394-401. 1930.

Stevens, Frank Lincoln. The compound oospherc of Albugo Bliti. Bot. Gaz. 28: 149176, 225-245. 1899.

. Gamctogencsis and fertilization in Albugo. Bot. Gaz. 32: 77-98, 157169, 238-261. 1901.

1902.

- Studies in the fertilization of Phycomycetes. Bot. Gaz. 34: 420-425.

and A. C. Stevens. Mitosis of the primary nucleus in Synchytrinm decipiens. Bot. Gaz. 35: 405-415. 1903.

Stokes, John H. Schaudinn: a biographical appreciation. Science 74: 502-506. 1931. 
Strasburger, Eduard. Zur Entwicklungsgeschichte der Sporangien von Trichia fallax. Bot. Zeit. 42: 305-316, 321-326. 1884. 374.1897.

Strickland, Hugh Edwin, and others. Series of propositions for rendering the nomenclature of zoology uniform and permanent. Rept. 12th meeting British Assoc. 1842: 106-121. 1843.

Subrahmanyan, R. On somatic division, reduction division, auxospore-formation and sex differentiation in Navicula halophila (Grun.) Cl. Jour. Indian Bot. Soc. Iyengar Commemoration Volume: 239-266. 1947.

Svedelius, Nils. An evaluation of the structural evidences for genetic relationships

in plants: algae. Proc. Internat. Congr. PI. Sci. Ithaca 1: 457-471. 1929.
. Zytologisch-Entwicklungsgeschichtliche Studien über Galaxaura, eine diplobiontische Nemalionales-Gattung. Nova Acta Reg. Soc. Sci. Upsaliensis ser. 4, 13, no. 4: 1-154. 1942.

Swellengrebel, N. H. Zur Kenntnis der Cytologie von Bacillus maximus buccalis (Miller). Centralbl. Bakt. Abt. 2, 16: 617-628, 673-681. 1906.

54: 623-629. 1910.

Swezy, Olive. Binary and multiple fission in Hexamitus. Univ. California Publ. Zool. 16: 71-88. 1915.

-. The genera Monocercomonas and Polymastix. Univ. California Publ. Zool. 16: 127-138. 1916.

Swingle, Deane B. Formation of the spores in the sporangia of Rhizopus nigricans and of Phycomyces nitens. United States Dept. Agr. Bur. Pl. Ind. Bull. 37: 1-40. 1903.

Swingle, Walter T. Zur Kenntniss der Kern- und Zelltheilung bei den Sphacelariaceen. Jahrb. wiss. Bot. 30: 297-350. 1897.

Tatum, E. L., and T. T. Bell. Neurospora. III. Biosynthesis of thiamin. American Jour. Bot. 33: 15-20. 1946.

and Joshua Lederberg. Gene recombination in the bacterium Escherichia coli. Jour. Bact. 53: 673-684. 1947.

R. W. Barratt, Nils Fries, and David Bonner. Biochemical mutant strains of Neurospora produced by physical and chemical treatment. American Jour. Bot. 37: 38-46. 1950.

Taylor, William Randolph. Recent studies of Phaeophyceae and their bearing on classification. Bot. Gaz. 74: 431-441. 1922.

Thaxter, Roland. On the Myxobacteriaceae, a new order of Schizomycetes. Bot. Gaz. 17: 389-406. 1892.

. Contributions from the Cryptogamic Laboratory of Harvard University. XL. New or peculiar Zygomycetes. 2. Syncephalastrum and Syncephalis. Bot. Gaz. 24: 1-15. 1897.

- Contributions toward a monograph of the Laboulbeniaceae. Mem. American Acad. 12: 187-429. 1896; 13: 217-469. 1908; 14: 311-426. 1924; 15 : 427-580. 1926; 16: 1-435. 1931.

Theissen, F. Hemisphaeriales. Ann. Myc. 11: 468-469. 1913.

Thélohan, P. Observations sur les myxosporidies et essai de classification de ces organismes. Bull. Soc. Philomath. Paris sér. 8, 4: 165-178. 1892.

Thom, C'harles, and Margaret B. Church. The Aspergilli. Baltimore. 1926. 
and Kenneth B. Raper. A manual of the Aspergilli. Baltimore. 1945.

Thomas, R. C. Composition of fungus hyphae I. The Fusaria. American Jour. Bot. 15: 537-547. 1928.

Thompson, R. H. Immobile Dinophyceae. I. New records and a new species. American Jour. Bot. 36: 301-308. 1949.

Thuret, Gustave.Recherches sur les zoospores des algues. Ann. Sci. Nat. Bot. sér. 3, 14: 214-260. 1850.

- Recherches sur la fécondation des fucacées suivies d'observations sur les anthéridies des algues. Ann. Sci. Nat. Bot. sér. 4, 2: 197-214. 1854; 3: 5-28. 1855.

372-382. 1875.

van Tieghem, Ph. Sur la classification des basidiomycètes. Jour. de Bot. 7: 77-87. 1893.

Tilden, Josephine E. A classification of algae based on evolutionary development, with special reference to pigmentation. Bot. Gaz. 95: 59-77. 1933.

. The algae and their life relations. Minneapolis. 1935.

Tippo, Oswald. A modern classification of the plant kingdom. Chron. Bot. 7: 203206. 1942.

du Toit, P. J. Zur Systematik der Piroplasmen. Arch. Prot. 39: 84-104. 1918.

de Toni, J. B. Sylloge Algarum. 5 vols. Padua. 1889-1924.

Tseng, C. K. Utilization of seaweeds. Sci. Month. 59: 37-46. 1944.

. The terminology of seaweed colloids. Science 101: 597-602. 1945.

Tulasne, L.-R., and C. Tulasne. Mémoire sur les ustilaginées comparées aux urédinées. Ann. Sci. Nat. Bot. sér. 3, 7: 12-127. 1847.

Tulasne, R., and R. Vendrely. Demonstration of bacterial nuclei with ribonuclease. Nature 160: 225-226. 1947.

Turner, John P. Division and conjugation in Euplotes patella Ehrenberg with special reference to nuclear phenomena. Univ. California Publ. Zool. 33: 193-258. 1930.

Úlehla, Vladimir. Die Stellung der Gattung Cyathomonas From. im System der Flagellaten. Ber. deutschen bot. Gess. 29: 284-292. 1911.

Vanterpool, T. C., and G. A. Ledingham. Studies on "browning" root rot of cereals I. The association of Lagena radicicola n. gen.; n. sp., with root injury in wheat. Canadian Jour. Res. 2: 171-194. 1930.

Vlk, Vladimir. Uber die Struktur der Heterokontengeisseln. Beih. bot. Centralbl. 49, Abt. 1: 214-220. 1931.

. Uber die Geisselstrukutur der Saprolegnieenschwärmer. Arch. Prot. 92: 157-160. 1939.

Vokes, Margaret Martin. Nuclear division and development of sterigmata in Coprinus atramentarius. Bot. Gaz. 91: 194-205. 1931.

Vuillemin, Paul. Remarques sur les affinités des basidiomycètes. Jour. de Bot. 7: 164174. 1893.

Wager, Harold. The life-story and cytology of Polyphagus Euglenae. Ann. Bot. 27: 173-202. 1913.

Walker, Leva B. Studies on Ascoidea rubescens-II. Cytological observations. Mycologia 27: 102-127. 1935.

Wallengren, Hans. Studier öfver ciliata infusorier II. Acta Univ. Lundensis 31, part 2, no. 7: 1-72. 1895. 
Wehmeyer, Lewis E. A biologic and phylogenetic study of the stromatic Sphaeriales. American Jour. Bot. 13: 575-645. 1926.

Weimer, J. L. Some observations on the spore discharge of Pleurage curvicolla (Wint.) Kuntze. American Jour. Bot. 7: 75-77. 1920.

Weiser, Jaroslav. A new classification of the Schizogregarina. Jour. Protozool. 2: 6-12. 1955.

Weisz, Paul B. Morphogenesis in protozoa. Quart. Rev. Biol. 29: 207-229. 1954.

Wenyon, Charles Morley. Some observations on a flagellate of the genus Cercomonas. Quart. Jour. Micr. Sci. n. s. 55: 241-260. 1910.

2 vols. London. 1926.

West, G. S. A treatise on the British freshwater algae. Cambridge. 1904.

von Wettstein, Richard. Handbuch der systematischen Botanik. 2 vols. Leipzig and Wien. 1901-1908.

Whelden, Roy M. Cytological studies in the Tremellaceae II. Exidia. Mycologia 27: 41-57. 1935.

Wichterman, Ralph. Cytogamy: a new sexual process in joined pairs of Paramecium caudatum. Nature 144: 123-124. 1939.

- Cytogamy: a sexual process occurring in living joined pairs of Paramecium caudatum and its relation to other sexual phenomena. Jour. Morph. 66: 423-451. 1940.

Williams, A. E., and R. H. Burris. Nitrogen fixation by blue-green algae and their nitrogenous composition. American Jour. Bot. 39: 340-342. 1952.

Williams, J. Lloyd. Reproduction in Dictyota dichotoma. Ann. Bot. 12: 559-560. 1898.

Willstätter, Richard, and Arthur Stoll. Untersuchungen über Chlorophyll. Methoden und Ergebnisse. Berlin. 1913.

Wilson, C. M. Cytological study of the life history of Dictyostelium. American Jour. Bot. 40: 714-718. 1953. 743-749. 1955.

Wilson, Harriet L. Gracilariophila, a new parasite on Gracilaria confervoides. Univ. California Publ. Bot. 4: 75-84. 1910.

Wilson, H. V. Notes on a species of Pelomyxa. American Nat. 34: 535-550. 1900.

Wilson, Thomas B., and John Cassin. On a third kingdom of organized beings. Proc. Acad. Nat. Sci. Philadelphia 1863: 113-121. 1864.

Winogradsky, Sergius. Ueber Schwefelbacterien. Bot. Zeit. 45: 489-507, 513-523, 529-539, 545-559, 569-576, 585-594, 606-610. 1887.

213-231, 257-275, 760-771. 1890.

. Clostridium Pastorianum, seine Morphologie und seine Eigenschaften als Buttersäureferment. Centralbl. Bakt. Abt. 2, 9: 43-54, 107-112. 1902.

Winslow, C.-E. A., Jean Broadhurst, R. E. Buchanan, Charles Krumweide Jr., L. A. Rogers, and George H. Smith. The families and genera of bacteria. Jour. Bact. 2: 505-566. 1917.

Winter, F. W. Zur Kenntnis der Thalamophoren. Arch. Prot. 10: 1-113. 1907.

Wolters, Max. Die Conjugation und Sporenbildung bei Gregarinen. Arch. mikr. Anat. 37: 99-138. 1891.

Woodcock, H. M. The haemoflagellates: a review of present knowledge reiating to the trypanosomes and allied forms. Quart. Jour. Micr. Sci. n. s. 50: 151-331. 1906. 
On the occurrence of nuclear dimorphism in a Halteridium parasitic in the chaffinch, and the probable connection of this parasite with a trypanosome. Quart. Jour. Micr. Sci. n. s. 53: 339-349. 1909.

- Studies on avian haematoprotozoa. I. On certain parasites of the chaffirch (Fringilla coelebs) and the redpoll (Linota rufescens). Quart. Jour. Micr. Sci. n. s. 55: 641-740. 1910.

Woodruff, Lorande Loss, and Rhoda Erdmann. A normal periodic reorganization process without cell fusion in Paramaecium. Jour. Exp. Zool. 17: 425-520. 1914. 436-438. 1926.

Woronin, M. Plasmodiophora Brassicae, Urheber der Kohlpflanzen-Hernic. Jahrb. wiss. Bot. 11: 548-574. 1878.

Yamanouchi, Shigeo. The life history of Polysiphonia violacea. Bot. Gaz. 41: 425433. 1906.

- The life history of Polysiphonia violacea. Bot. Gaz. 42: 401-449. 1906. - Mitosis in Fucus. Bot. Gaz. 47: 173-197. 1909.

. The life history of Cutleria. Bot. Gaz. 54: 441-502. 1912.

Young, Edward Lorraine, III. Studies on Labyrinthula. The etiologic agent of the wasting disease of eel-grass. Amreican Jour. Bot. 30: 586-593. 1943.

Zederbauer, E. Geschlechtliche und ungeschlechtliche Fortpflanzung von Ceratium hirundinella. Ber. deutschen bot. Gess. 22: 1-8. 1904.

Ziegler, A. W. Meiosis in the Saprolegniaceae. American Jour. Bot. 40: 60-66. 1953.

ZoBell, Glaude E. The term "pillbox" for describing diatoms. Chron. Bot. 6: 389. 1941.

Zopf, Wilhelm. Die Pilzthicre oder Schlcimpilze. Breslau. 1885. zugleich ein Beitrag zur Phytopathologie. Lcipzig. 1885.

Zuelzer, Margarethe. Bau und Entwicklung von Wagnerella borealis Mereschk. Arch. Prot. 17: 135-202. 1909. 


\section{INDEX}

\section{OF NAMES OF ORGANISMS AND GROUPS}

Absidia, 123, 124

Acantharia, 189, 190, 195, 196, 197

Acanthochiasma, 197

Acanthocystida, 191, 193

Acanthocystidae, 193

Acanthocystis, 193

Acanthometra, 195, 197

Acanthometren, 197

Acanthometrida, 197

Acanthometron, 197

Acanthonida, 197

Acanthophracta, 195, 197

Acanthorhynchus, 218

Acanthospora, 218

Acanthosporida, 218

Acanthosporidae, 218

Acaulopage, 124

Acephalina, 215

Acervulina, 187

Acervulinida, 187

Acetobacter aceti, 24

Acetobacteriacea, 20, 24

Acctobacteriaceae, 24

Achlya, 70, 79

Achlya caroliniana, 78

Achlyogeton, 118

Achlyogetonacea, 115, 117

Achlyogetonaceae, 117

Achnanthea, 76

Achnantheae, 76

Achnanthes, 76

Achnanthaceac, 76

Achromatiacea, 33

Achromatiaceae, 33

Achromatium, 33

Achromatium oxaliferum, 32, 33

Achromobacter, 22

Achromobacteriacea, 19, 21

Achromobacteriaceae, 21

Acineta, 235

Acinetae, 235

Acinetaria, 235

Acinetida, 235

Acinetidae, 235

Acinetina, 235

Acinetoidea, 235

Acnidosporidea, 207

Acrasidae, 203

Acrasina, 203

Acrasis, 203

Acrita, 37

Acrochaetiacea, 47

Acrochaetiaceae, 47

Acrochaetium, 47

Actinelius, 197

Actinellida, 197
Actiniscea, 61, 62

Actinisceae, 62

Actinocephalida, 217, 218

Actinocephalidae, 218

Actinocephalus, 218

Actinolophus, 193

Actinomma, 195

Actinomma Asteracanthion, 196

Actinomonadida, 191

Actinomonadidae, 191

Actinomonas, 190, 193

Actinomyces Bovis, 25

Actinomycetaceae, 25

Actinomycetalea, 18, 24

Actinomycetales, 24

Actinomyxida, 219, 221

Actinophryida, 191, 193

Actinophryidae, 193

Actinophrys, 193

Actinophrys Sol, 193

Actinopoda, 189

Actinopodea, 189

Actinosphaerium, 193

Actinosphaerium Eichhornii, 192, 193

Actipylea, 195, 197

Actipyleen, 195

Actipylida, 197

Actipylina, 197

Acystosporidia, 190

Acyttaria, 179

Adelea, 211

Adeleida, 211, 212

Adeleidae, 211

Adeleidea, 211

Adeleina, 211

Adeleoidae, 211

Adelina, 211

Adinida, 98, 99

Adiniferidea, 96, 98

Aecidium, 147

Acrobacter aerogenes, 22

Agaricacea, 151, 153

Agaricaceac, 150, 151

Agaricales, 150

Agaricini, 151

Agaricus campestris, 119, 145, 152, 153

Agarics, 152

Aggregata, 209

Aggregata Eberthi, 210

Aggregatida, 210, 212

Aggregatidae, 210

Aglaozonia, 88

Agrobacterium, 23

Agrobacterium tumefaciens, 23

Agrostis, 148

Agyriales, 137 
Agyrium, 137

Ahnfeldtia, 49

Akinetocystida, 216

Akinetocystidae, 216

Akinetocystis, 216

Akinetosporeae, 86

Albuginacea, 80, 81

Albuginaceae, 81

Albugo, 80, 81

Albugo Bliti, 80

Albugo Tragopogonis, 80

Alcaligenes fecalis, 22

Aleuria rutilans, 136

Algae, 9, 10, 69, 113, 118, 120, 177, 224

Algae, bluc-green, 2, 3, 12, 13, 14, 17, 30, $37,41,117,118$

Algae, brown, 39, 69, 53, 179, 203

Algae, green, $38,41,53,69,82,117,118$, 128,203

Algae, red, 37, 39, 41, 82, 128, 140

Algae Zoosporeae, 86

Algen, 29, 120

Allantocystida, 216

Allantocystidae, 216

Allantocystis, 216

Allogromia, 183

Allogromiida, 183

Allogromiidae, 183

Allomorphina, 187

Allomyces, 111, 112, 113, 118

Allomyces anomalus, 116

Allomyces Arbuscula, 112, 115

Allomyces cystogenes, 112

Allomyces javanicus, 112,114

Almond, 141

Alvcolina, 185

Alveolinea, 185

Alveolinella, 185

Alveolinellidae, 185

Alveolinida, 185

Alveolinina, 185

Alternaria, 142

Alwisia, 175

Amanita, 152

Amanita muscaria, 152

Amaurochaetacea, 174, 175

Amaurochactaceae, 175

Amaurochaete, 175

Amauroc hacteae, 171

Amaurochactidae, 175

Amaurosporales, 171

Amiba diffluens, 37, 157, 201

Amiba divergens, 202

Ammodiscida, 185

Ammodiscidac, 185

Ammodiscus, 185

Ammodochidac, 62

Amocba, 71, 118, 124, 157, 189, 201

Anotha Proteus, 202

Amorisen, 201

Amoctida, 10, 201

Amoctidar, 10,201
Amoebina, 201

Amoebodiniaceae, 101

Amoebogeniac, 219

Amoebosporidia, 215

Amoebosporidies, 215

Amoebosporidiidae, 215

Amorphoctista, 37

Amorphozoa, 37

Amphibia, 220

Amphiacantha, 219

Amphiamblys, 219

Amphidinium, 101

Amphilonche, 197

Amphilothida, 103

Amphimonadaceae, 61, 158

Amphimonadidae, 61

Amphisolenia, 103

Amphisolenia laticincta, 104

Amphistcgina, 187

Amphistomina, 191

Anabaena, 35

Anabaena circinnalis, 13

Anabaena inaequalis, 32

Ancylistales, 81

Ancylistes, 125

Ancylistinaeae, 81

Ancmeae, 171

Angiococcus, 28

Angiogastres, 152

Angiospermeae, 82, 91

Animacule, 18

Animal kingdom, Animalia, Animals, 1, 2, $4,6,10,68,95,111,113,159,163$, $167,206,214,220,223,231,233,235$

Anisochytridiales, 69

Anisochytrids, 57

Anisolpidiaceae, 69

Anisoplidium, 69

Anisolpidium Ectocarpii, 70

Anisonema, 109

Anisonema truncatun, 108

Anisonemida, 105, 108

Anisonemidae, 108

Anisonemina, 108

Anomalinidae, 187

Anopheles, 213

Anoplophryida, 230

Anoplophryinea, 229, 230

Anthophysis, 59

Anucleobionta, 6, 12

Ape, 213

Aphanizomenon, 35

Aphanomycopsis, 81

Aphrothoraca, 190, 193

Aphrothoracida, 190

$\Lambda$ planosporcac, 86

Aplosporidies, 218

Apodachlya, 79

Apodachlyella, 79

Apodinidae, 102

Apodinium, 102

Appendiculatae, $7: 3$ 
Apple, 139, 148

Araceae, 67

Arachnula, 191

Araiospora, 79

Arcella, 205

Arcellidae, 205

Arcellina, 205

Archaelagena, 186

Archaias, 184, 185

Archangiacea, 28

Archangiaceae, 28

Archangium, 28

Archegregarina, 215

Archephyta, 17

Archezoa (of Haeckel), 17

Archezoa (of Perty), 223

Archi-Monothalamia, 183

Archimycetae, 110

Archimycetes, 110, 111

Archiplastidea, 18, 29

Archiplastideae, 30

Arcyria, 176

Arcyriacea, 174, 176

Arcyriaceae, 176

Arcyriidae, 176

Arthropods, 211, 212, 222

Arthrospira, 35

Asclepiadaceae, 161

Ascobolacea, 135

Ascochyta, 141

Ascocorticium, 137, 145

Ascocyclus, 88

Ascoidea, 130

Ascoidea rubescens, 127

Ascoideaceae, 130

Ascomycetae, 125

Ascomycetes, $120,125,140,142,145$

Ascomyceten, 125

Ascosporeac, 125

Askcleta, 193

Aspergillus, 130, 131

Asper illiales, 130

Aspidisca, 232

Aspirotricha, 229

Aspirotrichaceae, 229

Astasia, 96, 107

Astasiaceae, 107

Astasiaca, 96, 105, 107

Astasiidae, 107

Astasina, 107

Asterigerina, 187

Asterigerinida, 187

Asterigerinidae, 187

Asterocyclina, 188

Asterocystis, 43

Asterophlyctis, 117

Astcma, 94, 96, 105

Astomaticae, 74

Astomina, 230

istraranthida, 199

Astracanthidae, 199

Astrodisculus, 193
Astrolophida, 197

Astrolophus, 197

Astrorhiza, 183

Astrorhizida, 183

Astrorhizidaceae, 183

Astrorhizidac, 183

Astrorhizidea, 183

Astrorhizina, 183

Ataxophragmidae, 186

Ataxophragmidea, 186

Ataxophragmium, 186

Athene noctua, 162

Aulacantha, 199

Aulacanthida, 199

Aulacanthidae, 199

Aulactinium, 199

Aulesphaera, 199

Aulosphaerida, 199

Auricularia, 146

Auricularia Auricula, 146

Auriculariacea, 146, 148

Auriculariaceae, 146

Auriculariales, 146

Auriculariineae, 145, 146

Auricularineae, 146

Autobasidiomycetes, 146

Aves, 6

Axonoblasteae, 51

Azoosporidae, 191

Azoosporidca, 191

Azoosporidia, 190

Azotobacter, 14

Azotobacter Chroococcum, 23

Azotobacteriacca, 19, 23

Azotobacteriaceae, 23

Babesia, 214

Babesia bigemina, 206, 212, 214

Babesiida, 211, 214

Babesiidae, 214

Bacillacea, 19, 21

Bacillacei, 21

Bacillaria, 69, 75

Bacillariacea, 11, 55, 65, 69, 72

Bacillariaceae, 71

Bacillariales, 53, 71

Bacillarieae, 71

Bacillarioidcae, 71

Bacillariophyceac, 71

Bacillariophyta, 71

Bacillus, 21

Bacillus alvei, 21

Bacillus Amylobacter, 21

Bacillus anthracis, 21

Bacillus, colon, 22

Bacillus, gas, 22

Bacillus Radicicola, 23

Bacillus, Shiga, 22

Bacillus subtilis, 18, 21

Bacteria, 2, 3, 4, 6, 7, 12, 13, 14, 17, 18, $30,38,118,119,189,222,224,231$ 
Bacteriaceae, 21

Bacteriophyta, 17

Bacteroides, 22

Badhamia, 177

Balantidium, 230

Balantidiunı coli, 230

Bangia, 43

Bangia fuscopurpurea, 43

Bangiacea, 41

Bangiaceae, 41, 43

Bangialea, 40, 41, 52

Bangiales, 41

Bangieae, 41

Bangiincae, 41

Bangioideae, 41

Barbulanympha, 169

Barley, 6

Barrouxia, 210

Bartonella bacilliformis, 21, 214

Bartonellaceae, 20

Bartramia, 219

Bartramiidae, 218

Basidiobolacea, 125

Basidiobolaceae. $125^{\circ}$

Basidiobolus, 119, 121

Basidiobolus ranarum, 125

Basidiomycetae, 142

Basidiomyceten, 142

Basidionycetes, 121, 127, 128, 141, 142, 145

Basidiosporeae, 142

Bathysiphon, 183

Batrachospcrmaceae, 47

Batrachospcrmum, 47

Bdellospora, 124

Beetles, 177, 215, 217

Beggiatoa, 24, 30, 31, 32, 35

Beggiatoacea, 34, 35

Beggiatoaceae, 35

Bicoecaccae, 67

Bicoecidea, 67

Bicoekida, 67

Bicosocca, 67

Biddulphia, 74

Biddılphiaccae, 74

Biddulphica, 74

Biddulphicae, 74

Biflagellatae, 76

Bikoecidae, 67

Bikoccina, 67

Birds, 6, 210, 212, 213

Bitunicatac, 129

Blakeslecit, 12.4

Blastocaulis, 26, 27

Blastorladia, 112, 113

Blastocladiacea, 110, 112

Blastocladiaceac. 112

Blastocladiales, 111

Blastocladiella, 112, 113

Blastocladiella cystogena, 115

Blastocladiineae, 111

Blastoderma, 130
Blastodinida, 100, 102

Blastodinidae, 102

Blastodinides, 102

Blastodinium, 102

Blastosporaceae, 44

Blepharisma, 230

Blue grass, 148

Blue-green algae, see Algae, Blue-green

Bodo, 159, 160, 199, 209, 212

Bodo edax, 161

Bodo Lacertae, 159

Bodonaceae, 159

Bodonidac, 159

Bodonidca, 158

Bodonina, 159

Boletus, 151

Bolivina, 188

Borelis, 185

Borrelia, 29

Borrelia recurrentis, 28,29

Borrelia Vincenti, 29

Botrida, 198

Botrydiaceae, 67

Botrydiales, 63

Botrydiopsis, 66

Botrydium, 65, 67

Botryococcacea, 65, 66

Botryococcaceae, 66

Botryococcus, 66

Botryoglossum, 52

Botryoidea, 198

Botrytis, 140, 142

Bovista, 155

Braadrudosphaeridae, 60

Brachycystida, 217

Brefeldia, 175

Brefeldiaceac. 175

Brefeldiidae, 175

Brehmiella, 59

Brchmiella chrysohydra, 54

Brown algae, sce Algae, Brown

Brucella, 22

Bulgariacea, 135

Bulimina, 188

Buliminida, 188

Buliminina, 188

Bumilleria, 66, 73

Bursaria, 230

Bursariidae, 230

Bursarina, 230

(abbage, 178

Calcarcae, 171

Calcarina, 187

Calcarinidae, 187

Calciconus, 60

Calciconus vitreus, 56

Calcisolenia, 60

Calcisolenidae, 60

Callocolax, 50

(a)lopluyllis, 50 
Calonectria, 142

Calonema, 177

Calonemeae, 171

Calonympha, 168

Calonymphida, 166, 167, 168

Calonymphidae, 168

Calothrix, 36

Calvatia, 155

Calyptosphaera, 60

Calyptosphaera insignis, 56

Camerina, 188

Camerinidae, 188

Camptonema, 193

Camptonematidae, 193

Campuscus, 191

Candida, 142

Cannobotryida, 198

Cannopilus, 63

Cannosphaerida, 199

Cannosphaeridae, 199

Cantharellales, 150

Carageen, 49

Carboxidomonas, 24

Carchesium, 233

Carchesium polypinum, 225

Carpomitra, 88

Carpomycetae, 119

Carpophyceae, 40

Carposporeen, 128

Caryococcus, 21

Caryospora, 210

Caryotropha, 211

Cassidulina, 188

Cassidulinida, 188

Cassidulinidae, 188

Castanellida, 200

Castanellidae, 200

Castanidium, 200

Cat, 6, 210

Catenariopsis, 69

Catenochytridium, 118

Cattle, 206, 214

Caulleryella, 215

Caulleryellidae, 215

Caulobacter, 26, 27

Caulobacter vibrioides, 26

Caulobacteriacea, 27

Caulobacteriaceae, 27

Caulobacterialea, 18, 25, 26

Caulobacteriales, 25

Cayeuxina, 186

Cellulomonas, 22

Cenolarcus, 195

Centipedes, 207, 210, 211

Centricae, 73, 74

Cepedia, 229

Cephalina, 217

C'éphalopodes, 182

Cephalothamnium, 59

Cephalothamnium Cyclopum, 54

Cephalotrichinae, 18

Ceramiales, 51
Ceramiea, 51, 52

Ceramieae, 51

Ceratiidae, 103

Ceratiomyxa, 177, 221

Ceratiomyxa fruticulosa, 177, 178

Ceratiomyxacea, 177

Ceratiomyxaceae, 177

Ceratium (dinoflagellate), 103

Ceratium (myxomycete), 177

Ceratium Hirundinella, 103

Ceratomyxa, 221

Ceratomyxidae, 221

Ceratophyllus fasciatus, 160

Ceratospora, 216

Cercobodo, 159

Cercobodonidae, 159

Cercomonadida, 159

Cercomonadidae, 159

Cercomonadinea, 158

Cercomonas, 159, 161

Cercomonas Davainei, 165

Cercomonas Hominis, 165

Cercomonas longicauda, 160

Cercomonas obliqua, 165

Cercospora, 138, 139, 142

Chaenia, 229

Chaetangieae, 47

Chactoceraceae, 74

Chaetoceros, 74

Chaetocladiaceae, 124

Chaetocladium, 123, 124

Chaetoproteida, 159, 163

Chaetoproteidae, 163

Chaetoproteus, 158, 160, 163, 202

Chaidae, 201

Chaidea, 201

Chalarothoraca, 190, 193

Chalarothoracida, 190

Challengerida, 200

Challengeridae, 200

Challengeron, 200

Chamaesiphon, 35, 36

Chamaesiphon incrustans, 32

Chamaesiphonacea, 34, 35

Chamaesiphonaceae, 33, 35

Champia, 51

Champiea, 51

Champieae, 51

Chantransia, 47

Chantransiaceae, 47

Chaos Protheus, 200, 201, 202

Chaosidae, 201

Chapmania, 187

Chapmaniida, 187

Chapmaniidae, 187

Characiopsis, 66

Characiopsis gibba, 64

Chestnut, 139

Chiastolida, 197

Chiastolus, 197

Chicken, 210

Chilodon, 230 
Chilodon uncinatus, 225

Chilodontida, 230

Chilomastigidae, 165

Chilomastix, 165

Chilomastix davainei, 165

Chilomastix Hominis, 165, 237

Chilomastix Mesnili, 165

Chilomonadaceae, 98

Chilomonas, 94, 109

Chilomonas Paramaecium, 97

Chilostomella, 187

Chilostomellida, 187

Chilostomellidae, 187

Chlamydodon, 230

Chlamydodonta, 230

Chlamydodontida, 230

Chlamydodontidae, 230

Chlamydomonas, 61, 111

Chlamydomyxa, 191

Chlamydomyxidea, 190

Chlamydophora, 190, 193

Chlamydophorida, 190

Chlamydothrix ochracea, 32, 36

Chlamydotrichacea, 34

Chlamydotrichaceae, 36

Chlamydozosceae, 20

Cihloramoeba, 66

Chloramoeba heteromorpha, 64

Chloramoebacea, 65, 66

Chloramoebaceac, 66

Chloramoebidae, 66

Chlorarachnidae, 66

Chlorobacteriaceae, 31

Chlorobacterium, 33

Chlorobiacea, 31, 237

Chlorobium, 31

Chlorobotrydiaceae, 66

Chlorochromonas, 66

Chlorochytridion, 111

Chloromonadaccae, 109

Chloromonadales, 63, 105

Chloromonadida, 105

Chloromonadidae, 109

Chloromonadina, 63, 96, 105

Chloromonadinae, 94, 105

Chloromonadineac, 105

Chloromonads, 94

Chloromyxca, 221

Chloromyxées, 221

Chloromyxida, 221

(hloromyxidac, 221

Chloromyxum, 2?1

Chlorosaccacea, 6.5

Chlorosaccaceac, 65

Chlorosaccus, 55, 65, 66

Chlorosaccus fluidus, 6.1

Chlorotheciacea, 65, 66

Chlorotheciaceae, 66

Choanephoracear, 124

Choano-Flagellata, 67

Choanocystidac, 194

Choanocystis, 194, 216
Choanoflagellata, 57, 61, 67, 68

Choanoflagellates, 57, 158

Choanosporidae, 216

Chondria, 52

Chondrieae, 51

Chondrioderma, 177

Chondrococcus, 28

Chondromyces, 28

Chondromyces aurantiacus, 26

Chondromyces crocatus, 26

Chondrus, 51

Chondrus crispus, 49

Chonotricha, 230, 231, 237

Chonotrichida, 230

Chordariacca, 88

Chordariaceae, 87

Chordariales, 87

Chordarieae, 87

Chromatiacea, 31, 237

Chromatiaceae, 31

Chromatium, 31

Chromobacterium, 22

Chromomonas, 98

Chromulina, 61, 62

Chromulina Pascheri, 56

Chromulinaceae, 62

Chromulinales, 61

Chromulinidae, 62

Chroococcacea, 33

Chroococcaceae, 33

Chroococcales, 33

Chroococcus, 32, 33

Cihrysamoeba, 63

Chrysamoebida, 62, 63

Chrysamoebidae, 63

Chrysapsis, 62

Cihrysarachniaceae, 63

Chrysarachnion, 63

Chrysidella, 98

Chrysocapsa, 59

Cihrysocapsa paludosa, 54

Chrysocapsacea, 58, 59

Chrysocapsaceac, 59

Chrysocapsales, 61

Chrysocapsidae, 59

Chrysocapsina, 61

Chrysocapsinae, 61

Chrysocapsineac, 55, 61

Chrysochromulina, 58

Chrysococcus, 62

Cinrysocrinus, 63

Chrysodendron, 59

Chrysomonadaceac, 59

Chrysomonadales, 61

Chrysomonadida, 61

Chrysomonadidac, 62

Chrysomonadina, 59, 61, 62

Chrysomonadinac, 61

Chrysomonadinea, 57

Chrysomonadineate, 55, 57, 61

Chrysomonads, 53, 83

Chrysomonas, 62 
Chrysophaeum, 109

Chrysophyceae, 53, 55, 95

Chrysophycophyta, 53

Chrysophyta, 53

Chrysopyxis, 60

Chrysosphaera, 62

Chrysosphaeracea, 61, 62

Chrysosphaeraceae, 62

Chrysosphaerales, 61

Chrysosphaerella, 62

Chrysosphaerineae, 55, 61

Chrysospora, 62

Chrysothylakion, 63

Chrysotrichaceae, 60

Chrysotrichales, 61

Chrysotrichineae, 55, 61

Chytridiacea, 117, 118

Chytridiaceae, 110, 118

Chytridiales, 113

Chytridieae, 110

Chytridieen, 110, 118

Chytridineae, 110

Chytridinae, 110

Chytridinea, $111,113,116$

Chytridineac, 110, 113

Chytridium, 69, 110, 113, 118

Chytridium Olla, 110

Chytrids, 76, 110, 111, 119, 121, 125, 130, 178

Chytriodinium, 102

Cienkowskiaccae, 177

Ciliata, 223, 228, 233

Ciliatea, 228

Cilio-flagellata, 94

Cilioflagellata, 96, 102

Ciliophora, 39, 223, 237

Ciliophryidae, 191

Ciliophrys, 193

Circoporida, 200

Circoporidae, 200

Circoporus, 200

Cladochytriacea, 115, 117

Cladochytriaceae, 117

Cladochytrium, 110, 117

Cladococcida, 195

Cladococcus, 195

Cladopyxida, 103

Cladosporium, 142

Cladothrix dichotoma, 33

Clastoderma, 175

Clathracea, 155

Clathraceae, 155

Clathrochloris, 31

Clathrulina, 194

Clathrulinida, 191, 194

Clathrulinidae, 194

Claudea, 51

Clavaria, 151

Clavariacea, 151

Clavariaceae, 151

Clavariei, 151

Clavati, 150
Claviceps purpurea, 139

Clonothrix fusca, 32,36

Closterium, 125

Clostridium, 21

Clostridium botulinum, 21

Clostridium butyricum, 21

Clostridium Pastorianum, 21

Clostridium septicum, 21

Clostridium tetani, 21

Cnemidospora, 217

Cnidosporidea, 219

Cnidosporidia, 219, 220

Coccaceac, 20

Coccidia, 207, 210

Coccidians, 260, 209, 210, 212, 215

Coccididae, 210

Coccidiidea, 210

Coccidiomorpha, 207, 210

Coccidium, 210

Coccidium Schubergi, 207

Coccogonales, 33

Coccogonea, 31, 32, 33

Coccogoneae, 33

Coccolithaceae, 60

Coccolithidae, 60

Cocclithina, 60

Coccolithophora, 60

Coccolithophoridae, 55, 60

Coccolithus, 60

Coccomyces, 134

Coccomyxa, 221

Coccomyxida, 221

Coccomyxidae, 221

Cocconeidaceae, 76

Cocconeis, 72, 73, 76

Cocconemaceae, 75

Cocconcmidae, 222

Coccosphaera, 60

Coccospora Slavinae, 222

Coccosporida, 222

Coccosporidae, 222

Coccus, 20

Cochliodinium, 101

Cochliopodiidae, 202

Cochliopodium, 202

Cochlonema, 124

Cockroach, 169, 217, 219

Codonoecina, 67

Codonosiga, 67

Codonosigidae, 67

Codosiga, 67

Coeloblastca, 46

Cocloblasteae, 51

Coclodendrida, 200

Coelodendrum, 199, 200

Coelomonadina, 105, 109

Coelosphaerium, 33

Coelosporidiidae, 218

Coelosporidium, 219

Coenenia, 203

Cofiec, 148

Colaciacea, 105 
Colaciaceae, 105

Colaciidae, 105

Colacium, 105

Colacium Arbuscula, 106

Coleosporiacea, 148

Coleosporiaceae, 148

Coleosporium, 143

Coleosporium Vernoniae, 143

Colepina, 229

Coleps, 229

Colletotrichum, 139, 140

Collida, 195

Collodaria, 194

Colloderma, 177

Collodermataceae, 177

Collosphaera, 195

Collosphaera Huxleyi, 196

Collosphaerida, 195

Collozoida, 195

Colpidium campylum, 227

Colpoda, 229

Colpodaea, 229

Colpodella, 189

Colpodidae, 229

Columniferae, 171

Comatricha, 175

Completoria, 125

Compsopogon, 44

Compsopogonacea, 41,44

Compsopogonaceae, 44

Concharida, 200

Concharidae, 200

Conchulina, 205

Conferva, 66

Confervaceae, 66

Confervales, 63

Confervoidea, 63

Conger niger, 161

Conidiobolus, 125

Coniferinae, 9

Conifers, 148

Coniomycetes, 140

Conjugatae, 117

Conradiella, 62

Coprinus, 143, 152

Coprinus atramentarius, 153

Copromonas subtilis, 108

Cora, 151

Corallinaccae, 50

(iorallinea, 50

Corallineae, 50

Cordyceps, 139

(Corcocolax, 50

Corethron, 74

Cormobionta, 6

Cornuspira, 185

Coronympha, 168

Corticium, 151

Corynebacteriacca, 19, 20

Corynebacteriaccac, 20

(Corynbacteriidac, 20

Coryndbacterium, 20, 21
Corynebacterium diphtheriae, 20

Coryneum, 141

Coryneum Beijerinckii, 141

Coscinodiscaccae, 74

Coscinodiscea, 74

Coscinodiscus, 74

Costia, 165

Costiidae, 165

Cothurnia, 233

Councilmania, 203

Crab, 218

Craigia, 163

Craspedomonadaceae, 67

Craspedomonadina, 67

Craspedotella, 102

Craterellus, 151

Craterium, 177

Crenothrix polyspora, 32,36

Crenotrichacea, 35, 36

Crenotrichaceae, 36

Cribraria, 175

Cribrariacca, 173, 175

Cribrariaceae, 171, 175

Cribrariales, 171, 173

Cribrariidae, 175

Cribrospira, 186

Cristellaria, 187

Cristispira, 29

Cristispira Veneris, 26

Crithidia, 162

Cromodromys, 199

Cronartiacea, 148

Cronartiaceae, 148

Cronartium, 148

Cronartium ribicola, 148

Cryptobia, 160, 161, 209, 212

Cryptobiidae, 161

Cryptocalpis, 198

Cryptocapsales, 97

Cryptocapsineae, 95

Cryptocercus, 166, 169, 170

Cryptochrysis, 98

Cryptococcacea, 97, 98

Cryptococcaceae, 98

Cryptococcales, 96, 97

Cryptococcincac, 95

Cryptococcus, 98, 130

Cryptocystes, 219,222

Cryptomonadaceae, 98

Cryptomonadalea, 96

Crypiomonadales, 96

Cryptomonadida, 97

Cryptomonadidae, 98

Cryptomonadina, 96, 97, 98

Cryptomonadinae, 96

Cryptomonadineae, 95, 96

Cryptomonads, 94, 194

Cryptomonas, 97, 98, 199

Cryptonemeae, 50

Cryptonemiales, 50

Cryptoneminae, 50

Cryptophyceae, 94, 96 
Cryptospermea, 46, 47

Cryptospermeae, 47

Ctenomyces, 131

Ctenostomata, 230, 231

Citenostomida, 231

Ctenostomina, 231

Cumagloia, 47

Cuncolina, 186

Cunninghamella, 124

Cup fungi, 134

Cupulata, 129, 134, 137, 145

Cupulati, 134

Currants, 148

Cutleria, 88

Cutlcriacea, 88

Cutlerialea, 85, 88

Cutleriales, 88

Cyanomonas, 98

Cyanophyceae, 29

Cyanophyta, 17, 30

Cyathomonas, 97, 98

Cyathus, 155

Cyclammina, 186

Cyclidina, 230

Cyclidium, 230

Cycloclypeidae, 188

Cycloclypeina, 188

Cycloclypeus Carpenteri, 188

Cyclodinidae, 229

Cyclonexis, 59

Cyclonympha, 171

Cyclonymphidae, 169

Gycloposthium, 231

Cyclosiphon, 188

Cyclosporales, 91

Cyclosporeae, 82, 91

Cyclotella, 72, 73, 74

Cylindrospermum, 35

Cylindrospermum majus, 32

Cylindrosporium Pruni, 134

Cymbalopora, 180, 182, 187

Cymbella, 72, 73, 75

Cymbellea, 75

Cymbelleae, 75

Cyphoderia, 191

Cyrtellaria, 198

Cyrtida, 198

Cyrtoidea, 198

Cyrtophora, 62, 63

Cystidium, 198

Cystobasidium, 147

Cystobasidium sebaceum, 145

Cystochytrium, 69

Cystoflagellata, 94, 96, 99

Cytophaga Hutchinsonii, 26, 28

Cytophagacea, 28

Cytophagaceae, 28

Cytosporidia, 207

Cyttariacea, 135
Dacryomitra, 150

Dacryomyces, 150

Dacryomycetacea, 150

Dacryomycetaceae, 150

Dacryomycetalea, 146,150

Dacryomycetales, 150

Dacryomycetineae, 150

Dactylophorida, 218

Dactylophoridae, 218

Dactylophorus, 218

Dactylosphaerium, 202

Daedalea, 151

Daldinia, 139

Dallingeria, 58

Dasyea, 51

Daucina, 188

Deer, 214

Delacroixia, 125

Delesseria, 51

Delesseria sinuosa, 49

Delesseriea, 51

Dematiaceae, 142

Dematiea, 142

Dematieae, 142

Dematiei, 141

Dendrocometes, 236

Dendrocometida, 236

Dendrocometidae, 236

Dendrocometina, 236

Dendromonadina, 59

Dendromonas, 59

Dendromonas virgaria, 54

Dendrosoma, 235

Dendrosomatidae, 235

Dendrosomida, 235

Dendrosomidae, 235

Dendrosomina, 235

Dentilina, 184

Derepyxis, 60

Dermateacea, 135

Dermatocarpa, 146, 152

Dermatocarpi, 152, 171

Dermocarpa, 36

Dermocarpa protea, 32

Dermocentor, 20

Desmarestia, 88, 89

Desmarestiacea, 88

Desmarestales, 87

Desmobacteriales, 33

Desmocapsa, 99

Desmocapsales, 98, 99

Desmocapsineae, 95, 99

Desmokontae, 94, 98, 99

Desmomastix, 99

Desmomonadales, 98, 99

Desmomonadineae, 95, 99

Desmothoraca, 190, 194

Desmothoracida, 190

Desmotrichum, 88

Deuteromycetes, 140

Deutschlandiaceae, 60

Devescovina, 167 
Devescovinida, 167

Devescovinidae, 167

Devescovininae, 167

Diachea, 175

Dianema, 176

Dianemaceae, 176

Diaporthe, 139

Diatoma, 75

Diatomaceae, 69, 75

Diatomea, 53, 69, 71, 74

Diatomeae, 53, 69, 71, 74

Diatoms, 53, 71, 83, 117, 118

Diatrype, 139

Dictydiaethaliaceae, 175

Dictydiaethaliidae, 175

Dictydiaethalium, 175

Dictydium, 175

Dictyocha, 63

Dictyocha Fibula, 56

Dictyochaceae, 62

Dictyochidae, 62

Dictyoconoides, 187

Dictyoconus, 186, 198

Dictyophora, 155

Dictyosiphonales, 89, 91

Dictyosteliaceae, 203

Dictyosteliaceen, 203

Dictyostelidae, 203

Dictyostelium, 203

Dictyostclium discoideum, 204

Dictyostelium mucoroides, 204

Dictyota, 87

Dictyotacea, 87

Dictyotaceae, 86, 87

Dictyotales, 82, 86

Dictyotea, 85,86

Dictyoteae, 82, 86

Dictyuchus, 78,79

Didesmis, 231

Didiniidae, 229

Didinium, 229, 235

Didinium nasutum, 225

Didymiacea, 175, 177

Didymiaccae, 177

Didymidae, 177

Didymiidae, 177

Didymium, 177

Didymohelix ferruginea, 27

Didymophyes, 218

Didymophyida, 218

Didymophyidae, 218

Difflugia, 201, 205

Difflugiida, 205

Difflugiidae, 205

Dileptus, 230

Dinastigamocba, 159

Dimorpha, 193

Dinychota, 17

Dinamocha (dinoflagellate), 101

Dinamodba (amocla) , 16, 202

Dinamoebidina, 100, 101, 237

Dinamocbidium varians, 101, 104
Dinastridium, 100

Dinenympha, 166

Dinenymphida, 165,166

Dinenymphidae, 166

Dinifera, 102

Diniferidea, 103

Dinobryaceae, 60

Dinobryina, 58, 60

Dinobryon, 58, 60

Dinocapsaceae, 100

Dinocapsales, 99, 100

Dinocapsina, 99

Dinocapsineae, 95, 99

Dinococcales, 99, 100

Dinococcina, 99

Dinococcineae, 96, 100

Dinoclonium, 100

Dinocloniaceae, 100

Dinoflagellata, 94, 102

Dinoflagellatae, 94, 95

Dinoflagellates, 94, 199

Dinoflagellida, 103

Dinophyceae, 94,103

Dinophysida, 103

Dinophysis, 103

Dinothrix, 100

Dinotrichales, 99, 100

Dinotrichineae, 96, 99

Dioxys, 66

Dioxys Incus, 64

Diplococcus, 20

Diplococcus pneumoniae, 20

Diploconida, 197

Diploconus, 197

Diplocystida, 216

Diplocystidae, 216

Diplocystis, 216

Diplodia, 141

Diplodinium, 224, 231

Diplomita, 60

Diplophlyctis, 117

Diplophysalis, 191

Diplophysalis stagnalis, 192

Dipodascus, 130

Dipodascus albidus, 132

Discellacea, 141

Discellaceae, 141

Dischizae, 215

Discida, 195

Disciformia, 73

Discoasteridac, 60

Discoidea, 195

Discolichenes, 134

Discomycetes, 133, 134

Discophrya, 235

Discophryida, 235

Discophryidac, 235

Discorbis, 180,182

Discorbis mediterranensis, 182

Discorbis orbicularis, 182

Discosiphacra, 60

Disporées, 209 
Distephanus, 63

Distephanus Speculum, 56

Distigma, 107

Distomata, 163

Distomataceae, 166

Distomatinales, 163

Distomatineae, 163

Ditripodiidae, 62

Doassansia, 149

Dobellia binucleata, 210

Dobeliida, 210

Dobclliidae, 210

Dog, 210

Dolichocystida, 209, 214

Doliocystida, 216

Doliocystidae, 216

Doliocystis, 216

Dorataspida, 197

Dorataspis, 197

Dorataspis costata, 196

Dothideaceae, 137

Dothideales, 137, 138, 139, 140, 141

Drepanidium, 211

Duboscqia, 222

Dudresnaya purpurifera, 49

Dumontieae, 50

Earth star, 155

Earthworm, 215, 216

Eberthella, 22

Eberthella typhi, 22

Ebriaceae, 55, 62

Ebriidae, 62

Ebriopsidac, 62

Echinocystida, 189

Echinoderms, 216

Echinosteliaceac, 175

Echinostelium, 175

Ectocarpales, 86

Ectocarpea, 86

Ectocarpeae, 86

Ectocarpineae, 86

Ectocarpus, 70, 83, 86, 87

Ectocarpus Mitchelliae, 204

Ectocarpus siliculosus, 83

Ectosporeae, 177

Ectrogella, 81

Ectrogellacea, 81

Ectrogellaceae, 81

Eel, 161

Egregia Menziesii, 90, 91

Eimeria, 210

Eimerida, 210

Eimeridae, 210

Eimeridea, 210

Eimcriidea, 210

Eimeriinea, 210

Eimerioidae, 210

Elaeorhanis, 193

Elaphomyces, 131

Ellipsoidina, 188
Elphidium, 186, 187

Elphidium crispum, 181

Elvella, 135

Empusa, 125

Enchelia, 229

Enchelina, 229

Enchelis, 229

Enchelyidae, 229

Endamoeba, 202, 203

Endamoeba disparita, 202

Endamoeba histolytica, 202

Endamoebida, 201, 202

Endamoebidae, 202

Endocochlus, 124

Endogonacea, 123, 124

Endogonaceae, 124

Endogone, 123, 124

Endogonei, 124

Endolimax, 203

Endomyces, 130

Endomycetacea, 130

Endomycetaceae, 130

Endomycetalea, 129

Endomycetales, 129

Endosporea, 171

Endosporeae, 171

Endosporinei, 171

Endothia parasitica, 139

Endothyra, 186

Endothyridae, 186

Endothyrina, 186

Enerthenema, 175

Enerthenemaceae, 175

Enerthenemea, 174, 175

Entamoeba, 202, 203

Entamoeba coli, 202

Entamoeba dystenteriae, 202

Entamoeba gingivalis, 202

Enteridiea, 171

Enteridieae, 171

Enterobacteriaceae, 21

Entodiniomorpha, 230, 231

Entodiniomorphina, 231

Entodinium, 231

Entomophthora, 125

Entomophthoracea, 124

Entomophthoraccac, 124

Entomophthorales, 124

Entomophthorinea, 121, 124

Entomophthorineae, 124

Entophlycis, 113, 117

Entophysalidales, 33

Entosiphon sulcatum, 108

Eocronartium, 143, 147

Eocronartium muscicola, 145

Eouvigerina, 188

Ephelota, 236

Ephelotida, 236

Ephelotidae, 236

Ephelotina, 236

Ephemera vulgata, 222

Epiblasteae, 50 
Epichrysis, 56, 62

Epiclintes, 233

Epidinium, 231

Epipyxis, 60

Epipyxis utriculus, 54

Epistylis, 233

Eremascus, 130

Eremascus albidus, 127

Eremospermeae, 77

Erica, 9

Ericae, 9

Erysiphe, 127, 132, 133

Erysiphe graminis, 132

Erysiphea, 133

Erysipheae, 133

Erythrocladia, 44

Erythropsis, 101

Erythrotrichia, 44

Erythrotrichia carnea, 44

Erythrotrichiaceae, 44

Erwina, 22

Erwinia amylovora, 22

Escherichia coli, 14, 15, 22

Ethmosphaerida, 195

Euactinomyxidae, 222

Euasci, 130

Eubacteria, 18, 25

Eubacteriales, 18

Eubasidii, 145

Euchrysomonadina, 61

Euchrysomonadinae, 61

Eucomonympha, 169

Eucyrtidina, 198

Eucyrtidium, 198

Eucyrtidium carinatum, 196

Eudesme, 88

Euflorideae, 44

Euglena, 38, 94, 107, 116, 117, 125

Euglena acus, 106

Euglena Spirogyra, 106, 107

Euglena viridis, 106

Euglenaceae, 105

Englenales, 105

Euglenamorpha, 105

Euglenida, 105

Euglenids, 94, 106

Euglenina, 105

Eugleninae, 94, 105

Euglenineac, 96, 105

Euglenocapsineae, 96

Euglenoidina, 96, 105

Euglenophycophyta, 94

Euglenophyta, 94

Euglypha, 191

Euglyphida, 191

Euglyphidac, 191

Eugregarinaria, 217

Eugregarinida, 217

Eumycetes, 119

Eumyectozoina, 171

Eumyeophyta, 119

Eunotia, 75
Eunotiaceae, 75

Eunotiea, 75

Eunotieae, 75

Euphorbiaceae, 161

Euplotes, 227, 232, 233, 234

Euplotes Patella, 225, 226, 232

Eupodiscales, 73

Eurotium, 131

Eurychasma, 81

Eurychasmidium, 81

Eurysporea, 221

Eutreptia, 105

Excipula, 141

Excipulaceae, 141

Exidia, 143

Exoascalea, 129, 137

Exoascales, 137

Exoascus, 137

Exobasidiacea, 151

Exobasidiaceae, 151

Exobasidiales, 150

Exobásidiineae, 150

Exobasidium, 151

Exosporea, 171, 177

Exosporeae, 177

Exosporinei, 177

Exuviaclla, 99

Fasciolites, 185

Fauchea, 51

Faucheocolax, 51

Felis Catus, 6

Ferns, 125, 148

Filicineae, 1

Fisherinidae, 185

Fishes, 165, 210, 211, 219, 220, 222

Flabellina, 184, 187

Flagellata, 6, 55, 94, 96, 105

Flagellatae, 94

Flagellates, 10, 53, 55, 76, 94, 118

Flagellato-Eustomata, 105

Flagellato-Pantostomata, 158

Flatworms, 216

Flavobacterium, 22

Flea, 160

Flexostylida, 185

Floridea, 47, 50, 51

Florideae, 6, 40, 44, 51

Floridées, 40, 51

Floridincae, 44

Flowers of $\tan , 177$

Fly, 213

Foaina, 167

Folliculina, 230

Fomes, 151

Foraminifera, 179, 182, 183, 185

Foraminifères, 179, 182

Foraminifcrida, 179

Forficulc, 217

Fragilaria, 75

Fragilariaceae, 75 
Fragilariea, 75

Fragilarieae, 75

Frogs, 125, 210, 211

Frondicularia, 187

Fucaceae, 91

Fucales, 91

Fucea, 91

Fuceae, 91

Fucineae, 91

Fucacées, 82

Fucoidea, 83, 86, 91

Fucoideae, 53, 82

Fucus, 53, 91, 93

Fucus vesciculosus, 93

Fuligo septica, 177

Fungi, 39, 69, 76, 110, 119, 146, 150, 172

Fungi, bird's-nest, 155

Fungi imperfecti, 140

Fungilli, 39, 206

Furcellariea, 46, 50

Furcellarieae, 50

Fusarium, 142

Fusiformis, 29

Fusobacterium, 29

Fusulina, 188

Fusulinida, 188

Fusulinidae, 188

Galaxaura, 47

Galera tenera, 153

Gallionella, 27

Gallowaya, 148

Gammarus, 233

Gamocystis, 217

Ganymedes, 216

Ganymedida, 216

Ganymedidae, 216

Gasteromycetes, 152

Gastrobionta, 6

Gastrocarpeae, 50

Geaster, 155

Gelidiaceae, 49

Gelidialea, 46, 49, 50

Gelidiales, 49

Gelidieae, 49

Gelidium, 50, 51

Geophonus, 186, 187

Geoglossacea, 135

Giardia, 163, 166

Giardia enterica, 164, 166

Giardia Lamblia, 166

Gibberella, 142

Gigantomonas, 167

Gigartina mammilosa, 49

Gigartinales, 47

Gigartineae, 47

Gigartininae, 47

Glandulina, 187

Glaucocystis, 33

Glaucoma, 229

Glaucoma pyriformis, 227
Glenodinium, 94, 103

Globigerina, 184, 188

Globigerinida, 188

Globigerinidea, 183, 187

Globorotalia, 187

Globorotaliidae, 187

Glococapsa, 33

Gloeochaete, 33

Gloeochrysis, 62

Gloeodiniaceae, 100

Gloeodinium, 100

Gloeosporium, 139, 140, 141

Gloeotrichia, 36

Gloiophycea, 31, 32, 33

Gloiophyceae, 29, 33

Glomerella, 126, 127, 139, 140

Glomerella cingulata, 139

Glugea, 222

Glugeida, 222

Glugeidae, 222

Glugeidea, 222

Glugeidées, 222

Goat, 210

Gomphonema, 72, 75

Gomphonemaceae, 75

Gomphonemea, 75

Gomphonemeae, 75

Gomphosphaeria, 33

Gonapodiaceae, 112

Gonapodiineae, 112

Gonapodya, 112

Goniaulax, 103

Gonimophyllum, 52

Goniodoma, 103

Goniostomum, 109

Goniotrichaceae, 43

Goniotrichopsis, 43

Goniotrichum, 43

Gonococcus, 20

Gonospora, 216

Gooseberries, 146

Goussia, 209, 210

Goussia Schubergi, 207, 208, 237

Gracilaria, 49

Grains, 149

Granuloreticulosa, 179

Graphidiacea, 134

Graphidiaceae, 134

Graphidiales, 133

Grasses, 149

Green algae, see Algae, Green

Gregarina, 206, 217

Gregarina conica, 217

Gregarina cuneata, 217

Gregarina ovata, 217

Gregarinae, 206, 216

Gregarinarien, 217

Gregarines 206, 209, 215, 219

Gregarinida, 207, 217

Gregarinidae, 217

Gregarinidia, 207

Gregarininea, 217 
Gregarinoidae, 217

Gregarinoidea, 217

Gregarinomorpha, 207

Gromia, 179, 191

Gromida, 191

Guepinia, 150

Guepinia apathularia, 145

Gurleya, 222

Guttulina, 203

Guttulina sessilis, 204

Guttulinacea, 201, 203

Guttulinaceae, 203

Guttulineae, 203

Guttulineen, 203

Guttulinidae, 203

Guttulinopsis, 203

Gymnamoebae, 201

Gymnamoebida, 201

Gymnascales, 130

Gymnoascaceae, 130

Gymnoascus, 131

Gymnocraspedidae, 67

Gymnodiniacea, 99, 100

Gymnodiniaceae, 100

Gymnodiniales, 99

Gymnodinida, 100

Gymnodinidae, 100

Gymnodiniidae, 100

Gymnodinina, 99

Gymnodinioidae, 99

Gymnodinium, 100

Gymnodinium Lunula, 101, 104

Gymnodinium striatum, 104

Gymnogongrus, 49

Gymnosporangium, 143, 148

Gymnosporidae, 211

Gymnosporidiida, 209, 211

Gymnostomata, 229

Gymnostomataceae, 229

Gymnostomina, 229

Gyrodinium, 101

Gyromonas, 166

Gyrophragmium, 152

Gyrosigma, 75

Hacmamocba, 213

Hacmamocba malariac, 213

Hacmamoeba vivax, 213

Haemogregarina, 211

Haemogregarinida, 211, 212

Haemogregarinidac, 211

Haemogregarinina, 211

Hacmoproteidac, 212

Hacmoproteus, 213

Harmoproteus Columbae, 212, 213

Haemosporidac, 211

Hacmosporidia, 207, 211, 212

Hacmosporidiida, 211

Haliarchnion, 49

Halicryptina, 1 ก8

Haliomina, 195
Haliomma capillaris, 196

Haliommatina, 195

Halkyardia, 187

Halopappaceae, 60

Halopappus, 60

Halosphaeraceae, 66

Halteria, 231

Halteridiida, 212

Halteridiidae, 212

Halteridium, 212

Halteriidae, 231

Halterina, 231

Hantkenina, 187

Hantkeninidae, 187

Hantschia, 75

Haploactinomyxidae, 222

Haplobacteriacei, 18

Haplocyta, 215

Haplodinium, 99

Haplospora, 87

Haplosporangium, 124

Haplosporangium lignicola, 122

Haplosporidia, 218

Haplosporidies, 218

Haplosporidiida, 218

Haplosporidiidae, 218

Haplosporidiidea, 209, 218

Haplosporidium, 218

Haplostichinae, 82

Haplozoonidae, 102

Hauerinina, 185

Hedriocystis, 194

Helicosorina, 185

Heliodiscus, 195

Heliodiscus Phacodiscus, 196

Heliolithae, 58

Helioflagellida, 189

Helioflagellidae, 191

Heliozoa, 63, 157, 189, 190, 205

Heliozoariae, 189, $190^{\circ}$

Heliozoida, 189

Helminthocladeac, 47

Helminthosporium, 142

Helotiacea, 135

Helvellacea, 135

Helvellales, 134

Helvellineae, 134

Hemiascales, 130

Hemiasceac, 130

Hemiasci, 129

Hemiascineac, 130

Henibasidii, 145, 149

Hemicristellaria, 187

Hemicyclomorpha, 18

Hemidinium, 101

Hemileia vastatrix, 148

Hemisphaeriaceae, 134

IIemisphacriales, 133

Hemitrichia, 177

Henitrichia intorta, 176

Hemophilus, 22

Henneguya, 221 
Hepatozoon, 211

Herpetomonas, 161, 162

Heterocapsaceae, 65

Heterocapsales, 63

Heterocapsineae, 55, 63

Heterocarpea, 41, 44, 52

Heterocarpeae, 40,44

Heterochlorida, 63

Heterochloridaceae, 66

Heterochloridae, 66

Heterochloridales, 63

Heterochloridea, 63

Heterochloridineae, 55, 63

Heterochromonas, 59

Heterococcales, 63

Heterococcineae, 55, 63

Heterodermaceae, 175

Heterodermeae, 171

Heterogeneratae, 82

Heterohelicida, 188

Heterohelicidae, 188

Heterohelix, 188

Heterokonta, 11, 55, 83

Heterokontae, 53, 55, 63

Heteromastigoda, 158

Heteromonadina, 59

Heteronema, 109

Heteronemidae, 108

Heterophryida, 191, 193

Heterophryidae, 193

Heterophrys, 193

Heterosiphonales, 63

Heterosiphoneae, 55, 63

Heterostegina, 188

Heterotricha, 228, 230

Heterotrichaceae, 230

Heterotrichales, 63

Heterotrichida, 230

Heterotrichina, 230

Heterotrichineae, 55, 63

Hexacontium, 195

Hexaconus, 197

Hexactinomyxon, 222

Hexamastix, 167

Hexamastix Termopsidis, 164

Hexamita, 163, 166

Hexamitidae, 166

Hirmocystis, 217

Hodotermitidae, 167

Hoferellus, 221

Holocyclomorpha, 18

Holomastigotoides, 169

Holomastigotoidida, 169

Holomastigotoididae, 169

Holophrya, 229

Holophryidae, 229

Holotricha, 228, 229

Holotrichida, 229

Homalogonata, 69

Homo sapiens, 6

Honey bees, 222

Hoplonympha, 169
Hoplonympha natator, 170

Hoplonymphida, 169

Hoplonymphidae, 169

Hoplorhynchus, 218

Hordeum vulgare, 6

Hormogonales, 34

Hormogoneae, 34

Horse, 231

Hyalobryon, 60

Hyalodiscida, 201, 202

Hyalodiscidae, 202

Hyalodiscus, 202

Hyaloklossia, 211

Hyaloria, 149

Hyalospora, 217

Hydnacea, 151

Hydnaceae, 151

Hydnangiacea, 155

Hydnangiaceae, 155

Hydnei, 151

Hydnum, 151

Hydra, 203, 233

Hydramoeba, 203

Hydrocoleum, 35

Hydrogenomonas, 24

Hydruracea, 61, 62

Hydruraceae, 62

Hydruridae, 62

Hydrurina, 62

Hydrurus, 61

Hydrurus foetidus, 56, 62

Hyella, 36

Hymenogastraceae, 155

Hymenogastrales, 152

Hymenogastrea, 155

Hymenogastrei, 155

Hymenogastrineae, 152

Hymenomonadacea, 58, 60

Hymenomonadaceae, 60

Hymenomonadidae, 60

Hymenornonas, 60

Hymenomycetales, 150

Hymenomycetes, 150

Hymenomycetineae, 150

Hymenothecii, 150

Hymenostomata, 229

Hyperammina, 183

Hyperamminidae, 183

Hypermastigida, 168

Hypermastigina, 158, 166, 168

Hyphochytriacea, 69

Hyphochytriaceae, 69, 117

Hyphochytrialea, 57, 61, 69, 70, 111

Hyphochytriales, 69

Hyphochytrium, 69, 117

Hyphochytrium catenoides, 70

Hyphomycetes, 121, 140, 141

Hypnodiniaceae, 100

Hypocreaceae, 137

Hypocreales, 137, 138, 139, 142

Hypodermia, 146, 147

Iiypodermii, 147 
Hypomyces, 142

Hypomyces Solani var. Gucurbitae, 126, 127

Hypotricha, 228, 232, 233

Hypotrichaceae, 233

Hypotrichida, 233

Hypotrichina, 233

Hysterangiacea, 155

Hysterangiaceae, 155

Hysteriacea, 134

Hysteriaceae, 133, 134

Hysteriales, 133, 141

Hysteriineae, 133, 134

Hysterophyta, 119

Ichthyophthirius, 229

Ichthyosporidium, 219

Imperforida, 183

Infusoires, 223

Infusoires succurs, 235

Infusoria, 2, 37, 95, 118, 223, 228, 232, 235

Inoperculata, 135

Inophyta, 39, 119

Insects, 69, 113, 117, 118, 124, 125, 155, $159,161,165,167,216,217,220$

Invertebrates, 161, 210, 211, 215, 216

Iodamoeba, 203

Irish moss, 49

Irpex, 151

Isoachlya, 79

Isocarpeae, 69

Isochrysidaceae, 59

Isochrysidae, 59

Isochrysidales, 57

Isogeneratae, 82

Isospora, 210

Janczcwskia, 52

Jarrina, 210

Joenia, 169

Joeniidac, 169

Joeniidea, 168

Jocnina, 169

Joenopsis, 169

Jola, 147

Junipers, 148

Kalotermes, 169

Kalotermitidae, 167

Kalotermitinace, 166, 168

Karyamoebina, 203

Karyolysus, 211

Kelps, 82, 83, 89, 90

Keramosphacra, 185

Kcramosphaeridac, 185

Keramosphaerina, 185

Kerona, 233

Klebsiclla (bacterium) , 7, 22
Klebsiella pneumoniae, 22

Klebsiella (flagellate), 7

Klebsiella alligata, 106

Klossia, 211

Klossiella, 211

Kofoidia, 168, 169

Kofoidiida, 169

Kofoidiidae, 169

Kurthia, 21

Kurthiacea, 19, 21, 237

Laboulbenia, 140

Laboulbenia Guerinii, 140

Laboulbenia Rougetii, 140

Laboulbeniaceae, 140

Laboulbenialea, 129, 140

Laboulbeniales, 140

Laboulbenieae, 140

Laboulbeniineae, 140

Laboulbeniomycetes, 140

Labyrinthula, 203, 204

Labyrinthula macrocystis, 203

Labyrinthulida, 201, 203

Labyrinthulidae, 203

Lachnea scutellata, 127, 136

Lachnobolus, 176

Lacrymaria, 229

Lactobacillaceae, 20

Lactobacillus, 20

Lactobacteriaceae, 20

Lagena (oomycete), 82

Lagena (rhizopod), 82, 184, 187

Lagenaceae, 187

Lagenidae, 186

Lagenidea, 185

Lagenidiacea, 81, 82

Lagenidiaceae, 82

Lagenidialea, 76, 81, 111, 118

Lagenidiales, 81

Lagenidium, 82

Lagenina, 186

Lagenocystis, 82, 237

Lagenocystis radicicola, 82, 237

Lagynida, 191

Lagynion, 63

Lagynis, 191

Laminaria, 91

Laminaria yezoensis, 92

Laminariaceae, 89

Laminariales, 89

Laminariea, 85, 89

L.aminaricac, 89

Iampoxanthium, 195

Lampramocbac, 205

Lamproderma, 175

Lamprodermaceac, 175

Lamprospora lciocarpa, 136

Lamprosporales, 171

Lankesteria, 216

Larcarida, 195

Larcoidea, 195 
Latrostium, 69

Laurencia, 52

Leangium, 177

Leathesia, 88

Lecudina, 216

Lecudinidae, 216

Leeches, 161, 211

Legerella, 211

Leidyopsis, 169

Leishmania, 162

Leishmania brasiliensis, 162

Leishmania Donovani, 162

Leishmania tropica, 162

Lemanea, 47

Lemna, 69

Lenticulina, 187

Lenticulites, 187

Lentospora, 221

Lenzites, 151

Leocarpus, 177

Leocarpus fragilis, 176

Lepidoderma, 177

Lepidoderma Chailletii, 176

Lepochromulina, 62

Leptodiscida, 100, 102

Leptodiscidae, 102

Leptodiscus, 102

Leptolegnia, 79

Leptomitaceae, 79

Leptomitales, 77

Leptomitea, 77, 79

Leptomiteae, 79

Leptomitus, 79

Leptomonas, 162

Leptospira, 29

Leptospira icteroides, 29

Leptospira icterohaemorrhagiae, 29

Leptospironympha, 169

Leptostromatacea, 141

Leptostromataceae, 141

Leptotheca, 221

Leptothrix, 27

Leptothrix ochracea, 27, 36

Leptotrichacea, 27

Leptotrichaceae, 20

Leptotrichacei, 20, 27

Leptotrichia, 20

Leucocytozoidae, 212

Leucocytozoon, 213

Leuvenia, 66

Liagora tetrasporifera, 47,49

Licea, 175

Liceacea, 173, 175

Liceaceae, 175

Liceales, 171

Liceidae, 175

Lichenes, 119

Lichens, 119, 120

Ligniera, 179

Lindbladia, $175^{\circ}$

Lionotus, 230

Listeria, 21
Lithocampe, 198

Lithochytridina, 198

Lithocircus, 198

Lithocircus productus, 196

Lithocolla, 193

Lithocollidae, 193

Lithocyclia, 195

Lithocyclidina, 195

Lithocystis, 216

Litholophida, 197

Litholophus, 197

Lituola, 186

Lituolidaceae, 186

Lituolidae, 186

Lituolidea, 185, 186

Lituolina, 186

Liverworts, 10

Lizards, 211

Lobosa, 201

Loborhiza, 117

Lobster, 211

Lof tusia, 186

Lof tusiidae, 186

Lof tusiina, 186

Lophomonadidae, 169

Lophomonadida, 168, 169

Lophomonadina, 168

Lophomonas, 168, 169

Loxodes, 230

Lychnaspis, 197

Lycogala, 172, 175

Lycogala epidendrum, 176

Lycogalaceae, 171, 175

Lycogactida, 174, 175

Lycogalactidae, 175

Lycogalales, 171

Lycogalopsis, 155

Lycogalopsis Solmsii, 145

Lycoperdacea, 155

Lycoperdaceae, 155

Lycoperdales, 152

Lycoperdineae, 152

Lycoperdon, 155

Lyngbya, 13, 35

Lytothecii, 152

Macrocystis pyrifera, 90, 91

Macromastix, 58

Macrotrichomonas, 167

Macrotrichomonas pulchra, 164

Maize, 6

Mallomonadidae, 62

Mallomonadinea, 61, 62

Mallomonas, 61, 62

Mallomonas roseola, 56

Mammals, 166, 210

Man, Mankind, Men, 6, 159, 165, 210, 213,230

Margarita, 176

Margaritaceae, 176

Margaritida, 174, 176 
Margaritidae, 176

Massospora, 124, 125

Mastigamoeba, 158, 163

Mastigamoeba aspera, 160

Mastigamoebidae, 163

Mastigella, 163

Mastigophora, 6, 55, 94, 95

Mastotermitidae, 167

Matthewina, 186

Mayorella, 202

Mayorellida, 201, 202

Mayorellidae, 202

Medusetta, 200

Medusettida, 200

Megachytriaceae, 118

Megachytrium, 118

Melampsora, 143

Melampsoracea, 148

Melampsoraccae, 148

Melanconiacea, 141

Melanconiaceae, 141

Melanconialea, 141

Melanconiales, 141

Melanophycea, 11, 55, 82

Melanophyceae, 82

Melanospermeae, 82

Melitangium, 28

Melosira, 72, 73, 74

Melosiraceae, 74

Melosireae, 74

Meningococcus, 20

Menoidium, 103, 107, 109

Menoidium incurvum, 108

Menospora, 218

Menosporida, 218

Menosporidae, 218

Meridiea, 75

Meridieae, 75

Meridion, 75

Meridionaceae, 75

Merismopedia, 33

Merocystis, 211

Merogregarina, 215

Mcrogregarinida, 215

Mcrogregarinidae, 215

Merolpidiaceae, 117

Meroselenidium, 215

Mcsocaena, 63

Mesogloia, 88

Mesogloiacra, 88

Metachaos, 202

Metadevescovina, 167

Metaphyta, 6

Mctasporcae, 117

Mctazoa, 6

Mctchnikovella, 219

Metchnikovellida, 219

Metchnikovellidac, 219

Methanomonas, 24

Micrococcacea, 19, 20

Micrococcaceae, 20

Micrococcus, 20
Microcoleus, 35

Microglena, 62

Micromycopsis, 117

Micropeltidacea, 134

Micropeltidaceae, 134

Microrhopalodina, 166

Microsphaera, 132, 133

Microsphaera alni, 133

Microsporidia, 222

Microsporidies, 222

Microthyriacea, 134, 141

Microthyriaceae, 134

Microthytriales, 133

Miescher's tubes, 206

Mieschersche Schläuche, 206, 214

Mikrogromia, 183

Miliola, 182, 185, 201

Milioles, 179

Miliolida, 185

Miliolidae, 185

Miliolidea, 183, 185

Miliolina, 185

Mindeniella, 79

Mischococcacea, 65, 66

Mischococcaceae, 66

Mischococcus, 66

Mites, 211

Mitraspora, 221

Mitrati, 134

Molds, 142

Molds, water, 77

Mollisiacea, 135

Monaden, 189

Monades, 59

Monadidae, 59, 60

Monadidea, 158

Monadina, 57, 58, 59, 158

Monadineae Tetraplasteae, 191

Monadineae Zoosporeac, 191

Monads, collared, 38

Monas, 38, 54, 59, 60, 158

Monas amyli, 189

Monas Okenii, 31

Monascus, 131

Monera, 6, 12

Monercs, 12, 189

Monilia, 135, 140, 142

Monilia sitophila, 139

Moniliacea, 142

Moniliaceae, 142

Moniliales, 141

Monkcys, 213

Monoblepharella, 112

Monoblepharella Taylori, 114

Monoblepharidacea, 112

Monoblcpharidaceac, 112

Monoblepharidalca, 111, 114

Monoblcpharidales, 111

Monoblepharideae, 110

Monoblepharidincae, 110,111

Monoblepharis, 111, 112

Monocercomonadida, 167 
Monocercomonadidae, 167

Monocercomonas, 167

Monocercomonoides, 165

Monocilia, 66

Monociliaceae, 66

Monocystid gregarines, 209

Monocystida, 216

Monocystidae, 216

Monocystidea, 209, 215

Monocystiden, 216

Monolpidiaceae, 118

Monomychota, 17

Monopylaria, 190, 196, 198

Monopylea, 198

Monopyleen, 198

Monopylida, 198

Monopylina, 198

Monoschizae. 215

Monosiga, 67, 68

Monosomatia, 179, 183

Monosporea, 210

Monosporées, 209

Monostomina, 191

Morchella, 135

Morchella conica, 136

Mortierella, 124

Mortierellacea, 123, 124

Mortierellaceae, 124

Mosquitoes, 162, 213

Moss, Irish, 49

Mosses, 10

Mouse, Mice, 211, 214

Mrazekia, 222

Mrazekiida, 222

Mrazekiidae, 222

Mucedinaceae, 142

Mucedineae, 142

Mucedines, 129, 130, 135

Mucor, 121, 123

Mucor Mucedo, 121, 123

Mucoracea, 123

Mucoraceae, 123

Mucorales, 121

Mucorina, 121, 128

Mucorineae, 121

Mucorini, 121

Mucronina, 188

Mushrooms, 145, 151

Mussels, 211, 218

Mutinus, 155

Mycetalia, 119

Mycetoideum, Regnum, 119

Mycetosporidium, 179

Mycetozoa, 119, 157, 171, 176, 203

Mycetozoen, 171, 172

Mycetozoida, 171

Mychota, 1, 4, 6, 8, 10, 12

Mycobacteriacea, 25

Mycobacteriaceae, 25

Mycobacterium, 25

Mycobacterium leprae, 25

Mycobacterium tuberculosis, 25
Mycochytridinae, 113

Mycoderma mesentericum, 24

Mycophyceae, 77

Mycophyta, 119

Mycoporacea, 139

Mycosphaerella, 139

Mycosphaerella personata, 138

Myrioblepharis, 112

Myriogloiacea, 88

Myrionema, 89

Myrionematacea, 88

Myriospora, 211

Myxidiea, 221

Myxidiées, 221

Myxidiida, 221

Myxidiidae, 221

Myxidium, 221

Myxobacter, 28

Myxobacteria, 12, 14

Myxobacteriacea, 28

Myxobacteriaceae, 27, 28

Myxobacteriales, 27

Myxobactralea, 26, 27

Myxobactrales, 27

Myxobolea, 221

Myxobolées, 221

Myxobolida, 221

Myxobolidae, 221

Myxobolus, 221

Myxoceratida, 221, 237

Myxoceros, 221, 237

Myxoceros Blennius, 220, 221, 237

Myxoceros sphaerulosa, 221, 237

Myxochloridae, 66

Myxochrysidaceae, 63

Myxochrysidae, 63

Myxochrysis, 63

Myxochytridinae, 113

Myxococcacea, 28

Myxococcaceae, 28

Myxococcus, 28

Myxococcus coralloides, 26

Myxocystoda, 99

Myxogastres, 171

Myxomycetes, 10, 157, 171, 172, 178

Myxomyceten, 172

Myxomycidium flavum, 143

Myxomycophyta, 171

Myxophyceae, 17, 29, 30

Myxophykea, 29

Myxophyta, 171

Myxoproteus, 221

Myxoschizomycetae, 27

Myxoschizomycetes, 18, 27

Myxosoma, 221

Myxosomatida, 221

Myxosomatidae, 221

Myxosporidia, 206, 219, 220

Myxothallophyta, 171

Myzocytium, 82 
Naegelliella, 62

Naegelliellaceae, 62

Naegelliellidae, 62

Naegleria, 159

Najadea, 60

Nassellaria, 198

Nassellida, 198

Nassoidea, 198

Nassula, 230

Nassulidae, 230

Nautilus, 182, 186, 187

Navicula, 72, 73, 75

Naviculaceae, 75

Naviculales, 74

Naviculea, 75

Naviculeae, 75

Neactinomyxon, 222

Nebela, 205

Nebelida, 205

Nebelidae, 205

Nectria, 141, 142

Nectria cinnabarina, 139

Nectrioidaceae, 141

Nectrioideae, 141

Neisseria gonorrhoeae, 20

Neisseria intracellularis, 20

Neiseria meningitidis, 20

Neisseria Weichselbaumii, 20

Neisseriacea, 19, 20

Neisseriaceae, 20

Neisseriacées, 20

Nemalion, 47

Nemalion multifidum, 49

Nemalionales, 47

Nemalioninae, 47

Nemastomatales, 47

Nematochrysidaceae, 60

Nematochrysis, 61

Nematocystida, 219

Nematodes, 113, 118, 124

Nematothecia, 141

Nematothecii, 141

Neogregarina, 215

Neosporidia, 206, 207, 219

Nephroselmidacea, 98

Nephrosemidaceae, 98

Nephrosclinidac, 98

Nephroselmis, 98

Nereocystis, 89

Nercocystis Luctkcana, 90, 91

Neurospora, 139, 140

Neurospora crassa, 127

Neusinidae, 186

Neusina, 186

Nerskia, 27

Nidularia, 155

Nidulariaceae, 155

Nidulariales, 152

Nidularica, 155

Nidularici, 155

Nidulariincas, 152

Nina, 217,218
Nitrobacter, 24

Nitrobacter Winogradskyi, 24

Nitrobacteriacea, 20, 24

Nitrobacteriaceae, 24

Nitromonas, 24

Nitrosococcus, 24

Nitrosococcus nitrosus, 24

Nitrosomonas europaea, 24

Nitrosomonas javanensis, 24

Nitzschia, 75

Nitzschiacea, 75

Nitzschiaceae, 75

Noctiluca, 95, 99, 102

Noctiluca miliaris, 102

Nectiluca scintillans, 102, 104

Noctilucae, 94, 99

Noctilucida, 100, 102

Noctilucidae, 102

Nodosalida, 186

Nodosarella, 188

Nodosaria, 184,187

Nodosarida, 186

Nodosaridae, 186

Nodosarina, 186, 188

Nodosaroum, 186

Nodosinella, 186

Nodosinellida, 186

Nodosinellidae, 186

Nonion, 184, 187

Nonionidea, 187

Nonionideae, 187

Nonionina, 187

Nosema, 222

Nosema bombycis, 206, 222

Nosematidae, 222

Nostoc, 35

Nostocacea, 34,35

Nostocaceae, 35

Nostochineae, 33

Nowakowskiella, 118

Nowakowskiellacea, 117, 118

Nowakowskiellaceae, 118

Nubecularina, 185

Nucleophaga, 118

Nuda, 201

Nummulitaceae, 188

Nummulites, 188

Nummulitida, 188

Nummulinidae, 188

Nummulitina, 188

Nummulitinidea, 183, 185, 188

Oats, 148

Ochromonadaceac, 59, 60

Ochromonadalea, 54, 56, 57, 61, 64, 67, 85,165

Ochromonadales, 57

Ochromonadidae, 59

Ochromonas, 58, 59, 60

Ochromonas granularis, 54

Octomitus, 166 
Octomyxa, 179

Octospora, 222

Oicomonadacea, 159, 161

Oicomonadaceae, 161

Oicomonadidae, 161

Oidium, 142

Oikomonas, 161

Oligochaet worms, 222

Oligonema, 177

Oligosporea, 209, 210

Oligotricha, 230

Oligotrichaceae, 230

Oligotrichida, 230

Oligotrichina, 230

Olpidiacea, 115, 118

Olpidiaceae, 118

Olpidopsidacea, 81

Olpidiopsidaceae, 81

Olpidiopsis, 81

Olpidium, 113, 118

Olpidium Allomycetos, 116

Ommatida, 195

Onygena, 131

Oodinidae, 102

Oomycetes, $11,53,55,65,76,78,111$, $118,119,121,125,127,177,178,179$

Oosporeae, 77

Opalina, 225, 227, 229

Opalinalea, 228, 237

Opalinida, 228

Opalinidae, 228, 229

Opalinina, 229

Opalininea, 228

Opalinoca, 225, 229

Operculata, 135

Operculina, 188

Ophiocytiaceae, 66

Ophiocytium, 66

Ophiocytium parvulum, 66

Ophiotheca, 176

Ophrydium, 233

Ophryocystis, 215

Ophryocystida, 215

Ophryocystidae, 215

Ophryodendrida, 236

Ophryodendridae, 236

Ophryodendrina, 236

Ophryodendron, 236

Ophryoglena, 229

Ophryoglenidae, 229

Ophryoscolecidae, 231

Ophryoscolecids, 225

Ophryoscolecina, 231

Ophryoscolex, 231

Ophthalmidium, 184, 185

Opisthokonta, 39, 110,12i, 237

Opistokonten, 111

Orbitoides, 188

Orbitoidida, 188

Orbitoididae, 188

Orbitolina, 186

Orbitolinida, 186
Orbitolinidae, 186

Orbitolites, 185

Orbulina, 188

Orbulinida, 188

Orcadella, 175

Orcadellaceac, 175

Orcadellidae, 175

Orcheobius, 211

Orobias, 188

Ortholithinae, 58

Orthopteran, 217

Orthosporeae, 117

Oscillaria malariae, 213

Oscillatoria, 30, 35, 36

Oscillatoria Princeps, 13

Oscillatoria splendida, 32

Oscillatoriacea, 34, 35

Oscillatoriaceae, 35

Owl, 162

Ox, Oxen, 162, 231

Oxymonadida, 165, 166

Oxymonadidae, 166

Oxymonadina, 163

Oxymonas, 163, 166

Oxyphysis, 103

Oxyrrhis, 101

Oxyrrhis marina, 101

Oxytocum, 103

Oxytricha, 233

Oxytrichidae, 233

Oxytrichina, 233

Pacinia, 23

Pacinia cholerae-asiaticae, 23

Padina, 87

Palatinella, 62

Pantostomatales, 158

Pantostomatida, 158

Pantostomatineae, 158

Paradinıda, 98

Pardinidae, 98

Paradinium Pouchetii, 97, 98

Paraisotricha, 231

Parajoenia, 167

Paramaecium, 223, 224, 225, 226, 227, 229

Paramaecium Aurelia, 226, 227

Paramaecium Bursaria, 226

Paramaecium caudatum, 226

Paramaecium multimicronucleatum, 226

Parameciina, 229

Paramoeba Eilhardi, 98

Paramoebida, 98

Paramoebidae, 98

Paramoecidae, 229

Parasitella, 123

Parvobacteriaceae, 22

Pasteurella avicida, 22

Pasteurella pestis, 22

Pasteurellacea, 19, 22, 23, 237

Pasteuria, 26, 27 
Patellariacea, 135

Patellina, 181, 182, 185

Patouillardina, 149

Patouillardina cinerea, 145

Pavonina, 188

Peach, 137

Pectobacterium, 23

Pectobacterium carotovorum, 23

Pedangia, 186

Pedilomonas, 111

Pedinella, 62, 63

Pegidia, 188

Pegidiida, 188

Pegidiidae, 188

Pelodictyon, 31

Pelomyxa, 202

Pelomyxa carolinensis, 200, 201

Pelomyxa palustris, 202

Peneroplidae, 185

Peneroplidea, 185

Peneroplidina, 185

Peneroplis, 181, 184, 185

Penicillium, 130, 131

Penicillium notatum, 25, 131

Pennatae, 74

Pentatrichomonas, 165'

Pentatrichomonas obliqua, 164, 167, 237

Peranema, 108, 109

Peranema trichophorum, 108

Peranemaceac, 108

Peranemina, 108

Perforida, 186

Periblasteae, 47

Perichaena, 176

Perichaenacea, 174, 176

Perichaenaceae, 176

Peridinaea, 102, 103

Peridinea, 96

Peridineae, 94, 96, 103

Peridiniaceae, 103

Pcridiniales, 102

Peridinidae, 103

Peridinina, 103

Peridinioidae, 103

Peridinium, 94, 103

Peridinium cinctum, 104

Perionella, 66

Peripylaria, 194

Peripylea, 194

Peripylern, 194

Peripylida, 194

Peripylina, 194

Perisporia, 131

Perisporiacea, 129, 131

Perisporiaceae, 131

Perisporiales, 131

Peritricha, 233

Peritrichaceae, 233

Peritrichida, 233

Peritrichinae, 18

Peritromidae, 233

Peritromina, 233
Peritromus, 233

Peronospora, 81

Peronosporacea, 80, 81

Peronosporaceae, 81

Peronosporales, 80

Peronosporina, 76, 80

Peronosporinae, 80

Peronosporineae, 80

Peziza, 127, 135

Peziza domiciliana, 127

Pezizacea, 135

Pezizales, 134

Pezizineae, 134

Pestallozia, 141

Pfeifferella mallei, 22

Phacidiaceae, 133, 134

Phacidiacei, 133

Phacidialea, 129, 133, 135

Phacidiales, 133

Phacidiea, 134, 141

Phacidieae, 134

Phacidineae, 133, 134

Phacus, 94, 106, 107

Phaenocystes, 219

Phaenocystida, 219

Phaeocapsa, 98

Phacocapsaceae, 98

Phacocapsales, 96

Phaeococcus, 98

Phaeoconchia, 198, 199

Phaeocystia, 198

Phacocystina, 199

Phacocystis, 58

Phacocystis globosa, 54

Phacodaria, 199

Phacodariae, 198

Phaeodermatium, 63

Phaeogromia, 198, 199

Phacophyceae, 53, 82, 95

Phacophycophyta, 53

Phacophyta, 39, 53

Phacoplakaceae, 98

Phacoplax, 98

Phacosphaera, 59

Phacosphacria, 190, 196, 198, 199

Phaeosporales, 86

Phacosporeae, 82, 86

Phacothamion, 61

Phacothamnionacea, 58, 60

Phacothamnionaccae, 60

Phacozoosporea, 85, 86, 87

Phacozoosporeae, 86

Phagomyxa, 179

Phalanasteriaceae, 67

Phalanasteriidae, 67

Phalanasterium, 67

Phalanasterium digitatum, 68

Phallaceae, 155

Phallales, 152

Phallineac, 152

Phalloidea, 155

Phalloidei, 155 
Phallus, 155

Phlebotomus, 21

Phleospora, 139

Phlyctidiacea, 115, 117

Phlyctidiaceae, 117

Phlyctidium, 117

Phlyctorhiza, 117

Phoma, 141

Phomaceae, 141

Phomales, 141

Phomatacea, 141

Phomataceae, 141

Phomatalea, 141

Phomatales, 141

Phormidium, 32, 35

Phragnidium, 147, 148

Phragmidium violaceum, 147

Phycochromaceae, 29

Phycomyces, 123, 124

Phycomyces nitens, 122

Phycomyceten, 76

Phycomycetes, 76

Phycomycophyta, 76

Phyllactinia, 132, 133

Phyllactinia corylea, 127

Phyllophora, 49

Phyllosiphon, 67

Phyllosiphonacea, 67

Phyllosiphinaceae, 67

Physaraceae, 171, 177

Physarales, 171, 174

Physarea, 174, 177

Physaridae, 177

Physarum, 177

Physarum notabile, 176

Physarum polycephalum, 176

Physematium, 189, 195

Physoderma, 115, 117

Physodermataceae, 117

Physomonas, 59

Phytodiniacea, 99, 100

Phytodiniaceae, 100

Phytodinidae, 100

Phytodinium, 100

Fhy tomastigophorea, 55

Phytomonas (bacterium), 7, 23

Phytomonas (flagellate), 7, 161

Phytomonas Donovani, 160

Phytomyxida, 111, 171, 177

Phytomyxidae, 179

Phytomyxinae, 177

Phytomyxini, 177

Phytophthora, 80

Phytophthora infestans, 81

Phytosarcodina, 171

Phytozoidea, 94, 105

Pigeon, 212

Pileati, 150

Pileocephalus, 218

Pilobolus, 121, 124

Pinaciophora, 193

Pinacocystis, 193
Pines, 148

Pinnularia, 72, 75

Pipetta, 195

Piptocephalidacea, 123, 124

Piptocephalidaceae, 124

Piptocephalis, 123, 124

Piroplasma, 214

Pisces, 1

Plagiotomidae, 230

Plagiotomina, 230

Planopulvinulina, 187

Planorbulina, 187

Planorbulinidae, 187

Plant kingdom, Plantae, Plants, 1, 2, 4, 6, $8,10,24,38,61,67,95,113,117,118$, $130,137,148,151,161,177,179,202$

Plasmodida, 213

Plasmodidae, 213

Plasmodiida, 211

Plasmodiophora, 179

Plasmodiophora Brassicae, 178

Plasmodiophoraceae, 179

Plasmodiophorales, 177

Plasmodiophorea, 179

Plasmodiophoreae, 179

Plasmodiophoreen, 179

Plasmodiophorina, 177

Plasmodium, 212, 213

Plasmodium falciparum, 214

Plasmodium malariae, 213

Plasmodium vivax, 213

Plasmodroma, 157

Plasmopara viticola, 81

Platychrysis, 58

Platygloea, 147

Platynoblasteae, 51

Platysporea, 221

Plectascales, 130

Plectascineae, 130

Plectellaria, 198

Plectida, 198

Plectobasidiales, 152

Plectobasidiineae, 152

Plectofrondicularia, 188

Plectoidea, 198

Plectoncma, 36

Plectonida, 198

Pleurage curvicolla, 128

Pleurocapsa, 36

Pleurocapsacea, 35, 36

Pleurocapsaceae, 36

Pleuromonas (dinoflagellate), 99

Pleuromonas (zoomastigote), 159

Pleuronemidae, 230

Pleurosigma, 75

Pleurostomella, 188

Pleurostomellida, 188

Pleurostomellidae, 188

Pleurotricha, 233

Pleurotrichidae, 233

Pleurotus, 152

Pleurotus ostreatus, 152 
Plistophora, 222

Plistophoridae, 222

Plocapsilina, 186

Plocapsilinidae, 186

Plowrightia morbosa, 140

Pne umobacillus, 22

Podangium, 28

Podaxacea, 152

Podaxaceae, 152

Podaxon, 152

Podocyathus, 236

Podophrya, 235

Podophyridae, 235

Podophryina, 235

Podosphaera, 132, 133

Polyangiaceae, 28

Polyangidae, 27

Polyangium, 28

Polychaos, 202

Polychytrium, 117

Polycystidea, 209, 216

Polycystina (of Ehrenberg), 189, 198

Polycystina (of Delage and Hérouard), 217

Polydinida, 101

Polygastrica, 223

Polykrikida, 100, 101

Polykrikos, 101

Polymastigida, 158, 163, 164

Polymastigidae, 165

Polymastigina, 158, 163, 165

Polymastix, 163, 165

Polymastix melolonthae, 164

Polymorphina, 187

Polymorphinida, 187

Polymorphinidae, 187

Polymorphinina, 187

Polymyxa, 178, 179

Polyphagaceae, 117

Polyphagus, 111, 117

Polyphagus Euglcnae, 116, 117

Polyporacea, 151

Polyporaceae, 151

Polyporales, 150

Polyporei, 151

Polyporus, 151

Polysiphonia nigrescens, 49

Polysiphonia violacea, 45,46

Polysiphonieac, 51

Polysomatia, 179, 185

Polysphondylium, 203

Polysphondylium violaceum, 204

Polysporea, 209, 211

Polystichinae, 82

Polystictus, 151

Polystomella, 186, 187

Polystomclla crispa, 181

Polystomellina, 187

Polythalamia, 179, 185

Polytoma, 61

Pontifex, 202

Pontisina, 81
Pontosphaera, 60

Pontosphaeraceae, 60

Porospora, 218

Porosporida, 218

Porosporidae, 218

Porphyra, 43

Porphyra laciniata, 42

Porphyra tenera, 42, 43

Porphyra umbilicaris, 42, 43

Porphyraceae, 43

Porphyrea, 41, 43

Porphyreae, 43

Porphyridiacea, 41

Porphyridiaceae, 41

Porphyridiales, 41

Porphyridium, 3, 40

Porphyridium cruentum, 41

Postelsia palmaeformis, 90, 91

Poteriochromonas, 60

Poteriodendron, 67

Poteriodendron petiolatum, 68

Pouchetia, 101

Pouchetiida, 100, 101

Pouchetiidae, 101

Prasiola, 3, 40, 44

Prasiolaceae, 44

Primalia, 37

Primigenium, Regnum, 37

Proboscoidella, 166

Progastréades, 94, 95

Pronoctiluca, 101

Prorocentraceae, 99

Prorocentrales, 99

Prorocentridae, 99

Prorocentrina, 99

Prorocentrinea, 98

Prorocentrinen, 99

Prorocentrum, 99

Prorodon, 229

Protamoeba, 189

Protcomyxa, 189, 190

Proteomyxiae, 189, 190

Protcomyxida, 189

Proteromonadidae, 159

Proteromonadina, 158

Proteromonas, 159

Proterospongia Hacckcli, 68

Protcus difflucns, 201

Protcus vulgaris, 22

Protista, 4, 6, 37, 189

Protiste's trichocystifères, 94, 95

Protoascineae, 130

Protobasidioniycetes, 145, 146, 150

Protobionta, 6, 37

Protochrysis, 98

Protociliata, 228

Protortista, 1, 4, 6, 8, 10, 37

Protodermicac, 171

protodinifer, 101

Protodiniferida, 100, 101

Protodinifcridae, 101

Protodiscineae, 137 
Protodontia Uda, 145

Protoflorideae, 41

Protogenes, 189

Protomastigales, 158

Protomastigida, 158

Protomastigina, 158

Protomastigineae, 158

Protomonas, 189, 191

Protomonadina, 158

Protomyces, 130

Protoopalina, 229

Protoopalinidae, 229

Protophyta, 6, 12, 18

Protoplasta, 39, 111, 157

Protoplasta filosa, 190

Protopsis, 101

Protozoa, 6, 12, 29, 37, 39, 223

Prowazekia, 159

Prunoidea, 195

Prunopliracta, 197

Prymnesiidae, 58

Prymnesium, 58

Pseudomonas, 23

Pseudomonas aeruginosa, 23

Pseudospora, 159, 189, 191

Pseudosporea, 191

Pseudosporeae, 191

Pseudosporeen, 191

Pseudosporidae, 191

Pseudotetracdron, 66

Pseudotetraedron neglectum, 64

Psorosperms, 206

Psychodière, Regne, 37

Psychodiés, 37

Pteridomonas, 193

Pterocephalus, 218

Pterospora, 216

Ptychodiscida, 103

Puccinia, 143, 147, 148

Puccinia graminis, 147,148

Puccinia Malvacearum, 148

Pucciniaceae, 148

Pucciniales, 147

Puffballs, 155, 172

Punctariales, 89

Pycnospermeae, 82, 89

Pylaiella, 86

Pyrenomycetales, 138

Pyrenomycetes, 137

Pyrenomycetineae, 137

Pyrgo, 185

Pyrocystis, 100

Pyronema, 127, 134, 135, 137

Pyronema confluens var. igneum, 127

Pyronemacea, 135

Pyrrhophycophyta, 94

Pyrrhophyta, 39, 94, 182

Pyrsonympha, 166

Pyrsonymphina, 163

Pythiacea, 80

Pythiaceae, 80
Quadrula, 205

Rabbit, 210

Raciborskya, 100

Radaisia, 36

Radioflagellata, 190

Radiolaria, 189, 190, 194, 196

Radiolariae, 189

Radiolarida, 189

Ralfsia, 87, 89

Ralfsiacea, 88

Ramularia, 139

Ramulinina, 187

Raphidophrys, 193

Raphidozoum, 195

Rat, 160

Ravenelia, 148

Red algae, sce Algae, Red

Regne Psychodière, 37

Regnum Mycetoideum, 119

Regnum Primigenium, 37

Reophacida, 186

Reophacidae, 186

Reophax, 186

Reptiles, 212, 220

Reticularia, 175, 179

Reticulariacea, 174, 175

Reticulariaceae, 175

Reticularieae, 171

Reticulitermes, 171

Reticulosa, 179

Retortomonadidae, 165

Retortomonadina, 163

Retortomonas, 163, 165

Rhabdogeniae, 207

Rhabdosphacra, 60

Rhipidiacea, 77, 79

Rhipidiaceae, 79

Rhipidium, 79

Rhizammina, 183

Rhizamminidae, 183

Rhizaster, 63

Rhizidiacea, 115, 117

Rhizidiaceae, 117

Rhizidiomyces, 69

Rhizidiomyces apophysatus, 70

Rhizidiomycetaceae, 69

Rhizidium, 113, 117

Rhizinacea, 135

Rhizo-Flagellata, 158

Rhizobiacea, 19, 22, 23

Rhizobiaceae, 22

Rhizobium, 23

Rhizobium Leguminosarum, 23

Rhizochloridaceae, 66

Rhizochloridae, 66

Rhizochloridales, 63

Rhizochloridea, 63

Rhizochloridineae, 55, 63

Rhizochloris, 66

Rhizochrysidaceae, 63 
Rhizochrysidae, 63

Rhizochrysidina, 61

Rhizochrysidinae, 61

Rhizochrysidineae, 55

Rhizochrysis, 61, 63

Rhizochrysis Scherffeli, 56

Rhizocryptineae, 95

Rhizoctonia, 142

Rhizodiniales, 99, 101

Rhizodininae, 95, 99

Rhizoflagellata, 157,158,160,178, 192

Rhizomastigaceae, 163

Rhizomastigida, 158

Rhizomastigina, 158, 163

Rhizomastix, 163

Rhizopoda, 6, 63, 157, 172, 179, 184, 200, 205

Rhizopoda radiaria, 189, 194

Rhizopods, 179

Rhizopodes, 179

Rhizopogonacea, 155

Rhizopogonaceae, 155

Rhizopus, 121

Rhizopus nigricans, 122, 124

Rhizosolenia, 74

Rhizosoleniacea, 74

Rhizosoleniaceae, 74

Rhodobacillacea, 31, 237

Rhodobacillus, 31

Rhodobacteria, 30, 31

Rhodobacteriaceae, 31

Rhodochaetacea, 41, 43

Rhodochaetaceae, 43

Rhodochaete, 43

Rhodochorton, 47

Rhodomelaceae, 51

Rhodomeleae, 51

Rhodomonas, 98

Rhodomonas baltica, 97

Rhodophyceac, 6, 40

Rhodophycophyta, 40

Rhodophyllis, 49

Rhodophyta, 39, 40, 44

Rhodopseudomonas, 31

Rhodospermeae, 40

Rhodospirillum, 31

Rhodymeniacea, 51

Rhodymeniaceac, 51

Rhodymeniales, 51

Rhodymonicac, 51

Rhodymeninac, 51

Rhoicosphenia, 76

Rhoicosphenia curvata, 72

Rhopalodia, 75

Rhynchocystida, 216

Rhynchocystidae, 216

Rhynchocystis, 216

Rhynchomonas, 159

Rickettsia Mclophagi, 21

Rickettsia Prowazckii, 21

Rickcttsia Rickettsii, 21

Rickcttsiacca, 19, 20, 118
Rickettsiaceae, 20

Rivularia, 36

Rivulariacea, 34, 36

Rivulariaceae, 36

Roach, 166, 168, 170

Rodents, 211

Roesia, 69

Rosaceae, 148

Rotalia, 184, 187

Rotaliaceae, 187

Rotalida, 187

Rotalidae, 187

Rotalidea, 187

Rotalina, 187

Rotifers, 113, 118, 219

Rozella, 118

Rugipes, 202

Rupertia, 187

Rupertiidae, 187

Russula, 143

Russula emetica, 145

Rusts, 145, 147

Rye, 148

Saccamminidae, 183

Saccharomyces cerevisiae, 130

Saccharomycetacea, 130

Saccharomycetaceae, 130

Saccharomycetes, 130

Saccinobaculus, 163, 166

Sagosphaerida, 199

Sagrina, 188

Salmonella, 22

Salpingoeca, 67

Salpingoeca ampullacea, 68

Salpingoeca Clarkii, 68

Salpingoecidae, 67

Sappinia, 203

Sappinia diploidea, 203

Sappinia pedata, 204

Sappiniaceae, 203

Sappiniidae, 203

Saprolcgnia, 76, 79

Saprolegnia ferax, 78

Saprolegnia mixta, 78

Saprolcgniaccae, 77

Saprolcgniales, 77

Saprolegnica, 77

Saprolegnicac, 77

Saprolcgniineae, 77

Saprolegnina, 77

Saprolegninae, 77

Sapromyces, 79

Saprospira, 29

Sarcina, 20

Sarcocystida, 214

Sarcocystidac, 214

Sarcocystidca, 214

Sarcocystis, 214

Sarcocystis Miescheriana, 214

Sarcocystis Muris, 214 
Sarcodina, 6, 172, 200

Sarcosporidia, 207, 214

Sargassaceae, 91

Sargassea, 92

Sargasseae, 92

Sargassum, 93

Sargassum Horneri, 93

Sarkodina, 63. 157, 200

Schaudinella, 216

Schaudinellida, 216

Schaudinellidae, 216

Schinzia Leguminosarum, 23

Schizocystida, 215

Schizocystidae, 215

Schizocystinea, 215

Schizocystis, 215

Schizodinium, 102

Schizogoniacea, 41, 44

Schizogoniaceae, 44

Schizogonium, 44

Schizogregarinaria, 215

Schizogregarinida, 209, 215

Schizomycetae, 17, 18

Schizomycetes, 18, 206

Schizomycophyta, 17

Schizophyta, 12, 18

Schizophytae, 12

Schizosporea, 18

Schläuche, Mieschersche, 206, 214

Sciadiaceae, 66

Sciadophora, 218

Sclerocarpa, 129, 133, 135, 137, 145

Sclerocarpi, 137

Scleroderma, 143

Sclerodermataceae, 155

Sclerodermatales, 152

Sclerodermea, 155

Sclerodermei, 155

Sclerotinia, 140

Sclerotinia cinerea, 135, 136

Scytomonas pusilla, 108

Scytonema, 36

Scytonematacea, 34, 35

Scytonemataceae, 35

Sebacina, 149

Sebacina sublilacina, 145

Sebdenia, 49

Selenidium, 215

Seleniida, 215

Seleniidae, 215

Selenococcidiida, 211

Selenococcidiidae, 211

Sclenococcidinea, 210

Selenococcidium intermedium, 211

Sennia, 97, 98

Sepedonei, 141

Septata, 217

Septobasidium, 147

Septoria, 139, 141

Sheep, 210, 214

Shigella, 22

Shigella dysenteriae, 22
Serratia, 22

Siderocapsa, 27

Sideromonas, 27

Sicdleckia, 215

Silicina, 185

Silicoflagellata, 55, 56, 57, 61, 62, 64, 67, 69

Silicoflagellatae, 55, 62

Silicoflagellidae, 62

Silicoflagellina, 61

Silkworms, 206, 222

Sinuolinea, 221

Siphonaria, 117

Siphonogenerina, 188

Siphonomycetae, 77

Siphonophyceae, 55

Siphonotestales, 62

Sirolpidiacea, 81

Sirolpidiaceae, 81

Sirolpidium, 81

Sirosiphon, 36

Sirosiphonacea, 34, 36

Sirosiphonaceae, 36

Slavina, 222

Smuts, 145, 149

Snails, 161, 211

Snakes, 210

Snyderella, 168

Snyderella Tabogae, 164

Solenodinium, 199

Sorangiacea, 28

Sorangiaceae, 28

Sorangium, 28

Soranthera, 89

Sorites, 185

Soritidae, 185

Soritina, 185

Sorodiscus, 179

Sorophoreen, 203

Sorosphaera, 179

Sphacelaria, 86

Sphacelarialea, 85, 86

Sphacelariales, 86

Sphacelariea, 86

Sphacelarieae, 86

Sphaeractinomyxon, 222

Sphaerastrum, 193

Sphaerellaria, 194

Sphaeria, 138, 141

Sphaeria Scirpi, 128

Sphaeriaceae, 137

Sphaeriales, 137, 138, 139, 141

Sphacrida, 195

Sphaeridea, 194

Sphaerioidaceae, 141

Sphaerioideae, 141

Sphaerita, 118

Sphaerobolacea, 155

Sphaerobolaceae, 155

Sphaerobolus, 155

Sphaerocapsa, 197

Sphaerocapsida, 197 
Sphaerocladia, 112, 113

Sphaerococcales, 47

Sphaerococcoidea, $46,47,50$

Sphaerococcoideae, 47

Sphaeroeca, 67

Sphaeroidea, 195

Sphaeroidina (genus of Rhizopoda), 187

Sphaeroidina (family of Radiolaria), 195

Sphaeromyxa, 221

Sphaerophracta, 197

Sphaerophrya, 235

Sphaeropsidales, 141

Sphaeropsideae, 141

Sphaerospora, 221

Sphaerosporida, 221

Sphaerosporidae, 221

Sphaerosporea, 221

Sphaerotheca, 127, 133

Sphaerotheca pannosa, 133

Sphaerotilacea, 33

Sphacrotilaceae, 33

Sphaerotilalea, 30, 33, 237

Sphaerotilus, 30

Sphaerotilus natans, 33

Sphaerozocn, 194

Sphaerozoida, 195

Sphaerozoum, 189, 195

Spirillacea, 19, 23

Spirillaceae, 23

Spirillina, 181, 182, 185

Spirillinidea, 185

Spirillinina, 185

Spirillum, 24

Spirochaeta, 29

Spirochaeta cytophaga, 26, 27

Spirochaeta plicatilis, 28, 29

Spirochaetacca, 29

Spirochaetaceae, 29

Spirochaetae, 27

Spircchactalea, 28

Spirochaetales, 28

Spirochacts, 12, 14, 166, 167

Spirochona, 233, 235

Spirochonidac, 231

Spirochonina, 230, 231

Spirocystida, 215

Spirocystidae, 215

Spirocystidées, 215

Spirocystis, 215

Spirodinium, 231

Spirodiscus, 66

Spirodiscus fulvus, 64, 66

Spirogyrales, 121

Spirolina, 185

Spironema, 222

Spirophyllum, 27

Spirostomum, 230

Spirotricha, 230

Spirotrichida, 230

Spirotrichonympha, 168, 169

Spirotrichonymphidac, 169

Spirotrichonymphina, 168
Spirulina, 35

Sponges, 37,67

Spongocarpeae, 50

Spongospora, 179

Spongurida, 195

Spongurus, 195

Sporobolomyces, 145

Sporochnales, 87

Sporochnea, 88

Sporochnoidea, 85, 87, 89

Sporochnoideae, 87

Sporochnus, 93

Sporodinia, 124

Sporochytriaceae, 117

Sporomyxa, 179

Sporozoa, 111, 206, 207, 219

Sporozoans, 21, 162

Sporozoaires, 207

Sporozoaria, 206, 207

Spumaria, 177

Spumariaceae, 177

Spumellaria, 194, 195

Spyrida, 198

Spyridieae, 51

Spyridina, 198

Spyroidea, 198

Squamarieae, 50

Squids, 210

Staphylococcus, 20

Staurocyclia, 195

Staurojoenina, 169

Staurojocnina assimilis, 170

Staurojoeninida, 169

Staurojoeninidae, 169

Stelangium, 28

Stemonitaceae, 171, 175

Stemonitales, 171, 174

Stemonitea, 174, 175

Stemonitidae, 175

Stemonitis, 175

Stemonitis splendens, 176

Stenophora, 217

Stenophorida, 217

Stenophoridae, 217

Stentor, 227, 230

Stentor cocruicus, 225

Stentoridae, 230

Stentorina, 230

Stcphanida, 198

Stephanonympha, 168

Stcphida, 198

Stephoidea, 198

Stercotestales, 62

Stcreum, 151

Stictaccac, 134

Stictea, 134

Sticteae, 134

Stictidacrar, 134

Stictideae, 133

Stigonema, 36

Stigonemataccae, 36

Stilbaceac, 142 
Stilbeae, 142

Stilbellacea, 142

Stilbellaceae, 142

Stilbosporei, 141

Stilbum, 142

Stilophora, 88

Stilotricha, 233

Stipitochloridac, 66

Stipitococcacea, 65, 66

Stipitococcaceae, 66

Stipitococcus, 66

Stokesiella, 60

Stomaticae, 74

Stomatoda, 223, 228, 233

Stomatophora, 216

Stomatophorida, 216

Stomatophoridae, 216

Streblomastigida, 165, 166

Streblomastigidae, 166

Streblomastix, 163, 168

Streblomastix Strix, 164, 166

Streblonema, 86

Streptococcus, 20

Streptomyces, 25

Streptomycetaceae, $25^{\circ}$

Streptothrix, 25

Striatae, 74

Stylobryon, 60

Stylocephalida, 218

Stylocephalidae, 218

Stylocephalus, 218

Stylochrysalis, 59

Stylocometes, 236

Stylodinium, 100

Stylonychia, 227, 232, 233

Stylopage, 124

Stylopyxis, 60

Stylorhynchidae, 218

Stypocaulon, 83, 84, 86

Suctorea, 235

Suctoria, 235

Surirella, 71, 73, 75

Surirella saxonica, 72, 73

Surirellaceae, 75

Surirellea, 75

Surirelleae, 75

Swine, 210, 214

Symbelaria, 194

Symploca Muscorum, 13

Synactinomyxida, 222

Synactinomyxidae, 222

Synactinomyxon, 222

Synchytriacea, 115, 117

Synchytriaceae, 117

Synchtrium, 117

Syncephalastrum, 124

Syncephalastrum racemosum, 122

Syncephalis, 123, 124

Syncephalis nodosa, 122

Syncephalis pycnosperma, 122

Syncollaria, 194

Syncrypta, 59
Syncryptaceae, 59

Syncryptida, 58, 59

Syncryptidae, 59

Syncystida, 216

Syncystidae, 216

Syncystis, 216

Syndinidae, 102

Syncdra, 72, 75

Syntamiidae, 86

Synura, 55, 59

Synura Uvella, 54

Synuraceae, 59

Syracosphaera, 60

Syracosphaera Quadricornu, 56

Syracosphaeraceae, 60

Syracosphaeridae, 60

Syracosphaerinae, 57, 60

Tabellaria, 75

Tabellariaceae, 75

Tabellariea, 75

Tabellarieae, 75

Taphrina, 127, 137

Taphrina aurea, 137

Taphrina deformans, 127, 136, 137

Teliosporeae, 142

Telomyxa, 222

Telomyxa glugeiformis, 222

Telomyxida, 222

Telomyxidae, 222

Telosporidea, 207

Telosporidia, 207

Tentaculifera, 224, 228, 235

Teratonympha, 171

Teratonympha mirabilis, 170

Teratonymphida, 169

Teratonymphidae, 169

Termites, 166, 167, 168, 169

Termitidae, 168

Termopsis, 166, 168

Testacea, 205

Testacida, 205

Testaceolobosa, 205

Tetractinomyxida, 222

Tetractinomyxidae, 222

Tetractinomyxon, 222

Tetradinium, 100

Tetradinium javanicum, 104

Tetrahymena, 229

Tetrahymena Geleii, 227

Tetramitaceae, 165

Tetramitida, 165

Tetramitidae, 165

Tetramitina, 165

Tetramitus, 165

Tetramyxa, 179

Tetrasporeae, 82, 86

Tetrasporées, 209

Tetrataxis, 186

Textularia, 182, 186

Textulariaceae, 186 
Textularidae, 186

Textularidea, 185

Textularina, 186

Textulinida, 186

Thalamophora, 179

Thalassicolla, 189, 194, 195

Thalassicollen, 194, 195

Thalassicollida, 195, 199

Thallochrysidacea, 62, 63

Thallochrysidaceae, 63

Thallochrysis, 63

Thamnidium, 124

Thaumatomastix, 109

Thaumatomonadidae, 109

Thaumatonema, 109

Thaumatonemidae, 109

Thecamoeba, 202

Thecamoebae, 205

Thecamoebida, 201, 202

Thecamoebidae, 202

Theileria, 214

Theileridae, 214

Thelephora, 151

Thelephoracea, 151

Thelephoraceae, 151

Thelephorei, 151

Thelohania, 222

Theoconus, 198

Thiere, 172

Thiobacillus, 24

Thiobacteria, 30, 31, 35'

Thiorhodaceae, 31

Thioploca, 35

Thiospira, 24, 31

Thiospirillum, 31

Thiothrix, 35

Thoracosphaeraceae, 60

Thoracosphaeridae, 60

Thorea, 47

Thraustochytriacea, 81,82

Thraustochytriaceae, 82

Thraustochytrium proliferum, 82

Thraustotheca, 79

Ticks, 161, 206

Tilletia, 149

Tilletia Tritici, 145

Tilletiacea, 149

Tilletiaceae, 149

Tilopteridales, 86

Tilopteridea, 87

Tilopterideae, 87

Tilopteris, 87

Timothy, 148

Tinoporidea, 187

Tinoporus, 187

Tintinnidac, 231

Tintinnids, 224

Tintinnina, 231

Tintinnodea, 231

Tintinnoinca, 231

Tipulocystis, 215

Toads, 125
Toadstools, 151

Tokophrya, 235

Tokophrya Lemnarum, 234

Tolypothrix, 35, 36

Torula, 130

Torulopsis, 130

Toxonema, 222

Tracheliidae, 230

Trachelina, 230

Trachelius, 230

Trachelomonas, 94, 106, 107

Transchelia, 143

Tremella, 149

Tremella Auricula, 146

Tremellacea, 149

Tremcllaceae, 149

Tremellales, 149

Tremellina, 146, 149, 150

Tremellineae, 146, 149

Tremellinei, 149

Tremellini, 149

Tremellodendron, 149

Trepomonadida, 165, 166

Trepomonadidae, 166

Trepomonas, 166

Treponema, 29

Treponema macrodentium, 29

Treponema microdentium, 29

Treponema pallidum, 28, 29

Treponema pertenue, 29

Treponematacea, 29

Treponcmataceae, 29

Tretomphalus, 180

Triactinomyxon, 222

Triactinomyxidae, 222

Tribonema, 65, 66, 73, 95

Tribonema bombycina, 64

Tribonematacea, 65,66

Tribonemataceae, 66

Triceratium, 74

Tricercomitus, 167

Tricercomitus Termopsidis, 164

Trichamoeba, 202

Trichia, 176, 177

Trichiacca, 174, 176

Trichiaceae, 171, 176

Trichiales, 171, 174

Trichiidae, 177

Trichina, 177

Trichinaceae, 176

Trichoblasteae, 51

Trichocystifères, Protistes, 94, 95

Trichodina, 235

Trichodinidac, 235

Trichomitus, 166

Trichomonadida, 166, 167

Trichomonadidae, 166, 167

Trichomonadina, $158,164,166$

Trichomonads, 165

Trichomonas, 166,167

Trichomonas hominis, 165

Trichomonas tenax, 164, 167 
Trichomonas Termopsidis, 168

Trichomonas vaginalis, 167

Trichonympha, 168, 169, 170

Trichonympha Campanula, 168, 170

Trichonympha sphaerica, 168

Trichonymphida, 169

Trichonymphidae, 169

Trichonymphidea, 168

Trichonymphina, 168

Trichophyton, 142

Trichospermi, 152, 171

Trichostomata, 229

Tridictyopus elegans, 196

Trigonomonas, 166

Triloculina, 184, 185

Trimastigaceae, 58

Trimastigida, 58, 165

Trimastigidae, 58

Trimastix, 58

Trinema, 191

Triplagia, 198

Triposolenia, 103

Triposolenia Ambulatrix, 104

Tripylaria, 199

Tripylea, 199

Tripyleen, 199

Tripylina, 199

Triticina, 188

Trochammina, 186

Trochamminida, 186

Trochamminidae, 186

Trochamminina, 186

Truffles, 135

Tryblidacea, 134

Tryblidaceae, 134

Tryblidieae, 133

Trypanophidae, 161

Trypanophis, 161

Trypanoplasma, 161

Trypanoplasmida, 159, 161

Trypanoplasmidae, 161

Trypanosoma, 162

Trypanosoma Brucii, 160, 162

Trypanosoma Cruzi, 162

Trypanosoma equinum, 162

Trypanosoma equiperdum, 162

Trypanosoma Evansi, 162

Trypanosoma gambiense, 162

Trypanosoma Lewisi, 160

Trypanosomata, 158

Trypanosomatidae, 161

Trypanosomes, 161, 212

Trypanosomidae, 161

Trypanosomidea, 158

Tuberacea, 135

Tuberaceae, 134

Tuberales, 134

Tuberculariaceae, 141

Tuberculariea, 141

Tubercularieae, 141

Tubercularini, 141

Tuberineae, 134
Tubifcr, 175

Tubiferaceac, 175

Tubiferida, 174, 175

Tubiferidae, 175

Tubinella, 185

Tubulina, 175

Tubulinaceae, 175

Tubulinidae, 175

Tuburcinia, 149

Tulasnella, 149, 150

Tulasnella sphaerospora, 145

Tulasnellales, 149

Tulostoma, 155

Tulostomataceae, 155

Tulostomea, 155

Tulostomei, 155

Tunicates, 216

Turillina, 188

Turkeys, 210

Turtles, 211

Tuscarilla, 200

Tuscarora, 200

Tuscarorida, 200

Ulvina aceti, 24

Unbina aceti, 24

Uncinula, 132, 133

Uniflagellatae, 110

Urceolaria, 235

Urceolaridae, 235

Urceolarina, 235

Urceolus, 109

Uredinacea, 148

Uredinaceae, 148

Uredinales, 145, 147

Uredineae, 147

Urédinées, 147

Uredo, 147

Uredo linearis, 147

Urnula, 235

Urocentridae, 230

Urocentrina, 230

Urocentrum, 230

Uroglena, 59

Uroglenopsis, 59

Uroleptus, 233

Uromyces, 143

Urophagus, 166

Urophlyctis, 117

Urospora, 216

Urosporida, 216

Urosporidae, 216

Urosporidium, 218

Urostyla, 233

Urostylida, 233

Urostylidae, 233

Ustilaginacea, 149

Ustilaginaceae, 149

Ustilaginalcs, 149

Ustilaginea, 146, 149

Ustilagineae, 149 
Ustilago, 149

Ustilago Heufleri, 145

Ustilago Hordei, 145

Uterini, 134, 137

Uvella, 59

Uvellina, 188

Uvigerina, 188

Uvigerinida, 188

Uvigerinidae, 188

Vacuolaria, 65, 109

Vacuolaria viridis, 108

Vacuolariaceae, 109

Vaginicola, 233

Vaginifera, 233

Vaginulina, 187

Vahlkampfia, 202, 203

Valsa, 139

Valvulina, 186

Valvulinidae, 186

Vampyrella, 118, 189, 191, 192

Vampyrellacea, 191

Vampyrellaceae, 191

Vampyrelleae, 191

Vampyrellidae, 191

Vampyrellidea, 190

Vaucheria, 67, 76

Vaucheria Gardneri, 64

Vaucheria sessilis, 64

Vaucheriacea, 57, 63, 64

Vaucheriaceae, 63, 67

Vaucheriales, 63

Vaucherioideae, 55

Venturia, 139

Venturia inaequalis, 139

Verbeekina, 188

Vermes, 9

Verneulina, 186

Verneulinidae, 186

Veronica, 69

Verrucariacea, 139

Vertebralina, 184, 185

Vertebratcs, 161, 165, 166, 167, 210, 211

Vibrio, 23

Vibrio Protheus, 201

Virgulina, 188

Volvox Chaos, 201

Vorticclla, 223, 226, 233, 235

Vorticcllidae, 233

Vorticcllina, 233

Vorticiales, 179

Vorticialis, 186,187

Vulvulina, 186

Wagnerella, 193, 194

Wardia, 221
Water molds, 77

Whales, 71

Wheat, 148

Wood roach, 166, 169

Worms, 215, 217, 220

Worms, annelid, 216, 219, 221

Worms, oligochaet, 222

Worms, polychaet, 211

Worms, siphunculid, 210

Woronina, 179

Woroninaceae, 179

Woroninidae, 179

Wrangelieae, 47

Xanthomonadina, 63

Xanthomonas, 23

Xenococcus, 36

Xiphacantha, 197

Xylaria, 139

Zanardinia, 88

Zea Mays, 6

Zelleriella, 229

Zonaria, 87

Zooflagellata, 157

Zoomastigina, 157

Zoomastigoda, 157, 178

Zoomastigophorea, 157

Zoopagacea, 123, 124

Zoopagaccac, 124

Zoopagales, 121

Zoopage, 124

Zoophagus, 81

Zoosporidae, 191

Zoosporidea, 191

Zoosporidia, 190

Zoothamnium, 233

Zooxanthellac, 194

Zostera, 203

Zschokkella, 221

Zygochytrium, 118

Zygocystis, 216

Zygocystida, 216

Zygocystidae, 216

Zygomycetcae, 121

Zygomycetcn, 121

Zygomycetes, 76, 118, 120, 121, 122, 127, 141

Zygophyccac, 53

Zygophyta, 53

Zygorhynchus, 124

Zygostephanus, 198

Zythiacea, 141

Zythiaccac, 141 











